
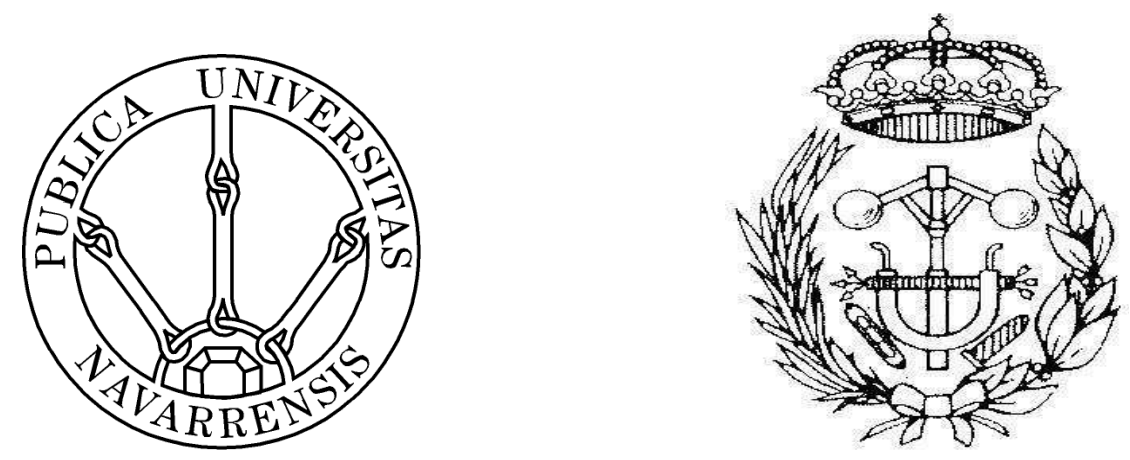

ESCUELA TÉCNICA SUPERIOR DE INGENIEROS TÉCNICOS INDUSTRIALES Y DE TELECOMUNICACIÓN

Titulación:

INGENIERO TÉCNICO INDUSTRIAL MECÁNICO

Título del proyecto:

SISTEMAS DE GESTIÓN DE LA CALIDAD

JULEN IRURITA ALZUETA PEDRO MARÍA VILLANUEVA ROLDÁN

PAMPLONA,28 DE JUNIO 2012 


\section{ÍNDICE}

1.- INTRODUCCIÓN Y OBJETIVOS 7

1.1.- INTRODUCCIÓN

1.2.- OBJETIVOS 9

2.- EVOLUCIÓN HISTÓRICA DE LA CALIDAD 10

2.1.- ANTECEDENTES DE LA CALIDAD 10

2.2.- EVOLUCIÓN DEL CONCEPTO DE CALIDAD 12

2.2.1.- PRIMERA ETAPA DE LA CALIDAD: INSPECCIÓN 12

2.2.2- SEGUNDA ETAPA DE LA CALIDAD: CONTROL

2.2.3.- TERCERA ETAPA DE LA CALIDAD: INSPECCIÓN 15

2.2.4.- CUARTA ETAPA DE LA CALIDAD 18

2.3.- DEFINICIÓN DE CALIDAD 20

2.4.- BENEFICIOS DE LA CALIDAD 22

2.4.1.- CALIDAD COMO AHORRO 22

2.4.2.- CALIDAD Y PRODUCTIVIDAD 23

2.4.3.- CALIDAD Y RENTABILIDAD 23

2.4.4.- OTROS DEFECTOS DE LA CALIDAD 24

2.5.- CALIDAD TOTAL 25

$\begin{array}{ll}\text { 2.5.1.- FUNDAMENTOS } & 25\end{array}$

2.5.2.- CIRCUNSTANCIAS QUE HAN INFLUIDO EN LA CULTURA

2.5.3.- OBJETIVOS DE LA CALIDAD TOTAL 26

2.5.4.- CARACTERÍSTICAS BÁSICAS 26

2.6.- PRINCIPIOS FUNDAMENTALES DE LA CALIDAD TOTAL 28

2.6.1.- ORIENTACIÓN HACIA LOS RESULTADOS 28

2.6.2.- ORIENTACIÓN AL CLIENTE 28

2.6.3.-LIDERAZGO 30

2.6.4.- EBFOQUE ORIENTADO A PROCESOS 30

2.6.5.- DESARROLLO E IMPLICACIÓN DE LAS PERSONAS 31

2.6.6- MEJORA CONTINUA 32

2.6.7.- ENFOQUE DEL SISTEMA PARA LA GESTIÓN 33

2.6.8.- RELACIÓN MUTUAMENTE BENEFICIOSA CON LOS
PROVEEDORES

2.6.9.- OBSTÁCULOS A LA CALIDAD TOTAL 34

2.7.- LA FILOSOFÍA DE LOS GURÚS DE LA CALIDAD 34

2.7.1.- LA FILOSOFÍA DE DEMING

2.7.2.- JURAN Y LA TRILOGÍA DE LA CALIDAD 42

2.7.3.- CROSBY Y EL CERO DEFECTOS 44 
2.7.4.- KAORU ISHIKAWA 47

2.7.5.- FEIGENBAUM $\quad 50$

2.7.6- TAGUCHI $\quad 50$

3.- MODALIDADES PARA LA GESTIÓN DE LA CALIDAD TOTAL 52

3.1.- LA NORMA ISO 9001:2008 54

3.1.1.- OBJETIVOS $\quad 54$

3.1.2.-PRINCIPIOS DE GESTIÓN

3.1.3.- REQUISITOS DE LA DOCUMENTACIÓN 56

3.1.4.- APARTADOS DE LA NORMA 57

3.1.5.- PROCEDIMIENTOS 58

3.1.6.- SISTEMA DE GESTIÓN DE LA CALIDAD 59

3.1.7.- RESPONSABILIDADE DE LA DIRECCIÓN 60

3.1.8.- GESTIÓN DE RESCURSOS 61

3.1.9.- REALIZACIÓN DEL PRODUCTO 63

3.1.10.- MEDICIÓN, ANÁLISSI Y MEJORA 65

3.2.- MODELOS DE EXCELENCIA

3.2.1.- MODELO DE DEMING 67

3.2.1.1.- Los diez criterios de evaluación de la gestión de la calidad de la Organización

3.2.3.- MODELO MALCOLM BALDRIGE 72

$\begin{array}{ll}\text { 3.2.2.1.- Propósitos y objetivos } & 73\end{array}$

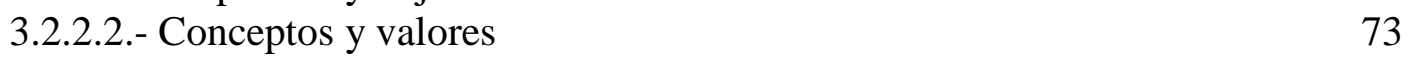

3.2.2.3.- Marco general del modelo de excelencia: una perspectiva de $\begin{array}{ll}\text { sistemas } & 78\end{array}$

$\begin{array}{lr}\text { 3.2.3.- MODELO EFQM } & 106\end{array}$

$\begin{array}{ll}3.2 .3 .1 .- & 106\end{array}$

3.2.3.2.- conceptos fundamentales de la excelencia 107

$\begin{array}{ll}\text { 3.2.3.3.- Modelo EFQM de la excelencia } & 110\end{array}$

3.2.3.4.- Esquema Lógico REDER 117

$\begin{array}{ll}\text { 3.2.3.5.- Puntuar el Premio EFQM a la excelencia } & 122\end{array}$

$\begin{array}{lr}\text { 4.- KAIZEN Y 5S } & 124\end{array}$

$\begin{array}{lr}\text { 4.1.- KAIZEN } & 124\end{array}$

$\begin{array}{ll}\text { 4.1.1.- INTRODUCCIÓN } & 124\end{array}$

4.1.2.- PRINCIPIOS DEL KAIZEN 125

4.1.3.- INSTRUMENTOS DEL KAIZEN 126

4.1.4.- EL KAIZEN EN EL GEMBA 131

4.2.- $5 \mathrm{~S} \quad 134$

4.2.1.- INTRODUCCIÓN 134

$\begin{array}{ll}4.2 .2 .-5 \mathrm{~S} & 135\end{array}$

$\begin{array}{ll}\text { 4.2.2.1.- Seiri } & 136\end{array}$

$\begin{array}{ll}\text { 4.2.2.2.- Seiton } & 136\end{array}$ 
$\begin{array}{ll}\text { 4.2.2.3.- Seiso } & 137\end{array}$

$\begin{array}{ll}4.2 .2 .4 .- \text { Seiketsu } & 138\end{array}$

$\begin{array}{lr}4.2 .2 .5 .- \text { Shitsuke } & 139\end{array}$

$\begin{array}{ll}\text { 4.2.3.- BENEFICIOS } & 139\end{array}$

4.2.4.- COMO APLICAR LA METODLOGÍA DE IMPLANTACIÓN AUTÓNOMA 5S 140

$\begin{array}{ll}\text { 4.2.4.1.- Dedicación } & 140\end{array}$

4.2.4.2.- Participantes en la implantación de las 5S 140

4.2.4.3.- Etapas a cubrir en cada una de las 5S 142

5.- SEIS SIGMA

5.1.- HISTORIA 144

5.2.- ¿QUÉ ES SEIS SIGMA? 144

5.3.- LA MÉTRICA DE SEIS SIGMA 146

5.4.- PRINCIPIOS DE SEIS SIGMA 150

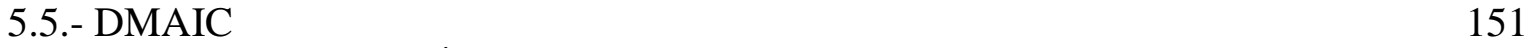

5.5.1.- DEFINICIÓN 151

5.5.2.- MEDICIÓN 152

5.5.3.- ANÁLISIS 153

5.5.4.- MEJORA 154

$\begin{array}{ll}\text { 5.5.5.- CONTROLAR } & 155\end{array}$

5.6.- HERRAMIENTAS PARA DMAIC 157

5.7.- ESTRUCTURA 157

$\begin{array}{ll}\text { 5.7.1.- LA ALTA DIRECCIÓN } & 158\end{array}$

$\begin{array}{ll}\text { 5.7.2.- EL CHAMPION } & 158\end{array}$

$\begin{array}{ll}\text { 5.7.3.- EL MASTER BLACK BELT } & 159\end{array}$

$\begin{array}{lr}\text { 5.7.4.- EL BLACK BELT } & 159\end{array}$

$\begin{array}{ll}\text { 5.7.5.- EL GREEN BELT } & 160\end{array}$

5.7.6.- EL DUEÑO DEL PROYECTO 160

5.7.7.- LOS MIEMBROS DEL EQUIPO 160

5.8.- EQUIPO DE MEJORA DE SEIS SIGMA 161

5.9.- ESTRATEGIA DE IMPLANTACIÓN DE SEIS SIGMA 161

6.- SISTEMAS INTEGRADOS DE GESTIÓN DE LA CALIDAD, MEDIOAMBIENTE Y PREVENCIÓN DE RIESGOS LABORALES 165

6.1.- INTRODUCCIÓN 165

6.2.- ENFOQUE DE IMPLANTACIÓN E INTEGRACIÓN 166

6.3.- INTEGRACIÓN POR PROCESOS 167

6.4.- RELACIÓN ENTRE LOS SISTEMAS DE GESTIÓN 171

6.5.- DISEÑO DE UN SISTEMA INTEGRADO 174

6.6.- IMPLANTACIÓN DE UN SISTEMA INTEGRADO 177

6.7.- AUDITORÍA DEL SISTEMA INTEGRADO 179

6.8.- VENTAJAS DE LA INTEGRACIÓN DE SISTEMAS 180

6.9.- GESTIÓN AMBIENTAL 181 
6.9.1.- ISO 14001:2004

6.9.2.-REQUISITOS EMAS NO CONTEMPLADOS EN LA ISO 14001

6.10.- GESTIÓN DE LA PREVENCIÓN DE RIESGOS LABORALES

6.10.1.-ESTRUCTURA DEL PLAN DE PREVENCIÓN

6.10.2. - OHSAS 18001:2007

6.10.3.- RELACIÓN ENTRE OHSAS 18001, OHSAS 18002 E ILO-OHS 2001

6.11.- UNE 66177: GUÍA PARA LA INTEGRACIÓN DE LOS SISTEMAS DE GESTIÓN.

6.11.2.- EVALUACIÓN DEL NIVEL DE MADUREZ EN LA GESTIÓN POR PROCESOS

\section{8.- ARTÍCULOS DE INVESTIGACIÓN SOBRE LA GESTIÓN DE LA CALIDAD Y SUS SISTEMAS}

8.1.- A longitudinal study of TQM implementation: factors influencing success and failure

8.2.- Quality management practices and operational performance: empirical evidence on Spanish industry

8.3.- Quality management practices and competitive performance: Empirical evidence from Japanese manufacturing companies

8.4.- A replication study of a theory of quality management underlying the Deming management method: insights from an Italian context

8.5.- Implementation of Deming's style of quality management: An action research study in a plastics company

8.6.- Investigating total quality management practice's inter-relationships in ISO 9001:2000 certified organisations

8.7.- Implementation of a quality management system according to the ISO 9000 family in a Greek small-sized winery: A case study.

8.8.- A study on the critical factors of ISO 9001:2000 and organizational performance of Indian manufacturing firms

8.9. - Impact of Baldrige National Quality Award Criteria on organizational quality performance

8.10.- Relevance of Baldrige constructs in an international context: A study of national culture

8.11.- An empirical assesment of the EFQM Excellence Model: Evaluation as a 
Tqm framework relative to the MBNQA

8.12.- Selection effective management tolos on setting European Foundation for

Quality Management (EFQM) model by a quality function deployment

(QFD) approach

8.13. - Business improvement strategy or useful tool? Analysis of the application of the $5 \mathrm{~S}$ concept in Japan, the UK and the US

8.14.-Quality improvement supported by the 5S, an empirical case study of Mexican organisations

8.15.- Critical success factors of Six Sigma implementations in Italian companies

8.16.- The envolving theory of quality management: The role of Six Sigma

8.17.- Integrated Management Systems - three different levels of integration

8.18.- How integrated are enviromental, quality and other standarized

management systems? An empirical

8.19.-Integrating Management Systems: A dinámic study of Spanish firms

8.20.- Integrated management systems: experiences in Italian organizations

8.21.- Applying quality award criteria in R\&D Project assessment

8.22.- The effect of TQM on performance in R\&D environments: A perspective from South Korean firms 


\section{1.- INTRODUCCIÓN Y OBJETIVOS}

\section{1.- INTRODUCCIÓN}

El concepto de calidad ha ido evolucionando a lo largo de los años, ampliando objetivos y variando la orientación. Hoy en día podemos definir la calidad como "todas las formas a través de las cuales la empresa satisface las necesidades y expectativas de sus clientes, sus empleados, las entidades implicadas financieramente y toda la sociedad en general".

Se puede decir que su papel ha tomado una importancia creciente al evolucionar desde un mero control o inspección, hasta convertirse en uno de los pilares de la estrategia global de la empresa que hoy conocemos como Gestión de la Calidad Total.

Su filosofía proporciona una concepción global que fomenta la Mejora Continua en la organización y la involucración de todos sus miembros, centrándose en la satisfacción tanto del cliente interno como del externo. Podemos definir esta filosofía del siguiente modo: Gestión (el cuerpo directivo está totalmente comprometido) de la Calidad (los requerimientos del cliente son comprendidos y asumidos exactamente) Total (todo miembro de la organización está involucrado, incluso el cliente y el proveedor, cuando esto sea posible).

Esta Gestión de la Calidad Total se lleva a cabo mediante la implantación de un sistema de gestión de la calidad.

Un Sistema de Gestión de la Calidad es una estructura operacional de trabajo, bien documentada e integrada a los procedimientos técnicos y gerenciales, para guiar las acciones de la fuerza de trabajo, la maquinaria o equipos, y la información de la organización de manera práctica y coordinada y que asegure la satisfacción del cliente y bajos costos para la calidad.

En otras palabras, un Sistema de Gestión de la Calidad es una serie de actividades coordinadas que se llevan a cabo sobre un conjunto de elementos (Recursos, Procedimientos, Documentos, Estructura organizacional y Estrategias) para lograr la calidad de los productos o servicios que se ofrecen al cliente, es decir, planear, controlar y mejorar aquellos elementos de una organización que influyen en satisfacción del cliente y en el logro de los resultados deseados por la organización.

A lo largo del tiempo los diferentes sistemas de gestión de la calidad también han evolucionado. En un principio nos encontrábamos con sistemas como la ISO 9000 y los modelos de excelencia.

La ISO 9000 es una normativa desarrollada por la ISO (International Standard Organization) para el aseguramiento de los sistemas de calidad de las organizaciones. 
En esta norma, se especifican una serie de requisitos que debe cumplir una organización. La principal característica de los sistemas de gestión de la calidad según norma Iso 9000 es que sirve para demostrar a terceros la calidad del sistema con las correspondientes ventajas comerciales que ello conlleva.

Los Modelos de Excelencia, son modelos dedicados a hacer tangible los principios de la calidad total para que sean aplicables a las organizaciones. Es preciso aclarar que los Modelos de Excelencia no son una norma y no se obtiene ningún certificado por terceras partes. Los Modelos de Excelencia son modelos compuestos de criterios y subcriterios que son evaluados en la organización para obtener sus puntos fuertes y débiles y definir planes de acción consecuentes.

Otros sistemas como las 5S y Seis Sigma han pasado con el tiempo de simples herramientas de la calidad, a filosofías puestas en marcha por grandes empresas y organizaciones para la mejora continua.

Las 5S, así denominado por la primera letra del nombre que en japonés designa cada una de sus cinco etapas, es una técnica de gestión japonesa basada en cinco principios simples cuyo objetivo es mejorar y mantener las condiciones de organización, orden y limpieza en el lugar de trabajo para mejorar las condiciones de trabajo, de seguridad, el clima laboral, la motivación personal y la eficiencia y, en consecuencia, la calidad, la productividad y la competitividad de la organización.

Por su parte, Seis Sigma es una filosofía de trabajo y una estrategia de negocios, la cual se basa en el enfoque al cliente, en un manejo eficiente de los datos y metodología y diseños robustos, que permite eliminar la variabilidad en los procesos y alcanzar en nivel de defectos menor o igual a 3,4 defectos por millón con la consiguiente reducción de los costes, reducción de los tiempos de ciclo, alta satisfacción del cliente y efectos en el desempeño de la organización.

Recientemente, se ha comenzado ha hablar de la integración de sistemas de gestión en la empresa. Además de los sistemas de gestión de la calidad, se han comenzado a implantar otros sistemas de gestión para controlar y mejorar los aspectos más sensibles de la organización relacionados con el medio ambiente y la prevención de riesgos laborales (PRL). Esto supone una multiplicación de recursos y, en consecuencia, un elevado coste por lo que se ve a los sistemas integrados de gestión como una solución para implantar estos sistemas conjuntamente en lugar de por separado.

Por último, vemos como las actividades de I+D+i se han convertido en elementos muy importantes en las empresas y organizaciones. Así se ha comenzado ha hablar de gestión de la calidad en investigación.

Promover la calidad en investigación es tratar de mejorar de forma continua las prácticas de investigación de forma que permitan garantizar los resultados y productos de la investigación, y asegurar la trazabilidad de los procesos y actividades de investigación. Los métodos e instrumentos de gestión de calidad en investigación facilitan la puesta en 
marcha de buenas prácticas: científicas y de investigación, que finalmente de forma indirecta concurren en mejorar la calidad de los resultados de la investigación.

\section{2.- OBJETIVOS}

Los objetivos de este proyecto son:

- Observar la evolución del concepto de calidad.

- Estudiar los diferentes sistemas de gestión de la calidad y su evolución.

- Ver cuáles son las nuevas tendencias en lo que se refiere a la gestión de la calidad.

- Realización de un artículo sobre uno de los temas estudiados, que en este caso será los sistemas integrados de gestión

A estos objetivos se llegará por medio de dos vías de estudio:

1. Estudio por medio de diferentes medios bibliográficos.

2. Estudio de artículos de investigación sobre calidad de la base científica de la UPNA.

Estas dos vías nos sirven para diferenciar las dos partes de este proyecto previas a la realización del artículo ejemplo:

1. Parte bibliográfica en la que se explica la teoría sobre los sistemas de gestión de la calidad.

2. Comentarios a los artículos de investigación. 


\section{2. -EVOLUCIÓN HISTORICA DE LA CALIDAD}

\section{1.- ANTECEDENTES DE LA CALIDAD}

Es intrínseco al hombre el deseo de superación, lo cual ha sido el elemento clave para el avance tecnológico y cultural de la humanidad. En este proceso destaca también el propósito de hacer las cosas bien, como algo natural al ser humano.

El concepto de calidad ha ido evolucionando a lo largo de los años, ampliando objetivos y variando la orientación. Se puede decir que su papel ha tomado una importancia creciente al evolucionar desde un mero control o inspección, hasta convertirse en uno de los pilares de la estrategia global de la empresa.

La historia de la humanidad está directamente ligada con la calidad desde los tiempos más remotos; el hombre al construir sus armas, elaborar sus alimentos y fabricar su vestido observa las características del producto y enseguida procura mejorarlo. La práctica de la verificación de la calidad se remonta a épocas anteriores al nacimiento de Cristo. En el año 2150 a. C., la calidad en la construcción de casas estaba regida por el Código de Hammurabi, que establecía que "si un constructor construye una casa y no lo hace con buena resistencia y la casa se derrumba y mata a los ocupantes, el constructor debe ser ejecutado". Los fenicios también utilizaban un programa de acción correctiva para asegurar la calidad, con el objeto de eliminar la repetición de errores. Los inspectores simplemente cortaban la mano de la persona responsable de la calidad insatisfactoria. Los aztecas y otros pueblos antiguos comenzaron a establecer guías de calidad. El tratado más antiguo que se presenta fue descubierto en Egipto y data del año 1450 a.C. e indica como un inspector egipcio puede comprobar la perpendicularidad de un bloque de piedra con ayuda de una cuerda.

Situándonos en la época artesanal, la calidad suponía hacer bien las cosas a cualquier costo. Los objetivos seguidos por el artesano eran, por lo tanto, satisfacer el orgullo personal (su prestigio) y satisfacer al comprador. En definitiva, el producto era una obra de arte. Esto supone que el artesano vende los productos, compra las materias primas y trabaja con una metodología basada en su experiencia profesional. Ya entonces el gobierno fijaba normas como pesas y medidas de forma que el artesano podía inspeccionar y comparar los productos pudiendo establecer un patrón de calidad.

Posteriormente, durante la industrialización, el concepto de calidad fue sustituido por el de producción (hacer muchas cosas, no importa con que calidad). El objetivo de este modo de fabricación era el de satisfacer la demanda de bienes (generalmente escasos) y el aumento de beneficios.

En la Segunda Guerra Mundial, el concepto de calidad equivalía a asegurar la eficacia del armamento (sin importar el costo) con la mayor y más rápida producción (eficacia + plazo $=$ calidad $)$. El objetivo era garantizar la disponibilidad de un armamento eficaz en cantidad y momento precisos. 
Durante la posguerra, en Japón el concepto de calidad equivalía a "hacer las cosas bien a la primera". El objetivo de esta filosofía de trabajo era minimizar los costos a través de la calidad, satisfacer a los clientes y aumentar la competitividad de estas empresas.En el resto de los países, sin embargo, se volvió al objetivo de la época anterior, la industrialización. No se contempla la calidad, sólo se trata de producir cuanto más mejor, satisfacer la demanda de bienes para reconstruir los países afectados por la guerra.

En este tiempo se analiza el trabajo y se descompone en actividades sencillas. Estas actividades se realizan por personas especializadas en pequeñas tareas. De este modo nace el trabajo en cadena; el trabajo pasa de ser organizado por un artesano industrial a ser planificado por los ingenieros. Como consecuencia disminuye el periodo de aprendizaje y aumenta la productividad. Esto supone un aumento de la competitividad, pero un descenso del nivel de vida y de la satisfacción de los trabajadores. Como efectos "secundarios" aparece un descenso de la calidad por apatía, descuido, mala coordinación entre distintas funciones, etc.

Llega un momento en el que el cliente comienza a exigir más calidad. Entonces se comienza a buscar que el grado de adaptación de un producto a su diseño sea el óptimo. En esta época surge el Control de Calidad, en el sentido de inspección de las características de un producto y satisfacer las necesidades técnicas y de producción. De este modo, la calidad se identifica con la ausencia de defectos. Originado por este control de calidad surge un conflicto entre la función de fabricación (a la búsqueda de aumentar la productividad) y la de control de calidad (cuya función era detectar todos los defectos posibles). Pero entonces resulta que el cliente busca otras cosas o, aunque el producto cumpla las especificaciones del diseño, no es aceptado por el mercado. En ese momento surge la necesidad de cambiar el sistema de gestión y nace la Gestión de la Calidad. El concepto de calidad se mide mediante el grado de satisfacción de las necesidades del cliente. Los objetivos, por lo tanto, serán satisfacer al cliente, mantener la calidad, reducción de los costos y mejorar la competitividad de la empresa.

Es entonces cuando aparece el Aseguramiento de la Calidad. El concepto básico de este Sistema de Calidad supone garantizar el nivel de calidad del producto, esto es, que el resultado de la actividad de la empresa sea el que se pretende y no una sorpresa. El punto débil de este sistema es que no contempla la mejora del producto, ni define sistemas para captar la voz del cliente. Para mejorar en estos aspectos aparece la mejora continua, herramienta utilizada de diferentes maneras en cada empresa según sus necesidades y métodos de trabajo. La mejora continua está basada en una serie de pequeñas mejoras que van haciendo avanzar poco a poco a la empresa en diferentes aspectos.

Las empresas más comprometidas en materia de calidad han comenzado recientemente

a incorporar un sistema de gestión denominado Gestión de Calidad Total. Este proceso supone integrar el concepto de calidad en todas las fases del proceso y a todos los departamentos que tienen alguna influencia en la calidad final del proceso y/o servicio prestado al cliente. 
Actualmente, los "gurús" de la calidad llegan aún más lejos. Taguchi define la calidad como el grado de pérdida para la sociedad. El objetivo, por lo tanto es buscar el método de producción que supone un coste mínimo para la sociedad. En este concepto entran otro tipo de consideraciones, como pueden ser las relaciones con el medio ambiente, la satisfacción de los trabajadores, etc.

Esto hace suponer que en un futuro el concepto de calidad se identifique con la satisfacción por el trabajo bien hecho. Los objetivos buscados pasarían a ser la satisfacción interna (empresa), la satisfacción externa (cliente y sociedad en general), y una alta competitividad en un mercado en el que la calidad se considerará como un derecho.

\section{2.- EVOLUCIÓN DEL CONCEPTO DE CALIDAD}

La calidad ha experimentado un profundo cambio hasta llegar a lo que hoy conocemos por Calidad Total, como sinónimo de gestión empresarial para conseguir la satisfacción de los clientes, los empleados, los accionistas y de la sociedad, en su sentido más amplio.

Aunque suele decirse que el concepto de calidad es un concepto moderno (siglo XX), desde que el hombre es hombre, se aprecia una preocupación por el trabajo bien hecho.Siempre ha existido un concepto intuitivo de calidad. Desde el significado inicial de calidad, como los atributos del producto, hasta el actual, aplicado a todas las actividades de la empresa, y por lo tanto a su gestión, se ha recorrido un largo camino. Merece la pena conocer este recorrido histórico para comprender mejor y de forma más profunda su verdadero significado.

La evolución del concepto de calidad en el siglo XX ha sido muy dinámica. Se ha ido acomodando a la evolución de la industria, habiéndose desarrollado diversas teorías, conceptos y técnicas, hasta llegar a lo que hoy en día se conoce como Calidad Total. Estas teorías se han desarrollado principalmente en los países más avanzados y emprendedores como Estados Unidos y Japón, siendo en este último donde se inició la implantación en las empresas de la Calidad Total, su cultura y sus técnicas y herramientas. Los sistemas de gestión de la calidad han experimentado una evolución paralela a la evolución de los sistemas productivos y al concepto de calidad: control de la calidad, aseguramiento de la calidad y Calidad Total.

\subsection{1.- PRIMERA ETAPA DE LA CALIDAD: INSPECCIÓN}

La inspección es la acción de medir, examinar, ensayar, comparar con calibres una o más características de un producto o servicio y comparación con los requisitos especificados para establecer su conformidad.

El control de la calidad por inspección está enraizado en los talleres de finales del siglo XIX y principios del XX, donde las labores de producción e inspección están separadas y son desarrolladas por personas distintas, siendo el inspector el responsable de calidad. Esta es la concepción de Taylor de inicios del siglo XX. 
Antes del siglo XX, la producción de bienes era llevada mayoritariamente de forma artesanal. El mismo operario realiza todas las operaciones, o gran parte de ellas, para fabricar un producto. El operario es capaz de realizar las distintas operaciones que se precisan para realizar todo el proceso de fabricación, y a medida que avanza en el proceso de montaje va inspeccionando los componentes ya montados. Es una inspección asociada a la producción, y es una inspección no estandarizada.

En sus orígenes, la calidad era costosa porque consistía en rechazar todos los productos defectuosos si era posible, lo que representaba otro coste adicional. La calidad era responsabilidad exclusiva del departamento de inspección de calidad. Era la época en que el término calidad estaba asociado totalmente a la calidad del producto. Toda la atención estaba focalizada en la función de producción, en la fábrica, en el taller. El objetivo era que el producto cumpliera con unos requerimientos, unas especificaciones técnicas y evitar que llegara al mercado un defecto. Esta es la época que se ha conocido como "Etapa de control de la calidad por inspección".

En el sector de la automoción, esta época se va definiendo en la medida que Ford va introduciendo modificaciones en su sistema de montaje. A principios del siglo XX, con la aparición del modelo Ford $\mathrm{T}$, disminuye de forma drástica la cantidad de operaciones asignadas a cada trabajador. Esta división del trabajo en tareas lleva a la especialización. La chispa de genio que tuvo Ford en la primavera de 1913, en su nueva planta de Highland Park en Detroit, consiste en introducir la cadena de montaje móvil, que colocaba al coche delante del obrero.

Con la Revolución Industrial los sistemas de fabricación dieron un giro: se pasó a producir piezas intercambiables que, posteriormente, eran ensambladas en una secuencia preestablecida de operaciones. Para minimizar los problemas del ensamble final, las piezas se diseñaban bajo unos patrones que garantizaban su uniformidad, y al final de la línea de producción se comprobaba si el artículo era conforme con el estándar preestablecido, dando lugar a la inspección. El trabajo se hace cada vez más repetitivo, y obviamente más monótono, pero se consiguen unas reducciones en coste significativas.

Con esta especialización en todos los terrenos, aparecen también los especialistas en control de calidad. Aparecen especialistas en mantenimiento, la función del ingeniero industrial para diseñar máquinas especiales, ingenieros de planta para planificar la producción, equipos de limpieza y otros operarios y trabajadores auxiliares especializados.

Así queda claramente separada la función de producción y la de inspección. El sistema lleva a que la gente de planta tiene como objetivo principal producir, mejorar índices de productividad. Lo importante por tanto es no parar la cadena. De esta forma se da prioridad a la producción por encima de la calidad.

Durante los primeros años del siglo XX se van definiendo las tareas del inspector y refinándose los métodos de inspección. Esta evolución va desde la mera observación visual de las tareas realizadas por los aprendices y oficiales por parte del maestro, hasta el 
establecimiento de herramientas de medida que permiten detectar si el producto cumple con las especificaciones y características establecidas. La función de inspección consistía básicamente en examinar de cerca y de forma crítica el trabajo para comprobar su calidad y detectar los errores. Lo importante era que el producto cumpliera con los estándares establecidos porque se pensaba que el cliente juzgaba la calidad tomando como base la uniformidad, la cual era sólo posible si el fabricante se ceñía a esas especificaciones. Los sistemas primitivos de inspección no aportan ningún elemento de prevención ni ningún plan de mejora.

A medida que el volumen de producción va aumentando y se va extendiendo la producción en masa en todos los sectores industriales, la inspección masiva se hace cada vez más difícil y cara. En estos momentos, a principios de los años 30, un grupo de ingenieros de la Bell Telephone Laboratorios en USA desarrolla unas técnicas estadísticas para reducir el área de inspección.

\subsection{2.- SEGUNDA ETAPA DE LA CALIDAD: CONTROL ESTADÍSTICO}

El control de la calidad es el conjunto de técnicas y actividades, de carácter operativo, utilizadas para verificar los requisitos relativos a la calidad del producto o servicio.

Walter Shewhart llevo a cabo una serie de investigaciones que posteriormente fueron plasmadas en el libro "Economía del control de calidad en los productos fabricados", en el que define el control en las fábricas, desarrolla técnicas para evaluar la producción y plantea diversos modos de mejorar la calidad.

Shewhart, de la Bell Telephone, en 1931 estudia la manera de conseguir la mayor cantidad de información sobre la calidad de los productos a partir de la menor cantidad posible de datos de inspección, así como establecer un método de representación de los datos de forma que facilite la detección de anomalías. Aparece la preocupación por el mismo proceso de producción, por el estudio de los datos que permitan extraer conclusiones más allá de si esta pieza cumple o no con las especificaciones. Con las aportaciones de Shewhart, se podrá analizar cómo se comporta el proceso de producción.

Shewhart es el primero en reconocer que la variabilidad (diferencia entre piezas o producto idénticos) es consustancial a la producción industrial. Es algo intrínseco a los procesos productivos. Existe y se puede medir y controlar. Para ello, Shewhart desarrolla unas herramientas estadísticas, basadas en leyes de probabilidad. El objetivo inicial no es eliminar esa variabilidad, sino distinguir las fluctuaciones aceptables, que son pequeñas y no asignables a ninguna causa conocida, de aquellas variaciones que claramente indican la existencia de algún problema o anomalía. Una vez detectadas las anomalías "asignables" a una causa, se podrá analizar la causa y establecer alguna medida correctora.

El trabajo de Shewhart se centró en el desarrollo de técnicas estadísticas simples y métodos de representación gráfica que permitían ver cuando las fluctuaciones superaban un rango aceptable. Siguieron otras investigaciones en técnicas de muestreo, para conocer el tamaño de muestra que aseguraba un buen conocimiento de la cantidad de defectos de 
todo el lote. Estos métodos se popularizaron durante la Segunda Guerra Mundial en Estados Unidos, donde fueron aplicados de manera masiva, permitiendo inspeccionar un gran número de piezas a través de muestras de tamaño relativamente pequeño. También durante la Segunda Guerra Mundial se extendió el uso de gráficos de control de medidas y de rangos de Shewhart, ya que era exigencia del ejército americano para sus proveedores.

Los años comprendidos entre la Primera Guerra Mundial y el final de la Segunda son años en los que "The War Production Board" es el principal cliente de las empresas americanas. La empresa debe ofrecer unos productos ajustados a unas especificaciones, y esto prima sobre otras consideraciones o aspectos. Este organismo promocionó la utilización de las técnicas de Control Estadístico de Procesos (SPC). Los proveedores del ejército utilizaron las técnicas SPC para complacer al ejército americano, pero sin aprovechar el potencial que dan tales herramientas. En todo caso, las técnicas de Shewhart, denominadas "Control Estadístico de Procesos", se fueron extendiendo y popularizando.

Sin embargo, el proceso de control de la calidad basado en métodos estadísticos sigue siendo responsabilidad del departamento especializado. El proceso de detección de errores y corrección sigue siendo reactivo. No se proponen actividades de prevención. En la época en la que se generaliza este tipo de instrumentos del control de la calidad, la dirección todavía no confía en los trabajadores de planta para que lleven a cabo el muestreo y las tareas de control de la calidad.

Es evidente que la era del control de la calidad a través de estas técnicas estadísticas es

un avance significativo respecto a la era de la inspección: económicamente es más eficiente. Sin embargo adolece todavía de los problemas del enfoque precedente: es rígido y mecánico, no es preventivo, y se limita a las funciones productivas, no implicando al resto de la organización. El SPC se diferencia de la era anterior basada en la inspección, en el enfoque. Ahora se estudia el propio proceso de fabricación: su variabilidad. Antes, la atención se centraba en el mismo producto. Hasta finales de los cincuenta no hay innovaciones importantes. Son unos años en los que domina la demanda en la economía norteamericana; se vende todo lo que se produce.

El muestreo se convierte en una tarea de final de la línea de producción, ya que prima la producción por encima de la calidad. Las empresas estaban mucho más preocupadas por aumentar la producción, para satisfacer la demanda, que en la calidad de lo producido. Esto y la incorrecta aplicación del SPC provocaron que se volviera a la idea de producir cuanto más mejor e inspeccionar al final para separa lo bueno de lo malo.

\subsection{3.- TERCERA ETAPA DE LA CALIDAD: ASEGURAMIENTO}

El aseguramiento de la calidad es el conjunto de acciones, planificadas y sistemáticas, que son necesarias para proporcionar la confianza adecuada de que un producto o servicio va a satisfacer los requisitos dados sobre la calidad. 
Los nuevos sistemas de calidad, además del control en la fabricación, incluyen el desarrollo de nuevos productos o el servicio al cliente. Aunque el control estadístico del proceso siguió siendo una forma de prevenir defectos, a partir de los años cincuenta aparecieron nuevos elementos que dieron un giro al control de la calidad: los costes de calidad, el control total de la calidad, la ingeniería de fiabilidad y el cero defectos.

El paso a esta nueva etapa se produce cuando se admite que el control estadístico de la calidad también tiene implicaciones en la administración de la empresa y no exclusivamente para el departamento de producción. Una vez que el control de la variación de los procesos se realice de modo efectivo, los especialistas enfocarán sus esfuerzos hacia el diseño de métodos de trabajo que permitan evitar errores antes de que ocurran. Así surgen los enfoques de aseguramiento de la calidad.

Aquí destaca la familia de normas ISO 9000 de 1994. De hecho, en aquella versión se anunciaba en el mismo título que era una normativa para el aseguramiento de la calidad.

En la actual versión se ha quitado el término "aseguramiento de la calidad". El título de la de ésta es "UNE-EN ISO 9001. Sistemas de gestión de la calidad. Requisitos". En esta última se define el término "aseguramiento de la calidad" como "parte de la gestión de la calidad orientada a aumentar la capacidad de cumplir con los requisitos de la calidad" (ISO 9000:2000. UNE-EN ISO 9000: Sistemas de gestión de la calidad. Fundamentos y vocabulario", AENOR). Así, el aseguramiento de la calidad es el desarrollo de un sistema interno que con el tiempo genera datos que indicarán que el producto o servicio ha sido fabricado según las especificaciones y que cualquier error ha sido detectado y borrado del sistema. El aseguramiento de la calidad necesita de auditorías para evidenciar la integridad del sistema de producción a través de inspecciones independientes. El diseño de los productos, su fiabilidad y rendimiento, pasarán a ser en estos años factores clave de competitividad. Se exige el trabajo coordinado de todos los departamentos que intervienen en el diseño, fabricación, instalación y mantenimiento del producto.

En términos de Garvin (1988), el aseguramiento de la calidad vio una vía de evolución que llevó a la calidad desde una perspectiva estrecha, totalmente en manos de los especialistas, a otra mucho más amplia, que incluía una gestión mucho más extensa. Ya no era eficaz la diferenciación y la especialización de los trabajos. Ahora era necesario un mayor conocimiento de las implicaciones de calidad en toda la fuerza trabajadora, en la dirección y, por supuesto, en el cliente. La calidad comenzó a convertirse en algo más que una preocupación del especialista. Las mejoras en la calidad no podrían tener lugar sin el compromiso de los trabajadores de la planta. La implicación de todos los departamentos de la empresa en la función calidad es una de las mayores aportaciones de esta era. Otra aportación de esta era de la calidad es el enfoque hacia la prevención. Lo importante es encontrar las raíces del problema y corregirlas, buscando soluciones y estandarizando estas soluciones para evitar que vuelvan a producirse. Eso se logra dirigiendo los esfuerzos de la organización hacia la planificación de procedimientos de trabajo, así como hacia el diseño de productos que prevengan errores desde su diseño. 
J. Juran publicó en 1951 el libro Manual de la calidad, en el que planteó el estudio de los costes de calidad y de los ahorros que se podían conseguir si se actuaba adecuadamente. Consideraba que algunos costes de producción, como los de prevención y otros de control de calidad, eran inevitables, pero los costes relacionados con los productos defectuosos, como el material de desecho, las horas invertidas en reparaciones, el retrabajo, el tiempo para atender reclamaciones o la pérdida de clientes insatisfechos, se podían evitar. Suprimiendo todos estos costes e invirtiendo en el mejoramiento de la calidad se conseguirían ahorros sustanciales.

Armand Feigenbaum fue el primero en proponer el concepto de Control Total de la

Calidad (TQC). Su idea era que no se podían fabricar productos de alta calidad si el departamento de producción trabajaba de forma aislada. Para que el control de calidad fuera efectivo, este control debía comenzar con el diseño del producto y terminar cuando éste estuviera en manos de un cliente satisfecho. Para ello proponía tres etapas básicas: control del nuevo diseño, control del material que se recibe y, por último, control a pie de máquina. En estas etapas deberían participar varios departamentos a través de grupos interfuncionales de trabajo, pues, según este autor, la calidad debía ser trabajo de todos y de cada uno de los que intervinieran en cada etapa del proceso. Entre estos planteamientos de Juran y Feigenbaum había una serie de coincidencias.

Ambos consideraban muy importante medir los costes de calidad y opinaban que era necesario un nuevo tipo de profesional de la calidad que no se limitara a utilizar las tradicionales técnicas de inspección y medición. Estos expertos debían de encargarse de la planificación de la calidad o de la medición de la calidad, para lo cual no bastaría con tener conocimientos estadísticos. En esta etapa, junto con los planteamientos de Juran y Feigenbaum, se desarrollaron otros argumentos basados en la probabilidad y en la estadística: la ingeniería de fiabilidad, que pretendía una gran garantía del desempeño aceptable de los productos. Esta corriente tuvo sus orígenes en las exigencias de fiabilidad de los equipos electrónicos del Departamento de Defensa. La fiabilidad, junto con las modernas técnicas de la teoría de la probabilidad, condujeron a establecer relaciones entre los ratios de fallos y el tiempo que permitieron diseñar programas para comprobar las situaciones extremas o estimar los niveles de fiabilidad en producciones a gran escala. Como un primer paso para mejorar la fiabilidad y disminuir los ratios de fallos, esta disciplina utilizó técnicas de predicción como el análisis modal de fallos y efectos o la retroalimentación procedente de informes sobre el número de fallos de los productos actuales.

El último de los conceptos de esta etapa, el cero defectos, se centró en las expectativas de los directivos y en las relaciones humanas. Surgió en una empresa de armamento de los Estados unidos que alcanzó su objetivo de producir misiles sin ningún defecto. Según sus directivos, la razón por la cual no había perfección era simplemente porque la misma no había sido esperada; por tanto, cuando la dirección exigió perfección esta se produjo. Los programas de cero defectos se basaron en la idea de hacer ver entre los trabajadores que las tareas se podían hacer bien a la primera, lo cual requería motivación, entrenamiento o el desarrollo de técnicas para la resolución de problemas. 


\subsection{4- CUARTA ETAPA DE LA CALIDAD: CALIDAD TOTAL}

La Calidad Total es una sistemática de gestión a través de la cual la empresa satisface las necesidades y expectativas de sus cliente, de sus empleados, de los accionistas y de toda la sociedad en general, utilizando los recursos de que dispone: personas, materiales, tecnología, sistemas productivos, etc.

En esta etapa, aunque se siguen utilizando los métodos y prácticas de la etapa anterior, se producen importantes cambios en los planteamientos: la calidad pasa a ser de interés para la alta dirección, se la relaciona con la rentabilidad, se la define desde el punto de vista del cliente y se la incluye dentro del proceso de planificación estratégica. Es más, para algunos es un factor clave de competitividad. Este cambio de actitud es consecuencia de diversas fuerzas externas, entre la que destaca la fuerte competencia japonesa.

A partir de los años sesenta la calidad, precio y fiabilidad de los productos japoneses en los mercados internacionales empezaron a ser una amenaza para las empresas estadounidenses. Con la crisis del petróleo se puso de manifiesto la distancia existente entre ambas industrias. Al principio la debilidad de la industria americana frente a su competencia japonesa se trató de explicar por causas ajenas a la empresa (cultura, sindicatos de empresa, empleo, etc.), pero tales argumentos no siempre fueron válidos.

El interés competitivo de los directivos occidentales les llevó a buscar nuevos argumentos y encontraron que aunque nada era nuevo (las herramientas y técnicas habían sido previamente importadas por Japón desde Occidente), eran diferentes algunos aspectos tales como su utilización más uniforme, más colaboración entre departamentos, énfasis en el cliente, etc. Estas experiencias llevaron a un importante cambio en la forma de concebir la calidad, pues no bastaba una producción sin defectos o con un control estadístico, sino que la calidad pasó a ser definida desde la perspectiva del cliente. Esto implicó la necesidad de estudios de mercado para comparar la calidad con otros competidores o considerar la vida del producto más allá del momento de su venta. La gestión estratégica de la calidad utiliza métodos y herramientas de las etapas anteriores, pero, a diferencia de ellas, tiene una relación más estrecha con la rentabilidad de la empresa, es más sensible a los aspectos competitivos, considera la perspectiva del cliente y defiende la mejora continua de los procesos. La gestión estratégica puede mejorar la competitividad de las empresas porque la alta dirección la considera el punto de partida para planificar de forma estratégica toda la actividad de la empresa, de tal forma que al cliente se le entregan productos que responden a sus necesidades y con una calidad superior a la de sus competidores.

La gestión de la calidad ha ido evolucionando hacia una visión cada vez más global, más orientada hacia los aspectos humanos y hacia la mejora de los procesos de dirección de las organizaciones. La evolución hacia este nuevo enfoque es consecuencia de los retos 
a los que tiene que enfrentarse las empresas en los mercados actuales. Estos pueden sintetizarse en los siguientes puntos:

1. Globalización de los mercados, que ha supuesto un aumento de la competencia al añadir a ésta la dimensión internacional, con una amplitud no conocida anteriormente.

2. Clientes exigentes, con expectativas y necesidades cambiantes y cada vez más elevadas.

3. Aceleración del cambio tecnológico, que implica ciclo de vida el producto cada vez más cortos.

4. Éxito de las forma pioneras más globales y participativas de gestión de la calidad.

Para hacer frente a estas nuevas exigencias no es suficiente con los enfoques de calidad precedentes. Es necesario un sistema de gestión de la calidad orientada en su totalidad al mercado; una orientación, que además, ha de tener carácter multidimensional y ha de ser dinámica. El carácter multidimensional viene dado por la necesitad de competir en un sector industrial globalizado en diseño, precio, calidad, capacidad de distribución, imagen, etc.

La orientación dinámica en los nuevos sistemas de gestión de calidad es necesaria ya que todas las variantes que configuran la competitividad están sometidas a cambios frecuentes. Ya se ha visto que la empresa es un sistema abierto en constante relación con proveedores, clientes, y otros stakeholders (accionista, directivos, trabajadores, otras empresas, partes de la sociedad que se relacionan con la empresa, etc.) y debe mantener relaciones equilibradas y estables para satisfacer a todos estos grupos de interés. El liderazgo de la dirección es aquí indispensable para implantar un buen sistema de la calidad.

Las diferencias más importantes entre los enfoques anteriores y la gestión de la calidad total son:

1. La orientación al cliente, que está relacionada con las condiciones de los mercados actuales.

2. El liderazgo en la dirección, como requisito indispensable para implantar el sistema de Gestión de la Calidad Total.

3. El establecimiento de formas de dirección, diseño de la organización y políticas de recursos humanos, que propicien la participación, el compromiso y la cooperación.

4. La aplicación de un enfoque global de dirección.

Las cuatro eras estudiadas pueden resumirse en el siguiente cuadro: 


\begin{tabular}{|c|c|c|c|c|}
\hline Empresa & $\begin{array}{c}\text { OBJETIVOS } \\
\text { defectos }\end{array}$ & $\begin{array}{c}\text { ORIENTACIÓN } \\
\text { producto }\end{array}$ & IMPLICACIÓN & MÉTODOS \\
\hline $\begin{array}{c}\text { Control del } \\
\text { producto }\end{array}$ & $\begin{array}{c}\text { Control de } \\
\text { productos } \\
\text { de inspección }\end{array}$ & $\begin{array}{c}\text { Reducción de } \\
\text { inspecciones }\end{array}$ & $\begin{array}{c}\text { Departamento } \\
\text { de calidad }\end{array}$ & $\begin{array}{c}\text { Medición y } \\
\text { verificación } \\
\text { estadística }\end{array}$ \\
\hline $\begin{array}{c}\text { Control del } \\
\text { proceso }\end{array}$ & $\begin{array}{c}\text { Organización } \\
\text { y coordinación }\end{array}$ & $\begin{array}{c}\text { Aseguramiento } \\
\text { y prevención }\end{array}$ & $\begin{array}{c}\text { Dep. de } \\
\text { calidad, } \\
\text { producción, I+D... }\end{array}$ & $\begin{array}{c}\text { Sistemas, } \\
\text { técnicas y } \\
\text { programas }\end{array}$ \\
\hline $\begin{array}{c}\text { Gestión de la } \\
\text { calidad total }\end{array}$ & $\begin{array}{c}\text { Impacto } \\
\text { estratégico }\end{array}$ & $\begin{array}{c}\text { Toda la } \\
\text { organización }\end{array}$ & $\begin{array}{c}\text { Satisfacción } \\
\text { plena del cliente }\end{array}$ & $\begin{array}{c}\text { Planificación } \\
\text { estratégica }\end{array}$ \\
\hline
\end{tabular}

Tabla 1 Cuadro resumen de la evolución de la calidad.

Aunque se han presentado las cuatro eras separadamente la realidad es que se han ido solapando a lo largo del tiempo y quizá hoy en día nos encontremos con los cuatro paradigmas conviviendo en distintas áreas del planeta.

\section{3.- DEFINICIÓN DE CALIDAD}

¿Qué significa calidad? En música se refiere a un determinado grupo de componentes armónicos de un sonido. En el contexto social, puede referirse a un estado de la élite. Podría ser el sabor o el tamaño de una manzana, la textura de una tela, o la dimensión de un producto. Por lo tanto la calidad es una característica o un conjunto de características de algo. En la industria, ese algo es un producto; una de las mercancías o servicios que se producen para su venta.

Un gran número de organizaciones y expertos han buscado una definición para el concepto de calidad, pero lo cierto es que no existe una específica que pueda considerarse como la más correcta. Lo cierto es que las distintas ideas o definiciones de lo que se entiende por calidad han surgido para dar respuesta a los continuos cambios empresariales.

Las nuevas definiciones no han sustituido a las más antiguas, sino que ambas han continuado usándose sin poderse establecer la mejor entre todas ellas. En el contexto de las empresas industriales desde comienzos de siglo XX, y tal vez antes, se entendía la calidad como:

"El grado en que un producto cumplía con las especificaciones técnicas que se habían establecido cuando fue diseñado”.

Posteriormente fue evolucionando el concepto de calidad, que la norma UNE 66-001 define como: 
"La adecuación al uso del producto o, más detalladamente, el conjunto de propiedades y características de un producto o servicio que le confieren su aptitud para satisfacer unas necesidades expresadas o implícitas".

Más recientemente el concepto de calidad ha trascendido hacia todos los ámbitos de la empresa y así actualmente se define como:

"Todas las formas a través de las cuales la empresa satisface las necesidades y expectativas de sus clientes, sus empleados, las entidades implicadas financieramente y toda la sociedad en general”.

Podemos ver que esta última definición engloba a la segunda y esta a su vez a la primera.

La evolución que ha sufrido la calidad en el tiempo permite establecer cuatro enfoques básicos de su definición:

- Calidad es Excelencia.

- Calidad es Valor.

- Calidad es Conformidad con las especificaciones.

- Calidad es igualar o exceder las Expectativas de los clientes.

El concepto más antiguo y utilizado de calidad es excelencia, es decir, lo mejor. Se remonta a los filósofos griegos, de tal forma que para Platón la excelencia era algo absoluto, la más alta idea de todo. Este concepto ha sido recuperado más recientemente por diversos autores, y lo han asimilado con la calidad.

La calidad como excelencia es un concepto universalmente reconocible que señala un estándar elevado y difícil de alcanzar. Por otro lado, esta perspectiva puede ser un recurso para obtener beneficios tanto desde el punto de vista del marketing como de los recursos humanos. Ofrecer "lo mejor" es un argumento fácil para proporcionar valor al consumidor y en muchos casos es la base de la publicidad de las empresas; además es un buen argumento para ganar el compromiso y aceptación de los empleados.

Este tradicional concepto adquiere una nueva dimensión cuando la calidad comienza a ser considerada por la teoría económica, junto con el precio, como otro de los determinantes de la elección del consumidor. Autores como Abbott y Feigenbaum opinaron que los diferentes niveles tanto en el precio como en la calidad eran importantes para las decisiones de los consumidores, mientras que hasta los años cincuenta para la teoría económica el precio era el único determinante para la elección del consumidor. La calidad empieza a ser entendida como lo mejor, pero condicionado por el actual uso y el precio de venta para el consumidor.

Esta visión pone de manifiesto la búsqueda de lo mejor, pero no a cualquier precio. 
Adoptar el concepto de calidad como valor permite, en primer lugar, tener en cuenta atributos como el precio, duración, excelencia, etc. En segundo lugar, centra la atención de las empresas tanto en alcanzar la eficiencia interna (conformidad con las especificaciones) como en la eficacia externa (satisfacer las necesidades de los clientes). La calidad entendida como conformidad con las especificaciones aparece vinculada al desarrollo de la industria de armamento en los Estados Unidos, si bien ello no hubiera sido posible sin los nuevos sistemas de producción en masa o sin los revolucionarios avances tecnológicos surgidos durante el siglo. Antes de los años treinta el objetivo principal de la calidad es fabricar piezas intercambiables que permitan altos volúmenes de producción.

Tras los años treinta, y con los nuevos conceptos aportados por el control estadístico de procesos y las muestras estadísticas, se clarifica el concepto de calidad. Juran incluye en su definición tanto la excelencia como la conformidad. Entre los inconvenientes de esta definición destaca el hecho de que los clientes no suelen evaluar un producto en términos de su conformidad con las especificaciones internas. Los clientes valoran más otros detalles en la venta, servicio posventa, etc.

A medida que la sociedad norteamericana y el resto de economías occidentales se han convertido en economías de servicios, el concepto de calidad ha experimentado una considerable transformación. Por un lado, el concepto de calidad se ha ampliado a los servicios y, por otro, se ha incluido el punto de vista del consumidor. Del concepto de conformidad con las especificaciones se pasa a un concepto basado en el cliente.

\section{4. -BENEFICIOS DE LA CALIDAD}

\subsection{1. - CALIDAD COMO AHORRO}

Cuando se plantea en una empresa ofrecer calidad a los clientes, lo primero que se piensa es que la calidad tiene un precio, es decir la mejora de calidad irá unida a un aumento en los costes de la empresa. Sin embargo esta idea no es del todo cierta, pues la relación entre calidad y coste es distinta en función de cómo se definan las variables. En general se puede hablar de dos puntos de vista:

1. Si la definición de calidad es la basada en el producto, es decir, como la cantidad de algún atributo o ingrediente de dicho producto, entonces es claro que existe una relación positiva entre calidad y coste. Variaciones que afecten a la duración de los productos, a su aspecto, a su desempeño etc., requerirán mejores materiales, más horas de mano de obra u otros recursos que aumentarán el coste. Esta perspectiva es la que suele predominar en la mayoría de las empresas.

2. Si la calidad se define como conformidad con las especificaciones, esto es, ausencia de fallos, se puede decir que la relación es negativa. Los costes de mejorar la calidad serán inferiores a los ahorros generados, tanto directamente, por la eliminación de pérdidas de tiempo, como indirectamente por la disminución de 
gastos de garantía indemnizaciones y pérdida de imagen de la empresa. Todo esto sin tener en cuenta el posible aumento de las ventas derivado de una mayor competitividad y las mejores relaciones con los clientes.

Este último punto de vista ha sido adoptado por muchas empresas japonesas y justifica su permanente interés por la mejora continua, ya que calidad es entendida como ausencia de defectos y los costes como coste de una deficiente calidad. Para hacer más compresible esta relación se estudiarán los costes de calidad con más detalle más adelante.

\subsection{2.- CALIDAD Y PRODUCTIVIDAD}

Tradicionalmente se opinaba que calidad y productividad eran incompatibles, porque si se perseguía la calidad bajaba la producción, y si se perseguía la productividad la calidad se resentía. Sin embargo, los criterios modernos de gestión de la calidad apuntan que es precisamente la falta de calidad lo que origina una baja productividad.

Esta relación se puede concretar si la productividad se mide como el ratio de output (sin defectos) entre inputs y la calidad como conformidad, es decir, como el porcentaje de unidades producidas sin defectos. Cualquier mejora de la calidad, es decir, disminución de unidades defectuosas, supone un incremento de los outputs sin defectos, por lo que aumenta el ratio que mide la productividad. A la misma vez la necesidad de recursos es menor, pues los desechos y los retrabajos son reducidos, por lo que, igualmente, mejora la productividad.

\subsection{3.- CALIDAD Y RENTABILIDAD}

Entre calidad y rentabilidad existe igualmente una correlación positiva que puede estudiarse a través de dos vías: el mercado y los costes. En el primer caso, si la empresa mejora la calidad, normalmente también lo hace la reputación de la empresa y, en consecuencia, la satisfacción y la lealtad de los clientes. Ante esto se producen dos efectos:

1. Aumentan las ventas y, por tanto, la cuota de mercado.

2. La empresa puede incrementar sus precios y mejorar sus ingresos.

Si la empresa logra unos mayores ingresos y, por otro lado, disminuye los costes, mejora sus beneficios y su rentabilidad.

En el segundo caso la rentabilidad se incrementa por la mejora de la fiabilidad y la conformidad de los productos, dado que la productividad es mayor, disminuyen los costes de retrabajos y desechos y disminuyen los costes derivados de garantías e indemnizaciones.

Los dos primeros efectos suponen reducir los costes de fabricación y el tercero, reducir los de servicio. En cualquier caso, menores costes implican mayor beneficio y rentabilidad. 


\subsection{4.- OTROS EFECTOS DE LA CALIDAD}

Los resultados de una adecuada gestión de la calidad van más allá del aumento de la productividad, de la rentabilidad o de la disminución de los costes. Se producen otros efectos en las empresas como:

- Mejora de la imagen comercial y el marketing-producto: Una estrategia basada en la calidad promueve la venta y es el soporte idóneo para el mantenimiento o incremento de precios. Además, en la medida en que los clientes se sientes satisfechos con el nivel de calidad recibido se generan unos beneficios adicionales derivados de la publicidad que realizan a potenciales cliente.

- Facilita la adopción de nuevos sistemas de producción: Con un bajo porcentaje de defectos la empresa puede plantearse la automatización de sus procesos con las garantías necesarias para conseguir una alta productividad y una mayor flexibilidad ante las exigencias del mercado.

- Aumenta la motivación, la involucración y la satisfacción de los empleados: Los empleados encuentran más argumentos para sentirse satisfechos en el trabajo y para seguir mejorando en el mismo.

Como conclusión se puede decir que la calidad es una de las inversiones más rentables para una empresa si se compara con la cuantía de dicha inversión (tiempo, recursos humanos, etc.) con todos los beneficios que genera (mayor participación en el mercado, ventas a mejores precios, costes más bajos y excelentes relaciones con los clientes).

Estos beneficios pueden resumirse en la siguiente figura:

INTERNO

EXTERNO

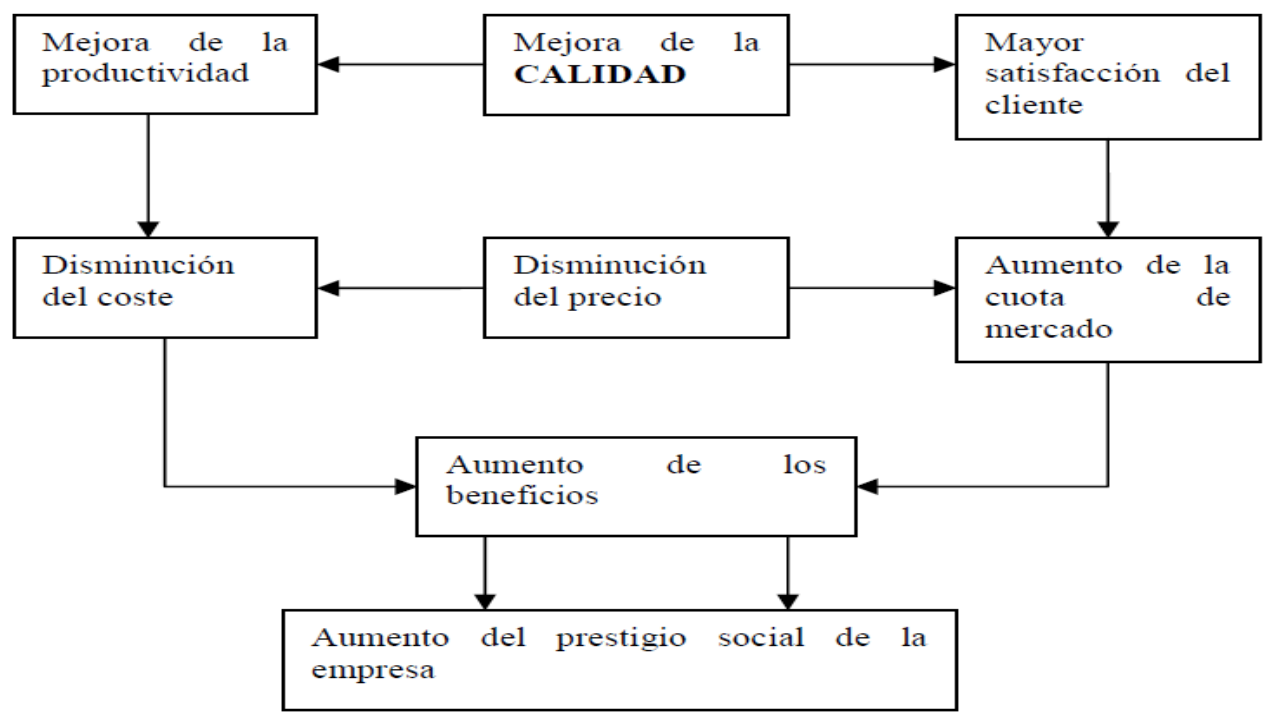

Figura 1. Contribución de la calidad al beneficio de la empresa 


\section{5.- CALIDAD TOTAL}

\subsection{1.- FUNDAMENTOS}

La Calidad Total es el estadio más evolucionado dentro de las sucesivas transformaciones que ha sufrido el término Calidad a lo largo del tiempo. En un primer momento se habla de Control de Calidad, primera etapa en la gestión de la Calidad que se basa en técnicas de inspección aplicadas a producción. Posteriormente nace el Aseguramiento de la Calidad, fase que persigue garantizar un nivel continuo de la calidad del producto o servicio proporcionado. Finalmente se llega a lo que hoy en día se conoce como Calidad Total, un sistema de gestión empresarial íntimamente relacionado con el concepto de Mejora Continua y que incluye las dos fases anteriores.

Su filosofía proporciona una concepción global que fomenta la Mejora Continua en la organización y la involucración de todos sus miembros, centrándose en la satisfacción tanto del cliente interno como del externo. Podemos definir esta filosofía del siguiente modo: Gestión (el cuerpo directivo está totalmente comprometido) de la Calidad (los requerimientos del cliente son comprendidos y asumidos exactamente) Total (todo miembro de la organización está involucrado, incluso el cliente y el proveedor, cuando esto sea posible).

Es una estrategia que busca garantizar, a largo plazo, la supervivencia, el crecimiento y la rentabilidad de una organización optimizando su competitividad, mediante: el aseguramiento permanente de la satisfacción de los clientes y la eliminación de todo tipo de desperdicios. Esto se logra con la participación activa de todo el personal, bajo nuevos estilos de liderazgo; siendo la estrategia que bien aplicada, responde a la necesidad de transformarlos productos, servicios, procesos estructuras y cultura de las empresas, para asegurar su futuro.

\subsection{2.- CIRCUNSTANCIAS QUE HAN INFLUIDO EN LA CULTURA DE LA CALIDAD TOTAL}

\section{Externas}

- La globalización.

- El conocimiento de derechos y productos por los consumidores, volviéndose clientes más exigentes.

- Mayor competencia (por lo anterior) y los empresarios deben ofertar más calidad al menor precio.

\section{Internas}

- Gastos de gestión por mala calidad.

- Poca implicación del personal.

- Insatisfactorio aprovechamiento de los recursos de la empresa. 


\subsection{3.- OBJETIVOS DE LA CALIDAD TOTAL}

Al definir la Calidad Total se hacía alusión a la misma como una estrategia de Gestión con el propósito de conseguir unos objetivos, los cuales abarca los siguientes campos:

\begin{tabular}{|c|c|}
\hline Comerciales & $\begin{array}{l}\text { - } \text { Conocer y satisfacer los requisitos de todos los clientes. } \\
\text { - Responder satisfactoriamente a sus expectativas. } \\
\text { - } \text { Lograr mantenerlo como cliente y atraer a otros nuevos. } \\
\text { - } \text { Mejora continua de la imagen de la empresa. } \\
\text { - Aumentar la implantación de la empresa en el mercado. }\end{array}$ \\
\hline Económicos & 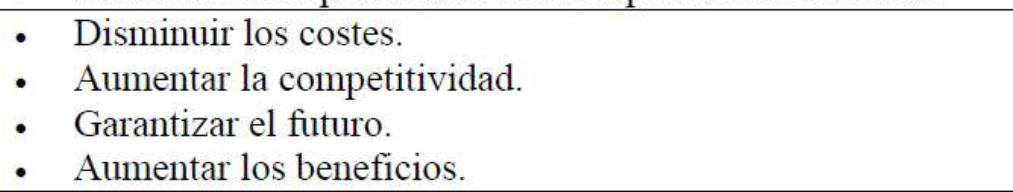 \\
\hline Técnicos & $\begin{array}{l}\text { - Lograr controlar y mejorar los procesos. } \\
\text { - } \text { Apostar por la prevención y la mejora continua. } \\
\text { - Optimizar los procesos e implantar innovaciones. } \\
\text { - Investigación e incorporación de nuevas tecnologías. } \\
\text { - Uso masivo de diversas técnicas y herramientas de calidad. } \\
\text { - Evaluación. }\end{array}$ \\
\hline Humanos & $\begin{array}{l}\text { - Aumentar y canalizar la información y la formación. } \\
\text { - Cambiar la cultura y el modo de hacer las cosas. } \\
\text { - } \text { Potenciar las iniciativas y la responsabilidad de todos los } \\
\text { empleados. } \\
\text { - Lograr la participación e implicación de todos los } \\
\text { departamentos. } \\
\text { - Puesta en práctica de forma conjunta. }\end{array}$ \\
\hline
\end{tabular}

Tabla 2 Objetivos de la Calidad

\subsection{4.- CARACTERÍSTICAS BÁSICAS}

El concepto de calidad se ha ido transformando con el paso del tiempo y de acuerdo a las exigencias del propio mercado, dando así un nuevo concepto sobre la Calidad, donde el producto o servicio se diseña en función de los requerimientos y necesidades del consumidor, teniendo en cuenta también conceptos como, el precio, el tiempo, etc.

De acuerdo a estas exigencias, el concepto de Calidad engloba 3 características básicas.

- Calidad de diseño.

- Calidad de fabricación.

- Calidad de vida del trabajador.

Y la suma de estos da como resultado la "Calidad Total". 


\section{- Calidad de diseño}

La calidad de diseño es básicamente la adecuación del producto y/o servicio a las necesidades y requerimientos del consumidor.

Básicamente es una planeación a conciencia del producto y/o servicio que se va a ofrecer a la comunidad.

Deberán tenerse en cuenta 5 puntos claves para que se dé dicha calidad de diseño:

1. Segmentar el mercado para identificar el nicho o nichos de mercado al que habremos de dirigirnos.

2. Realizar la adecuada y completa investigación de mercado para cada nicho al que nos dirigiremos.

3. Adecuar el producto o servicio de acuerdo a las necesidades, gustos y preferencias detectadas en la investigación de mercado.

4. Definir los métodos de producción a utilizar.

5. Equipar a la organización con los elementos necesarios para la producción del producto o servicio, así como los cursos de capacitación para el personal.

\section{- Calidad de fabricación}

Hay que conseguir una adecuación de la empresa haciéndola mucho más flexible y operando con recursos mínimos para la manufactura, logrando ventajas competitivas en rapidez de respuesta y costos reducidos, con lo que se satisface al cliente.

Es la metodología que ayuda a eliminar las actividades que no añaden valor. Analiza el flujo de información y materiales en todas las áreas de su planta para reducción de desperdicios y la mejora de los procesos.

Se trata de un poderoso enfoque de gestión orientado a conseguir a largo plazo un modelo superior de fabricación (aunque el enfoque es también aplicable en servicios).

\section{- Calidad de vida de los trabajadores}

Hay que darles a los trabajadores de todos los niveles un clima organizacional óptimo, ya que de eso depende el trabajo realizado.

Para que se de un agradable clima organizacional, debe de contarse con un líder que asesore a los trabajadores, pero debe tenerse muchísimo cuidado de que este líder no se convierta en un capataz que ordene y haga sentir a los trabajadores que no se les tiene 
confianza. Ya que esto afectara en el nivel de desempeño de los trabajadores. Puesto que sentirán limitada su capacidad para tomar decisiones y hasta pueden perder el gusto y la entrega por su trabajo.

\section{6. -PRINCIPIOS FUNDAMENTALES DE LA CALIDAD TOTAL}

La concepción actual de la calidad responde a la aportación de diversas teorías surgidas a lo largo del siglo XX. Hoy en día la Calidad Total es el compendio de las mejores prácticas en el ámbito de la gestión de organizaciones, a las cuales se les suele denominar Principios de la Calidad Total - Excelencia.

\subsection{1.- ORIENTACIÓN HACIA LOS RESULTADOS}

El éxito continuado depende del equilibrio y la satisfacción de las expectativas de todos los grupos de interés que de una forma u otra participan en la organización: clientes, proveedores, empleados, todos los que tienen intereses económicos en la organización y la sociedad en general. La dirección debe satisfacer equilibradamente las necesidades de estos grupos e interés.

\subsection{2.- ORIENTACIÓN AL CLIENTE}

Hasta ahora la gestión empresarial estaba basada en la búsqueda de la competitividad en el interior de la organización, considerándose la eficacia de la producción como la principal fuente de ventaja competitiva. Como consecuencia de ello, las variables coste y precio han sido de vital importancia en la gestión.

Frente a este planteamiento estratégico surge el modelo de Calidad Total-Excelencia que hace trabajar a toda la organización en la búsqueda de la satisfacción del cliente.

Este enfoque hacia el cliente trae consigo una serie de ventajas:

- Ganar su confianza y fidelidad.

- Protección contra la competencia.

- Adaptación a los cambios de las necesidades del consumidor.

- Capacidad para retomar posiciones de mercado pérdidas.

- Rentabilidad a largo plazo.

La satisfacción del cliente depende del valor percibido en el producto o servicio con respecto a las expectativas que tenía. El lograr una mayor satisfacción del cliente podrá conseguirse bien mejorando el producto o servicio prestado o bien generando expectativas más realistas. Sin embargo, la satisfacción del cliente no es estática sino dinámica: evoluciona a lo largo del tiempo por diversas causas. Son las organizaciones excelentes, obsesionadas por deleitar a sus clientes, quienes a largo plazo consiguen su fidelización.

Para ello hay que seguir varios pasos: 
Satisfacción del cliente $=\frac{\text { valor percibido }}{\text { expectativas }}$

1. Identificar al cliente. Es necesario saber quién es nuestro cliente para poder conocer cuales son sus necesidades y exigencias.

2. Definir sus necesidades. Hay que prestar atención a lo que el cliente necesita, escucharle y prestar atención a sus solicitudes. Hay que conseguir la mayor información posible en este punto.

3. Trasladar los requisitos del cliente a especificaciones del producto. El producto diseñado debe cumplir con los requisitos del cliente, que cumpla con lo que el cliente espera y desea e incluso los supere.

4. Fabricar el producto conforme a las especificaciones.

5. Medir la satisfacción del cliente. Hay que utilizar indicadores y actuar sobre los resultados obtenidos, buscando de ese modo la mejora continua.

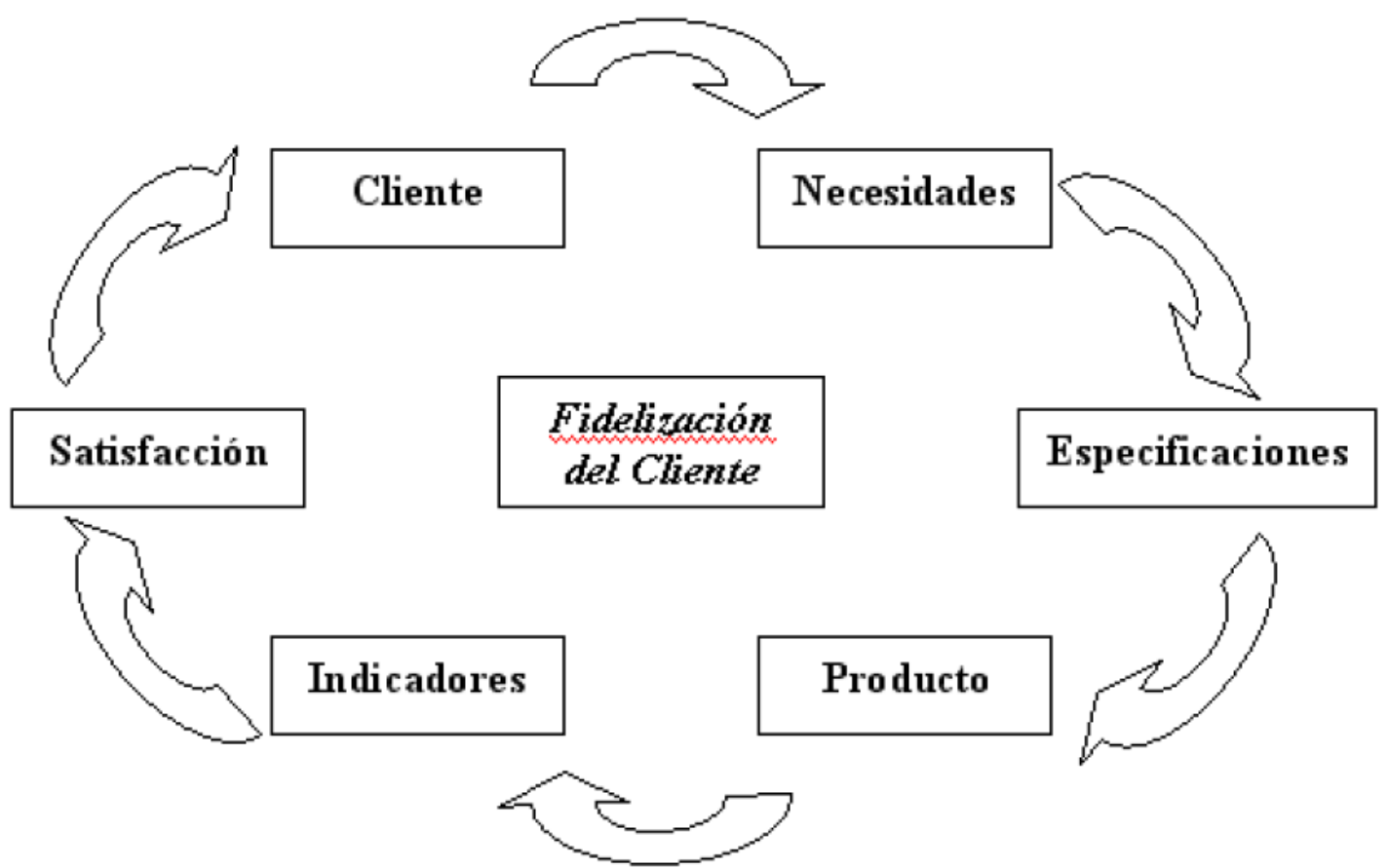

Figura 2. La consecución de la satisfacción del cliente

Se definen tres factores fundamentales que influyen directamente en la satisfacción del cliente: 
- Producto o servicio: Diseño, calidad de las materias primas, calidad del producto o servicio, homogeneidad, fiabilidad.

- Ventas y postventa: Publicidad, garantías, devoluciones, quejas, servicio plazo precio,...

- Cultura: Valores que la organización proyecta consciente o inconscientemente.

Por consiguiente, es importante que la organización recoja información de los clientes en dos momentos diferentes: a priori, sus necesidades y a posterior, el grado en que han conseguido satisfacerlas.

\subsection{3.- LIDERAZGO}

La Calidad Total-Excelencia es una estrategia porque trata de dirigir y coordinar acciones para conseguir la competitividad empresarial o la mejora de la eficiencia de la organización, según los casos, ahora y en el futuro. No es un programa de actividades, ni una técnica o conjunto de herramientas. Tampoco es un sistema. Es una estrategia, y como tal implica ponerla en práctica de forma que todas las decisiones y actuaciones sean resultado de dicha estrategia.

En este sentido, el papel de la dirección en el proceso hacia la Calidad Total-Excelencia es el de lograr que esta estrategia de gestión se despliegue por toda la organización, asumiendo el liderazgo del proyecto para conseguir que se integre en la cultura de la organización. Esta cultura debe transmitirse de arriba a abajo, siendo el primer requisito necesario que la dirección demuestre en sus propias actuaciones su compromiso con la Calidad Total-Excelencia. Además, los directivos y demás líderes de la organización deberán ser facilitadores de todos los medios necesarios: comunicación, formación, fondos, tiempo, apoyo, etc.

\subsection{4.- ENFOQUE ORIENTADO A PROCESOS}

La organización es un conjunto de procesos que generan productos o servicios. Estos procesos son normalmente interdepartamentales o interfuncionales.

La tradicional gestión de la organización por funciones o departamento

se debe completar con la gestión por procesos para adaptarse mejor a las necesidades de los clientes y por lo tanto, mejorar de la competitividad de la organización.

La gestión por procesos consta de los siguientes pasos:

1. Identificar los procesos fundamentales de la organización (Estratégicos, Operativos y de Apoyo).

2. Organizar los procesos. 
3. Nombrar los responsables o propietarios de los procesos y los equipos de mejora.

4. Revisar los procesos.

5. Establecer acciones y objetivos de mejora sobre estos procesos.

La gestión de estos procesos se basa en los hechos, la medición y la información.

En demasiadas ocasiones se tiene tendencia a gestionar y tomar decisiones basadas en opiniones. Frente a ello se debe realizar un esfuerzo por acudir a buscar los datos allí donde se encuentren y tomar las decisiones basándose en ellos. Los datos suelen requerir un esfuerzo para transformarlos en información útil o en indicadores que nos permitan tomar decisiones e una manera acertada.

La experiencia ha demostrado que el uso de un grupo de sencillas herramientas permite resolver el $80 \%$ de los problemas de las organizaciones.

(¿cómo?)

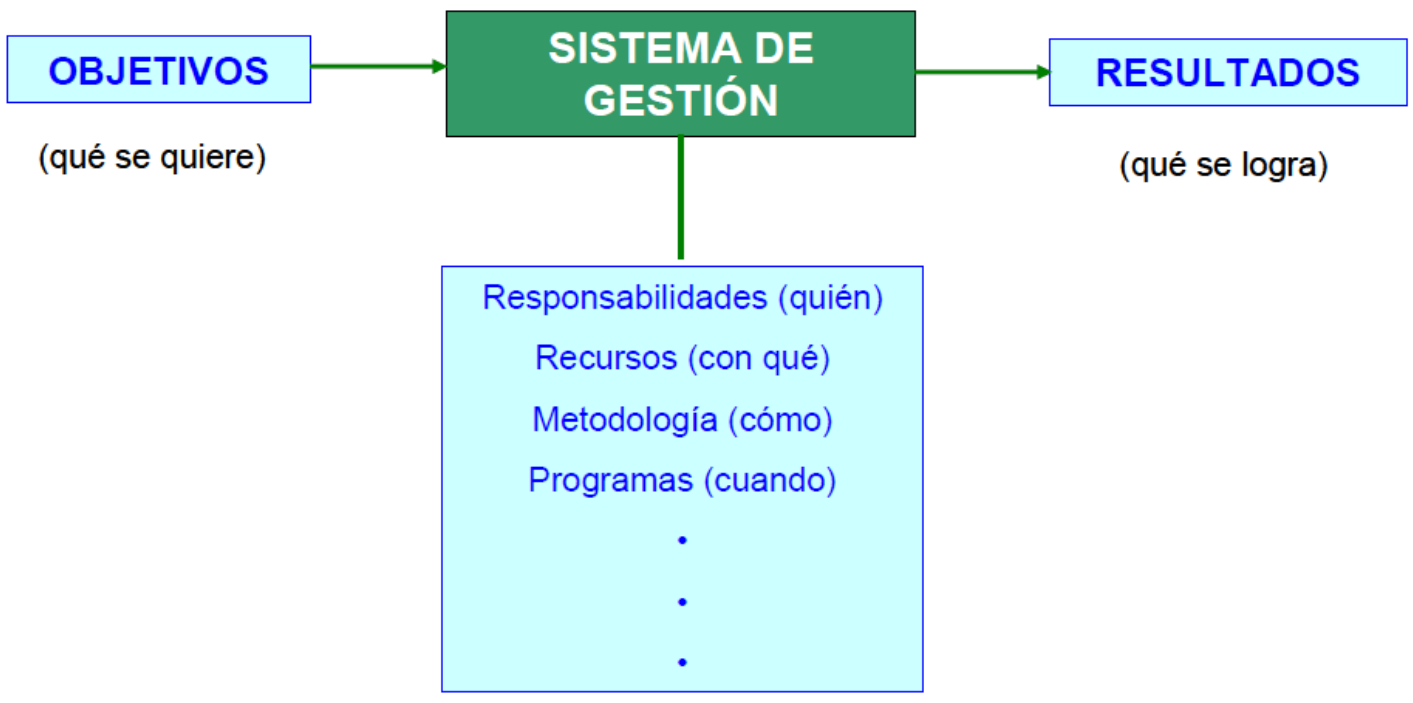

Figura 3. Enfoque basado en Procesos

\subsection{5.- DESARROLLO E IMPLICACIÓN DE LAS PERSONAS}

Es responsabilidad de la dirección de las organizaciones el pleno desarrollo del potencial de las personas que trabajan en ella, así como involucrarles y hacerles partícipes del proyecto de la misma. Para lograrlo deberá llevar a cabo diversas iniciativas estableciendo o reforzando los mecanismos de comunicación y participación. 


\subsection{6.- MEJORA CONTINUA}

Shewhart definió la mejora continua como un ciclo de cuatro fases PDCA (Plan-DoCheck-Act). Si se es capaz de aplicar este ciclo a todas las actividades de la organización, los resultados en poco tiempo se verían mejorados de forma sustancial.

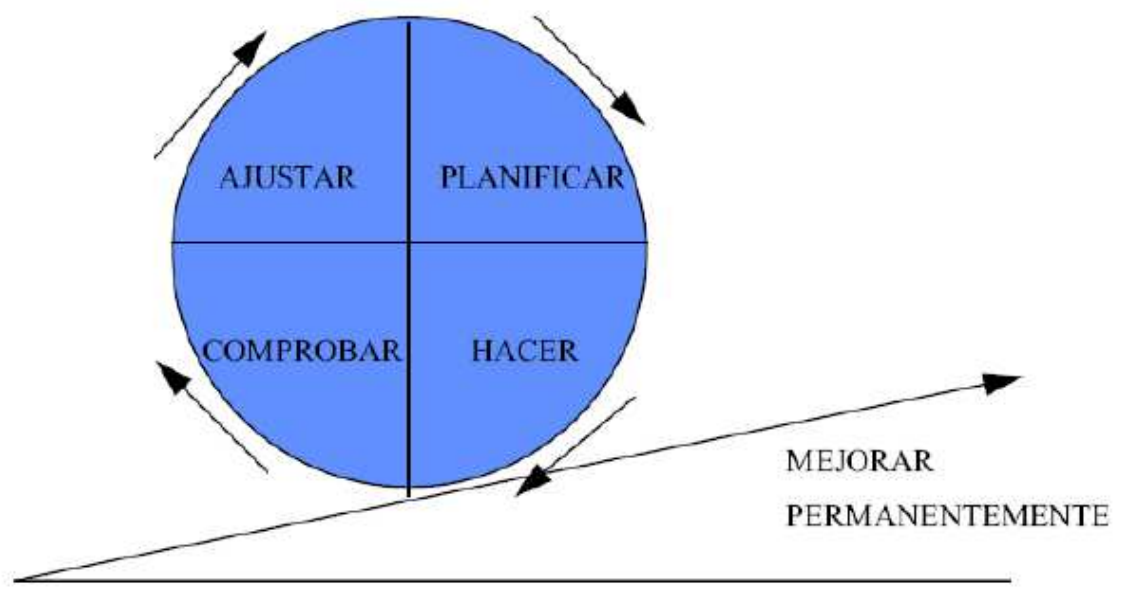

Figura 4. Ciclo PDCA de Shewhart

Hay que buscar continuamente la satisfacción del cliente, la mejora continua de las actividades y los resultados. Para ello hay que definir los objetivos y luego las acciones para conseguirlos.

La dirección debe establecer la forma de actuar y la organización de la empresa. Debe tener claro los factores de éxito, los problemas, las operaciones de mejora, los recursos y acciones que se van a realizar. Conviene crear una imagen de qué se desea para los próximos cinco, diez o quince años. Se define la política de calidad, se implementa y se audita periódicamente.

Es necesario tener proyectos de mejora. Estos pueden venir de varias fuentes: clientes, trabajadores, auditorias, amfe, sugerencias, círculos de calidad, análisis de valor, revisiones de diseño, etc. Para los proyectos y la mejora continua en general se usa el ciclo PDCA o la Trilogía de Juran. Se establece una jerarquía de las soluciones, se priorizan y se definen las acciones correspondientes. Se evalúan los logros, se comparan con los objetivos y se vuelve a empezar. 


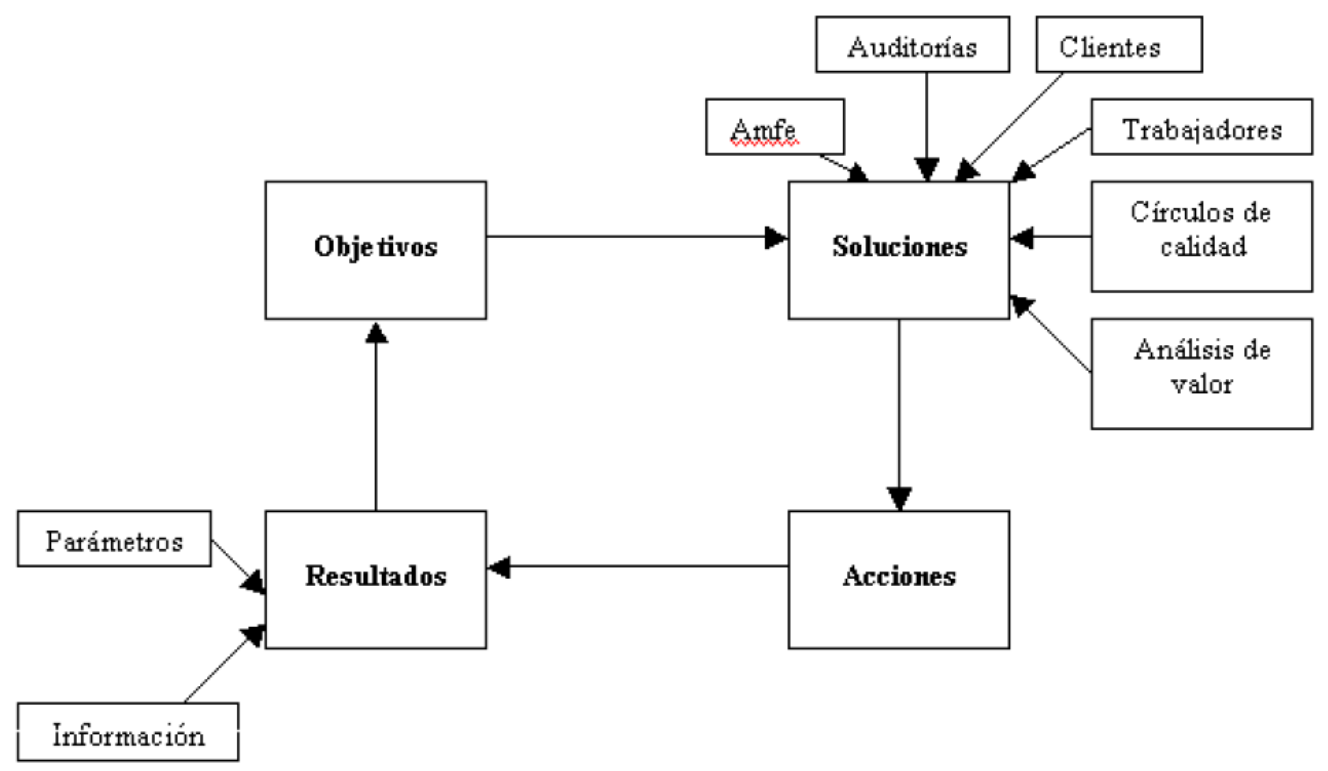

Figura 5. Mejora continua.

\subsection{7.- ENFOQUE DEL SISTEMA PARA LA GESTIÓN}

Un sistema de gestión de la calidad pretende, además de asegurar la calidad del producto, asegurar y aumentar la satisfacción del cliente, para alcanzar los objetivos marcados.

Para que una actividad proporcione unos resultados favorables es fundamental una buena gestión, sin ella los objetivos y metas marcados son mucho más difíciles de lograr, e incluso aunque se consigan, los resultados obtenidos siempre serán mejores si existe una buena gestión y una adecuada organización en todos los ámbitos de la empresa, tales como suministro de materiales, capital, instalaciones o recursos humanos.

Una organización está formada por gran cantidad de recursos de todo tipo, los cuales es preciso optimizar para garantizar la eficacia del sistema, de modo que no se produzca ningún gasto innecesario y se alcancen los objetivos previstos.

\subsection{8.- RELACIÓN MUTUAMENTE BENEFICIOSA CON LOS PROVEEDORES}

Una buena relación de una empresa con sus suministradores es fundamental, supone que ambas partes puedan aumentar sus beneficios, optimizar sus costes y sus recursos, y además, a través de un buen acuerdo, pueden responder conjuntamente de una forma más rápida y flexible a las necesidades de un mercado cambiante y las exigencias de los clientes.

Las relaciones entre empresas y proveedores han experimentado múltiples cambios en los últimos años, debido fundamentalmente a la evolución existente en el mercado que 
hace que cada uno tenga que ser el mejor en su actividad si quiere ser competitivo. Es preciso que las organizaciones dediquen especial atención a la elección de sus proveedores ya que dependen de ellos en gran medida. Las organizaciones deben establecer con sus proveedores y otras empresas colaboradoras en proyectos vínculos estables basados en la confianza y en establecer relaciones mutuamente beneficiosas.

Las relaciones de asociación con proveedores están basadas en la confianza y en una integración adecuada pactando y satisfaciendo sus requerimientos legítimos para, generar con ello mejoras de valor añadido a los clientes.

\subsection{9.- OBSTÁCULOS A LA CALIDAD TOTAL}

\begin{tabular}{|c|c|}
\hline La dirección & $\begin{array}{l}\text { - Falta de compromiso. } \\
\text { - Incapacidad de liderazgo. } \\
\text { - Falta de prevención y dificultad de resolver obstáculos. } \\
\text { - Frenos a la participación y a escuchar sugerencias. } \\
\text { - Rechazo a la delegación de tareas y responsabilidades. } \\
\text { - Falta de canales de información. } \\
\text { - Existencia de clanes o grupos de presión. } \\
\text { - Falta de recursos materiales y/o mandos. }\end{array}$ \\
\hline La organización & $\begin{array}{l}\text { - Empirismo de los expertos. } \\
\text { - Preocupación por la cantidad en detrimento de la calidad. } \\
\text { - Sistemas demasiado centralizados, burocratizados y rígidos. } \\
\text { - Carencias de poder del asesor o responsable de calidad. } \\
\text { - Mal funcionamiento de los grupos o comités de calidad. } \\
\text { - Una organización muy compartimentada y apartada. } \\
\text { - Repetición del tratamiento de problemas por varios grupos. }\end{array}$ \\
\hline El personal & $\begin{array}{l}\text { - Resistencia al cambio. } \\
\text { - Falta de formación o motivación. } \\
\text { - Desconocimiento de lo que supone el cambio cultural } \\
\text { producido. } \\
\text { - Miedos y recelos, sobre todo de los mandos. } \\
\text { - Hábitos y tareas rutinarias. } \\
\text { - Problemas para trabajar en equipo. } \\
\text { - Dificultades para expresarse y aportar ideas. } \\
\text { - Carencia de información y responsabilidades. }\end{array}$ \\
\hline $\begin{array}{l}\text { La táctica y la } \\
\text { estrategia }\end{array}$ & $\begin{array}{l}\text { - Carencia de comunicación y formación. } \\
\text { - Problema de tipo financiero. } \\
\text { - Dificultades de comprensión y transmisión de los objetivos. } \\
\text { - Entender la Calidad Total como una moda. } \\
\text { - Riesgo de realizar mal el proceso de implantación. } \\
\text { - Peligro de contrapartidas en vez de asunción del proyecto. } \\
\text { - Centrarse demasiado en la documentación. }\end{array}$ \\
\hline
\end{tabular}

Figura 6. Obstáculos a la Calidad Total

\section{7.- LA FILOSOFÍA DE LOS GURÚS DE LA CALIDAD}

Como ya hemos comentado en los capítulos anteriores, la revolución de la calidad que se produjo en Japón tras la segunda guerra mundial recibió un impulso definitivo con las 
conferencias sobre gestión y control de la calidad impartidas por una serie de expertos procedentes de Estados Unidos. En la actualidad a estos primeros expertos que hicieron hincapié en la importancia de la gestión de la calidad para la competitividad empresarial se les conoce como los "gurús de la calidad". De ellos sobresalen por encima de los demás W. Edwards Deming, Joseph M. Juran y Philip B. Crosby, tanto por la relevancia de sus contribuciones como por su impacto directo sobre la gestión empresarial. En el presente capítulo se presentarán las principales contribuciones de estos tres gurús de la calidad, junto a las de Ishikawa, Taguchi y Feigenbaum.

\subsection{1- LA FILOSOFÍA DE DEMING}

William Edwards Deming (1900- 1993), fue un estadístico estadounidense, profesor universitario, autor de textos, consultor y difusor del concepto de calidad total. Su nombre está asociado al desarrollo y crecimiento de Japón después de la Segunda Guerra Mundial.

Se doctoró en física y trabajó para la Western Electric en los años 20-30. Deming estuvo especialmente interesado en los métodos estadísticos de Walter Shewhart. Comenzó aplicando técnicas estadísticas a distintos procesos productivos, consiguiendo mejorar de forma considerable la productividad, si bien no se conformó con llevar a la práctica estos métodos, sino que los desarrolló de forma notable. Deming afirma que los métodos estadísticos proporcionan el único método de análisis que sirve de guía para entender los fallos y reducirlos.

Sus enseñanzas no fueron bien acogidas en occidente, donde la tradición decía que calidad y productividad eran incompatibles. Sin embargo, fue un auténtico revolucionario para las empresas japonesas, enseñando a mejorar la calidad a través del control estadístico y de la reducción de la variabilidad. Su relevancia en Japón fue tal que el premio japonés de la calidad lleva su nombre desde su creación en 1951.

Aunque en un principio se centró en la estadística, posteriormente se orientó hacia la gestión de la calidad. Así, afirma que la dirección juega un papel principal en la mejora de la calidad y los resultados a largo plazo. La calidad lleva a más productividad, al reducirse los costes derivados de reprocesos, errores y retrasos y al mejorar la utilización de la maquinaria y de los materiales. A su vez, esta mejora de la productividad conduce a un mayor poder competitivo a largo plazo, como se aprecia en su conocida reacción en cadena. 


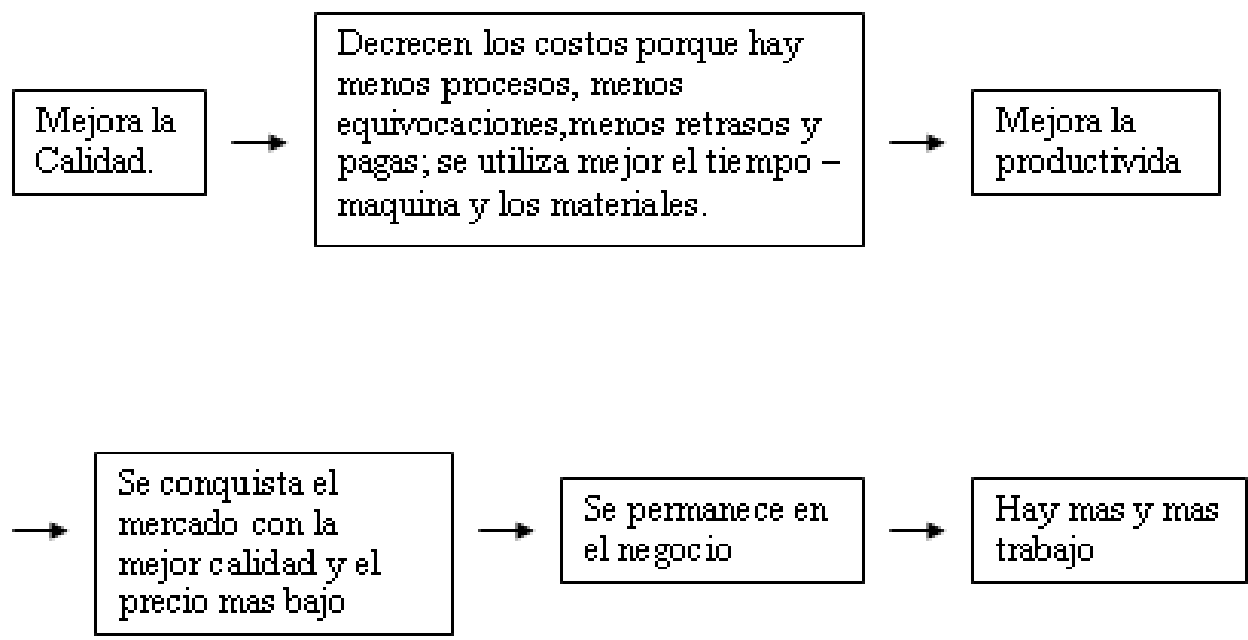

Figura 7: reacción en cadena

Deming afirma que todo proceso es variable y cuanto menor sea la variabilidad del mismo mayor será la calidad del producto resultante. En cada proceso pueden generarse dos tipos de variaciones o desviaciones con relación al objetivo marcado inicialmente: variaciones comunes y variaciones especiales. Solo efectuando esta distinción es posible alcanzar la calidad. Las variaciones comunes están permanentemente presentes en cualquier proceso como consecuencia de su diseño y de sus condiciones de funcionamiento, generando un patrón homogéneo de variabilidad que puede predecirse y, por tanto, controlarse. Las variaciones no asignables o especiales tienen, por su parte, un carácter esporádico y puntual provocando anomalías y defectos en la fabricación perfectamente definidos, en cuanto se conoce la causa que origina ese tipo de defecto y por tanto se puede eliminar el mismo corrigiendo la causa que lo genera. El objetivo principal del control estadístico de procesos es detectar las causas asignables de variabilidad de manera que la única fuente de variabilidad del proceso sea debido a causas comunes o no asignables, es decir, puramente aleatorias.

El cambio cultural que Deming propone para las organizaciones está expresado claramente en sus famosos 14 puntos, cuya validez fue demostrada en la práctica por el propio Deming.

\section{-Los Catorce Puntos de Deming.}

\section{1) Crear constancia en el propósito}

Crear un propósito constante hacia la mejora del producto y del servicio, con el objetivo de llegar a ser competitivos, consolidar la empresa y proporcionar empleos. Este punto indica que una empresa tiene que tener bien claro el propósito y su función que desempeña, mejorándolo constantemente, implementando la invasión, la mejora continua, teniendo en cuenta las fortalezas y debilidades de la empresa. 


\section{2) Adoptar una nueva filosofía}

Implementar una nueva filosofía en la empresa, representa un cambio en la educación de todos los involucrados, entrenamiento y alegría en el trabajo, junto con la responsabilidad de cambiar la forma de pensar y trabajar respecto a la calidad.

\section{3) Cesar la dependencia de la inspección en masa}

Tratar de evitar la inspección masiva, en vez de ello controlar los procesos a medida que el producto vaya avanzando y evitar retrabajos y desperdicios que se traducen en mayores costos y aumentar la calidad de los procesos.

La Calidad debe ser diseñada en el producto desde el principio, no puede crearse a través de la Inspección. La inspección provee información sobre la calidad del producto final, pero el costo de los defectos son pasados al consumidor aunque este solo reciba productos de primera calidad.

4) Acabar con la práctica de hacer negocios sobre la base del precio solamente. En vez de ello minimizar los costos totales trabajando con un solo proveedor.

En vez de buscar un proveedor que nos brinde el precio más bajo, buscar aquel o aquellos que representen mas confiabilidad en su entregas, en la calidad de sus productos y a buen precio, muchas de las veces dejamos toda la responsabilidad en un solo proveedor que nos deja poco satisfechos con su desempeño.

Tratar a los proveedores con respeto, en forma transparente y sencilla. No es trabajar más duro, es trabajar más inteligentemente.

\section{5) Mejorar constante y continuamente todos los procesos de planificación, producción y servicio.}

Una empresa tiene que estar en una mejora constante para asegurar la calidad mediante el uso de herramientas estadísticas, tales como los gráficos de control y programas de mantenimiento que ayudan a eliminar las causas especiales. Cuando se mejora un proceso, mejora el conocimiento del proceso al mismo tiempo. Mejoramiento del producto y el proceso van mano a mano con mayor comprensión y mejor teoría. La Organización debe tener un proceso para obtener retroalimentación (feedback) de los clientes sobre sus productos y servicios. Debe trabajar en las variables más críticas primero, por cuanto así tendrá más impacto en la Calidad.

\section{6) Implantar la formación en el trabajo.}

Implementar las capacitaciones en el trabajo a todo el personal de acuerdo a sus funciones eliminando el entrenamiento entre los trabajadores. Muchas de las veces el entrenamiento en las empresas entre trabajadores no es muy recomendable ya que se eles 
enseña a los nuevos empleados únicamente el conocimiento que tiene un trabajador de mayor rango y nunca se le transmite el conocimiento completo.

Para mejorar hay que eliminar el léxico "debería haber sabido" de nuestro vocabulario y trabajar con lo que realmente pasó, no con hipotéticos "deberían haber".

\section{7) Adoptar e implantar el liderazgo.}

Implementar el liderazgo en los supervisores y en la gente de mayor rango significa buena señal de que las cosas pueden salir bien. Un líder debe tener la capacidad necesaria para reconocer las destrezas de los que tiene a su alrededor, talentos y habilidades de los que trabajan con él; en pocas palabras, ayudar donde se necesita.

Un Líder sabe cómo mejorar el Sistema en el cual él y su gente trabajan, no amenaza ni implora. Trata de crear en todo el mundo interés y reto en el trabajo, y alegría para realizarlo.

\section{8 ) Desechar el miedo.}

Eliminar el temor fortaleciendo la seguridad en sus trabajadores, proveer la seguridad y un ambiente de confianza en los trabajadores, así se eliminaran muchos problemas con la calidad. Cuando el miedo es utilizado para mejorar el desempeño individual, esta meta no se logra. El uso del miedo evita que la gente piense, les roba el orgullo y la alegría de trabajar y mata toda forma de motivación intrínseca. El miedo es causa de incalculable desperdicio y pérdidas.

\section{9) Derribar las barreras entre las áreas de staff.}

Promover el trabajo en conjunto; es decir, que todos los departamentos trabajen con el objetivo de lograr una meta en común, para evitar problemas de comunicación y mantener la misión de la empresa.

Diseñar en equipo descubre los valores de las personas. La Gerencia debe ayudar a utilizar los talentos y las habilidades de la gente en beneficio de la Empresa, y lograr la voluntad para destinar el tiempo necesario para comprender el problema, y evitar que años de tradición y cultura organizacionales entraben el proceso para trabajar juntos.

El rol del gerente es:

- Comprender el sentido del sistema

- Fomentar en su gente el deseo de aprender

- Saber que tiene tres fuentes de poder:

1. Formal,

2. Conocimiento,

3. Personalidad y Poder de Persuasión.

- Creara confianza. 
10) Eliminar los slogans, exhortaciones y metas para la mano de obra.

Evitar la presión en los trabajadores para aumentar la productividad, con reglas amenazantes y lemas fuera de lugar, permitiendo que los trabajadores formulen sus propios lemas, así como evitar los slogans fraudulentos que no cumplan con la realidad interna de la empresa.

\section{1) Eliminar los cupos numéricos para la mano de obra y los objetivos numéricos para la dirección.}

Eliminar las tasas de producción obligatorias hace que los empleados se sientan menos presionados y realicen su trabajo mecánicamente, sin tomar en cuenta otros aspectos como la calidad y más si no se les proporcionan herramientas ni recursos necesarios para lograrlos.

12) Eliminar las barreras que privan a las personas de sentirse orgullosas de su trabajo.

Desechar las culpas al trabajador, muchas de las veces, las fallas en calidad se dan por errores en el sistema y la mala elección o implementación del mismo y se deben analizar todos esos puntos para establecer un criterio acertado de cuáles son las causas de los problemas.

\section{3) Estimular la educación y la auto mejora de todo el mundo.}

Implementar la capacitación y educación dentro de la empresa, resaltando el trabajo en equipo y aplicar el estudio de nuevas tecnologías y técnicas matemáticas que ayuden a mejorar la productividad que los ayuden a ser más competitivos y explotar al máximo las habilidades del personal y ser más competitivos en el mercado.

14) Poner a trabajar a todas las personas de la empresa para conseguir la transformación.

Trabajar desde la alta gerencia hasta operadores, todos en conjunto para la aplicación de estos untos y tener personal especializado en la implementación de los mismos para levantar el interés y entusiasmo en todas las personas que conforman esta empresa.

Estos 14 puntos ofrecen un marco para la acción y otorgan a la dirección la base para la formulación de un plan para la mejora. Deming establece que para mejorar la calidad, aplicando los pasos anteriores se tiene que utilizar el conocido como ciclo PDCA o ciclo de Deming (aunque fue propuesto inicialmente por Shewhart). Dicho ciclo propone seguir las siguientes fases en la solución de cualquier problema:

Planificar (Plan): Significa individualizar el problema, recoger datos, estudiar las relaciones causa-efecto y ver las hipótesis de solución. 
Realizar (Do): Consiste en llevar a cabo lo establecido en el plan.

Controlar (Check): Compara el plan inicial con los resultados obtenidos.

Actuar (Act): Actuar para corregir los problemas encontrados, prever posibles problemas futuros y establecer las condiciones que permitan mantener el proceso de forma estable e iniciar un nuevo proceso de mejora.

Una vez finalizado el ciclo, éste volverá a repetirse nuevamente partiendo del conocimiento acumulado en el anterior ciclo, lo que supone un modelo de mejora continua que difiere por completo del sistema tradicional de gestión.

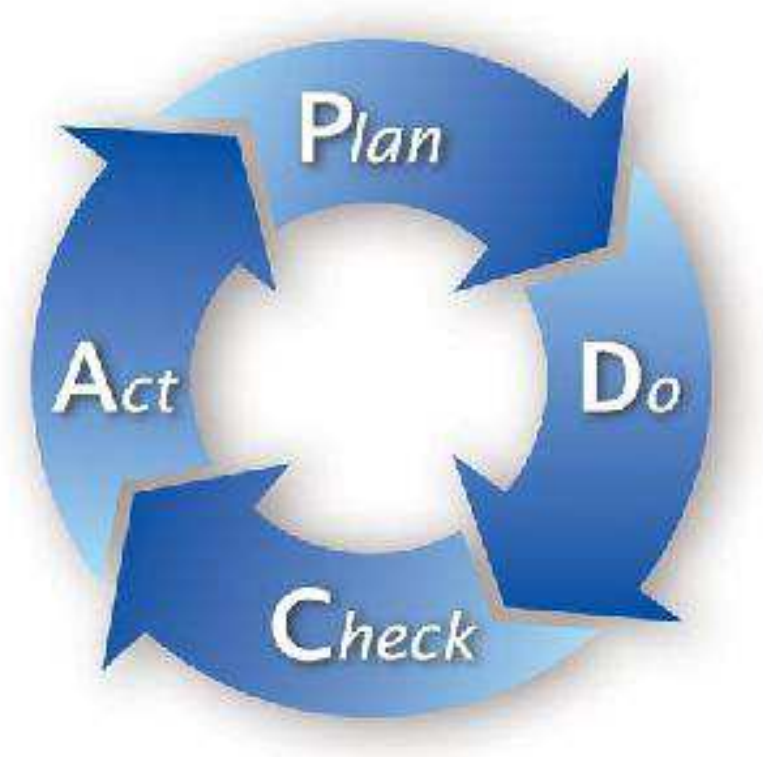

Figura 8 Ciclo de Deming

Según Deming para aplicar este estilo de gestión hay que luchar contra una serie de enfermedades mortales y obstáculos en la forma de gestión de las empresas de occidente.

\section{-Las Siete Enfermedades de la Gerencia de Deming}

\section{Falta de constancia de propósito.}

Una compañía que carece de constancia en la búsqueda de su propósito no cuenta con planes a largo plazo para permanecer en el negocio.

\section{2. Énfasis en las utilidades a corto plazo.}

Velar por aumentar las ganancias trimestrales sin una visión a largo plazo socava la calidad y la productividad. 


\section{Evaluación del desempeño, clasificación según el mérito o análisis anual del desempeño.}

Los efectos de estas prácticas pueden llegar a ser muy perjudiciales si se usan inadecuadamente o de forma excesiva fomentando la rivalidad y destruyendo el trabajo en equipo.

Las evaluaciones de desempeño estimulan el desempeño a corto plazo pero en general, tiende a provocar que disminuya la implicación entre los miembros del equipo y en consecuencia, que merme el rendimiento.

La utilización de este tipo de evaluaciones supone que muchas veces, se haga recaer la culpa de los malos resultados obtenidos a los niveles inferiores. Es por ello que, a la hora de analizar donde esta el fallo, debemos recordar el análisis realizado por Kaouru Ishikawa, otro de los padres de la calidad, que demuestra que los trabajadores son únicamente responsables del 15\% de los errores, mientras la gestión llevada a cabo por la gerencia es la responsable del $85 \%$ de los errores o irregularidades.

\section{La movilidad de la gerencia.}

Como consecuencia de la visión a corto plazo y la administración basada únicamente en las cifras visibles, hace que el gerente se esté moviendo de una empresa a otra buscando una mejor situación apoyado por los buenos resultados a corto plazo conseguidos en su anterior puesto. Los gerentes que cambian de un puesto a otro nunca acabarán de entender la compañía que dirigen en profundidad, por lo tanto no serán capaces de introducir cambios a largo plazo necesarios para una adecuada gestión.

\section{Manejar una compañía basándose únicamente en cifras visibles.}

Asegura Deming que "Las cifras más importantes son desconocidas e imposibles de conocer". La contabilidad financiera clásica es incapaz de cuantificar los denominados "activos intangibles". Este concepto hace referencia a aspectos tales como: fidelidad de los clientes, calidad del producto, la participación del mercado, el grado de calificación de los empleados y la capacidad gerencial. Estos aspectos deben ser conocidos y ser tenidos en cuenta por el gestor, por que sin ellos la empresa esta destinada al fracaso a largo plazo.

\section{Costos médicos excesivos.}

Los costos de cuidado de la salud y las tasas de absentismo debido a enfermedades han aumentado con rapidez a lo largo de los años. El efecto a largo plazo ha sido un deterioro en competitividad. 


\section{Costos excesivos de garantía}

Constituyen el precio directo de la no calidad. Los clientes insatisfechos deben ser resarcidos ante la imposibilidad de conseguir un producto o servicio que se ajuste a los requisitos marcados por el cliente.

Una categoría menor de obstáculos ( obstáculos para el crecimiento de las empresas ) incluye:

1. Descuidar la planificación a largo plazo.

2. Confiar solamente en la tecnología para resolver problemas.

3. Buscar ejemplos que seguir en lugar de desarrollar soluciones.

4. Excusas tal como "Nuestros problemas son diferentes".

5. Una escuela obsoleta que creía que la habilidad de gestión se puede enseñar en la clase ${ }^{1}$

6. Confianza en el departamento de control de calidad en lugar de en los gestores, supervisores, gerentes de compras y trabajadores.

7. Culpar a los trabajadores que solamente son responsables del $15 \%$ de los errores, mientras el sistema deseado por los gerentes es responsable del $85 \%$ de las consecuencias indeseadas.

8. Confiar en la inspección de calidad en lugar de mejorar la calidad del producto.

Fuera de estas siete enfermedades Deming hace hincapié en la necesidad de romper las barreras que hay entre los departamentos. De nada sirve que las personas trabajen bien en el seno de sus respectivos departamentos si se producen conflictos entre los distintos departamentos que conforman la compañía persiguiendo objetivos diferentes sin una política común. Si las metas finales de cada uno de los departamentos son distintas esto podría acabar con la compañía. Es mejor trabajar en equipo, trabajar para la compañía.

Por último debemos tener en cuenta que toda actividad es un proceso y puede ser mejorado, pero para ello todos los niveles de la organización deben pertenecer a un mismo equipo.

\subsection{2.- JURAN Y LA TRILOGÍA DE LA CALIDAD}

Joseph Juran jugó junto a Deming un papel destacado en las enseñanzas de la mejora de la calidad de la industria japonesa durante los años 50. Estuvo desde un principio orientado a la gestión, centrándose con posterioridad en la planificación de la calidad.

En 1951 publica Quality Control Handbook, uno de los manuales de calidad más completos que existen.

Para Juran la calidad se define como la adecuación al uso, la cuál se alcanza en primer lugar por una adecuación del diseño del producto (calidad de diseño) y en segundo lugar por el grado de conformidad del producto final con ese diseño (calidad de fabricación o conformidad). Una de sus principales aportaciones es la denominada trilogía de la calidad, 
en la que indica la relación existente entre planificación, control y mejora de la calidad. Para Juran la calidad no surge de forma accidental sino que debe ser planificada.

\section{TRILOGÍA DE JURAN}

1.- La planificación de la calidad consiste en acercarse al cliete actual y al potencila, e investigar sus necesidades, que son cambiantes. Se pretende conocer a través de estas investigaciones las demandas del cliente en cuanto a características deseadas en el producto. Para lograr integrar las necesidades del cliente en los productos se debe en primer lugar identidicar a los clientes. En este intento, Juran diferenciará entre cliente externo (ajeno a la empresa) y cliente interno (que será todo miembro de la organización afectado por el producto). Las demandas de los clientes son finalmente transferidas al diseño del producto y del proceso productivo para obtener un producto final acorde con dichas necesidades del cliente.

2.- El control de la calidad es un complemento indispensable de la planificación, actuando como un sistema de retroalimentación. Según Juran el control no debe limitarse a la dirección, sino que deben emprenderlo todos los empleados de la empresa. El proceso de control comienza evaluando el comportamiento real de la calidad, comparándolo con los objetivos inicialmente establecidos, para finalmente actuar sobre las posibles desviaciones.

3.- La mejora de la calidad trata de realizar los cambios oportunos para que se alcancen niveles de calidad más elevados que en periodos anteriores. Juran propuso la siguiente secuencia para la rasolución de problemas en aras de la mejora de la calidad:

a. Probar la necesidad de mejora.

b. Identificar los proyectos de mejora.

c. Organizar los equipos para cada proyecto.

d. Diagnosticar las causas del problema.

e. Proporcionar un remedio y probar su efectividad.

f. Gestionar la resistencia al cambio por parte de los trabajadores.

g. Instituir controles para mantener las mejoras logradas. 


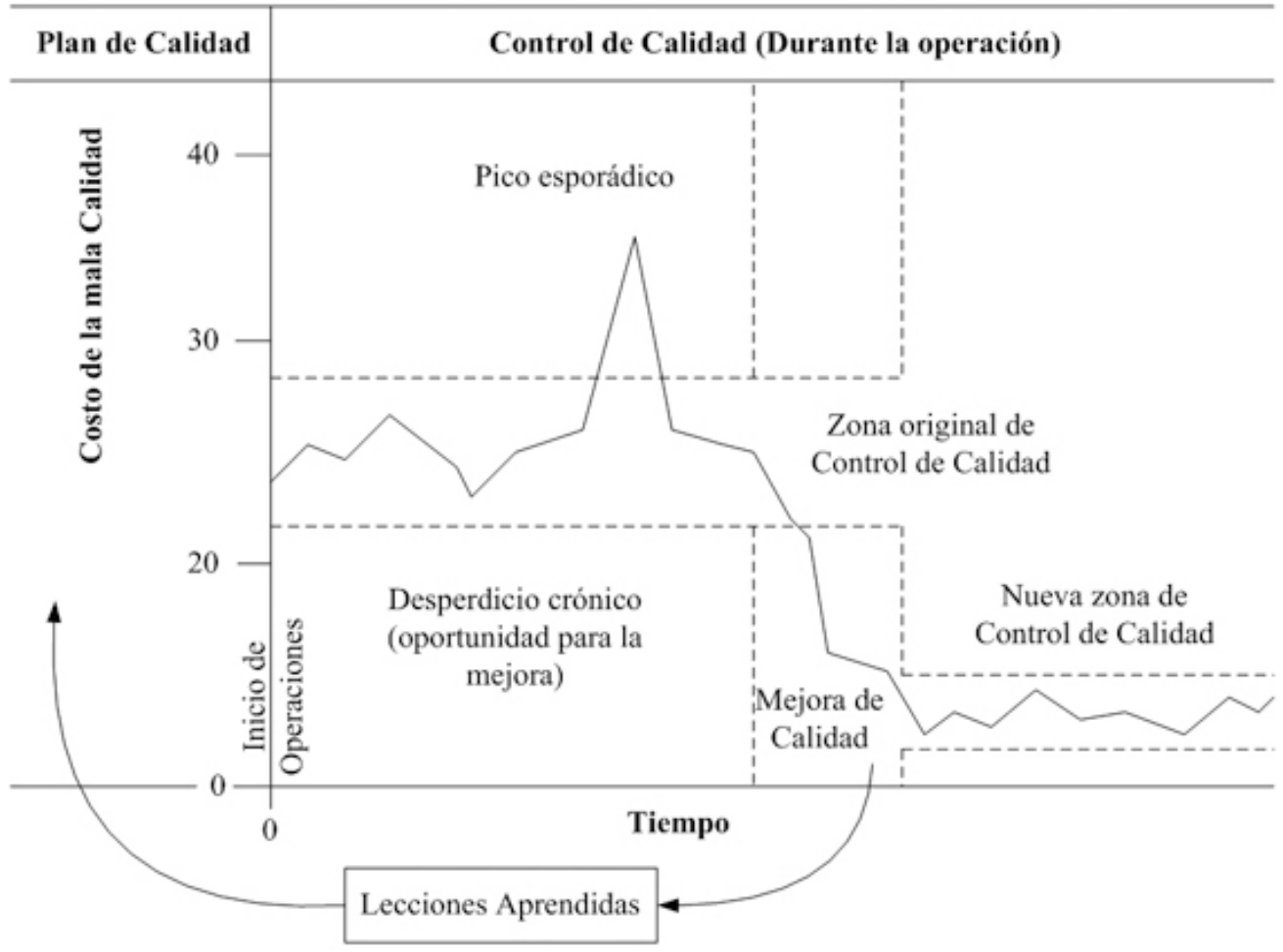

Figura 9 Trilogía de Juran

Al igual que Deming, aboga por que sea la dirección la que lleve a la organización a la mejora de la calidad. La clave es que la calidad tiene que ser puesta en práctica de arribaabajo. Juran fue el primero en aplicar el principio de Pareto para mejorar la calidad distinguiendo los pocos pero vitales problemas, de los muchos pero triviales (poco importantes). Diferenció entre problemas esporádicos y problemas crónicos. Los esporádicos son dramáticos y deben recibir atención inmediata, mientras que los problemas crónicos ocurren durante un largo periodo. Es en éstos en los que se debe centrarse un proceso de mejora continua y en los que la dirección debe jugar un papel destacado.

Muchos aspectos de la filosofía de Juran y Deming son similares (compromiso de la alta dirección, la necesidad de mejorar, el uso de técnicas de control de la calidad y la importancia de la formación), sin embargo, no están de acuerdo en todos sus puntos. Así Juran creía que Deming estaba equivocado al afirmar que la dirección debía eliminar el miedo ya que el creía que el miedo puede sacar a la superficie lo mejor de las personas.

\subsection{3- CROSBY Y EL CERO DEFECTOS}

Philip B. Crosby fue vicepresidente corporativo de calidad en International Telephone and Telegraph y consultor de empresas, así como autor de varios libros ( "Quality is free", vendió más de un millón de ejemplares). Define la calidad como conformidad con los requisitos y asegura que las empresas despilfarran recursos realizando incorrectamente 
procesos y repitiéndolos. Así, llega a afirmar de que "considero que en las empresas de servicios una de cada tres personas está dedicada a tiempo completo a rehacer las cosas, verificar las cifras o pedir disculpas a alguien". De ahí que su teoría se apoye en el "cero defectos" y en "hacerlo bien a la primera".

El cero defectos se consigue estableciendo una política de prevención para lograr trabajar sin errores. Justifica los costes de prevención argumentando que los efectos negativos de los costes de no calidad para la organización serían mayores. Evitar los defectos es esencial en cualquier actividad o parte de la empresa, ya que cuando algo sale mal en un área, repercute en toda la organización. Para eliminarlos totalmente se debe suprimir cualquier nivel aceptable de errores, así como dar importancia tanto a los problemas numerosos pero triviales como a los escasos pero vitales.

El cero defectos consiste en hacer lo acordado en el momento acordado, implica contar con requisitos claros, capacitación, actitud positiva y un plan. Para mejorar la calidad debe existir un director de calidad que no debe responsabilizarse de los problemas sobre calidad (ya que el responsable será quien lo produzca o permita) y una dirección comprometida que actúa de forma coherente con las políticas establecidas.

Para Crosby la mejora de la calidad debe basarse en lo que denominó los absolutos de la gestión de la calidad:

1.-Definir la calidad como el cumplimiento de los requisitos establecidos

2.-El sistema que causa la calidad es la prevención

3.-El único estándar de rendimiento válido es el cero defectos

4.-La única medida válida de la actuación de la organización es el coste de calidad

Derivado de esta clasificación, propone un programa de 14 pasos para mejorar la calidad:

1. Compromiso de la dirección: Establecer el compromiso de la administración de participar en el programa de calidad para, de esta manera asegurar la cooperación de todos y cada uno de los miembros de la organización.

2. Equipo de mejora: Formar un equipo de mejora de calidad con representantes de cada departamento.

3. Mejora de la calidad: Definir indicadores de calidad de cada actividad de la compañía con el objeto de medir dónde se encuentran problemas reales y potencial de calidad.

4. Coste de la calidad: Evaluar el costo de la falta de calidad como un indicador que proporcione evidencia de dónde es más conveniente para la compañía, desde el punto de vista económico, tomar acciones correctivas.

5. Conciencia de la calidad: Desarrollar una conciencia de calidad y preocupación de todos los empleados por la mejora continua de la organización. 
6. Acción correctora: Realizar acciones formales para corregir los problemas identificados a través de pasos previos.

7. Planificación cero defecto: Establecer un comité para poner en práctica un programa de cero defectos.

8. Formación supervisor: Capacitar a los supervisores y empleados en la forma de llevar a cabo su parte en el programa de mejoramiento de la calidad.

9. El día cero defectos: Realizar un día "Cero defectos" que simbolice y ayude a que todos los empleados comprendan que ha habido un cambio en la compañía en lo que se refiere a calidad.

10. Establecer un objetivo: Alentar a las personas para que establezcan objetivos de mejora para sí misma y sus grupos, generalmente sobre una base de 30 a 90 días.

11. Eliminar las causas del error: Identificar los problemas que impiden que el trabajo se realice libre de errores y de eliminar sus causas.

12. Reconocimiento: Establece un programa de reconocimiento para aquellos que logren sus objetivos de calidad a través de su participación en el programa de mejoramiento de la calidad.

13. Consejos de calidad: Crear consejos de calidad compuesto por personal del staff administrativo y líderes de los equipos de calidad, que realicen reuniones frecuentes con el objeto de comunicarse unos con otros y determinar las acciones requeridas para mejorar la calidad.

14. Repítalo: Realizar de nuevo los pasos anteriores, destacando que el programa de mejoramiento de la calidad nunca termina. El ciclo completo del programa puede variar, pero normalmente dura entre 12 y 18 meses, lo cual depende de las circunstancias propias de cada empresa.

Adicionalmente, Crosby recomienda lo siguiente en lo que él llama su "prescripción para la salud corporativa":

- Asegurarse de que toda la gente haga su trabajo correctamente en forma rutinaria.

- Todas las acciones del programa de mejoramiento de la calidad deberán estar encaminadas a asegurar un crecimiento lucrativo y constante a la compañía.

- Anticipar constantemente las necesidades de los clientes.

- Planear la administración del cambio.

- Crear un entorno laboral en el que el personal esté orgulloso de trabajar.

Por otro lado, la vacuna de calidad de Crosby es una idea para representar la necesidad que tiene toda organización de prevenir la falta de conformidad con las especificaciones del producto. La vacuna debería tener los siguientes ingredientes:

- Integridad. Todos en la organización deberán dedicarse a encontrar cuáles son los requisitos y necesidades de los clientes.

- Sistemas. La administración de calidad, la educación en calidad y el énfasis en la prevención de los defectos deberán abarcar toda la compañía. 
- Comunicaciones. Se debe contar con un suministro continuo de información que ayude tanto a identificar como a eliminar errores y desperdicios, con un programa de reconocimiento.

- Operaciones. Deberán ser tareas de rutina proveer de educación y capacitación a los empleados, y contar con procedimientos para identificar oportunidades de mejoramiento.

- Políticas. Definir políticas de calidad claras.

Las Seis C De Crosby:

1. Comprensión

2. Competencia

3. Compromiso

4. Comunicación

5. Corrección

6. Continuidad

Las Tres T De Crosby:

1. Tiempo

2. Talento

3. Tesoro

\subsection{4.- KAORU ISHIKAWA}

Kaoru Ishikawa, ingeniero japonés discípulo de Deming y Juran, extendió el desarrollo de la calidad a todos los miembros de la organización, destacando por su clara orientación hacia las personas. Afirma que la dirección de la empresa debe estar basada en hechos y orientada al cliente, con la calidad como primera variable a considerar.

Una de sus metas fue conseguir que se educara en técnicas estadísticas a todo el personal de la empresa, desde el nivel más bajo hasta la alta dirección, haciendo sencillo el control estadístico. Para ello explicó herramientas de fácil aprendizaje y aplicación como el histograma, diagramas de Pareto, gráficos de control y el diagrama de causa-efecto, también conocido como de espina de pescado o de Ishikawa.

Este autor fue quien formalizó los círculos de calidad en el año 19860.

Los elementos clave de su filosofía se pueden resumir en los siguientes puntos:

-La calidad empieza con la educación y termina con la educación.

-El primer paso hacia la calidad es conocer las necesidades de los clientes.

-El estado ideal del control de calidad ocurre cuando ya no es necesaria la inspección.

-Elimine la causa raíz y no los síntomas.

-El control de calidad es responsabilidad de todos los trabajadores en todas las divisiones.

-No confunda los medios con los objetivos. 
-Ponga la calidad en primer término y dirija su vista hacia las utilidades a largo plazo.

-La mercadotecnia es la entrada y salida de la calidad.

-La gerencia superior no debe mostrar enfado cuando sus subordinados les presenten los hechos.

$-95 \%$ de los problemas de una empresa se pueden resolver con simples herramientas de análisis.

-Aquellos datos que no tengan información dispersa (variabilidad) son falsos.

Como ya se ha dicho antes sus mayores aportaciones fueron la demostración de la importancia de las 7 herramientas de la calidad, la creación del diagrama de Ishikawa y la formalización de los círculos de la calidad.

\section{Las 7 herramientas básicas para la administración de la calidad}

1. Hojas de control (implican la frecuencia utilizada en el proceso, así como las variables y los defectos que atribuyen).

2. Histogramas (visión gráfica de las variables).

3. Análisis Pareto (clasificación de problemas, identificación y resolución).

4. Análisis de causa y efecto o Diagrama de Ishikawa (busca el factor principal de los problemas a analizar).

5. Diagramas de dispersión (definición de relaciones).

6. Gráficas de control (medición y control de la variación).

7. Análisis de Estratificación

\section{Diagrama de Ishikawa}

También llamado diagrama de causa-efecto, se trata de un diagrama que por su estructura ha venido a llamarse también: diagrama de espina de pez, que consiste en una representación gráfica sencilla en la que puede verse de manera relacional una especie de espina central, que es una línea en el plano horizontal, representando el problema a analizar, que se escribe a su derecha. Es una de las diversas herramientas surgidas a lo largo del siglo XX en ámbitos de la industria y posteriormente en el de los servicios, para facilitar el análisis de problemas y sus soluciones en esferas como lo son; calidad de los procesos, los productos y servicios.

El problema analizado puede provenir de diversos ámbitos como la salud, calidad de productos y servicios, fenómenos sociales, organización, etc. A este eje horizontal van llegando líneas oblicuas -como las espinas de un pez- que representan las causas valoradas como tales por las personas participantes en el análisis del problema. A su vez, cada una de estas líneas que representa una posible causa, recibe otras líneas perpendiculares que representan las causas secundarias. Cada grupo formado por una posible causa primaria y las causas secundarias que se le relacionan forman un grupo de causas con naturaleza común. Este tipo de herramienta permite un análisis participativo mediante grupos de mejora o grupos de análisis, que mediante técnicas como por ejemplo la lluvia de ideas, 
sesiones de creatividad, y otras, facilita un resultado óptimo en el entendimiento de las causas que originan un problema, con lo que puede ser posible la solución del mismo.

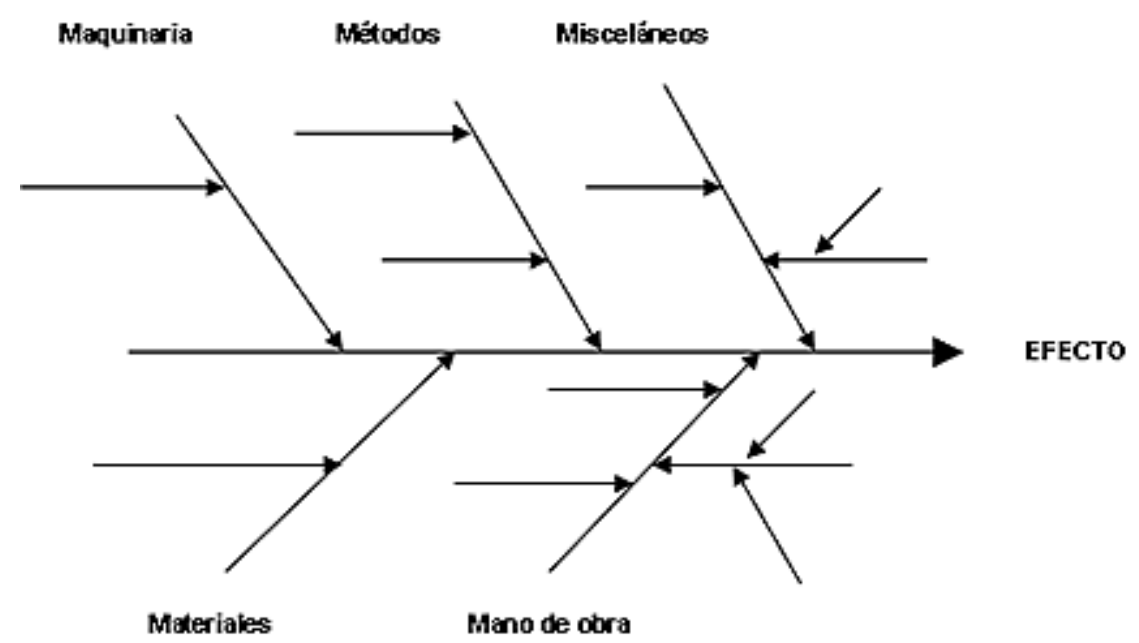

FACTORES CAUSALES

Figura 10 Diagrama de Ishikawa

\section{Círculos de calidad}

La idea básica de los Círculos de Calidad consiste en crear conciencia de calidad y productividad en todos y cada uno de los miembros de una organización, a través del trabajo en equipo y el intercambio de experiencias y conocimientos, así como el apoyo recíproco. Todo ello, para el estudio y resolución de problemas que afecten el adecuado desempeño y la calidad de un área de trabajo, proponiendo ideas y alternativas con un enfoque de mejora continua.

Así definiremos los círculos de calidad como:

"Grupo natural de trabajo, conformado por empleados de una misma institución o empresa que realizan tareas similares y que voluntariamente se reúnen con regularidad, en horas de trabajo, para identificar las causas de los problemas de sus trabajos y proponer soluciones a la gerencia”. 


\subsection{5- FEIGENBAUM}

Armand V. Feigenbaum es conocido por haber sido el primero en utilizar la frase "control de calidad total". Concebía la calidad como una herramienta estratégica empresarial que requiere involucrar a toda la organización. Aunque el empleo de técnicas estadísticas es importante, la clave de la gestión de calidad son las relaciones humanas.

El control de calidad total debe comenzar con un control de los nuevos diseños, estableciendo procedimientos documentados y empleando técnicas que garanticen que las necesidades del cliente sean tenidas en cuenta desde las primeras etapas del proceso de diseño. En segundo lugar, es necesario realizar un control de compras para garantizar la calidad de los suministros de nuestros proveedores. Finalmente, debe existir un control del producto que incluirá todos los procedimientos documentados necesarios para garantizar que el producto fabricado es conforme a las especificaciones establecidas inicialmente.

Introdujo el concepto de "fábrica oculta" o "fábrica fantasma" para hacer referencia a que los rechazos disminuían la capacidad real de la planta, debido a la repetición de trabajos y a no hacer las cosas bien desde el principio. Además fomentó el empleo de los costes de calidad como herramienta de medición y evaluación de la calidad.

Feigenbaum originó el concepto de ciclo industrial, es decir, 1 desarrollo de un producto desde el concepto hasta el servicio ofrecido después de su salida al mercado y defendió la utilización de un sistema de gestión de calidad como ISO 9000. La responsabilidad de la calidad recae únicamente sobre quien realizó el trabajo. La calidad del producto es tan importante que los trabajadores deben tener la autoridad para parar la producción en el momento en que a parezca un problema de calidad.

Su filosofía se resume en sus tres pasos hacia la calidad:

1.- Liderazgo de calidad:

Administración basada en la planificación y no en la reacción ante el error.

2.- Tecnología de calidad moderna:

Implicación de todo el personal en la resolución de problemas de calidad.

3.- Compromiso organizacional:

Capacitación y motivación continuas de toda la fuerza de trabajo e integración de la calidad en la planificación de la empresas.

\subsection{6.- TAGUCHI}

Genichi Taguchi nacido en 1924 en Tokamachi, Japón es un ingeniero y estadístico. Desde la década de 1950 en adelante, Taguchi desarrolló una metodología para la aplicación de Estadísticas para mejorar la calidad de los productos manufacturados. El método Taguchi ha sido controvertido entre algunos estadísticos occidentales 
convencionales, pero otros han aceptado muchos de los conceptos introducidos por él como extensiones válidas para el conjunto de los conocimientos.

Genichi Taguchi concede el papel principal, en el control de calidad, al diseño del producto y al diseño del proceso de fabricación. Pone énfasis en realizar un diseño y planificación inicial adecuados que reduzcan las posibles variaciones en el proceso. De esta manera se disminuye el tiempo y los costes que serían precisos en el futuro para solventar esas desviaciones. Es decir, se trata de evitar la inspección final de los productos, asegurándose de que se fabrican bien la primera vez, no siendo por tanto necesario corregir ningún defecto una vez fabricados.

Otra de sus aportaciones fue la función de pérdida de la calidad con la que calcula los gastos ocasionados al surgir una desviación entre las especificaciones fijadas o establecidas y lo realmente conseguido. Sin embargo, esta visión es limitada ya que los costes económicos no se producen únicamente cuando los productos no cumplen con las especificaciones. 


\section{3.- MODALIDADES PARA LA GESTIÓN DE LA CALIDAD TOTAL}

En muchas ocasiones, los empresarios y directivos se encuentran con la importante confusión que existe en relación con los términos de Calidad Total, Modelos de Excelencia e Iso 9000.

Básicamente, y a modo de introducción, la definición de cada uno de estos conceptos es:

- Calidad Total: una filosofía en la que se busca la excelencia en los resultados de las organizaciones.

- Modelos de excelencia: son modelos dedicados a hacer tangible los principios de la calidad total para que sean aplicables a las organizaciones.

- Iso 9000: Es una normativa desarrollada por la ISO (International Standard Organization) para el aseguramiento de los sistemas de calidad de las organizaciones.

Tras estas definiciones, pasemos a desarrollar qué similitudes y diferencias tienen estos conceptos. Las similitudes entre todos estos conceptos son:

1. Todos han sido creados para la mejora de resultados empresariales

2. Todos están relacionados con la calidad, aunque a distintos niveles y con distintos significados del concepto.

Y, ¿cuáles son las diferencias?

1. La Calidad Total es una filosofía,

2. Los modelos de excelencia son modelos de Calidad Total

3. La norma Iso 9000 pretende gestionar / asegurar la calidad de los sistemas.

Si se quieren definir las relaciones entre los distintos conceptos, la relación entre los Modelos de Excelencia y la Calidad Total es que los Modelos de Excelencia son modelos desarrollados para hacer práctica los principios de la calidad total; ésto es necesario ya que la Calidad Total es una filosofía y los Modelos de Excelencia ayudan a desarrollar los conceptos de la Calidad Total. En la relación entre la Iso 9000 y los modelos de Excelencia, la Iso 9000 puede, y suele ser una parte de los Modelos de Excelencia .

En la versión de la Iso 9000 del año 94, la norma estaba básicamente enfocada a determinados procesos mientras que el enfoque de los Modelos de Excelencia es mucho más amplio contemplando las organizaciones desde un enfoque mucho más global. Sin embargo, en la revisión de la Iso 9000 del año 2000, ésta tiende mucho más hacia el concepto de Calidad Total ahondando más en los conceptos de procesos, en el enfoque al cliente, la gestión de recursos, etc. con lo que se acerca mucho más a los Modelos de la Excelencia. La Iso 9000 del año 2008 no incorpora nuevos requisitos, sino cambios para aclarar los requisitos ya existentes en la Norma ISO 9001, de la versión 2000. 
Ahondando en éstas ideas, la calidad total es una filosofía empresarial nacida en Japón que parte del concepto de "calidad de producto", entendiendo como tal el cumplimiento de especificaciones. Este concepto ha ido evolucionando hacia el concepto de Calidad

Total que es mucho más amplio y no está enfocado en el producto sino en la calidad de toda la organización.

Sin embargo, esta filosofía necesitaba ser práctica de alguna manera y por ello surgieron distintos modelos de calidad total como el Efqm a nivel Europeo, el Malcolm Baldrige en Estados Unidos y el Premio Deming en Japón, aunque los tres modelos tienen muchos elementos similares.

Es preciso aclarar que los Modelos de Excelencia no son una norma y no se obtiene ningún certificado por terceras partes. Los Modelos de Excelencia son modelos compuestos de criterios y subcriterios que son evaluados en la organización para obtener sus puntos fuertes y débiles y definir planes de acción consecuentes.

Los Modelos de Excelencia, básicamente se emplean para la evaluación de las organizaciones, bien por personal interno o externo, llegando a conocer cual es su estado respecto al ideal de Excelencia así como las oportunidades de mejora. Posiblemente la problemática más importante de estos modelos es que, aunque existen distintas metodologías para el desarrollo de la evaluación, éstas son tan buenas como lo son los evaluadores.

Sin embargo, los sistemas de la calidad según norma Iso 9000 se desarrollan empleando la norma Iso 9000 y su familia. En esta norma, se especifican una serie de requisitos que debe cumplir una organización. Tras la adecuación de la organización a la normativa y el desarrollo de su correspondiente documentación que refleja el "modus operandi" de la organización (manuales de calidad y de procedimientos), una organización certificadora neutral analiza si realmente la organización cumple con los requisitos de la normativa. Si el sistema está correctamente desarrollado, la entidad certificadora emitirá el correspondiente certificado indicando la conformidad del sistema.

La principal característica (y ventaja) de los sistemas de gestión (antes aseguramiento) de la calidad según norma Iso 9000 es que sirve para demostrar a terceros la calidad del sistema con las correspondientes ventajas comerciales que ello conlleva. El problema viene por la importancia comercial que supone el obtener la certificación del sistema, ya que hay muchas organizaciones que se vuelcan para conseguir este certificado sin pensar en los conceptos de la calidad. Acabando en muchas ocasiones con organizaciones con menos calidad que la inicial, aunque eso sí, certificadas.

Como conclusión, las organizaciones deberían introducir los Modelo de Excelencia ya que realmente mejoran los resultados empresariales y dentro de él, por su repercusión en varios criterios, el desarrollo de las normas Iso 9000.

Calidad Total: Filosofía Empresarial y de Gestión. 
Modelos de Excelencia: Aquellos que mediante la autoevaluación permiten a las empresas valorar cómo se encuentran respecto al ideal de la Calidad Total, permiten a la organización acceder a un premio de excelencia.

Normativa de Calidad: pretende gestionar / asegurar la calidad de los sistemas, las organizaciones obtienen una acreditación respecto a terceros, respecto al cumplimiento de dicha norma.

\subsection{LA NORMA ISO 9001: 2008}

La empresa tiene que definir el alcance de su sistema de gestión de la calidad. Debe definir a qué productos y actividades se aplica. La norma ISO 9001:2008 es aplicable a cualquier organización, independientemente del tipo, tamaño, o producto suministrado.

\subsubsection{OBJETIVO}

La norma ISO 9001 son los requisitos mínimos que debe cumplir un Sistema de Gestión de la Calidad. Sirve para su aplicación interna, certificación y para fines contractuales. Es una guía para la Gestión de la Calidad y describe los requerimientos generales para garantizar la calidad.

\subsubsection{PRINCIPIOS DE GESTIÓN}

La nueva ISO 9001 adapta la anterior a los principios de la Calidad Total. Se basa en 8 principios para la gestión de la calidad total:

\section{- Enfoque al cliente.}

Con este enfoque se obtiene como resultado el cumplimiento de los requerimientos del cliente y el hecho de esforzarse por excederlos, así como conseguir su satisfacción. La organización depende de lo que el cliente quiere por lo que hay que entender las necesidades para poder satisfacer sus requerimientos y superar las expectativas. Hay que tener en cuenta que este principio los comerciales de una compañía lo tendrán muy en cuenta, mientras que en producción no piensan tanto en el cliente, es por ello que se pone éste énfasis en el cliente. Tiene que existir un acercamiento del cliente a la empresa.

\section{- Liderazgo.}

Este principio se basa en crear un ambiente de trabajo interno en el que todos están involucrados e impulsados por la alta dirección en la consecución de los objetivos. La dirección se tiene que implicar, liderar, establecer objetivos, que exista un buen ambiente de trabajo. La dirección se encarga de motivar, impulsar, dar recursos y apoyar al Sistema de Gestión de la Calidad. Se trata de establecer un sistema de gestión que vaya más allá de 
la simple administración. Tienen que existir líderes, pero no solo en la dirección sino también a nivel de los operarios.

\section{- Participación del personal.}

La participación de todo el personal en el Sistema de Gestión de la Calidad es la esencia de la organización, en la que todos los empleados deben de tomar conciencia de que son parte del Sistema y que su labor es parte esencial del aseguramiento de la calidad.

El personal es el activo más valioso, lo que diferencia. Las personas son el eje principal de la organización y se deben usar sus habilidades y capacidades con efectividad para el beneficio de la organización. Debe existir cooperación y participación. Tienen el conocimiento tácito y en todos los niveles. Cada operario en su puesto de trabajo conoce lo que está haciendo. Es importante que colaboren en el diseño del puesto de trabajo, en la formación de los compañeros, planificación de horarios, sugerencias, grupos de mejora...

\section{- Enfoque basado en los procesos.}

Identifica el Sistema de Gestión de la Calidad como un proceso. Se gestionan recursos y actividades para obtener los resultados deseados para obtener una mayor eficiencia. Hay procesos organizativos: compra, aprovisionamiento, devoluciones, contabilidad, producción... Hay que identificar los procesos clave en la empresa que afectan a varias funciones y hacer de ellos el objeto de nuestra actividad y mejora. Es importante definir responsables con visión global, que vean la repercusión de los procesos en los departamentos y sus relaciones, propongan mejoras, establezcan indicadores...

\section{- Enfoque del sistema para la gestión.}

Lleva a la mejora de la eficiencia y la eficacia por medio de la identificación, la comprensión y la gestión por procesos interrelacionados para alcanzar unos objetivos determinados. El Sistema de Gestión de la Calidad comprende tanto los procesos de realización del producto como los de gestión, seguimiento y medición. Se obtiene pues, que en una organización se tienen los procesos interrelacionados. En muchos casos las salidas de unos son las entradas de otros.

\section{- Mejora continua.}

Es el objetivo permanente de la organización. Según la norma ISO 9000:2008 mejora de la calidad es una "actividad recurrente para aumentar la capacidad para cumplir los requisitos". Siempre se puede mejorar, aunque en unos casos más que otros o con mayores costes.

\section{- Enfoque basado en hechos para tomar decisiones.}

Este principio está basado en analizar los datos y la información que se obtiene del sistema para tomar las decisiones oportunas. Las decisiones siempre se van a basar en esta información con una visión objetiva, con sentido común, ponderación y equilibrio. 
- Relaciones mutuamente beneficiosas con el proveedor.

Es fundamental la relación entre proveedor-cliente y la comprensión de su interdependencia ya que los unos dependen de los otros. La relación de beneficio mutua aumenta la capacidad de ambos para crear valor. No se trata de ver la empresa aislada en su entorno, hay que gestionar la cadena de suministro, establecer relaciones de confianza con los proveedores, ayudarles y que nos ayuden. Conviene establecer sistemas de colaboración, mejora, calidades concertadas...

\subsubsection{REQUISITOS DE DOCUMENTACIÓN}

Son cuatro los documentos exigidos por las normas ISO 9000.

- Manual de calidad.

Define las prácticas y la política de calidad de la organización. Describe el Sistema de Calidad. Es la referencia que sirve para conocer el sistema. Cuando se solicita la certificación es el primer documento que pide el organismo certificador.

- Procedimientos.

Describen las responsabilidades y autoridades de los distintos departamentos o áreas respecto a la conformidad. Indican quién hace, qué hace, cómo y cuándo.

- Instrucciones de trabajo.

Explica cómo se deben realizar las distintas actividades.

- Registros.

Son la evidencia objetiva de que los principios y actividades se han implantado tal y como se han definido en el manual de calidad, procedimientos e instrucciones de trabajo. 


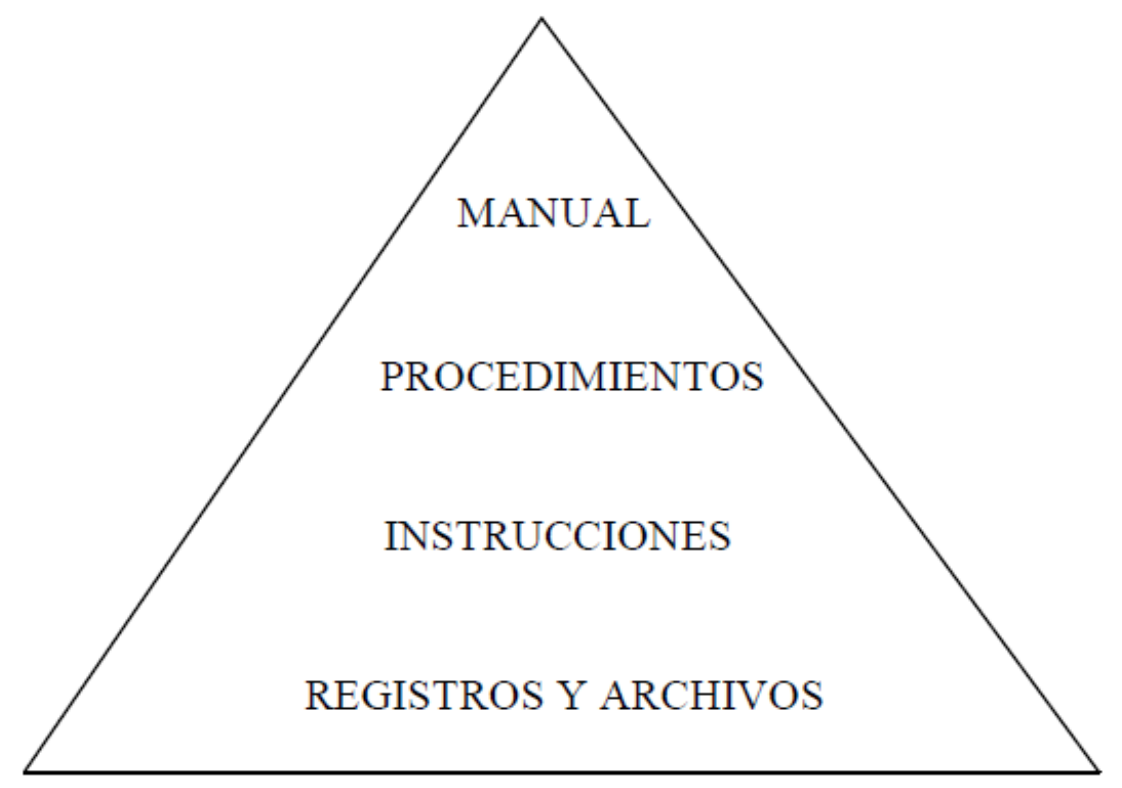

Figura 11. La pirámide de los documentos.

\subsubsection{APARTADOS DE LA NORMA}

La norma está compuesta por las siguientes secciones:

1-. Objeto y campo de aplicación.

2-. Normas para consulta.

3-. Términos y definiciones.

4-. Sistema de Gestión de la calidad.

5-. Responsabilidad de la dirección.

6-. Gestión de los recursos.

7-. Realización del producto.

8-. Medición, análisis y mejora.

Cada sección está a su vez dividida en diferentes puntos que se dividen en más apartados.

Esta norma tiene un enfoque basado en los procesos, tal y como se ha comentado en uno de los ocho principios en que basa su gestión. Son cinco las secciones principales de la norma:

- Sistema de gestión de la calidad.

- Responsabilidad de la dirección.

- Gestión de los recursos.

- Realización del producto.

- Medición, análisis y mejora. 
En la siguiente gráfica se observan los vínculos entre los procesos de las secciones

4 a 8. Los clientes juegan un papel decisivo ya que sus necesidades definen los requisitos que son la entrada. Hay que evaluar la información de la percepción del cliente sobre la organización acerca de si ha cumplido los requisitos que ha establecido. El seguimiento de la satisfacción del cliente es otro elemento significativo.

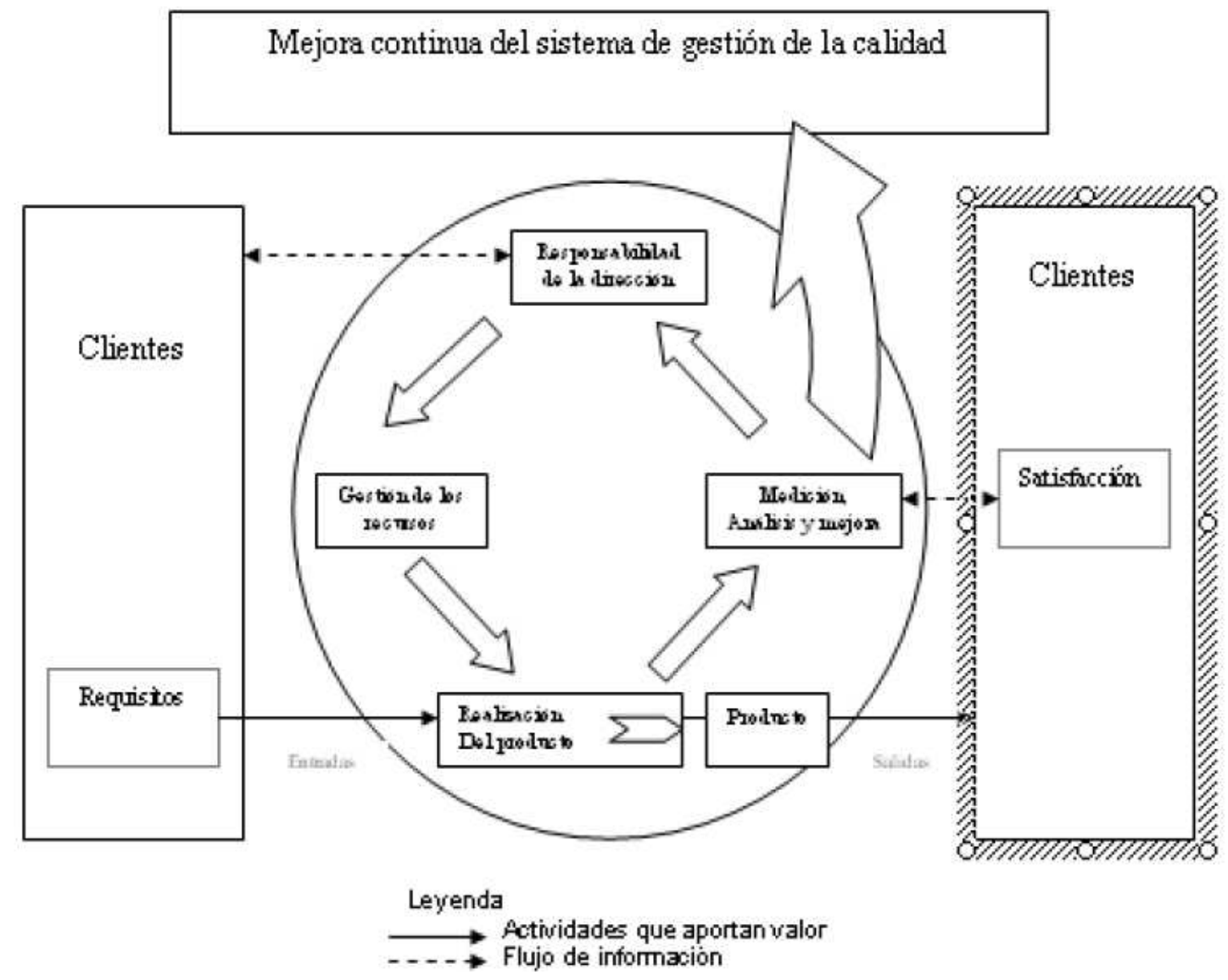

Figura 12. El ciclo de los procesos.

\subsubsection{PROCEDIMIENTOS}

Exige sólo 6 procedimientos obligatorios:

1- Control de los documentos del sistema de calidad.

2- Control de los registros de calidad.

3- Procedimiento para la realización de auditorías internas.

4- Identificación y control de productos no conformes.

5- Procedimiento para las acciones correctivas.

6- Procedimiento para las acciones preventivas. 
El resto los deja libres.

\subsubsection{SISTEMAS DE GESTIÓN DE LA CALIDAD}

Deben establecerse el Sistema de Gestión de la Calidad y los procesos. Para conseguirlos deben estar implantados, mantenidos y mejorados continuamente.

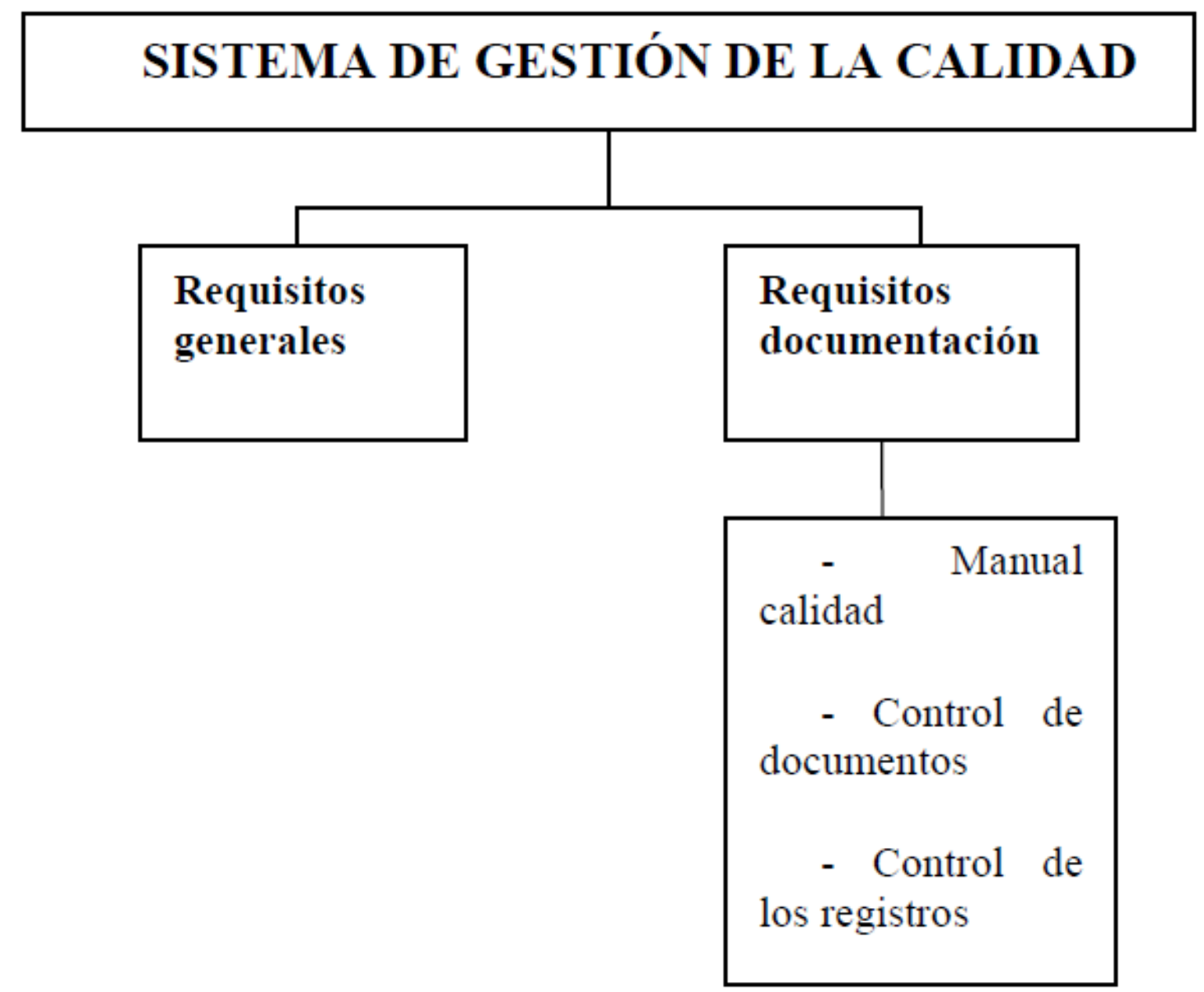

Figura 13. Sistema de Gestión de la Calidad.

En relación con los procesos necesarios y sus interrelaciones establece la obligación de:

- Identificar los procesos necesarios para el SGC y su aplicación a través de la organización.

- Determinar la secuencia e interacción de estos procesos.

- Determinar los criterios y métodos necesarios para asegurarse de que tanto la operación como el control de estos procesos sean eficaces. 
- Asegurarse de la disponibilidad de recursos e información necesarios para apoyar la operación y el seguimiento de estos procesos.

- Realizar el seguimiento, la medición y el análisis de estos procesos.

- Implementar las acciones necesarias para alcanzar los resultados planificados y la mejora continua de estos procesos.

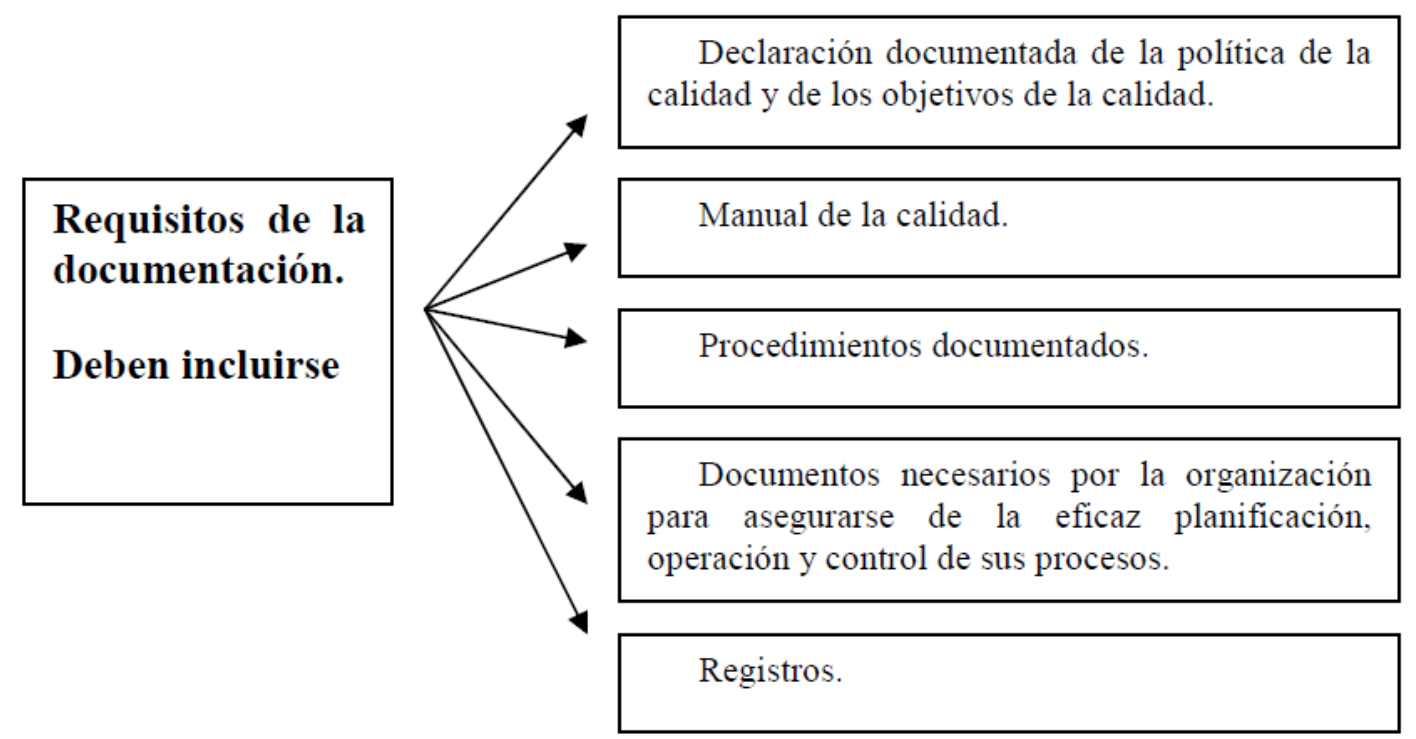

Figura 14. Requisitos de la documentación.

\subsubsection{RESPONSABILIDADES DE LA DIRECCIÓN}

Es el compromiso de la dirección, las responsabilidades y su liderazgo. Puede resultar difícil ya que a veces los directivos se centran en otros temas. Ser líder tampoco es fácil. Ese compromiso consiste en:

- Comunicar a la organización la importancia de satisfacer tanto los requisitos del cliente como los legales y reglamentarios.

- Establecer la política de calidad.

- Asegurar que se establecen los objetivos de la calidad.

- Llevar a cabo las revisiones.

- Asegurar la disponibilidad de recursos.

Para conseguir todo esto, debe definir qué tipo de cliente se tiene, qué espera, sus necesidades. Hay que concienciar. Los objetivos tienen que ser medibles. Para asegurar que es sistema es eficaz y consistente, hay que revisar el SGC periódicamente. Se analizan los resultados de las auditorías, las informaciones de los clientes... Se debe tener toda la información pertinente en relación con los resultados de los informes de calidad. 
Hay que definir las responsabilidades y autoridades dentro de la empresa y ser comunicadas. Tiene que existir un organigrama en el que se define la jerarquía y los puestos de trabajo. Esto lo deben conocer todos los empleados. La dirección también debe establecer procesos de comunicación interna para asegurar la eficacia del sistema.

La dirección debe asignar a una persona de la propia dirección como representante con autoridad para:

- Asegurarse de que se establecen, implementan y mantienen los procesos necesarios para el Sistema de Gestión de la Calidad.

- Informar a la alta dirección sobre el desempeño del Sistema de Gestión de la

Calidad y de cualquier necesidad de mejora.

- Asegurarse de que se promueva la toma de conciencia de los requisitos del cliente en todos los niveles de la organización.

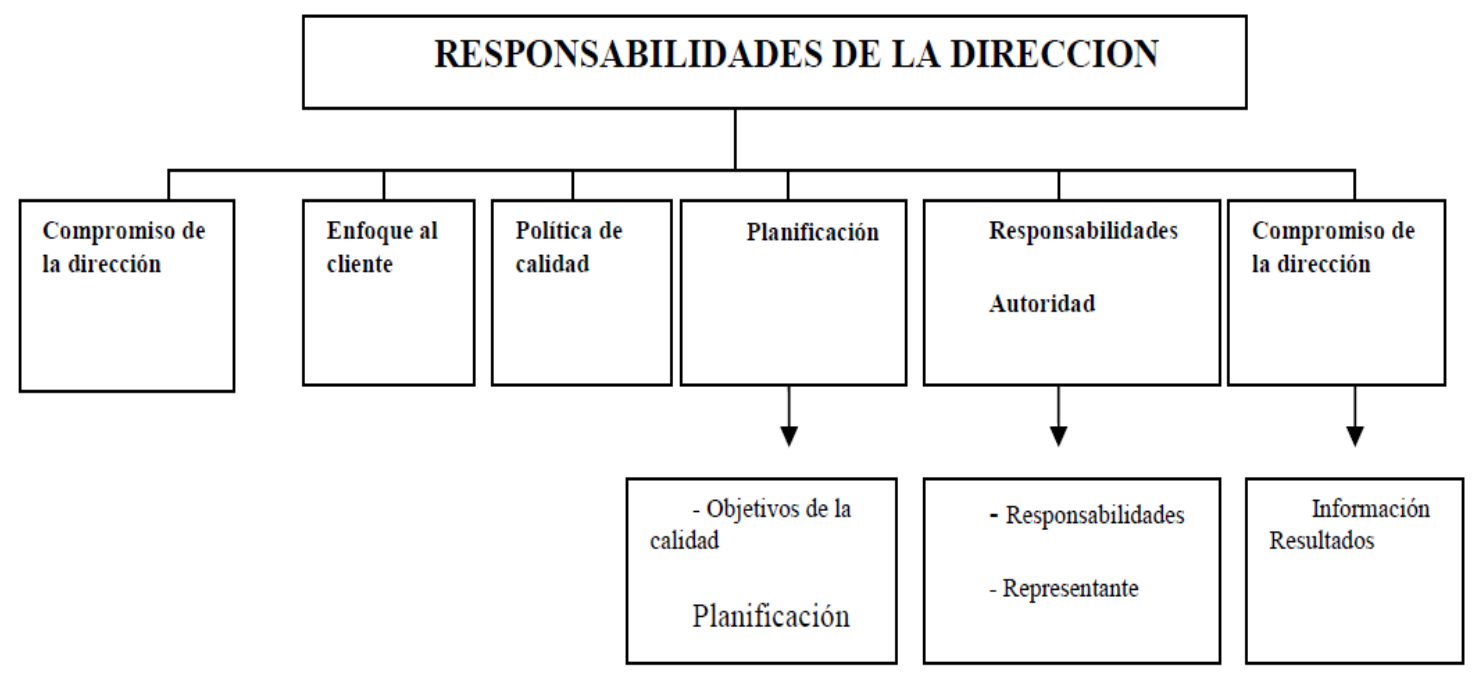

Figura 15. Responsabilidades de la dirección.

\subsubsection{GESTIÓN DE RECURSOS}

La organización debe determinar y proporcionar los recursos necesarios para implementar y mantener el SGC y mejorar continuamente su eficacia y aumentar la satisfacción del cliente mediante el cumplimiento de sus requisitos.

Los recursos que deben de asignarse son:

- Recursos humanos. Deben tener las cualidades, habilidades y experiencias necesarias para desarrollar su actividad. La norma ahora quiere que las empresas tengan identificadas las actividades y necesidades de cada puesto de trabajo. También hay que evaluar la formación de los trabajadores. 


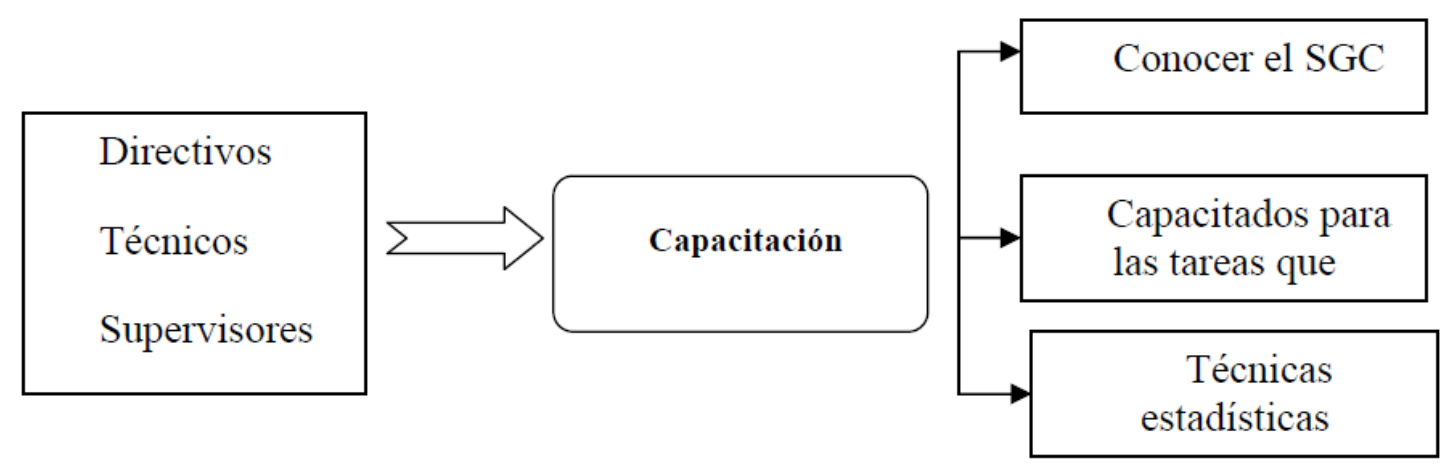

El personal que realice trabajos que afecten a la calidad del producto debe ser competente con base en la educación, formación, habilidades y experiencia apropiadas.

Figura 16. Capacidades del personal.

- Infraestructura. Es el sistema de instalaciones y equipamientos permanentes de una organización. Debe tener capacidad para conseguir al conformidad del producto incluyendo los espacios de trabajo, los servicios de apoyo y los equipos.

- Ambiente de trabajo. Tiene que ser adecuado para lograr que el producto sea conforma. El entorno tiene que ser ordenado, con buena iluminación, buena ergonomía...

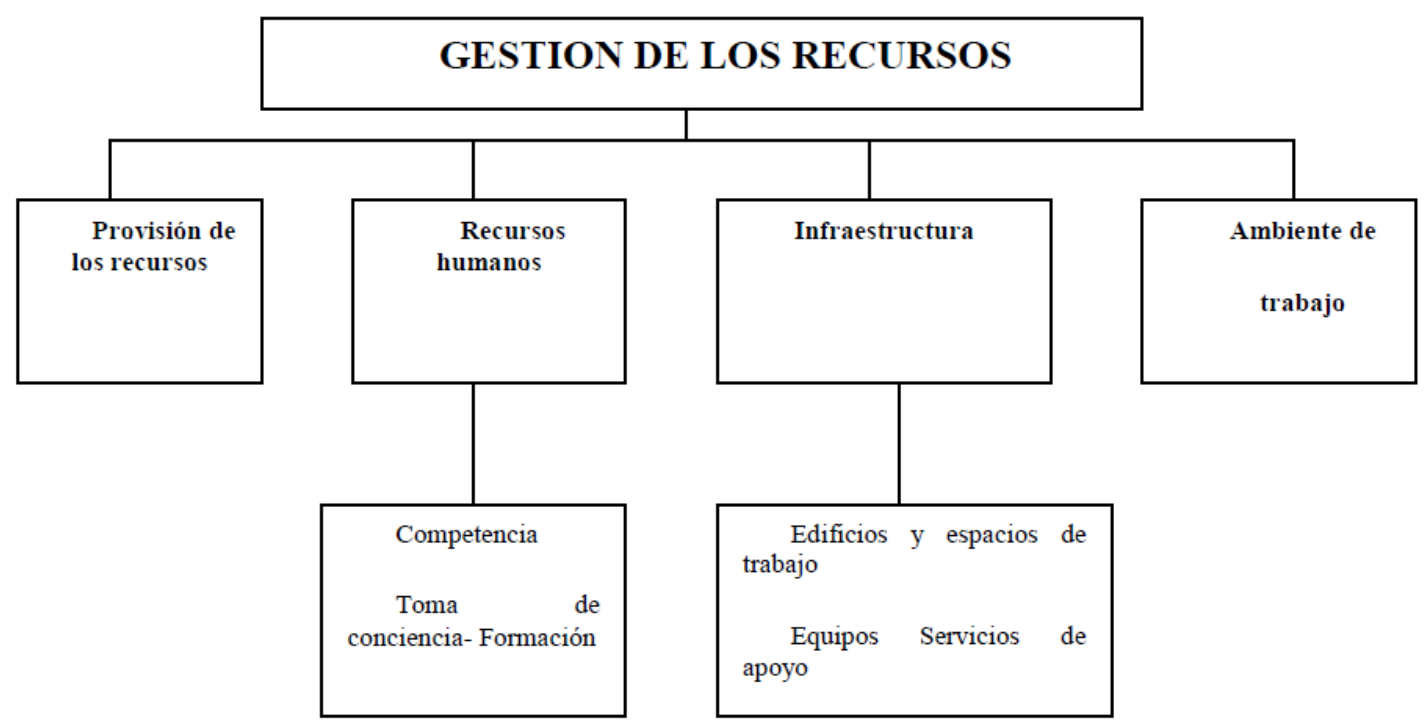

Figura 17. Gestión de los recursos. 


\subsubsection{Realización del Producto}

La calidad se consigue el la realización del producto, consiguiendo la conformidad.

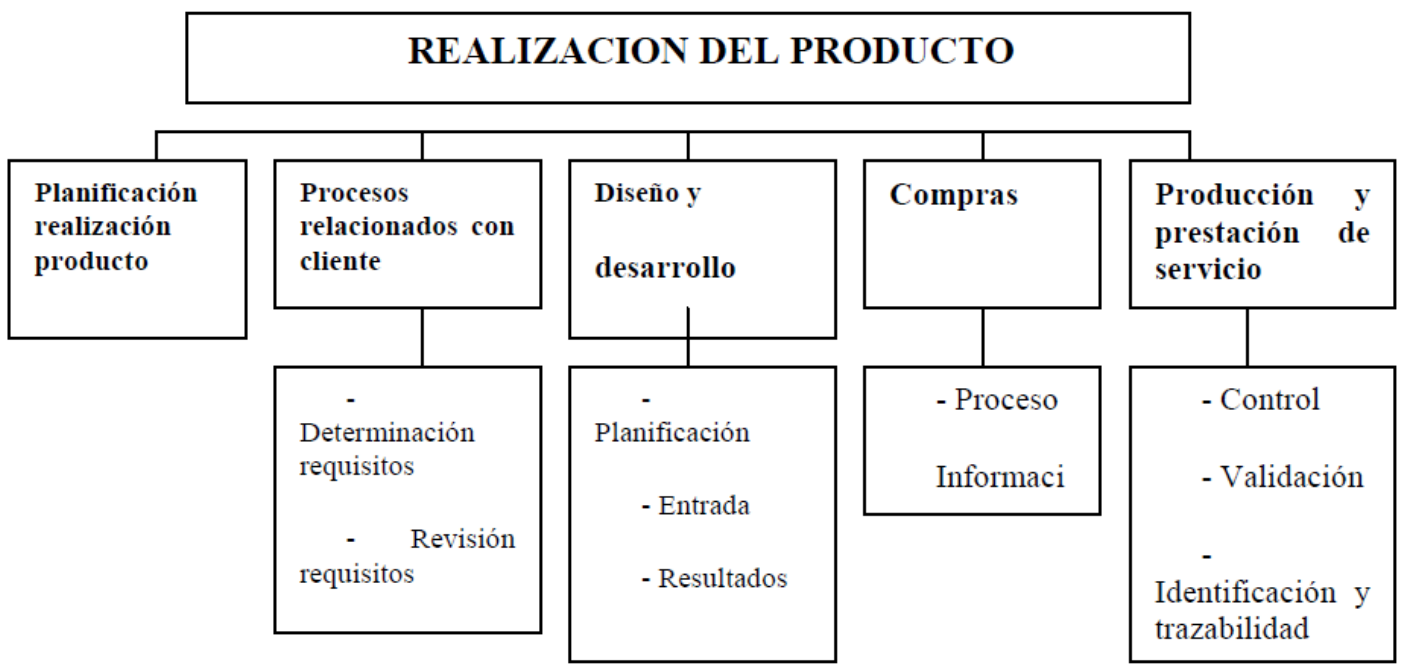

Figura 18. Realización del producto.

La planificación de realización del producto debe ser consistente con otros requisitos del SGC. Debe de estar documentada e incluir:

- Objetivos de la calidad y requisitos para el producto.

- Los procesos, documentos y recursos específicos del producto.

- Actividades requeridas de verificación, validación, seguimiento, inspección y ensayo/prueba específicas para el producto así como los criterios para la aceptación del mismo.

- Los registros que sean necesarios para proporcionar evidencia de que los procesos de realización y el producto resultante cumplen los requisitos.

También hay que establecer los requisitos de los procesos relacionados con los clientes:

- Determinar los requisitos relacionados con el producto. Tanto los necesarios para su uso como los legales.

- Revisar los requisitos relacionados con el producto. Asegurarse que los requisitos del producto están definidos, las diferencias entre los requisitos del contrato y los expresados anteriormente están resueltas y que la organización tiene capacidad para cumplir con los requisitos.

- Establecer canales de comunicación con el cliente.

Respecto al diseño y desarrollo del producto la norma establece:

- Planificar el diseño y desarrollo. Se deben determinar las etapas de diseño y desarrollo, la revisión, verificación y validación, responsabilidades y autoridades de cada etapa. 
- Los elementos de entrada para el diseño y desarrollo. Deben incluir los requisitos funcionales, de desempeño y legales, reglamentos aplicables información de diseños anteriores y cualquier otro requisito esencial para el diseño y desarrollo.

- Los resultados del diseño y desarrollo. Hay que establecer un sistema para asegurarse que los productos son buenos. Estos resultados deben cumplir los requisitos, proporcionar información apropiada, contener o hacer referencia a los criterios de aceptación y especificar las características del producto esenciales para el uso seguro y correcto.

- Revisiones del diseño y desarrollo. Deben realizarse revisiones sistemáticas de acuerdo con lo planificado.

- Verificación del diseño y desarrollo para asegurarse que los resultados cumplen con los requisitos de los elementos de entrada. Deben mantenerse registros.

- Validación del diseño y desarrollo para asegurarse de que el producto es capaz de satisfacer los requisitos para su aplicación especificada o uso previsto. Deben mantenerse registros.

- Control de los cambios en el diseño. Deben identificarse y mantenerse registros, revisarse, verificarse, validarse y aprobarse.

En cuanto a las compras, hay que establecer un sistema para asegurarse que los productos adquiridos cumplen con los requisitos y se debe realizar una evaluación y selección de los proveedores permanente.

- Proceso de compras. El producto adquirido debe cumplir los requisitos de compra especificados. Se debe evaluar y seleccionar a los proveedores en función de su capacidad para suministrar los productos según los requisitos de nuestra organización. Deben establecerse criterios de evaluación y selección y realizarse un seguimiento de los resultados.

- Información de las compras. Incluir en la información de las compras facilitada al proveedor la descripción del producto, requisitos, condiciones, equipos, procesos... siempre por escrito.

- Verificación de los productos comprados. Establecer e implementar la inspección u otras actividades para asegurarse de que el producto comprado cumple los requisitos de compra especificados.

Para la producción y prestación del servicio:

- Control de la producción y de la prestación del servicio. Se deben planificar y llevar a cabo bajo condiciones controladas que incluyan la información pertinente, equipos, seguimiento y medición, entrega...

- Validación de los procesos de la producción y de la prestación del servicio donde los productos resultantes no se pueden verificar mediante actividades de seguimiento $\mathrm{o}$ medición posteriores. Debe demostrar la capacidad de los procesos para alcanzar los resultados. Se deben establecerse criterios de revisión y aprobación de procesos, de equipos, de calificación del personal, el uso de métodos y procedimientos, registros y la revalidación. 
- Identificación y trazabilidad. Identificar el producto por medios adecuados, a través de toda la realización del producto. Identificar el estado del producto respecto los requisitos de medición y seguimiento.

- Propiedad del cliente. Identificar, verificar, proteger y mantener los bienes del cliente cuando esté bajo el control de la organización. Cualquier incidencia debe ser registrada y comunicada.

- Preservación del producto durante el proceso interno y la entrega al destino, incluyendo identificación, manipulación, embalaje, almacenamiento y protección.

Control de los dispositivos de seguimiento y de medición. Consiste en definir el seguimiento y medición, los dispositivos y los procesos para realizarlos correctamente.

- Calibrar a intervalos regulares con patrones de referencia.

- Ajustar o reajustar.

- Identificarse para determinar el estado de calibración.

- Protección contra ajusten que pueden invalidar los resultados.

- Proteger contra los daños durante su manipulación, mantenimiento y almacenamiento.

Además hay que mantener registros.

\subsubsection{MEDICIÓN, ANÁLISIS Y MEJORA}

Con este apartado de la norma se pretende que la organización planifique e implemente los procesos de seguimiento, análisis y mejora necesarios para demostrar la conformidad del producto, asegurarse de la conformidad del SGC y mejorar continuamente su eficacia.

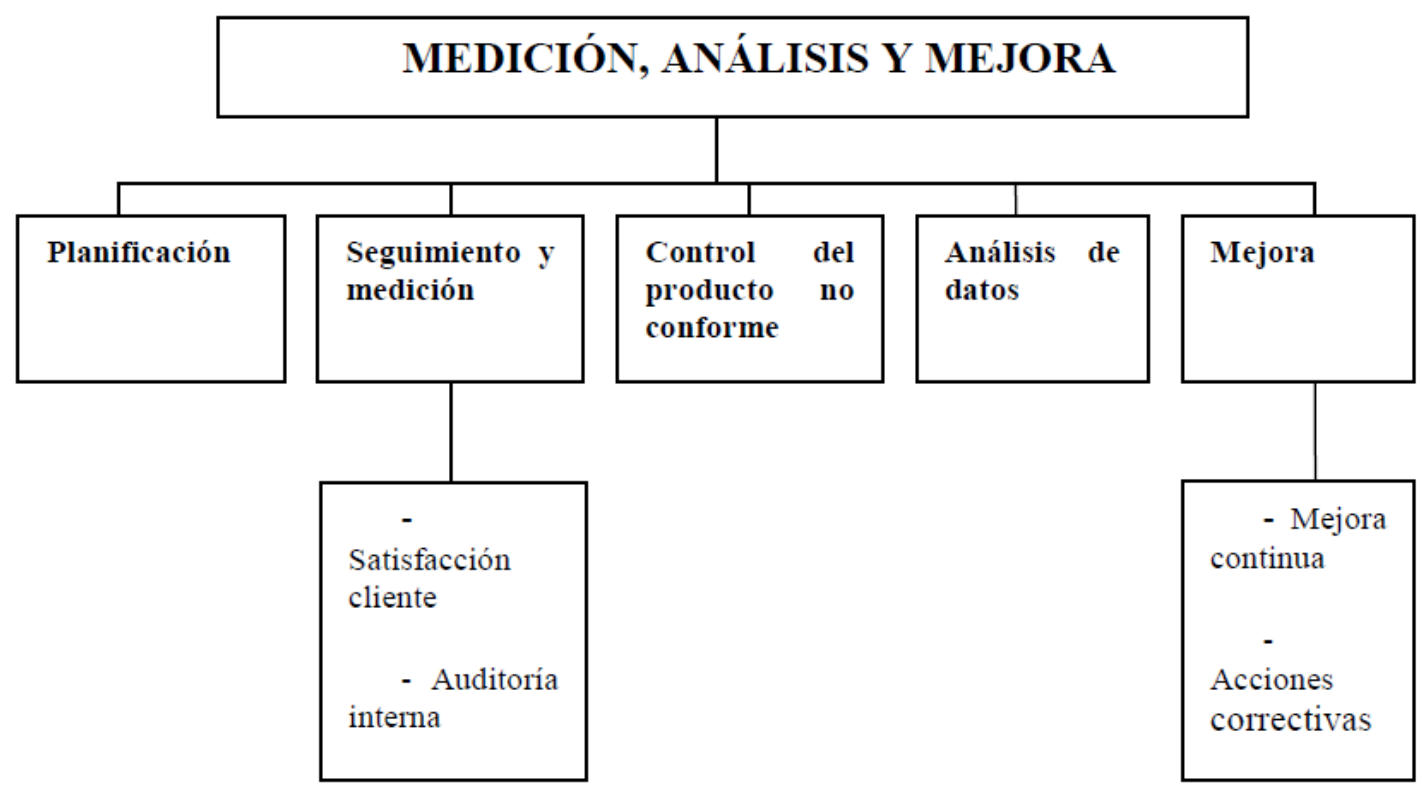

Figura 19: Medición, análisis y mejora.

El primer punto de esta sección es el seguimiento y medición: 
- Satisfacción del cliente: Se debe realizar un seguimiento de la información del cliente respecto a su satisfacción con el cumplimiento de los requisitos.

- Auditorías internas: Se deben realizar a intervalos planificados para determinar que el SGC es conforme con las disposiciones planificadas, con los requisitos de la norma

y con los requisitos del SGC establecidos por la organización y se ha implementado y mantiene de manera eficaz.

- Seguimiento y medición de los procesos: Hay que aplicar métodos para el seguimiento y cuando sea posible la medición de los procesos.

- Seguimiento y medición del producto: La organización debe medir y hacer un seguimiento de las características del producto para verificar que se cumplen los requisitos del mismo.

Respecto al control del producto no conforme la norma establece que se deben tratar:

- Tomando acciones para eliminar la no conformidad detectada.

- Autorizando su uso, liberación o aceptación bajo concesión por una autoridad pertinente y, cuando sea aplicable, por el cliente.

- Tomando acciones para impedir su uso o aplicación originalmente previsto.

El análisis de datos es otro de los apartados de esta sección, que dice que se debe determinar, recopilar y analizar los datos apropiados para demostrar la idoneidad y la eficacia del SGC y para evaluar dónde puede realizarse la mejora continua de la eficacia del SGC. Se incluyen datos generados del resultado del seguimiento y medición y cualesquiera otras fuentes pertinentes. Se deben usar técnicas estadísticas.

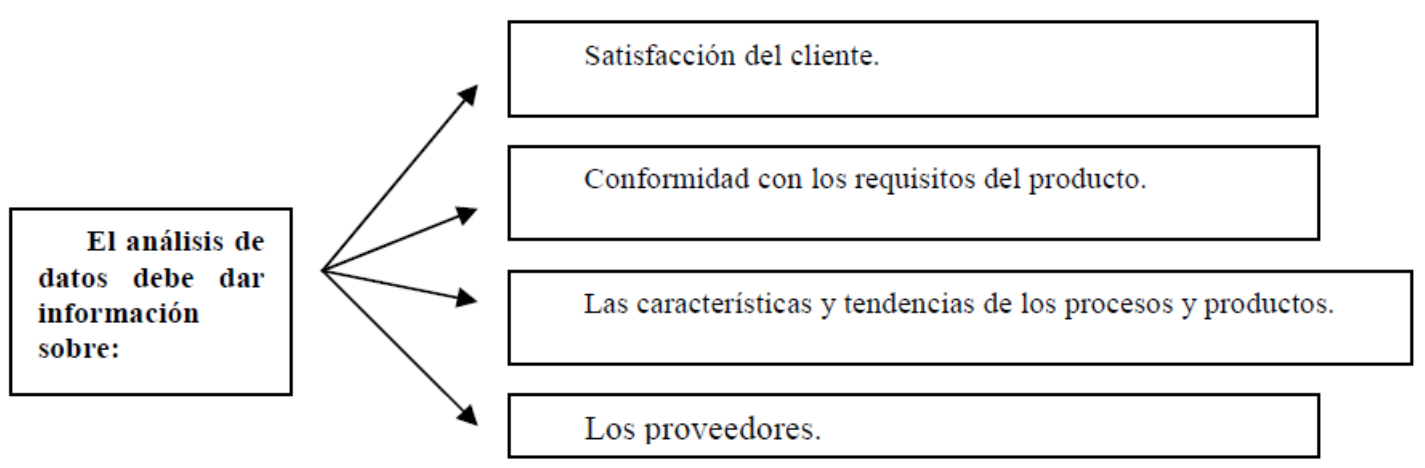

Figura 20 Análisis de datos.

La mejora es un punto importante de esta sección y la divide en tres subapartados: mejora continua, acciones correctivas y acciones preventivas. 


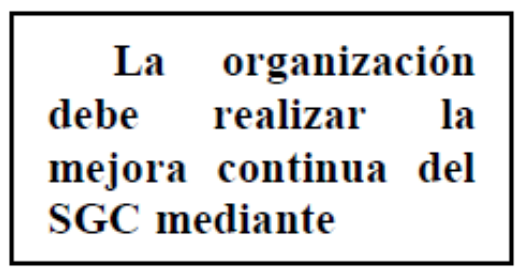

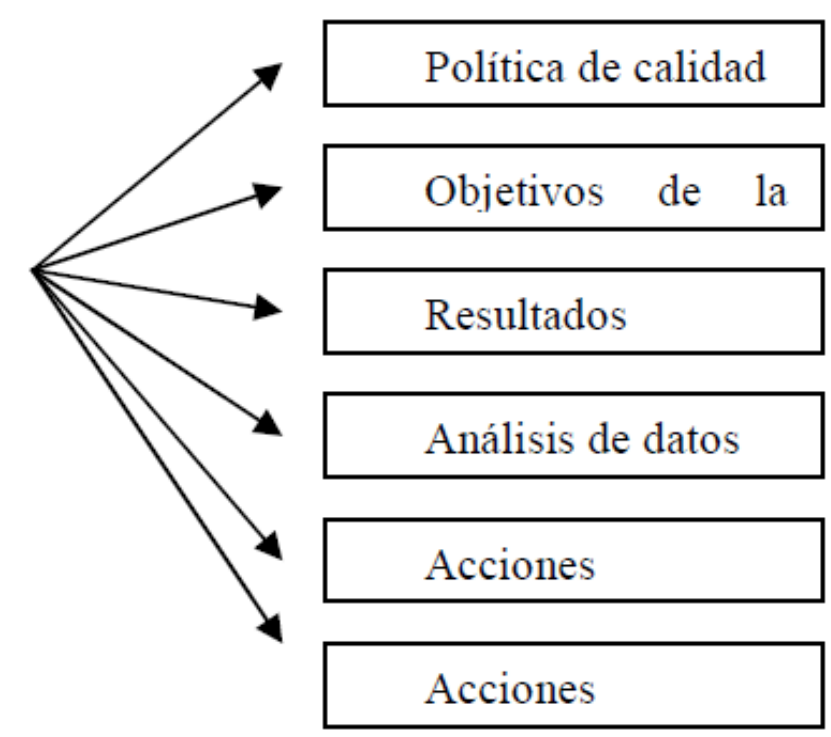

Figura 21 Mejora continua del SGC.

La organización debe tomar acciones que sirvan para eliminar las causas de las no conformidades con objeto de prevenir que vuelvan a ocurrir. Las acciones correctivas deben ser apropiadas a los efectos de las no conformidades encontradas. La organización también debe determinar acciones para eliminar las causas de no conformidades potenciales para prevenir su ocurrencia. Las acciones preventivas deben ser apropiadas a los efectos de los problemas potenciales.

\section{2-MODELOS DE EXCELENCIA}

\subsection{1.- MODELO DEMING}

El Premio Nacional de Calidad de Japón se instituyó en 1951. Fue la organización JUSE ( Union of Japanese Scientists and Engineers ) quien lo creó y le dio el nombre de "Deming", en honor al Dr. Deming, en reconocimiento a su labor en la difusión del Control de Calidad, además de por la buena relación que guardaba con JUSE. El Premio Deming ha sido clave para la implantación en Japón de la cultura de la Calidad Total.

Este modelo recoge la aplicación práctica de las teorías japonesas del Control Total de la Calidad (TQC) o control de calidad en toda la empresa (CWQC).

La evaluación del Premio Deming no requiere que los participantes sigan un modelo previamente definido por el Comité del Premio Deming. En lugar de esto, se espera que los participantes entiendan su actual situación, establezcan sus propios objetivos y que 
mejoren y transformen ellos mismos toda la organización en su conjunto. Así pues, no solamente los resultados conseguidos y el procedimiento usado para conseguir los mismos es evaluado, sino también la efectividad que se espera conseguir en el futuro. Así, el Comité evalúa si los puntos tratados por los participantes son adecuados a la situación de su organización, si todas sus actividades ( investigación y desarrollo, diseño, compras, producción, inspección, comercialización,...) son los objetivos más altos que la organización se imponga en el futuro.

En el Premio Deming existen varias categorías a las que pueden optar las diferentes empresas, en función de las características de las mismas.

Para optar al Premio, además de otros requisitos, es necesaria la realización de una Memoria. La Memoria es un documento que describe la promoción e implantación de actividades de control de calidad, desde el momento de su introducción hasta el presente, incluyendo los efectos o resultados obtenidos. Debe ser escrita de forma simple y fácil de entender. La Memoria Corporativa debe cubrir todas y cada una de las unidades de negocio. En función de la estructura de la compañía candidata, además de la Memoria corporativa, cada unidad de negocio ha de preparar una Memoria. La Memoria Corporativa ha de estar organizada de manera que conste de una Introducción en la que se trata el perfil de la compañía y las razones para introducir el Control de Calidad y una descripción de cada uno de los diez criterios de que consta el Modelo.

El modelo recoge diez criterios de evaluación de la gestión de calidad de la organización:

1. Políticas y objetivos

2. Organización

3. Flujo de Información y su utilización

4. Estandarización

5. Educación y su diseminación (Desarrollo y utilización de los Recursos Humanos)

6. Aseguramiento de la Calidad

7. Gestión y control

8. Mejora

9. Resultados

10. Planes para el futuro

\subsubsection{1- LOS 10 CRITERIOS DE EVALUACIÓN DE LA GESTIÓN DE LA CALIDAD DE LA ORGANIZACIÓN.}

\section{Políticas y objetivos}

Se analiza como se establecen las políticas de dirección, calidad y control de calidad, y cómo se transmiten a todos los sectores de la empresa. También se evalúa si los contenidos de esta política son adecuados y si se presentan con claridad. 
Subcriterios:

- Políticas de calidad y de control de calidad, y su lugar en la gestión global del negocio.

- Claridad de las políticas (objetivos y mediciones prioritarias).

- Métodos y procesos para el establecimiento de las políticas.

- Relación de las políticas con los planes a corto y largo plazo.

- Comunicación (despliegue) de las políticas, comprensión y gestión para alcanzarlas.

- Liderazgo de los ejecutivos y mandos

\section{Organización}

Se evalúa si los campos de responsabilidad y autoridad están claramente definidos y cómo se promueve la cooperación entre departamentos. También se evalúa cómo está organizada la empresa para llevar a cabo el control de la calidad.

\section{Subcriterios:}

-Idoneidad de la estructura organizativa para el control de calidad y situación del compromiso de los empleados.

-Claridad de la autoridad y responsabilidad.

-Situación de la coordinación interdepartamental.

-Situación de las actividades de comités y equipos de proyectos.

-Situación de las actividades del personal.

-Relaciones con compañías asociadas (compañías del grupo, proveedores, subcontratistas, compañías de ventas, etc.).

\section{Flujo de Información y su utilización}

Se evalúa cómo se recoge y transmite la información, procedente tanto del interior como del exterior de la compañía, en todos sus niveles y organizaciones. Se evalúa cuáles son los sistemas usados y la rapidez con que la información es recogida, transmitida, evaluada y utilizada.

\section{Subcriterios:}

-Idoneidad de la recogida y comunicación de información externa.

-Idoneidad de la recogida y comunicación de información interna.

-Situación de la aplicación de técnicas estadísticas para el análisis de los datos.

-Idoneidad de la conservación de la información.

-Situación de la utilización de la información.

-Situación de la utilización de los ordenadores para el proceso de los datos.

\section{Estandarización}


Se evalúan los procedimientos para el establecimiento, revisión y derogación de estándares y la forma en la que se controlan y sistematizan, así como el uso que se hace de los estándares para la mejora de la tecnología de la empresa.

\section{Subcriterios:}

-Idoneidad del sistema de estándares.

-Procedimientos para establecer, revisar y eliminar estándares.

-Rendimiento actual en el establecimiento, revisión y eliminación de estándares.

-Contenidos de los estándares.

-Situación de la utilización y adherencia a los estándares.

-Situación del desarrollo, manejo y utilización sistemática de tecnologías

\section{Educación y su diseminación. Desarrollo y utilización de los Recursos Humanos.}

Se evalúa cómo se enseña lo que es el control de calidad y cómo reciben los empleados el entrenamiento en calidad, mediante cursos de formación o del trabajo diario. Se analiza el grado en que el concepto de control de calidad y las técnicas estadísticas han sido comprendidas y son utilizadas. Dentro de esta categoría, se analiza el papel de los círculos de calidad.

Subcriterios:

-Planes de formación y entrenamiento y sus resultados.

-Situación de la concienciación en calidad, concienciación en gestión de trabajos y entendimiento del control de calidad.

-Situación del soporte y motivación hacia el autodesarrollo y autorrealización.

-Situación del entendimiento y utilización de los conceptos y métodos estadísticos.

-Situación del desarrollo de los círculos de control de calidad y de las sugerencias de mejora

--Situación del soporte del desarrollo de los recursos humanos en compañías asociadas.

\section{Aseguramiento de la Calidad}

Se evalúa cómo se enseña lo que es el control de calidad y cómo reciben los empleados el entrenamiento en calidad, mediante cursos de formación o del trabajo diario. Se analiza el grado en que el concepto de control de calidad y las técnicas estadísticas han sido comprendidas y son utilizadas. Dentro de esta categoría, se analiza el papel de los círculos de calidad:

\section{Subcriterios:}

-Planes de formación y entrenamiento y sus resultados.

-Situación de la concienciación en calidad, concienciación en gestión de trabajos y entendimiento del control de calidad.

-Situación del soporte y motivación hacia el autodesarrollo y autorrealización. 
-Situación del entendimiento y utilización de los conceptos y métodos estadísticos.

-Situación del desarrollo de los círculos de control de calidad y de las sugerencias de mejora.

-Situación del soporte del desarrollo de los recursos humanos en compañías asociadas.

\section{Gestión y control}

Se evalúa cómo se realizan las revisiones periódicas de los procedimientos empleados para el mantenimiento y mejora de la calidad. También se analiza cómo están definidas la autoridad y las responsabilidades sobre estas materias, y se evalúa el uso de gráficos de control y de otras técnicas estadísticas.

Subcriterios:

-Rotación del ciclo de gestión (PDCA).

-Métodos para determinar los puntos de control.

-Situaciones de control interno.

-Situación de la toma de medidas temporales y permanentes.

-Situación de sistemas de gestión operativos para costes, cantidades, entregas, etc.

-Relación entre el sistema de aseguramiento de la calidad y otros sistemas de gestión operativos

\section{Mejora}

Se evalúa cómo se seleccionan y analizan los problemas críticos o no relativos a la calidad y cuál es el uso que se hace de estos análisis. Se evalúan los métodos empleados y el uso que se hace de las herramientas estadísticas.

\section{Subcriterios:}

-Métodos de selección de temas (problemas importantes y asignación de prioridades).

-Enlace entre los métodos analíticos y la tecnología intrínseca.

-Situación de la utilización de métodos estadísticos para el análisis.

-Utilización de los resultados de los análisis.

-Situación de la confirmación de resultados de mejoras y su transferencia a actividades de mantenimiento y control.

-Contribución de las actividades de los círculos de control de calidad.

\section{Resultados}

Se evalúan los resultados producidos en la calidad de productos y servicios gracias ala implantación del control de calidad, y si se están produciendo y vendiendo bienes o servicios de suficiente calidad. Se comprueba también si ha existido mejora en los productos y servicios suministrados desde el punto de vista de la calidad, del coste y de la cantidad, y también si la empresa en su conjunto ha mejorado, no sólo en calidad y 
beneficios, sino en el modo científico de pensar de sus directivos y de sus empleados, en la motivación y en otros beneficios intangibles.

\section{Subcriterios:}

-Resultados tangibles (como calidad, entrega, coste, beneficio, seguridad y medio ambiente).

-Resultados (efectos) intangibles.

-Métodos para medir y mantener resultados (efectos).

-Satisfacción de los clientes y de los empleados.

-Influencia en compañías asociadas.

-Influencia en las comunidades locales e internacionales.

\section{Planes para el futuro}

Se evalúa si los puntos fuertes y débiles en la situación actual son adecuadamente reconocidos, y en qué modo se realiza la planificación para la mejora de la calidad.

Subcriterios:

-Situación del aseguramiento de las situaciones actuales.

-Planes futuros para mejorar problemas.

-Proyección de cambios en el entorno social y en los requisitos de los clientes, y planes futuros basados en estos cambios proyectados.

-Relaciones entre la filosofía de gestión, la visión y los planes a largo plazo.

-Continuidad de las actividades de control de calidad.

-Concreción de los planes futuros

\subsection{2.- MODELO MALCOLM BALDRIGE}

El Premio Nacional de Calidad Malcolm Baldrige se crea en Estados Unidos en 1987, por la necesidad de las organizaciones de competir en el mercado internacional, surge el proyecto del Premio Nacional de la Calidad Americano, con la misión de sensibilizar al país y a las industrias, promocionando la utilización dela Gestión de Calidad Total como método competitivo de gestión empresarial y de disponer de un medio de reconocer formal y públicamente los méritos de aquellas firmas que los hubieran implantado con éxito.

El modelo Malcolm Baldrige establece que los líderes de la organización deben estar orientados a la dirección estratégica y a los clientes. También deben dirigir, responder y gestionar el desempeño basándose en los resultados. Las medidas y los indicadores del desempeño y el conocimiento organizativo deben ser la base sobre las que construir las estrategias clave. Estas estrategias deben estar relacionadas con los procesos y con la 
alineación de los recursos. De este modo, se conseguirá una mejora en el desempeño general de la organización y la satisfacción de los consumidores y de los grupos de interés

\section{Propósitos del Modelo de Excelencia}

El Modelo de Excelencia constituye una base para la realización de autoevaluaciones organizacionales y para proporcionar retroalimentación a sus usuarios. Adicionalmente, el Modelo tiene tres importantes roles para fortalecer la competitividad de las organizaciones:

1- Ayudar a mejorar sus prácticas de gestión, capacidades y resultados.

2-Facilitar la comunicación y el intercambio de información sobre mejores prácticas entre organizaciones de todo tipo.

3- Servir de herramienta de trabajo para comprender y gestionar el desempeño la planificación y las oportunidades de aprendizaje.

\subsubsection{1-PROPÓSITOS Y OBJETIVOS}

\section{Objetivos del Modelo de Excelencia}

El Modelo de Excelencia está diseñado para ayudar a las organizaciones a usar un enfoque integrado para la gestión del desempeño organizacional que resulte en:

1- Proporcionar permanentemente mayor valor a los clientes y grupos de interés, contribuyendo a la sostenibilidad de la organización.

2-La mejora de la eficacia y de las capacidades de toda la organización.

3- Aprendizaje, tanto organizacional como personal.

El premio trata de promover entre las empresas:

-La preocupación por la calidad

-La comprensión de los requerimientos para alcanzar la excelencia en la gestión.

-El intercambio de información sobre estrategias empresariales con éxito y los beneficios derivados de la implantación de dichas estrategias.

\subsubsection{2- CONCEPTOS Y VALORES}

Cada criterio del Malcolm Baldrige se basa en unos conceptos y valores fundamentales, que son los siguientes:

\section{1- Liderazgo visionario}


La alta dirección de la organización debe fijar la dirección, establecer la orientación hacia el cliente, determinar valores claros y visibles y establecer altas expectativas de desempeño. La dirección, valores y expectativas de desempeño deben equilibrar las necesidades de todos los grupos de interés. Los líderes requieren garantizar el desarrollo de estrategias, sistemas y métodos para alcanzar el desempeño de excelencia, estimulando la innovación y construyendo conocimientos y capacidades organizacionales, es decir, asegurando la sostenibilidad organizacional.

\section{2- Excelencia impulsada por el cliente}

La calidad y el desempeño son juzgados por los clientes de la organización. Por ello, la organización debe tomar en cuenta los aspectos que proporcionan valor: todas las características de los productos y servicios y todos los canales de acceso de los clientes. Ello lleva a generar nuevos clientes, satisfacción, preferencia, referencias positivas, retención, lealtad y a la expansión de los negocios. La excelencia impulsada por el cliente comprende tanto aspectos presentes como futuros: comprender las necesidades actuales de los clientes y anticiparse a sus futuros deseos y a otras potencialidades del mercado.

\section{3- Aprendizaje organizacional y personal}

Alcanzar los más altos niveles de desempeño organizacional requiere de un enfoque hacia el aprendizaje organizacional y personal correctamente ejecutado. El aprendizaje organizacional incluye tanto la mejora continua de los enfoques existentes como el cambio significativo, conducente éste último, a nuevas metas y enfoques. El aprendizaje debe estar integrado a la forma en que la organización opera. Ello quiere decir que el aprendizaje: (1) es parte regular del trabajo diario; (2) se practica a nivel individual, de unidad de trabajo y organizacional; (3) permite la solución de los problemas en sus orígenes (causa raíz); (4) está enfocado en la creación y difusión del conocimiento en toda la organización; y (5) es impulsado por oportunidades que producen cambios significativos e importantes. Las fuentes para el aprendizaje incluyen las ideas de los colaboradores, la investigación y desarrollo, la información de clientes, las “mejores prácticas” y el benchmarking.

\section{4- Valoración de las personas y de los asociados}

El éxito de una organización depende cada vez más de la diversidad, conocimientos, habilidades, creatividad y la motivación de las personas y asociados de la organización.

Valorar a las personas significa estar comprometido con su satisfacción, desarrollo y bienestar. Ello implica, prácticas laborales de alto desempeño, más flexibles hechas a la medida de personas con diversos lugares de trabajo y con diferentes necesidades de vida familiar. Los principales retos en el área de valoración de las personas incluyen (1) demostrar el compromiso de la alta dirección con el éxito de las personas, (2) proveer 
reconocimiento que vaya más allá del sistema de compensación formal, (3) ofrecer desarrollo y el crecimiento dentro de la organización, (4) compartir el conocimiento de la organización de manera que las personas puedan servir mejor a los clientes y contribuir a alcanzar los objetivos estratégicos, (5) crear un ambiente que fomente la toma de riesgos y la innovación y, (6) crear un ambiente de apoyo para una fuerza de trabajo diversa.

\section{5- Agilidad}

El éxito en los cambiantes entornos competitivos globales exige agilidad: la capacidad para generar respuestas rápidas y flexibilidad. Los aspectos relacionados con el comercio electrónico requieren respuestas más rápidas, flexibles y personalizadas. Los negocios enfrentan ciclos cada vez más cortos para introducir nuevos y mejores productos y servicios, asimismo las organizaciones sin fines de lucro y de gobierno son cada vez más requeridas a responder más rápido a aspectos sociales nuevos o emergentes. Las mejoras considerables en los tiempos de respuesta frecuentemente requieren la simplificación de las unidades de trabajo y de los procesos, o, la habilidad para desarrollar rápidos cambios considerables, de un proceso a otro. El entrenamiento cruzado y personas con autoridad delegada son activos valiosos ese exigente ambiente.

\section{6- Orientación hacia el futuro}

En el ambiente competitivo actual, crear una organización sostenible requiere la comprensión de los factores de corto y largo plazo que afectan la organización y el mercado. La búsqueda del crecimiento sostenido y del liderazgo en el mercado implican una marcada orientación hacia el futuro y una voluntad para realizar compromisos a largo plazo con los grupos de interés claves (clientes, colaboradores, proveedores, accionistas, estado y comunidad). En la planificación estratégica la organización debería anticipar factores múltiples tales como las expectativas de los clientes, las nuevas oportunidades de negocios y para la formación de asociaciones / alianzas, el incremento de la globalización de los mercados, los desarrollos tecnológicos, el entorno evolutivo del comercio electrónico, cambios en los clientes y segmentos de mercado, la evolución de los requerimientos legales, cambios en las expectativas y necesidades de la comunidad y la sociedad, y, los movimientos estratégicos realizados por los competidores. Los objetivos estratégicos y la asignación de recursos deben reflejar estas influencias. La orientación hacia el futuro incluye el desarrollo de los colaboradores y proveedores, lograr un efectivo planeamiento de la sucesión, la búsqueda de oportunidades para la innovación y la anticipación aspectos de responsabilidad social y preocupación pública.

\section{7- Gestión para la innovación}

Innovación significa llevar a cabo cambios significativos para mejorar los productos, servicios, procesos y operaciones de la organización y crear nuevo valor para los grupos de 
interés de la organización. La innovación debería conducir a la organización hacia nuevas dimensiones de desempeño. La innovación ya no es estrictamente el campo de acción de los departamentos de investigación y desarrollo, la innovación es importante para todos los aspectos de las operaciones y para todos los procesos. Las organizaciones deberían ser estructuradas de tal manera que la innovación se convierta en parte de la cultura de aprendizaje. La innovación debería estar integrada al trabajo diario y ser respaldada por el sistema de mejora del desempeño. La innovación se sustenta en el conocimiento acumulado de la organización y de los colaboradores. Por lo tanto, la habilidad para diseminar y capitalizar rápidamente este conocimiento resulta crítica para alcanzar la innovación organizacional.

\section{8- Gestión basada en hechos}

Las organizaciones dependen de indicadores y análisis del desempeño. Los indicadores deben proceder de las necesidades del negocio y de la estrategia de la organización y, deberían proporcionar datos e información críticos sobre procesos, productos y resultados claves. Muchos grupos de datos e información son requeridos para la gestión del desempeño. Las áreas de medición del desempeño incluyen: desempeño de clientes, productos y servicios; comparaciones de desempeño operativo, de mercado y competitivo; desempeño de proveedores, colaboradores, de costos y financiero; y, de buen gobierno y cumplimiento. Para facilitar el análisis, los datos deben ser segmentados, por ejemplo, por mercados, líneas de producto, grupos de colaboradores.

\section{9- Responsabilidad social}

La alta dirección requiere hacer que la organización acentúe sus responsabilidades con la sociedad, genere comportamientos éticos y logre una buena práctica ciudadana. Los líderes deben ser modelos para la organización enfocándose en la ética y en la protección d la salud, seguridad y el ambiente. La protección de la salud, seguridad y el ambiente deben comprender las operaciones de la organización así como, los ciclos de vida de los productos y servicios.

Asimismo, es necesario fomentar decididamente la conservación de los recursos y la reducción de los desperdicios en sus orígenes. El planeamiento debería anticipar los impactos adversos de la producción, entrega, transporte, uso y disposición de los productos. El planeamiento efectivo debería prevenir problemas, proporcionar respuestas inmediatas si los problemas ocurren y hacer que estén disponibles la información y el apoyo necesarios para mantener el conocimiento, la seguridad y la confianza del público. 


\section{0- Orientación hacia la obtención de resultados y la creación de valor}

Los indicadores del desempeño de una organización deben orientarse hacia los resultados claves. Los resultados, a su vez, deberían ser usados para crear y equilibrar el valor para todos los grupos de interés claves: clientes, empleados, accionistas, proveedores, asociados, estado y comunidad. Al crear valor para todos los grupos de interés, la organización crea lealtad, contribuye al crecimiento económico y aporta a la sociedad. Para armonizar las aspiraciones, a veces conflictivas y cambiantes que el equilibrio de valor implica, la estrategia organizacional debería explícitamente incluir los requerimientos claves de los grupos de interés. Esto ayudará a garantizar que las acciones y planes sean coherentes con las diferentes necesidades de los grupos de interés y, eliminar, impactos adversos en cualquiera de ellos. El uso de un conjunto balanceado de indicadores de desempeño preventivas ofrece un medio eficaz para comunicar prioridades a corto y largo plazo, monitorear el desempeño actual y proporcionar una sólida base para mejorar los resultados.

\section{1-Perspectiva de sistema}

El Modelo de Excelencia proporciona una perspectiva de sistema para gestionar la organización y sus procesos clave con el objetivo de alcanzar resultados o desempeño de excelencia. Los siete Criterios y los Valores y Conceptos Centrales constituyen los bloques de la estructura y el mecanismo de integración del sistema. Sin embargo, una gestión exitosa del desempeño requiere síntesis, alineamiento e integración, específicos a cada organización. Síntesis significa observar a la organización como un todo y orientarse hacia requerimientos clave de negocio, incluidos los objetivos estratégicos y planes de acción. Alineamiento significa usar los vínculos claves entre los requerimientos del Modelo de Excelencia para asegurar la consistencia de planes, procesos, indicadores y acciones. La integración se construye sobre el alineamiento, de manera que, los componentes del sistema de gestión del desempeño funcionan de una manera completamente interconectada.

Estos conceptos son descritos en el "Marco General del Modelo de Excelencia" de la página siguiente. Una perspectiva de sistema implica que la alta dirección esté enfocada en las orientaciones estratégicas y en los clientes. Ello quiere decir que la alta dirección hace seguimiento, responde y gestiona el desempeño con base en los resultados. La perspectiva de sistema también comprende el uso de indicadores y del conocimiento organizacional para construir las estrategias claves. Esto significa vincular las estrategias con los procesos clave y alinear los recursos para mejorar el desempeño global y satisfacer a los clientes y grupos de interés.

De este modo, para alcanzar el éxito, la perspectiva de sistema implica gestionar a la organización, así como a cada uno de sus componentes. 
-Estos valores y conceptos, son creencias y comportamientos arraigados, encontrados en las organizaciones de alto desempeño. Son además, la base para integrar requerimientos operativos y de desempeño en un marco orientado hacia la obtención de resultados, lo que, a su vez, crea una base para la acción y la retroalimentación.

Los criterios del Modelo Baldrige ofrecen una perspectiva completa del sistema de gestión de la organización. La base del sistema está formada por las siete categorías y los valores del modelo. Para alcanzar el éxito, es necesaria una visión de conjunto de toda la organización, representada por la estructura del modelo y, al mismo tiempo, un enfoque más profundo delas principales áreas que vienen identificadas en las categorías del mismo.

\subsubsection{3.- MARCO GENERAL DEL MODELO DE EXCELENCIA: Una Perspectiva de Sistemas}

Los Valores y Conceptos Centrales del Modelo de Excelencia se encuentran comprendidos en los siguientes siete Criterios:

1. Liderazgo

2. Planeamiento Estratégico

3. Orientación hacia el Cliente y el Mercado

4. Medición, Análisis y Gestión del Conocimiento

5. Orientación hacia las Personas

6. Gestión de Procesos

7. Resultados

El gráfico que figura a continuación ofrece el marco que conecta e integra los criterios. 


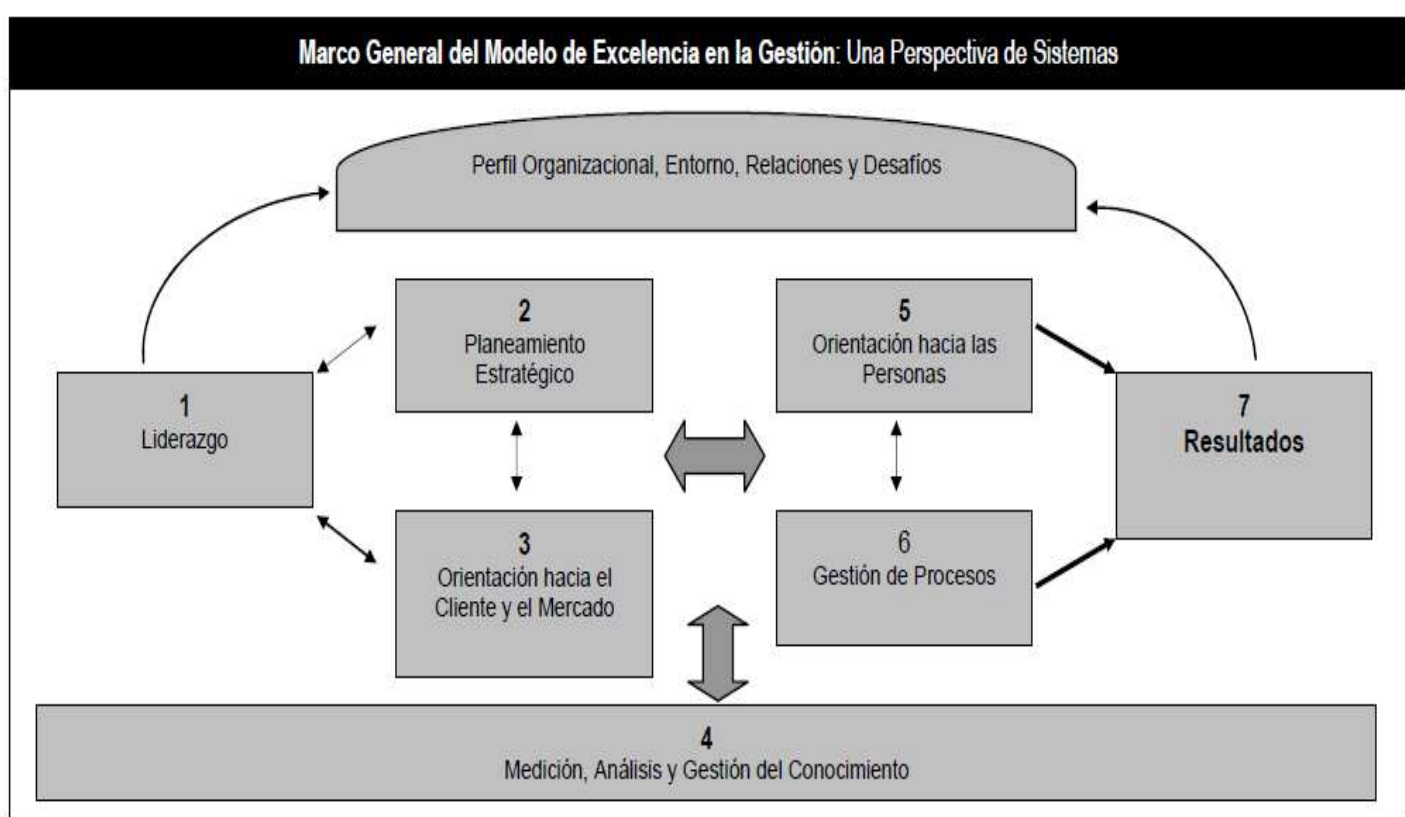

Figura 22 Marco General del Modelo de Excelencia

De la parte superior a la inferior el marco contiene los siguientes elementos básicos:

\section{Perfil Organizacional}

El Perfil Organizacional (parte superior del gráfico) fija el contexto para la forma como la organización opera. El entorno, relaciones de trabajo claves, y los desafíos estratégicos sirven como un "paraguas" guía para el sistema de gestión del desempeño organizacional.

\section{Sistema}

El sistema está comprendido por los seis Criterios del Modelo de Excelencia en el centro del gráfico que definen los procesos, y, por un séptimo Criterio de resultados. Liderazgo (Criterio 1), Planeamiento Estratégico (Criterio 2), y Orientación hacia el Cliente y el Mercado (Criterio 3) representan la tríada del liderazgo. Estos Criterios están ubicados juntos para subrayar la importancia del liderazgo orientado hacia la estrategia y hacia los clientes. La alta dirección establece la dirección y busca oportunidades futuras para la organización.

Orientación hacia las Personas (Criterio 5), Gestión de Procesos (Criterio 6) y Resultados (Criterio 7) representan la tríada de los resultados. Las personas y procesos clave de la organización llevan a cabo el trabajo de la organización que genera los resultados de negocio. Todas las acciones apuntan hacia los resultados de negocio: el 
conjunto de resultados de desempeño de productos y servicios, clientes y mercado, financieros y de desempeño operativo interno, así como los resultados de las personas y de responsabilidad social.

La flecha horizontal en el centro de la figura, une la tríada del liderazgo con la tríada de los resultados, un vínculo crítico para el éxito organizacional. Además, la flecha indica la fundamental relación entre Liderazgo (Criterio 1) y Resultados (Criterio 7). La flecha de "doble cabeza" representa la importancia de la retroalimentación en un eficaz sistema de gestión del desempeño.

\section{Base del Sistema}

Medición, Análisis y Gestión del Conocimiento (Criterio 4) es crítico para la gestión eficaz de la organización y para un sistema basado en hechos orientado a mejorar el desempeño y la competitividad. La medición, análisis y la gestión del conocimiento sirven como base para el sistema de gestión del desempeño.

\section{Estructura de los Criterios}

Los siete Criterios presentados en el gráfico se subdividen en Subcriterios y Áreas de Análisis:

\section{Subcriterios}

Existen 19 Subcriterios, cada uno de los cuales apunta a un requerimiento principal del Modelo.

\section{Áreas de Análisis}

Los Subcriterios comprenden una o más Áreas de Análisis. Las organizaciones deben enfocar sus respuestas a los requerimientos específicos de estas Áreas. 


\section{Modelo de Excelencia en la Gestión - Criterios y Subcriterios}

\section{P. Perfil Organizacional}

P.1 Descripción de la Organización

P.2 Desafíos de la Organización

\section{Criterios / Subcriterios}

Puntuación

1. Liderazgo

1.1 Liderazgo de la Alta Dirección 70

1.2 Buen Gobierno y Responsabilidad Social

50

2. Planeamiento Estratégico

2.2 Despliegue de Estrategias

3. Orientación hacia el Cliente y el Mercado

3.1 Conocimiento del Cliente y del Mercado 40

3.2 Relaciones con el Cliente y Satisfacción 45

4. Medición, Análisis y Gestión del Conocimiento

4.1 Medición, Análisis y Evaluación del Desempeño Organizacional 45

4.2 Gestión de la Información y del Conocimiento 45

5. Orientación hacia las Personas

5.1 Sistemas de Trabajo

5.2 Aprendizaje y Motivación de las Personas

5.3 Bienestar y Satisfacción de las Personas

6.1 Procesos de Creación de Valor 45

6.2 Procesos de Soporte y Planeamiento Operativo 40

7. Resultados

7.1 Resultados de Productos y Servicios

7.2 Resultados de Orientación hacia el Cliente 70

7.3 Resultados Financieros y de Mercado 70

7.4 Resultados de la Orientación hacia las Personas 70

7.5 Resultados de la Eficacia Organizacional 70

7.6 Resultados de Liderazgo y Responsabilidad Social 70

Figura 23 Puntuación para los criterios y sbucriterios 


\section{P- Perfil Organizacional}

El Perfil Organizacional es importante porque:

- Es el punto de partida más apropiado para una autoevaluación;

- Ayuda a identificar brechas potenciales en información clave y se enfoca en requerimientos de desempeño y resultados clave;

- Es usado por los evaluadores para comprender la organización y lo que ésta considera importante.

- Puede también ser usado como una autoevaluación inicial. Si se identifica aspectos conflictivos o con poca o nula información, es posible que el Perfil Organizacional sirva como una evaluación completa, por lo que,

- Puede ser usada para el planeamiento de acciones.

El Perfil Organizacional es un resumen general de la organización, presenta las influencias más importantes referidas a como opera, así como, los desafíos clave que son enfrentados.

\section{P.1 Descripción de la Organización}

¿Cuáles son las características organizacionales clave?

Describa el entorno de operaciones de la organización y las relaciones clave con clientes, proveedores, asociados y otros grupos de interés.

Incluya respuestas a las siguientes preguntas:

\section{A. ENTORNO ORGANIZACIONAL}

(1) ¿Cuáles son los principales productos y servicios de la organización?, ¿cuáles son los mecanismos de entrega usados para proveer los productos y servicios a los clientes?

(2) ¿Cuáles son los elementos principales de la cultura de la organización?, ¿cuáles son las declaraciones de propósito, visión, misión y valores?

(3) ¿Cuál es el perfil de los colaboradores?, ¿cuáles son las categorías y tipos de colaboradores?, ¿cuáles son sus niveles educacionales?, incluya las características de la fuerza de trabajo, la diversidad de puestos existente, las unidades de negociación organizadas, el uso de colaboradores temporales, y requerimientos de seguridad especiales.

(4) ¿Cuáles son las tecnologías, equipos e instalaciones principales? 
(5) ¿Cuál es el entorno legal bajo el que la organización opera?, ¿cuáles son las regulaciones de salud ocupacional y seguridad aplicables; los requerimientos de acreditación, certificación; los estándares relevantes en la industria y; regulaciones ambientales, financieras y de producto?

\section{B. RELACIONES ORGANIZACIONALES}

(1) ¿Cuál es la estructura de la organización y su sistema de gobierno?, ¿cuáles son las relaciones de reporte entre el directorio, la alta dirección y las organizaciones vinculadas, según corresponda?

(2) ¿Cuáles son los clientes, grupos de interés y los segmentos de mercado claves? ¿cuáles son los requerimientos clave para los productos, servicios y operaciones?, ¿cuáles son las diferencias entre estos requerimientos y expectativas entre clientes, grupos de interés y segmentos de mercado, según sea apropiado?

(3) ¿Cuál es el rol que los proveedores, asociados y distribuidores juegan en los procesos de creación de valor y en los de soporte?, ¿qué rol juegan, si fuera el caso, en los procesos de innovación?

(4) ¿Cuáles son las más importantes relaciones de asociación y mecanismos de comunicación desarrollados con proveedores y clientes clave?

\section{P.2 Desafíos de la Organización}

¿Cuáles son los desafíos organizacionales clave?

Describa el entorno competitivo de la organización, los desafíos estratégicos clave y el sistema de mejora del desempeño.

Incluya respuestas a las siguientes preguntas:

\section{A. ENTORNO COMPETITIVO}

(1) ¿Cuál es la posición competitiva de la organización?, ¿cuál es el tamaño y crecimiento relativos de la organización en la industria y en los mercados que atiende?, ¿cuál es el número y tipo de competidores y aliados clave de la organización?

(2) ¿Cuáles son los principales factores que determinan el éxito respecto a los competidores?, incluya cualquier cambio en curso que afecte la posición competitiva y, las oportunidades para la colaboración, según sea apropiado.

(3) ¿Cuáles son la fuentes clave disponibles de datos comparativos y competitivos de la industria?, ¿cuáles son las fuentes clave de datos comparativos para procesos análogos 
fuera de la industria?, ¿qué limitaciones, si las hubiera, existe en la obtención de dichos datos?

\section{B. DESAFÍOS ESTRATÉGICOS}

¿Cuáles son los desafíos de negocio, operativos y de recursos humanos claves de la organización?, ¿cuáles son los desafíos estratégicos asociados a la sostenibilidad de la organización?

\section{SISTEMA DE MEJORA DEL DESEMPEÑO}

¿De que manera se mantiene una orientación hacia la mejora del desempeño, incluido el aprendizaje organizacional?, ¿de qué manera se alcanza la evaluación y mejora sistemática de los procesos clave?

El Perfil Organizacional no debería tomar más de cinco páginas.

\section{1.- LIDERAZGO}

El Criterio Liderazgo examina la manera en que la alta dirección dirige y hace sostenible a la organización.

Además evalúa el gobierno de la organización y la manera en que se abordan las responsabilidades éticas, legales y las referidas a la comunidad.

\subsection{Liderazgo de la Alta Dirección (70 puntos) Proceso}

¿De qué manera lidera la alta dirección?

Describa la manera en que la alta dirección dirige y hace sostenible a la organización. Describa como la organización se comunica con los colaboradores e impulsa el alto desempeño.

Incluya respuestas a las siguientes preguntas:

\section{A. VISIÓN Y VALORES}

(1) ¿De qué manera la alta dirección establece la visión y los valores de la organización?, ¿de qué manera la alta dirección despliega la visión y los valores de la organización a través del sistema de liderazgo, a todos los colaboradores, proveedores y asociados clave, clientes y a otros grupos de interés, según sea apropiado?, ¿de qué manera sus acciones personales reflejan un compromiso con los valores de la organización? 
(2) ¿De qué manera la alta dirección crea un ambiente que promueva una conducta ética y legal?

(3) ¿De qué manera la alta dirección crea una organización sustentable?, ¿de qué manera la alta dirección establece un ambiente adecuado para la mejora del desempeño, el logro de la misión, el alcance de los objetivos estratégicos, para la innovación y para la agilidad organizacional?, ¿de qué manera la alta dirección establece un ambiente adecuado para el aprendizaje organizacional y de los colaboradores?, ¿de qué manera la alta dirección participa en el planeamiento de la sucesión y el desarrollo de los futuros líderes de la organización?

\section{B. COMUNICACIÓN Y DESEMPEÑO ORGANIZACIONAL}

(1) ¿De qué manera la alta dirección se comunica, facultando y motivando, con todos los colaboradores en toda la organización?, ¿de qué manera la alta dirección promueve la comunicación franca y de doble vía en toda la organización?, ¿de qué manera la alta dirección toma un rol activo en la premiación y refuerzo de los colaboradores para apoyar el alto desempeño y la orientación al cliente y al negocio?

(2) ¿De qué manera la alta dirección crea una orientación a la acción para alcanzar los objetivos organizacionales, mejorar el desempeño y lograr la visión?, ¿de qué manera la alta dirección asegura que las expectativas de desempeño organizacional incluyen una orientación hacia la creación y balance de valor para los clientes y otros grupos de interés?

\subsection{Buen Gobierno y Responsabilidad Social (50 puntos) Proceso}

¿De qué manera se ejerce el buen gobierno y se abordan las responsabilidades sociales?

Describa el sistema de gobierno de la organización. Describa de qué manera la organización gestiona sus responsabilidades sociales, asegura un comportamiento ético y desempeña una buena práctica ciudadana.

Incluya respuestas a las siguientes preguntas:

\section{A. BUEN GOBIERNO ORGANIZACIONAL}

(1) ¿De qué manera la organización aborda los siguientes factores clave referidos al sistema de gobierno?:

- Responsabilidad por las acciones de gestión

- Responsabilidad fiscal

- Transparencia en las operaciones y en la selección y políticas de declaración para los miembros del directorio, según sea apropiado 
- Independencia en las auditorias internas y externas

- Protección de los intereses de los grupos de interés y de los accionistas, según sea apropiado

(2) ¿De qué manera se evalúa el desempeño de la alta dirección, incluido el ejecutivo principal?, ¿de qué manera se evalúa el desempeño del directorio, según sea apropiado?, ¿de qué manera la alta dirección y el directorio usan estas evaluaciones de desempeño para mejorar la eficacia de su liderazgo personal así como la del sistema de liderazgo, según sea apropiado?

\section{B. COMPORTAMIENTO LEGAL Y ÉTICO}

(1) ¿De qué manera aborda los impactos adversos en la sociedad de los productos, servicios y operaciones de la organización?, ¿de qué manera anticipa las preocupaciones del público por los productos, servicios y operaciones actuales y futuros?, ¿cómo se prepara para estas preocupaciones de manera proactiva, incluyendo el uso de procesos basados en recursos sostenibles, según sea apropiado?, ¿cuáles son los procesos, indicadores y metas clave de cumplimiento para alcanzar y sobrepasar los requerimientos regulatorios y legales, según sea apropiado?, ¿cuáles son los procesos, indicadores y metas claves para gestionar los riesgos asociados a los productos, servicios y operaciones?

(2) ¿De qué manera la organización promueve y asegura el comportamiento ético en todas las interacciones?, ¿cuáles son los procesos e indicadores para establecer y hacer seguimiento al comportamiento ético en la estructura de gobierno, en toda la organización, y en las interacciones con los clientes, asociados y otros grupos de interés?, ¿de qué manera se hace seguimiento y toma acción frente al incumplimiento del comportamiento ético?

\section{APOYO A LAS COMUNIDADES CLAVE}

¿De qué manera la organización respalda y fortalece activamente a las comunidades claves?, ¿de qué manera identifica a las comunidades claves y determina las áreas de énfasis para la participación y el respaldo organizacional?, ¿cuáles son las comunidades clave de la organización?, ¿de qué manera la alta dirección y los colaboradores contribuyen a mejorar estas comunidades?

\section{Planeamiento Estratégico (85 puntos)}

El Criterio Planeamiento Estratégico examina la manera en que la organización desarrolla objetivos estratégicos y planes de acción. También evalúa la forma en la que los objetivos estratégicos y planes de acción definidos son desplegados, modificados (si es requerido) y medidos en su progreso. 


\subsection{Desarrollo de Estrategias (40 puntos) Proceso}

¿De qué manera desarrolla la estrategia?

Describa como la organización establece la estrategia y los objetivos estratégicos, incluyendo la forma cómo se abordan los desafíos estratégicos y las metas relacionadas.

Incluya respuestas a las siguientes preguntas:

\section{A. PROCESO DE DESARROLLO DE LA ESTRATEGIA}

(1) ¿De qué manera la organización lleva a cabo el planeamiento estratégico?, ¿cuáles son las etapas clave del proceso?, ¿quiénes son los participantes clave?, ¿cuáles son los horizontes temporales de planeamiento de corto y largo plazo?, ¿cómo son establecidos estos horizontes de planeamiento?, ¿de qué manera el proceso de planeamiento estratégico aborda estos horizontes de planeamiento?

(2) ¿De qué manera asegura que el planeamiento estratégico considere los siguientes factores clave?, ¿de qué manera colecta y analiza los datos e información pertinente a estos factores como parte del proceso de planeamiento estratégico?:

- Fortalezas, oportunidades, debilidades y amenazas

- Indicadores anticipados de cambios mayores en aspectos tales como tecnología, mercados, competencia y entorno regulatorio

- Sostenibilidad organizacional de largo plazo y continuidad en emergencias

- La habilidad para ejecutar el plan estratégico

\section{B. OBJETIVOS ESTRATÉGICOS}

(1) ¿Cuáles son los objetivos estratégicos claves y el cronograma para alcanzarlos?, ¿cuáles son las metas más importantes para estos objetivos estratégicos?

(2) ¿De qué manera los objetivos estratégicos se hacen cargo de los desafíos identificados en la respuesta P.2 del Perfil Organizacional?, ¿cómo se asegura que los objetivos estratégicos equilibren los desafíos y oportunidades de corto y largo plazo?, ¿cómo se asegura que los objetivos estratégicos equilibren las necesidades de todos los grupos de interés claves?

\subsection{Despliegue de Estrategias (45 puntos) Proceso}

¿De qué manera despliega la estrategia? 
Describa la manera en que la organización traduce los objetivos estratégicos en planes de acción. Resuma los planes de acción y los indicadores de desempeño claves relacionados de la organización. Proyecte el desempeño futuro de la organización a través de estos indicadores clave.

Incluya respuestas a las siguientes preguntas:

\section{A. DESARROLLO Y DESPLIEGUE DE PLANES DE ACCIÓN}

(1) ¿De qué manera se desarrollan y despliegan los planes de acción para alcanzar los objetivos estratégicos claves?, ¿de qué manera se asigna recursos para asegurar el cumplimiento de los planes de acción?, ¿cómo se asegura que los cambios clave resultantes de los planes de acción puedan mantenerse?

(2) ¿De qué manera se establecen y despliegan los planes de acción modificados, si las circunstancias requieren un cambio en los planes y la rápida ejecución de los planes nuevos?

(3) ¿Cuáles son los planes de acción claves a corto y largo plazo?, ¿cuáles son los cambios importantes, si los hubiera, en los productos y servicios, clientes y mercados y en la manera de operar?

(4) ¿Cuáles son los planes de recursos humanos claves derivados de los objetivos estratégicos y planes de acción de corto y largo plazo?

(5) ¿Cuáles son los indicadores de desempeño claves para el seguimiento del progreso de los planes de acción?, ¿de qué manera se asegura que el sistema global de medición de los planes de acción logre el alineamiento organizacional?, ¿cómo se asegura que el sistema de medición comprenda todas las áreas de despliegue y a todos los grupos de interés claves?

\section{B. PROYECCIÓN DEL DESEMPEÑO}

Para los indicadores de desempeño clave identificados en 2.2A(5), ¿cuáles son las proyecciones de desempeño para los horizontes de planeamiento de corto y largo plazo?, ¿cómo se compara la proyección de desempeño con el desempeño de los competidores o de organizaciones comparables?, ¿cómo se compara con benchmarks claves, metas y el desempeño pasado, según sea apropiado? Si existen brechas de desempeño presentes o proyectadas contra los competidores o contra organizaciones comparables, ¿cómo es que son abordadas? 


\section{Orientación hacia el Cliente y el Mercado (85 puntos)}

El Criterio Orientación hacia el cliente y el mercado examina la manera en que la organización determina los requerimientos, necesidades, expectativas y preferencias de los clientes y mercados. También examina la forma en que la organización construye relaciones con los clientes y determina los factores clave que conducen a la adquisición, satisfacción, lealtad, retención de clientes, así como a la expansión y sostenibilidad del negocio.

\subsection{Conocimiento del Cliente y del Mercado (40 puntos) Proceso}

¿De qué manera utiliza el conocimiento del cliente y el mercado?

Describa la manera en que la organización determina los requerimientos, necesidades, expectativas y preferencias de los clientes y mercados para asegurar la actualidad de los productos y servicios y para desarrollar nuevas oportunidades de negocio.

Incluya respuestas a las siguientes preguntas:

\section{A. CONOCIMIENTO DEL CLIENTE Y DEL MERCADO}

(1) ¿De qué manera identifica clientes, grupos de clientes, y segmentos de mercado?, ¿de qué manera determina qué productos y servicios, presentes y futuros, son ofrecidos a estos clientes, grupos de clientes y segmentos de mercado?, ¿cómo incluye a los clientes de los competidores y a otros clientes y mercados potenciales en esta determinación?

(2) ¿De qué manera escucha y aprende a determinar los requerimientos, necesidades y cambios en las expectativas claves de los clientes (incluidas las características de producto y servicio) y su importancia relativa para las decisiones de compra o de relación de los clientes?, ¿de qué manera esos métodos de determinación varían entre los diferentes clientes o grupos de clientes?, ¿de qué manera utiliza información relevante y retroalimentación de clientes actuales y pasados, incluyendo información de marketing y ventas, datos sobre lealtad y retención de clientes, análisis ganancia y perdida9 y quejas, para fines del planeamiento del productos y servicios, marketing, mejora de procesos, y desarrollar nuevas oportunidades de negocio?, ¿cómo se utiliza esta información y retroalimentación para tornarse más orientado al cliente y satisfacer mejor las necesidades y deseos de los clientes?

(3) ¿De qué manera mantiene vigentes los métodos de escucha y aprendizaje respecto a las necesidades y estrategia de la organización, incluyendo los cambios en el mercado?

\subsection{Relaciones con el Cliente y Satisfacción (45 puntos) Proceso}

¿De qué manera construye relaciones y mejora la satisfacción y lealtad de los clientes? 
Describa la manera en que la organización construye relaciones para adquirir, satisfacer, retener e incrementar la lealtad de los clientes. Describa también como la organización determina la satisfacción de los clientes.

Incluya respuestas a las siguientes preguntas:

\section{A. CONSTRUCCIÓN DE RELACIONES CON LOS CLIENTES}

(1) ¿De qué manera construye relaciones para adquirir clientes, para alcanzar y superar sus expectativas y para incrementar su lealtad, la repetición de negocios, y para ganar referencias positivas?

(2) ¿Cuáles son los mecanismos de acceso de los clientes claves?, ¿de qué manera estos mecanismos de acceso permiten a los clientes buscar información, llevar a cabo negocios y efectuar quejas?, ¿cómo determina los requerimientos de contacto con el cliente claves para cada mecanismo de acceso?, ¿cómo se asegura que dichos requerimientos de contacto sean desplegados a todos los colaboradores y procesos involucrados en la cadena de respuesta al cliente?

(3) ¿De qué manera se gestionan las quejas de los clientes?, ¿cómo se garantiza que se resuelvan las quejas, de manera efectiva y oportuna?, ¿de qué manera se minimiza la insatisfacción de los clientes, y según sea apropiado, la pérdida de repetición de negocios?, ¿de qué manera las quejas recibidas son contabilizadas y analizadas para su utilización en la mejora de la organización y de los asociados?

(4) ¿De qué manera los métodos para construir relaciones y proveer acceso a los clientes se mantienen actualizados con las necesidades y estrategia de la organización?

\section{B. DETERMINACIÓN DE LA SATISFACCIÓN DEL CLIENTE}

(1) ¿De qué manera determina la satisfacción, insatisfacción y lealtad del cliente?, ¿cómo difiere esta determinación entre grupos de clientes?, ¿de qué manera se asegura que los indicadores capturen información procesable para enfocarse en exceder las expectativas de los clientes?, ¿de qué manera se asegura que los indicadores capturen información procesable para asegurar futuros negocios y ganar referencias positivas con los clientes, según sea apropiado?, ¿cómo utiliza la información de la satisfacción e insatisfacción de los clientes para la mejora?

(2) ¿De qué manera hace seguimiento a los clientes en relación a la calidad de los productos, servicios y transacciones para recibir retroalimentación oportuna y procesable?

(3) ¿De qué manera obtiene y utiliza la información de la satisfacción de los clientes para ser evaluada con la satisfacción de los clientes de los competidores, la satisfacción de 
los clientes de otras organizaciones que proveen productos y servicios similares y / o con benchmarks de la industria?

(4) ¿De qué manera mantiene vigentes los métodos para determinar la satisfacción respecto a las necesidades y estrategia de la organización?

\section{Medición, Análisis y Gestión del Conocimiento (90 puntos)}

El Criterio Medición, Análisis y Gestión del Conocimiento examina la manera en la que la organización selecciona, recolecta, analiza, gestión y mejora los activos de datos, información y conocimiento. También evalúa la manera como la organización evalúa el desempeño.

\subsection{Medición, Análisis y Evaluación del Desempeño Organizacional (45 puntos) Proceso}

¿De qué manera mide, analiza y evalúa el desempeño organizacional?

Describa la manera en que la organización mide, analiza alinea, evalúa y mejora los datos e información de desempeño, en todos los niveles y en todas las áreas de la organización.

Incluya respuestas a las siguientes preguntas:

\section{A. MEDICIÓN DEL DESEMPEÑO}

(1) ¿De qué manera selecciona, recolecta, alinea e integra los datos e información para hacer seguimiento a las operaciones diarias y al desempeño global de la organización, incluyendo el progreso relativo a los objetivos estratégicos y a los planes de acción?, ¿cuáles son los indicadores de desempeño organizacional claves?, ¿cómo usa estos datos e información para apoyar la toma de decisiones e innovación organizacionales?

(2) ¿De qué manera selecciona y asegura el uso efectivo de datos e información comparativa clave para apoyar toma de decisiones operativas y estratégicas y la innovación?

(3) ¿De qué manera mantiene vigente el sistema de medición del desempeño respecto a las necesidades y estrategia de la organización?, ¿cómo asegura que el sistema de medición del desempeño sea sensible a los cambios rápidos o inesperados, sean estos organizacionales o externos?

\section{B. ANÁLISIS Y EVALUACIÓN DEL DESEMPEÑO}

(1) ¿De qué manera se evalúa el desempeño y las capacidades organizacionales?, ¿de qué manera la alta dirección participa en estas evaluaciones?, ¿qué tipos de análisis son 
llevados a cabo para apoyar estas evaluaciones y para asegurar que las conclusiones sean validas?, ¿cómo usa estas revisiones para evaluar el éxito, el desempeño competitivo, y el progreso relativo en los objetivos estratégicos y planes de acción organizacionales?, ¿de qué manera usa estas revisiones para evaluar la habilidad de la organización para responder rápidamente a las cambiantes necesidades y desafíos organizacionales en el ambiente operativo?

(2) ¿De qué manera los hallazgos de la evaluación de desempeño se convierten en prioridades para la mejoras continua y discontinua y en oportunidades para la innovación?, ¿cómo estas prioridades y oportunidades son desplegadas a los niveles de unidades de trabajo y funcional a través de la organización, para posibilitar el apoyo efectivo a la toma de decisiones, según sea apropiado?, ¿de qué manera las prioridades y oportunidades son desplegadas a los proveedores, asociados y aliados, para asegurar el alineamiento organizacional?

\subsection{Gestión de la Información y del Conocimiento (45 puntos) Proceso}

¿De qué manera se gestiona la información y el conocimiento organizacionales?

Describa la manera en que la organización asegura la calidad y disponibilidad de los datos e información necesarios referentes a los colaboradores, proveedores, asociados y clientes. Describa cómo la organización construye y gestiona sus activos de conocimiento.

Incluya respuestas a las siguientes preguntas:

\section{A. DISPONIBILIDAD DE DATOS E INFORMACIÓN}

(1) ¿De qué manera asegura la disponibilidad de los datos y la información requeridos?, ¿cómo se garantiza que éstos sean accesibles a los colaboradores, proveedores, asociados y clientes, según sea apropiado?

(2) ¿De qué manera garantiza que el hardware y software sean confiables, seguros y puedan ser usados fácilmente?

(3) ¿De qué manera asegura la continua disponibilidad de los datos y la información, incluida la disponibilidad de los sistemas de hardware y software en la eventualidad de una emergencia?

(4) ¿De qué manera mantiene vigentes los mecanismos para asegurar la disponibilidad de los datos y la información (incluidos los sistemas de hardware y software) respecto a las necesidades y estrategia de la organización, así como también con los cambios tecnológicos en el entorno operativo de la organización?

\section{B. GESTIÓN DEL CONOCIMIENTO ORGANIZACIONAL}


¿De qué manera se gestiona el conocimiento organizacional para alcanzar lo siguiente?:

- La recolección y transferencia del conocimiento de los colaboradores

- La transferencia de conocimiento relevante de y a los clientes, proveedores, asociados y aliados

- La identificación rápida, difusión e implementación de las mejores prácticas

\section{CALIDAD DE LOS DATOS, INFORMACIÓN Y CONOCIMIENTO}

¿De qué manera se asegura las siguientes características de los datos, información y conocimiento organizacionales?:

- exactitud

- integridad y confiabilidad

- oportunidad

- seguridad y confidencialidad

\section{Orientación hacia las Personas (85 puntos)}

El Criterio Orientación hacia las Personas examina la manera en que los sistemas de trabajo de la organización, así como, la gestión del aprendizaje y la motivación, permiten a todos los colaboradores desarrollar y utilizar su máximo potencial en concordancia con los objetivos globales, estrategia y planes de acción de la organización. También se examinan los esfuerzos de la organización por establecer y mantener un lugar de trabajo y clima de respaldo conducentes a la excelencia en el desempeño y al crecimiento personal y organizacional.

\subsection{Sistemas de Trabajo (35 puntos) Proceso}

¿De qué manera apoya a los colaboradores para que lleven a cabo el trabajo de la organización?

Describa la manera en la que el trabajo y los puestos apoyan a todos los colaboradores y a la organización a alcanzar un alto desempeño. Describa cómo las remuneraciones, el progreso en la carrera, y otras prácticas laborales relacionadas, permiten a los colaboradores y a la organización alcanzar un alto desempeño.

Incluya respuestas a las siguientes preguntas:

\section{A. ORGANIZACIÓN Y GESTIÓN DEL TRABAJO}


(1) ¿De qué manera organiza y gestiona el trabajo y los puestos, incluidas las habilidades, para promover la cooperación, iniciativa, facultamiento, innovación y la cultura organizacional?, ¿de qué manera organiza y gestiona el trabajo y los puestos, incluidas las habilidades, para promover la flexibilidad para mantenerse al día con las necesidades del negocio y para alcanzar los planes de acción?

(2) ¿De qué manera los sistemas de trabajo permiten capitalizar las diversidad de ideas, culturas y pensamiento de los colaboradores y de las comunidades con las que la organización interactúa (comunidades de donde proceden las personas contratadas y los clientes)?

(3) ¿De qué manera se logra la comunicación efectiva y la difusión de conocimientos en las unidades de trabajo, los puestos y ubicaciones en general?

\section{B. SISTEMA DE GESTIÓN DEL DESEMPEÑO DE LOS COLABORADORES}

¿De qué manera el sistema de gestión del desempeño de las personas, incluida la retroalimentación a los colaboradores, respalda el alto desempeño y contribuye al logro de los planes de acción?, ¿de qué manera el sistema de gestión del desempeño de las personas apoya la orientación hacia los clientes y el negocio?, ¿de qué manera las prácticas de remuneración, reconocimiento y de recompensa e incentivo relacionadas, refuerzan el trabajo de alto desempeño y la orientación hacia los clientes y el negocio?

\section{RECLUTAMIENTO Y PROGRESO EN LA CARRERA}

(1) ¿De qué manera identifica las características y habilidades necesarias para los colaboradores potenciales?

(2) ¿Cómo recluta, contrata y retiene a nuevos colaboradores?, ¿de qué manera se asegura que los colaboradores representan la diversidad de ideas, culturas y pensamiento de la comunidad en la que se recluta?

(3) ¿De qué manera se alcanza un efectivo planeamiento de la sucesión de los miembros de la alta dirección y de otras posiciones gerenciales?, ¿cómo se gestiona el efectivo progreso en la carrera de todos los colaboradores de la organización?

\subsection{Aprendizaje y Motivación de las Personas (25 puntos) Proceso}

¿De qué manera contribuye al aprendizaje y motivación de los colaboradores?

Describa la manera en que la educación, la capacitación y el desarrollo de la carrera apoyan el logro de los objetivos organizacionales y contribuyen al alto desempeño. Describa cómo la educación, la capacitación y el desarrollo de la carrera permiten ampliar el conocimiento, habilidades y capacidades de los colaboradores. 
Incluya respuestas a las siguientes preguntas:

\section{A. EDUCACIÓN, CAPACITACIÓN Y DESARROLLO DE LOS COLABORADORES}

(1) ¿De qué manera la educación y capacitación contribuyen al logro de los planes de acción?, ¿de qué manera la educación, capacitación y desarrollo de los colaboradores abordan las necesidades clave asociadas con la medición del desempeño, la mejora del desempeño y el cambio tecnológico?, ¿de qué manera el enfoque de educación, capacitación y desarrollo equilibra los objetivos organizacionales de corto y largo plazo con las necesidades de los colaboradores, el avance en el aprendizaje y el progreso en la carrera?

(2) ¿De qué manera la educación, capacitación y desarrollo abordan las necesidades organizacionales clave asociadas con la orientación para nuevos colaboradores, diversidad, prácticas de negocio éticas y desarrollo de la gestión y liderazgo?, ¿de qué manera los enfoques de educación, capacitación y desarrollo abordan las necesidades organizacionales clave asociadas con el lugar de trabajo en los colaboradores y la seguridad del ambiente?

(3) ¿De qué manera busca y utiliza los aportes de los colaboradores y de sus supervisores y gerentes, respecto a las necesidades de educación, capacitación y desarrollo?, ¿cómo incorpora los activos del aprendizaje y conocimiento organizacionales en la educación y capacitación?

(4) ¿De qué manera se entrega la educación y la capacitación?, ¿de qué manera busca y utiliza los aportes de los colaboradores y de sus supervisores y gerentes al determinar los enfoques de entrega de la educación y capacitación?, ¿cómo utiliza los enfoques, formales e informales, de entrega de educación y capacitación, incluidos el mentoring y otros enfoques, según sea apropiado?

(5) ¿De qué manera apoya el uso de conocimientos y habilidades nuevos en el puesto y retiene este conocimiento para su uso en la organización a largo plazo? , ¿de qué manera transfiere sistemáticamente el conocimiento de los colaboradores de salida o retirados?

(6) ¿Cómo evalúa la eficacia de la educación y la capacitación, considerando los desempeños individual y organizacional?

\section{B. MOTIVACIÓN Y DESARROLLO DE LA CARRERA}

¿De qué manera motiva a los colaboradores a desarrollar y utilizar su máximo potencial?, ¿de qué manera la organización utiliza mecanismos formales o informales para ayudar a los colaboradores a alcanzar los objetivos de desarrollo y aprendizaje del puesto y 
la carrera?, ¿de qué manera los gerentes y supervisores ayudan a los colaboradores a alcanzar dichos objetivos?

\subsection{Bienestar y Satisfacción de las Personas (25 puntos) Proceso}

¿De qué manera contribuye al bienestar y a la satisfacción creciente de los colaboradores?

Describa la manera en que la organización mantiene un lugar de trabajo y un clima de respaldo que contribuyan al bienestar, satisfacción y motivación de todos los colaboradores.

Incluya respuestas a las siguientes preguntas:

\section{A. LUGAR DE TRABAJO}

(1) ¿De qué manera se asegura y mejora los aspectos de salud, seguridad y ergonomía en el lugar de trabajo de forma proactiva?, ¿de qué manera participan los colaboradores en estos esfuerzos de mejora?, ¿cuáles son los indicadores de desempeño u objetivos de mejora para cada uno de estos factores clave del lugar de trabajo?, ¿cuáles son las diferencias significativas en estos lugares de trabajo, en los indicadores de desempeño, o en las metas, si los diferentes grupos de colaboradores y unidades de trabajo tuvieran diferentes ambientes de trabajo?

(2) ¿De qué manera se asegura la preparación del ambiente de trabajo en la eventualidad de desastres o emergencias?

\section{B. RESPALDO Y SATISFACCIÓN DE LOS COLABORADORES}

(1) ¿De qué manera determina los factores claves que afectan el bienestar, la satisfacción y la motivación de los colaboradores?, ¿cómo estos factores son segmentados en el caso de una fuerza de trabajo diversa y de diferentes categorías y tipos de colaboradores, según sea apropiado?

(2) ¿De qué manera apoya a los colaboradores a través de servicios, beneficios y políticas?, ¿cómo son estos diseñados a la medida de las necesidades de una fuerza de trabajo diversa y para diferentes categorías y tipos de colaboradores, según sea apropiado?

(3) ¿Qué métodos de evaluación e indicadores, formales e informales, utiliza para determinar el bienestar, satisfacción y motivación de las personas?, ¿cómo difieren estos métodos e indicadores en el caso de una fuerza de trabajo diversa y a diferentes categorías y tipos de colaboradores?, ¿cómo utiliza otros indicadores tales como retención de colaboradores, ausentismo, agravios, seguridad y productividad, para evaluar y mejorar el bienestar, satisfacción y motivación de los colaboradores? 
(4) ¿De qué manera relaciona los hallazgos de la evaluación con los resultados de negocio claves a fin de identificar prioridades para mejorar el lugar de trabajo y el clima de respaldo a las personas?

\section{Gestión de Procesos (85 puntos)}

El Criterio Gestión de Procesos examina los aspectos clave de la gestión de procesos de la organización, incluyendo los procesos de productos, servicios y organizacionales para la creación de valor; y, los procesos de soporte claves. Este Criterio comprende todos los procesos clave y unidades de trabajo.

\subsection{Procesos de Creación de Valor (45 puntos) Proceso}

¿Cómo identifica y gestiona los procesos clave?

Describa la manera en que la organización identifica y gestiona los procesos de creación de valor para entregar valor a los clientes y lograr el éxito y crecimiento organizacional.

Incluya respuestas a las siguientes preguntas:

\section{A. PROCESOS DE CREACIÓN DE VALOR}

(1) ¿De qué manera la organización determina procesos de creación de valor claves?, ¿cuáles son los procesos de productos, servicios y de negocios para la creación y agregación de valor?, ¿de qué manera estos procesos contribuyen a la rentabilidad, sostenibilidad y el éxito organizacional, según sea apropiado?

(2) ¿De qué manera determina los requerimientos de los procesos de creación de valor claves, considerando la información de los clientes, proveedores, asociados y aliados, según sea apropiado?, ¿cuáles son los requerimientos claves para estos procesos?

(3) ¿De qué manera diseña estos procesos de manera que alcancen todos los requerimientos clave?, ¿de qué manera incorpora tecnología nueva, el conocimiento organizacional y la potencial necesidad de agilidad en el diseño de estos procesos?, ¿cómo incorpora el tiempo de ciclo, la productividad, el control de costos, y otros factores de eficiencia y eficacia en el diseño de estos procesos?, ¿de qué manera se implementan estos procesos para asegurar que se alcancen los requerimientos de diseño?

(4) ¿Cuáles son los indicadores de desempeño claves utilizados para el control y mejora de los procesos de creación de valor?, ¿de qué manera las operaciones diarias de estos procesos aseguran se alcancen los requerimientos clave de desempeño?, ¿cómo son usados los indicadores internos de proceso en la gestión de estos procesos?, ¿de qué manera es usada la información de entrada de los clientes, proveedores, asociados y aliados en la gestión de estos procesos, según sea apropiado? 
(5) ¿De qué manera se minimiza los costos globales asociados a las inspecciones, pruebas y auditorias de proceso o desempeño, según sea apropiado?, ¿de qué manera se previenen defectos, errores de servicio, reprocesos $\mathrm{y}$, se minimizan los costos por garantías, según sea apropiado?

(6) ¿De qué manera se mejora los procesos de creación de valor, para alcanzar mejor desempeño, para reducir la variabilidad, mejorar los productos y servicios, y para mantenerlos al día con las necesidades y estrategia?, ¿de qué manera las mejoras y conocimientos son aprendidos y compartidos por otras unidades y procesos de la organización, para avanzar hacia el aprendizaje e innovación organizacionales?

\subsection{Procesos de Soporte y Planeamiento Operativo (40 puntos) Proceso}

¿Cómo identifica y gestiona los procesos de soporte y el planeamiento operativo?

Describa la manera en que la organización identifica y gestiona los procesos de soporte y lleva a cabo el planeamiento operativo.

Incluya respuestas a las siguientes preguntas:

\section{A. PROCESOS DE SOPORTE}

(1) ¿De qué manera la organización determina los procesos de soporte claves?, ¿cuáles son los procesos de soporte claves que apoyan a los procesos de creación de valor?

(2) ¿Cómo determina los requerimientos principales de los procesos de soporte, incorporando información de entrada de clientes, proveedores, asociados y aliados, internos y externos, según sea apropiado?, ¿cuáles son los requerimientos clave para estos procesos?

(3) ¿De qué manera se diseñan estos procesos de forma que se cumplan todos los requerimientos clave?, ¿de qué manera incorpora nueva tecnología, el conocimiento organizacional y la potencial necesidad de agilidad en el diseño de estos procesos?, ¿cómo incorpora el tiempo de ciclo, la productividad, el control de costos, y otros factores de eficiencia y eficacia en el diseño de estos procesos?, ¿de qué manera se implementan estos procesos para asegurar que se alcancen los requerimientos de diseño?

(4) ¿Cuáles son los indicadores de desempeño claves utilizados para el control y mejora de los procesos de soporte?, ¿de qué manera las operaciones diarias de estos procesos aseguran se alcancen los requerimientos clave de desempeño?, ¿cómo son usados los indicadores internos de proceso en la gestión de estos procesos?, ¿de qué manera es usada la información de entrada de los clientes, proveedores, asociados y aliados en la gestión de estos procesos, según sea apropiado? 
(5) ¿De qué manera se minimiza los costos globales asociados a las inspecciones, pruebas y auditorias de proceso o desempeño, según sea apropiado?, ¿de qué manera se previenen defectos, errores de servicio y reprocesos?

(6) ¿De qué manera se mejora los procesos de soporte, para alcanzar mejor desempeño, para reducir la variabilidad y para mantenerlos al día con las necesidades y estrategia?, ¿de qué manera las mejoras y conocimientos son aprendidos y compartidos por otras unidades y procesos de la organizacional, para avanzar hacia el aprendizaje e innovación organizacionales?

\section{B. PLANEAMIENTO OPERATIVO}

(1) ¿De qué manera la organización asegura que haya recursos financieros adecuados para apoyar las operaciones?, ¿cómo determina las necesidades de recursos para cumplir con las operaciones financieras cotidianas?, ¿de qué manera asegura que haya recursos adecuados para apoyar inversiones de negocio nuevas e importantes, según sea apropiado?, ¿cómo se evalúa el riesgo financiero asociado con las operaciones cotidianas y con las inversiones de negocio nuevas e importantes?

(2) ¿De qué manera asegura la continuidad de las operaciones en la eventualidad de una emergencia?

\section{Resultados (450 puntos)}

El Criterio Resultados examina el desempeño y la mejora en áreas de negocio claves de la organización como el desempeño de productos y servicios, la satisfacción del cliente, el desempeño financiero y de mercado, el desempeño de la orientación hacia las personas, el desempeño operativo y el desempeño del liderazgo y la responsabilidad social. También se examinan los niveles de desempeño con relación a los competidores y a otras organizaciones que proveen productos y servicios similares.

\subsection{Resultados de Productos y Servicio (100 puntos) Resultados}

¿Cuáles son los resultados del desempeño de los productos y servicios?

Resuma los resultados del desempeño de productos y servicios de la organización. Segmente los resultados por tipos o grupos de producto y servicio, grupos de clientes y, segmentos de mercado, según sea apropiado. Incluya datos comparativos apropiados.

Proporcione datos e información para responder a las siguientes preguntas:

\section{A. RESULTADOS DE PRODUCTOS Y SERVICIOS}


¿Cuáles son los niveles y tendencias actuales en los indicadores clave de desempeño de los productos y servicios que son importantes para los clientes?, ¿de qué manera estos resultados se comparan con el desempeño de los competidores y con el de otras organizaciones que proveen productos y servicios similares?

\subsection{Resultados de Orientación hacia el Cliente (70 puntos) Resultados}

¿Cuáles son los resultados de la orientación hacia el cliente?

Resuma los resultados de orientación hacia el cliente de la organización, incluya la satisfacción y la percepción de valor del cliente. Segmente los resultados por tipos o grupos de producto y servicio, grupos de clientes y, segmentos de mercado, según sea apropiado. Incluya datos comparativos apropiados.

Proporcione datos e información para responder a las siguientes preguntas:

\section{A. RESULTADOS DE LA ORIENTACIÓN HACIA EL CLIENTE}

(1) ¿Cuáles son los niveles y tendencias actuales en los indicadores clave de la satisfacción e insatisfacción de los clientes?, ¿de qué manera estos resultados se comparan con los niveles de satisfacción de los clientes de los competidores y con los de otras organizaciones que proveen productos y servicios similares?

(2) ¿Cuáles son los niveles y tendencias actuales en los indicadores clave de valor percibido por el cliente, incluida la lealtad y retención del cliente, las referencias positivas y otros aspectos para el establecimiento de relaciones con los clientes, según sea apropiado?

\subsection{Resultados Financieros y de Mercado (70 puntos) Resultados}

¿Cuáles son los resultados financieros y de mercado?

Resuma los resultados de desempeño financiero y de mercado claves de la organización, preséntelos por cliente o segmento de mercado, según sea apropiado. Incluya datos comparativos pertinentes.

Proporcione datos e información para responder a las siguientes preguntas:

\section{A. RESULTADOS FINANCIEROS Y DE MERCADO}

(1) ¿Cuales son los niveles y tendencias actuales en los indicadores clave de desempeño financiero, incluyendo indicadores globales de rentabilidad financiera, valor económico y, presupuestarias, según sea apropiado? 
(2) ¿Cuáles son los niveles y tendencias actuales en los indicadores clave de desempeño en el mercado, incluyendo la participación o posición de mercado, el crecimiento y el ingreso a nuevos mercados, según sea apropiado?

\subsection{Resultados de Orientación hacia las Personas (70 puntos) Resultados}

¿Cuáles son los resultados de la orientación hacia las personas?

Resuma los resultados clave de la orientación hacia las personas de la organización, incluyendo el desempeño del sistema de trabajo y el aprendizaje, el desarrollo, el bienestar y la satisfacción de los colaboradores. Segmente los resultados para abordar la diversidad de la fuerza de trabajo y los diferentes tipos y categorías de colaboradores, según sea apropiado. Incluya datos comparativos apropiados.

Proporcione datos e información para responder a las siguientes preguntas:

\section{A. RESULTADOS DE LAS PERSONAS}

(1) ¿Cuáles son los niveles y tendencias actuales en los indicadores clave de desempeño y eficacia del sistema de trabajo?

(2) ¿Cuáles son los niveles y tendencias actuales en los indicadores clave de aprendizaje y desarrollo de los colaboradores?

(3) ¿Cuáles son los niveles y tendencias actuales en los indicadores clave del bienestar, satisfacción e insatisfacción de los colaboradores?

\subsection{Resultados de la Eficacia Organizacional (70 puntos) Resultados}

¿Cuáles son los resultados de la eficacia organizacional?

Resuma los resultados de desempeño claves de la organización que contribuyen a la mejora logro de la eficacia organizacional. Segmente los resultados por tipos y grupos de producto y por segmentos de mercado, según sea apropiado. Incluya datos comparativos apropiados.

Proporcione datos e información para responder a las siguientes preguntas:

\section{A. RESULTADOS DE LA EFICACIA ORGANIZACIONAL}

(1) ¿Cuáles son los niveles y tendencias actuales en los indicadores clave de desempeño operativo de los procesos de creación de valor claves? Incluya indicadores de eficacia y eficiencia de productividad, tiempo de ciclo, desempeño de proveedores y asociados y, otros indicadores apropiados. 
(2) ¿Cuáles son los niveles y tendencias actuales en los indicadores clave de desempeño operativo de los otros procesos clave? Incluya indicadores de eficacia y eficiencia de productividad, tiempo de ciclo, desempeño de proveedores y asociados y, otros indicadores apropiados.

\subsection{Resultados de Liderazgo y Responsabilidad Social (70 puntos) Resultados}

¿Cuáles son los resultados de liderazgo y responsabilidad social?

Resuma los resultados del buen gobierno, liderazgo de la alta dirección y responsabilidad social, incluyendo evidencia de comportamiento ético, responsabilidad fiscal, cumplimiento legal y ciudadanía corporativa. Incluya datos comparativos apropiados.

Proporcione datos e información para responder a las siguientes preguntas:

\section{A. RESULTADOS DE LIDERAZGO Y RESPONSABILIDAD SOCIAL}

(1) ¿Cuáles son los resultados para los indicadores clave del cumplimiento de la estrategia y planes de acción de la organización?

(2) ¿Cuáles son los resultados para los indicadores clave de comportamiento ético y de confianza de los grupos de interés en la alta dirección y, de buen gobierno de la organización?, ¿cuáles son los resultados de los indicadores clave de los incumplimientos de comportamiento ético?

(3) ¿Cuáles son los hallazgos actuales clave y las tendencias en los indicadores clave de responsabilidad fiscal, tanto interna como externa, según sea apropiado?

(4) ¿Cuáles son los resultados para los indicadores clave de cumplimiento regulatorio y legal?

(5) ¿Cuáles son los resultados para los indicadores clave de ciudadanía corporativa en apoyo a las comunidades clave?

\section{SISTEMA DE PUNTUACIÓN}

La puntuación para las respuestas a los Subcriterios del Modelo de Excelencia se basa en dos dimensiones de evaluación: (1) Proceso y (2) Resultados. Los usuarios de los Criterios deben proporcionar información para estas dos dimensiones. A continuación se describen los factores específicos para estas dimensiones y se presenta la Guía de Puntuación. 


\section{Proceso}

"Proceso" se refiere a los métodos que la organización usa y mejora para abordar los requerimientos de los Subcriterios en los Criterios 1 al 6. Los cuatro factores para evaluar la dimensión "proceso" son "enfoque", "despliegue", "aprendizaje" e "integración" (E-DA-I).

"Enfoque" se refiere a:

- Los métodos usados para abordar el proceso

- El grado de pertinencia de los métodos respecto a los requerimientos del Subcriterio

- La eficacia en el uso de los métodos

- El grado en el que el enfoque es repetible y basado en datos e información confiable (sistemático)

“Despliegue" se refiere a la extensión en la que:

- El enfoque es aplicado al abordar los requerimientos del Subcriterio relevantes e importantes para la organización

- El enfoque es aplicado consistentemente

- El enfoque es usado por todas las unidades de trabajo apropiadas

"Aprendizaje" se refiere a:

- El refinamiento del enfoque a través de ciclos de evaluación y mejora

- El refuerzo a los cambios no incrementales (mejora discontinua) en los enfoques a través de la innovación

-Compartir refinamientos e innovaciones con otras unidades de trabajo y procesos relevantes en la organización

"Integración" se refiere a la extensión en la que:

-El enfoque está alineado con las necesidades organizacionales identificadas en otros requerimientos de Subcriterio

- Los indicadores, información y sistemas de mejora son complementarios al interior de los procesos y unidades de trabajo

- Los planes, procesos, resultados, análisis, aprendizaje y acciones son armónicas entre procesos y unidades de trabajo para apoyar las metas organizacionales globales 


\section{Resultados}

"Resultados" se refiere a las salidas generadas al abordar los requerimientos de los Subcriterios 7.1 al 7.6. Los cuatro factores usados para evaluar resultados son:

- Los niveles actuales de desempeño

- Tasa (ej. pendiente de la tendencia de los datos) y alcance o amplitud (ej. cuan ampliamente desplegado y compartido) de las mejoras de desempeño

- El desempeño relativo a comparaciones y/o benchmarks apropiados

- El vínculo de los indicadores de resultados (frecuentemente utilizando segmentación) con los requerimientos de desempeño de clientes importantes, productos y servicios, mercado, proceso y de planes de acción identificados en el Perfil Organizacional y en los Subcriterios de Proceso

\section{Clasificación de los Subcriterios y Dimensiones de Puntuación}

Los Subcriterios se clasifican de acuerdo a los tipos de información y datos que se espera sean proporcionados para las dos dimensiones de evaluación.

Los dos tipos de Subcriterios y sus designaciones son:

\section{Proceso}

\section{Resultados}

En los Subcriterios de "Proceso", el Enfoque - Despliegue - Aprendizaje - Integración están vinculados para enfatizar que las descripciones del Enfoque deberían indicar siempre el Despliegue, compatible con los requisitos específicos del Subcriterio. En la medida en la que los procesos maduran, las descripciones deberían indicar cómo ocurren sus ciclos de aprendizaje y, cómo funciona su integración con otros procesos y unidades. Aun cuando los factores Enfoque - Despliegue - Aprendizaje - Integración están vinculados, la retroalimentación para las organizaciones evaluadas refleja las fortalezas y oportunidades de mejora en cualquiera de los factores o su totalidad.

Los Subcriterios de "Resultados" buscan información que muestre los niveles de desempeño, tasas de mejora y datos comparativos relevantes para indicadores clave de desempeño organizacional. También buscan información sobre el alcance o amplitud de las mejoras del desempeño organizacional. Esto se encuentra directamente relacionado con el despliegue y el aprendizaje organizacional. Es decir, si los procesos de mejora son ampliamente compartidos y desplegados, estos deberían generar los resultados correspondientes. Por lo tanto, la puntuación para un Subcriterio de Resultados es un 
compuesto basado en el desempeño global, teniendo en cuenta el alcance o amplitud de las mejoras y su importancia para los requerimientos del Subcriterio y el negocio o la misión (véase el párrafo siguiente).

\section{La "Importancia" como una Aspecto a Considerar en la Puntuación}

Las dos dimensiones de evaluación descritas anteriormente son decisivas para la evaluación y la retroalimentación. Sin embargo, otra consideración crítica en la evaluación y la retroalimentación es la importancia de los procesos y los resultados reportados en los factores de negocio claves. Las áreas de mayor importancia deberían ser identificadas en el Perfil Organizacional y en Subcriterios tales como 2.1, 2.2, 3.1, 5.1 y 6.1. Los requisitos claves del cliente, el entorno competitivo, los objetivos estratégicos y los planes de acción claves son particularmente importantes.

\section{Asignación de Puntuación a las Respuestas}

Al asignar puntuación a las respuestas de los Subcriterios se deberían consideran las siguientes pautas:

- En las respuestas de los Subcriterios se debería incluir todas las Áreas de Análisis. Además, las respuestas deberían reflejar lo que es importante para la organización.

-Al asignar una puntuación a un Subcriterio, primero se debe decidir qué rango de puntuación (por ejemplo de 50\% a 65\%) describe mejor el nivel de logro de la organización tal como ha sido presentado en la respuesta al Subcriterio. La frase "describe mejor el nivel de logro de la organización" puede significar la existencia de algunas brechas - en uno o más factores E-D-A-I (proceso) o en los factores de resultados - en el puntuación escogido.

El nivel de logro de la organización está basado en un enfoque holístico, ya sea si evaluamos procesos o resultados, los factores (cuatro en ambos casos) se evalúan de manera agregada. No se trata de una evaluación independiente o "promediada" de cada uno de los factores. Asignar la puntuación correcta dentro del rango escogido requiere evaluar si la respuesta al Subcriterio está más cerca de las afirmaciones de los rangos de puntuación superior o inferior contiguos.

- Una puntuación de 50\% para un Subcriterio de "Proceso" representa un enfoque que cumple todos los requerimientos globales del Subcriterio, que se encuentra consistentemente desplegado y cubre a la mayoría de las unidades de trabajo involucradas en el Subcriterio. Un enfoque que ha pasado por algunos ciclos de mejora y aprendizaje y que aborda las necesidades organizacionales claves. Puntuaciones más altas reflejan mayores logros, demostrados con un despliegue más amplio, con niveles de aprendizaje organizacional significativos e integración en incremento. 
- Una puntuación de 50\% para el Subcriterio de "Resultados" representa una indicación clara de tendencias a la mejora y/o buenos niveles de desempeño, incluyendo datos comparativos apropiados, para las áreas de resultados consideradas en el Subcriterio y, que son importantes para el negocio o para la misión de la organización. Mejores niveles de resultados reflejan mejores tasas de mejora y/o niveles de desempeño, mejor desempeño comparativo así como una cobertura e integración más amplias con respecto a los requerimientos del negocio o a la misión de la organización.

\subsection{3- EL MODELO EFQM DE CALIDAD TOTAL}

\subsubsection{1.- INTRODUCCIÓN}

Este modelo surgió para obtener en Europa una ventaja competitiva mediante la Calidad Total. En septiembre de 1988, 14 empresas importantes de Europa crearon la Fundación Europea para la Gestión de la Calidad (European Foundation for Quality Management, E.F.Q.M.).

En 1991 se estableció el Premio Europeo a la Calidad y se anunció el modelo, patrocinado por la Comisión Europea. En octubre de 1992 se entregaron los primeros premios. En 1994 se constituye un grupo de trabajo para el sector público para la atención sanitaria, educación y otros organismos públicos. En 1996 eran 500 miembros de todos los países, sectores y organizaciones. En los años siguientes se fue modificando hasta que en 2010 se presentó la actual versión.

Su misión es:

- Apoyar a las empresas para convertir la calidad en un elemento de ventaja competitiva.

- Estimular y ayudar a los estamentos de Europa Occidental a participar en actividades para mejorar y promover la calidad.

El modelo EFQM se basa en la autoevaluación, como un examen global y sistemático de las actividades y resultados de la organización y comparándolo con el modelo de referencia de excelencia empresarial. La autoevaluación se puede hacer para un departamento, área, servicio o unidad de forma aislada. El uso de este modelo no supone una contraposición con otros enfoques como por ejemplo las normas ISO, sino que sirve como esquema de gestión.

Para las que quieren optar al premio, deben pasar una auditoría que la realizan inspectores especializados que valoran los criterios dando puntuaciones. De este modo la organización puede conocer cuáles son los puntos fuertes para mantenerlos y aprovecharlos y ver cuales se necesitan para el desarrollo, los puntos débiles, las zonas de mejora para aplicar acciones y seguimiento, las carencias, las áreas de mejora esenciales, 
cuales necesitan mayor atención, la evaluación de los progresos... En definitiva, establecer planes para la mejora continua. También sirve para poder compararse con otras compañías.

La premisa de este modelo es:

"La satisfacción del cliente, la satisfacción de los empleados y el impacto en la sociedad se consiguen mediante el liderazgo, la política y estrategia, gestión del personal, recursos y procesos, que llevan finalmente a la excelencia en los resultados de la organización."

Así, vemos cómo la creación de la EFQM obedeció al deseo de reconocer y fomentar el éxito sostenido y aportar directrices para quienes tratan de alcanzarlo. Esto se materializa mediante la integración de tres componentes que veremos a continuación:

1.- Conceptos Fundamentales de la Excelencia: Principios básicos que constituyen los cimientos esenciales para que cualquier organización alcance una excelencia sostenida.

2.-Modelo EFQM de Excelencia: Marco conceptual que ayuda a hacer realidad en la práctica los Conceptos Fundamentales y el esquema lógico REDER.

3.- Esquema lógico REDER: Herramienta poderosa de gestión y esquema dinámico de evaluación que constituye la columna vertebral que permite a la organización afrontar los retos que debe superar para hacer realidad la excelencia sostenida.

\subsubsection{2.- CONCEPTOS FUNDAMENTALES DE LA EXCELENCIA}

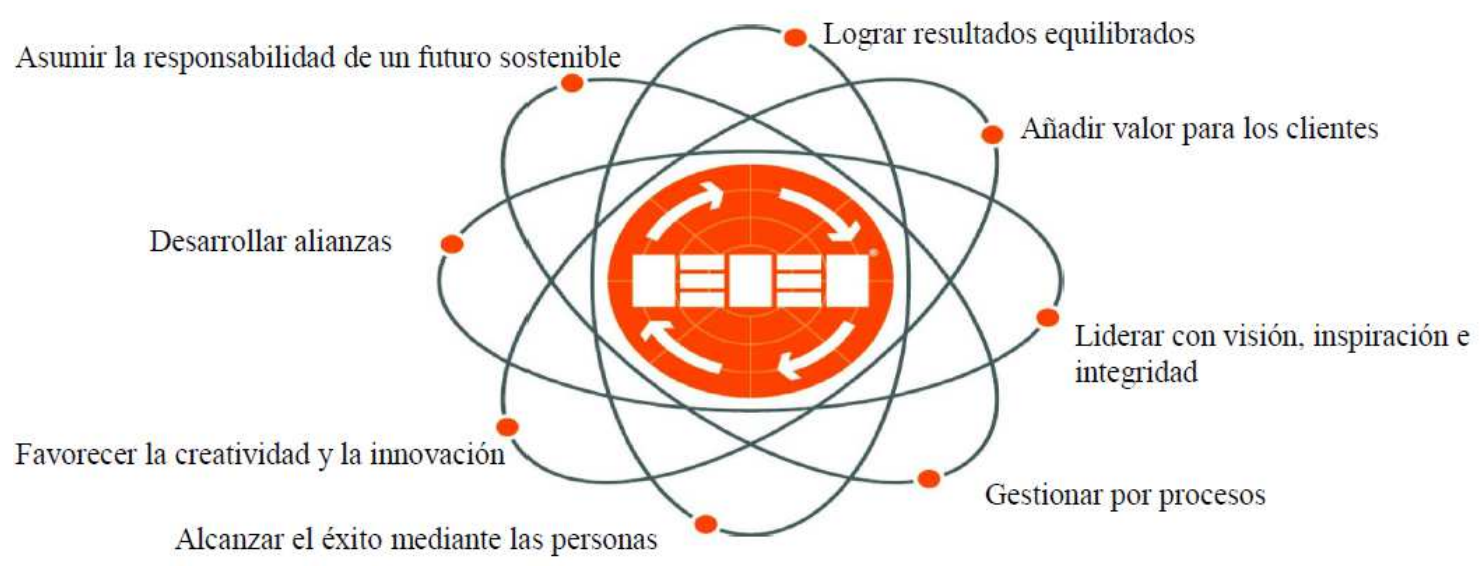




\section{1.- Lograr resultados equilibrados}

El equilibrio y la satisfacción de todos los grupos de interés de una organización con prioridades a corto y más largo plazo: clientes, proveedores, trabajadores, accionistas

y sociedad en general, son factores clave para su éxito continuado. El beneficio económico es obviamente sólo uno de los resultados clave. Deben ser considerados también todos aquellos resultados que son determinantes en el desarrollo de la organización en coherencia con la visión y objetivos estratégicos establecidos.

\section{2.- Añadir valor para los clientes}

El cliente es quien tiene la última palabra sobre la calidad del producto y servicio ofrecido por la organización, siendo su fidelización, un objetivo clave. Por ello, es necesario que la organización conozca las verdaderas necesidades y expectativas de los clientes actuales y potenciales en vistas a su plena satisfacción y a la maximización del valor generado en todo lo que se ofrece.

\section{3.- Liderar con visión, inspiración e integridad}

El compromiso de directivos y mandos en la estrategia que se despliega de forma estructurada y sistemática en la organización es lo que determina la asunción de unos valores compartidos por todos los miembros de la misma, facilitando que sean alcanzados los objetivos empresariales, siempre en coherencia con tales valores. Los líderes deben dar forma al futuro, actuando como modelo de referencia, respetando en sus comportamientos los principios éticos establecidos y asegurando que todos los miembros de la organización los cumplen. Cuidan de crear una cultura emprendedora, de implicación y pertenencia, y de responsabilidad.

\section{4.- Gestionar por procesos}

La prevalencia de la gestión por procesos frente a la gestión por funciones es lo que determina el desarrollo de actividades interrelacionadas de cooperación, las cuales de una manera sistemática han de permitir obtener informaciones fiables y las mejores decisiones respecto a las operaciones que son esenciales en la generación de valor. En tal sentido, los procesos y operaciones clave han de estar debidamente optimizadas y controladas.

Las personas han de estar plenamente implicadas en la revisión y mejora de los procesos en los que operan, asegurándose también que todos los riesgos laborales están controlados. Los procesos han de disponer de indicadores de resultados, vinculados claramente con los objetivos estratégicos y operativos establecidos. 


\section{5.- Alcanzar el éxito mediante las personas}

Las capacidades y potencialidades de las personas revierten de la mejor manera posible sobre la organización en base a la existencia de un conjunto de valores compartidos, de un clima de confianza y transparencia, y de la asunción de responsabilidades a todos los niveles, todo lo cual permite su desarrollo personal e intelectual, auspiciado por una organización que favorece la comunicación y el aprendizaje continuado. Debe existir un alineamiento de los objetivos individuales y de equipo con los de la organización, facilitándose la conciliación entre la vida laboral y personal, para lograr finalmente la plena implicación de las personas con la empresa. Solo con unas condiciones de trabajo dignas y percibidas como tales por los trabajadores, es posible tal implicación. También debe valorarse la dedicación, habilidades, talento y creatividad de las personas.

\section{6.-Favorecer la creatividad y la innovación}

La existencia de una cultura que se sustenta en la mejora continua en todos los ámbitos es lo que permite el desarrollo de actividades concebidas como oportunidades para el aprendizaje continuado y la innovación. La gestión del conocimiento al servicio de la organización es lo que permite que ésta obtenga el máximo rendimiento del pensamiento creativo de todos los miembros de la misma, respondiendo rápidamente a los nuevos retos. La innovación debe ser tanto tecnológica como organizacional para encontrar nuevas maneras de trabajar y nuevas formas de aprovechar las alianzas, los recursos y las competencias.

La innovación debe utilizarse también para mejorar la reputación de la organización, atraer nuevos clientes y talento, y por supuesto, retenerlo.

\section{7.- Desarrollar alianzas}

Las relaciones de confianza de la organización con sus proveedores y otros colectivos con los que debe comunicarse e interactuar son esenciales para compartir conocimientos y experiencias, y lograr, a través de proyectos comunes, la generación de valor compartido de una manera sostenible para todos. Las alianzas estratégicas en proyectos empresariales permiten aunar esfuerzos para asumir retos que individualmente no serían alcanzables, pudiendo así llegar más rápido y más lejos.

\section{8.- Asumir la responsabilidad de un futuro sostenible}

El respeto a los valores éticos, que son consustanciales al ser humano, más allá de normas y reglamentos, es lo que determina que la organización al servicio de la sociedad a la que pertenece, dé y reciba los beneficios que también necesita para su pervivencia a medio y largo plazo. Se considera tanto la sostenibilidad económica como la social y la ambiental. Se cuida en especial de que las personas tengan un entorno laboral seguro y saludable. 


\begin{tabular}{|c|c|c|}
\hline VERSIÓN 2010 & VERSIÓN 2003 & PRINCIPAL CAMBIO DE CONTENIDO \\
\hline $\begin{array}{l}\text { Lograr resultados } \\
\text { equilibrados }\end{array}$ & Orientación a resultados & $\begin{array}{l}\text { Centrado en desarrollar el conjunto de resultados clave respecto a la } \\
\text { visión y estrategia, permitiendo a los líderes adoptar decisiones eficaces } \\
\text { y oportunas. }\end{array}$ \\
\hline $\begin{array}{l}\text { Añadir valor para los } \\
\text { clientes }\end{array}$ & Orientación al cliente & $\begin{array}{l}\text { Centrado en definir y comunicar con claridad la propuesta de valor y la } \\
\text { participación activa en los procesos de diseño del producto y servicio. }\end{array}$ \\
\hline $\begin{array}{l}\text { Liderar con visión, } \\
\text { inspiración e integridad }\end{array}$ & $\begin{array}{l}\text { Liderazgo y } \\
\text { perseverancia en los } \\
\text { objetivos }\end{array}$ & $\begin{array}{l}\text { Concepto más dinámico, centrado ahora en la capacidad de los líderes de } \\
\text { ganarse el compromiso de todos los grupos de interés para la continuidad } \\
\text { exitosa de la organización. }\end{array}$ \\
\hline Gestionar por procesos & Gestionar por procesos & $\begin{array}{l}\text { Centrado ahora en cómo diseñar y enriquecer los procesos para realizar } \\
\text { la estrategia de principio a fin, más allá de los límites "clásicos" de la } \\
\text { organización }\end{array}$ \\
\hline $\begin{array}{l}\text { Alcanzar el éxito a } \\
\text { través de las personas }\end{array}$ & $\begin{array}{l}\text { Desarrollo e implicación } \\
\text { de las personas }\end{array}$ & $\begin{array}{l}\text { Centrado ahora en crear un equilibrio entre las necesidades estratégicas } \\
\text { de la organización y las expectativas y aspiraciones personales, al objeto } \\
\text { de ganar su compromiso a través de su participación. }\end{array}$ \\
\hline $\begin{array}{l}\text { Fomentar la creatividad } \\
\text { y la innovación }\end{array}$ & $\begin{array}{l}\text { Aprendizaje, innovación } \\
\text { y mejora contínua }\end{array}$ & $\begin{array}{l}\text { Ahora se reconoce la necesidad de desarrollar e involucrarse en redes y } \\
\text { hacer participar a todos los grupos de interés como fuentes potenciales } \\
\text { de innovación y creatividad. }\end{array}$ \\
\hline Desarrollar alianzas & Desarrollar alianzas & $\begin{array}{l}\text { El concepto se ha ampliado más allá de la cadena de valor de suministro } \\
\text { y reconoce que para alcanzar el éxito hay que crear alianzas diversas y } \\
\text { basarse en beneficios mutuos sostenibles. }\end{array}$ \\
\hline $\begin{array}{l}\text { Responsabilizarse de } \\
\text { un futuro sostenible }\end{array}$ & $\begin{array}{l}\text { Responsabilidad Social } \\
\text { Corporativa }\end{array}$ & $\begin{array}{l}\text { Ahora el concepto se centra en responsabilizarse activamente de la con- } \\
\text { ducta y de las actividades de la organización, gestionando su impacto en } \\
\text { la comunidad en general. }\end{array}$ \\
\hline
\end{tabular}

Tabla 3 Cambios con respecto a la versión del 2003

\subsubsection{3.- MODELO EFQM DE EXCELENCIA}

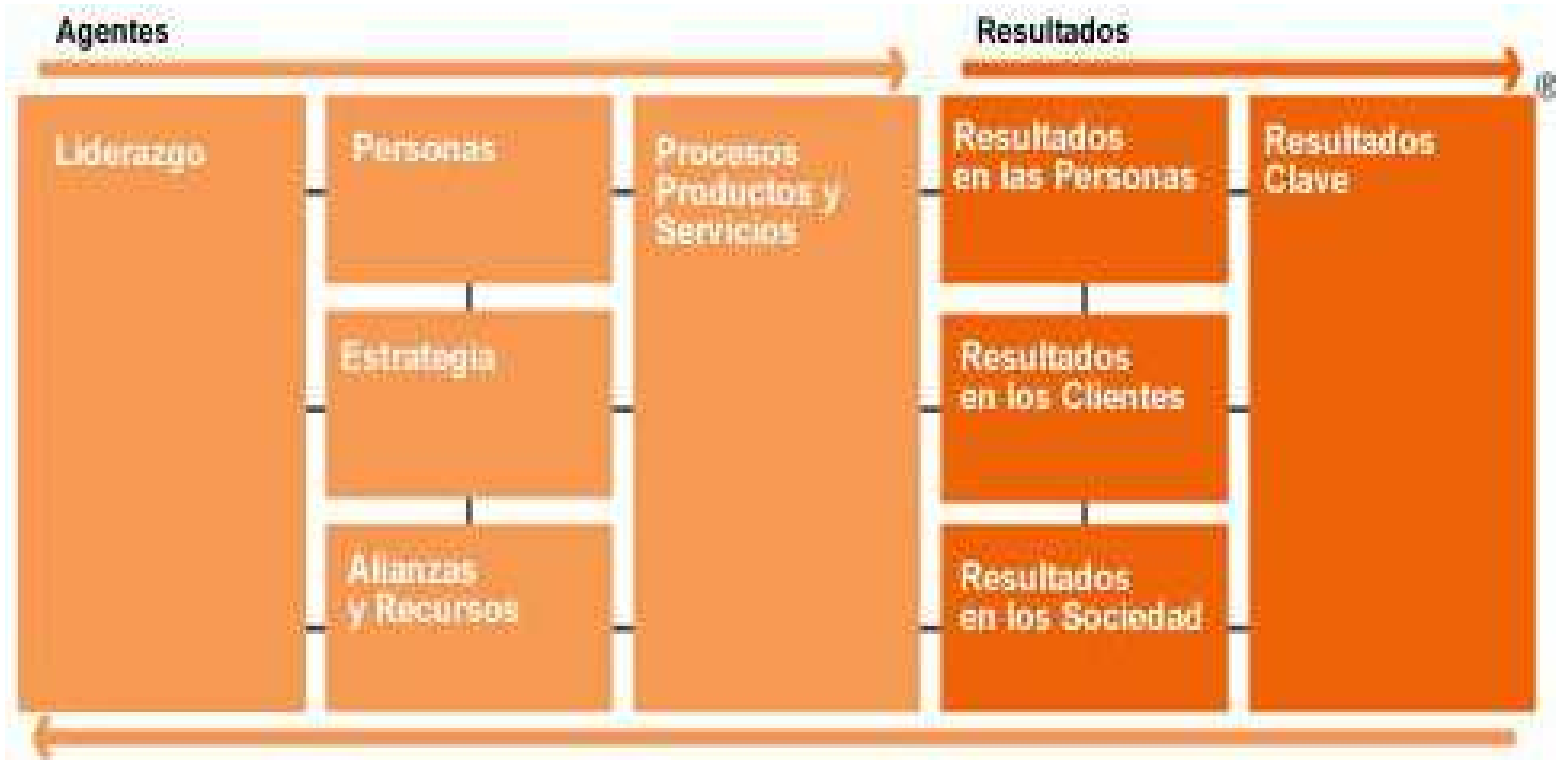

Figura 24 Marco general del Modelo EFQM

Aprendizaje, Creatividad e Innovación 
El Modelo EFQM de Excelencia representado en el diagrama anterior, es un marco de trabajo no prescriptivo basado en nueve criterios. Cinco de ellos son Agentes Facilitadores y cuatro son Resultados. Los criterios que hacen referencia a Resultados tratan sobre lo que la organización logra y como lo logra. Los Resultados son consecuencia de los Agentes Facilitadores, y los Agentes Facilitadores se mejoran utilizando la información procedente de los Resultados.

Las flechas subrayan la naturaleza dinámica del Modelo mostrando que el aprendizaje, la creatividad y la innovación ayudan a mejorar los Agentes Facilitadores que, a su vez, dan lugar a la mejora de los Resultados.

Cada criterio tiene una definición que explica su significado con carácter general. Para desarrollar los criterios en detalle, cada uno se apoya en un número variable de subcriterios. Estos subcriterios describen con más detalle lo que podría ser normal en una Organización Excelente y, por tanto, debería considerarse durante una evaluación.

Finalmente, cada subcriterio incluye una relación de elementos a considerar cuyo objetivo no es otro que aportar ejemplos que aclaren su significado. Muchos de estos elementos están directamente relacionados con los Conceptos Fundamentales mencionados anteriormente. Esta relación de elementos a considerar no es exhaustiva, ni tampoco es obligatorio abordar todos ellos. En el siguiente apartado veremos los criterios y subcriterios del Modelo.

\subsubsection{1.-Criterios y subcriterios}

\section{1.-Liderazgo}

Los directivos han de asumir su liderazgo definiendo las líneas directrices para la consecución de los objetivos empresariales e implicándose para el logro de las expectativas de los diferentes grupos de interés de la organización (trabajadores, proveedores, ...), ello en total coherencia con los valores éticos y de compromiso con las personas, motivándolas, reconociendo sus logros, y asegurando la correcta implantación del sistema.

El liderazgo se valora mediante cinco subcriterios:

1 a. Los líderes desarrollan la misión, visión, valores y principios éticos, actuando como modelo de referencia, en coherencia con una cultura democrática y de excelencia.

1 b. Los líderes definen, supervisan, revisan e impulsan tanto la mejora continua del sistema de gestión de la organización como de su rendimiento.

Los riesgos laborales se identifican y gestionan en todos los procesos, cuidando de su eliminación y minimización.

1 c. Los líderes se implican con los grupos de interés externos 
1d. Los líderes refuerzan una cultura de excelencia entre las personas de la organización.

Se fomenta la generación de nuevas ideas para impulsar la innovación y el desarrollo de la organización, apoyando a las personas para que hagan realidad sus planes, y reconociendo sus esfuerzos, oportuna y adecuadamente. Se cuida la igualdad de oportunidades y la diversidad

1 e. Los líderes se aseguran de que la organización sea flexible, gestionando el cambio de manera eficaz.

Se responde con prontitud con nuevos modos de trabajar para mantener una ventaja sostenida, aprendiendo continuamente de la realidad e inspirando confianza.

\section{2.- Estrategia}

La Dirección ha de formular políticas empresariales coherentes con su visión, y desarrollarlas con estrategias claramente centradas en todos los grupos de interés, apoyándose en un enfoque con planificación y organización adecuada y un despliegue para su implementación, con atención especial a los procesos clave que generan valor. Todo ello ha de ser revisado periódicamente.

Los cuatro subcriterios contemplados son los siguientes:

2 a. La estrategia se basa en comprender las necesidades y expectativas de los grupos de interés, utilizando indicadores para anticiparse a los avances en su entorno externo.

Cuidan de anticiparse al marco reglamentario y normativo, y van más allá del cumplimiento de mínimos establecidos para maximizar el valor de su aplicación.

2 b. La estrategia se basa en comprender el rendimiento de la organización y sus capacidades.

Analizan de qué manera afectan las nuevas tecnologías y los modos de gestión al rendimiento de la organización y a las necesidades de los trabajadores.

2 c. La estrategia y sus políticas de apoyo se desarrollan, revisan y actualizan.

Se cuida de equilibrar las necesidades de la organización y de los grupos de interés y trabajadores a la hora de planificar los objetivos actuales y futuros.

$2 \mathrm{~d}$. La estrategia y sus políticas de apoyo se comunican, implantan y supervisan.

Se alinean los objetivos individuales y estratégicos. Se comunica debidamente dando facultades para maximizar la contribución de las personas.

\section{3.- Personas}

El principal activo de toda organización son las personas que la integran. La empresa ha de facilitar el desarrollo profesional de sus miembros y ha de gestionar toda la información relativa al nivel de satisfacción de los trabajadores, ha de planificar las actividades de 
aprendizaje para su eficaz funcionamiento y mejora, ha de velar por unas idóneas condiciones de trabajo, ha de crear canales ágiles y adecuados de comunicación e información para implicar a las personas y facilitar su participación, contribuyendo a su motivación para obtener el desarrollo innovador de los procesos, productos y servicios. La organización debe potenciar, desarrollar, gestionar y obtener valor de las competencias de las personas (conocimientos, habilidades, experiencias y actitudes), así como de equipos y organización.

Los cinco subcriterios son:

3 a. Los planes de gestión de las personas apoyan la estrategia de la organización y se alinean con la estructura de la organización, las nuevas tecnologías y los procesos clave.

Se gestiona la selección, desarrollo de carreras, movimientos y planes de sucesión, para garantizar la equidad e igualdad de oportunidades. Se utilizan encuestas o cualquier otro tipo de información de los trabajadores para mejorar estrategias, políticas y planes de gestión de personas.

3 b. Se desarrolla el conocimiento y las capacidades de las personas

Se asegura que los planes de formación faciliten el desarrollo de las competencias actuales en base a las necesidades de las personas y de la organización, cuidando también de mejorar su capacidad de empleo. Existe el grado de delegación necesario para maximizar la contribución de las personas

3 c. Las personas están alineadas con las necesidades de la organización, implicadas, y asumen su responsabilidad.

Se promueve una cultura que valora la dedicación, el talento y la creatividad, posibilitándose la innovación en todos los ámbitos, incluidas las condiciones de trabajo. Se implica a las personas en la revisión y optimización de la eficacia y eficiencia de sus procesos.

3 d. Las personas se comunican eficazmente en toda la organización.

Se comparte información, conocimientos y mejores prácticas, fundamentándose ello en el diálogo.

3 e. Recompensa, reconocimiento y atención a las personas de la organización.

Se cuida de mantener entornos seguros y saludables y se fomenta una cultura de apoyo, reconocimiento y colaboración entre personas y equipos. Se acoge y respeta la diversidad de personas. Se asegura una adecuada conciliación de la vida laboral y familiar.

\section{4.- Alianzas y recursos}

La empresa debe gestionar sus activos tangibles: materiales, tecnológicos y financieros, e intangibles: capital intelectual, prestigio, cultura organizacional, etc., todo ello de la manera más eficiente. Para ello deben establecerse relaciones de trabajo con otros grupos de interés en la organización, respaldando la estrategia en un clima de confianza y de 
conocimientos compartidos para así conseguir el eficaz funcionamiento de los procesos, optimizando medios y minimizando costes. Hay que gestionar eficazmente su impacto social y ambiental. Los cinco subcriterios a considerar son:

4 a. Gestión de "partners" y proveedores para obtener un beneficio sostenible.

4 b. Gestión de los recursos económico- financieros para asegurar un éxito sostenido.

4 c. Gestión sostenible de ediificios, equipos, materiales y recursos naturales

Se demuestra una gestión activa del impacto de sus operaciones en la salud pública y en la seguridad y salud en el trabajo. Se minimiza el impacto ambiental satisfaciendo y excediendo los estándares y requisitos legales. Se optimiza el uso de sus activos tangibles asegurando el buen estado y la seguridad física en todo su ciclo de vida.

4 d. Gestión de la tecnología para hacer realidad la estrategia.

Se implican a las personas en el desarrollo de las tecnologías de acuerdo a sus necesidades y competencias para maximizar los beneficios generados. Se identifican y evalúan tecnologías alternativas que mejoren las capacidades de la organización, atendiendo a los aspectos ambientales y de seguridad y salud en el trabajo.

4 e. Gestión de la información y el conocimiento para apoyar una eficaz toma de decisiones y construir las capacidades de la organización.

Se valora y potencia la innovación organizacional, más allá de la tecnológica, revelando nuevas maneras de trabajar y nuevas maneras de aprovechar las alianzas, los recursos y las competencias.

\section{5.- Procesos, productos y servicios}

La gestión adecuada de la empresa debe basarse fundamentalmente en la secuencia de acciones que van añadiendo valor al producto o servicio, y no en las funciones que se desempeñan en la organización. Las personas y las unidades funcionales se interrelacionarán en un marco de cooperación para detectar y subsanar problemas. Se identificarán los procesos clave, potenciándolos y estableciendo objetivos de mejora, desarrollando un sistema de gestión orientado a la generación de valor en todas las etapas y asegurando que los productos y servicios cumplen los requisitos establecidos. También se verificará periódicamente la efectividad del sistema adoptado.

Su evaluación se realizará a través de cinco subcriterios:

5 a. Los procesos se diseñan y gestionan a fin de optimizar el valor para los grupos de interés.

Están definidos los responsables de los procesos con sus funciones para el control y mejora de todos los aspectos que les afectan Se hacen realidad las nuevas ideas evaluándose el impacto y valor añadido de las innovaciones y mejoras en los procesos.

5 b. Los Productos y Servicios se desarrollan para dar un valor óptimo a los clientes 
Se implica al personal en el desarrollo de nuevos e innovadores productos y servicios

5 c. Los productos y servicios se promocionan y se ponen en el mercado eficazmente.

5 d. Los Productos y Servicios se producen, distribuyen y gestionan eficazmente

Los productos y servicios se gestionan en todo su ciclo de vida considerando su impacto en la seguridad, la salud y el medio ambiente. Se implica al personal en la cadena de generación de valor.

5 e. Las relaciones con los clientes se gestionan y mejoran

\section{6.- Resultados en los clientes}

La organización debe satisfacer las necesidades de sus clientes, ofreciendo productos y servicios que se diferencien en lo posible del resto de ofertas existentes en el mercado, dando la información previa necesaria y realizando un seguimiento del producto y servicios asociados que añaden valor y producen satisfacción, seguridad y garantía de salud. Se demuestran resultados positivos al menos en tres años.

Los logros alcanzados en los clientes se evalúan a través de dos subcriterios:

6 a. Percepciones que de la organización tienen los clientes, derivadas de encuestas y otras fuentes de información. Pueden centrarse en: reputación e imagen, valor otorgado por los clientes a productos y servicios, a su distribución y al servicio de atención y apoyo recibido. Se valora también la fidelidad y compromiso del cliente.

6 b. Indicadores de rendimiento que den una idea clara de la eficacia del despliegue seguido. Pueden centrarse en: distribución, servicio y atención al cliente, con quejas, felicitaciones, y reconocimiento externo.

\section{7.-Resultados en las Personas}

Los logros alcanzados por la organización poseen una fuerte dependencia con la identificación de las personas con la estrategia y líneas seguidas por la empresa. Tales resultados serán satisfactorios si sintonizan con sus valores, si existe motivación y comunicación fluida, si existe un clima de confianza y se asumen responsabilidades, y si existe una preocupación por la seguridad y salud laboral en un buen clima de trabajo. Se demuestran resultados positivos al menos en tres años.

Estos resultados se valoran a través de dos subcriterios:

7 a. Percepciones que tienen las personas que integran la organización sobre el despliegue seguido. Pueden centrarse en satisfacción, implicación y compromiso; condiciones de trabajo; orgullo de pertenencia y profesional; liderazgo; formación y desarrollo de competencias y eficacia de la comunicación.

7 b. Indicadores de rendimiento sobre lo realizado para y con las personas. Pueden centrarse en: Implicación y compromiso, gestión de competencias y rendimiento, 
resultados de la gestión del liderazgo, formación y desarrollo de carreras, y comunicación interna.

\section{8.-Resultados en la Sociedad}

La empresa no es una organización independiente, sino que está inmersa en un entorno social en el que debe fomentar unos valores que estén en concordancia con el medio social y natural del que forma parte. Además de velar por el personal y sus clientes, también debe adquirir compromisos frente a una gestión sostenible que no comprometa los recursos naturales, minimizando el impacto ambiental de los procesos desarrollados y apoyando el bienestar de los trabajadores y la comunidad. Para ello acuerdan y desarrollan indicadores de resultados para determinar el éxito del despliegue de su estrategia social y ambiental. Se demuestran resultados positivos al menos en tres años. Los subcriterios de los resultados en la sociedad son:

8 a. Percepciones que tiene la sociedad derivadas de encuestas, agentes sociales, artículos de prensa, reconocimientos públicos, y otras fuentes de interés. Pueden centrarse en: impacto ambiental, imagen y reputación, premios y reconocimientos en prensa, e impacto del lugar de trabajo.

8 b. Indicadores de rendimiento de su gestión de su impacto en la sociedad. Pueden centrarse en: Resultados ambientales, resultados de seguridad y salud laboral, cumplimiento de la legislación y diferentes normativas, y resultados en la sociedad en general.

\section{9.-Resultados Clave}

Una cultura de excelencia, como se ha citado, está orientada a obtener unos resultados equilibrados clave, sean tanto económico-financieros como no económicos, basados en las necesidades y expectativas de los grupos de interés, y ello con visión de futuro. Se demuestran resultados positivos al menos en tres años. Los resultados clave se analizan a través de dos subcriterios:

9 a. Resultados Estratégicos clave. Pueden centrarse en: Resultados económicofinancieros, Gestión y control de presupuesto, volumen de productos y servicios clave, nivel de diversificación e internacionalización, y resultados de los procesos clave.

9 b. Indicadores Clave de Rendimiento. Pueden centrarse en: indicadores económicofinancieros, costes de los proyectos, indicadores de rendimiento de los procesos clave, rendimiento de "partners" y proveedores, avances alcanzados en tecnología, información y conocimiento. 


\subsubsection{4.- EL ESQUEMA LÓGICO REDER}

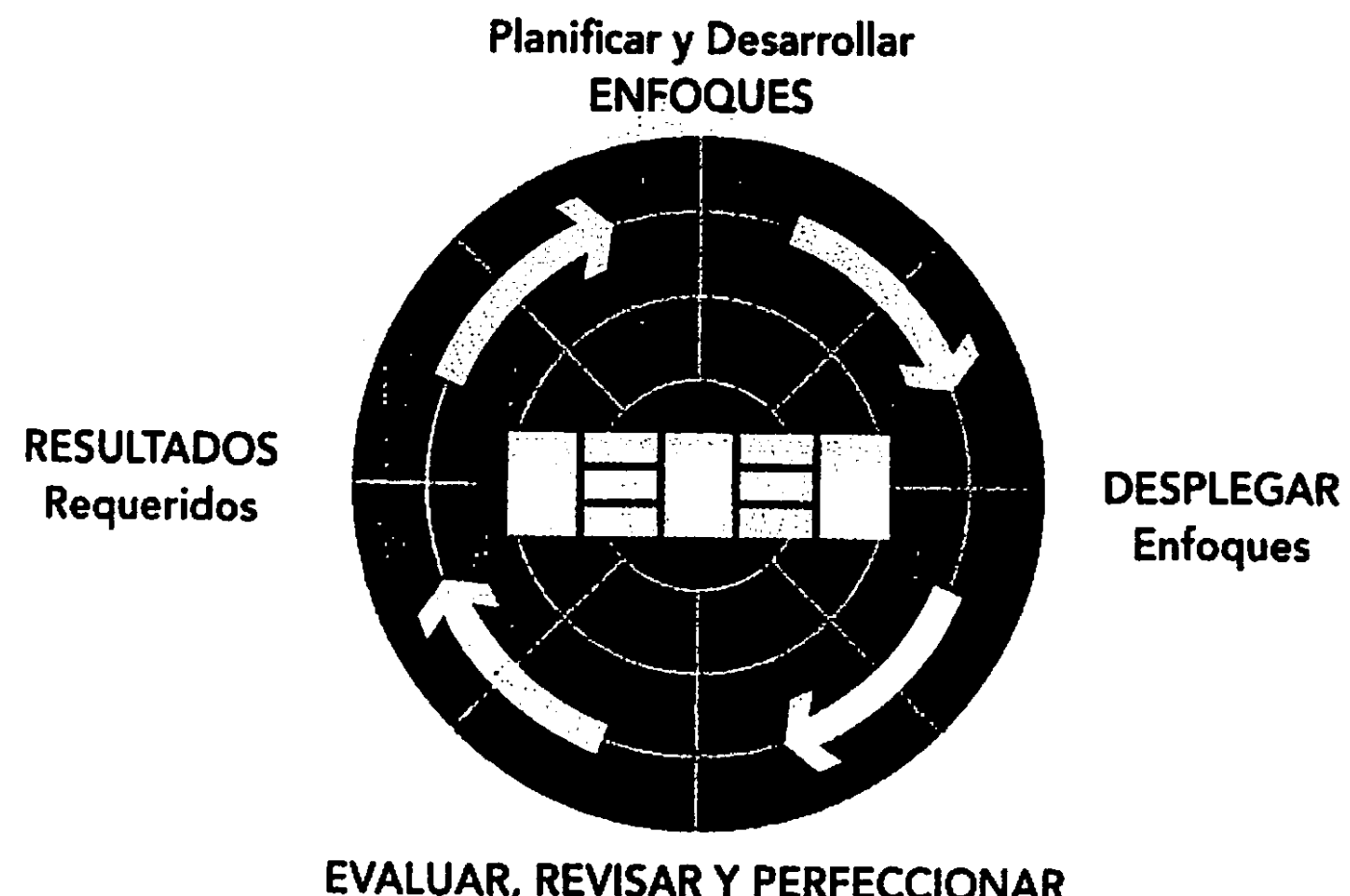

\section{Enfoques y Desplieque}

Figura 25 Esquema Lógico REDER

REDER es una poderosa herramienta de gestión y una manera estructurada de evaluar el rendimiento de una organización.

Según la lógica REDER, toda organización necesita:

-Establecer los Resultados que quiere lograr como pate de su estrategia.

- Planificar y desarrollar una serie de Enfoques sólidamente fundamentados e integrados que la lleven a obtener los resultados requeridos ahora y en el futuro.

- Desplegar los enfoques de manera sistemática para asegurar su implantación.

- Evaluar, revisar y perfeccionar los enfoques desplegados basándose en el seguimiento y análisis de los resultados alcanzados y en las actividades continuas de aprendizaje.

La matriz REDER de Agentes Facilitadores se utiliza para analizar los enfoques de los cinco criterios Agentes Facilitadores (Liderazgo; Estrategia; Personas; Alianzas y recursos; Procesos, productos y servicios). La matriz REDER de Resultados se utiliza para analizar los resultados contemplados en los cuatro criterios Resultados (Resultados en los clientes; Resultados en las personas; Resultados en la sociedad; Resultados clave). 
Para realizar un análisis con más rigor, las matrices REDER se descomponen en atributos:

\begin{tabular}{|c|c|}
\hline \multicolumn{2}{|l|}{ Análisis de AGENTES FACILITADORES } \\
\hline Elementos: & Atributos a evaluar (ver matriz) \\
\hline $\begin{array}{l}\text { ENFOOUE: Lo que una organización planifica hacer y sus razones. Un enfoque solli- } \\
\text { damente fundamentado tiene una logica clara, centrada en las necesidades actuales } \\
\text { y futuras de la organización; se hace realidad a través de procesos bien definidos; y } \\
\text { tiene una clara orientzción hacia las necesidades de los grupos de interés de los en- } \\
\text { foques utilizados. Además, los enfoques deben estar integrados, lo que significa que } \\
\text { apoyan claramente la estrategia y están vinculados a otros enfoques, cuando procede. } \\
\text { Con el tiempo. los enfoques se habrán perfeccionado incorporando mejoras a su es- } \\
\text { tructura. }\end{array}$ & $\begin{array}{l}\text { - Sölidamente } \\
\text { fundamentado. } \\
\text { - Integrado. }\end{array}$ \\
\hline $\begin{array}{l}\text { DESPLIEGUE: Lo que se hace para implantar sistemáticamente el enfoque en las áreas } \\
\text { consideradas relevantes para dicho enfoque. La implantación es sistemática cuando } \\
\text { ha sido planificada adecuadamente y se lleva a cabo de forma apropiada tanto para el } \\
\text { propio enfoque como para la organización, que deberá ser capaz de gestionar cam- } \\
\text { bios en los enfoques en un marco temporal adecuado. }\end{array}$ & - $\quad$ Implantado. \\
\hline $\begin{array}{l}\text { EVALUAR, REVISAR Y PERFECCIONAR: Lo que una organización hace para revisar, } \\
\text { perfeccionar y mejorar el enfoque y su despliegue. Una organización excelente modirá } \\
\text { periódicamente la eficiencia y eficacia del enfoque y su despliegue, y realizará activi- } \\
\text { dades de aprendizaje, y otras que generen creatividad e ideas, para modificar y crear } \\
\text { nuevos enfoques. El resultado de la medición, el aprendizaje y la creatividad se utiliza. } \\
\text { rá para identificar, establecer prioridades, planificar e implantar mejoras e innovación. }\end{array}$ & $\begin{array}{l}\text { - Medición. } \\
\text { - Aprendizaje y } \\
\text { Creatividad. } \\
\text { - Mejora e Innovación. }\end{array}$ \\
\hline
\end{tabular}

Tabla 4 Matriz REDER de agentes facilitadores 


\begin{tabular}{|c|c|}
\hline \multicolumn{2}{|l|}{ Análisis de RESULTADOS } \\
\hline Eienenios: & Atributos a evaliuar (ver matriz) \\
\hline $\begin{array}{l}\text { RELEVANCIA Y UTILIDAD: Los datos deben cubrir todos los aspectos de aquello que } \\
\text { se mide, deben ser oportunos, fiables, precisos, estar segmentados adecuadamente } \\
\text { y ser coherentes con la estrategia y las necesidades y expectativas de los grupos de } \\
\text { interés relevantes. Deben entenderse las relaciones que existen entre los diferentes } \\
\text { Resultados relevantes y cómo inciden unos sobre otros. Deben también estar identifi. } \\
\text { cados y priorizados los Resultados Clave para el grupo de interés analizado. }\end{array}$ & $\begin{array}{l}\text { - Ambito de aplicación y } \\
\text { Relevancia. } \\
\text { - Integridad. } \\
\text { - Segmentación. }\end{array}$ \\
\hline $\begin{array}{l}\text { RENDIMIENTO: En una organización excelente, los Resultados muestran tendencias } \\
\text { positivas y/o un buen rendimiento sostenido. Se establecen objetivos para los Resul- } \\
\text { todos Clave. Además, dichos objetivos son adecuados y se alcanzan o superan. Se } \\
\text { compara externamente el rendimiento de los Resultados Clave y dicha comparación } \\
\text { es favorable, especialmente, en relación con el mejor del sector y/o el mejor del mun- } \\
\text { do. Comprender las relaciones que existen entre los Agentes Facilitadores clave y los } \\
\text { Resulcados Clave de cada grupo de interés permitirá confiar en que este rendimiento } \\
\text { positivo será sostenible. }\end{array}$ & $\begin{array}{l}\text { - Tendencias. } \\
\text { - Objetivos. } \\
\text { - Comparaciones. } \\
\text { - Causas. }\end{array}$ \\
\hline
\end{tabular}

Tabla 5 Matriz REDER de resultados

En las dos páginas siguientes veremos las tablas: Tabla 6 Matriz redevaluar y los agentes facilitadores y Tabla 7 Matriz redevaluar y los agentes gestionar resultados 


\section{Matriz rederevaluar y los agentes FACILITADORES $^{\oplus}$}

\begin{tabular}{|c|c|c|c|c|c|c|c|c|c|c|c|c|c|c|c|c|c|c|c|}
\hline El enfoque & \multicolumn{3}{|l|}{$0 \%$} & \multicolumn{4}{|c|}{$25 \%$} & \multicolumn{5}{|c|}{$50 \%$} & \multicolumn{5}{|c|}{$75 \%$} & \multicolumn{2}{|r|}{$100 \%$} \\
\hline 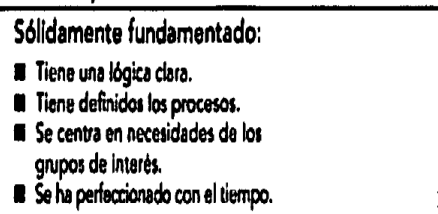 & \multicolumn{3}{|c|}{$\begin{array}{l}\text { Sin evidencia o } \\
\text { anecdotica }\end{array}$} & \multicolumn{4}{|c|}{ Alguna evidencia } & \multicolumn{5}{|c|}{ Evidencia } & \multicolumn{5}{|c|}{ Evidencia clara } & \multicolumn{2}{|r|}{$\begin{array}{l}\text { Evidencia } \\
\text { total }\end{array}$} \\
\hline $\begin{array}{l}\text { Integrado: } \\
\text { I Apoyala Politica y Estrotegia. } \\
\text { Estr vinculdado o otros enlogues, } \\
\text { cuando procede. }\end{array}$ & \multicolumn{3}{|c|}{$\begin{array}{l}\text { Sin evidencia o } \\
\text { anecóbtica }\end{array}$} & \multicolumn{4}{|c|}{ Alguna evidencia } & \multicolumn{5}{|c|}{ Evidencia } & \multicolumn{4}{|c|}{ Evidencia clara } & & \multicolumn{2}{|c|}{$\begin{array}{l}\text { Evidencia } \\
\text { total }\end{array}$} \\
\hline Total para Enfoque & 0 & \begin{tabular}{|l|l}
5 & 1 \\
\end{tabular} & & 15 & 20 & \begin{tabular}{l|l}
25 & 30
\end{tabular} & 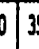 & & 104 & 455 & 55 & 60 & 65 & 570 & 75 & 8008 & & \begin{tabular}{|l|l|}
0 & 95 \\
\end{tabular} & 100 \\
\hline Despliegue & \multicolumn{3}{|l|}{$0 \%$} & \multicolumn{4}{|c|}{$25 \%$} & & \multicolumn{4}{|c|}{$50 \%$} & \multicolumn{5}{|c|}{$75 \%$} & \multicolumn{2}{|r|}{$100 \%$} \\
\hline 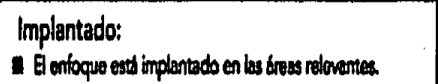 & \multicolumn{3}{|c|}{$\begin{array}{l}\text { Sin evidencia } 0 \\
\text { anecdbtica }\end{array}$} & \multicolumn{5}{|c|}{$\begin{array}{l}\text { Implantado en } \mathrm{Y} \text { do } \\
\text { las áreas relevantes }\end{array}$} & \multicolumn{4}{|c|}{$\begin{array}{l}\text { Implantado on kide } \\
\text { las areas relevantes: }\end{array}$} & \multicolumn{5}{|c|}{$\begin{array}{l}\text { Implentado ien zydde } \\
\text { Jes. áreas relevantes }\end{array}$} & \multicolumn{2}{|c|}{$\begin{array}{l}\text { Implantado en todas } \\
\text { las śreas relevantes }\end{array}$} \\
\hline 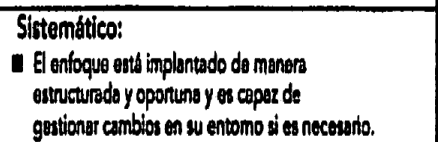 & \multicolumn{3}{|c|}{$\begin{array}{l}\text { Sin evidencia o } \\
\text { anecdótica }\end{array}$} & \multicolumn{4}{|c|}{ Alguna evidencis : } & \multicolumn{5}{|c|}{ Evidencis } & \multicolumn{5}{|c|}{ Exidencia clarg } & \multicolumn{2}{|c|}{$\begin{array}{l}\text { Evidencia } \\
\text { total }\end{array}$} \\
\hline Total para Despliegue & 0 & $5: 1$ & & 15 & 201 & 2530 & 3 & 4 & 0 & 45 & 55 & 60 & & 70 & 75 & $\infty$ & & \begin{tabular}{|l|l|}
0 & 95 \\
\end{tabular} & 100 \\
\hline Evaluar, Revisar y Perfeccionar & \multicolumn{3}{|l|}{$0 \%$} & \multicolumn{4}{|c|}{$25 \%$} & & & 50 & & & & & $75 \%$ & & & & $100 \%$ \\
\hline 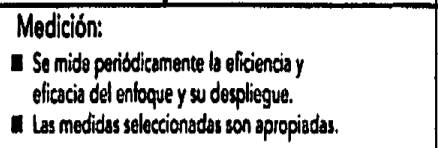 & $\begin{array}{l}\text { Sin eviden } \\
\text { anecóbt }\end{array}$ & $\begin{array}{l}\text { neizo } \\
\text { tica }\end{array}$ & & & guna & eviden & & & & Evide & & & & Evide & encia & clara & & & $\begin{array}{l}\text { Svidencia } \\
\text { total }\end{array}$ \\
\hline 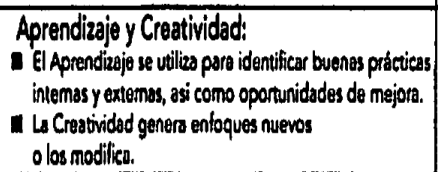 & $\begin{array}{l}\text { Sin eviden } \\
\text { anecdót }\end{array}$ & $\begin{array}{l}\text { ncia o } \\
\text { tica }\end{array}$ & & & guna & eviden & & & & Evide & & & & Evide & encia & clara & & & $\begin{array}{l}\text { Evidencia } \\
\text { cotal }\end{array}$ \\
\hline 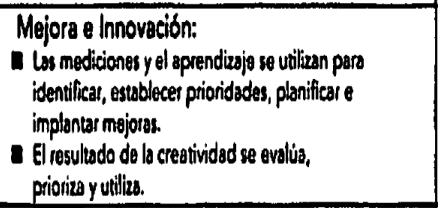 & $\begin{array}{l}\text { Sin eviden } \\
\text { anecdót }\end{array}$ & & & & guna & eviden & & & & Evide & & & & Evide & encia & clara & & & $\begin{array}{l}\text { Svidencia } \\
\text { total }\end{array}$ \\
\hline Total para Evaluar, Revisar y Perfeccionar & 0 & $5: 1$ & & 15 & (2): & \begin{tabular}{l|l}
25 & 30 \\
\end{tabular} & 3 & 14 & 1014 & 155 & 55 & $\infty 0$ & 65 & 50 & 75 & $\infty$ & 5 & \begin{tabular}{|l|l|}
0 & 95 \\
\end{tabular} & 100 \\
\hline Valoración Total & 0 & \begin{tabular}{l|l}
5 & 1 \\
5
\end{tabular} & & 15 & 20 & 2530 & 3 & & 0.4 & $15 \mid 50$ & 55 & $\infty$ & 65 & 70 & 75 & $\infty$ & & \begin{tabular}{|l|l|}
90 & 95 \\
\end{tabular} & 100 \\
\hline
\end{tabular}




\section{Matriz rederevaluar y los agentes gestionar LOS RESULTADOS ${ }^{\circ}$}

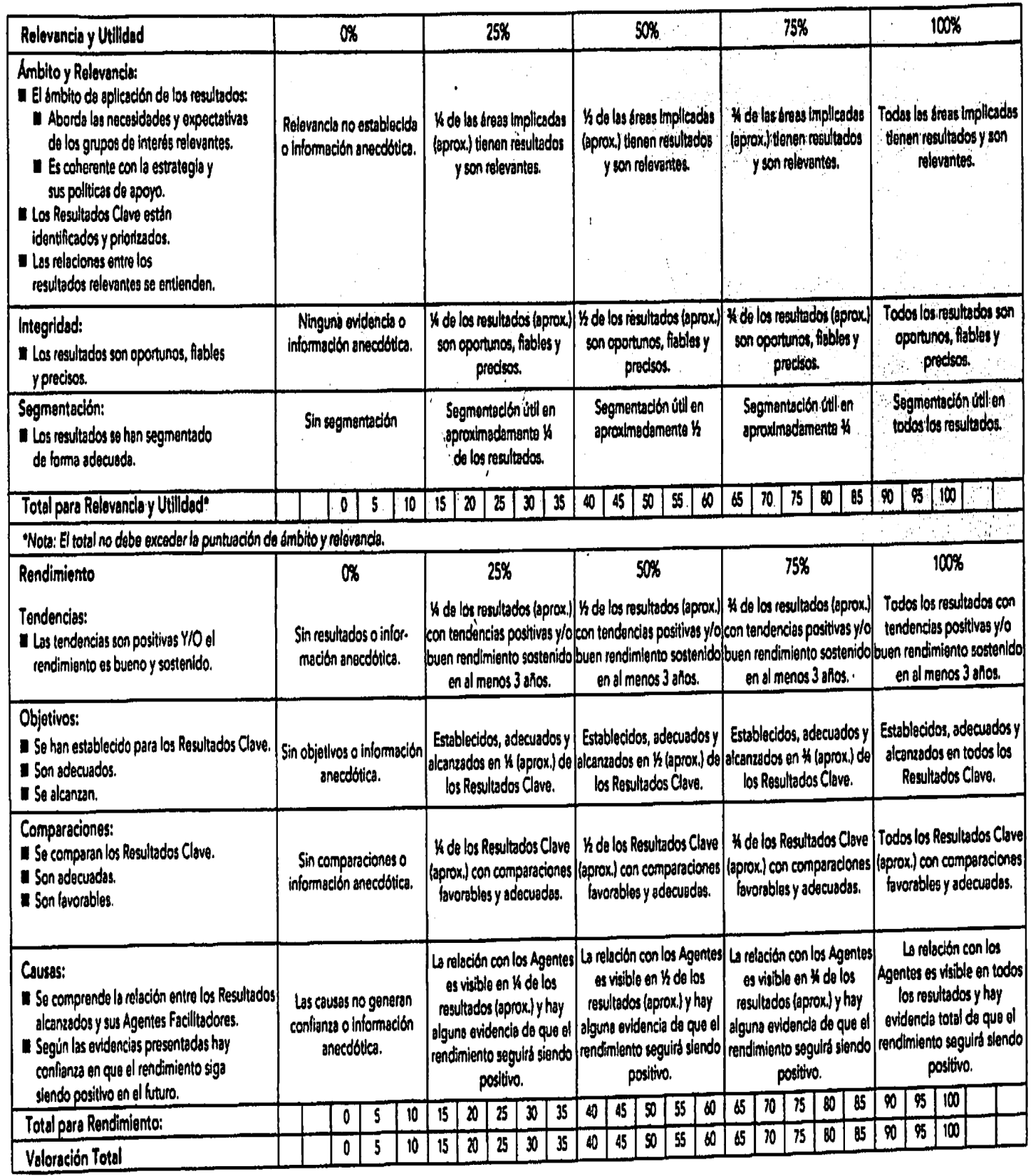




\subsubsection{5- PUNTUAR EL PREMIO EFQM A LA EXCELENCIA}

La herramienta REDER de Evaluación y Gestión es el método de evaluación utilizado para puntuar las memorias de las organizaciones que se presentan al Premio EFQM a la Excelencia y a la mayoría de los premios nacionales a la excelencia europeos. También la pueden utilizar organizaciones que deseen realizar autoevaluaciones o emplear la puntuación para actividades de benchmarking o de otra índole.

Al puntuar una organización mediante REDER, se asigna a cada uno de los nueve criterios del Modelo un peso específico que permitirá calcular el número total de puntos asignados a la organización. Los pesos específicos se establecieron inicialmente en 1991 tras un extenso ejercicio de consultas en toda Europa y se revisan en la EFQM cada cierto tiempo. A continuación se muestra el esquema de pesos específicos de 2010.
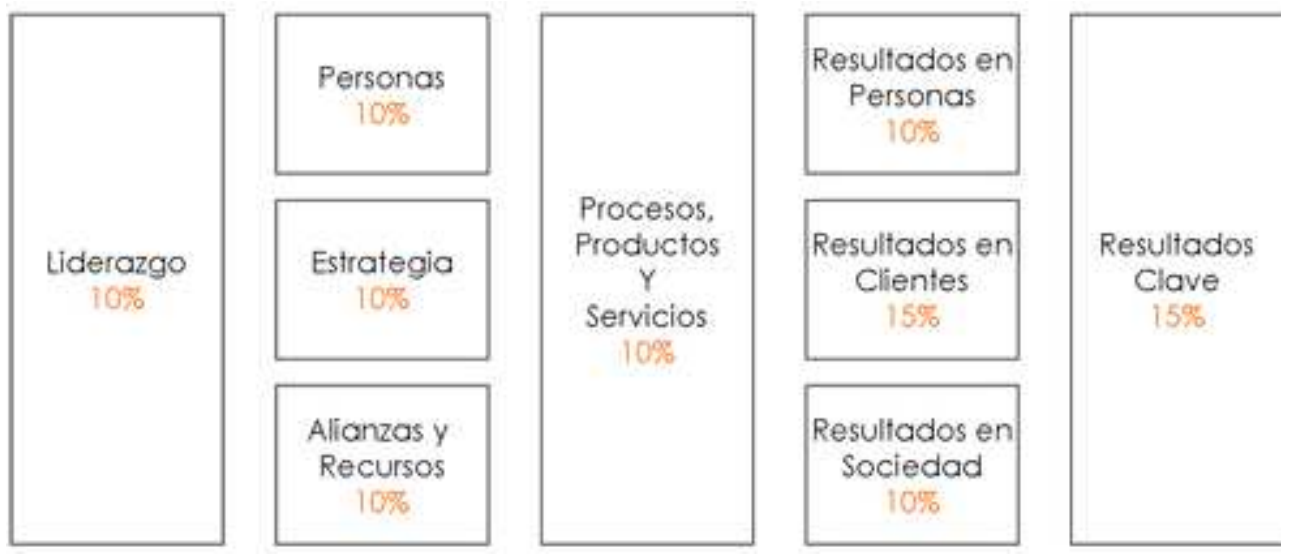

Figura 25 Porcentaje asignado a cada uno de los criterios

En general, dentro de cada criterio se le asigna el mismo peso específico a todos sus subcriterios; por ejemplo, el subcriterio $1 \mathrm{~b}$ supone el $20 \%$ de los puntos asignados al criterio 1 .

Cabe señalar no obstante, dos excepciones:

-Al subcriterio $6^{\mathrm{a}}$ se le asigna el $75 \%$ del total de puntos del criterio 6 y al $6 \mathrm{~b}$ el $25 \%$ restante.

- Al subcriterio $7^{\mathrm{a}}$ se le asigna el $75 \%$ del total de los puntos del criterio 7 y al $7 \mathrm{~b}$ el $25 \%$ restante.

El primer paso para obtener la puntuación es asignar un porcentaje a cada subcriterio mediante la matriz de puntuación REDER, para lo cual hay que tener en cuenta todos los elementos y atributos que la matriz contempla. A continuación se recopilan todos los porcentajes en la hoja denominada Resumen de la Puntuación y se realizan los cálculos matemáticos señalados en la hoja. La puntuación total se encuentra en una escala de 0 a 1000 puntos. 


\section{RESUMEN DE LA PUNTUACION}

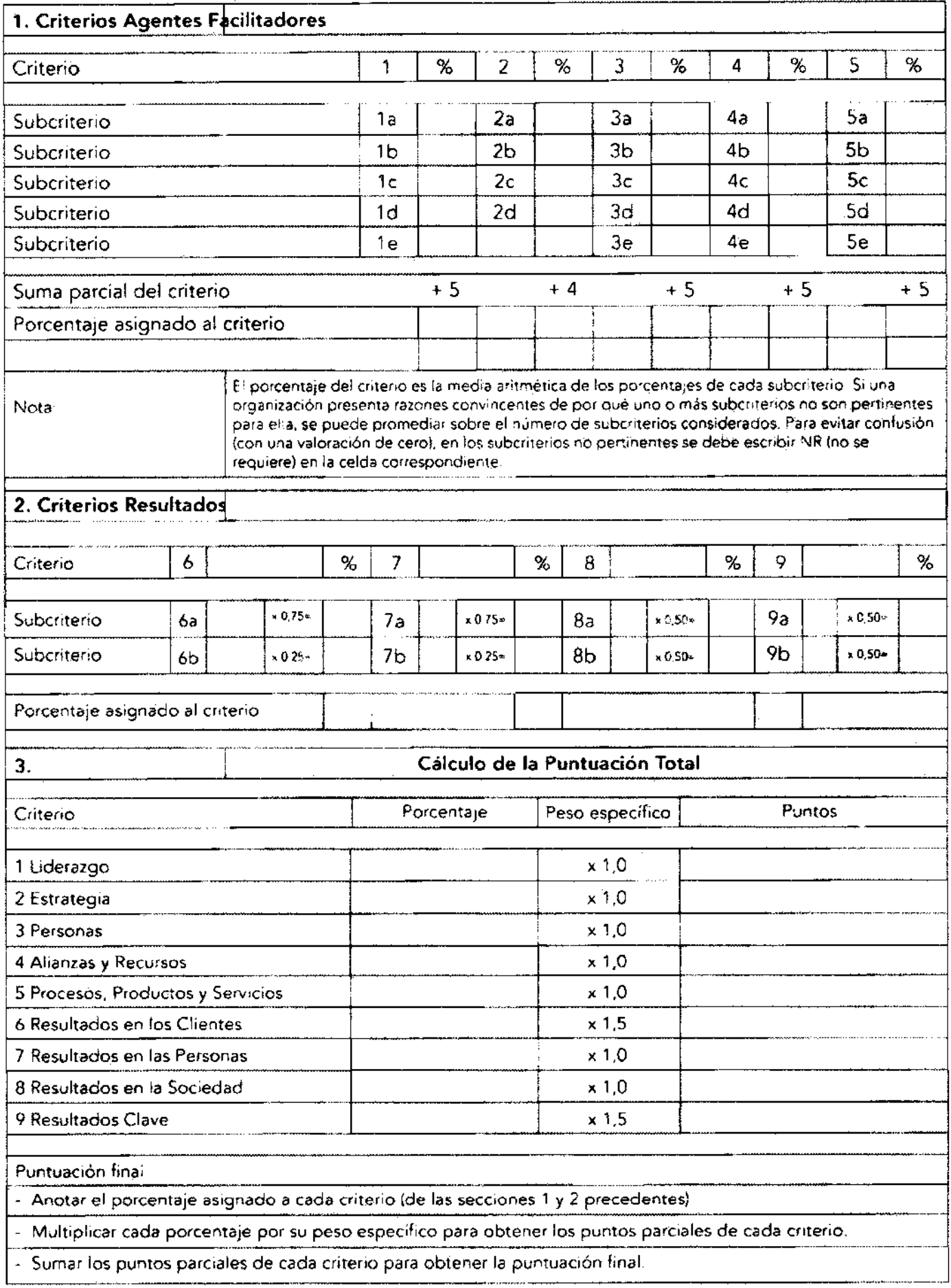

Tabla 6 Resumen de la puntuación 


\section{4.- KAIZEN Y 5S}

\section{1-KAIZEN}

\subsection{1-INTRODUCCIÓN}

Kaizen es un sistema enfocado en la mejora continua de toda la empresa y sus componentes, de manera armónica y proactiva.

La esencia de las prácticas administrativas más "exclusivamente japonesas" ya sean de mejoramiento de la productividad, actividades para el Control Total de la Calidad, círculo de control de calidad, entre otros, puede reducirse a una palabra: KAIZEN. Kaizen es el concepto de una sombrilla que involucra numerosas prácticas y herramientas que dentro de dicho marco filosófico y estratégico, permiten una mejora continua en la organización.

La esencia del kaizen es la simplicidad como medio de mejorar los estándares de los sistemas productivos y de gestión. La capacidad de analizar, motivar, dirigir, controlar, evaluar constituyen la razón de ser del kaizen. "Cuanto más simple y sencillo mejor".

Mejorar los estándares significa establecer estándares más altos. Una vez hecho esto, el trabajo de mantenimiento por la administración consiste en procurar que se observen los nuevos estándares. El mejoramiento duradero sólo se logra cuando la gente trabaja para estándares más altos. De este modo, el mantenimiento y el mejoramiento se han convertido en inseparables para la mayoría de los gerentes japoneses.

El Kaizen genera el pensamiento orientado al proceso, ya que los procesos deben ser mejorados antes de que se obtengan resultados mejorados.

El mejoramiento continuo se logra a través de todas las acciones diarias, por pequeñas que éstas sean, que permiten que los procesos y la empresa sean más competitivas en la satisfacción del cliente. La velocidad del cambio dependerá del número de acciones de mejoramiento que se realicen día a día y de la efectividad con que éstas se realicen, por lo que es importante que el mejoramiento continuo sea una idea internalizada por completo en la conducta de todos los miembros de la organización, convirtiéndose en una filosofía de trabajo y de vida.

El gran objetivo es haciendo uso de los sistemas antes mencionadas lograr el óptimo en materia de calidad, costos y entrega (QCD, quality, cost, delivery).

Calidad no sólo hace referencia a la calidad de los productos o servicios terminados, sino también a la calidad de los procesos que se relacionan con dichos productos o servicios. Costo se refiere al costo total, que incluye diseño, producción, venta y suministro de productos o servicios. Entrega significa despachar a tiempo el volumen solicitado. De tal forma cuando se cumplen las tres condiciones de calidad, costo y entrega, los clientes están plenamente satisfechos. 


\subsection{2.-PRINCIPIOS DEL KAIZEN}

\section{Enfoque en el cliente}

Uno de los objetivos más importantes de la cultura Kaizen es la satisfacción total del cliente. Es por eso que esta ideología no acepta la mediocridad, es decir o el producto y/o servicio cumplen con las especificaciones requeridas por el consumidor y generan valor de tal manera que incremente la satisfacción del mismo, o bien se elimina. Debido a esta premisa, se derivan los siguientes principios que contribuirán al cumplimiento de la misma.

\section{Realizar mejoras continuamente}

Para el Kaizen no hay descanso: una vez finalizada una tarea exitosamente la concentración se enfoca a mejorar esa misma tarea. Para las organizaciones Kaizen esta muy claro que lo que desarrollen hoy en diseños, costos, estándares, etc. no será suficiente para el mañana. Además son conscientes de que es más fácil y efectivo en costo y tiempo el perfeccionar un producto / servicio existente que crear uno nuevo.

\section{Reconocer abiertamente los problemas}

El tener presente que es importante mantener una comunicación abierta dentro de la organización en la cual se traten temas como por ejemplo los desaciertos o problemas que pueden ocurrir dentro de las misma, en donde queda claro que no hay culpables sino procesos por mejorar o problemas por solucionar, y en la cual no se buscan responsables sino las fallas en si, permite que las personas admitan sus errores, sus debilidades y por que no que soliciten apoyo. A diferencia de crear un ambiente en el que se ocultan o no se admiten las falencias, pues esto lleva a un continuo estancamiento en la efectividad de los procesos de la empresa.

\section{Promover la apertura}

Los rasgos característicos de una compañía Kaizen son básicamente el compartir, comunicarse ínter funcionalmente, y un liderazgo visible, por lo que la territorialidad, la apropiación y las barreras funcionales no encajan dentro de la filosofía Kaizen.

\section{Crear equipos de trabajo}

El trabajo en equipo juega un papel muy importante, ya que "los equipos constituyen los ladrillos de la estructura corporativa dentro de las organizaciones Kaizen” . es decir, la interconexión de varios equipos permite que la organización saque ventaja, pues gracias a esta metodología se genera motivación y sentido de pertenencia (ya que los equipos y sus líderes se sirven entre sí para lograr éxito personal y recompensas), además de fomentar la comunicación, la apertura y el compartir. 


\section{Manejar proyectos a través de equipos ínter funcionales}

Al trabajar en proyectos dentro de la organización, es necesario contar con la participación de todas las dependencias e incluso con recursos externos a la compañía como son los proveedores y el cliente, con el fin de obtener diferentes puntos de vista, colaboración y recursos que contribuyan al desarrollo de los mismos.

\section{Alentar los procesos apropiados de relaciones}

Las organizaciones Kaizen son conscientes de que si invierten en el entrenamiento de su gente en cuanto habilidades interpersonales, en especial en los gerentes y líderes quienes son los responsables de la armonía de la compañía, lograrán obtener no solo procesos sólidos, y la realización de los empleados sino también obtendrán los resultados esperados en cuanto al logro de la metas financieras.

\section{Desarrollar la autodisciplina}

Este es un elemento muy importante para cada uno de los miembros de una organización Kaizen, puesto que la autodisciplina permite que el ser humano se adapte a las situaciones que se presentan en la vida diaria y halle bienestar y comodidad mediante la afirmación de su fuerza interna lo que le permite relacionarse de una manera armoniosa con los demás.

\section{Información constante a los empleados}

El mantener informados a los empleados sobre la compañía desde la inducción como durante el tiempo en que estén empleados, es de vital importancia, puesto que si las personas se encuentran en la ignorancia en temas como la misión, valores, productos, desempeño, personal, planes de la compañía etc. no solo se limitarán a desempeñar sus funciones sin ir más allá, sino que también su motivación será muy baja y no tomarán los retos de la empresa como retos personales generando una actitud conformista.

\section{Fomentar el desarrollo de los empleados}

En este punto el empowerment es la definición de este principio, pues el entrenar a los integrantes de una compañía para que adquieran habilidades, estimularlos y sobretodo otorgarles responsabilidad en la toma de decisiones permite que las personas se desarrollen y así sean más eficientes en su trabajo.

\subsection{3.- INSTRUMENTOS DEL KAIZEN}

Teniendo una idea de cómo el Kaizen es planteado en las organizaciones con base en sus diez principios, es momento de tratar sobre algunas herramientas que sirven de soporte 
en las cuales se basa este raciocinio para desarrollarse completamente en sus procesos y técnicas:

1. Gestión de Calidad Total

2. Un sistema de producción justo a tiempo

3. Mantenimiento productivo total

4. Despliegue de políticas

5. Un sistema de sugerencias

6. Actividades de grupos pequeños

\section{1.- Gestión de la calidad total.}

Para los japoneses, calidad significa ser "adecuado para uso de los consumidores". La innovación técnica se propone corregir el producto desde el punto de vista del consumidor y no es una finalidad en sí misma.

Considerar el movimiento TQM como parte de la estrategia kaizen nos da una comprensión más clara del enfoque japonés. La gestión de calidad japonesa no debe considerarse estrictamente como una actividad de control de calidad, sino como una estrategia destinada a servir a la gerencia para lograr mayor competitividad y rentabilidad, logrando de tal forma a mejorar todos los aspectos del negocio.

La gestión de la calidad para el kaizen implica tanto el despliegue de políticas, como la construcción de sistemas de aseguramiento de calidad, estandarización, entrenamiento y educación, administración de costos y círculos de calidad.

\section{2.- El Sistema de Producción Justo a Tiempo (Just in Time - JIT)}

Tuvo su origen en la empresa automotriz Toyota y por tal razón es conocida mundialmente como Sistema de Producción Toyota. Dicho sistema se orienta a la eliminación de todo tipo de actividades que no agregan valor, y al logro de un sistema de producción ágil y suficientemente flexible que dé cabida a las fluctuaciones en los pedidos de los clientes.

Así, las funciones del JIT serán eliminar los desechos asociados a cualquier actividad, reducir o eliminar costosas acumulaciones de partes o bienes terminados y asegurar que siempre que se requieran de las existencias se encuentren disponibles inmediatamente.

Este sistema está sustentado por herramientas y conceptos tales como tiempo takt, kanban, celdas en formas de U, autonomación y reducción de estructuras.

Hacer factible el Just in Time implica llevar de forma continua actividades de mejora que ayuden a eliminar los mudas (desperdicios) en el lugar de trabajo (gemba). 
Los conceptos fundamentales en los que se basa el sistema JIT y a través de los cuales se desarrolla toda la filosofía de producción son los siguientes:

1. La flexibilidad en el trabajo (shojinka) que permite adecuar el número y funciones de los trabajadores a las variaciones de la demanda.

2. El fomento de las ideas innovadoras (soifuku) por parte del personal para conseguir mejoras constantes en el proceso de producción.

3. Y, el autocontrol de los defectos (jidoka) por parte de los propios procesos productivos para impedir la entrada de unidades defectuosas en los flujos de producción.

El JIT tiene cuatro objetivos esenciales:

1. Atacar los problemas fundamentales.

2. Eliminar despilfarros.

3. Buscar la simplicidad.

4. Diseñar sistemas para identificar problemas.

\section{3.- Mantenimiento Productivo Total (MPT)}

El mantenimiento productivo total está dirigido a la maximización de la efectividad del equipo durante toda la vida del mismo. El MPT involucra a todos los empleados de un departamento y de todos los niveles; motiva a las personas para el mantenimiento de la planta a través de grupos pequeños y actividades voluntarias, y comprende elementos básicos como el desarrollo de un sistema de mantenimiento, educación en el mantenimiento básico, habilidades para la solución de problemas y actividades para evitar las interrupciones.

La meta del TPM es la maximización de la eficiencia global del equipo en los sistemas de producción, eliminando las averías, los defectos y los accidentes con la participación de todos los miembros de la empresa. El personal y la maquinaria deben funcionar de manera estable bajo condiciones de cero averías y cero defectos, dando lugar a un proceso en flujo continuo regularizado. Por lo tanto, puede decirse que el TPM promueve la producción libre de defectos, la producción "justo a tiempo" y la automatización controlada de las operaciones.

El resultado final de la incorporación del TPM deberá ser un conjunto de equipos e instalaciones productivas más eficaces, una reducción de las inversiones necesarias en ellos y un aumento de la flexibilidad del sistema productivo. 
La alta administración debe crear un sistema que reconozca y recompense la habilidad y responsabilidad de todos par el MPT. Una vez que los trabajadores adquieren el hábito del mantenimiento y limpieza de su lugar de trabajo, han adquirido disciplina.

\section{4.- Despliegue de políticas}

El despliegue de la política se refiere al proceso de introducir las políticas para Kaizen en toda la compañía, desde el nivel más alto hasta el más bajo. La dirección debe establecer objetivos claros y precisos que sirvan de guía a cada persona y asegurar de tal forma el liderazgo para todas las actividades kaizen dirigidas hacia el logro de los objetivos. La alta gerencia debe idear una estrategia a largo plazo, detallada en estrategias de mediano plazo y estrategias anuales. La alta gerencia debe contar con un plan para desplegar la estrategia, pasarla hacia abajo por los niveles subsecuentes de gerencia hasta que llega a la zona de producción. Como la estrategia cae en cascada hacia las categorías inferiores, el plan debe incluir planes de acción y actividades cada vez más específicas.

Las metas anuales de utilidades y de Kaizen son establecidas sobre la base de metas de la compañía a largo y mediano plazo. Varios meses antes de que los altos gerentes se reúnan para formular estas metas anuales, existe una consulta vertical preliminar entre la alta administración y los gerentes divisionales y entre los gerentes divisionales y de departamento.

Un importante aspecto del despliegue de la política es su prioridad. El establecimiento de la prioridad es una parte inherente del diagrama de Pareto, con frecuencia utilizado en las actividades del círculo del control de calidad y este mismo concepto se aplica también en el despliegue de las metas. Debido a que son limitados los recursos que pueden movilizarse, es esencial que se asignen prioridades. Una vez que se ha hecho esto, puede desplegarse una lista cada vez más clara y específica de las medidas y planes de acción en los niveles inferiores de la administración.

A medida que las metas se abren paso hacia abajo, las declaraciones de la política de la alta administración son reenunciadas como metas cada vez más específicas y orientadas a la acción, convirtiéndose al final en valores cuantitativos precisos. Así, el despliegue de la política es un medio para que el cometido de la alta administración sea realizado por los niveles inferiores.

\section{5.- Sistema de sugerencias}

El sistema de sugerencias funciona como una parte integral del kaizen orientado a individuos, y hace énfasis en los beneficios de elevar el estado de ánimo mediante la participación positiva de los empleados. Los gerentes y supervisores deben inspirar y motivar a su personal a suministrar sugerencias, sin importar lo pequeña que sean. La meta primaria de este sistema es desarrollar empleados con mentalidad kaizen y autodisciplinados. 
Para que tengan éxito, los programas de sugerencias necesitan venderse internamente. Eventos especiales, publicidad, boletines internos y periódicos, juntamente con folletos promocionales precisos y vigorosos, son los ingredientes para mantener el sistema vivo y en buen funcionamiento. No hay que esperar que los sistemas sigan trabajando sin mantenimiento, revisión y nueva inspiración. Cumplidos estos ingredientes, los programas de sugerencias son un sistema muy valioso para cosechar ideas innovadoras.

El sistema de sugerencias es una parte integral del Kaizen orientado al individuo. La alta administración debe implantar un plan bien diseñado para asegurar que el sistema de sugerencias sea dinámico.

Los principales temas de sugerencias de las compañías japonesas son en orden de importancia:

- Mejoramientos en el trabajo propio.

- Ahorros en energía, material y otros recursos.

- Mejoramientos en el entorno de trabajo.

- Mejoramientos en las máquinas y procesos.

- Mejoramientos en artefactos y herramientas.

- Mejoramientos en el trabajo de oficina.

- Mejoramientos en la calidad del producto.

- Ideas para los nuevos productos.

- Servicios para y relaciones con el cliente.

- Otros.

Además de hacer a los empleados conscientes del Kaizen, los sistemas de sugerencias proporcionan a los trabajadores la oportunidad de hablar con sus supervisores y entre ellos mismos. Al mismo tiempo, proporcionan la oportunidad de que la administración ayude a los trabajadores a tratar con los problemas. De este modo, las sugerencias son una oportunidad valiosa para la comunicación bidireccional tanto en el taller como para el autodesarrollo del trabajador.

\section{6.- Actividades de grupos pequeños}

Entre las estrategias del kaizen se encuentran las actividades de grupos pequeños, siendo el más común el Círculo de Calidad. Los mismos no sólo persiguen temas atinentes a la calidad, sino también cuestiones relativas a costos, seguridad y productividad.

Cabe pues preguntarse: ¿qué es un círculo de calidad? 
1. Un círculo de calidad es un pequeño grupo de trabajadores que realizan tareas semejantes y se reúnen para identificar, analizar y solucionar problemas del propio trabajo, ya sea en cuanto a calidad o a productividad.

2. Los círculos de calidad son grupos de trabajadores con un líder o jefe de equipo que cuenta con el apoyo de la organización de la empresa, cuya misión es transmitir a la dirección propuestas de mejora de los métodos y sistemas de trabajo.

3. Los círculos de calidad se reúnen para estudiar un problema de trabajo o una posible mejora del producto, pero no basta con identificar los fallos o los aspectos a mejorar. La misión del círculo es analizar, buscar y encontrar soluciones, y proponer la más adecuada a la Dirección.

4. Los círculos de calidad suponen que los trabajadores no sólo aportan su esfuerzo muscular, sino también su cerebro, su talento y su inteligencia.

Entre los propósitos de los círculos de calidad y productividad se tienen:

a. Contribuir a desarrollar y perfeccionar la empresa.

b. Lograr que el lugar de trabajo sea cómodo y rico en contenido.

c. Aprovechar y potenciar al máximo todas las capacidades del individuo.

Mientras el concepto occidental del control de calidad hace hincapié en que el éxito del control de la calidad depende en gran medida de los gerentes e ingenieros, los japoneses agregaron la noción de que los trabajadores de la base también podrían desempeñar un papel importante para mejorar la calidad del producto y la productividad. Los japoneses ampliaron el concepto para crear lo que se denomina control total de calidad o círculos de control de calidad en los que participan los trabajadores de las líneas de producción y los empleados que trabajan fuera de la fábrica tales como los diseñadores de productos, el personal de mercadeo y ventas, y el personal de investigación y desarrollo. La idea subyacente en todo esto es que no es posible lograr el control de calidad en toda la empresa sin la participación de los obreros de fábrica.

\subsection{4.- EL KAIZEN EN EL GEMBA}

El gemba significa en japonés "lugar real", o sea donde tiene lugar la acción. El Kaizen en el gemba es por lo tanto, llevar a cabo la mejora continua en el lugar de la acción.

Todas las empresas practican tres actividades principales directamente relacionadas con la obtención de utilidades: desarrollo, producción y venta. Sin estas actividades, una 
empresa no puede existir. Por tanto, en un sentido amplio, gemba significa los lugares de estas tres actividades. En un contexto más restringido, gemba significa el lugar donde se forman los productos o servicios. En una empresa de servicios, gemba es donde los clientes entran en contacto con los servicios ofrecidos.

Dos actividades fundamentales tienen diariamente lugar en el gemba: el mantenimiento y el kaizen. El primero se relaciona con seguir los estándares existentes y mantener el statu quo, y el último se relaciona con el mejoramiento de tales estándares. Los supervisores del gemba participan activamente de ambas acciones, logrando como resultados calidad, costos, y entrega (QCD). De tal forma, una empresa que produce productos o servicios de calidad a un precio razonable y los entrega a tiempo satisface al cliente, y ellos a su vez permanecen leales.

Con el fin de llevar a cabo el QCD, la empresa debe gerenciar diariamente diversos recursos en forma apropiada. Estos recursos incluyen mano de obra, información, equipos y materiales. La eficiente administración diaria de recursos requiere estándares. Cada vez que surgen problemas o anomalías, el gerente o supervisor debe investigar, identificar la causa fundamental y reconsiderar los estándares existentes o implementar nuevos estándares para impedir su reaparición. Los estándares se convierten en parte integral del gemba kaizen y suministran la base para el mejoramiento diario. Así, al aplicarse en forma apropiada, el kaizen contribuye a mejorar la calidad, reducir los costos en forma considerable y satisfacer los requerimientos de entrega de los clientes, sin inversión o introducción de costosas tecnologías.

Tres actividades kaizen como lo son la estandarización las $5 \mathrm{~S}$ y la eliminación del muda (desperdicio) contribuyen al logro exitoso de el QCD. La estandarización, la eliminación del muda y las $5 \mathrm{~S}$ son fáciles de comprender e implementar, no requiriendo tecnologías o conocimientos complejos. Cualquier gerente, supervisor o empleado puede comprender y aplicar satisfactoriamente estas actividades de sentido común y bajo costo. La cuestión fundamental es formar la autodisciplina necesaria para mantenerlas.

\section{Estandarización}

Los estándares poseen los siguientes aspectos clave:

1. Representan la mejor, más fácil y más segura forma de realizar un trabajo.

2. Ofrecen la mejor manera de preservar el know-how y la experiencia.

3. Suministran una manera de medir el desempeño.

4. Muestran la relación entre causa y efecto.

5. Suministran una base para el mantenimiento y el mejoramiento.

6. Suministran objetivos e indican metas de entrenamiento. 
7. Suministran una base para el entrenamiento.

8. Crean una base para la auditoría o el diagnóstico.

9. Suministran un medio para evitar la recurrencia de errores y minimizar la variabilidad.

\section{Eliminar el muda (desperdicios y despilfarros)}

Los recursos (personas, máquinas, materiales) en cada proceso agregan valor o no lo hacen. Muda hace referencia a cualquier actividad que no agregue valor. Existen siete categorías clásicas de mudas:

1. Muda de sobreproducción. Es el producto de una mentalidad preocupada por las fallas en máquinas, productos defectuosos y ausentismos, entre otros, viéndose de tal forma obligado a producir más de lo necesario simplemente para tener un nivel mínimo de seguridad. Superar las razones que motivan esas inseguridades dará lugar tanto a una menor sobreproducción como a menores niveles de inventario, reduciendo de tal forma en gran medida los niveles de despilfarros.

2. Muda de inventario. Los productos terminados, semiterminados, repuestos y suministros que se mantienen en inventario no agregan valor alguno. Por el contrario, aumentan el costo de operaciones porque ocupan espacio y requieren equipos e instalaciones adicionales, tales como bodegas, elevadores de cargas y sistemas computarizados de bandas transportadoras entre otras. Además, una bodega requiere de recursos humanos adicionales para labores de operación y administración. Mientras el exceso de ítems permanece en inventario no se agrega ningún valor, y su calidad se deteriora con el transcurso del tiempo. El inventario es en gran medida el resultado de una sobreproducción. Si no existiera muda de inventario, podría evitarse una gran cantidad de despilfarro.

3. Muda de reparaciones / rechazo de productos defectuosos. El rechazo de los productos defectuosos interrumpe la producción y requiere una costosa repetición del trabajo. Muchos de los productos defectuosos frecuentemente deben descartarse, lo que implica importantes pérdidas de recursos.

4. Muda de movimiento. Cualquier movimiento del cuerpo de una persona que no se relacione directamente con la adición de valor, es improductivo. Para identificar este tipo de muda es necesario observar muy cuidadosamente la forma en la que los operadores usan sus manos y piernas. Luego se necesita redistribuir la colocación de las partes y desarrollar herramientas y soportes apropiados.

5. Muda de procesamiento. La tecnología o el diseño suelen ser muchas veces incompatibles con un nivel aceptable de eficiencia. Así un acceso indebidamente 
distante o un exceso en el procesamiento de la máquina, un accionar improductivo de la prensa y el quitar las virutas que quedan cuando se taladra una lámina constituyen todos ejemplos claros de muda de procesamiento que se pueden evitar. En muchos casos también el muda es producto de la falta de sincronización de los procesos.

6. Muda de espera. Este muda se presenta cuando las manos del operador están inactivas; cuando el trabajo de un operador se detiene debido a desbalances en la línea, falta de partes de recambio o tiempo de no trabajo y operación de las máquinas; o cuando simplemente el operador el operador supervisa una máquina mientras ésta realiza un trabajo que agrega valor. También tenemos una gran cantidad de muda en la forma de los segundos o minutos que el operador emplea esperando que llegue la siguiente pieza de trabajo. Durante este intervalo, el operador está simplemente observando la máquina.

7. Muda de transporte. El transporte es parte esencial de las operaciones, pero el movimiento de materiales o productos no agrega valor. Lo que es aun peor, con frecuencia ocurren daños durante el transporte.

Crear grupos de trabajo en todos los niveles de la organización, explicarles los distintos tipos de mudas, llevar un registros de los mismos y aplicar las diversas herramientas de gestión para su detección, análisis, medición y solución es un arma fundamental que produce efectos inmediatos en la rentabilidad de las empresas.

\section{Las $5 \mathrm{~S}$}

Su práctica constituye algo indispensable a la hora de lograr una empresa de calidad global. Las $5 \mathrm{~S}$ se desarrollan mediante un trabajo intensivo. Este apartado se ampliará en el siguiente apartado.

\section{2.-LAS 5S}

\subsection{1.- INTRODUCCIÓN}

El método de las $5 S$, así denominado por la primera letra del nombre que en japonés designa cada una de sus cinco etapas, es una técnica de gestión japonesa basada en cinco principios simples. Se inició en Toyota en los años 1960 con el objetivo de lograr lugares de trabajo mejor organizados, más ordenados y más limpios de forma permanente para conseguir una mayor productividad y un mejor entorno laboral.

El objetivo de la metodología de la $5 \mathrm{~S}$ es mejorar y mantener las condiciones de organización, orden y limpieza en el lugar de trabajo. No es una mera cuestión de estética. Se trata de mejorar las condiciones de trabajo, de seguridad, el clima laboral, la motivación 
personal y la eficiencia y, en consecuencia, la calidad, la productividad y la competitividad de la organización.

La metodología $5 \mathrm{~S}$ está dirigida a cualquier tipo de organización, ya sea industrial o de servicios, que desee iniciar el camino de la mejora continua. Las $5 \mathrm{~S}$ son universales, se pueden aplicar en todo tipo de empresas y organizaciones, tanto en talleres como en oficinas, incluso en aquellos que aparentemente se encuentran ordenados y limpios. Siempre se pueden evitar ineficiencias, evitar desplazamientos y eliminar despilfarros de tiempo y espacio.

Esta disciplina básica de organización, orden y limpieza debe practicarse por todos en la empresa, para disponer de un entorno donde el trabajo sea más eficiente y eficaz.

Una ejecución sistemática de la organización, orden y limpieza, permite:

- Disminuir el riesgo de cometer errores y estar en condiciones para obtener productos de alta calidad.

- Hacer más rápidamente el trabajo, reduciendo las operaciones sin valor.

En definitiva, hace el trabajo más fácil.

Conociendo la importancia de esta disciplina básica en el puesto de trabajo, las empresas que desean avanzar en una Gestión de la Calidad Total, deberían volver su atención y renovar sus esfuerzos para su aplicación. La organización, el orden y la limpieza deben ser uno de los primeros pasos que inicie una empresa, en su proceso de mejora. Así, no será solamente un requisito y un primer paso hacia la calidad, sino que es también una premisa para aumentar la productividad y para conseguir un entorno seguro y agradable. Estas actividades se encuentran íntimamente ligadas con los pilares de la gestión, tales como la motivación de los trabajadores y las relaciones de estos con los directivos, la calidad de los productos y servicios suministrados, la eficacia en los procesos y operaciones, la utilización de recursos, etc...

La organización del lugar de trabajo debe hacerse sobre unas bases económicas. Así conservar materiales innecesarios ocupa espacio y genera costes inútiles, no disponer de un lugar adecuado para cada cosa ni mantener cada cosa en su lugar dificulta la localización, utilización y reposición.

Corresponde a la dirección sentar las bases necesarias para su práctica efectiva, incluyendo esta disciplina entre sus prioridades y promoviendo actitudes respecto a la organización, el orden y la limpieza.

\subsection{2- 5S}

Como ya se ha dicho, las $5 \mathrm{~S}$ son las iniciales de cinco vocablos japonese correspondientes a la denominación de cada una de las 5 fases que componen este programa. 
Las tres primeras son las fases propiamente operativas. La cuarta ayuda a mantener el estado de las tres anteriores mediante la estandarización de las prácticas, y la última a desarrollar el hábito de su práctica y mejora continua en la actividad diaria.. Todas componen un enfoque integrado y se abordan de forma sucesiva, una tras otra.

\subsubsection{1.- Seiri - Clasificar}

Seiri o clasificar significa eliminar del área de trabajo todos los elementos innecesarios y que no se requieren para realizar nuestra labor.

Frecuentemente nos "llenamos" de elementos, herramientas, cajas con productos, carros, útiles y elementos personales y nos cuesta trabajo pensar en la posibilidad de realizar el trabajo sin estos elementos. Buscamos tener al rededor elementos o componentes pensando que nos harán falta para nuestro próximo trabajo. Con este pensamiento creamos verdaderos stocks reducidos en proceso que molestan, quitan espacio y estorban. Estos elementos perjudican el control visual del trabajo, impiden la circulación por las áreas de trabajo, inducen a cometer errores en el manejo de materias primas y en numerosas oportunidades pueden generar accidentes en el trabajo.

La primera "s" de esta estrategia aporta métodos y recomendaciones para evitar la presencia de elementos innecesarios.

El Seiri consiste en:

- Separar en el sitio de trabajo las cosas que realmente sirven de las que no sirven.

- Clasificar lo necesario de lo innecesario para el trabajo rutinario.

- Mantener lo que necesitamos y eliminar lo excesivo

- Separar los elementos empleados de acuerdo a su naturaleza, uso, seguridad y frecuencia de utilización con el objeto de facilitar la agilidad en el trabajo.

- Organizar las herramientas en sitios donde los cambios se puedan realizar en el menor tiempo posible.

- Eliminar elementos que afectan el funcionamiento de los equipos y que pueden conducir a averías.

- Eliminar información innecesaria y que nos puede conducir a errores de interpretación o de actuación.

\subsubsection{2.- Seiton - Orden}

Seiton consiste en organizar los elementos que hemos clasificado como necesarios de modo que se puedan encontrar con facilidad. 
Una vez hemos eliminado los elementos innecesarios, se define el lugar donde se deben ubicar aquellos que necesitamos con frecuencia, identificándolos para eliminar el tiempo de búsqueda y facilitar su retorno al sitio una vez utilizados .

Seiton permite:

- Disponer de un sitio adecuado para cada elemento utilizado en el trabajo de rutina para facilitar su acceso y retorno al lugar.

- Disponer de sitios identificados para ubicar elementos que se emplean con poca frecuencia.

- Disponer de lugares para ubicar el material o elementos que no se usarán en el futuro.

- En el caso de maquinaria, facilitar la identificación visual de los elementos de los equipos, sistemas de seguridad, alarmas, controles, sentidos de giro, etc.

- Lograr que el equipo tenga protecciones visuales para facilitar su inspección autónoma y control de limpieza.

- Identificar y marcar todos los sistemas auxiliares del proceso

- Incrementar el conocimiento de los equipos por parte de los operadores de producción.

\subsubsection{3.- Seiso - Limpieza}

Seiso significa eliminar el polvo y suciedad de todos los elementos de una fábrica.

La limpieza se relaciona estrechamente con el buen funcionamiento de los equipos y la habilidad para producir artículos de calidad. La limpieza implica no únicamente mantener los equipos dentro de una estética agradable permanentemente. Seiso implica un pensamiento superior a limpiar.

Exige que realicemos un trabajo creativo de identificación de las fuentes de suciedad y contaminación para tomar acciones de raíz para su eliminación, de lo contrario, sería imposible mantener limpio y en buen estado el área de trabajo. Se trata de evitar que la suciedad, el polvo, y las limaduras se acumulen en el lugar de trabajo.

Para aplicar Seiso se debe:

- Integrar la limpieza como parte del trabajo diario.

- Asumirse la limpieza como una actividad de mantenimiento autónomo: "la limpieza es inspección"

- Se debe abolir la distinción entre operario de proceso, operario de limpieza y técnico de mantenimiento. 
- El trabajo de limpieza genera conocimiento sobre el equipo. No se trata de una actividad simple que se pueda delegar en personas de menor cualificación.

- No se trata únicamente de eliminar la suciedad. Se debe elevar la acción de limpieza a la búsqueda de las fuentes de contaminación con el objeto de eliminar sus causas primarias

\subsubsection{4.- Seiketsu - Estandarización}

Seiketsu es la metodología que nos permite mantener los logros alcanzados con la aplicación de las tres primeras "s". Si no existe un proceso para conservar los logros, es posible que el lugar de trabajo nuevamente llegue a tener elementos innecesarios y se pierda la limpieza alcanzada con nuestras acciones.

Seiketsu implica elaborar estándares de limpieza y de inspección para realizar acciones de autocontrol permanente, la filosofía debe ser "nosotros debemos preparar estándares para nosotros". Cuando los estándares son impuestos, estos no se cumplen satisfactoriamente, en comparación con aquellos que desarrollamos gracias a un proceso de formación previo.

Desde décadas conocemos el principio escrito en numerosas compañías y que se debe cumplir cuando se finaliza un turno de trabajo: "Dejaremos el sitio de trabajo limpio como lo encontramos".

Este tipo frases sin un correcto entrenamiento en estandarización y sin el espacio para que podamos realizar estos estándares, difícilmente nos podremos comprometer en su cumplimiento.

Seiketsu pretende:

- Mantener el estado de limpieza alcanzado con las tres primeras "s"

- Enseñar al operario a realizar normas con el apoyo de la dirección y un adecuado entrenamiento.

- Las normas deben contener los elementos necesarios para realizar el trabajo de limpieza, tiempo empleado, medidas de seguridad a tener en cuenta y procedimiento a seguir en caso de identificar algo anormal.

- En lo posible se deben emplear fotografías de como se debe mantener el equipo y las zonas de cuidado.

- El empleo de los estándares se debe auditar para verificar su cumplimiento. 


\subsection{2..5.- Shitsuke - Disciplina y hábito}

Shitsuke significa convertir en hábito el empleo y utilización de los métodos establecidos y estandarizados para la limpieza en el lugar de trabajo. Podremos obtener los beneficios alcanzados con las primeras "s" por largo tiempo si se logra crear un ambiente de respeto a las normas y estándares establecidos.

Las cuatro "s" anteriores se pueden implantar sin dificultad si en los lugares de trabajo se mantiene la disciplina. Su aplicación nos garantiza que la seguridad será permanente, la productividad se mejore progresivamente y la calidad de los productos sea excelente.

Shitsuke implica un desarrollo de la cultura del autocontrol dentro de la empresa. Si la dirección de la empresa estimula que cada uno de los integrantes aplique el Ciclo Deming en cada una de las actividades diarias, es muy seguro que la práctica del Shitsuke no tendría ninguna dificultad. Es el Shitsuke el puente entre las 5 "s" y el concepto Kaizen. Los hábitos desarrollados con la práctica del ciclo PHVA se constituyen en un buen modelo para lograr que la disciplina sea un valor fundamental en la forma de realizar un trabajo.

Shitsuke implica:

- El respeto de las normas y estándares establecidas para conservar el sitio de trabajo impecable.

- Realizar un control personal y el respeto por las normas que regulan el funcionamiento de una organización.

- Promover el hábito de autocontrolar o reflexionar sobre el nivel de cumplimiento de las normas establecidas.

- Comprender la importancia del respeto por los demás y por las normas en las que el trabajador seguramente ha participado directa o indirectamente en su elaboración.

- Mejorar el respeto de su propio ser y de los demás.

\subsection{3.- BENEFICIOS}

Entre las diversas mejoras resultantes de la implantación de un sistema de calidad 5S, podemos resaltar:

- La implantación de las 5S se basa en el trabajo en equipo. Permite involucrar a los trabajadores en el proceso de mejora desde su conocimiento del puesto de trabajo. Los trabajadores se comprometen. Se valoran sus aportaciones y conocimiento. La mejora continua se hace una tarea de todos.

- Manteniendo y mejorando asiduamente el nivel de 5S conseguimos una mayor productividad que se traduce en menos productos defectuosos, menos averías, menos nivel de existencias o inventarios, menos accidentes, menos 
movimientos y traslados inútiles y menor tiempo para el cambio de herramientas.

- Mediante la organización, el orden y la limpieza logramos un mejor lugar de trabajo para todos, puesto que conseguimos más espacio, orgullo del lugar en el que se trabaja, mejor imagen ante nuestros clientes, mayor cooperación $\mathrm{y}$ trabajo en equipo, mayor compromiso y responsabilidad en las tareas y mayor conocimiento del puesto.

\subsection{4.- COMO APLICAR LA METODOLOGÍA DE IMPLANTACIÓN AUTÓNOMA 5S}

La metodología tiene dos fases de implantación, por las que hay que pasar sucesivamente, y varias etapas que hay que cubrir para cada una de las $5 \mathrm{~S}$.

Primeramente se realiza la implantación en un área piloto. De esta forma se aprende la metodología, se concentran esfuerzos y se asegura el éxito, y se cuenta con un claro ejemplo de mejora que estimula a la organización. Para llevar a cabo esta fase hay que elegir un equipo y un facilitador. El facilitador es la persona encargada de impartir la formación y proporcionar al equipo los medios necesarios. El éxito de la tarea requiere un fuerte compromiso de la dirección y una dedicación de recursos durante las tres primeras $\mathrm{S}$.

Posteriormente la implantación se extiende de forma progresiva al resto de áreas de la organización.

\subsubsection{1.- Dedicación}

No deben subestimarse los medios personales requeridos para desarrollar un proyecto de 5S. En gran medida, el tiempo a dedicar por los participantes en el proyecto dependerá de la situación de partida de la organización o empresa y del nivel de profundidad que se persiga en su ejecución. También influirá la intensidad con que se planifique el proyecto, es decir la duración prevista para su ejecución.

\subsubsection{2.- Participantes en la implantación de las $5 \mathrm{~s}$}

\section{-LA DIRECCIÓN}

Es la máxima responsable del programa $5 \mathrm{~S}$. Se necesita un firme convencimiento por su parte sobre la importancia de la Organización, el Orden y la Limpieza como disciplina básica en la actividad diaria de la empresa u organización para que un programa $5 \mathrm{~S}$ tenga éxito. El máximo responsable de la organización y su equipo directivo han de desempeñar un papel activo en el proceso, especialmente en las primeras experiencias de implantación. 
Sus funciones consisten en liderar el programa 5S, mantener un compromiso activo, promover la participación de todos los implicados y dar seguimiento al programa.

Una vez seleccionada el área de intervención, la Dirección debe asignar a los miembros del equipo de proyecto que se encargará de llevar a cabo la implantación. Este equipo estará formado por el facilitador y cinco o seis personas que estén estrechamente relacionadas con el área seleccionada.

\section{-EL FACILITADOR}

Es 1 apersona que va a coordinar el proyecto, guiando al equipo en la implantación de la metodología. Dado el contenido de su intervención, tendrá una dedicación personal intensa durante el desarrollo del proyecto. Como líder del equipo que desarrolla el proceso de implantación, sus funciones son:

- Formar a los miembros del equipo de proyecto en la metodología 5S.

- Ayudar a la Dirección en la planificación del proceso global de implantación de las 5S.

- Asegurar la disponibilidad de los medios logísticos necesarios, la eficacia de las reuniones y cualquier otra actividad de grupo.

- Coordinar la ejecución de las tareas y revisar el ritmo de ejecución.

- Aportar orientación y guía al equipo, actuando como un consultor interno.

- Velar por el seguimiento riguroso de la metodología.

- Informar a la Dirección sobre la evolución del proyecto

- Asegurar la permanente actualización de los indicadores en el panel 5S.

- Velar por el rendimiento y mejora de la situación alcanzada tras el proceso de implantación.

- Transferir la experiencia a otras áreas, guiando el proceso de extensión de la metodología y canalizando el conocimiento sobre $5 \mathrm{~S}$ en la empresa.

- Ser un experto conocedor de la metodología 5S, formarse continuamente y aprovechar todas las oportunidades de aprendizaje que se presenten

- $\quad$ Ser un buen coordinador de equipos.

\section{RESTO DE MIENBROS DEL EQUIPO}

Deben ser 5 o 6 personas que trabajen en el área donde se van a implantar las 5S. Por ejemplo el equipo lo pueden formar, el jefe de área, un encargado o mando intermedio, uno o dos empleados y un miembro de mantenimiento. Su funciones son:

- Conocer los conceptos y metodología 5S.

- Programar la ejecución de cada fase del proyecto.

- -Ayudar al facilitador en la formación del resto del personal del área de trabajo.

- Reunir información y analizar en equipo la situación actual. 
- Proponer ideas de mejora y decidir en grupo las soluciones a implantar.

- Establecer los planes de acción y ejecutar las accione acordadas en cada fase del proceso de implantación.

- Efectuar el seguimiento y analizar los indicadores del panel 5S.

- Proponer acciones correctoras ante las desviaciones o evoluciones negativas del nivel de Organización, Orden y Limpieza.

\section{OTROS PARTICIPANTES}

Además de estos participantes directos, otras personas pueden desempeñar un papel dinamizador u obstaculizador, según el caso, en el proyecto. Ser un obstáculo o una ayuda dependerá del comportamiento personal, la colaboración en la ejecución de las acciones y la rapidez y la calidad en la prestación de sus servicios. Por eso, la Dirección de be asegurarse que todos los interesados en el desarrollo o resultado del proyecto, estén bien informados desde la fase inicial y durante su avance.

\subsubsection{3.- Etapas a cubrir en cada una de las $5 \mathrm{~S}$.}

Cada una de las $5 \mathrm{~S}$ se desarrolla e implementa a través de una serie de etapas. Esta serie es la misma para cada una de las $5 \mathrm{~S}$.

Se comienza con unas sesiones de formación que resultan absolutamente necesarias para comprender la finalidad de lo que se va a hacer, motivar al equipo, definir nuevos conceptos, etc...

A continuación se visita de forma activa y estructurada el lugar de trabajo para comprobar la necesidad de mejora en la fase que se esté llevando a cabo, hablando de hechos y tocando aquello que estamos sometiendo a $5 \mathrm{~S}$. Se rellenan plantillas, se toman fotografías y se realizan actividades de e ejecución física.

La siguiente etapa es una actividad creativa y resolutiva en la que se toman decisiones y se formulan acciones para corregir las situaciones problemáticas identificadas durante la visita al área de trabajo.

Hacia el final de todo el proceso, se emprenden acciones para reforzar la situación conseguida tras las mejoras implantadas, actuando sobre las causas de los problemas para evitar su repetición y documentando la forma de proceder.

Para la implantación de cada una d las $5 \mathrm{~S}$, se aplica la estructura central de la metodología de las 5S, que consiste en aplicar los siguientes 7 pasos.

Paso 1: Formación.

Paso 2: Preparación del paseo 
Paso 3: Paseo

Paso 4: Análisis de mejoras

Paso 5: Ejecución de acciones de mejora

Paso 6: Acciones de consolidación

Paso 7: Indicadores 


\section{5.- SEIS SIGMA}

\section{1.- HISTORIA}

La historia de Seis Sigma se inicia en Motorola en los años 80 cuando Mikel Harry comienza a influenciar a la organización para que se estudie la variación en los procesos (enfocado en los conceptos de Deming), como una manera de mejorar los mismos. Estas variaciones son lo que estadísticamente se conoce como desviación estándar (alrededor de la media), la cual se representa por la letra griega sigma $(\sigma)$. Esta iniciativa se convirtió en el punto focal del esfuerzo para mejorar la calidad en Motorola, capturando la atención del entonces CEO de Motorola: Bob Galvin. Con el apoyo de Galvin, se hizo énfasis no sólo en el análisis de la variación sino también en la mejora continua, estableciendo como meta obtener 3,4 defectos (por millón de oportunidades) en los procesos; algo casi cercano a la perfección.

Esta iniciativa llegó a oídos de Lawrence Bossidy, quién en 1991 y luego de una exitosa carrera en General Electric, toma las riendas de Allied Signal para transformarla de una empresa con problemas en una máquina exitosa. Durante la implantación de Seis Sigma en los años 90 (con el empuje de Bossidy), Allied Signal multiplicó sus ventas y sus ganancias de manera dramática. Este ejemplo fue seguido por Texas Instruments, logrando el mismo éxito. Durante el verano de 1995 el CEO de GE, Jack Welch, se entera del éxito de esta nueva estrategia de boca del mismo Lawrence Bossidy, dando lugar a la mayor transformación iniciada en esta enorme organización.

El empuje y respaldo de Jack Welch transformaron a GE en una "organización Seis Sigma", con resultados impactantes en todas sus divisiones. Por ejemplo: GE Medical Systems recientemente introdujo al mercado un nuevo scanner para diagnóstico (con un valor de 1,25 millones de dólares) desarrollado enteramente bajo los principios de Seis Sigma y con un tiempo de escaneo de sólo 17 segundos (lo normal eran 180 segundos). En otra de las divisiones: GE Plastics, se mejoró dramáticamente uno de los procesos para incrementar la producción en casi 500 mil toneladas, logrando no sólo un beneficio mayor, sino obteniendo también el contrato para la fabricación de las cubiertas de la nueva computadora iMac de Apple.

\section{2.- ¿QUÉ ES SEIS SIGMA?}

Seis Sigma es una filosofía de trabajo y una estrategia de negocios, la cual se basa en el enfoque al cliente y usa hechos y datos para impulsar mejores resultados. Esta filosofía permite eliminar la variabilidad en los procesos y alcanzar en nivel de defectos menor o igual a 3,4 defectos por millón.

Los esfuerzos de Seis Sigma se dirigen a tres áreas principales:

- Mejorar la satisfacción del cliente 
- $\quad$ Reducir el tiempo del ciclo

- $\quad$ Reducir los defectos

Las mejoras en estas áreas representan importantes ahorros de costes, reducción de los tiempos de ciclo, oportunidades para retener a los clientes, capturar nuevos mercados y construirse una reputación de empresa de excelencia.

Podemos definir Seis Sigma como:

1. Una medida estadística del nivel de desempeño de un proceso o producto.

2. Un objetivo de lograr casi la perfección mediante la mejora del desempeño.

3. Un sistema de dirección para lograr un liderazgo duradero en el negocio y un desempeño de primer nivel en un ámbito global.

La estrategia Seis Sigma incluye el uso de herramientas estadísticas dentro de una metodología estructurada incrementando el conocimiento necesario para lograr de una mejor manera, más rápido y al más bajo costo, productos y servicios que la competencia.

La Estadística es utilizada en gran medida dentro de la metodología, pero hay que aclarar que está es un medio y no un fin. A los clientes no les importa que un producto haya sido producido bajo el esquema Seis Sigma, cuando tiene fallas o defectos, lo que les interesa es tener un producto de excelente calidad, a tiempo, sin defectos y que sea lo más económico posible.

El concepto Seis Sigma ayuda a conocer y comprender los procesos, de tal manera que puedan ser modificados al punto de reducir el desperdicio generado en ellos. Esto se verá reflejado en la reducción de los costos de hacer las cosas, a la vez que permite asegurar que el precio de los productos o servicios sean competitivos, no mediante la reducción de ganancias o reducción de los costos de hacer bien las cosas, sino de la eliminación de los costos asociados con los errores o desperdicios.

La filosofía Seis Sigma busca ofrecer mejores productos o servicios, de una manera cada vez más rápida y a más bajo costo, mediante la reducción de la variación de cualquiera de nuestros procesos. Aunque a muchas personas les ha costado entender, una de las grandes enseñanzas del Dr. Deming fue buscar el control de variación de los procesos lo cual es medido por medio de la desviación estándar.

La eliminación o reducción de la inspección es un punto muy importante dentro de la metodología, al seguir las diferentes técnicas; por ejemplo con el uso de sistemas PokaYoke entre otras la inspección deja de ser necesaria, se busca el origen de las causas de los defectos para eliminarlos al máximo. 
Seis Sigma funciona especialmente gracias a una comprensión total de las necesidades del cliente, del uso disciplinario del análisis de los datos y hechos, y de la atención constante a la gestión, mejora y reinvención de los procesos empresariales.

La metodología fomenta en gran medida el trabajo en equipo, debido a que en la mayoría de las herramientas, el mecanismo para proponer ideas que nos conducen a la solución de problemas, es el resultado de la participación de todas las personas involucradas. La mejora continua de los procesos es el objetivo común de cada uno de los miembros.

En un principio es difícil integrar a las personas para realizar sus proyectos y que dediquen el tiempo necesario para hacerlo, sin embargo cuando la gente adopta Seis Sigma como una Cultura además de realizar sus proyectos aplica la metodología en su trabajo diario, para la solución de problemas y mejora de los procesos.

El nivel de capacitación requerido es muy alto en la implementación, implica costos ocasionados por capacitación, tiempos, materiales, entre otros; sin embargo el retorno de la inversión puede ser muy grande, cuando los proyectos son bien conducidos, ya que los ahorros y/o mejoras que se presentan cuando un proyecto 6 sigma funciona son cuantiosos.

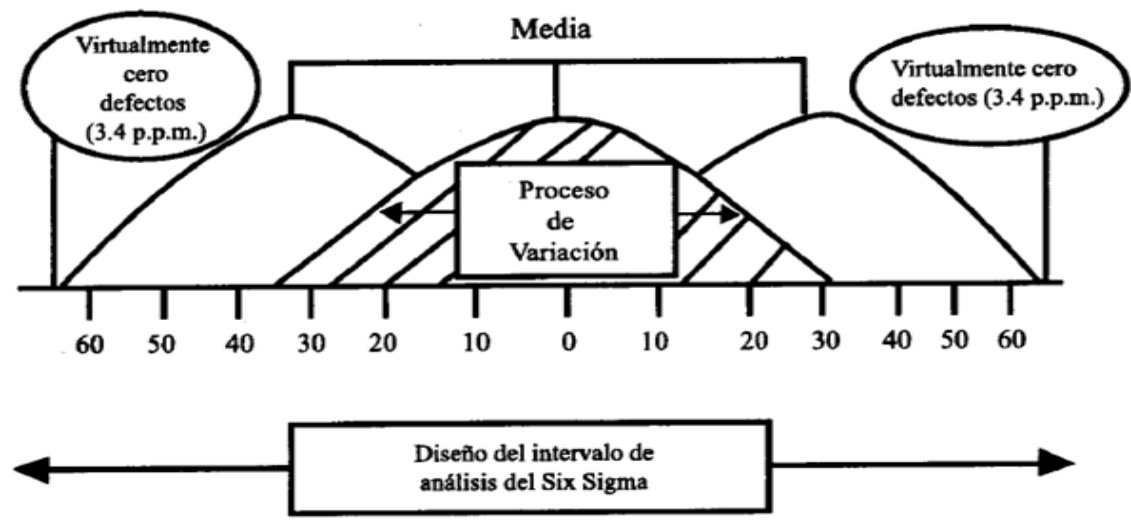

Figura 26 Gráfica Seis Sigma

\section{3.- LA MÉTRICA DE SEIS SIGMA}

Sigma es un parámetro estadístico de dispersión que expresa la variabilidad de un conjunto de valores.

La metodología Seis Sigma se basa en la curva de distribución normal para conocer la variación de cualquier actividad. La mayoría de los procesos productivos siguen una distribución normal, con una distribución de frecuencias siguiendo la campana de gauss, y con una probabilidad de que algunos valores queden fuera de los límites superior e inferior. Esta probabilidad es lo que se entiende como probabilidad de defecto. Una campana achatada y descentrada es consecuencia de grandes probabilidades de defectos. De forma 
gráfica el área de la campana de gauss que queda fuera de la zona marcada por los límites superior e inferior es justamente la probabilidad de defecto.

Sigma representa a la S, utilizada por los estadísticos para medir una variación. Cuando se aplica a un proceso de negocio, un nivel Sigma indica una unidad o valor de eficacia en procesos y procedimientos

En las tablas de distribución normal encontraremos una relación entre el área de la campana de fuera de los límites y la distancia $\mathrm{Z}$ definida como :

$\mathrm{Z}=(\mathrm{x}-\mathrm{X}) / \mathrm{s}$. Siendo Z el "Nivel Sigma”, X la media y s la desviación típica (sigma).

Así, a menor sigma (s), tendremos un mayor Nivel Sigma (Z) y en consecuencia habrá menos defectos. La relación entre la probabilidad de defecto (área de la curva de Gauss que queda fuera de los límites) y Z (distancia desde el valor medio a este límite) para una distribución normal se encuentra en las tablas correspondientes.

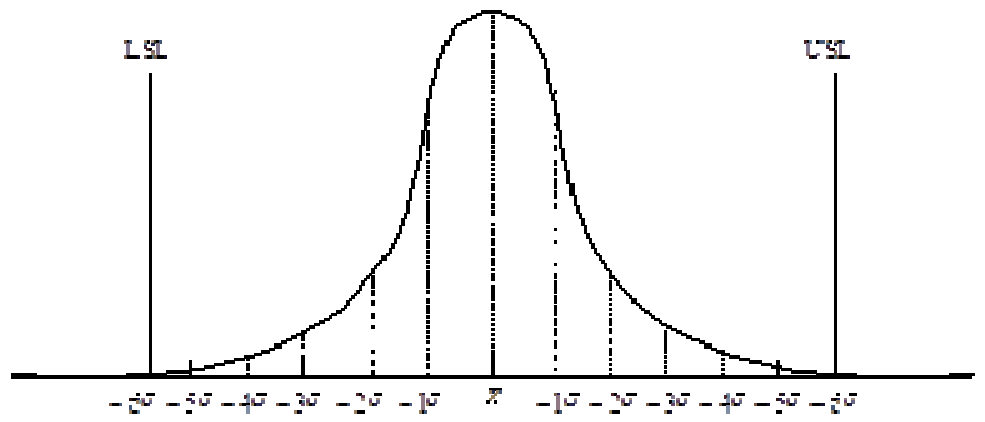

Figura 27 Distribución normal centrada.

Las relaciones de los diferentes niveles de calidad sigma no son lineales, ya que para pasar de un nivel de calidad a otro, el porcentaje de mejora del nivel de calidad que se tiene que realizar no es el mismo, cuando avanzamos a un nivel mayor el porcentaje de mejora será más grande.

La tabla siguiente muestra el porcentaje de mejora requerido para cambiar de un nivel sigma a otro mayor.

\begin{tabular}{|c|c|c|}
\hline Nivel actual & Cambio & $\begin{array}{c}\text { Porcentaje de mejora } \\
\text { requerido }\end{array}$ \\
\hline $3 \sigma$ & $4 \sigma$ & $10 \mathrm{x}$ \\
\hline $4 \sigma$ & $5 \sigma$ & $30 \mathrm{x}$ \\
\hline
\end{tabular}




\begin{tabular}{|l|l|l|}
\hline $5 \sigma$ & $6 \sigma$ & $40 \mathrm{x}$ \\
\hline
\end{tabular}

Tabla 7 Porcentajes para un cambio a una sigma mayor

El nivel sigma, es utilizado comúnmente como medida dentro del Programa Seis Sigma, incluyendo los cambios o movimientos "típicos" de $\pm 1.5 \sigma$ de la media. Para compensar las inevitables consecuencias de los errores de centrado de procesos, la media de la distribución se desplaza $\pm 1.5 \sigma$. Este ajuste proporciona una idea más realista de la capacidad del proceso a través de varios ciclos de manufactura. El desplazamiento puede ser en dirección positiva o negativa, pero nunca en ambas.

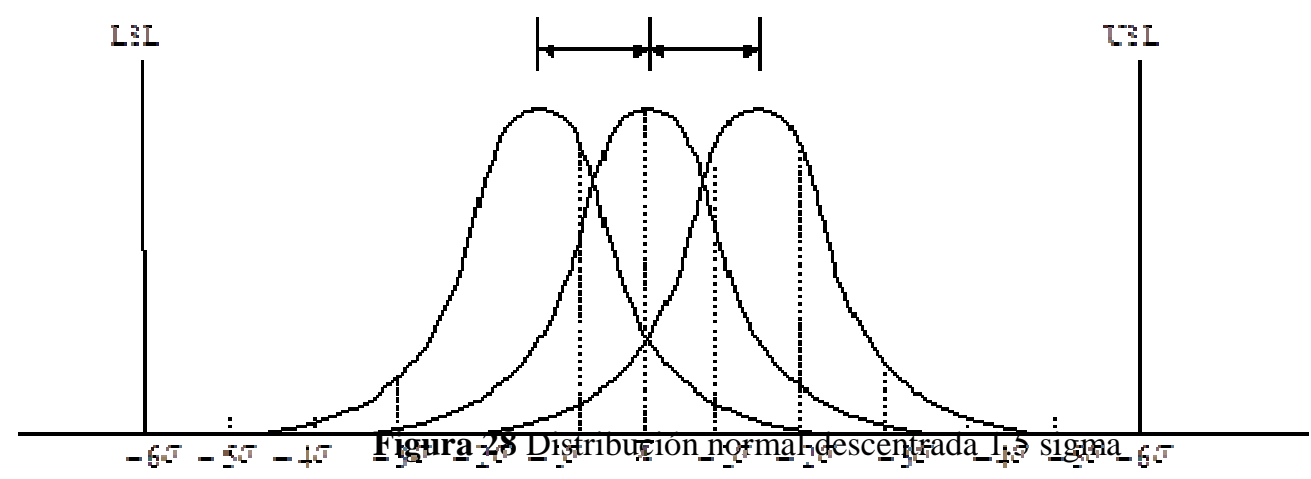

Por lo general, las compañías operan en el nivel 3 o 4 sigma, que equivale a unos 65807 y 6210 defectos por millón respectivamente, mientras quelas empresas con nivel $6 \sigma$ sólo generan 3,4 defectos por millón.

Así una empresa con nivel 6 sigma encuentra una mayor eficacia operativa , con la consecuente reducción de costes, mejora de la calidad, incremento de la satisfacción y aumento de la rentabilidad.

\begin{tabular}{|c|l|}
\hline $\begin{array}{c}\text { Nivel en } \\
\text { sigma }\end{array}$ & Defectos por millón de oportunidades \\
\hline 6 & 3.4 \\
\hline 5 & 233.0 \\
\hline 4 & $6,210.0$ \\
\hline 3 & $66,807.0$ \\
\hline
\end{tabular}




\begin{tabular}{|l|l|}
2 & $308,537.0$ \\
\hline 1 & $690,000.0$ \\
\hline
\end{tabular}

Tabla 8 Cantidad de defectos por cada nivel de sigma

Una medida que describe el grado en el cual el proceso cumple con los requerimientos es la capacidad del proceso. Los índices utilizados son $\mathrm{C}_{\mathrm{p}}$ y $\mathrm{C}_{\mathrm{pk}}$, Un nivel Seis Sigma tiene la habilidad de lograr índices de 2.0 y 1.5 respectivamente. Para lograr esta capacidad la meta a alcanzar de un programa Seis Sigma es producir al menos $99.99966 \%$ de calidad, no más de 3.4 defectos en un millón de piezas producidas en el largo plazo.

\begin{tabular}{|c|c|c|}
\hline $\begin{array}{c}\text { Nivel en } \\
\text { sigma }\end{array}$ & Porcentaj & $\begin{array}{c}\text { Defectos por millón de } \\
\text { oportunidades }\end{array}$ \\
\hline 6 & 99.99966 & 3.4 \\
\hline 5 & 99.9769 & 233.0 \\
\hline 4 & 99.379 & $6,210.0$ \\
\hline 3 & 93.32 & $66,807.0$ \\
\hline 2 & 69.13 & $308,537.0$ \\
\hline 1 & 30.23 & $690, .000 .0$ \\
\hline
\end{tabular}

Tabla 9 Porcentajes y cantidad de defectos a los que corresponden los diferentes niveles "Sigma"

Así, vemos como la medida en sigma se desarrolló para ayudarnos a:

1. Enfocar las medidas en los clientes que pagan por los bienes y servicios. Muchas medidas sólo se concentran en los costes, horas laborales y volúmenes de ventas, siendo éstas medidas que no están relacionadas directamente con las necesidades de los clientes.

2. Proveer un modo consistente de medir y comparar procesos distintos.

3. Es de suma importancia medir la capacidad del proceso en términos cuantificables y monitorear las mejoras a través del tiempo. 


\section{4.- PRINCIPIOS DE SEIS SIGMA}

\section{Principio 1: Enfoque genuino en el cliente}

El enfoque principal es dar prioridad al cliente. Las mejoras Seis Sigma se evalúan por el incremento en los niveles de satisfacción y creación de valor para el cliente.

\section{Principio 2: Dirección basada en datos y hechos}

El proceso Seis Sigma se inicia estableciendo cuales son las medidas claves a medir, pasando luego a la recolección de los datos para su posterior análisis. De tal forma los problemas pueden ser definidos, analizados y resueltos de una forma más efectiva y permanente, atacando las causas raíces o fundamentales que los originan, y no sus síntomas.

\section{Principio 3: Los procesos están donde está la acción}

Seis Sigma se concentra en el procesos, así pues dominando éstos se lograrán importantes ventajas competitivas para la empresa.

\section{Principio 4: Dirección proactiva}

Ello significa adoptar hábitos como definir metas ambiciosas y revisarlas frecuentemente, fijar prioridades claras, enfocarse en la prevención de problemas y cuestionarse por qué se hacen las cosas de la manera en que se hacen.

\section{Principio 5: Colaboración sin barreras}

Debe ponerse especial atención en derribar las barreras que impiden el trabajo en equipo entre los miembros de la organización. Logrando de tal forma mejor comunicación y un mejor flujo en las labores.

\section{Principio 6: Busque la perfección}

Las compañías que aplican Seis Sigma tienen como meta lograr una calidad cada día más perfecta, estando dispuestas a aceptar y manejar reveses ocasionales. 


\section{5.- DMAIC}

La metodología Seis Sigma es un método disciplinado de mejora de los procesos conformado por las fases siguientes: Definición, Medición, Análisis, Mejora y Control (DMAIC), como se explican con más detalle a continuación:

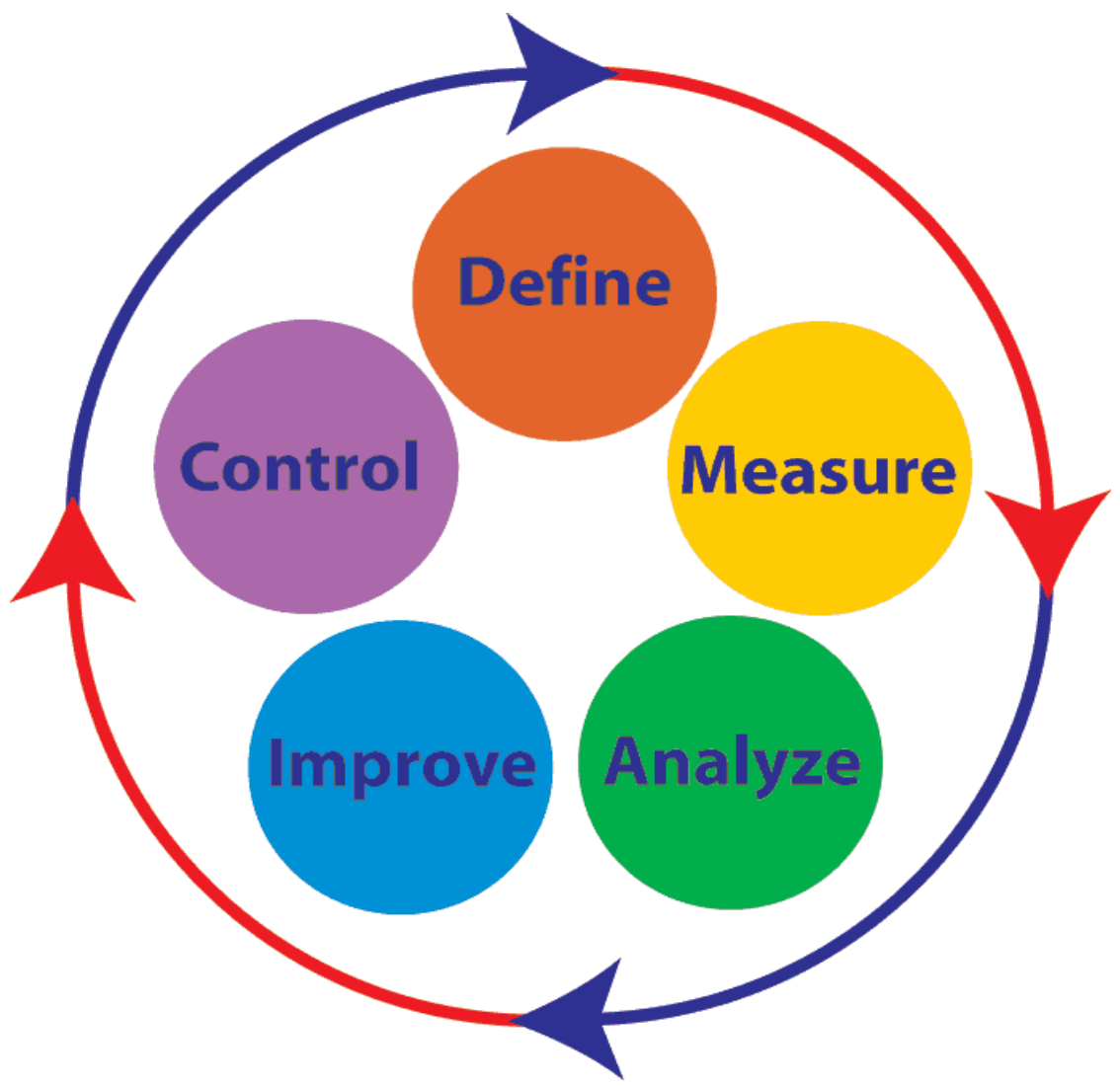

Figura 29 Fases de DMAIC

\subsection{1.-DEFINICIÓN}

La primera etapa de cualquier proyecto Seis Sigma es la perfecta Definición del proceso a mejorar. Si se seleccionan proyectos de forma incorrecta, entonces el programa de mejora continua fracasará porque no conseguirá obtener resultados y la dirección acabará desechando la iniciativa de mejora. Hay que definir claramente cuáles son las mejores oportunidades de mejora.

Para abordar esta etapa se debe tener perfectamente claro los objetivos, que son básicamente:

-Mejora de la calidad.

-Reducción de costes. 
-Satisfacción del cliente.

Esta etapa tiene una misión importante y complicada, pues Seis Sigma trabaja mejorando procesos concretos, por lo que hay que ser capaz de relacionar los procesos concretos de la empresa con la satisfacción del cliente.

Los principales pasos de la etapa de definición son:

-Determinar quiénes son los clientes externos e internos.

-Determinar sus necesidades.

-Traducir estas necesidades a características concretas de nuestros productos.

-Priorizar estas características por orden de importancia.

-Determinar el proceso responsable.

-Acotar la parte del proceso que se analizará.

En esta etapa se utilizarán diferentes herramientas, entre las que destacamos el QFD.

El QFD será una de las herramientas más importantes de esta etapa, que nos servirá para conocer la satisfacción del cliente. El objetivo básico del QFD es la determinación de las CTQ, es decir, las características críticas para la calidad. Todos los esfuerzos de mejora deben orientarse a satisfacer las CTQ del cliente.

\subsection{2.- MEDICIÓN}

El objetivo de esta etapa es medir el desempeño actual del proceso que se busca mejorar. Se utilizan los CTQs para determinar los indicadores y tipos de defectos que se utilizarán durante el proyecto. Posteriormente, se diseña el plan de recolección de datos y se identifican las fuentes de los mismos, se lleva a cabo la recolección de las distintas fuentes. Por último, se comparan los resultados actuales con los requerimientos del cliente para determinar la magnitud de la mejora requerida.

Medir persigue dos objetivos fundamentales:

- Tomar datos para validar y cuantificar el problema u oportunidad.

- Permitir y facilitar la identificación de las causas reales del problema.

Los diferentes pasos en la etapa de medida son:

\section{DEFINIR VARIABLES}

Variables continuas: La escala de medida se puede dividir en intervalos tan pequeños como se desee. 
Variables discretas: No se puede realizar una subdivisión en intervalos de mayor precisión.

Siempre que sea posible debemos utilizar variables continuas pues nos da una información más precisa.

\section{DEFINIR EL SISTEMA DE MEDIDA}

Las variables X's no son conocidas sino a través del sistema de que disponemos para su medida, como se observa en la figura. Este hecho, entraña una dificultad, a veces extraordinaria, a la hora de disponer de información útil para tomar decisiones sobre los procesos.

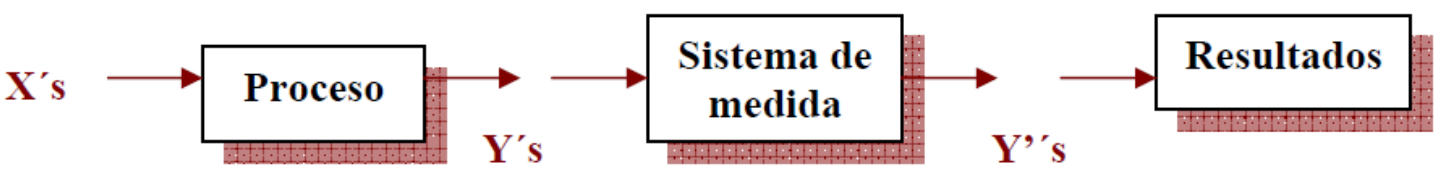

Figura 30 Validar sistemas de medida

La idea fundamental es que hay de disponer de un método que permita cuantificar la variación que introduce el sistema de medida para estar en condiciones de decidir si se puede asumir esa variación.

Lo que nos dirá si el sistema es apropiado es:

\section{$R \& R=\sigma$ sistema_de_medida/oobservada}

Es deseable que ese porcentaje sea inferior al 10\%, y en ningún caso superior al $30 \%$.

\section{ESTABLECER LÏMITES A LOS VALORES DE LAS VARIABLES}

Cuando, tanto las variables a medir como el sistema para efectuar esa medición están correctamente definidos, llega el momento, previo a la propia medida en sí, de ditiguir una medida "BUENA" de una medida "MALA".

\section{CÁLCULO DE LA CAPACIDAD DEL PROCESO}

Es la relación que nos indica, de algún modo, las posibilidades que tiene el proceso para cumplir con las especificaciones.

$$
\mathrm{Cp}=(\mathrm{LSE}-\mathrm{LSI}) / 6 \boldsymbol{\sigma}
$$

\subsection{3.- ANALIZAR}

En esta etapa se lleva a cabo el análisis de la información recolectada para determinar las causas raíz de los defectos y oportunidades de mejora. Posteriormente se tamizan las oportunidades de mejora, de acuerdo a su importancia para el cliente y se identifican y validan sus causas de variación. 
Indudablemente, conocer cómo estamos es el punto de partida esencial para poder mejorar. El orden lógico es que para poder mejorar necesitamos primero saber cuáles son las variables responsables de la variación para, seguidamente, determinar las relaciones causa-efecto entre estas variables y los resultados del proceso.

Lo que se pretende en la Etapa de Análisis es una disección preliminar del proceso que permita orientar la acción experimental que, en definitiva, será la que dará el conocimiento completo de las relaciones causales dentro del proceso.

Es vital que los ensayos experimentales sólo se realicen después de una Etapa de Análisis correctamente llevada a cabo pues, de lo contrario, el alto coste de los experimentos puede no dar el rédito que de ellos se espera.

Una de las herramientas más importantes en esta etapa será el AMFE.

El Análisis Modal de Fallos y Efectos (AMFE) es una metodología de trabajo en grupo muy estricta para evaluar un sistema, un diseño, un proceso y/o un servicio; en cuanto a las formas en las que ocurren los fallos. Para cada fallo, se hace una estimación de su efecto sobre todo el sistema y su seriedad. Además, se hace una revisión de las medidas planificadas con el fin de minimizar la probabilidad de fallo, o minimizar su repercusión.

Puede ser muy técnico (cuantitativo) o no (cualitativo), y utiliza tres factores principales para la identificación de un determinado fallo. Éstos son:

Ocurrencia: frecuencia con la que aparece el fallo.

Severidad: la seriedad del fallo producido.

Detectabilidad: si es fácil o difícil detectar el fallo.

\subsection{4.- MEJORA}

Se diseñan soluciones que ataquen el problema raíz y lleve los resultados hacia las expectativas del cliente. También se desarrolla el plan de implementación.

Los objetivos de la Etapa de Mejora son dos; en primer término determinar cuáles de todos los factores que condicionan la variabilidad del proceso son los realmente importantes y, en segundo lugar, desarrollar una relación matemática entre las entradas y salidas del proceso. 


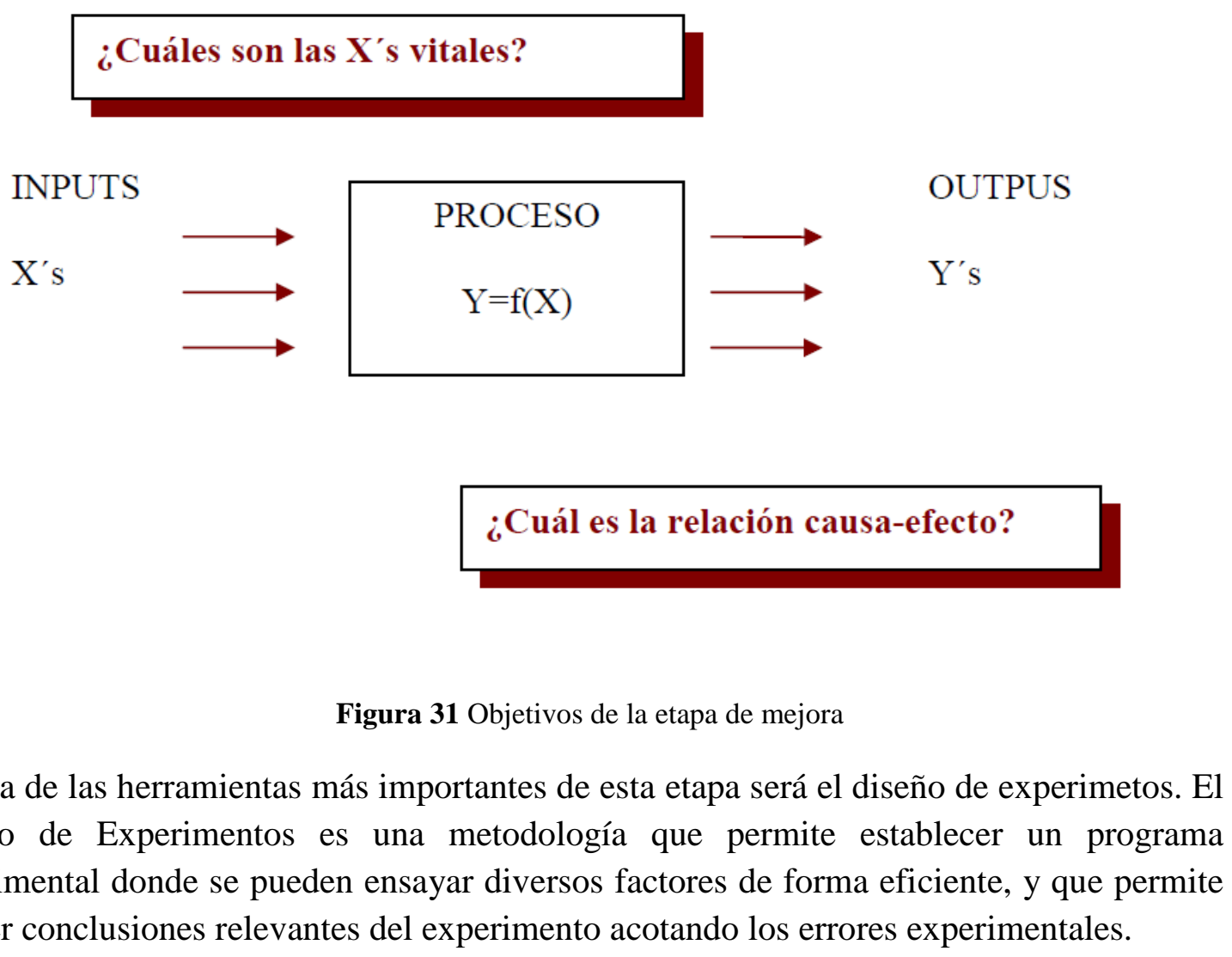

\subsection{5.- CONTROLAR}

Tras validar que las soluciones funcionan, es necesario implementar controles que aseguren que el proceso se mantendrá en su nuevo rumbo. Para prevenir que la solución sea temporal, se documenta el nuevo proceso y su plan de monitoreo.

Es necesario confirmar los resultados de las mejoras realizadas. Debe por tanto definirse claramente unos indicadores que permitan visualizar la evolución del proyecto. Los indicadores son necesarios pues no podemos basar nuestras decisiones en la simple intuición. Los indicadores nos mostrarán los puntos problemáticos de nuestro negocio y nos ayudarán a caracterizar, comprender y confirmar los procesos. Mediante el control de resultados lograremos saber si estamos cubriendo las necesidades y expectativas de nuestros clientes.

Esta etapa pretende asegurar que, una vez estabilizado el nuevo proceso, las condiciones de éste se vigilan a través de métodos estadísticos de control de procesos.

Los objetivos del control de procesos son los siguientes:

- Establecer tolerancias en las variables vitales. 
- Mantener las variables dentro de un intervalo de tolerancia a través de la implantación de un sistema de control adecuado.

- Utilizar gráficas de control para vigilar y controlar la variación de las variables

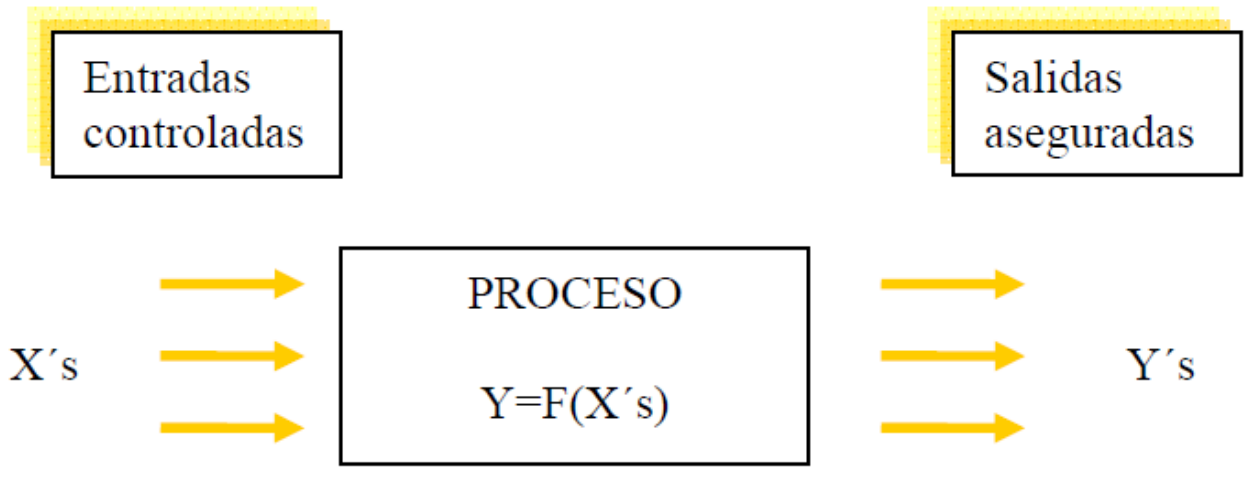

Figura 32 Diagrama de la etapa de control

Para poder efectuar un control fino sobre las variables vitales de un proceso es preciso utilizar métodos estadísticos. La idea es calcular unos límites estadísticos para el control de las variables, tales que resulte muy improbable que sean excedidos con la única explicación que el azar. 


\section{6.- HERRAMIENTAS UTILIZADAS EN LAS FASES DMAIC}

\begin{tabular}{|c|c|c|c|c|}
\hline Definir & Medir & Analizar & Mejorar & at \\
\hline $\begin{array}{l}\text { 1. Mapa de Proceso } \\
\text { 2. Despliegue de la } \\
\text { Función de Calidad } \\
\text { (QFD) } \\
\text { 3. Modelo Kano } \\
\text { 4. Diagrama Matricial } \\
\text { 5. Benchmarkin } \\
\text { 6. Costos de Calidad }\end{array}$ & $\begin{array}{l}\text { 1. Mapa de detallado } \\
\text { de Procesos } \\
\text { 2. Diagrama de Pareto } \\
\text { 3. Diagrama de Causa- } \\
\text { Efecto } \\
\text { 4. Diagrama de Árbol } \\
\text { 5. Diagrama de } \\
\text { Afinidad } \\
\text { 6. Métodos de } \\
\text { Muestreo } \\
\text { Estadístico } \\
\text { 7. Capacidad del } \\
\text { Sistema de Medición } \\
\text { 8. Distribución Normal } \\
\text { 9. Capacidad del } \\
\text { Proceso }\end{array}$ & $\begin{array}{l}\text { 1. AMEF } \\
\text { 2. Cartas Multi Vari } \\
\text { 3. Correlación } \\
\text { 4. Regresión lineal } \\
\text { Simple y lineal } \\
\text { Múltiple } \\
\text { 5. Pruebas de } \\
\text { Hipótesis } \\
\text { 6. Análisis de Varianza } \\
\text { (ANOVA) }\end{array}$ & $\begin{array}{l}\text { 1. Análisis de } \\
\text { Experimentos (DOE) } \\
\text { 2. Diseño Factorial } 2 \mathrm{~K} \\
\text { 3. Diseño Fracción } \\
\text { Factorial } \\
\text { 4. Diseño Taguchi } \\
\text { 5. Diseño de Mezclas } \\
\text { 6. Métodos de } \\
\text { Superficie de } \\
\text { Respuesta }\end{array}$ & $\begin{array}{l}\text { 1. Plan de Control } \\
\text { 2. Cartas de Control } \\
\text { 3. Poka Yoke } \\
\text { 4. Mejora continua } \\
\text { (Kaizen) } \\
\text { 5. Las } 5 \text { S's } \\
\text { 6. Kanban }\end{array}$ \\
\hline
\end{tabular}

Figura 33 Herramientas para las fases DMAIC

\section{7.-ESTRUCTURA}

Seis Sigma necesita para su práctica una estructura operativa especial, sin embargo no necesita ningún cambio en la estructura jerárquica de la empresa.

Una estructura típica operativa Seis Sigma aparece en el siguiente diagrama: 


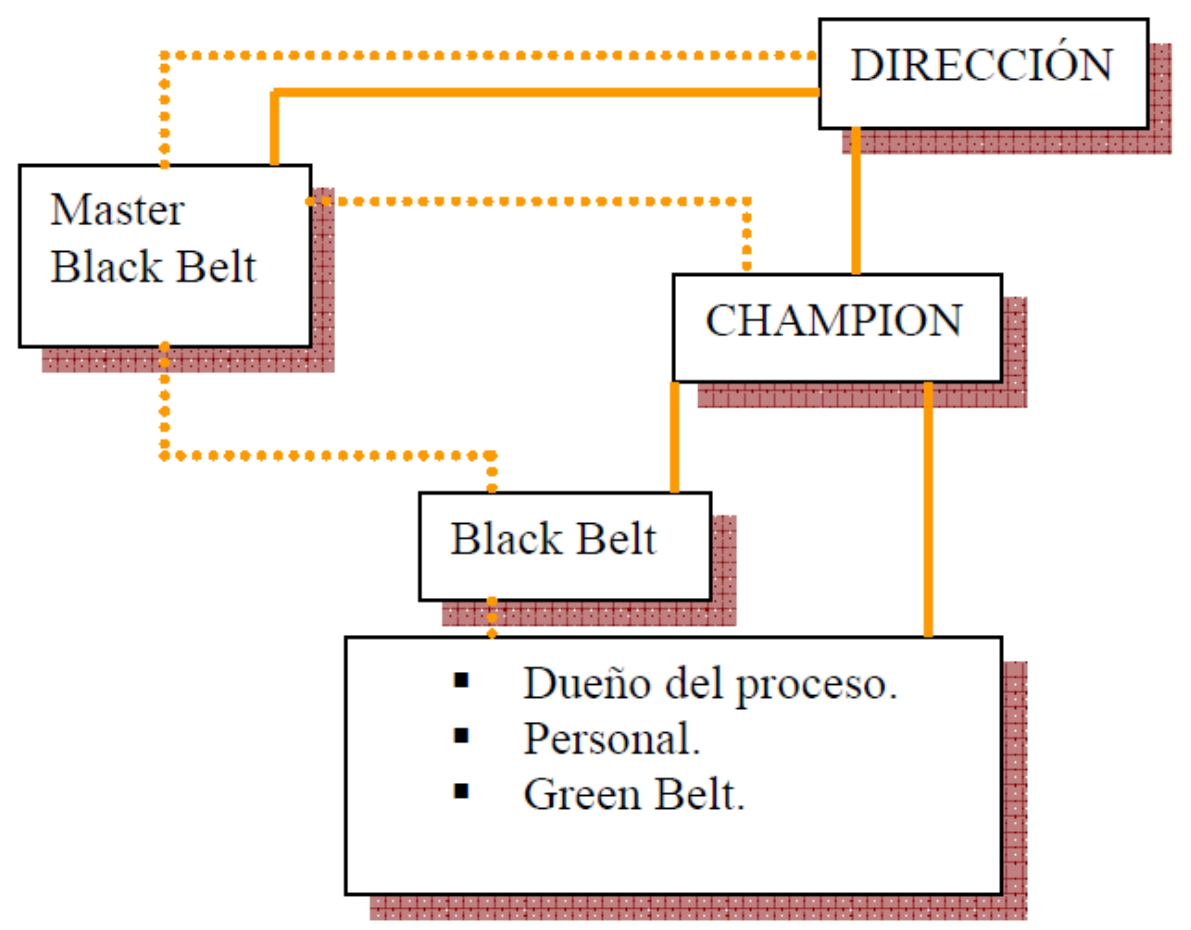

Relaciones jerárquicas

Relaciones tipo operativas

Figura 34 Relaciones jerárquicas y operativas en Seis Sigma

\subsection{1.- LA ALTA DIRECCIÓN}

La Alta Dirección (o Consejo Directivo) está formada por los altos directivos de la empresa reunidos en un foro diseñado para ayudarles a aprender una nueva forma de dirigir el negocio en contacto directo con los equipos de mejora del sistema Seis Sigma.

En su papel natural de liderazgo de la compañía, este grupo desarrolla y ejecuta el plan de implantación de Seis Sigma.

\subsection{2.- EL CHAMPION}

El champion es el máximo responsable del área de una empresa, normalmente un miembro del comité de Dirección o el responsable de Departamento; áreas de actuación tales como Recursos Humanos, Marketing, Fabricación, Suministros,... deben tener un Champion.

Las tareas básicas del champion son: 
-Detectar oportunidades de mejora.

-Liderar el programa de mejora.

-Ordenar las oportunidades de mejora según la importancia en la consecución de los objetivos de la empresa.

-Determinar cuales de esas oportunidades son abordables en un momento determinado según los recursos disponibles para ello.

-Lanzar proyectos de mejora concretos.

-Realizar un seguimiento del cambio.

-Sancionar los cambios a los procesos que se estimen convenientes.

-El champion, por tanto debe poseer unas cualidades importantes, con un convencimiento profundo de Seis Sigma y de la metodología.

\subsection{3.- EL MASTER BLACK BELT}

Jerárquicamente, el master black belt, dependerá directamente de la Dirección. Es muy importante que sea una persona respetada dentro de la organización, con ciertas dotes de líder, discreta y muy respetuosa con los demás, a la que cualquiera pueda pedir consejo sobre los problemas del día a día con total confianza. La dedicación del master black belt a los temas de mejora debe ser total y tener un profundo conocimiento de las técnicas estadísticas.

El master black belt debe:

-Actuar asesorando a la dirección sobre los mejores cursos de acción.

-Asesorar a los champions en el proceso de selección de proyectos de mejora.

-Asistir a los black belt en los problemas que éstos puedan encontrar en los diferentes grupos de trabajo.

-Será el encargado de formar a los black belt en las diferentes técnicas estadísticas y en sus funciones como facilitadores de grupos.

\subsection{4.- EL BLACK BELT}

El siguiente escalón dentro de los expertos en la metodología es el Black Belt. Debe ser una persona minuciosa y detallista, con suficiente conocimiento en las técnicas estadísticas y con tan sólo una dedicación parcial a proyectos de mejora.

El black Belt debe:

-Asesorar al Champion en la evaluación de propuestas de mejora. 
-Dirigir grupos de mejora.

-Formar al green belt y al personal.

\subsection{5.- EI GREEN BELT}

Son aquellas personas con incierto conocimiento de las técnicas estadísticas elementales y que, en ocasiones, pueden dirigir de forma casi autónoma un proyecto de mejora. Lo ideal sería que todos los dueños de procesos y los mandos intermedios fuese, al menos, Green Belt.

\subsection{6.- EL DUEÑO DEL PROYECTO}

En algún punto de la cadena jerárquica, por debajo del Champion, habrá que colocar a un responsable de cada uno de los procesos principales sobre los que se va a hacer actuar una y otra vez la rueda de la mejora continua. Esta persona se denomina el dueño del proceso, debe ser aquella que mejor conozca el proceso.

El dueño del proceso es quien se encarga de:

-Llevar el control del proceso.

-Medir el proceso.

-Asegurar que las mejoras que se acuerda llevar a la práctica acaban convirtiéndose en realidad.

-Avisar si en un momento dado el proceso se descontrola mostrando una variabilidad no esperada.

-Proponer actuaciones de mejora concretas.

-Liderar los grupos de mejora.

\subsection{7.- LOS MIENBROS DEL EQUIPO}

Los miembros del equipo son elegidos, de forma habitual, por su trabajo en el proceso que se está revisando. Ellos proporcionan el cerebro y los músculos para la recogida de los datos y su posterior análisis necesario para la mejora del proceso en cuestión.

Como casi nunca se dedican al proyecto a tiempo completo, deben acordar con su jefe inmediato cómo lo compaginarán con su trabajo diario. 


\section{6.- EQUIPO DE MEDJORA DE SEIS SIGMA}

El mismo atraviesa por seis fases:

1. Identificación y selección de proyectos. La Dirección considera los diversos proyectos de mejora presentados, seleccionando los más prometedores en función de posibilidades de implementación y de los resultados obtenibles. El proyecto tiene que tener un beneficio tanto para el negocio como para los clientes. El uso del Diagrama de Pareto es una herramienta beneficiosa para dicha selección.

2. Se procede a la formación de los equipos, entre los cuales se encuentra el Líder del Grupo (Cinturón Negro), para lo cual se involucrará a aquellos individuos que de acuerdo al Inventario Permanente de RR.HH. (ver Anexo, punto 14, al final del artículo) poseen las cualidades necesarias para integrarse al proyecto en cuestión.

3. Desarrollo del documento marco del proyecto. El documento marco es clave como elemento en torno al cual se suman las voluntades del grupo, sirviendo de guía para evitar desvíos y contradicciones. El mismo debe ser claro, fijar claramente los límites en recursos y plazos, y por sobre todas las cosas el objetivo supremo a lograr.

4. Capacitación de los miembros del equipo. Los mismos son capacitados, de no contar ya con conocimientos y/o experiencia en Seis Sigma, en estadísticas y probabilidades, herramientas de gestión, sistema de resolución de problemas y toma de decisiones, creatividad, pensamiento lateral, métodos de creatividad, PNL, planificación y análisis de procesos.

5. Ejecución del DMAIC e implementación de soluciones. Los equipos deben desarrollar los planes de proyectos, la capacitación a otros miembros del personal, los procedimientos para las soluciones, y son responsables tanto de ponerlos en práctica como de asegurarse de que funcionan (midiendo y controlando los resultados) durante un tiempo significativo.

6. Traspaso de la solución. Luego de cumplidos los objetivos para los cuales fueron creados, los equipos se disuelven y sus miembros vuelven a sus trabajos regulares o pasan a integrar equipos correspondientes a otros proyectos.

\section{7.- ESTRATEGIA DE IMPLANTACIÓN DE SEIS SIGMA}

La implementación de la filosofía Seis Sigma requiere que los directivos, Champions, Green Belt, Black Belt, técnicos y otros responsables del departamento de calidad que sean capaces de desempeñar el papel de administradores del sistema de calidad y de proporcionar técnicas específicas especializadas a los grupos de operación, para poder realizar sus proyectos. 
La selección adecuada de los proyectos tendrá una especial incidencia en el éxito de la implantación de la filosofía Seis Sigma en la empresa.

El resultado de proyecto general se mide por la suma del ahorro económico que ha presentado el mismo. Es importante que el Champion, directivos, Black Belts dediquen tiempo a discutir con los miembros del equipo en fase de formación y les ayuden a elegir correctamente el tema de su proyecto de mejora.

El nivel de capacitación requerido es muy alto en la implementación, implica costos ocasionados por capacitación, tiempos, materiales, entre otros; sin embargo el retorno de la inversión puede ser muy grande, cuando los proyectos son bien conducidos, ya que los ahorros y/o mejoras que se presentan cuando un proyecto 6 sigma funciona son cuantiosos.

Un plan exitoso de Seis Sigma comprende cuatro etapas fundamentales, cada una de las cuales está constituida por sub-etapas (las cuales pueden desarrollarse en forma paralela)

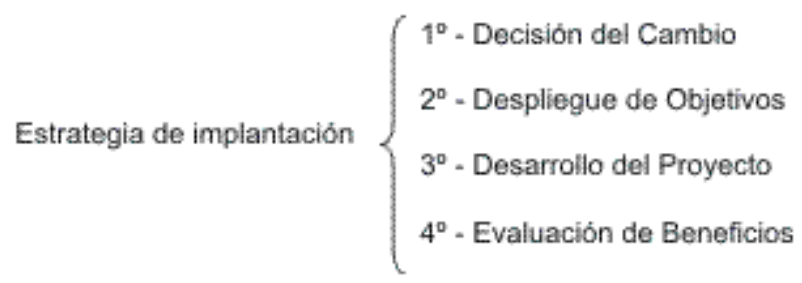

Figura 34 Estrategia de implantación

\section{Decisión del cambio}

Es necesario y primordial convencer y demostrar a los directivos de la empresa acerca de la imperiosa necesidad del cambio. Ello se logrará mejor si se muestra la evolución de los mercados en general y de la industria especifica en especial, tanto a nivel mundial como nacional y regional.

En segundo lugar, debe mostrarse claramente lo que acontece con la empresa, describiendo su evolución y comparándola con la de los actuales y futuros competidores. Debe dejarse en claro dónde estará la empresa dentro de cinco o diez años de no efectuar cambios, y dónde estarán las empresas que sí realicen tales cambios.

Demostrada la necesidad de instaurar un proceso de mejora continua, y de reingeniería si es necesario para cubrir rápidamente brechas de performance, el paso siguiente es demostrar las características y cualidades de Seis Sigma, mostrando además las diferencias de éste en relación a otros sistemas de calidad y mejora continua. 
De estar aplicando ya la empresa algún otro sistema o método de mejora continua, se hace menester evaluar los resultados que los mismos están brindando, para lo cual un buen método es evaluar el nivel de sigma que tienen sus procesos actualmente y compararlos (benchmarking) con los competidores globales.

La etapa siguiente consiste en el cambio de paradigmas de los directivos y personal superior de la empresa. Es necesario que eliminen de sus mentes que los errores son algo admisible y propio de la producción.

Se planifica estratégicamente definiendo claramente cuáles son los valores, la misión y visión de la empresa, para fijar con posterioridad objetivos a lograr para hacer factibles los objetivos de más largo plazo. En función de ello, se debe alcanzar una visión compartida con la cual se alcance la energía suficiente para lograr un trabajo en equipo que permita el logro de óptimos resultados en la puesta en marcha de Seis Sigma. En función de los planes, se asignan partidas presupuestarias a los efectos de su puesta en marcha y funcionamiento.

Se seleccionan los Líderes y Cinturones en función de sus conocimientos, capacidades y puestos que actualmente ocupan.

Se debe proceder a la capacitación y el entrenamiento de los diversos niveles de cinturones y liderazgos, como así también al resto del personal. Esta capacitación incluirá diferentes aspectos, dependiendo de las funciones y los niveles que cubra dicho personal. Se incluirán aspectos vinculados con el significado y funcionamiento de Seis Sigma, los métodos de resolución de problemas y toma de decisiones, trabajo en equipo, liderazgo y motivación, creatividad, control estadístico de procesos, diseño de experimentos, herramientas de gestión, AMFE, estadística y probabilidades, muestreo, satisfacción del consumidor, calidad y productividad, costo de calidad, sistemas de información, utilización de software estadístico, supervisión y diseño de proyectos, entre otros.

\section{Despliegue de objetivos}

Se establecen los sistemas de información, capacitación y supervisión apropiados al nuevo sistema de mejora.

Se incluyen en los sistemas de información y control (Cuadros de Mando Integral) los objetivos, indicadores e inductores relativos a Seis Sigma. De no existir un Cuadro de Mando Integral, se procede a elaborar un Cuadro de Indicadores de Seis Sigma.

Se forman los primeros grupos de trabajo en función de los proyectos seleccionados.

Los proyectos son seleccionados en función de los beneficios tanto para la empresa como, fundamentalmente, para el incremento en la satisfacción de los clientes y consumidores. 
Es conveniente comenzar con proyectos piloto para poner a prueba las técnicas y los conocimientos aprendidos, y demostrar además al resto de la organización acerca de los logros en la implementación del sistema.

\section{Desarrollo del proyecto}

Es primordial, antes que nada, definir los requerimientos de los clientes externos e internos, y la forma en que se medirá el logro de dichas especificaciones.

Los círculos de calidad o equipos de trabajo Seis Sigma (ETSS) proceden a aplicar la metodología DMAIC (Definir-Medir-Analizar-Mejorar-Controlar).

Se mantiene informado a los directivos acerca de la marcha de los diferentes proyectos.

\section{Evaluación de beneficios}

Se determinan las mejoras producidas luego de la implementación de los cambios resultantes del desarrollo de los diversos proyectos. Ello se manifiesta tanto en niveles de rendimiento como en niveles de sigma, DPMO y ahorros obtenidos.

Es conveniente hacer un seguimiento constante de los niveles de satisfacción, tanto de los clientes internos como externos. 


\section{6.- SISTEMAS INTEGRADOS DE GESTION DE LA CALIDAD, PREVENCIÓN DE RIEGOS LABORALES Y MEDIOAMBIENTE}

\section{1.- INTRODUCCIÓN}

Cualquier empresa u organización puede ser entendida como un conjunto de procesos que interactúan para dar un producto o un servicio de transporte al cliente. Estos procesos, que tienen lugar en distintos ámbitos de la organización y a distintos niveles, deben ser planificados, realizados y controlados con el fin de conseguir los resultados que se proponen, es decir, deben ser gestionados.

Si la organización se entiende como un conjunto de procesos, la gestión de la organización equivale a la gestión de todos los procesos que en ella tienen lugar. Deben ser administrados para conseguir la máxima eficacia y eficiencia empresarial y, en la medida en que se consideren las distintas variables de cada proceso y se gestionen de la mejor forma, se estará optimizando su funcionamiento.

La implantación de la norma ISO 9001 ha propiciado que las organizaciones familiaricen con la estructura de un sistema de gestión, documentando los distintos procesos, asignando responsabilidades y formalizando registros que permitan evidenciar el funcionamiento del sistema ante terceros.

Además, algunas organizaciones han comenzado a implantar otros sistemas de gestión para controlar y mejorar los aspectos más sensibles de la organización relacionados con el medio ambiente y la prevención de riesgos laborales (PRL). Esto supone una multiplicación de recursos y, en consecuencia, un elevado coste y obliga a preguntarse, ¿cuáles son las posibilidades reales de integración de los sistemas de gestión?

Existen muchas similitudes entre los conceptos de gestión de la calidad, gestión medioambiental y gestión de la prevención de riesgos laborales, ya que los principios de una buena gestión son los mismos, así como sus implantaciones y puntos normativos.

Hasta hace muy poco tiempo las funciones de calidad, medio ambiente y seguridad han seguido un desarrollo independiente y paralelo en el mundo industrial. Así, en muchas organizaciones la seguridad sigue dependiendo de recursos humanos, mientras que la calidad lo hace de operaciones, y medio ambiente se ubica en áreas técnicas.

Los tres sistemas han tenido un origen diferente, la calidad se ha desarrollado impulsada fuertemente por la competencia, por la necesidad de mejorar la competitividad empresarial.

La seguridad ha sido impulsada por el establecimiento de regulaciones gubernamentales y por la presión de las organizaciones sindicales, mientras que el medio ambiente lo ha hecho por la legislación y la sociedad.

Aún así, y gracias a todas las similitudes (documentación, procedimientos, auditorías, etc) que se encuentran entre los sistemas de gestión estandarizados, ISO 9001, ISO 14001 
y OHSAS 18001, las empresas españolas comienzan a optar por su integración con el obejtivo de obtener unos beneficios que aumenten la rentabilidad y fiabilidad de sus resultados. Así, en este apartado veremos los diferentes aspectos a tener en cuenta sobre un sistema integrado de gestión, la norma UNE 66177: Guía para la integración de los sistemas de gestión, y los aspectos característicos de los sistemas de gestión ambiental y de seguridad y salud ocupacional. (No se comentará los sistemas de gestión de la calidad con la ISO 9001 al haber sido comentados previamente).

\section{2.- ENFOQUES DE IMPLANTACIÓN Y DE INTEGRACIÓN}

El objetivo de un sistema de gestión integrada de la calidad, medio ambiente y PRL es la obtención de un mejor resultado empresarial gestionando las tres disciplinas de forma integrada, es decir, integrando los sistemas que las gestionan, los procesos que los soportan y las actividades que componen los procesos.

Estas disciplinas se pueden gestionar de manera independiente, en cuyo caso:

-Existen 3 manuales, 3 conjuntos de procedimientos y, si es el caso, 3 conjuntos de instrucciones.

- La implantación se hace de forma secuencial (3 periodos de implantación) y atendiendo a prioridades.

- Se aíslan conceptos.

En el caso de una gestión integrada:

- Existe un único manual de gestión. Los procedimientos e instrucciones generales no se duplican y, habitualmente, se elaboran por separado los procedimientos e instrucciones específicas de cada uno de los sistemas.

- La implantación es simultánea, por lo que el periodo de implantación total es más corto que si se implantaran los sistemas por separado.

- Se distribuyen esfuerzos y el sistema en su conjunto se diseña e implanta más rápido.

-Requiere una cuidadosa implantación.

Teniendo en cuenta la situación de partida de la organización, en cuanto a la existencia o no de algún sistema de gestión implantado, pueden darse dos situaciones bien distintas en relación con la implantación:

a) Organización con ISO 9001 implantada.

Cuando la organización ya tiene un sistema implantado y quiere implantar otro de los sistemas, es aconsejable seguir una de las siguientes alternativas:

1-Diseñar todo el sistema en paralelo, aprovechando del existente todo aquello que sea utilizable y dejando sólo común, en esta primera fase, las instrucciones operativas (o de detalle). En una segunda fase se abordaría la integración entre los dos sistemas. 
2- Desarrollar desde el principio el proyecto integrado. Esta estrategia es algo más arriesgada, puesto que introduce cambios en todo lo ya existente, pero permite llegar al punto final más rápido.

Las razones para elegir una estrategia $u$ otra dependen de la resistencia al cambio en la organización, grado de implicación de la Dirección en el proyecto, recursos puestos en juego y plazo para lograr el objetivo final.

b) Organización sin sistema ISO 9001 implantado.

En el caso de que la organización no tenga ningún sistema de gestión implantado, se deberá diseñar la estructura del sistema integrado y desarrollar de forma integrada todas las partes comunes desde el principio. En cuanto a las partes específicas para cada uno de los sistemas existen otras dos posibilidades:

1- Desarrollar, en una primera fase, todo lo concerniente a uno de los sistemas (calidad o medio ambiente), según las prioridades de la organización. Una vez implantada esta parte se continuaría con la siguiente. Esta opción tiene la ventaja de que permite obtener antes la certificación de uno de los sistemas (no olvidemos que, de momento, las certificaciones son independientes para cada uno de los sistemas).

2- Abordar el desarrollo de todas las partes específicas por procesos. De esta forma, con la lista de todos los procesos principales de la organización, se priorizan y se van desarrollando paulatinamente. Para asegurar el éxito, es importante que los primeros procesos a acometer (considerados piloto) no sean los de reto más difícil, tanto sea por la complejidad técnica como por la resistencia organizativa.

Recomendamos especialmente esta última estrategia, puesto que es más pedagógica para la organización, por el enfoque integrador dentro de la gestión de cada proceso.

\section{3.- INTEGRACIÓN POR PROCESOS}

El nuevo enfoque de trabajo de la ISO 9001 obliga a trabajar por procesos (entendemos por proceso la actividad que transforma elementos de entrada en elementos de salida con un valor añadido). Este enfoque ya lo realizaba la ISO 14001, por lo que la nueva metodología de calidad facilita la integración de ambos sistemas. El siguiente gráfico muestra la relación entre los modelos de gestión ISO 9001 e ISO 14001. 


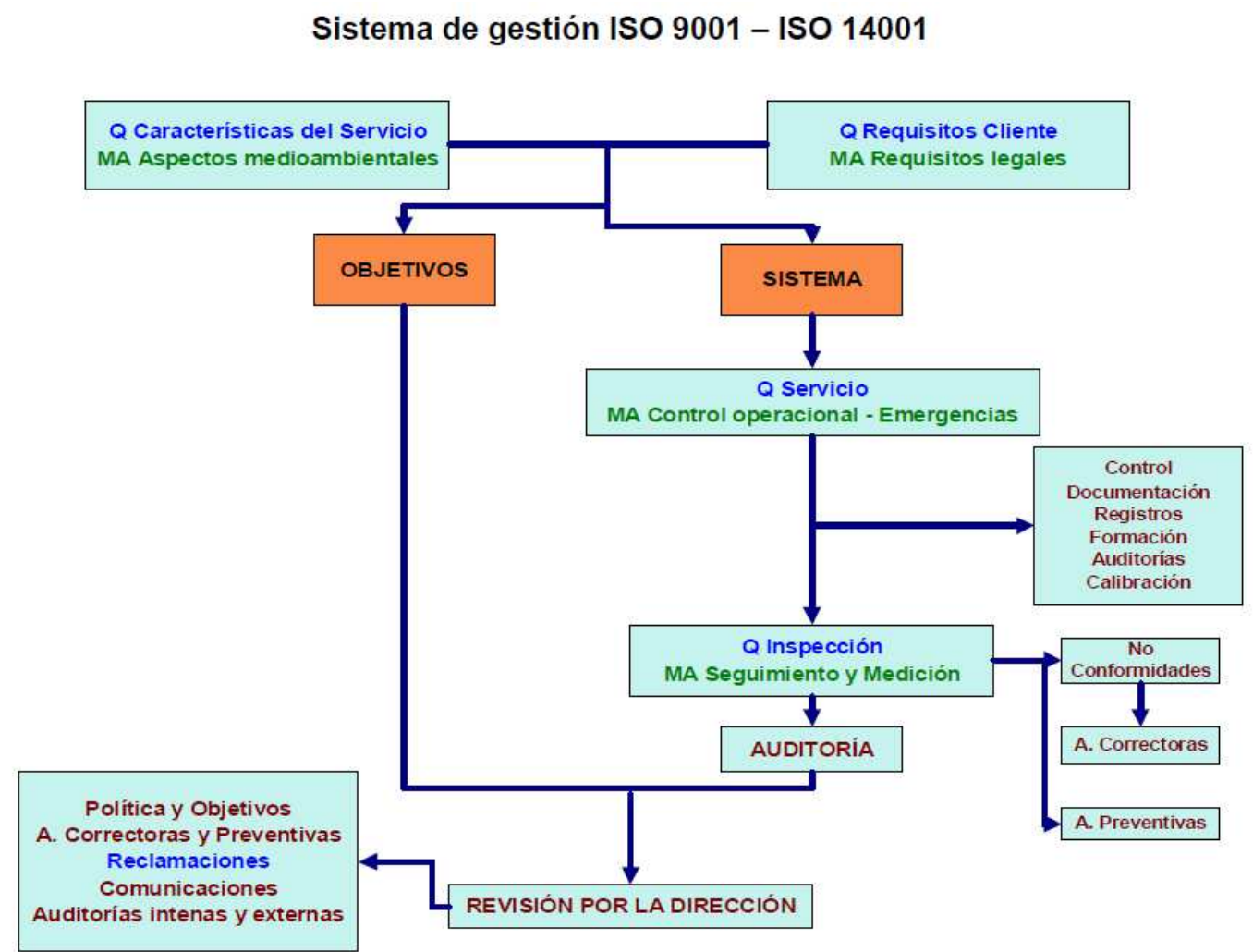

Figura 35 Relación entre ISO 9001 e ISO 14001

¿Cómo se integran los tres sistemas de gestión? Los sistemas de calidad, medio ambiente y PRL deben integrarse a través de la gestión por procesos. Para llevar a cabo la integración por procesos de una manera ordenada y coherente se han de seguir una serie de pasos en los que se combinarán los recursos (tanto materiales como humanos), el método o la sistemática a seguir, el medio ambiente y el entorno laboral.

Se realiza básicamente:

- A nivel operacional, es decir, integración en la base operativa, con el objetivo de que todas las personas, tanto los directivos como los técnicos y los operarios perciban y gestionen la calidad, el medio ambiente y la prevención de riesgos laborales como algo inseparable.

- A nivel de funcionamiento del sistema: dirección única del sistema, edición y control de la documentación común, sistemas de verificación y control comunes en la medida de lo posible, tratamiento común de las no-conformidades y acciones correctoras y preventivas.

El diseño del sistema de gestión integrada se lleva a cabo en cuatro etapas. Estas cuatro etapas consisten en la identificación de los procesos y de los requisitos (de calidad, medioambientales y de PRL), su despliegue (asignándolos a un método o sistemática), la integración de los métodos $\mathrm{y}$, por último, la integración de la documentación (documentos y manual). 
Finalizadas estas etapas, se ha de proceder a la implantación del sistema de gestión integrada, en la que se pondrán en marcha ciertas actividades, se comprobará el funcionamiento de ciertos cambios y el de todos los procesos que puedan haber resultado afectados de una u otra forma por la integración.

Para concluir con el proceso de la integración, es conveniente realizar una auditoría interna de todo el sistema integrado, por personal propio o contratado, en la que se verificarán de una manera objetiva e imparcial los procedimientos documentados y lo que se hace realmente en la organización. El comportamiento de cualquier proceso viene determinado por una serie de variables que, habitualmente, se conocen como las $\mathbf{5} \mathbf{M}$ :

-Los materiales tienen que cumplir las especificaciones o requisitos de calidad, medio ambiente y seguridad que se requieran.

- De la misma manera, las máquinas que participan en el proceso habrán de atender a estos requisitos.

- La mano de obra o los recursos humanos tienen que estar formados en dichas disciplinas.

- Los métodos con los que se vaya a trabajar tienen que respetar las exigencias que el sistema integrado determine.

- Y el medio o entorno ha de facilitar el cumplimiento de estos requisitos.

En la integración, cada una de estas variables tiene una influencia diferente en coste y tiempo:

- Materiales ..................... Influencia media
- Máquinas .................. Influencia baja
- Recursos Humanos ....... Influencia alta
- Métodos....................... Influencia alta
- Entorno .......................... Influencia baja

Los materiales, las máquinas y el entorno influyen desde el punto de vista de los requisitos y de la documentación, pero tienen influencia escasa desde el punto de vista de la gestión. Es, por lo tanto, razonable deducir que los dos aspectos sobre los que la organización tendrá que incidir para integrar sus sistemas de gestión son, por un lado, los métodos que aplica y, por otro, los recursos humanos con los que cuenta.

La integración de los sistemas de gestión de calidad, del medio ambiente y de la PRL será más sencilla cuanto más estructurada esté la organización. La integración ideal de los tres sistemas de gestión debería presentar las siguientes características:

- Responsable único de los tres sistemas y funciones de dirección técnica corporativa diferenciadas.

- Sistemas de gestión totalmente incorporados en las actividades operativas. Los requisitos de calidad, medio ambiente y PRL se entienden como una parte más de la tarea.

- Documentos y registros mínimos.

- Políticas, objetivos y metas coherentes. 
Es evidente que las situaciones de partida son muy diversas pero, en cualquier caso, se precisa un fuerte liderazgo de la Dirección y de su equipo de colaboradores para poner en marcha un sistema de gestión integrada eficiente. 


\section{4.- RELACIÓN ENTRE LOS SISTEMAS DE GESTIÓN}

\begin{tabular}{|c|c|c|}
\hline ISO $9001: 2000$ & ISO 14001:2004 & OSHAS: 18001 \\
\hline $\begin{array}{l}\text { Manual de calidad y documentación del sistema de } \\
\text { calidad. }\end{array}$ & $\begin{array}{l}\text { Documentación del sistema de gestión del } \\
\text { medio ambiente. }\end{array}$ & $\begin{array}{l}\text { Documentación del sistema de } \\
\text { gestión de la prevención de riesgos } \\
\text { laborales. }\end{array}$ \\
\hline Control de documentos. & Control de documentos. & Control de documentos. \\
\hline Control de los registros. & Control de los registros. & Control de los registros. \\
\hline Política de Calidad. & Política medioambiental. & $\begin{array}{l}\text { Política de prevención de riesgos } \\
\text { laborales. }\end{array}$ \\
\hline $\begin{array}{l}\text { Requisitos legales del producto. } \\
\text { Requisitos de Calidad de los clientes Registros (1). }\end{array}$ & $\begin{array}{l}\text { Procedimiento para identificar y tener acceso } \\
\text { a los requisitos legales. } \\
\text { Registro de la legislación medioambiental } \\
\text { aplicable. } \\
\text { Procedimiento para identificar los aspectos } \\
\text { medioambientales y para determinar su } \\
\text { significancia. } \\
\text { Registro del resultado de la evaluación de los } \\
\text { aspectos medioambientales (1). } \\
\end{array}$ & $\begin{array}{l}\text { Procedimiento para identificar y tener } \\
\text { acceso a los requisitos legales. } \\
\text { Registro de la legislación aplicable. } \\
\text { Procedimiento para identificar los } \\
\text { riesgos laborales. } \\
\text { Registro del resultado de la } \\
\text { evaluación de los riesgos laborales } \\
\text { (1). }\end{array}$ \\
\hline Objetivos de Calidad. & Objetivos y metas medioambientales. & $\begin{array}{l}\text { Objetivos y metas en la Prevención de } \\
\text { riesgos laborales. }\end{array}$ \\
\hline Planificación de la Calidad (2). & Programa de gestión medioambiental (2). & $\begin{array}{l}\text { Programa de gestión de la prevención } \\
\text { de riesgos laborales (2). }\end{array}$ \\
\hline Funciones y responsabilidades. & Funciones y responsabilidades. & Funciones y responsabilidades. \\
\hline Comunicación interna. & Comunicación interna y externa. & Comunicación interna y externa. \\
\hline Revisión por la dirección. & Revisión por la dirección. & Revisión por la dirección. \\
\hline $\begin{array}{l}\text { Recursos humanos. } \\
\text { Identificar las necesidades de formación. } \\
\text { Plan de formación. } \\
\text { Toma de conciencia. } \\
\text { Registros. }\end{array}$ & $\begin{array}{l}\text { Procedimiento para identificar las } \\
\text { necesidades de formación medioambiental. } \\
\text { Plan de formación. } \\
\text { Toma de conciencia. } \\
\text { Registros. }\end{array}$ & $\begin{array}{l}\text { Procedimiento para identificar las } \\
\text { necesidades de formación en } \\
\text { prevención de riesgos laborales. } \\
\text { Plan de formación. } \\
\text { Toma de conciencia. } \\
\text { Registros. }\end{array}$ \\
\hline \multicolumn{3}{|l|}{ Infraestructura y ambiente de trabajo. } \\
\hline Planificación de la realización del producto. & $\begin{array}{l}\text { Planificación del control operacional asociado } \\
\text { a los aspectos medioambientales. } \\
\text { Planes de emergencia. } \\
\end{array}$ & $\begin{array}{l}\text { Planificación de la prevención. } \\
\text { Planes de respuesta respecto a } \\
\text { situaciones de emergencia. } \\
\end{array}$ \\
\hline $\begin{array}{l}\text { Procesos relacionados con el cliente. } \\
\text { Determinación de los requisitos relacionados con el } \\
\text { producto. } \\
\text { Comunicación con el cliente. }\end{array}$ & $\begin{array}{l}\text { Aspectos medioambientales. } \\
\text { Comunicación interna y externa. }\end{array}$ & $\begin{array}{l}\text { Riesgos laborales. } \\
\text { Comunicación interna y externa. }\end{array}$ \\
\hline \multicolumn{3}{|l|}{ Diseño del producto. } \\
\hline $\begin{array}{l}\text { Proceso de compras. } \\
\text { Información de las compras. }\end{array}$ & $\begin{array}{l}\text { Procedimiento para comunicar a los } \\
\text { suministradores y subcontratistas los } \\
\text { requisitos medioambientales. }\end{array}$ & \\
\hline Producción y prestación del servicio. & Control operacional. & Control de las actuaciones. \\
\hline $\begin{array}{l}\text { Control de los dispositivos de seguimiento y } \\
\text { medición. }\end{array}$ & $\begin{array}{l}\text { Calibración y mantenimiento de los equipos } \\
\text { de inspección. }\end{array}$ & \\
\hline \multicolumn{3}{|l|}{$\begin{array}{l}\text { Seguimiento y medición de la satisfacción del } \\
\text { cliente }\end{array}$} \\
\hline Auditoria interna. & Auditoría interna. & $\begin{array}{l}\text { Auditoría del sistema de gestión de } \\
\text { prevención de los riesgos laborales. }\end{array}$ \\
\hline $\begin{array}{l}\text { Seguimiento y medición de los procesos. } \\
\text { Seguimiento y medición de los productos. }\end{array}$ & Procedimiento de control y medición. & $\begin{array}{l}\text { Procedimiento para el control activo. } \\
\text { Procedimiento para la verificación. }\end{array}$ \\
\hline Control del producto no conforme. & Procedimiento para las no conformidades. & $\begin{array}{l}\text { Procedimiento para las no } \\
\text { conformidades. Incidentes, } \\
\text { accidentes, enfermedades laborales. } \\
\end{array}$ \\
\hline \multicolumn{3}{|l|}{ Análisis de datos. } \\
\hline $\begin{array}{l}\text { Mejora continua. } \\
\text { Acciones correctivas y preventivas. }\end{array}$ & Acciones correctivas y preventivas. & Acciones correctivas y preventivas. \\
\hline
\end{tabular}
1.- Procedimientos especificos
2.- En formatos especíicos

Tabla 10 Relación entre los sistemas de gestión 


\begin{tabular}{|c|c|c|c|c|c|}
\hline \multicolumn{2}{|r|}{ OHSAS 18001:2007 } & \multicolumn{2}{|r|}{ ISO $14001: 2004$} & \multicolumn{2}{|r|}{ ISO $9001: 2000$} \\
\hline- & Introducción & - & Introducción & $\begin{array}{l}0 \\
0.1 \\
0.2 \\
0.3 \\
0.4\end{array}$ & $\begin{array}{l}\text { Introducción } \\
\text { Generalidades } \\
\text { Enfoque basado en } \\
\text { procesos } \\
\text { Relación con la norma } \\
\text { ISO } 9004 \\
\text { Compatibilidad con otros } \\
\text { sistemas de gestión }\end{array}$ \\
\hline 1 & $\begin{array}{l}\text { Objeto y campo de } \\
\text { aplicación }\end{array}$ & 1 & $\begin{array}{l}\text { Objeto y campo de } \\
\text { aplicación }\end{array}$ & 1 & $\begin{array}{l}\text { 1 Objeto y campo de } \\
\text { aplicación } \\
1.1 \text { Generalidades } \\
\text { 1.2 Aplicación }\end{array}$ \\
\hline 2 & Referencias normativas & 2 & Referencias normativas & 2 & Referencias normativas \\
\hline 3 & Términos y definiciones & 3 & Términos y definiciones & 3 & Términos y definiciones \\
\hline 4 & $\begin{array}{l}\text { Requisitos del sistema de } \\
\text { gestión de S Y SO (sólo } \\
\text { titulo) }\end{array}$ & 4 & $\begin{array}{l}\text { Requisitos del sistema } \\
\text { de gestión ambiental } \\
\text { (sólo titulo) }\end{array}$ & 4 & $\begin{array}{l}\text { Sistema de gestión de la } \\
\text { calidad (sólo titulo) }\end{array}$ \\
\hline 4.1 & Requisitos generales & 4.1 & Requisitos generales & $\begin{array}{l}4.1 \\
5.5 \\
5.5 .1\end{array}$ & $\begin{array}{l}\text { Requisitos generales } \\
\text { Responsabilidad, } \\
\text { autoridad y comunicación } \\
\text { Responsabilidad y } \\
\text { autoridad }\end{array}$ \\
\hline 4.2 & Política de S Y SO & 4.2 & Política ambiental & $\begin{array}{l}5.1 \\
5.3 \\
8.5 .1 \\
\end{array}$ & $\begin{array}{l}\text { Compromiso de la } \\
\text { dirección } \\
\text { Política de calidad } \\
\text { Mejora continua } \\
\end{array}$ \\
\hline 4.3 & Planificación (sólo titulo) & 4.3 & Planificación (sólo titulo) & 5.4 & Planificación (sólo titulo) \\
\hline 4.3 .1 & $\begin{array}{l}\text { Identificación de peligros, } \\
\text { valoración de riesgos y } \\
\text { determinación de los } \\
\text { controles }\end{array}$ & 4.3 .1 & Aspectos ambientales & $\begin{array}{l}5.2 \\
7.2 .1\end{array}$ & $\begin{array}{l}\text { Enfoque al cliente } \\
\text { Determinación de los } \\
\text { requisitos relacionados } \\
\text { con el producto } \\
\text { Revisión de los requisitos } \\
\text { relacionados con el } \\
\text { producto }\end{array}$ \\
\hline 4.3 .2 & Requisitos legales y otros & 4.3 .2 & $\begin{array}{l}\text { Requisitos legales } \\
\text { y otros requisitos }\end{array}$ & $\begin{array}{l}5.2 \\
7.2 .1\end{array}$ & $\begin{array}{l}\text { Enfoque al cliente } \\
\text { Determinación de los } \\
\text { requisitos relacionados } \\
\text { con el producto }\end{array}$ \\
\hline 4.3 .3 & Objetivos y programa (s) & 4.3 .3 & $\begin{array}{l}\text { Objetivos, metas y } \\
\text { programas }\end{array}$ & $\begin{array}{l}5.4 .1 \\
5.4 .2 \\
8.5 .1\end{array}$ & $\begin{array}{l}\text { Objetivos de calidad } \\
\text { Planificación del sistema } \\
\text { de gestión de la calidad } \\
\text { Mejora continua }\end{array}$ \\
\hline 4.4 & $\begin{array}{l}\text { Implementación y } \\
\text { operación (sólo titulo) }\end{array}$ & 4.4 & \begin{tabular}{|l} 
Implementación y \\
operación (sólo titulo)
\end{tabular} & 7 & $\begin{array}{l}\text { Realización del producto } \\
\text { (sólo titulo) }\end{array}$ \\
\hline 4.4 .1 & $\begin{array}{l}\text { Recursos, funciones, } \\
\text { responsabilidad, rendición } \\
\text { de cuentas y autoridad }\end{array}$ & 4.4 .1 & $\begin{array}{l}\text { Recursos, funciones, } \\
\text { responsabilidad, } \\
\text { responsabilidad y } \\
\text { autoridad }\end{array}$ & $\begin{array}{l}5.1 \\
5.5 .1 \\
5.5 .1 \\
6.1 \\
6.3\end{array}$ & $\begin{array}{l}\text { Compromiso de la } \\
\text { dirección } \\
\text { Responsabilidad y } \\
\text { autoridad } \\
\text { Representante de la } \\
\text { dirección } \\
\text { Provisión de recursos } \\
\text { Infraestructura }\end{array}$ \\
\hline
\end{tabular}

Tabla 11 Correspondencias entre OHSAS 18001, ISO 14001e ISO 9001 


\begin{tabular}{|c|c|c|c|c|c|}
\hline \multicolumn{2}{|r|}{ OHSAS 18001:2007 } & \multicolumn{2}{|r|}{ ISO 14001:2004 } & \multicolumn{2}{|r|}{ ISO $9001: 2000$} \\
\hline 4.4 .2 & $\begin{array}{l}\text { Competencia, formación y } \\
\text { toma de conciencia }\end{array}$ & 4.4 .2 & $\begin{array}{l}\text { Competencia, formación y } \\
\text { toma de conciencia }\end{array}$ & $\begin{array}{l}6.2 .1 \\
6.2 .2\end{array}$ & $\begin{array}{l}\text { Generalidades (Recursos } \\
\text { humanos) } \\
\text { Competencia, toma de } \\
\text { conciencia y formación } \\
\end{array}$ \\
\hline 4.4 .3 & $\begin{array}{l}\text { Comunicación, } \\
\text { participación y consulta }\end{array}$ & 4.4 .3 & Comunicación & $\begin{array}{l}5.5 .3 \\
7.2 .3\end{array}$ & $\begin{array}{l}\text { Comunicación interna } \\
\text { Comunicación con el } \\
\text { cliente }\end{array}$ \\
\hline 4.4 .4 & Documentación & 4.4 .4 & Documentación & 4.2 .1 & \begin{tabular}{|l|} 
Requisitos de la \\
documentación) \\
Generalidades \\
\end{tabular} \\
\hline 4.4 .5 & Control de documentos & 4.4 .5 & Control de documentos & 4.2 .3 & Control de documentos \\
\hline 4.4 .6 & Control operacional & 4.4 .6 & Control operacional & 7.1 & $\begin{array}{l}\text { Planificación de la } \\
\text { realización del producto }\end{array}$ \\
\hline & & & & 7.2 & $\begin{array}{l}\text { Procesos relacionados } \\
\text { con el cliente }\end{array}$ \\
\hline & & & & 7.2 .1 & $\begin{array}{l}\text { Determinación de los } \\
\text { requisitos relacionados } \\
\text { con el producto. }\end{array}$ \\
\hline & & & & 7.2 .2 & $\begin{array}{l}\text { Revisión de los requisitos } \\
\text { relacionados con el } \\
\text { producto }\end{array}$ \\
\hline & & & & 7.3.1 & $\begin{array}{l}\text { Planificación del diseño y } \\
\text { desarrollo }\end{array}$ \\
\hline & & & & 7.3.2 & $\begin{array}{l}\text { Elementos de entrada } \\
\text { para el diseño y desarrollo }\end{array}$ \\
\hline & & & & 7.3 .3 & $\begin{array}{l}\text { Resultados del diseño y } \\
\text { desarrollo }\end{array}$ \\
\hline & & & & 7.3.4 & $\begin{array}{l}\text { Revisión del diseño y } \\
\text { desarrollo }\end{array}$ \\
\hline & & & & 7.3 .5 & $\begin{array}{l}\text { Verificación del diseño y } \\
\text { desarrollo }\end{array}$ \\
\hline & & & & 7.3 .6 & $\begin{array}{l}\text { Validación del diseño y } \\
\text { desarrollo }\end{array}$ \\
\hline & & & & 7.3.7 & $\begin{array}{l}\text { Control de los cambios del } \\
\text { diseño y desarrollo }\end{array}$ \\
\hline & & & & 7.4 .1 & Proceso de compras \\
\hline & & & & 7.4 .2 & Información de compras \\
\hline & & & & 7.4 .3 & $\begin{array}{l}\text { Verificación de los } \\
\text { productos comprados }\end{array}$ \\
\hline & & & & 7.5 & $\begin{array}{l}\text { Producción y prestación } \\
\text { del servicio }\end{array}$ \\
\hline & & & & 7.5 .1 & $\begin{array}{l}\text { Control de la producción y } \\
\text { de la prestación del } \\
\text { servicio }\end{array}$ \\
\hline & & & & 7.5 .2 & $\begin{array}{l}\text { Validación de los } \\
\text { procesos de la producción } \\
\text { y de la prestación del } \\
\text { servicio }\end{array}$ \\
\hline & & & & 7.5 .5 & Preservación del producto \\
\hline 4.4 .7 & $\begin{array}{l}\text { Preparación y respuesta } \\
\text { ante emergencias }\end{array}$ & 4.4 .7 & $\begin{array}{l}\text { Preparación y respuesta } \\
\text { ante emergencias }\end{array}$ & 8.3 & $\begin{array}{l}\text { Control del producto no } \\
\text { conforme }\end{array}$ \\
\hline
\end{tabular}

Tabla 11 Correspondencias entre OHSAS 18001, ISO 14001 e ISO 9001 


\begin{tabular}{|c|c|c|c|c|c|}
\hline \multicolumn{2}{|c|}{ OHSAS 18001:2007 } & \multicolumn{2}{|r|}{ ISO 14001:2004 } & \multicolumn{2}{|r|}{ ISO $9001: 2000$} \\
\hline 4.5 & Verificación (sólo titulo) & 4.5 & Verificación (sólo titulo) & 8 & \begin{tabular}{|l} 
Medición, análisis y \\
mejora (sólo titulo)
\end{tabular} \\
\hline 4.5 .1 & $\begin{array}{l}\text { Medición y seguimiento } \\
\text { del desempeño }\end{array}$ & 4.5 .1 & Seguimiento y medición & $\begin{array}{l}7.6 \\
\\
8.1 \\
8.2 .3 \\
8.2 .4 \\
8.4 \\
\end{array}$ & $\begin{array}{l}\text { Control de los } \\
\text { dispositivos de } \\
\text { seguimiento y medición } \\
\text { (Medición, análisis y } \\
\text { mejora) } \\
\text { Generalidades } \\
\text { Seguimiento y medición } \\
\text { de los procesos } \\
\text { Seguimiento y medición } \\
\text { del producto } \\
\text { Análisis de datos }\end{array}$ \\
\hline 4.5 .2 & $\begin{array}{l}\text { Evaluación del } \\
\text { cumplimiento legal y } \\
\text { otros }\end{array}$ & 4.5 .2 & $\begin{array}{l}\text { Evaluación del } \\
\text { cumplimiento legal }\end{array}$ & $\begin{array}{l}8.2 .3 \\
8.2 .4\end{array}$ & $\begin{array}{l}\text { Seguimiento y medición } \\
\text { de los procesos } \\
\text { Seguimiento y medición } \\
\text { del producto }\end{array}$ \\
\hline 4.5 .3 & $\begin{array}{l}\text { Investigación de } \\
\text { incidentes, no } \\
\text { conformidades, } \\
\text { acciones correctivas y } \\
\text { preventivas }\end{array}$ & - & - & - & - \\
\hline 4.5 .3 .1 & $\begin{array}{l}\text { Investigación de } \\
\text { incidentes }\end{array}$ & - & -- & - & - \\
\hline 4.5 .3 .2 & $\begin{array}{l}\text { No conformidad, acción } \\
\text { correctiva y acción } \\
\text { preventiva }\end{array}$ & 4.5 .3 & $\begin{array}{l}\text { No conformidad, acción } \\
\text { correctiva y acción } \\
\text { preventiva }\end{array}$ & $\begin{array}{l}8.3 \\
8.4 \\
8.5 .2 \\
8.5 .3\end{array}$ & $\begin{array}{l}\text { Control del producto no } \\
\text { conforme } \\
\text { Análisis de datos } \\
\text { Acción correctiva } \\
\text { Acción preventiva }\end{array}$ \\
\hline 4.5 .4 & Control de los registros & 4.5 .4 & Control de los registros & 4.2 .4 & Control de los registros \\
\hline 4.5 .5 & Auditoría interna & 4.5 .5 & Auditoría interna & 8.2 .2 & Auditoría internas \\
\hline 4.6 & Revisión por la dirección & 4.6 & Revisión por la dirección & $\begin{array}{l}5.1 \\
5.6 \\
5.6 .1 \\
5.6 .2 \\
5.6 .3 \\
8.5 .1\end{array}$ & $\begin{array}{l}\text { Compromiso de la } \\
\text { dirección } \\
\text { Revisión por la dirección } \\
\text { (sólo título) } \\
\text { Generalidades } \\
\text { Información para la } \\
\text { revisión } \\
\text { Resultados de la } \\
\text { revisión } \\
\text { Mejora continua } \\
\end{array}$ \\
\hline
\end{tabular}

Tabla 11 Correspondencias entre OHSAS 18001, ISO 14001 e ISO 9001

\section{5.- DISEÑO DE UN SISTEMA INTEGRADO}

Una vez definida la situación de partida, las etapas a seguir son:

\section{-Identificación de los requisitos.}

La identificación de requisitos hace necesaria la realización de una evaluación o toma de datos, tanto de los requisitos de calidad como de los aspectos/impactos medioambientales y de los riesgos laborales, para señalar los que afectan a la actividad de la organización. También obliga a repasar los requisitos legales.

La identificación de los requisitos debe concluir con el mapa y flujo gramas de los procesos. 


\section{- Despliegue de los requisitos.}

Una vez identificados los procesos y los requisitos hay que circunscribirlos o asignarlos a un método (procedimiento). Se pueden integrar los requisitos en un mismo procedimiento o no.

Un procedimiento refleja las acciones operativas, de supervisión, de comunicación y de registro de datos de un proceso. Los responsables de cada acción deben ser identificados y los límites tienen que estar establecidos desde el principio.

Un procedimiento debe incluir:

- El objeto, que indica para qué se hace.

- El alcance, que establece el límite de aplicación.

- Los documentos de referencia, que son aquellos sobre los que se parte para elaborar el procedimiento.

- Las generalidades, que explican conceptos que aparecen en la redacción del procedimiento.

- La realización, que explica de qué actividades se trata, cómo, cuándo y quién las hace.

- Los anexos necesarios para completar el documento.

Además, en ellos debe identificarse el nombre de la organización, el título y código del documento, su número de edición y fecha y las firmas de quien lo ha elaborado y aprobado.

\section{-Integración de métodos y documentos}

Una vez escogido un estilo de procedimientos e instrucciones, la mayoría de documentos desarrollados tienen una estructura totalmente integrable (con alguna excepción: procedimiento o instrucción en forma de vídeo o fotografía). En el caso de procedimientos o instrucciones comunes la integración consiste en preparar el documento común y eliminar los particulares de cada sistema de gestión. Sin embargo, cuando los métodos sólo son aplicables a un sistema, no se pueden integrar. Un solo Manual tiene que integrar los elementos comunes e incorporar los elementos diferenciados.

En la tabla siguiente se relaciona una posible lista de los procedimientos de un sistema de gestión integrada. Por supuesto, las particularidades de cada organización pueden hacer variar dicho esquema, amén de las instrucciones de trabajo que la organización tenga a bien desarrollar por considerarlas de interés o imprescindibles. 


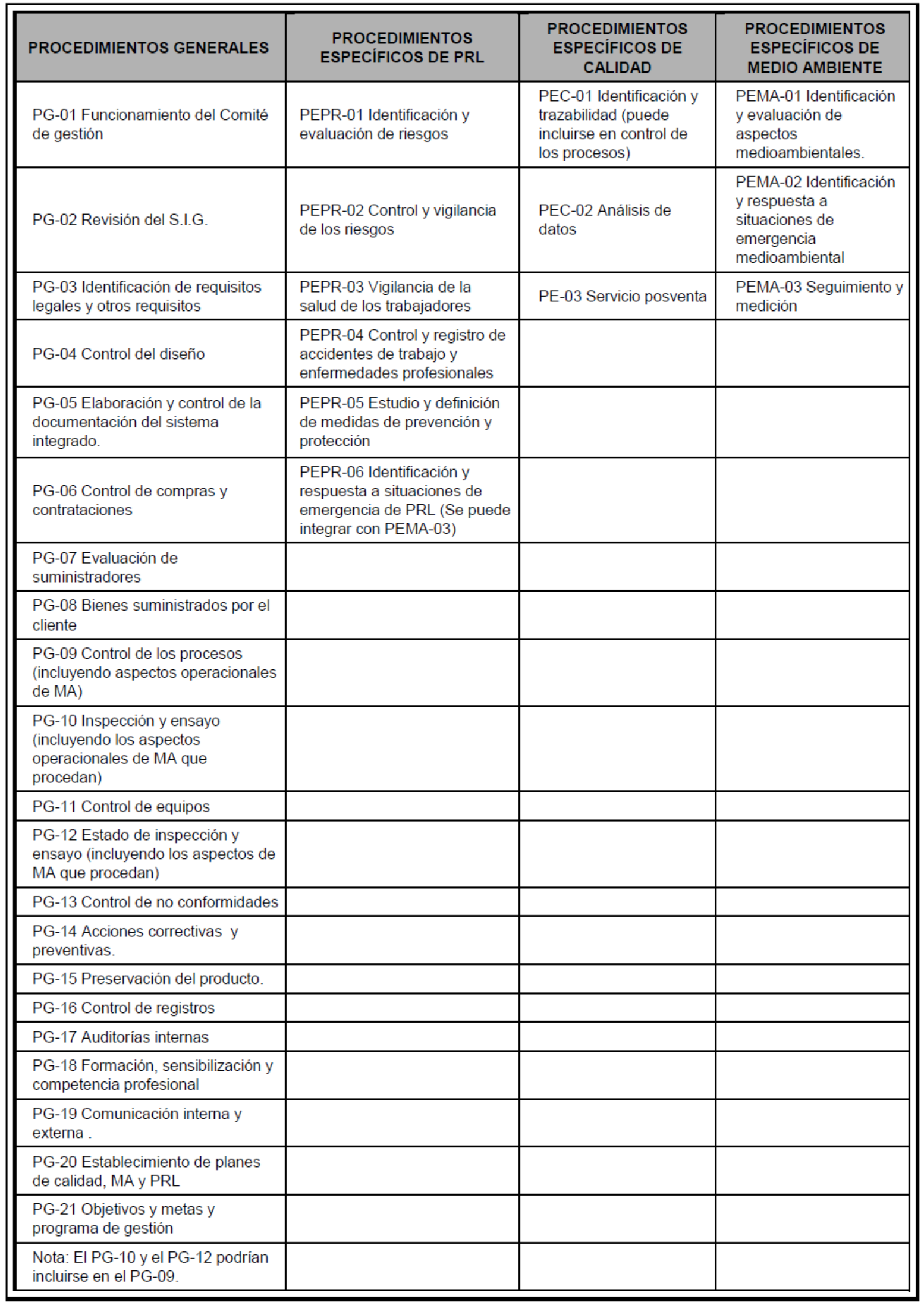

Tabla 12 Procedimientos de un sistema de gestión integrado 


\section{6- IMPLANTACIÓN DE UN SISTEMA INTEGRADO}

\section{A. Formación y sensibilización}

La formación mínima necesaria para el diseño e implantación de un sistema de gestión integrada se debe impartir en cuatro etapas diferentes.

\section{-Formación previa.}

Esta formación persigue que determinadas personas en la organización conozcan de forma exhaustiva cuáles son las herramientas y el tipo de gestión que se va a implantar (los conocimientos adquiridos se desplegarán más adelante en la organización). Tiene que haber un referente claro de quiénes son los expertos de cada tema, que además serán los encargados de diseñar o retocar el sistema. Las principales materias que debe abarcar esta formación son: normas y legislación, identificación, análisis y documentación de procesos, gestión por procesos, diagnosis,...

\section{-Formación durante el proceso de documentación.}

Una vez que ha sido diseñado el sistema de gestión integrada, se han identificado los requisitos y se han integrado los métodos y la organización, comienza el proceso de elaboración de la documentación. Para ello se proporciona formación a los equipos de trabajo dentro de las diferentes áreas en que se divide la organización. El objetivo es conseguir que las personas que elaboren la documentación lo hagan con criterio y método.

Las principales materias a tratar son: normas y legislación, adaptación de las normas a la organización, identificación, análisis y documentación de procesos, y gestión por procesos.

\section{- Formación durante el proceso de implantación}

Previamente a la implantación se debe formar a toda la plantilla en los distintos niveles:

Dirección, gestión y operación. El motivo es que la totalidad de la plantilla debe actuar conforme a los procedimientos que se han elaborado.

Las materias a impartir son: políticas, el sistema de gestión integrada,...

\section{-Formación para la auditoría}

Una vez que el sistema ha sido diseñado, se han elaborado los procedimientos, toda la organización ha sido informada, formado el personal y el sistema está implantado, es necesario que se audite. La auditoría consiste en comprobar que efectivamente las personas de la organización actúan conforme al sistema y que éste es adecuado y eficaz. La auditoría debe llevarse a cabo por personas independientes de la actividad auditada, por lo que puede tratarse de personas ajenas a la organización o bien de personas que pertenecen a la organización pero que se inscriben en áreas o departamentos diferentes al auditado.

Las materias en las que los auditores internos (calidad, medio ambiente y PRL) han de ser formados son las siguientes: planificación de la auditoría, realización de la auditoría, información de los resultados, acciones correctivas resultado de la auditoría. 


\section{B. Implantación}

Para abordar la implantación del sistema de gestión integrada hay que tener presente que las actividades que se citan a continuación sirven para el inicio de la implantación o puesta en marcha del sistema pero que, realmente, la implantación no termina con la realización de estas actividades, sino que el sistema debe ser objeto de un mantenimiento y mejora constante.

En primer lugar se debe elaborar el orden o calendario del desarrollo y/o modificación de los procedimientos y de su implantación, es decir, la planificación. En concreto deben quedar claros:

- La documentación que define el proceso o actividad y los objetivos finales y parciales de la implantación.

- Los responsables de documentación, aprobación e implantación.

- Los plazos para la realización de actividades.

- Los medios necesarios para su implantación (estos medios pueden ser humanos, metodológicos, formativos, de equipamiento, materiales, etc.).

- Los registros de datos a generar.

La implantación del sistema se tiene que realizar conforme a los planes establecidos y bajo la responsabilidad de las personas designadas. Dicha actividad consiste, fundamentalmente, en aplicar lo definido, en comprobar su cumplimiento y en evaluar su eficacia. Previamente se habrá distribuido la documentación correspondiente a cada puesto de trabajo y se habrán dado todas las explicaciones pertinentes al personal. El siguiente gráfico ilustra las etapas de la integración.

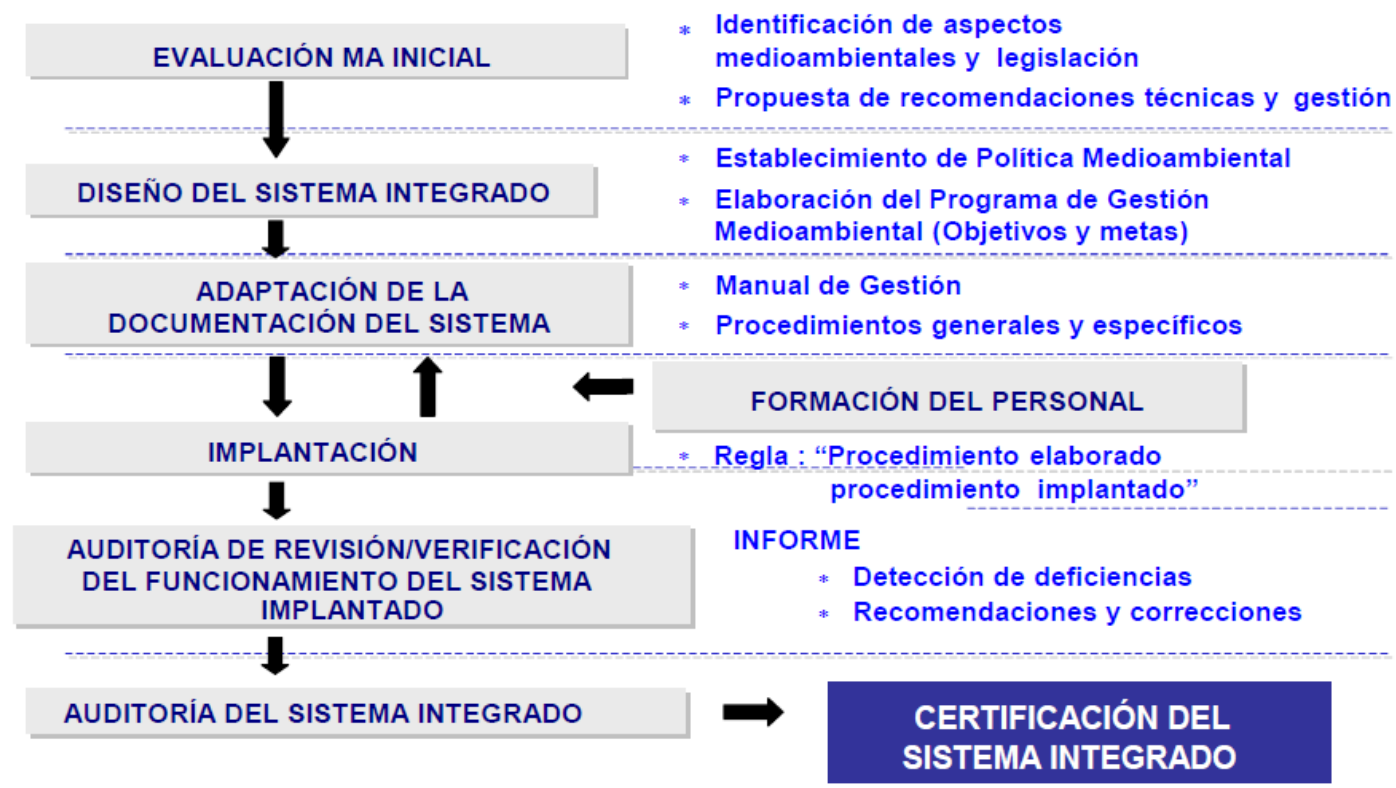

Figura 36 Etapas de la integración 


\section{7- AUDITORÍA DEL SISTEMA INTEGRADO}

En términos genéricos la auditoría puede ser entendida como una herramienta al servicio de la gestión de la organización, consistente en la evaluación sistemática, documentada, periódica y objetiva del funcionamiento adecuado de una actividad. Dicha evaluación puede realizarse desde diferentes ópticas: económica, de la calidad, de la seguridad, del medio ambiente, de la higiene y salud, etc.

En el caso que nos ocupa, entenderemos por auditoría conjunta del sistema integrado de la calidad, del medio ambiente y de la PRL, a la auditoría o sucesivas auditorías parciales que permiten comprobar si se cumplen en la organización las prácticas establecidas relativas a la calidad, al medio ambiente y a la prevención de riesgos laborales.

En la auditoría no sólo se ha de revisar del cumplimiento de procedimientos e instrucciones relativos a cada una de estas disciplinas. También se ha de verificar o determinar el grado de eficacia a la hora de alcanzar los objetivos propuestos en cada una de las tres materias que componen el sistema integrado. Otras líneas de investigación en la auditoría podrían ser las relativas a los costes internos de funcionamiento del sistema, por ejemplo, los costes asociados a no conformidades ( $i$ se han reducido, o por el contrario, han aumentado? ¿A qué ha sido debido? ¿Existen posibilidades de continuar reduciendo dichos costes?, etc.).

La auditoría no debe limitarse a una mera inspección documental y de registros. En un ambiente relajado, auditor y auditado deberían analizar cada una de las prácticas auditadas, los resultados conseguidos hasta la fecha y las posibilidades reales de mejora. La auditoría no es una inspección fiscal, sino que representa la oportunidad para hablar directamente con los empleados y que ellos cuenten sus impresiones directas sobre el procedimiento auditado (al fin y al cabo, las personas que están trabajando cada día en una tarea son las que poseen elementos de juicio para concluir si el método es el ideal, simplemente adecuado para los fines que se pretenden o presenta deficiencias, por ejemplo, de recursos materiales).

Durante la auditoría se deben revisar los informes anteriores de auditoría y el estado de las acciones correctivas que se abrieron en su día como respuesta a las no conformidades. Debe, asimismo, representar una oportunidad de informar a la Dirección del estado del sistema y de las posibilidades de mejora del mismo. Si el auditor es externo también puede aprovecharse para que, sin revelar datos o nombres confidenciales, asesore sobre el funcionamiento de estos sistemas en organizaciones del mismo sector o afines.

A continuación se citan una serie de normas que pueden utilizarse a la hora de planificar y realizar una auditoría interna.

\section{A. Normas de referencia en auditorías de gestión de la calidad y medio ambiente}

Actualmente está disponible la Norma ISO 19011 "Directrices para la auditoría medioambiental y de la calidad". El objetivo de esta norma de auditorías integradas, es dar respuesta a lo requerido por diferentes organizaciones en cuanto a homogeneizar auditorías en materia de gestión de la calidad y del medio ambiente, reduciendo plazos y costes, así como evitar incongruencias entre las auditorías de ambos sistemas. 


\section{B. Normas de referencia en auditorías de prevención de riesgos laborales}

Otra de las normas que existen en el ámbito de la PRL es la OSHAS 18001, editada por el BSI (British Standards, la entidad de normalización del Reino Unido).

OHSAS 18001 es una herramienta que ayuda a las organizaciones a identificar, priorizar y gestionar la salud y los riesgos laborales como parte de sus prácticas normales de negocio. La norma permite a la organización concentrarse en los asuntos más importantes de su negocio. Ha sido desarrollada para ser compatible con la ISO 9001 e ISO 14001, facilitando la integración de calidad, salud profesional y el medioambiente.

\section{8. - VENTAJAS DE LA INTEGRACIÓN DE SISTEMAS}

\section{- Alineamiento de las diferentes políticas y objetivos de la organización.}

Si bien las materias a integrar, no son contrarias en su fondo o filosofía ni entran en conflicto por tratarlas a un mismo tiempo, no es menos cierto que en ocasiones los esfuerzos se concentran más en unos aspectos que en otros, a veces sin razón aparente, otras por caprichos o creencias erróneas de la Dirección y, en el peor de los casos, por desconocimiento de los temas tratados. Al integrar los diferentes sistemas de gestión se asegura la distribución adecuada de los periodos de dedicación a cada uno de ellos, los recursos y las medias en cada una de las áreas.

\section{- Armonización de los diferentes criterios de gestión.}

La integración equilibra la importancia de cada área de gestión y evita el planteamiento reduccionista de quienes dicen "estamos certificados en calidad porque nos lo exige el mercado, en medioambiente para no tener problemas con la Administración... y lo de

PRL para no tener problemas ante un caso de accidente o una inspección".

Se trata de homogeneizar actuaciones, responsabilidades, terminologías y evitar duplicidades innecesarias: ¿por qué un determinado registro no puede servir para dar cumplimiento a un mismo requisito que aparece en los tres modelos?

\section{-Simplificación de la estructura documental del sistema.}

Integrar es sumar eliminando duplicidades. Los requisitos o prácticas comunes pueden simplificarse en un único documento, con lo que se obtiene un ahorro de dos documentos. Esto es más apreciable en los requisitos de gestión de los sistemas. Así, por ejemplo, un procedimiento sobre la gestión de acciones correctivas podría ser perfectamente válido para las tres disciplinas contempladas.

\section{-Menor esfuerzo global de formación del personal e implantación del sistema.}

Gracias a la similitud en los esquemas de funcionamiento de estos sistemas, una vez formado o explicado el funcionamiento de un sistema de gestión (por ejemplo, el de 
gestión de la calidad), los otros presentan diferencias mínimas en cuanto a su arquitectura. La formación adecuada consistiría en explicar los apartados comunes con el primero y resaltar los procedimientos o practicas específicas de cada uno de ellos.

\section{- Menor esfuerzo de mantenimiento del sistema.}

Al reducirse el número de los documentos que componen el sistema integrado respecto de los tres sistemas por separado, la redición de documentos, su distribución y difusión, etc., resulta más rápida y sencilla.

\section{- Integración de la información y el control de gestión.}

La información en materia de gestión de la calidad, del medio ambiente o de la prevención de riesgos laborales no se dispone en compartimentos estancos. La información de la organización está interrelacionada y de lo que se trata es de aprovechar esta circunstancia integrando toda la información en, por ejemplo, una buena red informática y de archivos.

\section{- Relacionabilidad de las diferentes tareas en un único puesto de trabajo.}

Se trata de que distintas tareas sean ejecutadas por una única persona, de modo que los criterios de actuación sean comunes en cuanto a su aplicación. De esta forma, encontramos hoy en día la función del Responsable de calidad, medio ambiente y PRL como el responsable del control (a modo de médico de cabecera) y del correcto funcionamiento de los tres sistemas. Al estar centralizado en la misma figura, dicho control aumenta en eficiencia. Sólo en grandes organizaciones estaría justificada la separación de la gestión de los tres sistemas en diferentes personas (aunque el sistema se encontrase igualmente unificado).

\section{- Reducción del tiempo y coste de mantenimiento del sistema.}

Baste el ejemplo del coste de las auditorías de seguimiento de las entidades de certificación: a menor documentación en juego menor tiempo de dedicación a la preparación y ejecución de la auditoría.

\section{9- GESTIÓN AMBIENTAL}

Contaminar el entorno resulta cada vez más caro, el principio"quien contamina paga" se debe tener muy en cuenta a la hora de llevar a la práctica actuaciones encaminadas a destruir el equilibrio ecológico natural establecido. No solamente se trata de reparar el daño provocado y de soportar una sanción económica, por otra parte una empresa que contamina transmite una imagen de empresa nada favorable en los criterios ecológicos muy influyentes hoy en día en los consumidores.

Las empresas punteras en gestión medioambiental han demostrado las ventajas alcanzadas en el ratio coste-beneficio por integrar en todos los nivels de su Organización 
parámetros ambientales, ya que en realidad son programas de ahorro y racionalización de los recursos.

La gestión ambiental es gestionar las actividades de las empresas que tienen, han tenido o pueden tener un impacto ambiental, mientras que un sistema de gestión ambiental es un instrumento de carácter voluntario dirigido a empresas $u$ organizaciones que quieren alcanzar un alto nivel de protección del medio ambiente en el marco del desarrollo sostenible. Un sistema de gestión ambiental se construye a base de acciones medioambientales y herramientas de gestión. Esas acciones interaccionan entre si para conseguir un objetivo claramente definido: protección medioambiental.

El objetivo perseguido por estos sistemas es garantizar una mejora en el comportamiento medioambiental de las empresas, en especial en todo lo relacionado con los recursos naturales, las emisiones contaminantes a la atmósfera, el consumo y vertido de aguas, el suelo y los niveles de ruido. Se deben crear una serie de procedimientos y hábitos de trabajo, generalmente ya llevados a la práctica en la empresa, pero que con estos sistemas normalizados de gestión se hace necesario asumirlos totalmente como una tarea más dentro de la organización. Se deben tener documentados todas las actuaciones todas las actuaciones de carácter medioambiental que realicen la empresa para demostrar el correcto cumplimiento de los requisitos de estos sistemas de gestón. El cumplimiento óptimo de estas normas puede ser validado en una auditoría por una empresa acreditada.

Las ventajas que se obtienen de un sistema de gestión medioambiental son los siguientes:

- Calidad en la gestión medioambiental.

- Reducción del riesgo medioambiental en la Organización. Disminución de cargas financieras debido a una gestión activa en reducir la contaminación, minimización de impuestos ambientales y ausencia de multas por no cumplir la legislación.

- Ahorro de recursos.

- Ventajas financieras por mejor control de operaciones.

- Comprobación de cumplimiento de legislación medioambiental.

- Posibilidad de aprender de los buenos ejemplos de otras empresas y organizaciones.

- Oportunidades de negocio en mercados donde los procesos de producción limpioa son importantes.

- Credibilidad y confianza con autoridades públicas, clientes y ciudadanos.

- Mejora de la calidad en lugares de trabajo e incentivo al fomentar la participación del empleado.

- Ventajas en el mercado y mejora de la imagen de la empresa al ser más positiva su relación con los grupos de presión.

Hoy en día mantener una correcta gestión medioambiental en la empresa es dar un valor añadido a la producción ya que influye decisivamente tanto en la imagen corporativa de la empresa como en la calidad del producto, además de en su coste, su comercialización y en suma, en la competitividad global. Desde el punto de vista teórico, las motivaciones de la empresa para reducir sus impactos ambientales se podrían resumir esquemáticamente diciendo que los costes podrían reducirse y que los ingresos se incrementarían. 
Como ya se ha mencionado, los sistemas de gestión ambientales pueden gestionarse mediante la norma ISO 14001 o por el Reglamento Europeo EMAS. En este proyecto veremos la norma Iso 14001:2004 (debido a su aportación a los sitemas integrados de gestión) y los requisitos del Reglamento Europeo EMAS no contemplados en la Iso 14001.

\subsection{1- ISO 14001:2004.}

\section{Objeto y campo de aplicación}

Esta Norma Internacional especifica los requisitos para un sistema de gestión ambiental, destinados a permitir que una organización desarrolle e implemente una política y unos objetivos que tengan en cuenta los requisitos legales y otros requisitos que la organización suscriba, y la información relativa a los aspectos ambientales significativos. Se aplica a aquellos aspectos ambientales que la organización identifica que puede controlar y aquellos sobre los que la organización puede tener influencia. No establece por sí misma criterios de desempeño ambiental específicos.

Esta Norma Internacional se aplica a cualquier organización que desee:

a) establecer, implementar, mantener y mejorar un sistema de gestión ambiental;

b) asegurarse de su conformidad con su política ambiental establecida;

c) demostrar la conformidad con esta Norma Internacional por:

1) la realización de una autoevaluación y autodeclaración, o

2) la búsqueda de confirmación de dicha conformidad por las partes interesadas en la organización, tales como clientes; o

3) la búsqueda de confirmación de su auto declaración por una parte externa a la organización; o

4) la búsqueda de la certificación/registro de su sistema de gestión ambiental por una parte externa a la organización.

Todos los requisitos de esta Norma Internacional tienen como fin su incorporación a cualquier sistema de gestión ambiental. Su grado de aplicación depende de factores tales como la política ambiental de la organización, la naturaleza de sus actividades, productos y servicios y la localización donde y las condiciones en las cuales opera.

Esta Norma Internacional también proporciona, en el anexo A, orientación de carácter informativo sobre su uso.

\section{Normas para consulta}

No se citan referencias normativas. Este apartado se incluye con el propósito de mantener el mismo orden numérico de los apartados de la edición anterior (ISO 14001:1996).

\section{Términos y definiciones}

Para el propósito de esta norma internacional se aplican las siguientes definiciones. 


\subsection{Auditor}

Persona con competencia para llevar a cabo una auditoría

\subsection{Mejora continua}

Proceso recurrente de optimización del sistema de gestión ambiental (3.8) para lograr mejoras en el desempeño ambiental global (3.10) de forma coherente con la política ambiental (3.11) de la organización (3.16)

NOTA No es necesario que dicho proceso se lleve a cabo de forma simultánea en todas las áreas de actividad.

\subsection{Acción correctiva}

Acción para eliminar la causa de una no conformidad (3.15) detectada

\subsection{Documento}

Información y su medio de soporte

NOTA 1 El medio de soporte puede ser papel, disco magnético, óptico o electrónico, fotografía o muestras patrón, o una combinación de éstos.

NOTA 2 Adaptada del apartado 3.7.2 de la Norma ISO 9000:2000.

\subsection{Medio ambiente.}

entorno en el cual una organización (3.16) opera, incluidos el aire, el agua, el suelo, los recursos naturales, la flora, la fauna, los seres humanos y sus interrelaciones

NOTA El entorno en este contexto se extiende desde el interior de una organización (3.16) hasta el sistema global.

\subsection{Aspecto ambiental}

Elemento de las actividades, productos o servicios de una organización (3.16) que puede interactuar con el medio ambiente (3.5)

NOTA Un aspecto ambiental significativo tiene o puede tener un impacto ambiental (3.7) significativo.

\subsection{Impacto ambiental}

Cualquier cambio en el medio ambiente (3.5), ya sea adverso o beneficioso, como resultado total o parcial de los aspectos ambientales (3.6) de una organización (3.16)

\subsection{Sistema de gestión ambiental SGA}

Parte del sistema de gestión de una organización (3.16), empleada para desarrollar e implementar su política ambiental (3.11) y gestionar sus aspectos ambientales (3.6)

NOTA 1 Un sistema de gestión es un grupo de elementos interrelacionados usados para establecer la política y los objetivos y para cumplir estos objetivos. 
NOTA 2 Un sistema de gestión incluye la estructura de la organización, la planificación de actividades, las responsabilidades, las prácticas, los procedimientos (3.19), los procesos y los recursos.

\subsection{Objetivo ambiental}

Fin ambiental de carácter general coherente con la política ambiental (3.11), que una organización (3.16) se establece

\subsection{Desempeño ambiental}

Resultados medibles de la gestión que hace una organización (3.16) de sus aspectos ambientales (3.6)

NOTA En el contexto de los sistemas de gestión ambiental (3.8), los resultados se pueden medir respecto a la política ambiental (3.11), los objetivos ambientales (3.9) y las metas ambientales (3.12) de la organización (3.16) y otros requisitos de desempeño ambiental.

\subsection{Política ambiental}

Intenciones y dirección generales de una organización (3.16) relacionadas con su desempeño ambiental (3.10), como las ha expresado formalmente la alta dirección

NOTA La política ambiental proporciona una estructura para la acción y para el establecimiento de los objetivos ambientales (3.9) y las metas ambientales (3.12).

\subsection{Meta ambiental}

Requisito de desempeño detallado aplicable a la organización (3.16) o a partes de ella, que tiene su origen en los objetivos ambientales (3.9) y que es necesario establecer y cumplir para alcanzar dichos objetivos

\subsection{Parte interesada}

Persona o grupo que tiene interés o está afectado por el desempeño ambiental (3.10) de una organización (3.16)

\subsection{Auditoría interna}

Proceso sistemático, independiente y documentado para obtener evidencias de la auditoría y evaluarlas de manera objetiva con el fin de determinar la extensión en que se cumplen los criterios de auditoría del sistema de gestión ambiental fijado por la organización (3.16)

NOTA 1 En muchos casos, particularmente en organizaciones pequeñas, la independencia puede demostrarse al estar libre el auditor de responsabilidades en la actividad que se audita.

\subsection{No conformidad}

Incumplimiento de un requisito

[ISO 9000:2000, 3.6.2] 


\subsection{Organización}

Compañía, corporación, firma, empresa, autoridad o institución, o parte o combinación de ellas, sean o no sociedades, pública o privada, que tiene sus propias funciones y administración

NOTA Para organizaciones con más de una unidad operativa, una unidad operativa por sí sola puede definirse como una organización.

\subsection{Acción preventiva}

Acción para eliminar la causa de una no conformidad (3.15) potencial

\subsection{Prevención de la contaminación}

Utilización de procesos, prácticas, técnicas, materiales, productos, servicios o energía para evitar, reducir o controlar (en forma separada o en combinación) la generación, emisión o descarga de cualquier tipo de contaminante o residuo, con el fin de reducir impactos ambientales (3.7) adversos

NOTA La prevención de la contaminación puede incluir reducción o eliminación en la fuente, cambios en el proceso, producto o servicio, uso eficiente de recursos, sustitución de materiales o energía, reutilización, recuperación, reciclaje, aprovechamiento y tratamiento.

\subsection{Procedimiento}

Forma especificada de llevar a cabo una actividad o proceso

NOTA 1 Los procedimientos pueden estar documentados o no.

NOTA 2 Adaptada del apartado 3.4.5 de la Norma ISO 9000:2000.

\subsection{Registro}

Documento (3.4) que presenta resultados obtenidos, o proporciona evidencia de las actividades desempeñadas

NOTA Adaptada del apartado 3.7.6 de la Norma ISO 9000:2000.

\section{Requisitos del sistema de gestión ambiental}

\subsection{Requisitos generales}

La organización debe establecer, documentar, implementar, mantener y mejorar continuamente un sistema de gestión ambiental de acuerdo con los requisitos de esta norma internacional, y determinar cómo cumplirá estos requisitos. La organización debe definir y documentar el alcance de su sistema de gestión ambiental.

\subsection{Política ambiental}

La alta dirección debe definir la política ambiental de la organización y asegurarse de que, dentro del alcance definido de su sistema de gestión ambiental, ésta: 
a) es apropiada a la naturaleza, magnitud e impactos ambientales de sus actividades, productos y servicios;

b) incluye un compromiso de mejora continua y prevención de la contaminación;

c) incluye un compromiso de cumplir con los requisitos legales aplicables y con otros requisitos que la organización suscriba relacionados con sus aspectos ambientales;

d) proporciona el marco de referencia para establecer y revisar los objetivos y las metas ambientales;

e) se documenta, implementa y mantiene;

f) se comunica a todas las personas que trabajan para la organización o en nombre de ella; $y$

g) está a disposición del público.

\subsection{Planificación}

\subsubsection{Aspectos ambientales}

La organización debe establecer, implementar y mantener uno o varios procedimientos para:

a) identificar los aspectos ambientales de sus actividades, productos y servicios que pueda controlar y aquellos sobre los que pueda influir dentro del alcance definido del sistema de gestión ambiental, teniendo en cuenta los desarrollos nuevos o planificados, o las actividades, productos y servicios nuevos o modificados; y

b) determinar aquellos aspectos que tienen o pueden tener impactos significativos sobre el medio ambiente (es decir, aspectos ambientales significativos).

La organización debe documentar esta información y mantenerla actualizada. La organización debe asegurarse de que los aspectos ambientales significativos se tengan en cuenta en el establecimiento, implementación y mantenimiento de su sistema de gestión ambiental.

\subsubsection{Requisitos legales y otros requisitos}

La organización debe establecer, implementar y mantener uno o varios procedimientos para:

a) identificar y tener acceso a los requisitos legales aplicables y otros requisitos que la organización suscriba relacionados con sus aspectos ambientales; y

b) determinar cómo se aplican estos requisitos a sus aspectos ambientales.

La organización debe asegurarse de que estos requisitos legales aplicables y otros requisitos que la organización suscriba se tengan en cuenta en el establecimiento, implementación y mantenimiento de su sistema de gestión ambiental.

\subsubsection{Objetivos, metas y programas}

La organización debe establecer, implementar y mantener objetivos y metas ambientales documentados, en los niveles y funciones pertinentes dentro de la organización. Los objetivos y metas deben ser medibles cuando sea factible y deben ser coherentes con la política ambiental, incluidos los compromisos de prevención de la contaminación, el 
cumplimiento con los requisitos legales aplicables y otros requisitos que la organización suscriba, y con la mejora continua.

Cuando una organización establece y revisa sus objetivos y metas, debe tener en cuenta los requisitos legales y otros requisitos que la organización suscriba, y sus aspectos ambientales significativos. Además, debe considerar sus opciones tecnológicas y sus requisitos financieros, operacionales y comerciales, así como las opiniones de las partes interesadas.

La organización debe establecer, implementar y mantener uno o varios programas para alcanzar sus objetivos y metas. Estos programas deben incluir:

a) la asignación de responsabilidades para lograr los objetivos y metas en las funciones y niveles pertinentes de la organización; y

b) los medios y plazos para lograrlos.

\subsection{Implementación y operación}

\subsubsection{Recursos, funciones, responsabilidad y autoridad}

La dirección debe asegurarse de la disponibilidad de recursos esenciales para establecer, implementar, mantener y mejorar el sistema de gestión ambiental. Estos, incluyen los recursos humanos y habilidades especializadas, infraestructura de la organización, y los recursos financieros y tecnológicos.

Las funciones, las responsabilidades y la autoridad se deben definir, documentar y comunicar para facilitar una gestión ambiental eficaz. La alta dirección de la organización debe designar uno o varios representantes de la dirección, quien, independientemente de otras responsabilidades, debe tener definidas sus funciones, responsabilidades y autoridad para:

a) asegurarse de que el sistema de gestión ambiental se establece, implementa y mantiene de acuerdo con los requisitos de esta Norma Internacional;

b) informar a la alta dirección sobre el desempeño del sistema de gestión ambiental para su revisión, incluyendo las recomendaciones para la mejora.

\subsubsection{Competencia, formación y toma de conciencia}

La organización debe asegurarse de que cualquier persona que realice tareas para ella o en su nombre, que potencialmente pueda causar uno o varios impactos ambientales significativos identificados por la organización, sea competente tomando como base una educación, formación o experiencia adecuadas, y debe mantener los registros asociados.

La organización debe identificar las necesidades de formación relacionadas con sus aspectos ambientales y su sistema de gestión ambiental. Debe proporcionar formación o emprender otras acciones para satisfacer estas necesidades, y debe mantener los registros asociados. La organización debe establecer y mantener uno o varios procedimientos para que sus empleados o las personas que trabajan en su nombre tomen conciencia de: 
a) la importancia de la conformidad con la política ambiental, los procedimientos y requisitos del sistema de gestión ambiental;

b) los aspectos ambientales significativos, los impactos relacionados reales $\mathrm{o}$ potenciales asociados con su trabajo y los beneficios ambientales de un mejor desempeño personal;

c) sus funciones y responsabilidades en el logro de la conformidad con los requisitos del sistema de gestión ambiental; $y$

d) las consecuencias potenciales de desviarse de los procedimientos especificados.

\subsubsection{Comunicación}

En relación con sus aspectos ambientales y su sistema de gestión ambiental, la organización debe establecer, implementar y mantener uno o varios procedimientos para:

a) la comunicación interna entre los diversos niveles y funciones de la organización;

b) recibir, documentar y responder a las comunicaciones pertinentes de las partes interesadas externas.

La organización debe decidir si comunica o no externamente información acerca de sus aspectos ambientales significativos y debe documentar su decisión. Si la decisión es comunicarla, la organización debe establecer e implementar uno o varios métodos para realizar esta comunicación externa.

\subsubsection{Documentación}

La documentación del sistema de gestión ambiental debe incluir:

a) la política, objetivos y metas ambientales;

b) la descripción del alcance del sistema de gestión ambiental;

c) la descripción de los elementos principales del sistema de gestión ambiental y su interacción, así como la referencia a los documentos relacionados;

d) los documentos, incluyendo los registros requeridos en esta Norma Internacional; y

e) los documentos, incluyendo los registros determinados por la organización como necesarios para asegurar la eficacia de la planificación, operación y control de procesos relacionados con sus aspectos ambientales significativos.

\subsubsection{Control de documentos}

Los documentos requeridos por el sistema de gestión ambiental y por esta norma internacional se deben controlar. Los registros son un tipo especial de documento y se deben controlar de acuerdo con los requisitos establecidos en el apartado 4.5.4.

La organización debe establecer, implementar y mantener uno o varios procedimientos para:

a) aprobar los documentos con relación a su adecuación antes de su emisión;

b) revisar y actualizar los documentos cuando sea necesario, y aprobarlos nuevamente; 
c) asegurarse de que se identifican los cambios y el estado de revisión actual de los documentos;

d) asegurarse de que las versiones pertinentes de los documentos aplicables están disponibles en los puntos de uso;

e) asegurarse de que los documentos permanecen legibles y fácilmente identificables;

f) asegurarse de que se identifican los documentos de origen externo que la organización ha determinado que son necesarios para la planificación y operación del sistema de gestión ambiental y se controla su distribución; y

g) prevenir el uso no intencionado de documentos obsoletos, y aplicarles una identificación adecuada en el caso de que se mantengan por cualquier razón.

\subsubsection{Control operacional}

La organización debe identificar y planificar aquellas operaciones que están asociadas con los aspectos ambientales significativos identificados, de acuerdo con su política ambiental, objetivos y metas, con el objeto de asegurarse de que se efectúan bajo las condiciones especificadas, mediante:

a) el establecimiento, implementación y mantenimiento de uno o varios procedimientos documentados para controlar situaciones en las que su ausencia podría llevar a desviaciones de la política, los objetivos y metas ambientales; y

b) el establecimiento de criterios operacionales en los procedimientos; $y$

c) el establecimiento, implementación y mantenimiento de procedimientos relacionados con aspectos ambientales significativos identificados de los bienes y servicios utilizados por la organización, y la comunicación de los procedimientos y requisitos aplicables a los proveedores, incluyendo contratistas.

\subsubsection{Preparación y respuesta ante emergencias}

La organización debe establecer, implementar y mantener uno o varios procedimientos para identificar situaciones potenciales de emergencia y accidentes potenciales que pueden tener impactos en el medio ambiente y cómo responder ante ellos. La organización debe responder ante situaciones de emergencia y accidentes reales y prevenir o mitigar los impactos ambientales adversos asociados. La organización debe revisar periódicamente, y modificar cuando sea necesario sus procedimientos de preparación y respuesta ante emergencias, en particular después de que ocurran accidentes o situaciones de emergencia.

La organización también debe realizar pruebas periódicas de tales procedimientos, cuando sea factible.

\subsection{Verificación}

\subsubsection{Seguimiento y medición}

La organización debe establecer, implementar y mantener uno o varios procedimientos para hacer el seguimiento y medir de forma regular las características fundamentales de sus operaciones que pueden tener un impacto significativo en el medio ambiente. Los procedimientos deben incluir la documentación de la información para hacer el 
seguimiento del desempeño, de los controles operacionales aplicables y de la conformidad con los objetivos y metas ambientales de la organización.

La organización debe asegurarse de que los equipos de seguimiento y medición se utilicen y mantengan calibrados o verificados, y se deben conservar los registros asociados.

\subsubsection{Evaluación del cumplimiento legal}

4.5.2.1 En coherencia con su compromiso de cumplimiento, la organización debe establecer, implementar y mantener uno o varios procedimientos para evaluar periódicamente el cumplimiento de los requisitos legales aplicables. La organización debe mantener los registros de los resultados de las evaluaciones periódicas.

4.5.2.2 La organización debe evaluar el cumplimiento con otros requisitos que suscriba. La organización puede combinar esta evaluación con la evaluación del cumplimiento legal mencionada en el apartado 4.5.2.1, o establecer uno o varios procedimientos separados. La organización debe mantener los registros de los resultados de las evaluaciones periódicas.

\subsubsection{No conformidad, acción correctiva y acción preventiva}

La organización debe establecer, implementar y mantener uno o varios procedimientos para tratar las no conformidades reales y potenciales y tomar acciones correctivas y acciones preventivas. Los procedimientos deben definir requisitos para:

a) la identificación y corrección de las no conformidades y tomando las acciones para mitigar sus impactos ambientales;

b) la investigación de las no conformidades, determinando sus causas y tomando las acciones con el fin de prevenir que vuelvan a ocurrir;

c) la evaluación de la necesidad de acciones para prevenir las no conformidades y la implementación de las acciones apropiadas definidas para prevenir su ocurrencia;

d) el registro de los resultados de las acciones preventivas y acciones correctivas tomadas; $y$

e) la revisión de la eficacia de las acciones preventivas y acciones correctivas tomadas.

Las acciones tomadas deben ser las apropiadas en relación a la magnitud de los problemas e impactos ambientales encontrados.

La organización debe asegurarse de que cualquier cambio necesario se incorpore a la documentación del sistema de gestión ambiental.

\subsubsection{Control de los registros}

La organización debe establecer y mantener los registros que sean necesarios, para demostrar la conformidad con los requisitos de su sistema de gestión ambiental y de esta Norma Internacional, y para demostrar los resultados logrados.

La organización debe establecer, implementar y mantener uno o varios procedimientos para la identificación, el almacenamiento, la protección, la recuperación, el tiempo de 
retención y la disposición de los registros. Los registros deben ser y permanecer legibles, identificables y trazables.

\subsubsection{Auditoría interna}

La organización debe asegurarse de que las auditorías internas del sistema de gestión ambiental se realizan a intervalos planificados para:

a) determinar si el sistema de gestión ambiental:

1) es conforme con las disposiciones planificadas para la gestión ambiental, incluidos los requisitos de esta Norma Internacional; y

2) se ha implementado adecuadamente y se mantiene; y

b) proporcionar información a la dirección sobre los resultados de las auditorías.

La organización debe planificar, establecer, implementar y mantener programas de auditoría, teniendo en cuenta la importancia ambiental de las operaciones implicadas y los resultados de las auditorías previas. Se deben establecer, implementar y mantener uno o varios procedimientos de auditoría que traten sobre:

- Las responsabilidades y los requisitos para planificar y realizar las auditorías, informar sobre los resultados y mantener los registros asociados;

- La determinación de los criterios de auditoría, su alcance, frecuencia y métodos.

La selección de los auditores y la realización de las auditorías debe asegurar la objetividad e imparcialidad del proceso de auditoría.

\subsection{Revisión por la dirección}

La alta dirección debe revisar el sistema de gestión ambiental de la organización, a intervalos planificados, para asegurarse de su conveniencia, adecuación y eficacia continuas. Estas revisiones deben incluir la evaluación de oportunidades de mejora y la necesidad de efectuar cambios en el sistema de gestión ambiental, incluyendo la política ambiental, los objetivos y las metas ambientales. Se deben conservar los registros de las revisiones por la dirección.

Los elementos de entrada para las revisiones por la dirección deben incluir:

a) los resultados de las auditorías internas y evaluaciones de cumplimiento con los requisitos legales y otros requisitos que la organización suscriba;

b) las comunicaciones de las partes interesadas externas, incluidas las quejas;

c) el desempeño ambiental de la organización;

d) el grado de cumplimiento de los objetivos y metas;

e) el estado de las acciones correctivas y preventivas;

f) el seguimiento de las acciones resultantes de las revisiones previas llevadas a cabo por la dirección; 
g) los cambios en las circunstancias, incluyendo la evolución de los requisitos legales y otros requisitos relacionados con sus aspectos ambientales; y

h) las recomendaciones para la mejora.

Los resultados de las revisiones por la dirección deben incluir todas las decisiones y acciones tomadas relacionadas con posibles cambios en la política ambiental, objetivos, metas y otros elementos del sistema de gestión ambiental, coherentes con el compromiso de mejora continua.

\subsection{2.- REQUISITOS EMAS NO CONTEMPLADOS EN ISO 14001}

\section{REQUISITOS EMAS NO CONTEMPLADOS EN ISO 14001}

La Unión Europea ha diseñado un mecanismo de reconocimiento oficial, conocido por el acrónimo EMAS, el cual se recoge en un reglamento de aplicación voluntaria (el Reglamento CEE 761/2001). Tanto la norma ISO 14001 como el reglamento EMAS proponen sistemas de gestión medioambiental muy similares y totalmente compatibles, aunque el modelo europeo es más exigente.

\section{Los requisitos del Reglamento CEE 761/2001 no contemplados en ISO 14001 son:}

- Realizar una implantación por centros productivos.

- Compromiso de adoptar las "mejores tecnologías disponibles" desde la política medioambiental.

- Evaluación y registro de efectos medioambientales.

- Los objetivos y metas deben garantizar mejoras en la actuación medioambiental (resultados concretos).

- Recomienda el uso de indicadores comprensibles, inequívocos y que permitan la

"comparación año a año y con los requisitos legales aplicables".

- Aplicar política y procedimientos a subcontratistas que trabajan en el propio centro.

- Frecuencia mínima de auditorías: 3 años.

- Mayor alcance de la auditoría: incluye la actuación medioambiental de la organización.

- Obligación de realizar una declaración pública y necesidad de acceso fácil y gratuito a la declaración de forma impresa.

- Validación anual obligatoria de la declaración pública (Verificador Medioambiental acreditado).

- Existencia de un organismo competente para el modelo EMAS del año y de un registro público único de ámbito europeo.

El siguiente cuadro resume los aspectos más destacados del Reglamento EMAS del año 2001 que afectan a la organización, al verificador, al organismo de acreditación y al organismo de registro. 


\begin{tabular}{|c|c|}
\hline PARTE IMPLICADA & ASPECTOS DEL REGLAMENTO EMAS 2001 QUE LE AFECTAN \\
\hline Organización & $\begin{array}{l}\text { - Abierto a cualquier tipo de organización } \\
\text { - Las organizaciones certificadas no tendrán que hacer revisión inicial } \\
\text { - Debe validarse anualmente los cambios de la declaración y ponerse a disposición pública } \\
\text { - Posibilidad de utilización de logo en la información validada } \\
\text { - Sugerencia de usar indicadores para que sea comparable en el tiempo y en el sector } \\
\text { - El cumplimiento de los objetivos y metas debe evaluarse como parte de la revisión } \\
\text { - La organización debe asegurar la participación activa de los trabajadores }\end{array}$ \\
\hline Verificador & $\begin{array}{l}\text { - Deberá comprobar que las frases que acompañan al logo son apropiadas y fiables, que no } \\
\text { induzcan a error y que sean significativas } \\
\text { - Comprobar cualquier documento público para las partes interesadas } \\
\text { - No podrá dar un informe favorable si detecta un incumplimiento legal } \\
\text { - Los Verificadores individuales deberán tener ámbito limitado de acreditación } \\
\text { - Cumplir con los requisitos de competencia profesional específicos requeridos al Verificador }\end{array}$ \\
\hline Organismo de Acreditación & $\begin{array}{l}\text { - Se crea un foro de Organismos de Acreditación } \\
\text { - No poner dificultades injustificadas a la supervisión } \\
\text { - La no satisfacción con el trabajo del verificador debe ser comunicada al organismo que lo } \\
\text { acreditó }\end{array}$ \\
\hline Organismo competente & $\begin{array}{l}\text { - Posibilidad de considerar la suspensión o retirada del registro } \\
\text { - Actualizar el listado de organizaciones mensualmente } \\
\text { - Considerar las observaciones de partes interesadas }\end{array}$ \\
\hline
\end{tabular}

Tabla 13 Aspecto del EMAS que afectan a la organización

Las organizaciones europeas que desean acceder a EMAS podrían hacerlo sin la necesidad de utilizar la norma ISO 14001 pero, en la práctica, la gran mayoría han comenzado a aplicar la norma ISO, que ofrece más orientación práctica y mayor flexibilidad. La participación en el sistema europeo puede ser un paso posterior para algunas organizaciones de transporte que necesiten reforzar su compromiso medioambiental. El propio texto del Reglamento EMAS del 2001 (anexo I, apartado A "Requisitos del Sistema de Gestión Medioambiental") dice "El sistema de gestión medioambiental se aplicará de acuerdo con los requisitos que se indican a continuación (sección 4 de la norma EN-ISO 14001)".

\section{VERIFICACIÓN DEL SGMA}

Una vez implantado el SGMA se puede obtener la verificación del mismo. Con el modelo europeo aparece en escena una nueva figura muy similar a la de los Organismos de Certificación, denominada "Verificador Medioambiental", cuya misión es realizar un examen global del sistema y dar fe sobre el cumplimiento de los requisitos del reglamento. El Verificador puede ser tanto una persona física como jurídica, aunque en la práctica la mayor parte de ellos coinciden con los propios Organismos de Certificación. Ambas figuras (verificación y certificación) comparten idénticos requisitos de independencia y competencia técnica, por lo que deben ser objeto de acreditación con arreglo a las mismas normas específicas.

El reglamento europeo contempla, además, la contribución de un organismo competente (en este caso, de tipo gubernamental y designado por cada estado miembro), cuyo papel 
consiste en aprobar la Declaración Medioambiental efectuada por la organización y permitir el acceso definitivo al Registro Europeo de reconocimiento oficial.

A continuación se muestra, en forma gráfica, el proceso de adhesión al modelo europeo:

\section{REGLAMENTO EUROPEO DE ECOGESTIÓN Y ECOAUDITORÍA}

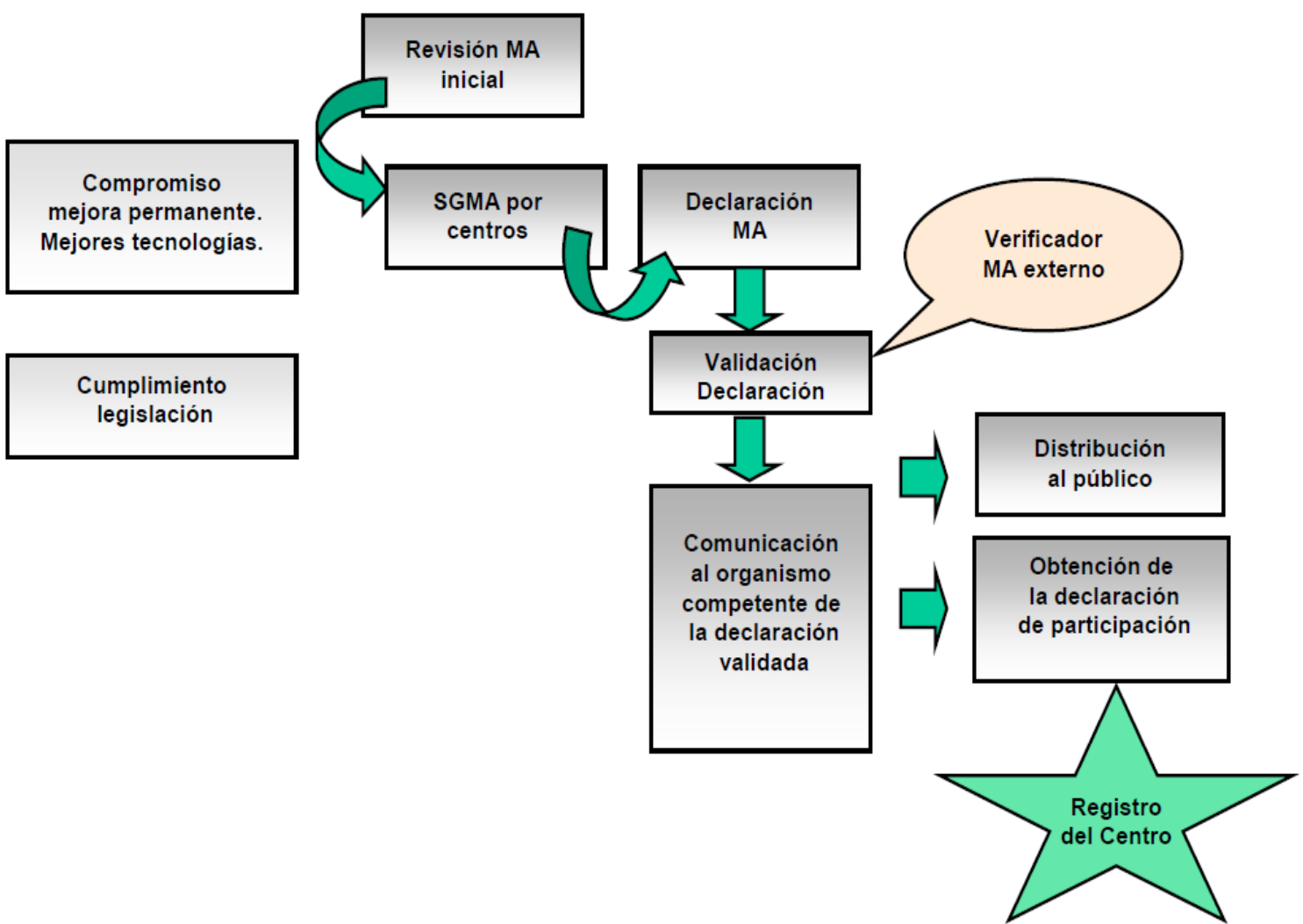

Figura 37 Reglamento europeo de ecogestión y auditoría

\section{DECLARACIÓN MEDIOAMBIENTAL}

La Declaración Medioambiental es un documento mediante el cual la organización que implanta un SGMA siguiendo el Reglamento EMAS da a conocer al público y a todas las partes interesadas sus actuaciones y resultados medioambientales, así como los esfuerzos que está realizando con la finalidad de reducir al máximo posible su impacto medioambiental.

\section{Contenidos mínimos de la Declaración Pública Medioambiental de EMAS:}

- Descripción de las actividades de la organización.

- Valoración de los problemas medioambientales significativos.

- Resumen cuantitativo de datos sobre efectos medioambientales.

- Política, objetivos y metas medioambientales.

- Entidad certificadora o verificadora del SGMA.

- Cambios producidos desde anteriores comunicaciones (tendencias). 
Esta Declaración Medioambiental se ha de redactar de manera resumida y en un lenguaje fácilmente comprensible. En las siguientes páginas se muestra un ejemplo de una Declaración Medioambiental de una organización de transportes. Debe subrayarse que se trata sólo de mostrar cómo otras organizaciones han enfocado el tema. Al tiempo, el propio ejemplo sirve para ilustrar la interrelación de los elementos básicos del SGMA acorde con EMAS.

\subsection{0- GESTIÓN DE LA PREVENCIÓN DE RIESGOS LABORALES}

La seguridad y la salud en el trabajo (SST) es una disciplina que trata de la prevención de las lesiones y enfermedades relacionadas con el trabajo, y de la protección y promoción de la salud de los trabajadores. Tiene por objeto mejorar las condiciones y el medio ambiente de trabajo. La salud en el trabajo conlleva la promoción y el mantenimiento del más alto grado de salud física y mental y de bienestar de los trabajadores en todas las ocupaciones. En este contexto, la anticipación, el reconocimiento, la evaluación y el control de los peligros que surgen en lugar de trabajo o dimanantes del mismo y que pudieran poner en peligro la salud y el bienestar de los trabajadores son los principios fundamentales del proceso que rige la evaluación y gestión de los riesgos. También se deberían tener en cuenta los posibles efectos en las comunidades vecinas y en el medio ambiente general.

El proceso básico de aprendizaje sobre la reducción de los peligros y los riesgos es el origen de los principios más complejos por los que se rige la SST en la actualidad. Hoy por hoy, el hecho de que sea imperativo controlar una industrialización galopante y su necesidad de fuentes de energía sumamente e inherentemente peligrosas, como la utilización de la energía nuclear, los sistemas de transporte y unas tecnologías cada vez más complejas, ha conducido a la elaboración de unos métodos mucho más complejos de gestión y evaluación de los riesgos.

En todos los ámbitos de la actividad humana, es preciso hallar un equilibrio entre los beneficios y los costos que supone la asunción de riesgos. En el caso de la SST, este complejo equilibrio está influido por muchos factores, como el rápido progreso científico y tecnológico, la gran diversidad del mundo del trabajo y su continua evolución, y la economía. El hecho de que la aplicación de los principios de SST conlleve la movilización de todas las disciplinas sociales y científicas es una medida clara de la complejidad de este ámbito.

El concepto de sistemas de gestión se utiliza con frecuencia en los procesos de toma de decisiones en las empresas $\mathrm{y}$, sin saberlo, también en la vida diaria, ya sea en la adquisición de equipo, en la ampliación de la actividad comercial o, simplemente, en la selección de un nuevo mobiliario. La aplicación de los sistemas de gestión de la seguridad y la salud en el trabajo (SG-SST) se basa en criterios, normas y resultados pertinentes en materia de SST. Tiene por objeto proporcionar un método para evaluar y mejorar los resultados en la prevención de los incidentes y accidentes en el lugar de trabajo por medio de la gestión eficaz de los peligros y riesgos en el lugar de trabajo. Es un método lógico y por pasos para decidir aquello que debe hacerse, y el mejor modo de hacerlo, supervisar los 
progresos realizados con respecto al logro de las metas establecidas, evaluar la eficacia de las medidas adoptadas e identificar ámbitos que deben mejorarse. Puede y debe ser capaz de adaptarse a los cambios operados en la actividad de la organización y a los requisitos legislativos.

Este concepto es un proceso basado en el principio del Ciclo Deming "Planificar-HacerVerificar-Actuar" (PHVA), concebido en el decenio de 1950 para supervisar los resultados de las empresas de una manera continua. Al aplicarse a la SST, "Planificar" conlleva establecer una política de SST, elaborar planes que incluyan la asignación de recursos, la facilitación de competencias profesionales y la organización del sistema, la identificación de los peligros y la evaluación de los riesgos. La fase "Hacer" hace referencia a la aplicación y puesta en práctica del programa de SST. La fase "Verificar" se centra en evaluar los resultados tanto activos como reactivos del programa. Por último, la fase "Actuar" cierra el ciclo con un examen del sistema en el contexto de la mejora continua y la preparación del sistema para el próximo ciclo. Un SG-SST es un conjunto de herramientas lógico, caracterizado por su flexibilidad, que puede adaptarse al tamaño y la actividad de la organización, y centrarse en los peligros y riesgos generales o específicos asociados con dicha actividad. Su complejidad puede abarcar desde las necesidades básicas de una empresa pequeña que dirige el proceso de un único producto en el que los riesgos y peligros son fáciles de identificar, hasta industrias que entrañan peligros múltiples, como la minería, la energía nuclear, la manufactura química o la construcción.

El enfoque del SG-SST asegura que:

- La aplicación de las medidas de prevención y protección se lleva a cabo de una manera eficiente y coherente.

- Se establecen políticas pertinentes.

- Se contraen compromisos.

- Se consideran todos los elementos del lugar de trabajo para evaluar los peligros y los riesgos.

- La dirección y los trabajadores participan en el proceso a su nivel de responsabilidad.

En la actualidad se reconoce que el enfoque de los sistemas de gestión ofrece una serie de ventajas importantes para la aplicación de la SST, algunas de las cuales ya hemos identificado. Un enfoque sistémico ajusta asimismo el programa general de seguridad y salud con el tiempo, por lo que las decisiones sobre el control de los peligros y la reducción de los riesgos mejoran progresivamente. Otras ventajas fundamentales son las siguientes:

- La posibilidad de integrar los requisitos en materia de SST en los sistemas de las empresas, la armonización de los requisitos en materia de SST con otros requisitos conexos, en particular aquéllos relativos a la calidad y al medio ambiente.

- La facilitación de un marco lógico sobre el cual establecer y poner en marcha un programa de SST que realice un seguimiento de todos los elementos que exigen la toma de medidas y la supervisión.

- La racionalización y mejora de los mecanismos, las políticas, los procedimientos, los programas y los objetivos de comunicación, de conformidad con un conjunto de normas aplicadas universalmente. 
- La aplicabilidad a las diferencias existentes en los sistemas normativos culturales y nacionales.

- El establecimiento de un entorno que conduzca a la creación de una cultura de prevención en materia de seguridad y salud.

- El fortalecimiento del diálogo social.

- La distribución de las responsabilidades en materia de SST a lo largo de la estructura jerárquica de gestión, de tal modo que se logre la participación de todos: directores, salariados y trabajadores tienen responsabilidades definidas en lo que respecta a la aplicación eficaz del sistema.

- La adaptación al tamaño y a la actividad de la organización, y a los tipos de peligros identificados.

- El establecimiento de un marco de mejora continua.

- La facilitación de un punto de referencia auditable con miras a la evaluación de los resultados.

Los sistemas de gestión de prevención de riesgos laborales (SGPRL) están contemplados, a la vez, en leyes y en normas voluntarias (Ley 31/95, normas ILO-OHS2001 y OHSAS 18001).

En este apartado veremos la estructura de un plan de prevención de riesgos laborales ejemplo, la norma OHSAS 18001:2007 (Debido a su aportación a los sistemas integrados de gestión) y la correspondencia entre la OHSAS 18001, OHSAS 18002 y la norma ILOOHS-2001.

\subsection{1.- ESTRUCTURA DE UN PLAN DE PREVENCIÓN}

1. POLÍTICA DE PREVENCIÓN

\subsection{POLÍTICA DE PREVENCIÓN DE LA EMPRESA}

\section{OBJETIVOS}

2.1. OBJETIVOS GENERALES

2.2. OBJETIVOS ANUALES

3. SISTEMA DE PREVENCIÓN DE RIESGOS LABORALES

3.1. DEFINICIÓN DEL SISTEMA DE PREVENCIÓN

3.1.1. Definición

3.1.2. Organigrama “EMPRESA EJEMPLO S.L.”

\subsection{DEPARTAMENTO DE PREVENCIÓN DE RIESGOS LABORALES}

3.2.1. Acta de constitución

3.2.2. Nombramiento y aceptación del trabajador

3.2.3. Hoja de responsables del sistema

3.2.4. Funciones y responsabilidades

3.2.5. Hoja de renuncia del trabajador

\subsection{DELEGADOS DE PREVENCIÓN}


3.3.1. Acta de reunión para la elección de delegados

3.3.2. Nombramiento y aceptación del delegado

3.3.3. Competencias y facultades del delegado

3.3.4. Obligaciones de la empresa

3.3.5. Hoja de renuncia del delegado

\subsection{COMITÉ DE SEGURIDAD Y SALUD}

3.4.1. Designación de representantes

3.4.2. Acta de constitución

3.4.3. Reglamento de funcionamiento interno

\subsection{GRUPOS DE TRABAJO}

3.5.1. Hoja de aceptación del trabajador

3.5.2. Funcionamiento interno de los grupos

3.5.3. Informe de la reunión

3.6. SERVICIO DE PREVENCIÓN AJENO (MEDICINA DEL TRABAJO)

3.6.1. Acuerdo de colaboración

3.6.2. Funciones y responsabilidades

\section{RESPONSABILIDADES DE LOS TRABAJADORES EN MATERIA DE PREVENCIÓN}

4.1. RESPONSABILIDADES DE LA DIRECCIÓN

4.2. RESPONSABILIDADES DE LOS MANDOS INTERMEDIOS

4.3. RESPONSABILIDADES DE LOS TRABAJADORES DE BASE

\section{CANALES DE COMUNICACIÓN}

\subsection{COMUNICACIONES DE DIRECCIÓN}

5.1.1. Comunicación del sistema de prevención a los mandos intermedios

5.1.2. Aceptación de propuesta realizada por el departamento de prevención

\subsection{DEPARTAMENTO DE PREVENCIÓN DE RIESGOS LABORALES}

5.2.1. Comunicación de propuestas a la dirección

5.2.2. Comunicación de responsabilidades preventivas a la dirección

5.2.3. Comunicación de responsabilidades preventivas a los mandos intermedios

5.2.4. Comunicación de responsabilidades preventivas a los trabajadores base

5.2.5. Comunicación de evaluaciones preventivas a los delegados de prevención

\subsection{DELEGADOS DE PREVENCIÓN}

5.3.1. Comunicación de propuestas al departamento de prevención

5.4. COMITÉ DE SEGURIDAD Y SALUD

5.4.1. Comunicación de propuestas al departamento de prevención

\subsection{GRUPOS DE TRABAJO}

5.5.1. Hoja para la captación de voluntarios

5.5.2. Comunicación de propuestas al departamento de prevención 


\subsection{SERVICIO DE PREVENCIÓN AJENO}

5.6.1. Comunicación de propuestas sobre salud laboral al departamento de prevención

5.6.2. Comunicación de los puestos de trabajo cuyos ocupantes deben obligatoriamente estar sometidos a reconocimientos médicos

\subsection{MANDOS INTERMEDIOS}

5.7.1. Justificante de impartición y recepción de información-formación sobre riesgos y medidas preventivas del puesto de trabajo

5.7.2. Documento de entrega de los equipos de protección individual

\section{CAPACITACIÓN}

\section{PROCEDIMIENTOS}

MP_PR - 01 Evaluación de riesgos

MP_PR - 02 Planificación de la actividad preventiva

MP_PR - 03 Formación inicial y continuada de trabajadores

MP_PR - 04 Información de los riesgos en los lugares de trabajo

MP_PR - 05 Señalización de seguridad

MP_PR - 06 E.P.I. y ropa de trabajo

MP_PR - 07 Inspecciones y revisiones de seguridad

MP_PR - 08 Mantenimiento preventivo

MP_PR - 09 Comunicación de los riesgos detectados y sugerencias de mejora

MP_PR - 10 Seguimiento y control de medidas correctoras

MP_PR - 11 Contratación y subcontratación

MP_PR - 12 Plan de emergencia

MP_PR - 13 Control de la documentación y de los registros de prevención

MP_PR - 14 Auditorias del sistema de prevención

\subsection{1.-OHSAS 18001:2007}

\section{OBJETO Y CAMPO DE APLICACIÓN}

Esta norma OHSAS (Occupational Health and Safety Assessment Series) especifica los requisitos para un sistema de gestión en seguridad y salud ocupacional ( $\mathrm{S}$ y $\mathrm{SO}$ ), para hacer posible que una organización controle sus riesgos de S y SO y mejore su desempeño en este sentido. No establece criterios de desempeño de S y SO determinados, ni incluye especificaciones detalladas para el diseño de un sistema de gestión.

Esta norma OHSAS es aplicable a cualquier organización que desee:

a) establecer un sistema de gestión en seguridad y salud ocupacional ( $\mathrm{S}$ y $\mathrm{SO}$ ) con el fin de eliminar o minimizar los riesgos para el personal y otras partes interesadas que pueden estar expuestas a peligros de $\mathrm{S}$ y $\mathrm{SO}$ asociados con sus actividades;

b) implementar, mantener y mejorar continuamente un sistema de gestión en S y SO;

c) asegurarse de su conformidad con la política en S y SO establecida;

d) demostrar la conformidad con esta norma OHSAS mediante:

1) una auto-evaluación y auto-declaración, o 
2) la búsqueda de confirmación de su conformidad por las partes que tienen interés en la organización, tales como los clientes, o

3) la búsqueda de confirmación de su auto-declaración por una parte externa a la organización, o

4) la búsqueda de la certificación/registro de su sistema de gestión en S y SO por una organización externa.

Todos los requisitos de esta norma OHSAS están previstos para ser incorporados a cualquier sistema de gestión en S y SO. El alcance de la aplicación dependerá de factores tales como la política en S y SO de la organización, la naturaleza de sus actividades, y los riesgos y complejidad de sus operaciones.

Esta norma OHSAS está prevista para tratar acerca de seguridad y salud ocupacional, y no acerca de otras áreas de salud y seguridad tales como programas de bienestar para los empleados, seguridad de los productos, daño a la propiedad o impactos ambientales.

\section{REFERENCIAS NORMATIVAS}

En la bibliografía se indican otras publicaciones que brindan información u orientación. Se recomienda consultar las ediciones más recientes de tales publicaciones. Específicamente, se recomienda consultar:

OHSAS 18002, Sistema de Gestión en Seguridad y Salud Ocupacional. Directrices para la implementación del documento OHSAS 18001.

Organización Internacional del Trabajo, Directrices relativas a los sistemas de gestión de la seguridad y la salud en el trabajo (ILO - OSH 2001).

\section{TÉRMINOS Y DEFINICIONES}

Para los propósitos de esta norma se aplican los siguientes términos y definiciones:

3.1 Riesgo aceptable. Riesgo que ha sido reducido a un nivel que la organización puede tolerar con respecto a sus obligaciones legales y su propia política en S y SO (3.16).

3.2 Auditoría. Proceso sistemático, independiente y documentado para obtener "evidencias de la auditoría" y evaluarlas de manera objetiva con el fin de determinar el grado en que se cumplen los "criterios de auditoría".

[ISO 9000:2005, 3.9.1]

NOTA 1 Independiente no significa necesariamente externo a la organización. En muchos casos, particularmente en las organizaciones más pequeñas, la independencia se puede demostrar mediante la ausencia de responsabilidad por la actividad que se audita.

NOTA 2 Para orientación adicional acerca de "evidencia de la auditoría" y "criterios de auditoría", véase la ISO 19011. 
3.3 Mejora continua. Proceso recurrente de optimización del sistema de gestión en S y SO (3.13), para lograr mejoras en el desempeño en S y SO (3.15), de forma coherente con la política en S y SO (3.16) de la organización (3.17).

NOTA 1 El proceso no necesariamente tiene lugar en todas las áreas de actividad simultáneamente.

NOTA 2 Adaptada de la ISO 14001:2004. 3.2.

3.4 Acción correctiva. Acción tomada para eliminar la causa de una no conformidad (3.11) detectada u otra situación no deseable.

NOTA 1 Puede haber más de una causa de una no conformidad.

NOTA 2 La acción correctiva se toma para prevenir que algo vuelva a producirse, mientras que la acción preventiva (3.18) se toma para impedir que algo suceda.

[ISO 9000:2005, 3.6.5]

3.5 Documento. Información y su medio de soporte.

NOTA El medio de soporte puede ser papel, magnético, óptico o electrónico, una fotografía o muestras patrón, o una combinación de estos.

[ISO 14001:2004, 3.4]

3.6 Peligro. Fuente, situación o acto con potencial de daño en términos de enfermedad (3.8) o lesión a las personas, o una combinación de estos.

3.7 Identificación del peligro. Proceso para reconocer si existe un peligro (3.6) y definir sus características.

3.8 Enfermedad. Condición física o mental adversa identificable, que surge, empeora o ambas, a causa de una actividad laboral, una situación relacionada con el trabajo o ambas.

3.9 Incidente. Evento(s) relacionado(s) con el trabajo, en el (los) que ocurrió o pudo haber ocurrido lesión o enfermedad (3.8) (independiente de su severidad), o víctima mortal.

NOTA 1 Un accidente es un incidente que da lugar a lesión, enfermedad o víctima mortal.

NOTA 2 Un incidente en el que no hay lesión, enfermedad ni víctima mortal también se puede denominar como "casi-accidente" (situación en la que casi ocurre un accidente)

NOTA 3 Una situación de emergencia (4.4.7) es un tipo particular de incidente.

3.10 Parte interesada. Persona o grupo, dentro o fuera del lugar de trabajo (3.23) involucrado o afectado por el desempeño en seguridad y salud ocupacional (3.15) de una organización (3.17). 
3.11 No conformidad. Incumplimiento de un requisito.

[ISO 9000:2005, 3.6.2; ISO 14001, 3.15]

NOTA Una no conformidad puede ser una desviación de:

- Estándares, prácticas, procedimientos de trabajo y requisitos legales pertinentes, entre otros.

- Requisitos del sistema de gestión de S y SO (3.13).

3.12 Seguridad y salud ocupacional (S y SO). Condiciones y factores que afectan o pueden afectar la salud y la seguridad de los empleados u otros trabajadores (incluidos los trabajadores temporales y personal por contrato), visitantes o cualquier otra persona en el lugar de trabajo (3.23).

NOTA Las organizaciones pueden estar sujetas a requisitos legales para la salud y la seguridad de las personas más allá de su lugar de trabajo inmediato, o quienes están expuestas a actividades en el lugar de trabajo.

3.13 Sistema de gestión de $\mathbf{S}$ y SO. Parte del sistema de gestión de una organización (3.17), empleada para desarrollar e implementar su política de S y SO (3.16) y gestionar sus riesgos de $\mathrm{S}$ y $\mathrm{SO}$ (3.21).

NOTA 1 Un sistema de gestión es un conjunto de elementos interrelacionados usados para establecer la política y objetivos y para cumplir estos objetivos.

NOTA 2 Un sistema de gestión incluye la estructura de la organización, la planificación de actividades (incluyendo, por ejemplo, valoración del riesgo y establecimiento de objetivos), responsabilidades, prácticas, procedimientos (3.19), procesos y recursos.

NOTA 3 Adaptada de la ISO 14001:2004, 3.8.

3.14 Objetivo de S y SO. Propósito en S y SO en términos del desempeño de S y SO (3.15), que una organización (3.17) se fija.

NOTA 1 Los objetivos se deberían cuantificar siempre que sea factible.

NOTA 2 El numeral 4.3.3 exige que los objetivos de $\mathrm{S}$ y SO sean consistentes con la política de S y SO (3.16).

3.15 Desempeño de $\mathbf{S}$ y SO. Resultados medibles de la gestión de una organización (3.17) en relación con sus riesgos de S y SO (3.21).

NOTA 1 La medición del desempeño de S y SO incluye la medición de la eficacia de los controles de la organización.

NOTA 2 En el contexto de sistemas de gestión de S y SO (3.13), los resultados también se pueden medir con respecto a la política de S y SO (3.16), objetivos de S y SO (3.14) y otros requisitos de desempeño de $\mathrm{S}$ y SO de la organización. 
3.16 Política de S y SO: Intenciones y dirección generales de una organización (3.17) relacionados con su desempeño de S y SO (3.13), expresadas formalmente por la alta dirección.

NOTA 1 La política de S y SO brinda una estructura para la acción y el establecimiento de los objetivos de S y SO (3.14).

NOTA 2 Adaptada de la ISO 14001:2004, 3.11.

3.17 Organización. Compañía, corporación, firma, empresa, autoridad o institución, o parte o combinación de ellas, sean o no sociedades, pública o privada, que tiene sus propias funciones y administración.

NOTA Para las organizaciones con más de una unidad operativa, una unidad operativa por sí sola se puede definir como una organización.

[ISO 14001:2004, 3.16]

3.18 Acción preventiva. Acción tomada para eliminar la causa de una no conformidad (3.11) potencial u otra situación potencial no deseable.

NOTA 1 Puede haber más de una causa para una no conformidad potencial.

NOTA 2 la acción preventiva se toma para prevenir que algo suceda, mientras que la acción correctiva (3.4) se toma para prevenir que vuelva a producirse.

[ISO 9000:2005, 3.6.4]

3.19 Procedimiento. Forma especificada para llevar a cabo una actividad o un proceso. NOTA Los procedimientos pueden estar documentados o no.

[ISO 9000:2005, 3.4.5]

3.20 Registro. Documento (3.5). Que presenta resultados obtenidos, o proporciona evidencia de las actividades desempeñadas.

[ISO 140001:2004, 3.20]

3.21 Riesgo. Combinación de la probabilidad de que ocurra un(os) evento(s) o exposición(es) peligroso(s), y la severidad de la lesión o enfermedad (3.8) que puede ser causada por el(los) evento(s) o exposición(es).

3.22 Valoración del riesgo. Proceso de evaluar el(los) riesgo(s) (3.21) que surgen de un(os) peligro(s), teniendo en cuenta la suficiencia de los controles existentes, y de decidir si el (los) riesgo(s) es (son) aceptable(s) o no.

3.23 Lugar de trabajo. Cualquier espacio físico en el que se realizan actividades relacionadas con el trabajo, bajo el control de la organización.

NOTA Cuando se considera lo que constituye un lugar de trabajo, la organización (3.17) debería tener en cuenta los efectos de la S y SO sobre el personal que, por ejemplo, 
se encuentra de viaje o en tránsito (por ejemplo: va en automóvil, en avión, en barco o en tren), está trabajando en las instalaciones de un cliente, o está trabajando en su propia casa.

\section{REQUISITOS DEL SISTEMA DE GESTIÓN DE S y SO}

\subsection{REQUISITOS GENERALES}

La organización debe establecer, documentar, implementar, mantener y mejorar en forma continua un sistema de gestión de S y SO de acuerdo con los requisitos de esta norma OHSAS, y debe determinar cómo cumplirá estos requisitos. La organización debe definir y documentar el alcance de su sistema de gestión de S y SO.

\subsection{POLÍTICA DE S Y SO}

La alta dirección debe definir y autorizar la política de S y SO de la organización, y asegurar que, dentro del alcance definido de su sistema de gestión de S y SO, ésta:

a) es apropiada para la naturaleza y escala de los riesgos de S y SO de la organización;

b) incluye un compromiso con la prevención de lesiones y enfermedades y con la mejora continua en la gestión y desempeño de S y SO;

c) incluye el compromiso de cumplir como mínimo los requisitos legales aplicables y otros requisitos que suscriba la organización, relacionados con sus peligros de $\mathrm{S}$ y SO.

d) proporciona el marco de referencia para establecer y revisar los objetivos de S y SO.

e) se documenta, implementa y mantiene.

f) se comunica a todas las personas que trabajan bajo el control de la organización, con la intención de que sean conscientes de sus obligaciones individuales de S y SO.

g) está disponible para las partes interesadas, y

h) se revisa periódicamente para asegurar que sigue siendo pertinente y apropiada para la organización.

\subsection{PLANIFICACIÓN}

\subsubsection{Identificación de peligros, valoración de riesgos y determinación de los controles}

La organización debe establecer, implementar y mantener un(os) procedimiento(s) para la continua identificación de peligros, valoración de riesgos y determinación de los controles necesarios.

El (los) procedimiento(s) para la identificación de peligros y la valoración de riesgos deben tener en cuenta:

a) actividades rutinarias y no rutinarias;

b) actividades de todas las personas que tienen acceso al sitio de trabajo (incluso contratistas y visitantes);

c) comportamiento, aptitudes y otros factores humanos; 
d) los peligros identificados que se originan fuera del lugar de trabajo con capacidad de afectar adversamente la salud y la seguridad de las personas que están bajo el control de la organización en el lugar de trabajo;

e) los peligros generados en la vecindad del lugar de trabajo por actividades relacionadas con el trabajo controladas por la organización;

NOTA 1 Puede ser más apropiado que estos peligros sean evaluados como un aspecto ambiental.

f) Infraestructura, equipo y materiales en el lugar de trabajo, ya sean suministrados por la organización o por otros;

g) Cambios realizados o propuestos en la organización, sus actividades o los materiales;

h) modificaciones al sistema de gestión de $\mathrm{S}$ y SO, incluidos los cambios temporales y sus impactos sobre las operaciones, procesos y actividades;

i) cualquier obligación legal aplicable relacionada con la valoración del riesgo y la implementación de los controles necesarios (véase también la nota del numeral 3.12);

j) el diseño de áreas de trabajo, procesos, instalaciones, maquinaria/equipos, procedimientos de operación y organización del trabajo, incluida su adaptación a las aptitudes humanas.

La metodología de la organización para la identificación de peligros y valoración del riesgo debe:

a) definirse con respecto a su alcance, naturaleza y oportunidad, para asegurar su carácter proactivo más que reactivo; y

b) prever los medios para la identificación, priorización y documentación de los riesgos y la aplicación de los controles, según sea apropiado.

Para la gestión del cambio, la organización debe identificar los peligros y los riesgos de $\mathrm{S}$ y SO asociados con cambios en la organización, el sistema de gestión de S y SO o sus actividades, antes de introducir tales cambios.

La organización debe asegurar que los resultados de estas valoraciones se consideran cuando se determinan los controles. Al determinar los controles o considerar cambios a los controles existentes, se debe contemplar la reducción de riesgos de acuerdo con la siguiente jerarquía:
a) eliminación;
b) sustitución;
c) controles de ingeniería;
d) señalización/advertencias o controles administrativos o ambos;
e) equipo de protección personal.

La organización debe documentar y mantener actualizados los resultados de la identificación de peligros, valoración de riesgos, y de los controles determinados. La organización se debe asegurar de que los riesgos de S y SO y los controles determinados se tengan en cuenta cuando establezca, implemente y mantenga su sistema de gestión de $\mathrm{S}$ y SO. 
NOTA 2 Para mayor orientación sobre la identificación de peligros, valoración del riesgo y determinación de controles, véase el documento OHSAS 18002.

\subsubsection{Requisitos legales y otros}

La organización debe establecer, implementar y mantener un(os) procedimiento(s) para la identificación y acceso a requisitos legales y de S y SO que sean aplicables a ella. La organización debe asegurar que estos requisitos legales aplicables y otros que la organización suscriba se tengan en cuenta al establecer, implementar y mantener su sistema de gestión de $\mathrm{S}$ y SO. La organización debe mantener esta información actualizada.

La organización debe comunicar la información pertinente sobre requisitos legales y otros, a las personas que trabajan bajo el control de la organización, y a otras partes interesadas pertinentes.

\subsubsection{Objetivos y programa(s)}

La organización debe establecer, implementar y mantener documentados los objetivos de S y SO en las funciones y niveles pertinentes dentro de la organización. Los objetivos deben ser medibles, cuando sea factible, y consistentes con la política de S y SO, incluidos los compromisos con la prevención de lesiones y enfermedades, el cumplimiento con los requisitos legales aplicables y otros requisitos que la organización suscriba, y con la mejora continua.

Cuando se establecen y revisan sus objetivos, una organización debe tener en cuenta los requisitos legales y otros que la organización suscriba, y sus riesgos de S y SO. Además, debe considerar sus opciones tecnológicas, sus requisitos financieros, operacionales y comerciales, así como las opiniones de las partes interesadas pertinentes.

La organización debe establecer, implementar y mantener un(os) programa(s) para lograr sus objetivos. El(los) programa(s) debe(n) incluir, como mínimo:

a) la asignación de responsabilidades y autoridad para lograr los objetivos en las funciones y niveles pertinentes de la organización, y

b) los medios y los plazos establecidos para el logro de los objetivos.

El(los) programa(s) se debe(n) revisar a intervalos regulares y planificados, y se debe(n) ajustar si es necesario, para asegurar que los objetivos se logren.

\subsection{IMPLEMENTACIÓN Y OPERACIÓN}

\subsubsection{Recursos, funciones, responsabilidad, rendición de cuentas y autoridad}

La alta dirección debe asumir la máxima responsabilidad por la S y SO y el sistema de gestión en S y SO. La alta dirección debe demostrar su compromiso: 
a) asegurando la disponibilidad de recursos esenciales para establecer, implementar, mantener y mejorar el sistema de gestión de S y SO;

NOTA 1 Los recursos incluyen los recursos humanos y las habilidades especializadas, la infraestructura organizacional y los recursos tecnológicos y financieros.

b) definiendo las funciones, asignando las responsabilidades y la rendición de cuentas, y delegando autoridad, para facilitar una gestión de S y SO eficaz; se deben documentar y comunicar las funciones, las responsabilidades, la rendición de cuentas y autoridad.

La organización debe designar a un miembro de la alta dirección con responsabilidad específica en S y SO, independientemente de otras responsabilidades y con autoridad y funciones definidos, para:

a) asegurar que el sistema de gestión de S y SO se establece, implementa y mantiene de acuerdo con esta norma OHSAS;

b) asegurar que se presentan informes sobre desempeño del sistema de gestión de $\mathrm{S}$ y SO a la alta dirección, para su revisión, y que se usan como base para la mejora del sistema de gestión de S y SO.

NOTA 2 El designado de la alta dirección (por ejemplo, en una organización grande es un miembro de la junta directiva o del comité ejecutivo) puede delegar algunos de sus deberes a un representante de la dirección subordinado, pero conservando la responsabilidad de rendir cuentas.

La identidad del delegado de la alta dirección se debe informar a todas las personas que trabajan bajo el control de la organización. Todos aquellas personas que tengan responsabilidad gerencial deben demostrar su compromiso con la mejora continua del desempeño en S y SO.

La organización debe asegurar que las personas en el lugar de trabajo asuman la responsabilidad por los aspectos de S y SO sobre los que tienen control, incluido el cumplimiento de los requisitos aplicables de S y SO de la organización.

\subsubsection{Competencia, formación y toma de conciencia}

La organización debe asegurar que cualquier persona que esté bajo su control ejecutando tareas que pueden tener impacto sobre la S y SO, sea competente con base en su educación, formación o experiencia, y debe conservar los registros asociados. La organización debe identificar las necesidades de formación relacionada con sus riesgos de S y SO y su sistema de gestión de S y SO. Debe suministrar formación o realizar otras acciones para satisfacer esas necesidades, evaluar la eficacia de la formación o de la acción tomada, y conservar los registros asociados.

La organización debe establecer, implementar y mantener un(os) procedimiento(s) para hacer que las personas que trabajan bajo su control tomen conciencia de: 
a) las consecuencias de $\mathrm{S}$ y $\mathrm{SO}$, reales y potenciales, de sus actividades laborales, su comportamiento, y los beneficios de S y SO obtenidos por un mejor desempeño personal;

b) sus funciones y responsabilidades, y la importancia de lograr conformidad con la política y procedimientos de S y SO y con los requisitos del sistema de gestión de S y $\mathrm{SO}$, incluidos los requisitos de preparación y respuesta ante emergencias (4.4.7);

c) las consecuencias potenciales de desviarse de los procedimientos especificados.

Los procedimientos de formación deben tener en cuenta los diferentes niveles de:

a) Responsabilidad, capacidad, habilidades de lenguaje y alfabetismo, y

b) Riesgo.

\subsubsection{Comunicación, participación y consulta}

\subsubsection{Comunicación}

En relación con sus peligros de $\mathrm{S}$ y $\mathrm{SO}$ y su sistema de gestión de $\mathrm{S}$ y $\mathrm{SO}$, la organización debe establecer, implementar y mantener un(os) procedimiento(s) para:

a) la comunicación interna entre los diferentes niveles y funciones de la organización;

b) la comunicación con contratistas y otros visitantes al sitio de trabajo.

c) recibir, documentar y responder a las comunicaciones pertinentes de las partes interesadas externas.

\subsubsection{Participación y consulta}

La organización debe establecer, implementar y mantener un(os) procedimiento(s) para:

a) la participación de los trabajadores en:

- la identificación de peligros, valoración de riesgos y determinación de controles;

- la investigación de incidentes;

- el desarrollo y revisión de las políticas y objetivos de S y SO;

- la consulta, en donde haya cambios que afectan su S y SO;

- la representación en asuntos de $\mathrm{S}$ y SO;

Los trabajadores deben estar informados acerca de sus acuerdos de participación, que incluyen saber quiénes son sus representantes en asuntos de $\mathrm{S}$ y SO.

b) la consulta con los contratistas, en donde haya cambios que afecten su S y SO.

La organización debe asegurar que las partes interesadas externas pertinentes sean consultadas acerca de asuntos relativos a $\mathrm{S}$ y SO, cuando sea apropiado. 


\subsubsection{Documentación}

La documentación del sistema de gestión de S y SO debe incluir:

a) la política y objetivos de $\mathrm{S}$ y SO;

b) la descripción del alcance del sistema de gestión de $\mathrm{S}$ y SO;

c) la descripción de los principales elementos del sistema de gestión de S y SO y su interacción, así como la referencia a los documentos relacionados;

d) los documentos, incluyendo los registros exigidos en esta norma OHSAS, y

e) los documentos, incluyendo los registros, determinados por la organización como necesarios para asegurar la eficacia de la planificación, operación y control de procesos relacionados con la gestión de sus riesgos de S y SO.

NOTA Es importante que la documentación sea proporcional al nivel de complejidad, peligros y riesgos relacionados, y que se mantenga en la mínima requerida por eficacia y eficiencia.

\subsubsection{Control de documentos}

Los documentos exigidos por el sistema de gestión de S y SO y por esta norma OHSAS deben ser controlados. Los registros son un tipo especial de documento y se deben controlar de acuerdo con los requisitos establecidos en el numeral 4.5.4.

La organización debe establecer, implementar y mantener un(os) procedimiento(s) para:

a) aprobar los documentos con relación a su adecuación antes de su emisión;

b) revisar y actualizar los documentos cuando sea necesario, y aprobarlos nuevamente;

c) asegurar que se identifican los cambios y el estado de revisión actual de los documentos;

d) asegurar que las versiones pertinentes de los documentos aplicables estén disponibles en los lugares de uso.

e) asegurar que los documentos permanezcan legibles y fácilmente identificables;

f) asegurar que estén identificados los documentos de origen externo determinados por la organización como necesarios para la planificación y operación del sistema de gestión de S y SO, y que su distribución esté controlada, y

g) prevenir el uso no intencionado de documentos obsoletos, y aplicarles una identificación adecuada en el caso de que se mantengan por cualquier razón.

\subsubsection{Control operacional}

La organización debe determinar aquellas operaciones y actividades asociadas con el (los) peligro(s) identificado(s), en donde la implementación de los controles es necesaria para gestionar el (los) riesgo(s) de S y SO. Debe incluir la gestión del cambio (4.3.1).

Para aquellas operaciones y actividades, la organización debe implementar y mantener:

a) los controles operacionales que sean aplicables a la organización y a sus actividades; la organización debe integrar estos controles operacionales a su sistema general de $\mathrm{S}$ y SO; 
b) los controles relacionados con mercancías, equipos y servicios comprados;

c) los controles relacionados con contratistas y visitantes en el lugar de trabajo;

d) procedimientos documentados para cubrir situaciones en las que su ausencia podría conducir a desviaciones de la política y objetivos de $\mathrm{S}$ y SO;

e) los criterios de operación estipulados, en donde su ausencia podría conducir a desviaciones de la política y objetivos de S y SO.

\subsubsection{Preparación y respuesta ante emergencias}

La organización debe establecer, implementar y mantener un(os) procedimiento(s) para:

a) identificar el potencial de situaciones de emergencia;

b) responder a tales situaciones de emergencia.

La organización debe responder a situaciones de emergencia reales y prevenir o mitigar consecuencias de S y SO adversas asociadas. Al planificar su respuesta ante emergencias, la organización debe tener en cuenta las necesidades de las partes interesadas pertinentes, por ejemplo, los servicios de emergencia y los vecinos.

La organización también debe probar periódicamente su(s) procedimiento(s) de respuesta ante situaciones de emergencia, en donde sea factible, involucrando las partes interesadas pertinentes cuando sea apropiado. La organización debe revisar periódicamente y modificar cuando sea necesario, su(s) procedimiento(s) de preparación y respuesta ante emergencias, en particular después de realizar pruebas periódicas y después que se han presentado situaciones de emergencia (4.5.3).

\subsection{VERIFICACIÓN}

\subsubsection{Medición y seguimiento del desempeño}

La organización debe establecer, implementar y mantener un(os) procedimiento(s) para hacer seguimiento y medir regularmente el desempeño de $\mathrm{S} Y \mathrm{SO}$. Esto(s) procedimiento(s) deben prever:

- medidas cuantitativas y cualitativas apropiadas a las necesidades de la organización;

- seguimiento al grado de cumplimiento de los objetivos de S y SO de la organización;

- seguimiento a la eficacia de los controles (tanto para salud como para seguridad);

- medidas proactivas de desempeño con las que se haga seguimiento a la conformidad con el (los) programa(s), controles y criterios operacionales de gestión de $\mathrm{S}$ y SO;

- medidas reactivas de desempeño para seguimiento de enfermedades, incidentes

(incluidos los accidentes y casi-accidentes) y otras evidencias históricas de desempeño deficiente en S y SO;

- registro suficiente de los datos y los resultados de seguimiento y medición para facilitar el análisis posterior de las acciones correctivas y preventivas.

Si se requiere equipos para la medición o seguimiento del desempeño, la organización debe establecer y mantener procedimientos para la calibración y mantenimiento de tales 
equipos, según sea apropiado. Se deben conservar registros de las actividades de mantenimiento y calibración, y de los resultados.

\subsubsection{Evaluación del cumplimiento legal y otros}

4.5.2.1 En coherencia con su compromiso de cumplimiento legal, (4.2c), la organización debe establecer, implementar y mantener un(os) procedimiento(s) para evaluar periódicamente el cumplimiento de los requisitos legales aplicables (4.3.2).

La organización debe mantener registros de los resultados de las evaluaciones periódicas.

NOTA La frecuencia de la evaluación periódica puede variar para diferentes requisitos legales.

4.5.2.2 La organización debe evaluar la conformidad con otros requisitos que suscriba (4.3.2). La organización puede combinar esta evaluación con la evaluación del cumplimiento legal mencionada en el numeral 4.5.2.1 ó establecer un(os) procedimiento(s) separados.

La organización debe mantener registros de los resultados de las evaluaciones periódicas.

NOTA La frecuencia de la evaluación periódica puede variar entre los otros requisitos que suscriba la organización.

\subsubsection{Investigación de incidentes. No conformidades y acciones correctivas y preventivas}

\subsubsection{Investigación de incidentes}

La organización debe establecer, implementar y mantener un(os) procedimiento(s) para registrar, investigar y analizar incidentes, con el fin de:

a) determinar las deficiencias de $\mathrm{S}$ y $\mathrm{SO}$ que no son evidentes, y otros factores que podrían causar o contribuir a que ocurran incidentes;

b) identificar la necesidad de acción correctiva;

c) identificar las oportunidades de acción preventiva;

d) identificar las oportunidades de mejora continua;

e) comunicar el resultado de estas investigaciones;

Las investigaciones se deben llevar a cabo de manera oportuna. Cualquier necesidad identificada de acciones correctivas $u$ oportunidades de acciones preventivas se debe abordar de acuerdo con las partes pertinentes del numeral 4.5.3.2. Los resultados de las investigaciones de incidentes se deben documentar y mantener.

\subsubsection{No conformidad, acción correctiva y acción preventiva}


La organización debe establecer, implementar y mantener un(os) procedimiento(s) para tratar la(s) no conformidad(es) real(es) y potencial(es), y tomar acciones correctivas y preventivas.

El(los) procedimiento(s) debe(n) definir los requisitos para:

a) identificar y corregir la(s) no conformidad(es), y tomar la(s) acción(es) para mitigar sus consecuencias de $\mathrm{S}$ y SO;

b) investigar la(s) no conformidad(es), determinar su(s) causa(s), y tomar la(s) acción(es) con el fin de evitar que ocurran nuevamente;

c) evaluar la necesidad de acción(es) para prevenir la(s) no conformidad(es) e implementar las acciones apropiadas definidas para evitar su ocurrencia;

d) registrar y comunicar los resultados de la(s) acción(es) correctiva(s) y la(s) acción(es) preventiva(s) tomadas, y

e) revisar la eficacia de la(s) acción(es) correctiva(s) y la(s) acción(es) preventiva(s) tomadas.

Cuando la acción correctiva y la acción preventiva identifican peligros nuevos o que han cambiado, o la necesidad de controles nuevos o modificados, el procedimiento debe exigir que las acciones propuestas sean revisadas a través del proceso de valoración del riesgo antes de su implementación.

Cualquier acción correctiva o preventiva tomada para eliminar las causas de las no conformidades reales o potenciales debe ser apropiada a las magnitud de los problemas, y proporcional al(los) riesgo(s) de S y SO encontrado(s). La organización debe asegurar que cualquier cambio necesario que surja de la acción correctiva y de la preventiva se incluya en la documentación del sistema de gestión de S y SO.

\subsubsection{Control de registros}

La organización debe establecer y mantener los registros necesarios para demostrar conformidad con los requisitos de su sistema de gestión de S y SO y de esta norma OHSAS, y los resultados logrados. La organización debe establecer, implementar y mantener un(os) procedimiento(s) para la identificación, el almacenamiento, la protección, la recuperación, la retención y la disposición de los registros. Los registros deben ser y permanecer legibles, identificables y trazables.

\subsubsection{Auditoría interna}

La organización debe asegurar que las auditorias internas del sistema de gestión de S y SO se lleven a cabo a intervalos planificados para:

a) determinar si el sistema de gestión de $\mathrm{S}$ y SO:

1) cumple las disposiciones planificadas para la gestión de $\mathrm{S}$ y $\mathrm{SO}$, incluidos los requisitos de esta norma OHSAS; y

2) ha sido implementado adecuadamente y se mantiene; y

3) es eficaz para cumplir con la política y objetivos de la organización;

b) suministrar información a la dirección sobre los resultados de las auditorías. 
El (los) programa(s) de auditorias se deben planificar, establecer, implementar y mantener por la organización, con base en los resultados de las valoraciones de riesgo de las actividades de la organización, y en los resultados de las auditorias previas.

El (los) procedimiento(s) de auditoría se deben establecer, implementar y mantener de manera que se tengan en cuenta:

a) las responsabilidades, competencias y requisitos para planificar y realizar las auditorias, reportar los resultados y conservar los registros asociados; y

b) la determinación de los criterios de auditoría, su alcance, frecuencia y métodos.

La selección de los auditores y la realización de las auditorias deben asegurar la objetividad y la imparcialidad del proceso de auditoria.

\subsection{REVISIÓN POR LA DIRECCIÓN}

La alta dirección debe revisar el sistema de gestión de S y SO. a intervalos definidos para asegurar su conveniencia, adecuación y eficacia continua. Las revisiones deben incluir la evaluación de oportunidades de mejora, y la necesidad de efectuar cambios al sistema de gestión de S y SO, incluyendo la política y los objetivos de S y SO. Se deben conservar los registros de las revisiones por la dirección.

Los elementos de entrada para las revisiones por la dirección deben incluir:

a) los resultados de las auditorías internas y las evaluaciones de cumplimiento con los requisitos legales aplicables y con los otros requisitos que la organización suscriba;

b) los resultados de la participación y consulta (4.4.3);

c) la(s) comunicación(es) pertinentes de las partes interesadas externas, incluidas las quejas;

d) el desempeño de S y SO de la organización;

e) el grado de cumplimiento de los objetivos;

f) el estado de las investigaciones de incidentes, acciones correctivas y acciones preventivas;

g) acciones de seguimiento de revisiones anteriores de la dirección.

h) circunstancias cambiantes, incluidos los cambios en los requisitos legales y otros relacionados con $\mathrm{S}$ y $\mathrm{SO}, \mathrm{y}$;

i) recomendaciones para la mejora.

Las salidas de las revisiones por la dirección deben ser coherentes con el compromiso de la organización con la mejora continua y deben incluir las decisiones y acciones relacionadas con los posibles cambios en:

a) desempeño en $\mathrm{S}$ y $\mathrm{SO}$;

b) política y objetivos de $\mathrm{S}$ y $\mathrm{SO}$;

c) recursos, y;

d) otros elementos del sistema de gestión de S y SO. 
Las salidas pertinentes de la revisión por la dirección deben estar disponibles para comunicación y consulta (4.4.3).

6.10.3.- RELACIÓN ENTRE OHSAS 18001, OHSAS 18002 e ILO-OSH: 2001. DIRECTRICES RELATIVAS A LOS SISTEMAS DE GESTIÓN DE SEGURIDAD Y SALUD EN EL TRABAJO

\section{INTRODUCCIÓN}

Esta parte identifica las diferencias clave entre las Directrices ILO-OSH: 2001 de la

Organización Internacional del Trabajo y los documentos OHSAS y presenta una evaluación comparativa de sus diferentes requisitos. Debe anotarse que no se identificaron áreas con diferencias significativas.

Por consiguiente, aquellas organizaciones que han implementado un sistema de gestión de S y SO que cumple la norma OHSAS 18001 pueden estar seguras que su sistema de gestión de $\mathrm{S}$ y SO será compatible con las recomendaciones de las directrices ILO-OHS. En el literal B.4 se presenta una tabla de correspondencia entre las cláusulas individuales del documento OHSAS y aquellas de las Directrices ILO-OSH.

\section{GENERALIDADES}

Los dos objetivos principales de las Directrices ILO-OSH son:

a) ayudar a los países a establecer un marco nacional de trabajo para los sistemas de gestión de seguridad y salud ocupacional, y

b) suministrar una guía a las organizaciones individuales para buscar la integración de los elementos de S y SO dentro de su política global y disposiciones administrativas.

OHSAS 18001 especifica los requisitos para los sistemas de gestión de S y SO, para posibilitar que las organizaciones controlen los riesgos y mejoren su desempeño de $\mathrm{S}$ y $\mathrm{SO}$. El documento OHSAS 18002 da las directrices para implementar la OHSAS 18001. Por tanto, los documentos OHSAS son comparables con la Sección 3 del documento ILO-OSH "Directrices relativas a los sistemas de gestión de la seguridad y la salud en el trabajo".

\section{ANÁLISIS DETALLADO DE LA SECCIÓN 3 DE LA GUÍA ILO-OSH CONTRA LOS DOCUMENTOS OHSAS}

\section{Objeto}

El enfoque de las Directrices ILO-OSH es hacia los trabajadores, mientras que el enfoque de la serie de normas OHSAS, es más amplio, incluye los empleados y otras partes interesadas.

Modelos de sistemas de gestión de S y SO 
Los modelos que describen los principales elementos de un sistema de gestión de $\mathrm{S}$ y SO son directamente equivalentes entre las Directrices ILO-OHS y los documentos OHSAS.

\section{ILO-OSH - Sección 3.2, Participación del trabajador}

En las Directrices ILO-OSH, subsección 3.2.4 se recomienda que: "El empleador debería asegurar, según corresponda, el establecimiento y el funcionamiento eficiente de un comité de seguridad y salud, y el reconocimiento de los representantes de los trabajadores en materia de seguridad y salud, de acuerdo con la legislación y las prácticas nacionales".

OHSAS 18001, 4.4.3, exige que la organización establezca un procedimiento para comunicación, participación y consulta, e involucre un espectro más amplio de partes interesadas (debido al objeto de aplicación más amplio del documento).

\section{ILO-OSH Sección 3.3. Responsabilidad y obligación de rendir cuentas}

Las Directrices ILO-OSH recomiendan en 3.3.1 (h), establecer programas de prevención y promoción de la salud. En las normas OHSAS no hay requisito para esto.

\section{ILO-OSH Sección 3.4 Competencia y formación}

La recomendación de las Directrices ILO-OSH, subsección 3.4.4: "La formación debería ofrecerse gratuitamente a todos los participantes y, cuando sea posible, durante las horas de trabajo". Este no es un requisito de los documentos OHSAS.

\section{ILO-OSH. Sección 3.10.4. Adquisiciones}

Las Directrices ILO-OSH enfatizan en que los requisitos en salud y seguridad de las organizaciones se deberían incorporar dentro de especificaciones de compra $o$ arrendamiento financiero.

Las normas OHSAS tratan los aspectos de adquisiciones mediante sus requisitos de valoración del riesgo, identificación de requisitos legales y establecimiento de controles operacionales.

\section{ILO-OSH Sección 3.10.5 Contratación}

Las Directrices ILO-OSH definen los pasos que se deben tomar para asegurar que los requisitos de seguridad y salud de una organización son aplicados a los contratistas (también suministran un resumen de las acciones necesarias para asegurar que estas se cumplan). Esto está implícito en OHSAS.

ILO-OSH Sección 3.12. Investigación de lesiones, enfermedades, dolencias e incidentes relacionados con el trabajo y su efecto en la seguridad y la salud 
Las Directrices ILO-OSH no exigen que las acciones correctivas o preventivas sean revisadas a través del proceso de valoración del riesgo antes de su implementación, como sí lo son en OHSAS 18001, 4.5.3.2.

\section{ILO-OSH Sección 3.13 Auditoría}

Las Directrices ILO-OSH recomiendan consultar para la selección de los auditores. Por contraste, los documentos OHSAS exigen que el personal auditor sea imparcial y objetivo.

\section{ILO-OSH Sección 3.16 Mejora continua}

Esta es una subcláusula separada en las Directrices ILO-OSH. En ella se presentan en detalle las disposiciones que se deberían tener en cuenta para lograr la mejora continua. En los documentos OHSAS se presentan en detalle disposiciones similares, que consecuentemente no tienen un numeral correspondiente. 


\section{CORRESPONDENCIA ENTRE LOS NUMERALES DEL DOCUMENTO OHSAS Y LOS NUMERALES DE LA GUÍA ILO - OHS}

\begin{tabular}{|c|c|c|c|}
\hline Numeral & OHSAS 18001 & Numeral & ILO - OSH \\
\hline- & Introducción & - & $\begin{array}{l}\text { Introducción } \\
\text { El Sistema de gestión la Seguridad y Salud en el } \\
\text { trabajo en la organización. }\end{array}$ \\
\hline- & Prólogo & & Organización Internacional del Trabajo \\
\hline 1 & Objeto y campo de aplicación & 1 & Objetivos \\
\hline 2 & Referencias normativas & - & Bibliografía \\
\hline 3 & Términos y definiciones & - & Glosario \\
\hline 4 & $\begin{array}{l}\text { Requisitos del sistema de gestión } \\
\text { de S Y SO (sólo titulo) }\end{array}$ & - & - \\
\hline 4.1 & Requisitos generales & 3 & $\begin{array}{l}\text { El Sistema de Gestión de la Seguridad y Salud en el } \\
\text { trabajo en la organización. }\end{array}$ \\
\hline 4.2 & Política de S Y SO & $\begin{array}{ll}3.1 \\
3.16\end{array}$ & $\begin{array}{l}\text { Política en materia de Seguridad y Salud en el trabajo } \\
\text { Mejora continua }\end{array}$ \\
\hline 4.3 & Planificación (sólo titulo) & - & Planificación y aplicación (sólo titulo) \\
\hline 4.3 .1 & $\begin{array}{|llr|}\text { Identificación de peligros, } \\
\text { Valoración de riesgos y } \\
\text { Determinación de los controles }\end{array}$ & $\begin{array}{l}.7 \\
3.8 \\
3.10 \\
3.10 .1 \\
3.10 .2 \\
3.10 .5\end{array}$ & $\begin{array}{l}\text { Examen inicial } \\
\text { Planificación, desarrollo y aplicación del sistema. } \\
\text { Prevención de los peligros } \\
\text { Medidas de prevención y control } \\
\text { Gestión del cambio } \\
\text { Contratación }\end{array}$ \\
\hline 4.3 .2 & Requisitos legales y otros & \begin{tabular}{|l|}
3.7 .2 \\
3.10 .1 .2
\end{tabular} & $\begin{array}{l}\text { (Examen inicial) } \\
\text { (Disposiciones de prevención y control) }\end{array}$ \\
\hline 4.3 .3 & Objetivos y programa (s) & $\begin{array}{l}3.8 \\
3.9 \\
3.16 \\
\end{array}$ & $\begin{array}{l}\text { Planificación, desarrollo y aplicación del sistema. } \\
\text { Objetivos en materia de seguridad y salud en el } \\
\text { trabajo } \\
\text { Mejora continua }\end{array}$ \\
\hline 4.4 & $\begin{array}{l}\text { Implementación y operación (sólo } \\
\text { titulo) }\end{array}$ & - & - \\
\hline 4.4 .1 & $\begin{array}{|lr|}\text { Recursos, funciones, } \\
\text { responsabilidad, rendición de } \\
\text { cuentas y autoridad }\end{array}$ & $\begin{array}{l}3.3 \\
3.8 \\
3.16\end{array}$ & $\begin{array}{l}\text { Responsabilidad y obligación de rendir cuentas } \\
\text { Planificación, desarrollo y aplicación del sistema. } \\
\text { Mejora continua }\end{array}$ \\
\hline 4.4 .2 & $\begin{array}{l}\text { Competencia, formación y toma } \\
\text { de conciencia }\end{array}$ & 3.4 & Competencia y capacitación \\
\hline 4.4 .3 & $\begin{array}{l}\text { Comunicación, participación y } \\
\text { consulta }\end{array}$ & $\begin{array}{l}3.2 \\
3.6\end{array}$ & $\begin{array}{l}\text { Participación de los trabajadores } \\
\text { Comunicación }\end{array}$ \\
\hline 4.4 .4 & Documentación & 3.5 & $\begin{array}{l}\text { Documentación del sistema de gestión de la seguridad } \\
\text { y la salud en el trabajo }\end{array}$ \\
\hline 4.4 .5 & Control de documentos & 3.5 & \begin{tabular}{|l} 
Documentación del sistema de gestión de la \\
Seguridad y la salud en el trabajo
\end{tabular} \\
\hline 4.4 .6 & Control operacional & $\begin{array}{l}3.10 .2 \\
3.10 .4 \\
3.10 .5\end{array}$ & $\begin{array}{l}\text { Gestión del cambio } \\
\text { Adquisiciones } \\
\text { Contratación }\end{array}$ \\
\hline 4.4 .7 & \begin{tabular}{|l|l|}
$\begin{array}{l}\text { Preparación y respuesta ante } \\
\text { emergencias }\end{array}$ & \\
\end{tabular} & 3.10 .3 & $\begin{array}{l}\text { Prevención, preparación y respuesta respecto de } \\
\text { situación de emergencia }\end{array}$ \\
\hline 4.5 & Verificación (sólo titulo) & - & Evaluación (Sólo titulo) \\
\hline 4.5 .1 & \begin{tabular}{|l}
$\begin{array}{l}\text { Medición y seguimiento del } \\
\text { desempeño }\end{array}$ \\
\end{tabular} & 3.11 & Supervisión y medición de los resultados \\
\hline
\end{tabular}

Tabla 14 Correspondencia entre los numerales de OHSAS e ILO-OHS. 


\begin{tabular}{|c|c|c|c|}
\hline Numeral & OHSAS 18001 & Numeral & ILO - OSH \\
\hline 4.5 .2 & $\begin{array}{l}\text { Evaluación del cumplimiento legal } \\
\text { y otros }\end{array}$ & - & - \\
\hline 4.5 .3 & $\begin{array}{l}\text { Investigación de incidentes, no } \\
\text { conformidades, acciones correctivas } \\
\text { y preventivas (sólo titulo) }\end{array}$ & - & - \\
\hline 4.5 .3 .1 & Investigación de incidentes & $\begin{array}{l}3.12 \\
3.16 \\
\end{array}$ & $\begin{array}{l}\text { Investigación de las lesiones, enfermedades, dolencias } \\
\text { e incidentes relacionados con el trabajo y su efecto en } \\
\text { la seguridad y la salud } \\
\text { Mejora continua }\end{array}$ \\
\hline 4.5.3.2 & $\begin{array}{l}\text { No conformidad, acción } \\
\text { correctiva y acción preventiva }\end{array}$ & 3.15 & Acción preventiva y correctiva \\
\hline 4.5 .4 & Control de los registros & 3.5 & $\begin{array}{l}\text { Documentación del sistema de gestión de la } \\
\text { seguridad y la salud en el trabajo }\end{array}$ \\
\hline 4.5 .5 & Auditoría interna & 3.13 & Auditoría \\
\hline 4.6 & Revisión por la dirección & $\begin{array}{l}3.14 \\
3.16\end{array}$ & $\begin{array}{l}\text { Examen realizado por la dirección } \\
\text { Mejora continua }\end{array}$ \\
\hline
\end{tabular}

Tabla 14 Correspondencia entre los numerales de OHSAS e ILO-OHS.

\subsection{1.- UNE 66177: GUÍA PARA LA INTEGRACIÓN DE LOS SISTEMAS DE GESTIÓN.}

La integración de sistemas de gestión no cuenta con una norma internacional,y las empresas implantan una metodología de integración según la estructura de su organización. Esto llevó diferentes países ha desarrollar guías para la integración. En 2005 Aenor desarrolla la UNE 66177: Guía para la integración de los sistemas de gestión.

\subsection{1.- UNE 66177:2005}

\section{OBJETO Y CAMPO DE APLICACIÓN}

Esta norma proporciona directrices para desarrollar, implantar y evaluar el proceso de integración de los sistemas de gestión de la calidad, gestión ambiental y gestión de la seguridad y salud en el trabajo, de aquellas organizaciones que han decidido integrar total o parcialmente dichos sistemas en busca de una mayor eficacia en su gestión y de aumentar su rentabilidad.

Esta norma no pretende reemplazar a las normas existentes sobre sistemas de gestión, sino ayudar a las organizaciones a abordar la implementación integrada de dichos sistemas, con el objetivo de desarrollar una visión compartida de la organización y, en consecuencia, a mejorar la eficacia y rentabilidad de su negocio.

Esta norma es aplicable a todo tipo de organizaciones, con independencia de su tamaño o tipo de actividad, y que apliquen o deseen aplicar uno o más sistemas de gestión. 
Asimismo, esta norma está constituida por orientaciones sobre cómo llevar a cabo la integración, y no ha sido concebida para su uso con fines contractuales o de certificación.

Además esta norma pretende:

- ayudar al equipo directivo a diseñar e implementar un sistema integrado de gestión, e

- identificar los métodos y herramientas aplicables durante la implementación de un sistema integrado de gestión.

Con objeto de aumentar la eficacia del proceso de integración, es recomendable que los usuarios de esta norma cuenten con un conocimiento previo mínimo de los principios y conceptos básicos de los sistemas de gestión. Véanse los anexos A y B.

Con objeto de enriquecer los contenidos de esta norma, se han incluido algunos comentarios identificados como ejemplos y notas.

\section{NORMAS PARA CONSULTA}

UNE-EN ISO 9000:2000 - Sistemas de gestión de la calidad. Fundamentos y vocabulario.

UNE-EN ISO 9001:2000 - Sistemas de gestión de la calidad. Requisitos.

UNE-EN ISO 14001:2004 - Sistemas de gestión ambiental. Requisitos con orientación para su uso.

UNE 150050:1999 - Gestión medioambiental. Vocabulario.

\section{TÉRMINOS Y DEFINICIONES}

A efectos de esta norma, se aplican los términos y definiciones de las Normas UNE-EN ISO 9000, UNE-EN ISO 14001, además de los siguientes:

3.1 accidente: Suceso no deseado que provoca la muerte, efectos negativos para la salud, lesión, daño o cualquier otra pérdida.

3.2 ciclo PHVA (Planificar, Hacer, Verificar, Actuar): Ciclo de mejora continua o ciclo de Deming. Se representa en inglés como ciclo PDCA (plan, do, check, act).

3.3 estrategias: Planes estructurados para lograr objetivos.

3.4 gestión integrada: Parte de la gestión general de la organización que determina y aplica la política integrada de gestión. Surge de la integración de las gestiones de la calidad, el medio ambiente y la seguridad y salud en el trabajo.

3.5 integración: Acción y efecto de aunar, dos o más políticas, conceptos, corrientes, etc., divergentes entre sí, fusionándolos en una sola que las sintetice. 
3.6 integración de los elementos comunes: Integración de los elementos de gestión de las normas de referencia implicadas en los sistemas a integrar, en lo que se refiere a documentación aplicable e implementación de los mismos.

3.7 mapa de procesos: Representación gráfica de la secuencia e interacción de los diferentes procesos que tienen lugar en una organización.

NOTA - El mapa de procesos es una herramienta de gran utilidad para la evaluación de los procesos de trabajo, contribuye a hacer visible el trabajo que se lleva a cabo en una organización de una forma distinta a como normalmente se percibe.

3.8 metas: Conjunto de requisitos detallados de actuación, cuantificados siempre que sea posible, aplicables a la organización o a partes de ésta.

3.9 nivel de madurez: Medida de la capacidad de una organización para alcanzar resultados a través de su conocimiento y experiencias en la aplicación de los sistemas de gestión.

3.10 parte interesada: Persona o grupo que tiene interés en el desempeño o éxito de la organización.

3.11 plan de integración: Programa de actividades planificadas cuyo objetivo es integrar los sistemas de gestión. El plan se desarrolla como fruto de un análisis previo, y suele contener los objetivos a conseguir, acciones a tomar, plazos, responsables y recursos.

3.12 política integrada de gestión: Directrices y objetivos generales de una organización, expresados formalmente por la alta dirección y relacionados con la gestión integrada de los sistemas.

3.13 riesgo: Combinación de la probabilidad y las consecuencias que se derivan de la materialización de un suceso peligroso especificado.

3.14 sistema integrado de gestión (SIG): Conjunto formado por la estructura de la organización, las responsabilidades, los procedimientos, los procesos y los recursos que se establecen para llevar a cabo la gestión integrada de los sistemas.

\section{ESTRUCTURA DEL PROCESO DE INTEGRACIÓN}

El proceso de integración de los sistemas de gestión de esta norma está basado en el ciclo PHVA (véase la figura 1), por ser éste un método de probada eficacia y rentabilidad, y porque facilita el desarrollo de un proyecto de integración de sistemas. Este proceso tiene por objetivo la definición e implantación en condiciones controladas de un plan de integración desarrollado específicamente en función de los objetivos, contexto y nivel de madurez de la organización. 


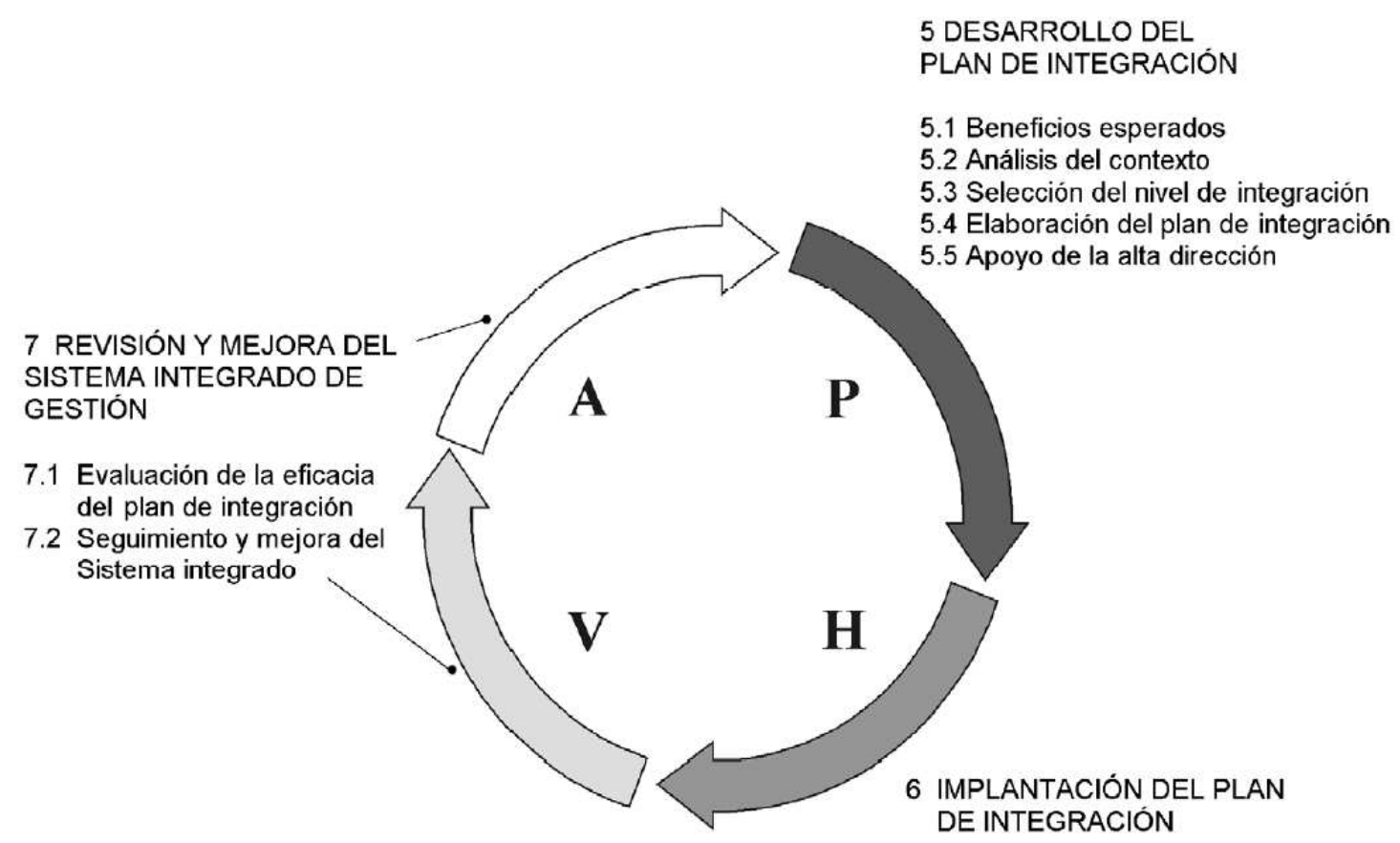

Fig. 1 - Aplicación del ciclo de mejora continua al proceso de integración de sistemas de gestión

Por ello el proceso de integración está estructurado en las siguientes tres grandes etapas, que se reflejan en el diagrama de flujo del proceso de integración de la figura 2 y que se desarrollan en los siguientes capítulos:

- En el capítulo 5: Desarrollo del plan de integración, que facilita las directrices para responder básicamente a las siguientes preguntas: ¿qué beneficios puedo esperar?, ¿qué voy a hacer?, ¿cuánto me va a costar?.

- En el capítulo 6: Implantación del plan de integración, que responde a la pregunta ¿cómo lo voy a hacer?.

- En el capítulo 7: Revisión y mejora, que responde a las preguntas ¿es eficaz y rentable la integración adoptada? ¿necesita mejoras?

Además, esta norma contempla los elementos identificados como críticos para el éxito en el proceso de integración, como son los siguientes:

- En el apartado 5.1: Identificación de los beneficios a conseguir.

- En el apartado 5.2: Análisis del contexto de la organización (riesgos, limitaciones, nivel de madurez en el uso de sistemas).

- En el apartado 5.3: Selección del nivel de integración adecuado a las posibilidades de la organización. 
- En el apartado 5.5: Involucración en el proyecto de la alta dirección y asignación de los recursos necesarios.

- En el capítulo 6: Actualización de la estructura funcional, coordinación, comunicación, involucración del personal

afectado, formación, redefinición de los procesos y documentación asociada.

\section{DESARROLLO DEL PLAN DE INTEGRACIÓN}

Es recomendable documentar los resultados alcanzados en la aplicación de los apartados $5.1,5.2$, y 5.3 , con objeto de

obtener el plan de integración descrito en el apartado 5.4.

\subsection{Beneficios esperados de la integración}

Este apartado responde a las preguntas:

- ¿qué beneficios podemos obtener de esta inversión?

- ¿qué dificultades deberemos superar en el proceso de integración?

La integración de sistemas alcanza normalmente a varias áreas de la organización, consume recursos, puede conllevar cambios funcionales y, en función de su complejidad, durar un considerable periodo. Por ello, teniendo en cuenta que las organizaciones poseen limitados recursos y gran cantidad de áreas de mejora potenciales, es necesario conocer el balance existente entre los beneficios esperados y los recursos necesarios, con objeto de asignar a este proyecto (integración), la prioridad adecuada y el apoyo de la alta dirección.

Por tanto en primer lugar, la organización debe identificar claramente cuáles son los beneficios que espera alcanzar.

Ejemplos de posibles beneficios son:

- Aumento de la eficacia y eficiencia en la gestión de los sistemas y en la consecución de los objetivos y las metas.

- Mejora de la capacidad de reacción de la organización frente a las nuevas necesidades o expectativas de las partes interesadas.

- Mayor eficiencia en la toma de decisiones por la dirección, al disponer de una visión global de los sistemas.

- Simplificación y reducción de la documentación y los registros.

- Reducción de recursos y del tiempo empleado en la realización de los procesos integrados. 
- Reducción de costes del mantenimiento del sistema y de evaluación externa ( simplificación del proceso de auditoría).

- Mejora de la percepción y de la involucración del personal en los sistemas de gestión, favoreciendo que toda la organización hable un único lenguaje de gestión.

- Mejora tanto de la comunicación interna como de la imagen externa, alcanzando mayor confianza de clientes y proveedores.

Asimismo la organización puede intentar definir las posibles dificultades con las que se puede encontrar, al objeto de planificar medidas que reduzcan su impacto.

Ejemplos de posibles dificultades:

- Dificultades derivadas de la resistencia al cambio por parte de la alta dirección y del personal de la organización.

- Necesidad de recursos adicionales específicos para planificar y ejecutar el plan de integración.

- Dificultad para elegir el nivel de integración adecuado al nivel de madurez de la organización.

- Mayor necesidad de formación del personal implicado en el sistema integrado de gestión.

Este inventario de beneficios esperados y dificultades potenciales, junto a los resultados del análisis del contexto (apartado 5.2) y método de integración (apartado 5.3), servirán para elaborar un balance que justifique la inversión que supone el proyecto de integración.

\subsection{Análisis del contexto}

Este apartado sirve para responder a las siguientes preguntas:

- ¿qué capacidad y experiencia posee mi organización para abordar el proceso de integración?

- ¿cuáles son las necesidades y expectativas de mis clientes y otras partes interesadas a las que debe satisfacer mi sistema integrado?

- ¿qué sistemas de gestión posee mi organización para dar respuesta a esas necesidades?

- ¿qué riesgos tiene la integración en mi organización?

La organización debería realizar un análisis del contexto, que sirva para identificar el mejor método de integración posible y los recursos necesarios para su ejecución. 
El contenido de este análisis debe contemplar al menos, los aspectos siguientes:

a) MADUREZ: Nivel de madurez o capacidad para la gestión por procesos.

Para determinar el nivel de madurez puede utilizarse el método de evaluación facilitado en el anexo C.

- Experiencia y eficacia en el uso de los sistemas de gestión y en el uso de herramientas de gestión.

- Estructura organizativa y funcional de la organización.

- Nivel de competencias del personal de la organización.

b) COMPLEJIDAD: Nivel de las necesidades y expectativas de clientes y otras partes interesadas (en el momento actual y en el medio plazo).

- Requisitos de clientes, de la sociedad y del personal de la organización. Requisitos de accionistas, propietarios o miembros societarios.

- Otros requisitos sectoriales o sociales que suscriba la organización.

- Estrategias de la propia organización.

\section{c) ALCANCE: Extensión de los sistemas de gestión}

- Inventario de los sistemas y normas de gestión implantados.

- Productos/servicios afectados por los sistemas de gestión actuales y futuros.

- Procesos involucrados en los sistemas de gestión y su documentación (mapa de procesos) para todos los sistemas.

d) RIESGO: Nivel de riesgo debido a incumplimientos legales o fallos asociados al proceso de integración

- Grado de cumplimiento de los requisitos legales y reglamentarios, asociados a los productos y servicios, a los aspectos ambientales y a la seguridad de los trabajadores y entornos de trabajo.

- Nivel de riesgo y valoración de las consecuencias inherentes al incumplimiento legal.

- Nivel de riesgo y valoración de las consecuencias o fallos derivados del proceso de implantación de la integración.

Se recomienda que la organización realice un análisis individual de cada una de estas variables, así como un análisis de su interrelación. Los resultados los puede clasificar en bajo, medio y alto, para facilitar su uso en el apartado 5.3 siguiente. 
Una vez que la organización haya realizado un análisis de los aspectos relacionados anteriormente estará en disposición de elegir el nivel de integración apropiado, siguiendo las etapas del diagrama de flujo de la figura 2.

NOTA 1 - La máxima eficacia del análisis se consigue al involucrar a todas las partes afectadas como pueden ser, los representantes de la dirección de los sistemas de gestión a integrar, las funciones implicadas en el sistema que se consideren necesarias y la alta dirección.

NOTA 2 - Como herramienta de gestión para el análisis de la situación de partida, puede ser interesante que la organización realice un análisis DAFO (análisis de las

\subsection{Selección del método de integración}

Este apartado establece las directrices para contestar a la siguiente pregunta: ¿qué método de integración puede aplicar mi organización, en función de mi nivel de madurez y de mi contexto?.

\subsubsection{Posibles métodos de integración mediante la gestión por procesos.}

Esta norma está basada en la gestión por procesos como mejor método para la integración de los sistemas de gestión. La gestión por procesos no sólo es una técnica, sino que su implantación requiere un cambio cultural en la organización, es decir, un suficiente desarrollo de su nivel de madurez o de experiencia en la gestión.

La aplicación de la gestión por procesos a los procesos productivos normalmente conlleva cambios organizativos (organigrama, responsabilidades, etc.) derivados de la necesidad de dotar a los "propietarios de procesos" de la responsabilidad, autoridad y capacidad necesaria para su gestión, así como para la gestión unificada de los requisitos y factores de los diferentes sistemas que se encuentran en cada proceso. Por ello, mayores niveles de gestión por procesos, requieren mayores niveles de madurez y viceversa.

Asimismo, la gestión por procesos se puede aplicar paulatinamente limitando su aplicación a ciertos procesos, áreas o sistemas, o aplicarla a la totalidad de los procesos de la organización. Por ello, en esta norma se recomiendan tres métodos de integración cuya aplicación está ligada al nivel de madurez o experiencia que posee la organización en la gestión por procesos.

Estos tres métodos son escalonados y complementarios, y su aplicación progresiva supone una mayor capacidad y calidad de la gestión de la organización.

Posibles métodos de integración a utilizar según el nivel de madurez:

1) Método Básico: Es un método muy rentable ya que requiere una inversión pequeña y se obtienen resultados importantes a corto plazo, debido a la optimización de los 
recursos destinados a la gestión de la documentación y a la gestión integrada de algunos procesos.

Este método no requiere experiencia en la gestión por procesos, y es abordable por todo tipo de organizaciones.

Las acciones que, a modo de ejemplo, pueden llevarse a cabo en este estadio son las siguientes:

a) Integrar las políticas de cada sistema de gestión en una política única de sistema integrado de gestión.

b) Integrar en un único "Manual" de gestión (directrices generales de actuación) la documentación de los sistemas de gestión que se aplican.

c) Definir las responsabilidades y funciones del personal relacionado con los procesos críticos para la gestión de la calidad, seguridad o gestión ambiental del producto o servicio.

d) Integrar la gestión de algunos procesos organizativos comunes a los dos o tres sistemas teniendo en cuenta los requisitos de cada sistema. Integrar también la documentación de estos procesos.

Ejemplos de procesos que son abordados en esta etapa son:

- Identificación y acceso a los requisitos legales.

- Elaboración y gestión de los documentos y registros.

- Gestión de no conformidades, y oportunidades de mejora.

- Auditoría y evaluación interna.

2) Método Avanzado: Este método supone la continuación natural del método "Básico", y su rentabilidad se consigue normalmente a medio plazo, ya que se requiere cierta experiencia para implantar eficazmente la gestión por procesos.

Para aplicar este método se necesita un nivel de madurez en la gestión por procesos suficiente, que supone alcanzar o superar el nivel 2 de la tabla del anexo C. Por ello, intentar aplicar este método sin la necesaria experiencia en la gestión por procesos puede suponer la aparición de problemas durante la integración.

Las acciones que, a modo de ejemplo, pueden ser abordadas en este estadio son las siguientes:

a) Desarrollo de un mapa de procesos que integra para los diferentes sistemas de gestión, los procesos gestión o estratégicos, los procesos operativos o clave y los procesos de soporte, y sus interrelaciones. 
b) Definición y gestión de los procesos que contemplan entre otros los siguientes factores: definición de propietarios, objetivos, indicadores, elementos de entrada y salida de los procesos, instrucciones que aplican a requisitos de varios sistemas, formación, planificación, procesos relacionados con el cliente, compras, producción y prestación del servicio, mantenimiento, equipos de seguimiento y medición, etc.

c) Revisión y mejora sistemática de los procesos teniendo en cuenta los requisitos de cada sistema.

Ejemplos de procesos que se pueden integrar son:

- Revisión por la dirección.

- Comunicación, información y participación.

- Procesos productivos y procesos críticos para la calidad, seguridad o gestión ambiental del producto o servicio.

3) Método Experto: Este método supone la continuación natural del método "Avanzado", y es un método muy rentable, ya que supone extender la integración a corto plazo del sistema de gestión por procesos existente a otras áreas o aspectos no contemplados hasta ahora, sin inversión adicional. Se pueden conseguir grandes resultados si se alinean los procesos con las estrategias de la organización.

Se requiere una gran experiencia en la gestión por procesos para aplicar este método (superior a 2 según la tabla del anexo $\mathrm{C}$ ).

Las acciones que, a modo de ejemplo, pueden ser abordadas en este estadio son las siguientes:

a) Establecer objetivos y metas, e indicadores integrados, así como "desplegar" los objetivos e indicadores a los procesos y subprocesos.

b) Incluir la "voz del cliente", a los proveedores y otras partes interesadas en el diseño de todos los procesos.

c) Extender la gestión por procesos a las actividades administrativas y económicas.

d) Involucrar a los proveedores en la mejora de los procesos.

\subsubsection{Selección del método de integración.}

La organización puede seguir el diagrama de flujo de la figura 2 para identificar el método de integración más apropiado a su situación específica y nivel de madurez. Para ello se necesita conocer los resultados de los análisis realizados de acuerdo con los apartados 5.1 y 5.2 . 


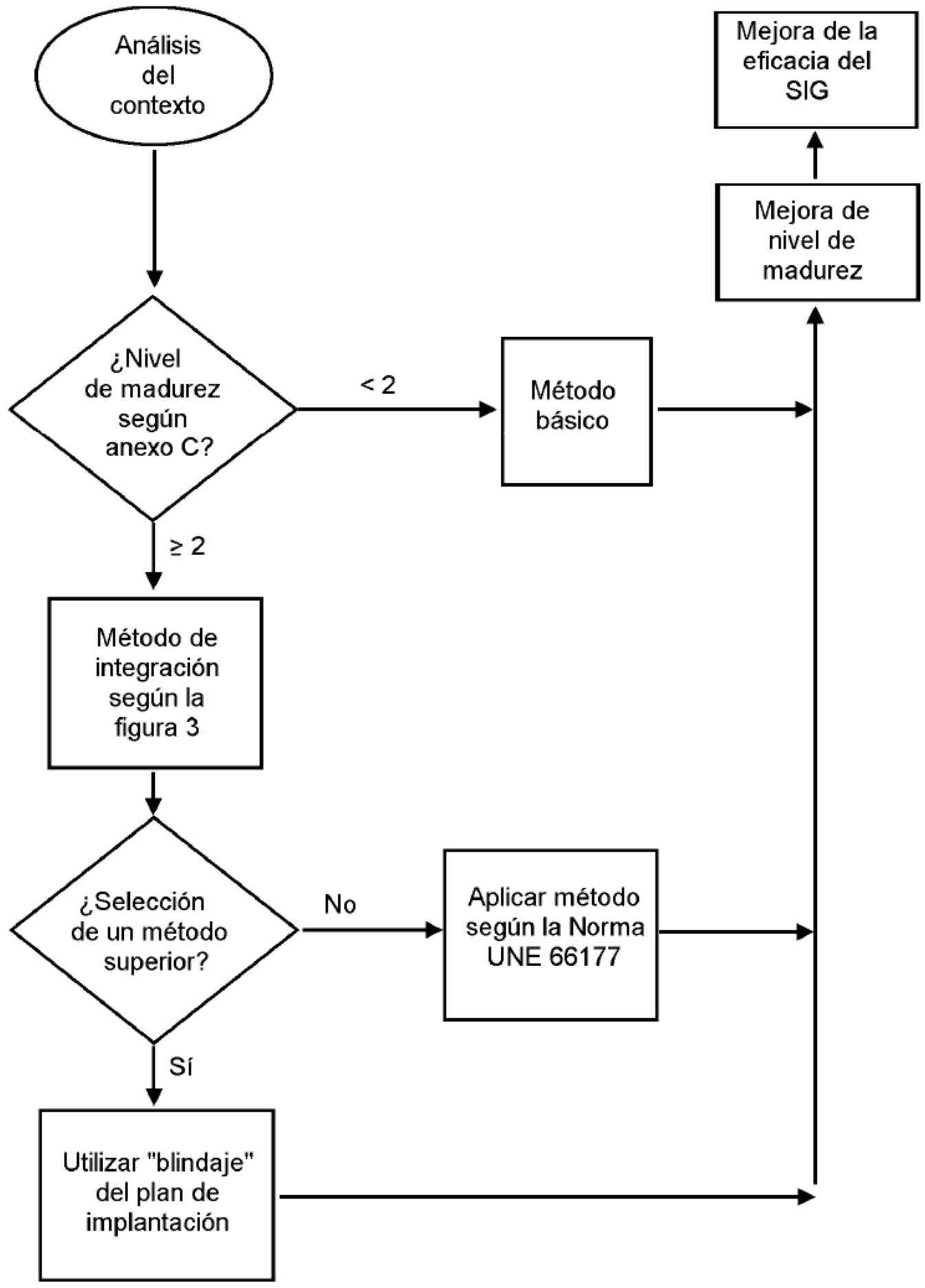

Fig 2: Diagrama de flujo para identificar el método de Integración apropiado

Para identificar el método de integración, el primer paso que la organización debe dar es aplicar el resultado del análisis del apartado 5.2 en relación al nivel de madurez de la organización en la gestión por procesos y, de esta forma, utilizar un método de integración adecuado a su capacidad o nivel de madurez. 
Para ello, la organización puede utilizar el método de autoevaluación del anexo C. De la aplicación de este método resulta que:

- Si la organización ve reflejado su nivel de madurez en la gestión por procesos en la situación descrita en el nivel 1 de la tabla del anexo $\mathrm{C}$, o no completa los requisitos descritos en el nivel 2 de la tabla, se recomienda que opte por el "Método Básico de Integración", ya que su capacidad de gestión así lo aconseja.

- Si la organización completa o supera los requisitos descritos en el nivel 2 de la tabla del anexo C, debe utilizar la figura 3 para conocer cuál es el método de integración apropiado.

El siguiente paso es utilizar el gráfico de la figura 3. La organización entrará en él con los resultados de los análisis realizados de acuerdo con el apartado 5.2. Es decir, situará cada una de las variables analizadas en el apartado 5.2:

Complejidad, Alcance y Riesgo en sus niveles alto, medio y bajo (eje $x$ ) y este resultado formará intersección con la recta del gráfico, identificando el método de integración correspondiente: básico, avanzado o experto (eje y).

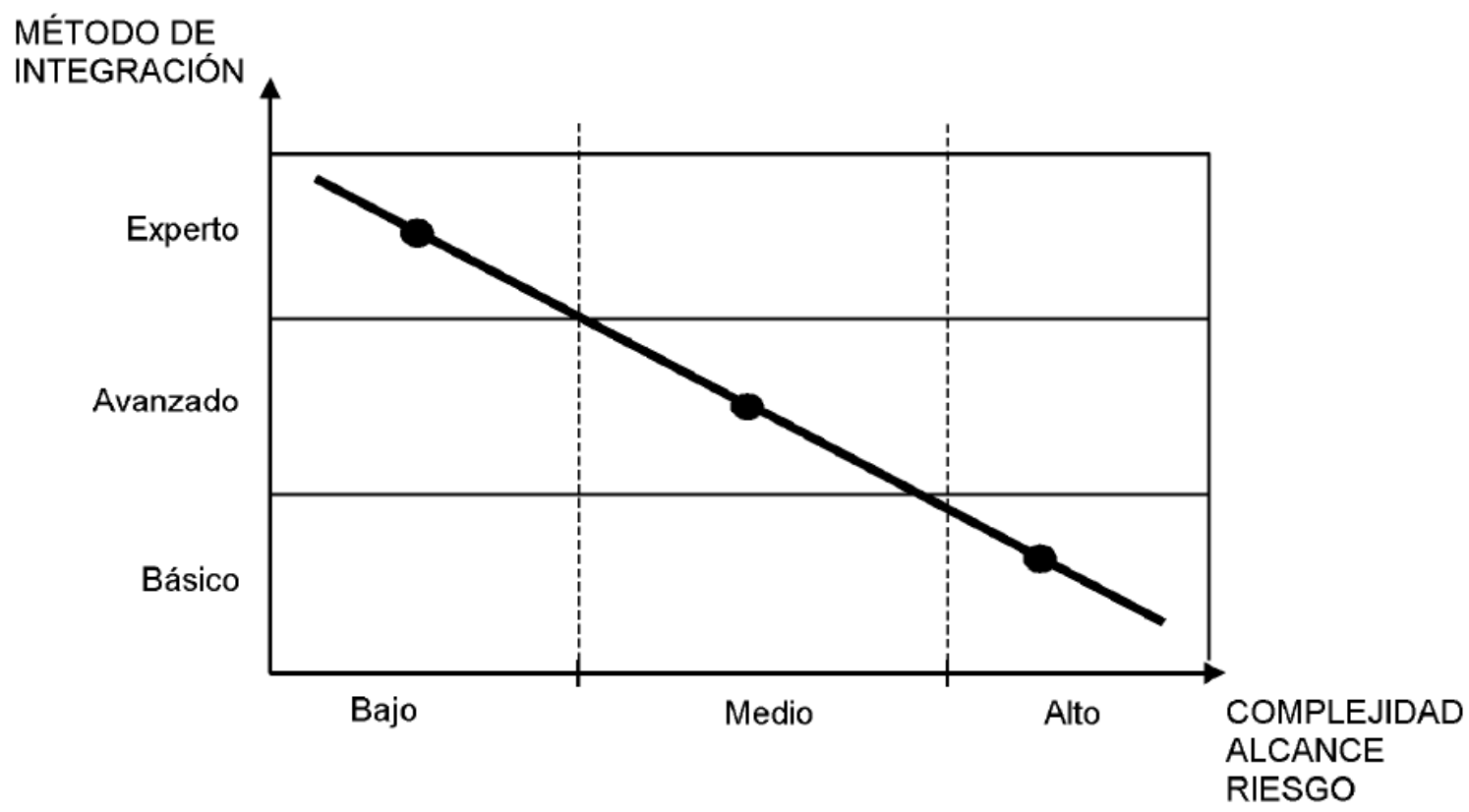

Fig 3: Gráfico para identificar el método de integración adecuado

Debido a que se conjugan simultáneamente diferentes variables, puede suceder que los puntos de intersección indiquen más de un método de integración (básico, avanzado, experto). Si la organización decide abordar la integración mediante un método superior es recomendable garantizar o "blindar" el plan de integración, con objeto de reducir el riesgo de problemas. En este caso se deben destinar una mayor cantidad de recursos al proceso de integración. 


\subsection{Elaboración del plan de integración}

Como resultado de las actuaciones descritas en los apartados 5.1, 5.2 y 5.3, se debe elaborar un plan de integración que sirva para ejecutar eficazmente y de forma controlada la integración de los sistemas planificada.

El plan de integración debe responder al menos a las siguientes preguntas:

— ¿qué objetivos persigue la integración y cual es el contexto de la organización?

- ¿qué voy a integrar: sistemas, procesos, etc.?

- ¿cuáles son los resultados del análisis del contexto? (5.2)

- ¿cómo lo voy a integrar: método elegido (básico, avanzado, experto), gradual o total?

- ¿qué plan de comunicación se va a llevar a cabo?

- ¿quién es el responsable y coordinador del proyecto de integración?

- ¿qué actividades hay que realizar (programa que indique el "qué”, quién y cuándo)

Para la integración de sistemas de gestión es necesario partir de una buena identificación de los procesos de la organización y de sus interacciones. En definitiva, una buena definición de todos los procesos y un mapa de procesos, en el que se indiquen los vínculos o interacciones entre ellos, cuando existan. A título de ejemplo en el anexo E se incluye un mapa de procesos para el sistema integrado de los sistemas de gestión de la calidad, de gestión ambiental y de gestión de la seguridad y salud en el trabajo.

El plan de integración puede incluir los siguientes contenidos:

- Grado de cumplimiento de los requisitos de los diferentes sistemas de gestión implantados, y grado de cumplimiento esperado con la integración.

- Coste y rentabilidad o beneficios estimados de la integración.

- Impacto previsto de la integración en la organización (organigrama, aspectos legales, sociales, técnicos, etc.).

- Una matriz DAFO, donde se resuman las debilidades que pudieran dar lugar a amenazas para la organización y las fortalezas que pueden representar oportunidades para ella.

- Procesos a los que se va a aplicar la integración.

- Organización actual de los procesos y su documentación, y la nueva estructura propuesta. 
- La composición y jerarquía de los nuevos documentos, los elementos integrados o específicos de cada sistema, etc.

- Recursos necesarios para desarrollar la integración a cada nivel.

- Acciones extraordinarias a realizar para minimizar los riesgos ("blindaje") en el caso de que se haya decidido abordar la integración mediante un método de integración superior al resultante en la figura 3.

NOTA 1 - Para la definición de los procesos pueden ser muy útiles métodos como 5M (maquinaria, mano de obra, método, material, mantenimiento).

NOTA 2 - La identificación de los responsables, recursos y plazos para cada actividad prevista, facilita su gestión.

\subsection{Apoyo de la alta dirección}

Dada la extensión de las actividades, los cambios que pueden provocar y las funciones afectadas en un proyecto de integración, se precisa una buena coordinación, por lo que es muy difícil implantar un plan de integración si no se consigue el apoyo de la alta dirección.

El apoyo de la alta dirección es especialmente necesario en el caso de aplicar el método avanzado, ya que puede originar cambios importantes en la organización que necesitarán ineludiblemente el apoyo de la dirección. Esto no sucede cuando se aplica el método básico o el método experto, ya que en general no supone grandes cambios.

El apoyo de la alta dirección se debe plasmar en aportar los recursos necesarios para llevar a cabo el plan aprobado, apoyar las acciones previstas y realizar el oportuno seguimiento al proyecto.

Es importante que la alta dirección designe un responsable del proyecto o coordinador (normalmente el representante de la dirección) con autoridad y visión global de los sistemas y conocedor de la problemática de la empresa, a ser posible neutral frente a los sistemas ya existentes.

Por ello es recomendable presentar un informe a la alta dirección que describa el proyecto de integración que se desea llevar a cabo. Este informe, que puede ser el propio plan de integración o un resumen del mismo, debería contestar a las siguientes preguntas:

- ¿qué beneficios me va a proporcionar la integración y cuando?

- ¿qué objetivos persigue la integración?

- ¿qué inversión y rentabilidad esperada tiene el proyecto?

- ¿cuál es el contexto inicial de la organización? ¿cuáles son los riesgos y problemas a superar? 
- ¿en que consiste el plan de integración?

- ¿cuándo termina el plan de integración?

- ¿puede tener el plan repercusiones en el organigrama, sociales o de otro tipo?

- ¿quién será el responsable del plan de integración?

Por ello, el informe puede estructurarse por ejemplo a través de los siguientes contenidos:

- inversión necesaria, rentabilidad y beneficios esperados;

- análisis del contexto (apartados 5.1, 5.2) y descripción de la situación futura indicando las actividades y funciones afectadas;

- método de integración propuesto (apartado 5.3);

- programa de actividades y organigrama del proyecto (apartado 5.4, capítulo 6);

- mecanismos de seguimiento (capítulo 7).

NOTA - Para la implementación de un sistema integrado de gestión los siguientes factores se consideran críticos:

- Apoyo, compromiso e implicación de los altos directivos;

- Visión global de la empresa y de sus factores clave para el éxito;

- Enfoque participativo.

\section{IMPLANTACIÓN DEL PLAN DE INTEGRACIÓN}

\subsection{Plan de integración}

La tarea del coordinador puede verse facilitada enormemente si se forma un comité o equipo de integración con los responsables de los distintos departamentos o sistemas a integrar (o sus respectivas áreas funcionales), y se planifican reuniones periódicas.

A las reuniones del equipo de integración, deberían asistir también los responsables de los procesos involucrados.

El equipo de integración puede planificar, entre otros, los siguientes asuntos:

- Un plan de comunicación sobre el plan de integración, que posibilite la involucración y la adhesión del personal afectado en el proyecto.

NOTA - Debido a que el sistema integrado de gestión se suele basar en la familia de Normas ISO 9000, se corre el peligro de encontrar una menor involucración del personal 
con los sistemas de gestión ambiental o de seguridad y salud en el trabajo, por lo que es recomendable garantizar las actividades de sensibilización en estas áreas.

- Consensuar la nueva interrelación de los procesos objeto de la integración.

- Definir responsables o "propietarios" de los procesos.

- Programar un calendario de reuniones para integrar cada uno de los procesos.

- La revisión y elaboración de los procesos y sus documentos, contemplando la elaboración de un único documento de gestión o "manual” que describa el sistema integrado de gestión.

NOTA 1 - Con objeto de promover la implicación del personal hasta los objetivos comunes, es recomendable integrar en una única política los aspectos de calidad, medio ambiente y seguridad y salud en el trabajo.

NOTA 2 - Para evitar solapes de autoridad se recomienda establecer una clara definición de responsabilidades.En el caso de que existan diferentes responsables para los sistemas, se debe prestar especial atención para coordinar sus intereses hacia los objetivos comunes. En este caso, puede ser aconsejable el uso de herramientas de trabajo en equipo.

NOTA 3 - La integración de los aspectos relativos a la calidad, seguridad y salud en el trabajo y el medio ambiente de los productos desde la fase de diseño aumenta la rentabilidad de los procesos.

NOTA 4 - Los documentos deberían desarrollarse aplicando criterios de máxima simplicidad y operatividad.

NOTA 5 - Normalmente el proceso de integración conlleva mucho trabajo en equipo. Por ello, se recomienda evitar discusiones por problemas de detalle o por competencias funcionales.

\subsection{Seguimiento del plan de integración}

La organización debería programar el seguimiento del plan de integración con una frecuencia que permita valorar el cumplimiento de los objetivos previstos y prever los cambios al plan que permitan el éxito de la integración. Los cambios conllevan normalmente la actualización del plan.

Los informes de la revisión deberían distribuirse a todas las partes implicadas en el proceso de integración.

\section{REVISIÓN Y MEJORA DEL SISTEMA INTEGRADO DE GESTIÓN}

Una vez implantado el sistema integrado de gestión, se recomienda incorporar su revisión periódica en la "revisión por la dirección" de acuerdo con los requisitos de las 
normas de gestión aplicables. Por ello, los resultados de las revisiones del plan de integración deberían ser considerados en la revisión general del sistema por la alta dirección.

La revisión del sistema integrado de gestión tiene ventajas sobre la revisión individual de cada sistema, ya que permite:

- un análisis global de los hechos y los resultados;

- mejorar la coherencia de las decisiones; y

- determinar las prioridades en los diferentes ámbitos del sistema integrado de gestión, aprovechando todas las sinergias disponibles.

Es recomendable que las oportunidades de mejora surgidas de la revisión se gestionen de acuerdo al procedimiento general de mejora de la organización. Asimismo es recomendable aplicar el enfoque basado en procesos a las acciones de mejora, de tal forma que no se separen éstas por cada sistema de gestión, sino tratarlas por procesos, salvo que existan situaciones específicas que así lo aconsejen.

\subsection{2.- EVALUACIÓN DEL NIVEL DE MADUREZ EN LA GESTIÓN POR PROCESOS}

La descripción incluida a continuación es necesaria para aplicar los apartados 5.2 y 5.3 de esta norma. Describe las características de los cinco niveles de madurez posibles de los sistemas de gestión de la organización, identificando situaciones habituales para reconocerlos.

El paso a un nivel superior supone que se satisface el nivel anterior.

Descripción del Nivel de Madurez Descripción de posibles situaciones de los sistemas de gestión

\section{INICIAL: Sin aproximación formal:}

La actividad o proceso se realiza total o parcialmente, pero no se documenta de manera adecuada.

- Descripción de posibles situaciones de los sistemas de gestión :

No es tenida en cuenta la voz del cliente, ni hay evidencia de mejora en los procesos y actividades.

No se han establecido los procesos ni los propietarios del proceso.

No se han definido las responsabilidades, en relación a los procesos.

Información limitada sólo a los procesos clave. 


\section{BASICO: Aproximación reactiva:}

La actividad o proceso se realiza totalmente y se documenta de manera adecuada existiendo mínimos datos de su seguimiento y revisión para la mejora.

- Descripción de posibles situaciones de los sistemas de gestión :

El sistema de gestión se basa en procedimientos, registros e instrucciones, que aseguran la calidad del producto o servicio.

Se evalúa a los proveedores de manera sistemática, y existen criterios de evaluación, pero no se les tiene en cuenta en el diseño de los procesos.

Se han definido y comunicado las responsabilidades y funciones del personal relacionado con los procesos críticos para la calidad, seguridad o gestión ambiental del producto o servicio.

Satisface la Norma UNE-EN ISO 9001.

\section{AVANZADO: Aproximación del sistema formal estable:}

La actividad o proceso se realiza y revisa; se toman acciones derivadas del seguimiento y análisis de datos. Existe tendencia a la mejora en etapas tempranas del proceso.

- Descripción de posibles situaciones de los sistemas de gestión :

El sistema de gestión de la calidad se ha basado en la identificación y documentación de los procesos de gestión o estratégicos, los procesos operativos o clave y los procesos de soporte, y sus interrelaciones, conformando así el mapa de procesos de la organización.

Están identificados los elementos de entrada y salida de los procesos.

Los procesos son revisados y mejorados de manera regular.

También se han definido objetivos concretos cuantitativos, para lo que existe el consiguiente indicador de seguimiento.

El personal conoce los procesos y es debidamente formado para el desempeño de sus funciones dentro de ellos.

Se definen y comunican, propietarios y personal vinculado para todos los procesos.

Se incluye la voz del cliente, proveedores y otras partes interesadas en el diseño de los procesos.

La dirección asegura que todos los procesos son eficaces para satisfacer a los clientes. 
La dirección ha definido un plan operativo para gestionar los procesos, donde se incluye: requisitos de entrada y salida, verificación y validación, oportunidades y acciones de mejora de procesos.

\section{EXPERTO: Énfasis en la mejora continua:}

La actividad o proceso se realiza, se revisa y se toman acciones derivadas del análisis de los datos. El proceso es eficaz y eficiente. Tendencia mantenida a la mejora.

- Descripción de posibles situaciones de los sistemas de gestión :

Existe evidencia de la mejora de los procesos gracias a la revisión sistemática.

Los procesos de gestión sistematizados incluyen actividades administrativas y económicas.

Los procesos del sistema cuentan con su propietario y personal vinculado identificado.

Existe un despliegue completo de indicadores y objetivos en todos los procesos y subprocesos.

Existe evidencia de la mejora de los procesos gracias a la revisión sistemática, bien a través de autoevaluaciones, revisiones del sistema por la dirección, u otras.

La organización se enfoca hacia la mejora de los procesos, para asegurar la creación de valor para todas las partes interesadas.

Se involucra a los proveedores en la mejora de los procesos.

Se han establecido alianzas con proveedores para mejorar la eficacia y eficiencia de los procesos.

La organización revisa periódicamente el desempeño del proceso para asegurar su coherencia con el plan operativo.

\section{PREMIO: Desempeño de “mejor en su clase”:}

La actividad se realiza y se revisa teniendo en cuenta lo que hacen los mejores en el sector y midiendo el nivel de satisfacción de las partes afectadas y se toman acciones derivadas del seguimiento de la revisión. Se mide la eficacia y eficiencia de la actividad y se mejora continuamente para optimizarla.

- Descripción de posibles situaciones de los sistemas de gestión :

Los procesos están optimizados y sus propietarios innovan con el fin de buscar nuevas oportunidades de mejora, por ejemplo mediante actividades planificadas y actividades de benchmarking. 
Los procesos guían la organización hacia la total satisfacción de los clientes y otras partes interesadas. 


\section{7.-CALIDAD EN I+D+ i}

\section{1.-. ¿DEQUÉ TRATA LA CALIDAD EN INVESTIGACIÓN?}

La calidad en investigación concierne a la calidad de los métodos empleados por los investigadores para obtener sus resultados. Promover la calidad en investigación es tratar de mejorar de forma continua las prácticas de investigación de forma que permitan:

- Garantizar los resultados y productos de la investigación

- Asegurar la trazabilidad de los procesos y actividades de investigación

No trata de la calidad de la investigación, pues ésta se evalúa por "pares" en los campos de investigación de cada área científica. Los métodos e instrumentos de gestión de calidad en investigación facilitan la puesta en marcha de buenas prácticas: científicas y de investigación, que finalmente de forma indirecta concurren en mejorar la calidad de los resultados de la investigación.

Los métodos e instrumentos de gestión de calidad en investigación se deben extender también a los procesos de apoyo y de gestión. La calidad en investigación de un Centro de Investigación afecta, en primer lugar, a los grupos de investigación que experimentan y manipulan, y analizan y miden .., pero también concierne a los servicios de administración y gestión que deben proveer a los grupos de los apoyos y servicios necesarios para que realicen su actividad. La calidad en investigación debería aplicarse a todo el conjunto de actores movilizados de forma colectiva según sus competencias para alcanzar objetivos comunes.

¿Por qué debe promoverse la Calidad en Investigación?

En principio, la puesta en marcha de acciones de calidad en los grupos de investigación es en la mayor parte de los casos voluntaria. Por tanto, deben percibirse por tanto los beneficios que pueden esperarse y lograrse, y deben compensar la inversión en tiempo y otros medios consagrada a la calidad en investigación.

\section{2-. BENEFICIOS ESPERADOS}

Los beneficios esperados, se resumen a continuación:

1. Proporcionar un marco general de acción para la investigación ganando tiempo para la creatividad

2. Ofrecer garantías y dar confianza

3. Responder mejor a las demandas de socios y destinatarios de la investigación

4. Mejorar la eficacia económica en un entorno de competencia

5. Capitalizar los resultados y mejorar la gestión del conocimiento

6. Mejorar la competitividad científica

7. Producir información y conocimiento científicos fiables 
8. Facilitar el trabajo en red, los intercambios y el diálogo entre grupos de investigación

\section{Proporcionar un marco general de acción para la investigación ganando tiempo para la creatividad}

En el proceso de investigación y de generación de conocimiento la creatividad es esencial. La creatividad es, de hecho, una de las características más propias y destacadas de la investigación. Se suele admitir que en los procesos de investigación, el $20 \%$ del tiempo se dedica a actividades innovadoras y creativas y el $80 \%$ a actividades rutinarias.

Si para este último tipo de actividades más clásicas y repetitivas se implantan métodos de gestión de calidad adaptados a la investigación, (P.Ej.: procedimientos para realización de medidas o ensayos bien definidos e implantados, ó para archivo y tratamiento de la documentación..etc), se podrá ganar tiempo para la reflexión y la innovación en la investigación.

\section{Ofrecer garantías y dar confianza}

Los grupos de investigación que mejoran la trazabilidad de sus actividades y la fiabilidad de sus resultados, o que, llegado el momento, acaban obteniendo marcas de calidad referidas a normas reconocidas:

- Pueden ofrecer más fácilmente garantías de sus resultados y dar confianza a quienes los utilizan

- Van adquiriendo una reputación de "calidad" tanto mayor cuanto más se implanten sistemas y herramientas de calidad que puedan ser verificadas por entidades externas

\section{Responder mejor a las demandas de socios y destinatarios de la investigación}

Organizarse para conocer mejor la demanda de los destinatarios y utilizadores finales de los resultados de investigación (es decir los "clientes"), es aumentar la capacidad de satisfacer sus expectativas. Es importante no olvidar que además de la comunidad científica y la sociedad en general, son "clientes" (y tanto o más principales):

- Los financiadores: públicos o privados en sus diferentes modalidades

- Los grupos de investigación con los que se colabora

- Otras partes interesadas

- Los clientes internos

Las herramientas de calidad pueden diseñarse para tener más específicamente en cuenta sus demandas y, así, satisfacerlas mejor a lo largo de todo el proceso de I+D. De esta forma, a través del empleo de buenas prácticas y de la solidez de los métodos empleados se puede conseguir finalmente una mejor calidad de los resultados obtenidos.

\section{Mejorar la eficacia económica en un entorno de competencia}




\section{A) Mejora de la posición competitiva}

La obtención de recursos económicos para realizar nuevos proyectos o líneas de investigación se produce en una situación de cada vez mayor concurrencia competitiva, de, cada vez, más competencia, tanto en los que se refiere a la obtención de fondos públicos como privados. En este contexto los grupos que por sus buenas prácticas de investigación y de laboratorio aumenten:

- Las garantías en la fiabilidad de sus resultados

- La seguridad de la buena gestión de los medios que les son confiados y del cumplimiento de los plazos establecidos

Podrán ver mejorada su posición competitiva en la obtención de fondos.

\section{B) Disminución de los costes de no calidad}

En el mundo industrial los costes asociados a no calidad pueden llegar a alcanzar, e incluso superar, el $20 \%$ de la facturación de las empresas. La "no calidad" en investigación también existe. Por ejemplo:

- Muestras mal etiquetadas o de origen dudoso que se convierten en no utilizables

- Instrumentos de medida mal mantenidos o no calibrados pueden descalificar y hacer volver a realizar una serie de medidas

- Medios de cultivo defectuosos que implican la no validez de un ensayo

- Ficheros de bases de datos mal almacenados que pueden dar lugar a volver a realizar nuevas campañas de observaciones,... etc.

Incidentes como los mencionados, fruto de la "no calidad" en la investigación, tienen como consecuencia importantes costes en términos:

- Financieros: despilfarro, cierre de líneas de investigación...

- Temporales: retrasos, incumplimiento de plazos...

Que disminuyen la credibilidad y la eficacia de los grupos de investigación y de los organismos a los que pertenecen. La utilización de técnicas de calidad en investigación pueden, sin duda, contribuir a disminuir los costes de "no calidad" en investigación.

\section{Capitalizar los resultados y mejorar la gestión del conocimiento}

Una parte muy importante de la capacidad de I+D de un equipo está constituida por la de los investigadores temporales. Los doctorandos, postdoctorales, investigadores en intercambio., etc. contribuyen, de forma importante, con su trabajo a la producción científica del equipo de acogida. Existen a este respecto, por una parte, unos periodos 
transitorios de acogida en que se deben preparar de forma adecuada la introducción e integración de estos miembros temporales en la organización. Los equipos de investigación que a través de un empeño en calidad formalizan de forma correcta los procesos de acogida, a través de sistemas claros que introduzcan a los nuevos miembros en cuestiones tales como:

- Procedimientos para los ensayos y medidas más habituales

- Procedimientos de utilización de equipos

- Procedimientos de manipulación de muestras y productos

- Condiciones de seguridad del laboratorio

- Archivo de la documentación. etc.

Están en condiciones de reducir el tiempo de aprendizaje e integración y ganarlo para la realización de investigación efectiva por parte de los investigadores temporales y de todo el grupo de investigación. Por otra parte, no siempre el trabajo de estas personas queda en el equipo de acogida una vez que finaliza el tiempo de estancia. Si no está correctamente registrado, el conocimiento científico de estas personas no se capitaliza ni deviene permanente en los grupos de acogida. Poner en marcha sistemas documentales eficaces permite:

- Mejorar la transmisión de la información

- Evitar la repetición de trabajos cuyos resultados no se hubieran sido registrados y validados correctamente

La anterior reflexión puede hacerse general, y no sólo en lo que se refiere los investigadores temporales, sino al conjunto de investigadores de un grupo de investigación: si no está correctamente gestionado el conocimiento científico del grupo de investigación, mediante sistemas documentales eficaces, éste no se capitaliza ni deviene permanente en los grupos de investigación.

\section{Mejorar la competitividad científica}

Si las buenas prácticas de investigación y de laboratorio ayudan a seleccionar los métodos más adecuados, gestionar mejor los equipos y los recursos científicos y obtener una fiabilidad mayor de los resultados, todo ello contribuirá de forma global a la mejora de la competitividad científica del equipo de investigación disminuyendo los riesgos.

Gestionar correctamente la trazabilidad de muestras, productos y actividades de investigación son además elementos que permiten poner en valor más fácilmente los resultados obtenidos y garantizar la propiedad intelectual de los trabajos realizados.

\section{Producir información y conocimientos científicos fiables}

Para hacer frente a las necesidades crecientes de información y a las nuevas preocupaciones de la sociedad, asociadas frecuentemente a los nuevos riesgos en áreas en que la evolución de los conocimientos es muy rápida, resulta indispensable movilizar las competencias y los conocimientos científicos para poder alimentar los debates en un clima de confianza. 
Los debates, sobre las relaciones entre ciencia y sociedad, realizados a partir de estereotipos, tópicos, "impresiones" y "miedos" dan lugar a situaciones de desconfianza. Estos debates deben poder establecerse a partir de conocimientos científicos fiables que permitan a los investigadores informar y rendir cuentas.

Sólo a partir de conocimientos científicos de los que se pueda asegurar su fiabilidad y trazabilidad, (que se obtienen con mayor facilidad a partir de la puesta en marcha efectiva de herramientas de gestión de calidad en investigación), se pueden establecer debates constructivos entre científicos y ciudadanos.

\section{Facilitar el trabajo en red, los intercambios y el diálogo entre grupos de investigación}

En la actualidad una gran parte de las actividades de investigación se organiza mediante proyectos realizados en red en el que participan investigadores de distintas instituciones que movilizan competencias y utilizan recursos complementarios. En este tipo de proyectos los objetivos deben estar bien definidos, los resultados obtenidos se revisan a intervalos periódicos y se trabaja con presupuestos fijos y negociados. Cuando los equipos de investigación de estos proyectos realizados en red:

- $\quad$ respetan las mismas prácticas y métodos de investigación.

- hablan el mismo lenguaje, proveniente de la utilización de herramientas de calidad comunes, el diálogo y los intercambios de información se ven facilitados.

Cuando en el seno de estas unidades de investigación en red formada por investigadores de equipos e instituciones diferentes se adopta un enfoque común de gestión de calidad en investigación, se produce un factor de cohesión al utilizar prácticas, procedimientos y metodologías comunes de cara a obtener objetivos, también, comunes.

Lo anterior facilita, asimismo, una mejor y mas eficaz utilización de equipamientos y plataformas tecnológicas, ya que se realiza según procedimientos comunes que son explícitos, conocidos, respetados y realizados por todos

\section{3- VISIÓN ESPAÑOLA: LAS NORMAS UNE}

La normalización de las actividades de I+D+i en España surgió a iniciativa del Gobierno y promovida por AENOR (Asociación Española de Normalización y Certificación) y asociaciones sectoriales interesadas en incentivar la I+D+i española. Así, a mediados de 2001 se constituyó el Comité Técnico de Normalización para actividades de $\mathrm{I}+\mathrm{D}+\mathrm{i}$, integrado por representantes de todos los sectores interesados, públicos y privados.

Esta iniciativa se enmarca en el objetivo que se fija España a partir del ingreso a la Unión Europea en 1986 de mejorar su participación en I+D+i para alcanzar los niveles de los otros países de Europa. Desde ese momento se desarrollan estrategias gubernamentales en esa dirección, que incluyen leyes fundamentales (como la llamada Ley de la Ciencia), la redacción de sucesivos planes nacionales de Investigación Científica, Desarrollo 
Tecnológico e Innovación, y la creación en las universidades de las Oficinas de Transferencia de Resultados de Investigación (OTRI).

Uno de los principales objetivos del plan es aumentar la participación privada en la inversión en $\mathrm{I}+\mathrm{D}+\mathrm{i}$ a niveles del $66 \%$. Para ello se adoptan medidas como la implantación de numerosos instrumentos financieros, en un marco fiscal de apoyo a la I+D+i reconocido como el mejor de Europa. Este incluye beneficios directos como anticipos rembolsables, créditos parcialmente rembolsables, o subvenciones no rembolsables; e indirectos como exenciones impositivas a las actividades de $\mathrm{I}+\mathrm{D}+\mathrm{i}$. Se establecen deducciones importantes $\mathrm{y}$ crecientes del gasto invertido en I+D y en IT.

Para solicitar los beneficios las empresas deben justificar sus actividades de $\mathrm{I}+\mathrm{d}+\mathrm{i}$ ante el ministerio de finanzas. Para ello se les requieren memorias tanto económicas como técnicas de los proyectos por los que cuales los solicitan. Es por lo tanto importante que desde el primer momento, organicen la gestión de $\mathrm{I}+\mathrm{D}+\mathrm{i}$ de manera ordenada, e individualizada por proyectos, para facilitar la preparación de la documentación. Muchas empresas encuentran dificultades en la interpretación de los conceptos de I+D e IT, cuyas definiciones y características son especificadas por la ley.

Es en este marco donde juega un rol fundamental la normalización de las actividades de I+D+i. Para ello se ha desarrollado un esquema de certificación de proyectos y de sistemas de gestión de $\mathrm{I}+\mathrm{D}+\mathrm{i}$ que facilita tanto la labor de los participes en el proyecto, orientándolos a realizarlo según una norma aceptada, como la de los organismos que tienen que evaluar proyectos de $\mathrm{I}+\mathrm{D}+\mathrm{i}$.

Si bien las empresas pueden obtener tanto subvenciones como deducciones por $\mathrm{I}+\mathrm{D}+\mathrm{i}$ realizando gestiones directas, se ha establecido a partir de 2003 un mecanismo opcional y voluntario que les aporta múltiples beneficios. Para demostrar que su proyecto se puede considerar un proyecto de $\mathrm{I}+\mathrm{D}+\mathrm{i}$ las empresas pueden presentar un Informe Motivado emitido por el ministerio de industria, que resulta de carácter vinculante para el de finanzas.

Para la solicitud del Informe Motivado se incluye como requisito previo una Certificación del Proyecto emitida por una entidad acreditada por ENAC. El Comité específico establecido en AENOR ha presentado en 2002 y actualizado en 2006 la familia de Normas UNE 166000, formada por:

- UNE 166000:2006 - Gestión de la I+D+i: Terminología y definiciones de las actividades de $\mathrm{I}+\mathrm{D}+\mathrm{i}$.

- UNE 166001:2006 - Gestión de la I+D+i: Requisitos de un proyecto de I+D+i.

- UNE 166002:2006 - Gestión de la I+D+i: Requisitos del Sistema de Gestión de $\mathrm{I}+\mathrm{D}+\mathrm{i}$.

- UNE 166004:2003 EX - Gestión de la I+D+i: Competencia y evaluación de auditores de sistemas de gestión de I+D+i.

- UNE 166006:2006 EX - Gestión de la I+D+i: Sistema de Vigilancia Tecnológica.

Esta familia de normas ya ha sido analizada en los trabajos anteriores de los autores. En 
ellos se ha mostrado que, a diferencia de otras normas de Gestión de Calidad, por ejemplo la ISO 9001:2000, la familia UNE 166000 aborda los procesos de diseño-desarrollovalidación, sin obviar los canales "a priori" de adquisición de información, y "a posteriori" de explotación de los resultados.

La tercera Norma UNE 166002 permite certificar los sistemas de gestión de $\mathrm{I}+\mathrm{D}+\mathrm{i}$ con el objetivo de "proporcionar indicaciones para organizar y gestionar eficazmente este tipo de proyectos en relación a la gestión de recursos, el análisis interno/externo de la situación tecnológica, la planificación y control de los objetivos y la gestión de la cartera de proyectos".

La implantación de un Sistema de Gestión de la I+D+i permite a las empresas, independientemente de su tamaño o del sector económico en que realice su actividad:

- Planificar, organizar y controlar las unidades de I+D+i, lo que redunda en un ahorro de recursos y en una mejora de la motivación e implicación de los empleados.

- Aportar un valor añadido de confianza en la actividad de I+D+i de la empresa a través de su sistema de gestión, facilitando la transferencia de tecnología.

- Mejorar su imagen empresarial y su competitividad.

- Llevar a cabo la necesaria vigilancia tecnológica que les permita anticiparse a los cambios del mercado e identificar nuevas oportunidades de mejora.

- Integrar la gestión de la I+D+i en el resto de sistemas de gestión implantados en la empresa.

- Establecer la interacción de la $\mathrm{I}+\mathrm{D}+\mathrm{i}$ con otros departamentos o divisiones de la empresa.

- Realizar el análisis, mejora continua y correcta medida de los resultados de sus actividades de investigación, desarrollo e innovación.

En definitiva, el objetivo de la Normalización y la Certificación de I+D+i en España es el demostrar de forma inequívoca ante cualquier parte interesada la naturaleza de las actividades que se desean realizar o están en desarrollo, así como la coherencia en el presupuesto o gastos incurridos y la capacidad de gestión de las Unidades gerenciadoras de estos proyectos, ya sean públicas o privadas. Para ello se requiere de auditores formados que además demuestren una vasta experiencia en el campo de la gestión de la investigación científica e innovación tecnológica.

\subsection{1.- UNE 166002:2006}

\section{OBJETO Y CAMPO DE APLICACION}

El objeto de la norma es proporcionar directrices que van más allá de los requisitos establecidos en otras normas de sistemas de gestión, con el fin de considerar tanto la eficacia como la eficiencia de un sistema de gestión de la I+D+i y por lo tanto el potencial de mejora de los resultados, así como la mejora de los procedimientos de transferencia interna de estos resultados para optimizar los procesos de innovación tecnológica de la organización. 
Esta norma contempla también, como una parte integrante del proceso de innovación tecnológica, la transferencia y la asimilación de tecnología. La implantación del sistema de gestión de la I+D+i, según lo establecido en esta norma, capacita a las organizaciones para reconocer tecnologías emergentes o nuevas tecnologías no aplicadas en su sector, cuya asimilación y posterior desarrollo les proporcionará la base para potenciar sus actividades de I+D+i y mejorar su competitividad.

La norma parte del compromiso de la alta dirección de las organizaciones en la mejora continua, a través del estable- cimiento de una política de $\mathrm{I}+\mathrm{D}+\mathrm{i}$ y de una revisión continua de la gestión. Los requisitos y directrices contenidos en esta norma capacitan a una organización para formular y desarrollar una política de innovación tecnológica y unos objetivos acordes con sus actividades, productos y servicios específicos, pero sin establecer aspectos prescriptivos para la formulación de las políticas de I+D+i. Se aplica a aquellos aspectos que la organización pueda controlar y sobre los que puede esperar que tenga influencia. La norma no establece, por sí misma, criterios concretos o exigencias específicas de actuación tecnológica, ni tampoco determina la profundidad que la gestión de la innovación tecnológica ha de tener en la organización, pero parte del reconocimiento de que las actividades de $\mathrm{I}+\mathrm{D}+\mathrm{i}$ son elemento fundamental para obtener la excelencia de las organizaciones.

Todos los requisitos de esta norma son genéricos y se pretende que sean aplicables a todas las organizaciones sin importar su tipo y tamaño y que, tras hacer un diagnóstico previo de su situación de $\mathrm{I}+\mathrm{D}+\mathrm{i}$, deseen:

a) Establecer las bases para iniciarse en las actividades de $\mathrm{I}+\mathrm{D}+\mathrm{i}$.

b) Definir, implantar, mantener al día y mejorar un sistema de gestión de la $\mathrm{I}+\mathrm{D}+\mathrm{i}$ de acuerdo con su política.

c) Demostrar frente a terceros el cumplimiento de los requisitos de esta norma y/o certificar el sistema de gestión de la I+D+i.

Cuando uno o varios requisitos de esta norma no se puedan aplicar debido a la naturaleza de la organización, pueden considerarse para su exclusión.

Cuando se realicen exclusiones, no se podrá alegar conformidad con esta norma, a menos que dichas exclusiones queden restringidas a los requisitos expresados en el apartado 4.4.6, y que tales exclusiones no afecten a la capacidad o responsabilidad de la organización para realizar el proceso de $\mathrm{I}+\mathrm{D}+\mathrm{i}$ que cumpla con las necesidades de las partes interesadas y los requisitos reglamentarios aplicables.

\section{DEFINICIONES}

Para los fines de esta norma se aplicarán las definiciones dadas en la Norma UNE 166000:2006 "Gestión de la I+D+i: Terminología y definiciones".

\section{NORMAS PARA CONSULTA}

UNE 166000:2006 — Gestión de la I+D+i: Terminología y definiciones.

\section{REQUISITOS}




\subsection{Modelo y sistema de gestión de la I+D+i}

\subsubsection{Generalidades.}

La organización debe establecer, documentar, implantar y mantener un modelo del proceso de $\mathrm{I}+\mathrm{D}+\mathrm{i}$, como por ejemplo el indicado en la introducción de esta norma, así como su sistema de gestión de la I+D+i y mejorar continuamente su eficacia de acuerdo con los requisitos de esta norma.

La organización debe:

a) Identificar las actividades de $\mathrm{I}+\mathrm{D}+\mathrm{i}$ que deben ser objeto del sistema de gestión de la $\mathrm{I}+\mathrm{D}+\mathrm{i}$ y aplicarlas a través de la organización.

b) Determinar la secuencia e interacción de estas actividades.

c) Determinar los criterios y métodos necesarios para asegurarse de que tanto la operación como el control de estas actividades sean eficaces.

UNE 166002:2006 - 10 -

d) Asegurarse de la disponibilidad de recursos e información necesarios para apoyar la operación y el seguimiento de estas actividades.

e) Realizar el seguimiento, la medición y el análisis de estas actividades y establecer los procedimientos para realizarlos.

f) Implantar las acciones necesarias para alcanzar los resultados planificados y la mejora continua de estas actividades. g) Establecer y documentar los mecanismos de protección y explotación de resultados.

La organización debe gestionar las actividades de acuerdo con los requisitos de esta norma. En los casos en que la organización opte por contratar externamente cualquier actividad de $\mathrm{I}+\mathrm{D}+\mathrm{i}$ que afecte a la conformidad del sistema de gestión de la $\mathrm{I}+\mathrm{D}+\mathrm{i}$ con los requisitos, la organización debe asegurarse de controlar tales actividades. El control sobre dichas actividades contratadas externamente debe estar identificado dentro del sistema de gestión de la I+D+i.

\subsubsection{Documentación.}

La documentación del sistema de gestión de la $\mathrm{I}+\mathrm{D}+\mathrm{i}$ debe incluir:

a) Declaraciones documentadas de una política de $\mathrm{I}+\mathrm{D}+\mathrm{i}$ y de objetivos de $\mathrm{I}+\mathrm{D}+\mathrm{i}$.

b) Los procedimientos documentados requeridos en esta norma.

c) Los documentos necesitados por la organización para asegurarse de la eficaz planificación, operación y control de las actividades de I+D+i.

d) Los registros requeridos por esta norma.

\subsubsection{Control de los documentos:}

Los documentos requeridos por el sistema de gestión de la $\mathrm{I}+\mathrm{D}+\mathrm{i}$ deben controlarse. Los registros son un tipo especial de documento y deben controlarse de acuerdo con los requisitos citados en el apartado 4.1.2.2. 
Debe establecerse un procedimiento documentado que defina los controles necesarios para:

a) Aprobar los documentos en cuanto a su adecuación antes de su emisión.

b) Revisar y actualizar los documentos cuando sea necesario y aprobarlos nuevamente.

c) Asegurar que se identifican los cambios y el estado de revisión actual de los documentos.

d) Asegurar que las versiones pertinentes de los documentos aplicables se encuentran disponibles en los puntos de uso. e) Asegurar que los documentos permanecen legibles y fácilmente identificables.

f) Asegurar que se identifican los documentos de origen externo y se controla su distribución.

g) Prevenir el uso no intencionado de documentos obsoletos y aplicarles una identificación adecuada en el caso de que se mantengan por cualquier razón.

\subsubsection{Control de los registros:}

Los registros deben establecerse y mantenerse para proporcionar evidencia de la conformidad con los requisitos así como de la operación eficaz del sistema de gestión de la I+D+i. Los registros deben permanecer legibles, fácilmente identificables y recuperables. Debe establecerse un procedimiento documentado para definir los controles necesarios para la identificación, el almacenamiento, la protección, la recuperación, el tiempo de conservación y la disposición de los registros.

\subsection{Responsabilidad de la dirección}

\subsubsection{Compromiso de la dirección.}

La alta dirección debe proporcionar evidencia de su compromiso con el desarrollo e implantación del sistema de gestión de la I+D+i, así como con la mejora continua de su eficacia:

a) Comunicando a la organización la importancia de las actividades de $\mathrm{I}+\mathrm{D}+\mathrm{i}$. b) Estableciendo la política de I+D+i.

c) Asegurando que se establecen los objetivos de I+D+i. d) Llevando a cabo las revisiones por la dirección.

e) Creando la Unidad de Gestión de la I+D+i y, cuando proceda, la Unidad de I+D+i. f) Asegurando la disponibilidad de recursos materiales.

g) Aprobando y revisando el presupuesto de $\mathrm{I}+\mathrm{D}+\mathrm{i}$.

h) Estableciendo la política de protección y explotación de resultados obtenidos.

\subsubsection{Enfoque a las partes interesadas.}

La alta dirección debe asegurar que las necesidades y expectativas de las partes interesadas en el proceso de $\mathrm{I}+\mathrm{D}+\mathrm{i}$ se consideran y se analizan. Como mínimo se pondrá:

- Atención a las demandas de suministradores y clientes. 
- Atención a la motivación e implicación de los empleados.

- Atención a las demandas de los accionistas.

- Atención a los requisitos legales y reglamentarios.

- Atención a las innovaciones y los cambios tecnológicos requeridos por el mercado.

\subsubsection{Política de I+D+i.}

La alta dirección debe asegurarse de que la política de I+D+i:

a) Es adecuada al propósito de la organización.

b) Incluye el compromiso de cumplir con los requisitos de esta norma y de mejorar continuamente la eficacia del sistema de gestión de la I+D+i.

c) Proporciona un marco de referencia para establecer y revisar los objetivos de I+D+i.

d) Es comunicada y entendida dentro de la organización.

e) Es revisada para su continua adecuación.

\subsubsection{Planificación}

\subsubsection{Objetivos de I+D+i:}

La alta dirección debe asegurarse de que los objetivos de $\mathrm{I}+\mathrm{D}+\mathrm{i}$ se establecen en las funciones y niveles pertinentes dentro de la organización. Los objetivos de $\mathrm{I}+\mathrm{D}+\mathrm{i}$ deben ser medibles y coherentes con la política de I+D+i.

\subsubsection{Planificación del sistema de gestión de la I+D+i:}

La alta dirección debe asegurarse de que:

a) La planificación del sistema de gestión de la $\mathrm{I}+\mathrm{D}+\mathrm{i}$ se realiza con el fin de cumplir los requisitos citados en el apartado 4.1.1, así como los objetivos de I+D+i.

b) Se mantiene la integridad del sistema de gestión de la I+D+i cuando se planifiquen e implanten cambios en éste.

c) Se fija la política de inversión en I+D+i, considerando los criterios de nivel de riesgo.

\subsubsection{Responsabilidad, autoridad y comunicación.}

La alta dirección debe asegurarse de que se constituye y funciona, de acuerdo con los requisitos de esta norma, la unidad de gestión de $\mathrm{I}+\mathrm{D}+\mathrm{i}$ y en su caso, si procede, la unidad de $\mathrm{I}+\mathrm{D}+\mathrm{i}$. La primera gestionará el sistema de $\mathrm{I}+\mathrm{D}+\mathrm{i}$ y los proyectos de $\mathrm{I}+\mathrm{D}+\mathrm{i}$ propios $\mathrm{o}$ externos, la segunda es la encargada de realizar las actividades de $\mathrm{I}+\mathrm{D}+\mathrm{i}$ que le sean asignadas (véase figura 2). En algunos casos puede darse la circunstancia de que ambas unidades coincidan en una sola.

\section{Unidad de Gestión de I+D+i}

- Utiliza las herramientas de I+D+i descritas en el apartado 4.4.1.

- Identifica y analiza problemas y oportunidades.

- Analiza y selecciona ideas de I+D+i. 
- Se encarga de la planificación, seguimiento y control de la cartera de proyectos.

- Realiza la transferencia de tecnología.

- Realiza el seguimiento, control y procedimiento de documentación de resultados.

- Realiza la protección y explotación de los resultados.

- Realiza la medición, análisis y mejora.

\section{Unidad de I+D+i}

- Utiliza las herramientas de I+D+i descritas en el apartado 4.4.1.

- Ejecuta los proyectos de I+D+i que le sean asignados.

- Genera conocimiento.

- Desarrolla nueva tecnología o mejorar la actual.

\section{Unidad de Gestión de I+D+i}

- Utiliza las herramientas de I+D+i descritas en el apartado 4.4.1.

- Identifica y analiza problemas y oportunidades.

- Analiza y selecciona ideas de I+D+i.

- Se encarga de la planificación, seguimiento y control de la cartera de proyectos.

- Realiza la transferencia de tecnologIa.

- Realiza el seguimiento, control y procedimiento de documentación de resultados.

- Realiza la protección y explotación de los resultados.

- Realiza la medición, análisis y mejora.

\section{Unidad de $\mathbf{I}+\mathrm{D}+\mathrm{i}$}

- Utiliza las herramientas de I+D+i descritas en el apartado 4.4.1.

- Ejecuta los proyectos de $\mathrm{I}+\mathrm{D}+\mathrm{i}$ que le sean asignados.

- Genera conocimiento.

- Desarrolla nueva tecnologIa o mejorar la actual.

Figura 38 Funciones de la Unidad de Gestión de I+D+i y de la Unidad de I+D+i

\subsubsection{Unidad de Gestión de I+D+i:}

La alta dirección debe asegurarse de que las funciones y las responsabilidades dentro de la unidad de gestión de I+D+i están definidas y son comunicadas dentro de la organización. La unidad de gestión de $\mathrm{I}+\mathrm{D}+\mathrm{i}$ debe tener, al menos, las funciones siguientes:

a) Utilizar las herramientas de I+D+i descritas en el apartado 4.4.1. b) Identificar y analizar problemas y oportunidades.

c) Analizar y seleccionar ideas de I+D+i.

d) Encargarse de la planificación, seguimiento y control de la cartera de proyectos.

e) Realizar la transferencia de tecnología.

f) Realizar el control, seguimiento y documentación de resultados. g) Realizar la protección y explotación de los resultados. 
h) Realizar la medición, análisis y mejora.

\subsubsection{Unidad de I+D+i:}

La alta dirección debe asegurarse de que las funciones y responsabilidades dentro de la unidad de I+D+i están definidas y son comunicadas dentro de la organización. La unidad de $\mathrm{I}+\mathrm{D}+\mathrm{i}$ debe tener, al menos, las funciones siguientes:

a) Utilizar las herramientas de I+D+i descritas en el apartado 4.4.1.

b) Ejecutar los proyectos de I+D+i que le sean asignados.

c) Generar conocimiento.

d) Desarrollar nueva tecnología o mejorar la actual.

\subsubsection{Establecimiento y estructura de las unidades de $I+D+i$ y de gestión de $I+D+i$}

\subsection{Establecimiento:}

La alta dirección debe definir el grado de centralización o de descentralización de las unidades de I+D+i. Para ello:

a) Se deben implantar unas organizaciones y estructuras operacionales que permitan una adecuada gestión y ejecución de los proyectos de $\mathrm{I}+\mathrm{D}+\mathrm{i}$. Cada proyecto debe considerar la necesidad de:

- Estructurar equipos flexibles para adaptarse a proyectos de diversos tipos y tamaños.

- La incorporación temporal de expertos externos a la unidad de I+D+i y/o la subcontratación parcial o completa del proyecto o de alguna de las tareas o fases del mismo.

b) Las actividades se deben desarrollar en línea con la autoridad y responsabilidad establecidas en los equipos de proyecto, y de estos con otras unidades.

\subsection{Estructura:}

La alta dirección debe definir las estructuras generales y la dependencia funcional de las unida- des de I+D+i, para ello:

a) Se deben desarrollar las estructuras organizativas de las unidades de $\mathrm{I}+\mathrm{D}+\mathrm{i}$ y/o de gestión de $\mathrm{I}+\mathrm{D}+\mathrm{i}$. c) Se deben definir y establecer las líneas de autoridad y de responsabilidad.

b) Se deben establecer los procedimientos operacionales, incluyendo los tipos de informes.

\subsubsection{Representante de la dirección:}

La alta dirección debe designar un miembro de la dirección quien, con independencia de otras responsabilidades, debe controlar las actividades de $\mathrm{I}+\mathrm{D}+\mathrm{i}$, incluyendo: 
a) Asegurarse de que se establecen, implantan y mantienen las actividades necesarias para el sistema de gestión de la

$\mathrm{I}+\mathrm{D}+\mathrm{i}$.

b) Informar a la alta dirección sobre el desempeño del sistema de gestión de la I+D+i y de cualquier necesidad de mejora.

c) Asegurarse de que se promueva la toma de conciencia de las actividades de $\mathrm{I}+\mathrm{D}+\mathrm{i}$ en todos los niveles de la organización.

\subsubsection{Comunicación interna:}

La alta dirección debe asegurarse de que se establecen los procesos de comunicación apropiados dentro de la organización y de que la comunicación se efectúa considerando la eficacia del sistema de gestión de la I+D+i.

\subsubsection{Revisión por la dirección}

\subsubsection{Generalidades:}

La alta dirección debe, a intervalos planificados, revisar el sistema de gestión de la I $+\mathrm{D}+\mathrm{i}$ de la organización, para asegurarse de su conveniencia, adecuación y eficacia continuas. La revisión debe incluir la evaluación de las oportunidades de mejora y la necesidad de efectuar cambios en el sistema de gestión de la $\mathrm{I}+\mathrm{D}+\mathrm{i}$, incluyendo la política de $\mathrm{I}+\mathrm{D}+\mathrm{i}$ y los objetivos de $\mathrm{I}+\mathrm{D}+\mathrm{i}$. Deben mantenerse registros de las revisiones por la dirección.

\subsubsection{Información para la revisión:}

La información para la revisión por la dirección debe incluir:

a) Resultados de auditorías.

b) Retroalimentación de las partes interesadas.

c) Seguimiento y medición del proceso de I+D+i.

d) Información del seguimiento y medición de los resultados del proceso de I+D+i. e) Estado de las acciones correctivas y preventivas.

f) Acciones de seguimiento de revisiones por la dirección previas.

g) Cambios que podrían afectar al sistema de gestión de la I+D+i.

h) Recomendaciones para la mejora.

\subsubsection{Resultados de la revisión:}

Los resultados de la revisión por la dirección deben incluir todas las decisiones y acciones relacionadas con:

a) La mejora de la eficacia del sistema de gestión de la I+D+i.

b) El uso de los recursos.

c) Las necesidades de recursos.

\subsection{Gestión de los recursos}




\subsubsection{Provisión de recursos.}

La organización debe determinar y proporcionar los recursos necesarios para:

a) Implantar y mantener una unidad de gestión de $\mathrm{I}+\mathrm{D}+\mathrm{i}$ y mejorar continuamente su eficacia.

b) Aumentar la satisfacción de las partes interesadas, dando respuestas a sus necesidades y expectativas.

c) Fomentar la cooperación con entidades externas que proporcionen conocimientos, metodologías, instrumentos, financiación, etc.

\subsubsection{Recursos humanos}

\subsubsection{Generalidades:}

El personal de la organización que realiza y gestiona actividades de $\mathrm{I}+\mathrm{D}+\mathrm{i}$ debe reunir los niveles de cualificación, formación, habilidades y experiencia profesional apropiados, que le califiquen como competente para las actividades que tenga asignadas. La clave del éxito de la $\mathrm{I}+\mathrm{D}+\mathrm{i}$ es la habilidad del personal para trabajar en equipo y su motivación e ilusión para llegar a resultados.

\subsubsection{Motivación del personal:}

La organización debe establecer los procedimientos necesarios para:

- Promover la toma de conciencia de la importancia de la I+D+i.

- Motivar e ilusionar al personal.

- Impulsar la participación de todo el personal.

- Fomentar la creatividad y el trabajo en equipo.

- Simplificar y facilitar las aportaciones de información de los distintos departamentos.

\subsubsection{Competencia, toma de conciencia y formación:}

La organización debe:

a) Determinar la competencia necesaria para el personal que realiza y gestiona actividades de I+D+i. b) Proporcionar formación o tomar otras acciones para satisfacer dichas necesidades.

c) Evaluar la eficacia de las acciones tomadas.

d) Asegurarse de que el personal de la organización que realiza y gestiona las actividades de $\mathrm{I}+\mathrm{D}+\mathrm{i}$ es consciente de la pertinencia e importancia de sus actividades y de cómo contribuyen al logro de los objetivos de $\mathrm{I}+\mathrm{D}+\mathrm{i}$.

e) Mantener los registros apropiados de la educación, formación, habilidades y experiencia.

\subsubsection{Infraestructura.}


La organización debe determinar, proporcionar y mantener la infraestructura necesaria para el proceso de $\mathrm{I}+\mathrm{D}+\mathrm{i}$. La infraestructura incluye, cuando sea aplicable:

a) Edificios, espacio de trabajo y servicios asociados.

b) Equipo para realizar las actividades de I+D+i.

c) Servicios de apoyo.

\subsubsection{Ambiente de trabajo.}

La unidad de $\mathrm{I}+\mathrm{D}+\mathrm{i}$ debe determinar y gestionar el ambiente de trabajo necesario para alcanzar los objetivos de I+D+i.

\subsection{Actividades de I+D+i}

Las actividades de $\mathrm{I}+\mathrm{D}+\mathrm{i}$ son las que realiza la Unidad de $\mathrm{I}+\mathrm{D}+\mathrm{i}$ para ejecutar los proyectos de $\mathrm{I}+\mathrm{D}+\mathrm{i}$ que le sean asignados para generar conocimiento y desarrollar tecnología o mejorar la actual, las que se contratan al exterior y las que realiza la unidad de gestión de I+D+i para gestionar el sistema de I+D+i.

\subsubsection{Herramientas.}

Las unidades de $\mathrm{I}+\mathrm{D}+\mathrm{i}$ y de gestión de $\mathrm{I}+\mathrm{D}+\mathrm{i}$ para desarrollar sus actividades deben utilizar las herramientas siguientes:

\subsubsection{Vigilancia tecnológica.}

El sistema de gestión de la $\mathrm{I}+\mathrm{D}+\mathrm{i}$ debe incluir un proceso de vigilancia tecnológica, cuyo objetivo sea:

- Realizar de manera sistemática la captura, el análisis, la difusión y la explotación de las informaciones científicas o técnicas útiles para la Organización.

- Alertar sobre las innovaciones científicas o técnicas susceptibles de crear oportunidades o amenazas.

\subsection{Identificación de las necesidades de información:}

Las unidades de $\mathrm{I}+\mathrm{D}+\mathrm{i}$ y de gestión de $\mathrm{I}+\mathrm{D}+\mathrm{i}$ deben identificar las necesidades de información tecnológica de la organización.

\subsection{Búsqueda, tratamiento y difusión de la información:}

Las unidades de I+D+i y de gestión de I+D+i deben establecer la naturaleza, las fuentes de información y los recursos. Se debe analizar la información y se debe establecer una sistemática para la difusión de esta: soporte y destinatarios.

\subsection{Valoración de la información:}


El conjunto de informaciones recogido por el sistema de vigilancia se debe integrar con la organización y se debe presentar adecuadamente para la toma de decisiones. (Un ejemplo de como integrar la información es mediante los mapas y perfiles tecnológicos que ofrecen una panorámica de lo que sucede en el sector considerado).

\subsubsection{Previsión tecnológica.}

En las unidades de $\mathrm{I}+\mathrm{D}+\mathrm{i}$ y de gestión de $\mathrm{I}+\mathrm{D}+\mathrm{i}$ se debe promover la reflexión para detectar nuevas ideas que permitan guiar el desarrollo de productos y/o procesos futuros por la organización.

\subsubsection{Creatividad.}

La creatividad, como proceso mental que ayuda a generar nuevas ideas, debe impulsarse dentro de la organización promoviendo la habilidad para abandonar las vías estructuradas y las maneras de pensar habituales para llegar a una idea que permita solucionar un determinado problema.

\subsubsection{Análisis externo e interno.}

Las unidades de I+D+i y de gestión de I+D+i deben establecer un sistema de comparación de la situación con la realidad exterior y de como la información fluye entre las diferentes partes de la organización.

\subsection{Análisis externo:}

Las unidades de $\mathrm{I}+\mathrm{D}+\mathrm{i}$ y de gestión de $\mathrm{I}+\mathrm{D}+\mathrm{i}$ deben establecer la sistemática para llevar a cabo el análisis externo como un instrumento que proporciona elementos de guía para que una organización pueda valorar la importancia de diferentes ideas innovadoras, comparando éstas con la realidad exterior. El análisis externo debe considerar aspectos como los siguientes:

- Identificar y caracterizar escenarios de evolución, basados en desarrollos tecnológicos.

- Identificar casos de éxito y de fracaso, con componente tecnológica, de proyectos externos.

- Obtener datos de evolución de los mercados en su sector.

- Realizar estudios tecnológicos comparativos de productos de la competencia.

- Identificar, valorar y proponer las oportunidades de alianzas tecnológicas.

\subsection{Análisis interno:}

Las unidades de $\mathrm{I}+\mathrm{D}+\mathrm{i}$ y de gestión de $\mathrm{I}+\mathrm{D}+\mathrm{i}$ deben establecer el procedimiento para analizar la estructura actual de la organización y los mecanismos de integración entre las diferentes partes de la misma, para establecer los cambios necesarios para que estos contribuyan efectivamente a la generación de ideas innovadoras. El análisis interno debe considerar aspectos como los siguientes:

- Inventariar recursos humanos y materiales susceptibles de uso en tareas de I+D+i. 
- Catalogar habilidades y conocimientos.

-Analizar factores de éxito y de fracaso de proyectos internos.

- Identificar las funciones básicas que se desarrollan en la organización y valorar su adecuación para generar ideas innovadoras.

\subsubsection{Identificación y análisis de problemas y oportunidades.}

La unidad de gestión de I+D+i debe establecer la sistemática para analizar los problemas y oportunidades que se presentan, teniendo en cuenta los principales resultados de $\mathrm{I}+\mathrm{D}+\mathrm{i}$ de interés para los mercados que son propios de la organización. Para la identificación y análisis de problemas y oportunidades se debe considerar aspectos como los siguientes:

- Analizar los resultados científicos y tecnológicos de acuerdo a la política de I+D+i de la organización.

- Seguir los resultados científicos y tecnológicos para anticiparse a los cambios.

- Identificar las barreras que nos impiden la utilización en la organización de los nuevos conocimientos y definir un plan para adquirir el conocimiento necesario que permita superar los problemas que aparecen durante el proceso de innovación.

- Identificar las posibles colaboraciones externas en materia de investigación y adquisición de conocimientos.

- Estimar las probabilidades de éxito de las alternativas planteadas.

- Colaborar en la estimación del coste de los proyectos de innovación y en el marketing de sus resultados.

- Analizar la coherencia entre la estrategia empresarial de la organización y los proyectos de I+D+i.

\subsubsection{Análisis y selección de ideas de I+D+i.}

La unidad de gestión de I+D+i debe identificar y establecer los criterios generales de evaluación y de selección de ideas a adoptar y desarrollar. Para ello se debe definir un método de selección de ideas. El método de selección debe valorar una serie de factores que tratarán de garantizar el éxito de la idea. Entre estos factores deben encontrarse los económicos, los productivos, los legales y los sociales, además de los de carácter tecnológico. El método de selección debe asegurar que para cada idea se identifican y definen aspectos como:

- Los escenarios de evolución.

- Los recursos necesarios.

- Las principales tareas.

- El impacto en términos de coste, así como en contribución a los objetivos de I+D+i y posición en el mercado.

- Los factores de riesgo.

- La probabilidad de éxito.

- Los beneficios esperables.

\subsubsection{Planificación, seguimiento y control de la cartera de proyectos:}


Las ideas una vez seleccionadas dan lugar a la definición de actividades de I+D+i. Cuando el grado de complejidad y concreción de las actividades de I+D+i sea relevante, se deben definir proyectos de $\mathrm{I}+\mathrm{D}+\mathrm{i}$ donde los resultados que cabe esperar se puedan describir y los recursos necesarios se puedan cuantificar. La unidad de gestión de $\mathrm{I}+\mathrm{D}+\mathrm{i}$ debe establecer una sistemática para llevar a cabo la planificación, seguimiento y control de la cartera de proyectos, considerando aspectos como los siguientes:

- Revisar y aprobar los proyectos.

- Propuesta de prioridades.

- Supervisar el progreso global y dirigir las revisiones periódicas.

- Elaborar informes de estado de situación y progreso de los proyectos, en base a la información proporcionada por la Unidad de I+D+i.

- Buscar fuentes de financiación.

- Buscar colaboraciones internas y externas.

- Valorar el impacto de la evolución del estado del arte relacionado con los proyectos.

\subsubsection{Transferencia de Tecnología:}

La unidad de gestión de $\mathrm{I}+\mathrm{D}+\mathrm{i}$ debe establecer la sistemática para mantener y documentar un sistema de transferencia de tecnología que considere tanto la tecnología propia como la posibilidad de incorporar tecnología ajena, considerando aspectos como los siguientes:

- Propiedad intelectual e industrial (patentes, modelos de utilidad, etc.).

- Contratos de adquisición y venta de tecnología.

- Asistencia técnica.

- Formación de joint-ventures.

- Cooperación y alianzas para acometer proyectos de I+D+i.

- Transferencia tecnológica de la universidad/organismos de I+D+i a la organización.

\subsubsection{Producto de I+D+i:}

La organización, una vez definidos los proyectos y con la colaboración de todas las partes interesadas, debe planificar y desarrollar el proceso necesario para la realización del producto de $\mathrm{I}+\mathrm{D}+\mathrm{i}$ que debe incluir, cuando proceda, las fases siguientes, que no necesariamente tienen carácter secuencial:

\subsubsection{Diseño básico:}

Las ideas seleccionadas que dan lugar a proyectos de $\mathrm{I}+\mathrm{D}+\mathrm{i}$ se deben concretar en un primer diseño básico en el que se recogen conocimientos científico-técnicos existentes o, si se recurre a la Investigación, las invenciones resultantes de los nuevos conocimientos generados. Este primer diseño básico debe contemplar aspectos como los siguientes:

- Descripción del diseño y perfilado de características.

- Planificación de recursos.

- Planos preliminares. 


\subsubsection{Diseño detallado:}

Con la información generada durante la fase de diseño básico se completan los detalles del diseño antes de las pruebas. Tanto durante esta fase como durante el diseño básico pueden surgir problemas que necesitan de Investigación externa o interna para su resolución. Los resultados de la Investigación darán lugar a modificaciones y cambios en los diseños básicos. El diseño detallado debe contemplar aspectos tales como:

-Descripción del diseño.

- Elementos de apoyo o infraestructura.

- Equipo de diseño.

- Estructura de comunicaciones.

- Como se implanta el proceso de diseño.

\subsubsection{Prueba piloto:}

Del diseño detallado surge un prototipo que es probado en esta fase. Durante esta fase se resuelven los problemas técnicos que puedan aparecer y la información que se genere se recircula a las fases de diseño para mejorar las prestaciones del prototipo según las especificaciones del proyecto, incluso puede dar lugar a una redefinición de las mismas. La prueba piloto debe contemplar aspectos tales como:

- Descripción de la situación real de trabajo.

- Procedimientos para adaptar y actualizar los cambios.

- Procedimientos para validar el prototipo.

\subsubsection{Rediseño, demostración y producción:}

Según el prototipo aprobado, debe fabricarse el producto resultante del proceso de $\mathrm{I}+\mathrm{D}+\mathrm{i}$, lo cual exige definir los medios y recursos de producción durante una etapa de demostraciones reales. Esto puede descubrir, de nuevo, facetas, aspectos y elementos del prototipo a modificar, retocar o cambiar. La información generada durante las demostraciones se recircula a las etapas anteriores para definir el prototipo de producción definitivo.

\subsubsection{Comercialización:}

Una vez resueltos todos los problemas de producción se alcanza la fase de comercialización del producto. En este momento se confronta el nuevo desarrollo con el mercado para ver realmente como éste satisface a las partes interesadas. Seguramente habrá de nuevo modificaciones y cambios a realizar, matices no apreciados en las fases anteriores, que deben tenerse en consideración.

\subsubsection{Control de cambios:}

Toda la información generada durante las fases referidas en el apartado 4.4.6 y los cambios a que dan lugar, deben estar documentados. El control de cambios implica las siguientes actividades: 
- Vigilancia sistemática del proyecto, especialmente con respecto a prestaciones, costes y calendario.

- Aprobación de las desviaciones contempladas.

- Registros adecuados de todos los cambios introducidos.

\subsubsection{Compras}

\subsubsection{Proceso de compras:}

La organización debe asegurarse de que las subcontrataciones y/o los productos adquiridos cumplen los requisitos especificados por la unidad de gestión de I+D+i. La organización debe seleccionar los proveedores en función de su capacidad para satisfacer las necesidades de la unidad de gestión de I+D+i.

\subsubsection{Información de las compras:}

La información debe describir el trabajo a subcontratar o el producto a comprar, incluyendo, cuando proceda:

- Requisitos para la aprobación de la compra.

- Requisitos para la calificación del personal subcontratado.

\subsubsection{Verificación de las compras:}

La organización debe establecer e implantar la inspección u otras actividades necesarias para asegurarse de que la entidad subcontratada o el producto comprado cumple los requisitos especificados. Cuando la organización quiera llevar a cabo la verificación en las instalaciones de la entidad subcontratada, la organización debe establecer en la información de subcontratación las disposiciones para la verificación pretendida.

\subsubsection{Resultados del proceso de $I+D+i$.}

Los resultados del proceso de $\mathrm{I}+\mathrm{D}+\mathrm{i}$ deben proporcionarse de tal manera que permitan evaluar el efectivo cumplimiento de los objetivos planteados en la política de I+D+i.

\subsubsection{Documentación de los resultados:}

La unidad de gestión de $\mathrm{I}+\mathrm{D}+\mathrm{i}$ debe establecer un sistema para informar de los resultados de $\mathrm{I}+\mathrm{D}+\mathrm{i}$, considerando aspectos como los siguientes:

- Informes finales de los proyectos.

- Descripción de las protecciones de los resultados obtenidos.

- Datos básicos, diagramas, dibujos e informes intermedios.

- Problemas y soluciones especificas, con las técnicas, procedimientos y equipos utilizados.

- Evaluaciones escritas de los proyectos en su conjunto, incluyendo el conocimiento adquirido para futuras actividades de $\mathrm{I}+\mathrm{D}+\mathrm{i}$. 


\subsubsection{Seguimiento y Medición:}

La unidad de gestión de $\mathrm{I}+\mathrm{D}+\mathrm{i}$ debe realizar el seguimiento y medición de los resultados del proceso de $\mathrm{I}+\mathrm{D}+\mathrm{i}$, considerando aspectos como los siguientes:

- Definir los criterios para la revisión, selección y aprobación de los resultados.

- Establecer los mecanismos necesarios para cuantificar los resultados conseguidos y compararlos con los objetivos establecidos en la política de $\mathrm{I}+\mathrm{D}+\mathrm{i}$ y de esta forma obtener una evidencia de la eficacia y eficiencia tecnológica alcanzada.

- La disponibilidad y uso de dispositivos de seguimiento y medición, cuando sea aplicable.

- Diseñar e implantar las medidas y acciones correctoras que se precisen.

- Identificar, durante el seguimiento, nuevas ideas de I+D+i o profundizar en las ya iniciadas.

\subsubsection{Protección y explotación de los resultados de las actividades de I+D+i.}

La unidad de gestión de I+D+i debe valorar la viabilidad y oportunidad de proteger y explotar los resultados obtenidos, considerando aspectos como los siguientes:

a) Definir los mecanismos internos de transferencia de tecnología.

b) Implantar los mecanismos de transferencia de tecnología.

c) Definir los acuerdos de transferencia de tecnología.

d) Identificar las alternativas para proteger los resultados.

e) Iniciar los procedimientos de patentes sobre los nuevos descubrimientos.

f) Establecer los niveles de confidencialidad de los resultados y determinar las medidas para asegurarla.

\subsection{Medición, análisis y mejora}

4.5.1 Generalidades. La Organización debe planificar, programar e implantar los procesos de seguimiento, medición, análisis y mejora de:

a) la ejecución de las actividades de $\mathrm{I}+\mathrm{D}+\mathrm{i}$;

b) el sistema de gestión de la $\mathrm{I}+\mathrm{D}+\mathrm{i}$;

c) su mejora continua.

La Organización debe realizar el seguimiento de la percepción de las partes interesadas con relación a la satisfacción de sus necesidades y expectativas.

\subsubsection{Auditorías internas.}

La Organización debe llevar a cabo a intervalos planificados auditorias internas para determinar si el sistema de gestión de la I+D+i:

a) es conforme con las disposiciones planificadas, con los requisitos de esta norma y con los requisitos del sistema de gestión de la $\mathrm{I}+\mathrm{D}+\mathrm{i}$ establecidos por la organización. 
b) se ha implantado y se mantiene de manera eficaz.

Se deben definir los criterios de auditoria, el alcance de la misma, su frecuencia y metodología. La selección de los auditores y la realización de las auditorías deben asegurar la objetividad e imparcialidad del proceso de auditoria. Los auditores no deben auditar su propio trabajo. Deben definirse, en un procedimiento documentado, las responsabilidades y requisitos para la planificación y la realización de auditorias, para informar de los resultados y mantener los registros.

\subsubsection{Seguimiento y medición del proceso de $\mathrm{I}+\mathrm{D}+\mathrm{i}$.}

La Organización debe aplicar métodos apropiados para el seguimiento del proceso de I + D $+\mathrm{i}$ implantado. Estos métodos deben demostrar la capacidad de las actividades de $\mathrm{I}+\mathrm{D}+\mathrm{i}$ para alcanzar los resultados previstos. Cuando no se alcancen los resultados previstos, deben determinarse las acciones a tomar.

\subsubsection{Seguimiento y medición de los resultados del proceso de I+D+i.}

La Organización debe medir y hacer un seguimiento de los resultados del proceso de $\mathrm{I}+\mathrm{D}+\mathrm{i}$, para verificar que se cumplen los requisitos de los mismos. Esto debe realizarse en las etapas apropiadas del proceso, de acuerdo con las disposiciones planificadas.

\subsubsection{Control de las desviaciones en los resultados esperados.}

La Organización debe asegurarse de que las desviaciones en los resultados esperados, se identifican y registran, con vistas a su posterior reutilización, si procede.

\subsubsection{Análisis de datos.}

La organización debe determinar, recopilar y analizar los datos apropiados para demostrar la idoneidad y la eficacia del sistema de gestión de la I+D+i y para evaluar donde puede realizarse la mejora continua de la eficacia del sistema de gestión de la I+D+i. Esto debe incluir los datos generados del resultado del seguimiento y medición del proceso de $\mathrm{I}+\mathrm{D}+\mathrm{i}$ y cualesquiera otras fuentes pertinentes. El análisis de datos debe proporcionar información sobre:

a) La satisfacción de las partes interesadas.

b) La conformidad con los requisitos de los resultados del proceso de I+D+i.

c) Las característica y las tendencias del proceso de I+D+i y de sus resultados.

\subsubsection{Mejora}

\subsubsection{Mejora continua:}

La organización debe mejorar continuamente la eficacia del sistema de gestión de la $\mathrm{I}+\mathrm{D}+\mathrm{i}$ mediante el uso de la política de $\mathrm{I}+\mathrm{D}+\mathrm{i}$, los objetivos de $\mathrm{I}+\mathrm{D}+\mathrm{i}$, los resultados de las auditorías, el análisis de datos, las acciones correctivas y preventivas y la revisión por la dirección. 


\subsubsection{Acción correctiva:}

La organización debe tomar acciones para eliminar la causa de no conformidades en el sistema de gestión de I+D+i, con objeto de prevenir que vuelva a ocurrir. Las acciones correctivas deben ser apropiadas a los efectos de las no conformidades encontradas. Debe establecerse un procedimiento documentado para definir los requisitos para:

a) Revisar las no conformidades.

b) Determinar la causa de las no conformidades.

c) Evaluar la necesidad de adoptar acciones para asegurarse de que las no conformidades no vuelvan a ocurrir. d) Determinar e implantar las acciones necesarias.

e) Registrar los resultados de las acciones tomadas. f) Revisar las acciones correctivas tomadas.

\subsubsection{Acción preventiva:}

La organización debe determinar acciones para eliminar las causas de no conformidades potenciales en el sistema de gestión de I+D+i para prevenir su ocurrencia. Las acciones preventivas deben ser apropiadas a los efectos de los problemas potenciales. Debe establecerse un procedimiento documentado para definir los requisitos para:

a) Determinar las no conformidades potenciales y sus causas.

b) Evaluar la necesidad de actuar para prevenir la aparición de no conformidades.

c) Determinar e implantar las acciones necesarias.

d) Registrar los resultados de las acciones tomadas. e) Revisar las acciones preventivas. 


\section{8.- ARTÍCULOS DE INVESTIGACIÓN SOBRE SOBRE LA GESTIÓN DE LA CALIDAD Y SUS SISTEMAS}

En este capítulo se estudiarán diferentes artículos de investigación de la base de datos científica de la UPNA sobre la gestión de la calidad y sus sistemas. Se verán uno a uno cada uno de los artículos estudiados, para ver los aspectos que cada autor nos enseña sobre el tema del que trata su trabajo.

\section{1.- A longitudinal study of TQM implementation: factors influencing success and failure - W.A. Taylor, G.H. Wright}

\section{1.-INTRODUCCIÓN}

En el presente artículo vemos la investigación que hicieron Taylor y Wright sobre los factores que influyen en el éxito o fracaso de la Gestión de la Calidad Total, y los beneficios que éstos traen a las empresas u organizaciones la practican.

Para su estudio se valen de dos encuestas realizadas a 109 compañías del Reino Unido, una en 1992 y otra en 1997, en las que les hacen preguntas sobre los siguientes factores:

- Certificación ISO 9000: al no haber llegado a la versión del 2000, tendremos en cuenta a la norma ISO como aseguramiento de la calidad.

- Tamaño de la organización.

- Número de clientes

- $\quad$ Tiempo desde la adopción de la Gestión de la Calidad Total

- Entendimiento del propósito y objetivos de la GCT.

- Entendimiento de la relación entre ISO 9000 y GCT.

- GCT como estrategia de planificación y negocios.

- Involucración de la alta dirección

- Involucración de los empleados.

Mediante la encuesta de 1992, Taylor y Wright ven el estado de la GCT de estas organizaciones, para más tarde en 1997 observar en cuáles de ellas ha tenido éxito, cuáles han fracasado y las razones para ello.

En estudios previos observaron las aportaciones de Dale et al. que promulga la necesidad de investigar la prácticas de gestión de la calidad total. Dean y Bowen promulgan la necesidad de integrar las prácticas de GCT con la planificación y estrategia, información de los procesos, satisfacción del cliente y mejora de los procesos. Por su parte Ghobadian y Gallear nos dicen que el éxito de la GCT radica en el nivel de los objetivos y la planificación, y no tanto en los métodos, herramientas y técnicas. 


\section{2.- RESULTADOS}

Los resultados mostraron que de las 109 organizaciones que formaron parte en la encuesta,67 encontraron algún tipo de beneficio gracias a la GCT y prosiguieron con ella, mientras que 42 cesaron en la práctica de la GCT por el no compromiso de la alta dirección (31\%), mayores beneficios de la ISO 9000 (24\%) y no entender los propósitos de la GCT (13\%), entre otras razones. Ahora veremos los factores estudiados en la encuesta.

\section{- Certificación ISO 9000}

En estudios previos Sun y Rao et al. encontraron beneficios al implantar la ISO 9000 y la GCT conjuntamente, mientras que Sohal y Tarziovski promulgaban que no había beneficios.

Los resultados de la encuesta de Wright y Taylor son estos:

- $\quad$ El 25\% de las empresas que no siguen con las prácticas de GCT es debido a que implantan la ISO 9000.

- $\quad$ En 1997, el 73\% de los que continuaron con la GCT, tienen la ISO 9000 implantada.

A pesar de que tener la certificación ISO 9000 hace que un 25\% de las empresas que no prosiguen con la GCT sea debido a esta razón, Wright y Taylor encuentran que no tiene importancia en el éxito o en el fracaso de la GCT. En la encuesta se puede ver como el rango de éxito y fracaso de la GCT (en empresas que prosiguen con la GCT), es parecido tanto en empresas con ISO 9000 como en empresas sin ella.

\section{-Tamaño de la empresa}

En estudios anteriores Welsh y White, y Gobhadian y Gallear promulgan que debido a la diferencia de estructura, procedimientos y recursos no se pueden aplicar las mismas prácticas en grandes empresas que en pequeñas empresas. Para Ahire y Golhar se puede aplicar lo mismo en ambas opciones, exceptuando que la pequeña empresa debería estar más enfocada al cliente. Para Powell, Hendricks y Singhal, implantar la GCT sería más difícil en grandes empresa ya que tendrían igual rentabilidad pero la formación sería mejor en la pequeña empresa.

En su encuesta, Wright y Taylor, ven como la mayoría de empresas que cesan las prácticas de GCT son pequeñas empresas. A pesar de ello, los resultados en las empresas que prosiguen con la implantación de la GCT, indican que tanto los porcentajes de éxito como los de fracaso son parecidos para grandes como pequeñas empresas.

\section{-Número de clientes}


En estudios anteriores, Choi y Eboch piensan que las empresas con mayor número de clientes deben enfocarse más hacia ellos para mantener su competitividad, que una empresas con menor número de clientes.

Aunque el $31 \%$ de las empresas que responden ala encuesta dicen tener un bajo número de clientes, Wright y Taylor observan que no hay asociación entre ello y el éxito de la implantación de la GCT.

\section{-Tiempo desde la adopción de la GCT.}

Tanto para todos los autores que estudiaron este factor, como para Wright y Taylor, las empresas que llevan más tiempo con GCT implantada tendrán mayor éxito. Esto es debido a que gracias un mayor tiempo desde la adopción, contarán con mayores oportunidades, mejor rendimiento y habrá un menor tiempo de desfase entre la inversión y los beneficios, debido a una mayor experiencia en las prácticas de la GCT.

\section{-Entendimiento del propósito de la GCT.}

En estudios anteriores, Tarziovski et al. comenta que el lastre de la GCT es que no se entiendan sus principios, como el compromiso de la alta dirección, la planificación, tiempo dedicado, recursos y sobretodo, el enfoque hacia el cliente. El problema consiste en la impaciencia de querer el regreso de la inversión en vez de realmente aplicar los principios.

Para Wright y Taylor, enfocarse hacia el cliente nos da nuevas oportunidades de añadir valor para el cliente y nos dará un mayor éxito. Esto es secundado por los resultados que encuentran. En 1992 solamente un 36\% estaba enfocada hacia el cliente. Cuando vuelven hacer su encuesta en 1997, ven como las empresas que siguen enfocando en factores internos, son las que no tiene éxito.

\section{-Relación entre ISO 9000 y GCT}

Antes de la versión del 2000 que lleva la norma hacia la gestión de la calidad total, esta estaba enfocada más hacia el aseguramiento de la calidad, lo que implicaba una confusión entre las empresas con la ISO y la GCT. Mediante su encuesta, Wright y Taylor ven como el éxito de la implantación de la GCT está asociado a ver la ISO 9000 como solamente una parte de la gestión de la calidad.

\section{-GCT como cuestión estratégica y de planificación}

Es importante tratar la GCT como una clave estratégica y no como una operacional.

Tanto en las encuestas de 1992 como 1997, a pesar de que las empresas responden que tienen planes estratégicos, Wright y Taylor observan que solamente los tienen en torno al $40 \%$. Éstas son la que los resultados indican un mayor éxito.

\section{-Implicación de la alta dirección}


Para Wright y Taylor, la implicación de la alta dirección es una parte importante en la adopción de la GCT. Miden este factor mediante dos casos, la respuesta a la encuesta por parte del director o la alta dirección, y ver si la lata dirección es la que se ocupa de la las iniciativas de la GCT. Los resultados ratifican que las empresas con la alta dirección implicada tienen mayor éxito.

\section{-Involucración de los empleados}

Aparte de la involucración de la alta dirección, también se necesita la involucración de los empleados. En 5 años sube del $20 \%$ al $76 \%$, por lo que se ve la importancia de este factor, y el mayor éxito de las que hacen que los empleados tomen parte en las prácticas de la GCT.

\section{3.-DISCUSIÓN Y CONCLUSIONES}

De las 109 empresas de la encuesta, 42 encontraron éxito en la implantación de la GCT.

De las que no prosiguen con la adopción de la GCT, el 38\% es debido a la falta de compromiso de la alta dirección o al mayor beneficio de la implantación única de la ISO 9000. Por su parte las que no tiene éxito es debido a la popularidad de la ISO, la falta de compromiso de la alta dirección, dar las responsabilidades a un solo manager de calidad y enfocarse únicamente los factores internos. Tres cuartas partes son pequeñas empresas sin recurso para abordar la implantación conjunta de ISO 9000 y GCT, centradas en los beneficios. A pesar de que las grandes empresas esperan más a los beneficios, los resultados nos hacen ver el parecido éxito en unas que en otras (de las que deciden la adopción).

Los factores importantes que influyen en el éxito de la CGT son:

- $\quad$ El tiempo desde la adopción.

- Entender la relación Iso-GCT.

- Entender el enfoque hacia el cliente.

- Involucración de la alta dirección y del empleado.

Así vemos como la alta dirección tiene que entender el propósito de la GCT, su relación con la ISO, sus beneficios, e involucrar al empleado.

\section{2.- Quality management practices and operational performance: empirical evidence on Spanish industry - J. Merino Diaz de Cerio. \\ 1.-INTRODUCCIÓN}

Las empresas manufactureras españolas han aceptado la idea de adoptar diferentes prácticas de Gestión de la Calidad en los últimos años. Han empezado a esforzarse en mejorar su ventaja competitiva mediante la mejora del rendimiento operacional en 
términos de costes, calidad y flexibilidad. Esta investigación se propone descubrir como la implantación de las prácticas de gestión de la calidad tiene un impacto en el rendimiento operacional, y ver que factores tienen más influencia.

En los últimos años numerosos estudios han relacionado las prácticas de la gestión de la calidad con resultados operacionales y promulgan que las compañías que adoptan modelos de calidad obtienen mejores resultados. La mayoría de estos estudios solamente relacionan las prácticas de gestión con el rendimiento operacional, sin tener en cuenta otras variables como el tamaño, el tipo de industria, el nivel de automatización, etc. En general veremos como la relación entre las prácticas de gestión de la calidad y los resultados es positiva y cuanto mayor sea el grado de implantación mejores resultados se obtendrán, aunque no todos los factores tendrán la misma implicación en el rendimiento operacional.

Para observar esto se obtendrán datos de diferentes empresas manufactureras españolas.

\section{2.- MARCO CONCEPTUAL, HIPÓTESIS Y VARIABLES}

Para la investigación se propone un marco conceptual basado en el modelo de Flynn et al. Encontraremos 5 dimensiones, relacionadas con el diseño del producto, proceso de transformación, relación con los proveedores, relación con el cliente y gestión de recursos humanos ( en el modelo de Flynn son dos dimensiones). Estas son las dimensiones primarias directamente relacionadas con la mejora de la calidad del producto. El marco establecido refleja el concepto expresado por Ahire y Golhar (1996), que son de la opinión de que el compromiso por parte de la gestión debe ser visto por la aplicación de un conjunto de estrategias que tengan en cuenta tres importantes partes interesadas en las operaciones de la organización: clientes, proveedores y empleados. La atención al cliente es muy importante para una eficiente iniciativa de gestión de la calidad.

Material de alta calidad de proveedores competentes, fiables y flexibles es un requisito previo para la calidad del producto acabado. Las estrategias que permiten a la empresa producir productos de alta calidad son los siguientes; la calidad en el diseño de los productos, garantía de calidad en los procesos mediante el uso de diferentes instrumentos y la utilización juiciosa de información interna y externa. Sin embargo, la clave del éxito radica en la gestión de los recursos humanos a través de la potenciación de los empleados y la creación de una estructura que promueve la participación y la formación. 


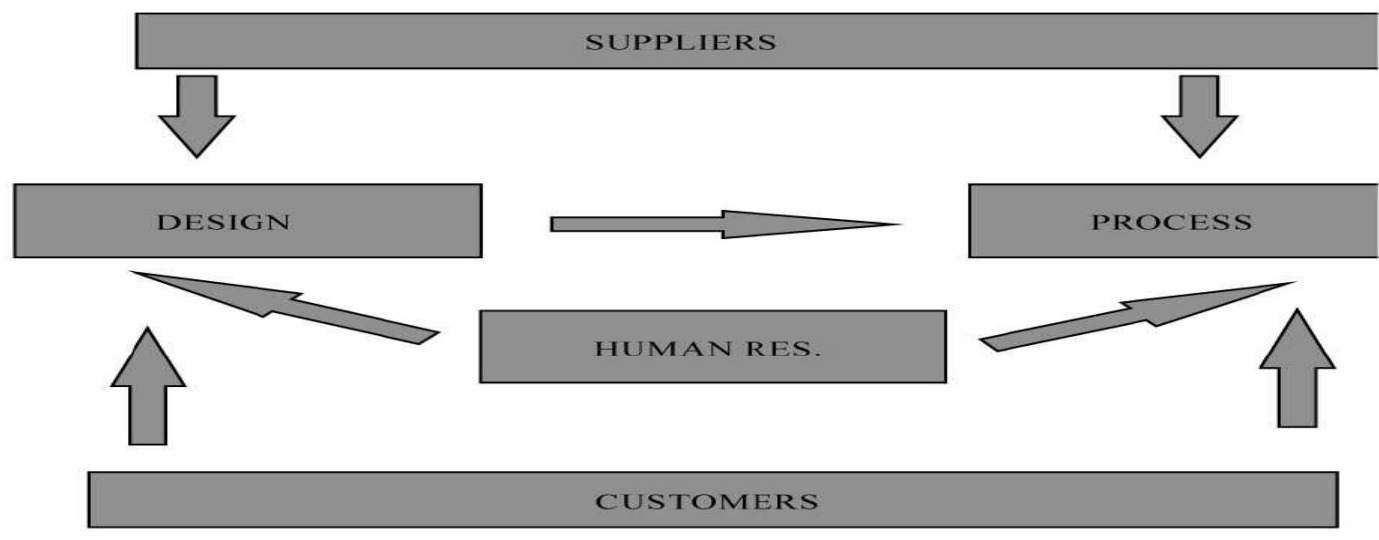

Figura 39 Modelo de Flynn

En estudios previos vemos la diferenciación entre el rendimiento financiero y el rendimiento operacional, y el pensamiento de que únicamente ya no se puede trabajar con el rendimiento financiero ya que medidas operacionales son necesitadas para la satisfacción del cliente, procesos internos y externos y las acciones de mejora e innovación de la organización que harán obtener un futuro retorno financiero.

Desde un punto de vista teórico, las prácticas de gestión de calidad contribuyen en la mejora del rendimiento operacional en la prevención de errores, lo que implicará una mejor utilización del material y recursos humanos, mayor velocidad en los procesos, y entrega a tiempo del producto. Todo esto implica un aumento de la satisfacción del cliente. Para investigar estas ideas se utiliza la siguiente hipótesis y el siguiente modelo de estudio estadísitco.

Hipótesis: Las fábricas que tienen una mejor implantación de las prácticas de gestión de calidad, obtendrán una mayor mejora en su rendimiento operacional.

Rendimiento operacional $=\mathrm{f}($ variable de gestión de la calidad; variables de control $)$

Para esta investigación se obtiene información de fábricas del sector manufacturero español con más de 50 empleados ( se exceptúan la empresa de refinamiento de aceite, la de electricidad, producción de agua e industria minera).

\section{3.- RESULTADOS}

Para obtener los resultados, se cuenta con diferentes variables dependientes, independientes y variables de control:

Variables dependientes: Las variables dependientes son las que relacionan la mejora del rendimiento operacional en comparación a 3 años atrás.

- EFFIC: indicador del coste del rendimiento ( mejora en el porcentaje de horas productivas con respecto al numero total de horas de presencia del personal). 
- RETURN: reducción del porcentaje de productos que se devuelven en las ventas.

- QFP: reducción del porcentaje de productos defectuosos finalizados

- $\quad$ QPP: reducción en el porcentaje de productos defectuosos en el proceso.

- PUNCT: porcentaje de cumplimiento de la fecha de entrega.

- SPEED: tiempo desde que se recibe el material hasta la entrega al consumidor.

Variables independientes: El esfuerzo hecho por las compañías para implantar las prácticas de gestión de la calidad es medido por las variable de gestión de calidad, que serán las variables independientes.

- DESPROD: prácticas relacionadas al diseño de nuevos productos.

- PROC: proceso de producción.

- SUP: relación con los proveedores.

- CUST: relación con el cliente.

- HUMRES: gestión de recursos humanos.

Variables de control:

- SIZE : tamaño de la empresa.

- SECTOR: tipo de industria

- TYPROD: tipo de producto.

- COMPET: mejora de la competitividad en los últimos 3 años.

- AUTOMAT: nivel de automatización.

- CLIMA: clima organizacional ( relación entre empleados y managers y satisfacción del empleado).

\section{Discusión de los resultados}

- El porcentaje de fábricas que observan mejora en sus resultados en los últimos 3 años muestran unos valores de un 59\% en EFFIC y un $73 \%$ en SPEED.

- $\quad$ El índice de gestión de calidad muestra una realción positiva con todas las medidas del rendimiento operacional.

- $\quad$ AUTOMAT muestra una fuerte y positiva relación con todas las medidas de rendimiento.

- La positiva relación entre AUTOMAT y QM, nos sugiere que las empresas españolas han optado por avanzar tecnológicamente para mejorar sus prácticas de gestión de calidad en la organización.

- El tamaño de la empresa size muestra valores estadísticamente positivos y significantes en relación a las variables del rendimiento. 
- $\quad$ CLIMA, TYPROD and COMPET muestran valores que las relacionan con las medidas de rendimiento.

Los resultados obtenidos confirman que existe relación entre las prácticas de gestión de la calidad y la mejora de rendimiento operacional.. En otra palabras, las fábricas con mayor nivel de implantación tienen más opciones de mejorar el rendimiento de fabricación. Mayor esfuerzo en la introducción de estas prácticas implica un mayor porcentaje de horas productivas, reduciendo el porcentaje de devoluciones de productos, productos acabados defectuosos y productos defectuosos en el proceso. También incrementa la probabilidad de llegar a un mayor porcentaje de cumplimiento de las fechas de entrega y una reducción del tiempo del proceso. Esto nos confirma que implantar prácticas de prevención de errores no solamente reduce el porcentaje de productos defectuosos, sino que mejoran la eficiencia al reducir el tiempo improductivo y la flexibilización de los procesos. Todo esto conlleva en una mejora del servicio al cliente y una ventaja competitiva.

El nivel de relación de las prácticas de gestión es mayor con los resultados basados en el tiempo, que con los resultados de calidad y costes.

El resto de variables nos dan los siguientes resultados:

- Pocos resultados son significantes excepto en el caso de AUTOMAT, que está asociada a la mejora de los resultados.

- El clima organizacional tienen una relación positiva con la mejora de la eficiencia de la productividad.

- DESPROD y HUMRES tienen una fuerte relación con el rendimiento. La gestión de los recursos humanos, como la involucración, el entrenamiento y el intercambio de la información, tiene más influencia en el rendimiento que el proceso, los proveedores y las técnicas utilizadas.

Los resultados observados son similares a los obtenidos en estudios anteriores que encuentran la relación positiva entre la implantación de las prácticas de gestión de la calidad y varias dimensiones del rendimiento operacional. El único estudio que difiere a esta investigación es el de Martinez Lorente et al (2000), pero vemos como en este estudio solo se considera los costes de producción como dimensión del rendimiento operacional.

\section{4.- CONCLUSIONES}

El propósito de la investigación ha sido analizar la relación entre las prácticas de gestión de la calidad y los resultados obtenidos. Las empresas españolas han realizado un gran esfuerzo para mejorar su rendimiento. La mayoría también ha mejorado varios indicadores del rendimiento operacional ( costes, calidad y tiempo).

La implantación de las prácticas de la gestión de la calidad están relacionadas con la mejora del rendimiento. La relación tiene más influencia con los factores basados en el 
tiempo que en los de calidad o costes. Por otra parte la gestión de los recursos humanos tiene más influencia que otros aspectos de la gestión de la calidad.

El mensaje que deja esta investigación para los líderes de las empresas es que deben insistir en la implantación de programas de calidad mediante el buen diseño del producto, proyectos de desarrollo, y la implantación de gestión de recursos humanos como la involucración, el entrenamiento y aprendizaje, y el intercambio de información.

Como conclusión general queda que la implantación de las prácticas de gestión de calidad están relacionadas con todos los resultados de fabricación analizados.

\section{3.- Quality management practices and competitive performance: Empirical evidence from Japanese manufacturing companies - Anh Chi Phan, Ayman Bahjat Abdallah, Yoshiki Matsui.}

\section{1.- INTRODUCCIÓN}

La gestión de la calidad ha sido reconocida como uno de los factores más críticos en el éxito de las compañías manufactureras de Japón. Se ha caracterizado por la participación de toda la compañía, énfasis en el entrenamiento del empleado, círculos de calidad, métodos estadísticos y campañas nacionales. Personas de todos los niveles de managers y trabajadores se han involucrado en la gestión de calidad total.

Esta investigación pretende encontrar la relación entre la gestión de la calidad y la competitividad en las compañías manufactureras japonesas. Para ello utiliza datos de 2 encuestas, una de los 1990's y otra de los 2000's en 27 compañías manufactureras japonesas. El objetivo principal es observar la estabilidad de la gestión de la calidad japonesa en estos años y examinar su influencia en la competitividad de las compañías manufactureras.

La gestión de la calidad representa actividades llevadas a cabo por toda la compañía para mejorar el nivel de calidad de los productos y enfocarse hacia el consumidor, mejora continua de la calidad e implicación del empleado para obtener una ventaja competitiva. El segundo componente, incluye diferentes aspectos sobre la competitividad en las compañías manufactureras como la calidad, los costes, las fechas de entrega y la flexibilidad. Las compañías japonesas producen productos de alta calidad a bajo coste, con un bajo tiempo de ciclo de producción. Gracias al control estadístico la variación de los procesos es eliminada, lo que implica menor varianza en los resultados y reduccíon de retrabajos, y una reducción de costes. La reducción del producto defectuoso implica una reducción en la inspección, tiempo de paradas de máquina, lo que hace la producción más rápida. En resumen, la alta calidad del producto está relacionada con los bajos costes, 
tiempo de entrega y alta flexibilidad. Ahora se observan las hipótesis investigadas en el estudio.

\section{2.- HIPÓTESIS}

Se espera que las compañías japonesas compartan similares características y estructura en su gestión de la calidad., basándose en el compromiso de la alta dirección, el liderazgo, calidad basada en el desarrollo de estrategias, enfoque hacia la gestión de recursos humanos, gestión de procesos y relaciones beneficiosas con los clientes y los proveedores. Se espera que durante 1990s-2000s la gestión de la calidad se mantenga enfocada en las actividades diarias como una rama para mejorar la competitividad.

Hipótesis 1: No hay diferencia entre las prácticas de gestión de calidad en las compañias manufactureras japonesas entre 1990s-2000s.

El siguiente factor a estudio es la relación entre la gestión de la calidad y la competitividad. Durante lo 1990s laos compañías japonesas mantuvieron su posición competitiva con grandes beneficios y alta productividad. Se espera que en los 2000s, la gestión de la calidad tenga esta misma contribución a la competitividad.

Hipótesis 2: No hay diferencia en la influencia de las prácticas de gestión de la calidad en la competitividad de las compañias japonesas entre 1990s-2000s.

Los resultados identifican elementos clave de la gestión de la calidad que tienen influencia en la competitividad de las compañías japonesas:

- Liderazgo: Se divide para su medida en liderazgo de la alta dirección y planificación estratégica.

- Recursos humanos: es un factor crítico para producir productos de calidad. Se divide para su medida en entrenamiento, resolución de problemas en grupos pequeños, sugerencias de los empleados y diseño multifuncional de los productos.

- Gestión de los procesos: contribuye a la mejora de la competitividad mediante la reducción de la varianza de los procesos. Se divide en control de procesos, y limpieza y organización.

- Retroalimentación de la información: describe como la compañía proporciona información a su personal, y esta información afecta a la competitividad en una manera oportuna y útil.

- Relación con los clientes y los proveedores: el enfoque en el cliente y el proveedor hace que la competitividad mejore mediante la mejora de la calidad, reducción de costes y satisfacción del cliente. Se divide en Involucración del consumidor e involucración de los proveedores.

La competitividad generalmente se refiere a la habilidad de la organización para sobrevivir en un mercado ofreciendo productos o servicios que atraen y satisfacen al 
consumidor. Para las compañías manufactureras, la calidad, los costes, el tiempo de entrega, la flexibilidad y el tiempo son los conceptos básicos para mejorar la competitividad. Este estudio utiliza 11 indicadores del rendimiento competitivo, para evaluar la competitividad: coste unitario de fabricación, productos conformes a las especificaciones, entrega a tiempo, entrega rápida, flexibilidad para cambiar la línea de productos, flexibilidad para el cambio del volumen, rotación de inventarios, tiempo de ciclo, rapidez en la introducción de nuevos productos, rendimiento y capacidad productiva, y atención al cliente y servicio.

\section{3.- RESULTADOS}

En esta sección se ve el efecto en el tiempo entre las prácticas de gestión de la calidad y su relación con la competitividad en las compañías japonesas.

El liderazgo de la ata dirección y la planificación estratégica son los aspectos más importantes. Los menos importantes son la involucración del cliente en los 1990s y el control de procesos en los 2000s. Se encuentran diferencias entre los dos periodos en los factores involucración del cliente, control de procesos, involucración del proveedor y resolución de problemas en grupos pequeños. De todos estos, solamente la involucración del cliente tiene más influencia en los 2000s que en los 1990s.

La mayor diferencia se ve en el control de procesos que pasa a tener menos importancia que en la etapa anterior. La involucración del cliente que presentaba el peor valor en los 1990s, crece en importancia y se coloca por detrás des liderazgo de la alta dirección, planificación y estrategia, y organización y limpieza. Se obtienen resultados similares en las dos etapas para estos factores: entrenamiento, liderazgo, planificación y estrategia, sugerencias de los empleados, diseño multifuncional de los productos, limpieza y liderazgo, y retroalimentación de la información.

Con todos estos datos indicamos que la hipótesis uno es válida al no poder probar diferencias.

Lo siguiente es ver la relación entre las prácticas de gestión de calidad y la competitividad. La competitividad se evalua similarmente en los dos periodos. Los managers japoneses evalúan la calidad de sus productos mediante la conformidad de estos con las especificaciones y el rendimiento y la capacidad productiva. En contraste, los factores con menor influencia son el coste unitario y la rotación de inventarios. Observados los resultados, las prácticas de gestión de la calidad están asociadas a todos lo indicadores de medida en ambos periodos.

En los 1990s los factores que más influencia tienen en la competitividad son el liderazgo de la alta dirección, el entrenamiento, planificación y estrategia, resolución de problemas en grupos pequeños, y control de procesos. Mientras, la rapidez en la introducción de nuevos productos, la capacidad productiva, el tiempo de ciclo, el coste unitario, y la conformación del producto respecto a las especificaciones están fuertemente 
relacionados a las prácticas de calidad. Como contraste la limpieza y organización, la flexibilidad para el cambio de producto y la entrega a tiempo tienen poca influencia en la competitividad.

En los 2000s la resolución de los problemas en grupos pequeños, las sugerencias de los empleados, la retroalimentación de la información y el entrenamiento tienen gran influencia en la competitividad, mientras la flexibilidad para el cambio de volumen, el coste unitario, la rapidez de la introducción del nuevo producto, y la atención al cliente y el servicio tienen una fuerte conexión con las prácticas de calidad. En contraste, la entrega rápida, la capacidad productiva, y la flexibilidad para cambiar la línea de productos tienen poca significancia en la competitividad.

Prácticas como las sugerencias de los empleados, la organización y la limpieza, la resolución de problemas en grupos pequeños y la retroalimentación de la información han pasado a tener más relación con la competitividad, mientras el liderazgo de la alta dirección, la planificación y estrategia, y el entrenamiento han pasado a tener una menor relación con los indicadores del rendimiento competitivo.

Por su parte, la entrega a tiempo, la flexibilidad en el cambio de volumen,y la atención al cliente y los servicios, pasan a tener mayor relación con las prácticas de gestión de la calidad, mientras la capacidad del producto, pierde peso y no se relaciona con ellas.

Para comprobar la hipótesis 2, se hace un análisis ANOVA. Se divide las compañías en dos grupos según su rendimiento competitivo ( grupo de alto y grupo de bajo rendimiento). Los resultados son los comentados a continuación. En los 1990s encontramos diferencia en los valores entre las de alto y bajo rendimiento, exceptuando las sugerencias de los empleados y la retroalimentación de la información. En los 2000s, se ven diferencias en la resolución de los problemas en grupos pequeños, las sugerencias de los empleados, el diseño multifuncional del producto, el orden y la limpieza, y el control de procesos. Por su parte no ve diferencias en el liderazgo de la alta dirección, el entrenamiento, la retroalimentación de la información y la involucración del cliente.

Por otro lado, no se encuentran diferencias para la planificación y estrategia y la involucración de los proveedores.

Así, el análisis de la hipótesis 2 indica que no puede ser rechazada y el análisis no puede probar diferencias en la relación entre las prácticas de gestión de calidad y el rendimiento competitivo.

\section{4.- CONCLUSIONES}

Durante los años 1990s y 2000s, las compañías manufactureras japonesas utilizaron la gestión de la calidad como un arma estratégica para mejorar su ventaja competitiva. La gestión de la calidad puede explicar el alto rendimiento en lo que se refiere a costes, confianza, flexibilidad, tiempo y servicio al cliente. El mantenimiento de la estructura de la 
gestión de la calidad en esta etapa permite a las compañías japonesas mantener su posición competitiva en el mercado.

El nivel de rendimiento competitivo es similar en ambos periodos. La mejora de la calidad, las entregas y la flexibilidad tienen altos valores en ambas etapas, mientras que los indicadores con peor influencia son el coste unitario y la rotación de inventario.

La estabilidad de las prácticas de gestión de la calidad japonesas y el rendimiento competitivo se explica desde el punto de vista que los conceptos de gestión de calidad están claramente instalados en la mayoría de las personas de compañías japonesas, independientemente de los productos y los procesos. La mayor competitividad se observa gracias a factores de recursos humanos.

En lo referente a los cambios entre etapas, las industrias japonesas se enfocan más hacia la satisfacción del consumidor debido a la demanda del consumidor en calidad.

Para mejorar los indicadores de rendimiento competitivo, se utilizan prácticas de gestión de calidad. Técnicas como la resolución del problema en grupo pequeños, las sugerencias de los empleados, la retroalimentación de la información y el entrenamiento han aumentado su influencia.

Otro importante descubrimiento es el cambio en los factores utilizados en la calidad del diseño. El diseño de alta calidad tiene que ser definido por otros factores no vistos en este estudio, como tecnología punta, métodos avanzados de fabricación o técnicas orientadas seis sigma.

Por último vemos como el rendimiento operativo empieza a depender más en la comunicación e intercambio de la información ( sugerencias de los empleados, resolución del problema en grupos pequeños, y retroalimentación de la información) en los 2000s, mientras se mantiene su enfoque en el diseño multifuncional, la implicación del cliente y el proveedor. Esta comunicación efectiva mejora el control estadístico de los proceso y permite a las personas compartir información que ayude a mejorar la competitividad de las industrias.

En resumen, los resultados encontrados en este estudio sugieren que hay elementos de la gestión de la calidad como el liderazgo, la gestión de procesos, y el intercambio de información, deben de ser investigados para obtener un mejor rendimiento competitivo. 
8.4.- A replication study of a theory of quality management underlying the Deming management method: insights from an Italian context Manus Rungtusanatham , Cipriano Forza , Roberto Filippini , John C. Anderson

\section{1.- INTRODUCCIÓN}

En este artículo se hablará de la universalidad sobre la aplicabilidad del Método de Gestión de Deming mediante la investigación en diferentes fábricas italianas. Mientras algunos autores piensas que es aplicable universalmente, otros creen que las prácticas japonesas no tendrán éxito sino se adaptan a las condiciones locales de cada empresa. Por ello se investiga sobre como y en qué culturas debe ser aplicado este método, o como debe ser modificado para su aplicación.

Especialmente hace hincapié en el estudio de Anderson et al. sobre su teoría sobre la gestión de la calidad basada en el modelo de Deming (que usa datos de fábricas de USA), para después comparar los resultados con los obtenidos en la presente investigación hecha en 3 industrias italianas.

\section{2.- TEORÍA DE LA GESTIÓN DE LA CALIDAD BASADA EN EL MODELO DE DEMING}

Anderson et al. realiza un estudio sobre el Modelo de Deming en 1995, en el que explica el proceso y la efectividad de adoptar el método de Deming. Identifica y define siete factores que describen y explican el impacto en el rendimiento de la organización que supone la adopción del modelo de Deming.

Estos siete factores derivados del método de Demig son: liderazgo visionario, cooperación interna y externa, aprendizaje, gestión por procesos, mejora continua, implicación del empleado y satisfacción del cliente.

Así Anderson postula 4 proposiciones para especificar la relación entre estos 7 factores.

1- El liderazgo visionario permite la simultánea creación de una organización de aprendizaje y cooperativa.

2- Una organización que fomenta la cooperación y el aprendizaje facilita la implantación de practicas de gestión de los procesos.

3- Las prácticas de la gestión de procesos implican una mejora continua de la calidad y la implicación del empleado

4- Una organización que apoya la mejora de la calidad y, la implicación y satisfacción del empleado, tendrá una mayor satisfacción de sus clientes. 
Más tarde, Anderson propone resultados a estas hipótesis mediante la recopilación de datos de fábricas norteamericanas. Al analizar los resultados, ve que éstos apoyan su hipótesis 1 y 3 , mientras que solo apoyan parcialmente la 2 y la 4 .

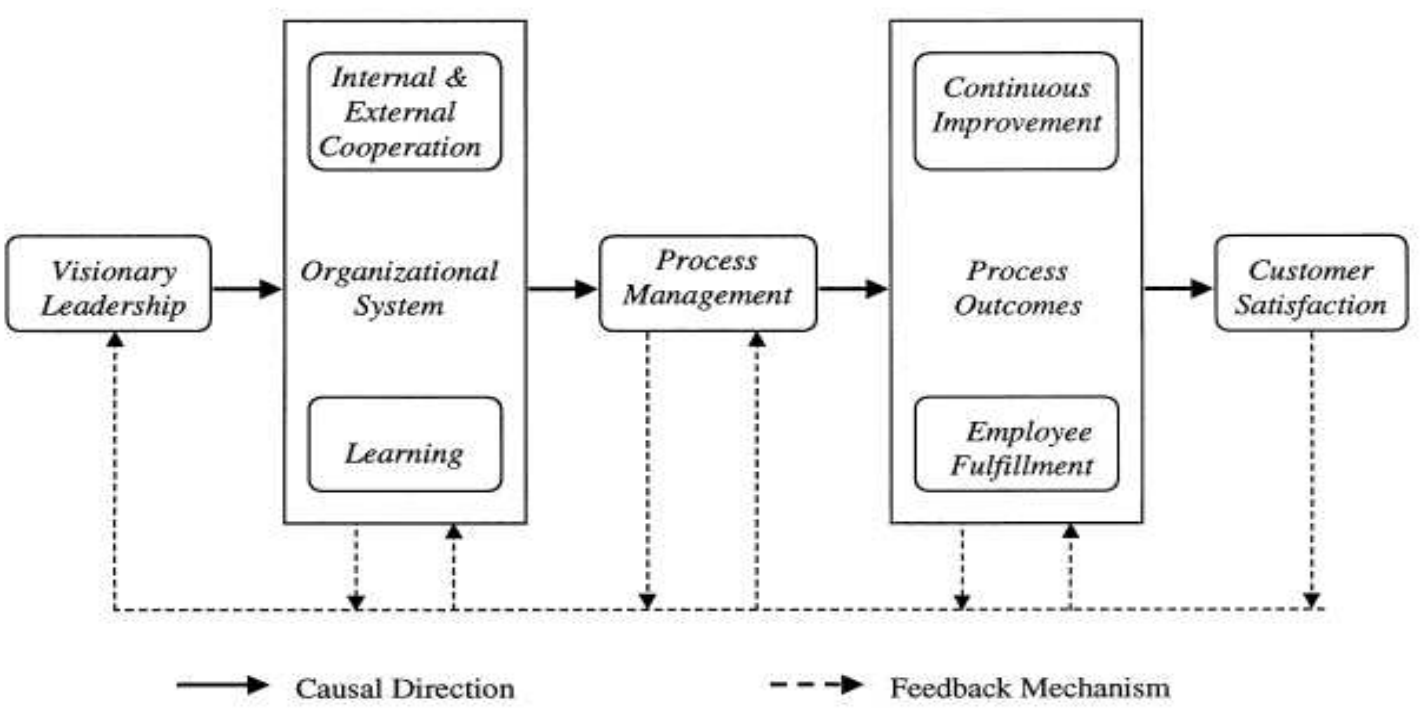

Figura 40 Teoría de Anderson de la gestión de la calidad basada en el método de Deming

\section{3.- ESTUDIO EN LAS FÁBRICAS ITALIANAS Y RESULTADOS}

Este estudio es consecutivo al de Anderson et al. y en el se buscan las similitudes y diferencias entre las dos investigaciones. Los datos para el estudio de Anderson fueron tomados en la fase 1 de la investigación de WORLD CLASS MANUFACTURING en fábricas de los EE.UU. en 1989-1990,mientras que los datos para este estudio se tomaron en la segunda fase en fábricas italianas en 1992 ( en esta segunda fase también se recogían datos en otros países europeos y Japón).

En el presente estudio, los 7 factores se utilizan como instrumentos de medida estadística para observar la relación entre las hipótesis. Las 4 proposiciones del modelo de Anderson se convierten en 8 hipótesis, perteneciendo 2 hipótesis a cada proposición (hipótesis 1 y 2 a proposición 1, y así secuencialmente).

Hipótesis 1: El liderazgo visionario está asociado a la cooperación interna y externa.

Hipótesis 2: El liderazgo visionario está asociado al aprendizaje.

Hipótesis 3: La cooperación interna y externa está asociada a la gestión de los procesos.

Hipótesis 4: El aprendizaje está asociado a la gestión de los procesos.

Hipótesis 5: La gestión de los procesos está asociada a la mejora continua. 
Hipótesis 6: La gestión de los procesos está asociada a la implicación y satisfacción del empleado.

Hipótesis 7: La mejora continua está asociada a la satisfacción del cliente.

Hipótesis 8: La implicación y satisfacción del empleado está asociada a la satisfacción del cliente.

Estas 8 hipótesis se relacionan mediante el siguiente modelo.

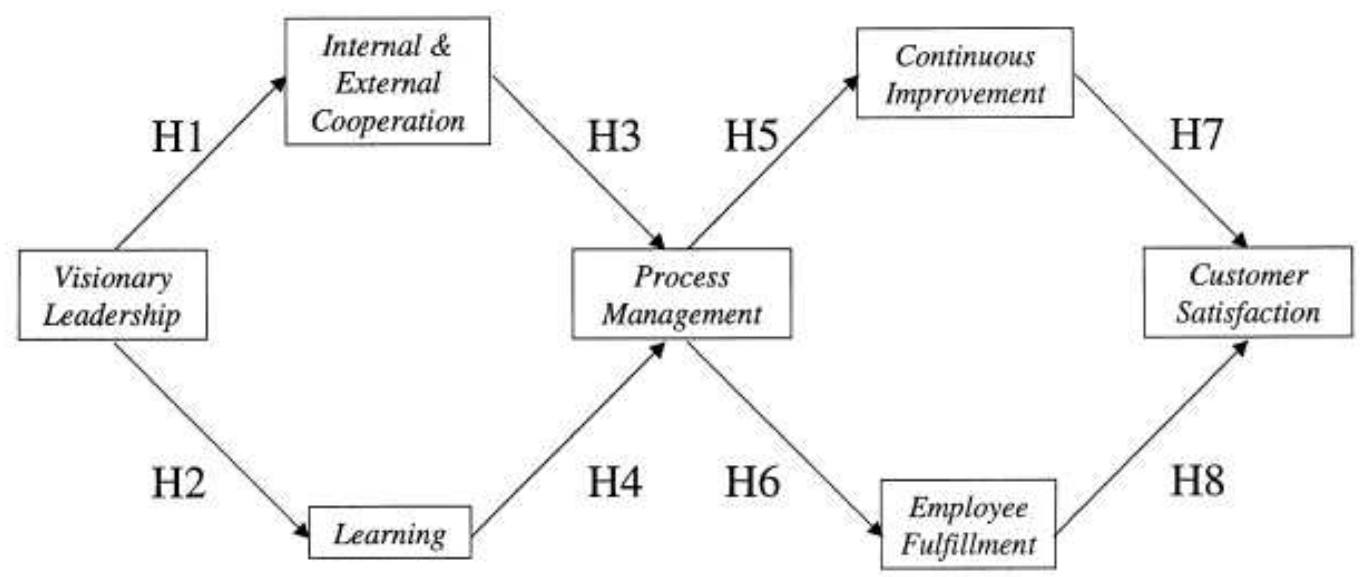

Figura 41 Modelo de relación de las 8 hipótesis

\section{-RESULTADOS}

Los resultados nos dan diferentes coeficientes para las hipótesis del modelo de relación entre los factores, sobre un nivel de significación de 0,05. Las hipótesis 1, 3 y 5 son apoyadas con unos coeficientes muy superiores al nivel de significación. Las hipótesis 2 y 7 están ligeramente por encima del nivel de significación, por lo que implican cierto nivel de importancia. Por su parte los coeficientes de las hipótesis 4,6 y 8 muestran que no tienen apoyo. Si nos referimos únicamente a las 4 proposiciones del estudio de Anderson, se ve como solamente la proposición 1 recibe el apoyo de los coeficientes. Por otra parte se estudia si las relaciones entre factores son directas, indirectas o tienen efectos inexplicables. Las relaciones directas son las que se ven en la figura que nos muestra la relación de las 8 hipótesis.

Una vez obtenidos los resultados, se compara el estudio de Anderson en las fábricas de E.E.U.U con el estudio en las fábricas italianas. Para ambos estudios las hipótesis 1,3 y 5 tienen relevancia, mientras que la hipótesis 4 no la tiene.

Por otra parte, la hipótesis 2 que cuenta con bastante apoyo en el estudio de Anderson, en el estudio italiano cuenta con un apoyo menor. La hipótesis 6 cuenta con algo de apoyo en el estudio norteamericano, mientras que en el italiano no tiene ningún apoyo. 
En lo que se refiere a las hipótesis 7 y 8, en el estudio de E.E.U.U. la satisfacción del cliente tiene correlación estadística con el liderazgo visionario y la implicación de los empleados solamente, mientras en esta investigación tiene correlación con todos los factores excepto la implicación del empleado.

\section{4.-CONCLUSIONES}

Se observa como el modelo de Anderson no se puede aplicar a otras culturas sin ninguna modificación, ya que su estudio está conducido en el contexto norteamericano. Como se ve en este estudio, habrá que hacer ciertas modificaciones para adaptar el modelo a otros países.

Aparte de las diferencias culturales, las diferencias en los estudios también pueden deberse a los instrumentos empleados para la recogida de datos.

En los estudios interculturales, los resultados similares se interpretan como una confirmación de que la teoría es aplicable universalmente. Así se podría decir que las diferentes hipótesis apoyadas en ambos estudios, podrían ser aplicables en diferentes culturas.

Tanto en el contexto italiano como en el norteamericano, los líderes de la organización juegan un rol crítico en la formación y comunicación del sistema organizacional. La cooperación hace más fácil la implantación de la gestión de los procesos. Ésta a su vez apoya la mejora continua de los procesos, los productos y la calidad de los servicios.

En ambos estudios el aprendizaje no facilita la gestión de los procesos. Esto se puede deber a la correlación observada entre el aprendizaje y la cooperación interna y externa, o en una definición inadecuada del aprendizaje.

Así como los resultados parecidos nos dan sensación de universalidad, diferentes resultados implican que la teoría no es de aplicabilidad universal. Por ejemplo, sobre la implicación del empleado se encuentran diferencias entre los dos estudios, derivadas de las diferencias culturales sobre lo que se entiende en cada país por implicación del empleado.

Estas diferencias culturales, pueden ser reconducidas mediante la adaptación de las prácticas en el contexto del país en la que se quiera implantar los diferentes métodos. 


\section{5.- Implementation of Deming's style of quality management: An action research study in a plastics company - Douglas N. Hales, Satya S. Chakravorty.}

\section{1.- INTRODUCCIÓN}

Los estudios de Anderson y Rungtusanatham vistos en el artículo 8.2 examinan la teoría del modelo de Deming, pero no explican la relación entre esta teoría y su implantación. En esta investigación se describe la implantación del modelo de Deming en una compañía de plásticos (miembro de la división Constar Inc que cuenta con 500 grupos para la creación de PVC, polipropileno, y resinas de nylon) para observar si la teoría es aplicable para la implantación dl modelo.

La investigación encuentra apoyo a dos de las cuatro proposiciones del modelo de Anderson, de las cuales una es solamente apoyada en los estudios de Anderson y Rungtusanatham. También se encuentran evidencias de una nueva relación entre la cooperación interna y externa y el aprendizaje, y descubre el carácter limitativo del factor cooperación interna y externa.

Para ello la compañía crea un grupo de liderazgo para la implantación llamado FOCUS formado y presidido por el manager general y seis equipos subordinados de calidad que representan las áreas funcionales de la fábrica.

\section{2.- DESCRIPCIÓN DE LA INVESTIGACIÓN CON RESPECTO AL MODELO DE DEMING}

La investigación se centra en torno a las 2 primeras proposiciones del modelo de Anderson et al. a partir de las cuales se observan las iniciativas para la implantación.

-Proposición 1: El liderazgo visionario facilita la simultánea creación de una organización de cooperación y aprendizaje.

El manager general promueve el liderazgo al implantar el modelo de Deming para mejorar el rendimiento de la empresa. Su liderazgo comienza con las charlas a los líderes, supervisores y empleados de la empresa para después realizar sesiones de aprendizaje y entrenamiento. Como resultado del entrenamiento, se crea el grupo FOCUS y los seis equipos de calidad.

Una ver formados estos grupos, los cambios en la mejora de los procesos para un éxito continuado, vendrán condicionados de factores como la creación de canales de comunicación entre managers y empleados para la cooperación entre ellos. Pero para esta cooperación hay diferentes barreras como la falta de recomendaciones por parte de los empleados en presencia de supervisores y la dependencia entre departamentos no observada por todos los miembros. Anderson define la mejora en cooperación y 
aprendizaje como un trabajo en equipo, compartiendo ideas, eliminando las tácticas de intimidación y una involucración de toda la organización.

Para ello el grupo FOCUS realiza entre los miembros de la organización un cuestionario para recibir ideas para la mejora continua que serían incentivadas si éstas son aplicadas, hasta que se ve que se siguen dando ideas sin incentivación. También realiza una encuesta en la que pide que se observen cuáles son lo problemas más importantes que forman una barrera en la mejora continua. Después de la encuesta se llega a la estas conclusiones. La cooperación se ve influenciada por las tácticas de intimidación de los supervisores a los empleados, las relaciones contradictorias entre empleados y superiores y la utilización de slogans sin sentido que no ayudan a la cooperación. El aprendizaje de la organización se ve mermado debido a un entrenamiento inadecuado, las barreras a la cooperación debido a la competitividad entre las diferentes divisiones de la compañía y la falta de programas que facilitan la mejora continua.

-Proposición 2: Una organización que fomenta la cooperación y el aprendizaje facilita la implantación de prácticas en la gestión de procesos.

La cooperación en la fábrica está asociada a la eliminación de la intimidación, eliminar las barreras a la cooperación y eliminar los slogans sin sentido, mientras que el aprendizaje es facilitado con un entrenamiento adecuado, promover el aprendizaje organizacional y la promulgación de la mejora continua. A continuación se ven los ejemplos que facilitan la cooperación y el aprendizaje.

Trabajar sin miedos: En muchas ocasiones se observa la penalización o el castigo al empleado cuando hay resultados adversos. Estas intimidaciones deben ser eliminadas y cambiadas por refuerzos positivos en caso de la obtención de buenos resultados. Gracias a ello los empleados empezarán a confiar en sus superiores, darán más ideas para mejora y la cooperación mejorará.

Eliminar las barreras a la cooperación: La competición interna entre las diferentes divisiones de la compañía y los conflictos entre departamentos de una misma división crean barreras a la cooperación que deben ser eliminadas mediante visitas entre las diferentes divisiones. Los conflictos entre departamentos se solucionan mediante grupos de discusión sobre sus diferencias.

Eliminar slogans: Los slogans no ayudan a mejorar. No tienen éxito porque solamente dicen que hay que mejorar, pero no promulgan como se ha de mejorar. Así al no comentar al empleado como se debe mejorar, las campañas no tienen éxito y como consecuencia, las siguientes campañas tampoco tendrán ningún éxito.

Entrenamiento adecuado: Si los miembros de la organización no tienen un entrenamiento adecuado, puede que sus esfuerzos no estén dirigidos hacia lo que la compañía necesita. La falta de un buen entrenamiento acarrea una peor productividad, un 
mayor número de bajas debido a lesiones y enfermedades, y un desperdicio de tiempo en la respuesta a los fallos en lo productos, maquinaria, etc.

Aprendizaje organizacional y mejora continua: La falta de comunicación y documentación para solucionar problemas hacen perder tiempo y dinero. Para mejorar la documentación y la información, esta empresa crea visitas anuales a las demás fábricas de la compañía para comparar y mejorar los procesos gracias a las ideas observadas en otras fábricas.

\section{3.-CONCLUSIONES}

La presente investigación estudia la implantación del modelo de Deming en una fábrica de plásticos.

Mediante el análisis de los problemas y las soluciones tomadas se observa el apoyo a las proposiciones 1 y 2 .

Se detalla la relación entre el liderazgo y la mejora de los procesos, y como el liderazgo del manager general crea un sistema organizacional de carácter cooperativo y dispuesto a participar en el aprendizaje. Mientras anteriores estudios habían apoyado la proposición 1 teóricamente, este estudio detalla su implantación en una organización.

Por otra parte, se encuentra apoyo total a la proposición 2 mientras que en previos estudios no era así. Para la proposición 3, que dice que las prácticas de la gestión de procesos implican una mejora continua de la calidad y la implicación del empleado, no se encuentras evidencias suficientes para su apoyo. Con la proposición 4, que dice que una organización que apoya la mejora de la calidad y la implicación y satisfacción del empleado tendrá una mayor satisfacción de sus clientes, también ocurre lo mismo.

Esta investigación apoya la idea de estudios anteriores que promulga que la cooperación interna y externa facilita el aprendizaje, y viceversa.

Por último, el factor de la cooperación interna y externa incluye la confianza como un elemento definicional. En esta investigación se encuentra su limitación en el sentido en que no se especificaba la confianza del empleado en los líderes o supervisores. Este es un elemento muy importante para reducir la relación adversa entre trabajadores y sus superiores. 


\section{6.- Investigating total quality management practice's inter- relationships in ISO 9001:2000 certified organisations - Christos V. Fotopoulos, Evangelos L. Psomas y Fotis K. Vouzas.}

\section{1.- INTRODUCCIÓN}

El propósito de este estudio es examinar las relaciones de las prácticas de la gestión de la calidad total en organizaciones griegas con ISO 9000 implantada. El estudio se centra en compañías que han implantado un sistema de gestión de la calidad de acuerdo a los estándares de la ISO 9001:2000. El 80\% son compañías de menos de 250 empleados lo que confirma la naturaleza de pequeña o mediana empresa de las compañías griegas. Una proporción del 75\% había aplicado la norma ISO 9001:2000 por lo menos durante tres años, mientras que el establecimiento inicial del sistema de calidad fue más fácil para un $63 \%$, ya que un simple cambio a la nueva norma fue suficiente, dado que ya habían sido certificados para la ISO 9000:1994. Sin embargo, la presencia de un consultor externo en gestión de calidad fue considerado útil para más del $75 \%$. El criterio para su selección fue su reputación en el mercado y no su costo. Dos tercios de las empresas consideran la norma ISO 9000 sólo un destino y no el final del viaje hacia la calidad.

\section{2.- RESULTADOS}

Conforme a diferentes estudios sobre la gestión de la calidad total se observan las siguientes prácticas: liderazgo, planificación estratégica de la calidad, gestión e involucración del empleado, gestión del proveedor, enfoque hacia el cliente, gestión de procesos, mejora continua, información y análisis, conocimiento y educación, y técnicas e instrumentos de la calidad.

En esta investigación se estudian como variables: gestión de la calidad (subvariables sobre la involucración de la alta dirección), involucración del empleado, enfoque hacia el cliente, gestión de los procesos y los datos, herramientas e instrumentos de calidad, y las relaciones entre ellas.

Los resultados indican:

- La involucración del empleado está directamente influenciada por la gestión de la calidad, y secundariamente por el uso de las herramientas de calidad.

- El enfoque hacia el cliente no parece motivar a los empleados a participar en el sistema de gestión de la calidad.

- La gestión de los procesos y los datos está directamente influenciada por el enfoque hacia el cliente y la gestión de la calidad, mientras el impacto de las herramientas de calidad es significante pero muy bajo. 
- La influencia de la involucración del empleado en la gestión del proceso y los datos no es estadísticamente significante.

\section{3.- CONCLUSIONES}

La mayoría de las compañías habían implantado las normas de aseguramiento de la calidad, antes de implantar la ISO 9001:2000. Esto ayuda a las compañías a hacer más fácil la implantación de las prácticas de gestión de la calidad de la ISO 9001:2000. Esta fue la intención de dos tercios de las compañías encuestadas. El uso de consultores externos también es una característica propia de estas compañías para una propicia implantación.

Los resultados han indicado que las prácticas sobre las que se deben enfocar las compañías con ISO 9001: 2000 son la gestión de la calidad, la involucración del empleado, el enfoque hacia el cliente, el uso de herramientas y técnicas de gestión de la calidad, y la gestión de los procesos y los datos.

La alta dirección debe ayudar al empleado para que participe en los esfuerzos para mejorar la calidad, en vez de las herramientas o técnicas. Para que la gestión de los procesos y los datos tengan efecto, el enfoque hacia el cliente es esencial. Este enfoque hacia el cliente implica una mejora en la gestión de datos y procesos y a su vez en las herramientas de la calidad.

Observando los resultados, la involucración el empleado no contribuye a la mejora de la gestión de los datos y los procesos, lo que se puede deber a la asignación de la tarea a altos ejecutivos y no a los empleados.

Las herramientas y técnicas de gestión de la calidad tienen su importancia, pero si no tienen apoyo de la alta dirección los empleados no se convencerán de la necesidad de su participación en el sistema, por lo que la mejora de la gestión de procesos y datos no se lograría.

\section{7.- Implementation of a quality management system according to the ISO 9000 family in a Greek small-sized winery: A case study.}

\section{1.- INTRODUCCIÓN}

En este estudio se observa la planificación e implantación de un sitema de gestión de la calidad acorde a los standares de la ISO 9000 en una pequeña bodega de Grecia. La alta dirección de la organización busca ganar todos los beneficios internos y externos a partir de la certificación de su SGC de acuerdo con los requisitos de la Norma Internacional ISO 9001:2000 y también para aumentar la cuota de mercado e introducirse en nuevos mercados. 
Las industrias de alimentación están obligadas a aplicar HACCP (análisis de peligros y puntos de control críticos). ISO 9001:2000 se centra en las necesidades y expectativas del cliente. Una de las expectativas de los clientes más importantes es tener productos alimenticios inocuos. ISO 9001:2000 permite a una organización integrar su sistema de gestión de calidad con la aplicación de un sistema de seguridad de los alimentos. El más común, en las industrias de alimentos y bebidas, es la simultánea funcionamiento de un SGC y un sistema de inocuidad de los alimentos, tales como HACCP. Con el fin de facilitar la aplicación del sistema de HACCP e ISO 9001 en los alimentos y las organizaciones de la bebida, ISO publicó la ISO 15161:2001, que proporcionó directrices sobre la aplicación de la norma ISO 9001:2000 para la industria alimentaria. La aplicación de un SGC según la norma ISO 9001:2000 y la adopción de un sistema de inocuidad de los alimentos como un sistema de HACCP en el sector vitivinícola proporciona un marco adecuado a la organización para garantizar las características de calidad y la seguridad de los productos finales.

\section{2.- RESULTADOS}

El desarrollo y la implantación de un sistema de gestión de la calidad es el resultado de un programa planificado de procedimientos cuya meta final es el funcionamiento eficaz del sistema y su incorporación al funcionamiento diario de la organización. La alta dirección juega un papel clave a la hora de que el sistema funciones como se había planificado.

La documentación del sistema identifica la metodología básica de funcionamiento de la bodega. La extensión de la documentación se define conforme al tamaño y tipo de actividades de la bodega, la complejidad e interacción d los procesos, y la competencia del personal y la necesidad de un plan de calidad. El sistema se ha diseñado y aplicado de una manera que cubre los requisitos de la norma ISO 9001:2000 y el siguiente alcance : "Producción y comercialización de vino tinto en el mercado griego e internacional ".

La alta dirección de la bodega ha identificado los principales procesos necesarios para el SGC y su aplicación en toda la organización: responsabilidad directiva -> gestión de los recursos -> proceso de compra -> adquisiciones -> realización del producto -> ventas y distribución -> satisfacción del cliente -> responsabilidad directiva.

La secuencia y la interacción de estos procesos ha determinado criterios y métodos necesarios para asegurarse de que tanto la operación y el control de estos procesos sean efectivos. Se han fijado los mecanismos adecuados de seguimiento, medición y el análisis de estos procesos, y se han puesto en marcha las medidas necesarias y las acciones para alcanzar los resultados planificados y continuos de mejora de estos procesos. Para todos los principales procesos de la organización, la administración ha identificado las entradas y salidas de estos procesos, los criterios mediante los cuales estos procesos sean aceptables, las medidas de control y vigilancia, y los indicadores de rendimiento para cada proceso. 
Todos los procedimientos documentados de la bodega de SGC se escriben en la misma forma. Estos incluyen el alcance del procedimiento, el campo de aplicación, el responsable del establecimiento, implantación y mantenimiento del procedimiento, la relevancia de la documentación del procedimiento y la descripción analítica del procedimiento. La alta dirección de la bodega decidió que debido a los bajos niveles de cualificación de sus trabajadores las instrucciones de trabajo deben estar escritas. Las instrucciones de trabajo como procedimientos documentados incluyen el alcance, el campo de aplicación, las personas responsables y la descripción analítica de las instrucciones

\section{3.- CONCLUSIONES}

Numerosas organizaciones han encontrado problemas durante la planificación e implantación del sistema de gestión de la calidad acorde a la familia ISO 9000. Los problemas más críticos son la preocupación del proceso de documentación, la falta de conocimiento y experiencia en ISO 9000, falta de tiempo y recursos, el compromiso de la alta dirección y el personal, y la creación de un sistema propio. Estos obstáculos son más obvios en pequeñas compañías cuyos factores más críticos son el tiempo productivo, gestión financiera y gestión de los recursos humanos.

Después del estudio inicial, se observa que la estructura de la organización está lejos de los requerimientos de la ISO 9000. Como la mayoría de las directivas no tenían experiencia en la implantación de la ISO 9000, la mayoría contratan consultores externos para asegurar que el funcionamiento inicial tenga éxito.

El problema sobre la falta de conocimiento y experiencia en ISO 9000, se soluciona mediante un entrenamiento en dos áreas. Primero sobre el entendimiento general de la ISO 9000, el papel de los documentos del sistema, las responsabilidades iniciales y los beneficios de la implantación del sistema. En segundo lugar, fueron entrenados en la comprensión de la realidad del día a día del proceso de actualización y la mejora de procesos y procedimientos.

Las visitas del manager de calidad a otras bodegas con sistemas de gestión de la calidad acordes a la ISO 9000 implantados, ayudan a la organización. El tiempo productivo y los recursos son otro área importante. Otro problema que se puede encontrar es el entrenamiento del personal, que se soluciona con un periodo de entrenamiento y unas propicias instrucciones de trabajo.

Como se sabe, la aplicación de la norma ISO 9001 requiere una sustancial cantidad de tiempo, recursos y esfuerzo. El tiempo productivo es un tema muy crítico para la organización. El proceso de planificación y establecimiento, incluyendo el de auditoría, tomó cerca de doce meses y durante ese periodo todo el personal de la bodega trabajó horas extras. Los recursos financieros y humanos, así como las infraestructuras son cuestiones que produjeron muchos problemas a la organización. La 
organización, debido a su pequeño tamaño, no podía permitirse dar responsabilidad exclusiva a los empleados o departamentos de las actividades de calidad. Por lo tanto las responsabilidades para la operación y el mantenimiento del SGC y otras responsabilidades de calidad se incluyeron entre otras responsabilidades del personal. La falta de recursos financieros para pagar el salario del consultor de calidad y la certificación fue otro problema. La solución para este problema vino del Ministerio griego de Desarrollo, a través de un plan para el aumento de la competitividad en las pequeñas y medianas empresas griegas (PYME).

Otro obstáculo fue el de lograr el compromiso de la fuerza laboral a la aplicación del SGC. La puesta en práctica requiere el compromiso y la cooperación de los empleados. Para ayudar a lograr este compromiso, la alta dirección garantizó que todos los empleados fueron informados de cómo el SGC les beneficiaria. La alta dirección, informó el personal de cómo el SGC podría ayudar a la organización en áreas críticas tales como la reducción de productos defectuosos, la mejora de la comunicación interna, el aumento de la satisfacción del cliente, el aumento de la cuota de mercado y las oportunidades de entrar en nuevos mercados.

El coste total de la implantación será la suma de los costes del consultor externo, el entrenamiento, costes de registro, inversión en equipos, colaboración con laboratorios externos y modificaciones funcionales.

Por otra parte, el sistema ayudaría a la organización en áreas críticas como la reducción de productos defectuosos, la mejora de comunicación interna, el aumento de la satisfacción del cliente, el aumento de la cuota de mercado, las oportunidades para entrar en nuevos mercados y la implementación global. Además, la implantación del SGC da beneficios adicionales a la bodega, tales como la disminución del costo de la calidad y los errores; mayor calidad del vino, los residuos de entrega reducidos, tiempo de entrega reducido, mejora de la productividad, y publicidad potencial. La comprensión de estos beneficios será la fuerza de la motivación de la bodega para continuar su camino hacia la mejora de la calidad.

\section{8.- A study on the critical factors of ISO 9001:2000 and organizational performance of Indian manufacturing firms - P.Padma, L. S. Ganesh y C.Rajendran}

\section{1.- INTRODUCCIÓN}

Esta investigación estudia los factores críticos de la ISO 9001:2000, y el efecto de la certificación ISO en el rendimiento de la organización. También se analiza la relación entre los atributos de las compañías y los factores críticos, asi como la relación entre los atributos de las compañías y los indicadores del rendimiento de la organización. Todo esto se obtiene de los resultados de una encuesta hecha entre 2002-2004 en una muestra de compañías manufactureras Indias con certificación ISO 9001:2000. 
Los factores críticos que se investigan para una implantación exitosa de un sistema de gestión de la calidad son: compromiso de la alta dirección, enfoque hacia el cliente, gestión de los procesos de calidad, mejora continua, medición seguimiento y control, y gestión de los recursos humanos. Los indicadores de rendimiento que se estudiarán son: satisfacción del cliente, moral de los empleados, crecimiento de las exportaciones, productividad total, reducción de los costes de calidad, rendimiento financiero total, competitividad, aumento de ventas, aumento de ganancias y la cuota de mercado.

\section{2.- RESULTADOS Y CONCLUSIONES}

Algunas de las principales conclusiones del estudio se resumen de la siguiente manera:

- Las empresas manufactureras de la India tienen en cuenta el compromiso de la alta dirección, el enfoque hacia el cliente, la gestión de los recursos humanos y el liderazgo efectivo como relativamente más importantes que los métodos y procedimientos que siguen.

- Las empresas tienen dificultades para cambiar sus métodos y procesos para mejorar la calidad, pero han empezado a darse cuenta de la importancia de la mejora continua.

- Las empresas experimentan una mayor reducción en los costes relacionados con la calidad, que puede ser debido a la utilización eficaz de los recursos, como indica la mejora del rendimiento operativo.

- Es evidente que hay un cambio significativo en todos los factores críticos e indicadores del rendimiento organizacional, que muestra que la implantación de la ISO 9001:2000 está justificada.

- Contrariamente a las expectativas normales, las empresas no orientadas a la exportación exhibieron niveles más altos de todos los factores críticos (excepto compromiso de la alta dirección) debidos a la presión que muestran en el mercado local.

- Las medianas empresas, están bajo mayor presión de cumplir con los requisitos de ISO 9001:2000 de manera estricta.

- Empresas de alto volumen de negocios experimentan las mayores variaciones en todos los factores críticos, ya que se dan cuenta de que al asignar más fondos para su mejora de la calidad, los esfuerzos son más fructíferos.

- Las empresas con menos experiencia, mantienen su entusiasmo e impulso para mejorar sus procesos de calidad, y por lo tanto presentan mayores cambios en el comportamiento del mercado.

- Las empresas nacionales tienen un mejor desempeño y rendimiento del mercado interno que las empresas internacionales. Dado que estas empresas deben concentrarse en relativamente pequeñas mercados en donde pueden manejar mejor el funcionamiento del mercado. 


\section{9. - Impact of Baldrige National Quality Award Criteria on organizational quality performance - S.M.Lee, B-H Rho y S.G.Lee.}

\section{1.- INTRODUCCIÓN}

El propósito de la investigación es observar la relación entre los criterios del MBNQA y el rendimiento de calidad de la organización. Especialmente se enfoca en el papel de la "calidad de la información y análisis", en el rendimiento de las industrias manufactureras koreanas. También se examina el impacto en la calidad del enfoque hacia el cliente y el mercado.

Basado en estudios previos, se adaptan los criterios de MBNQA como factores de gestión de calidad para las compañías koreanas. Los siete factores que se estudian son: liderazgo, información y análisis, planificación estratégica, enfoque al cliente y el mercado, gestión de recursos humanos, gestión de procesos y resultados de calidad.

Para observar las relaciones, se hace una encuesta a 109 managers koreanos que ya han participado en programas de gestión de la calidad. Este estudio compone un modelo con las 7 categorías comentadas anteriormente. El liderazgo, la planificación estratégica y el enfoque al cliente y el mercado, representan el grupo del liderazgo. Al poner las 3 categorías juntas se ve la importancia del liderazgo en la estrategia y el cliente. Por su parte la gestión de recursos humanos, la gestión de procesos y los resultados de calidad forman parte del grupo de resultados.

En el siguiente apartado se ve el modelo causal adaptando las categorías de Baldrige, y sus hipótesis y resultados.

\section{2.- HIPÓTESIS Y RESULTADOS}

Las relaciones entre las diferentes categorías se observan mediante las hipótesis del modelo causal:

- H1: El liderazgo tiene un efecto positivo en la gestión del cliente y el mercado.

- H2: El liderazgo tiene un efecto positivo en la planificación y estrategia.

- H3: La información de calidad y el análisis tiene un efecto positivo en la planificación y estrategia

- H4: La información de calidad y el análisis tiene un efecto positivo en la gestión de recursos humanos

- H5: La calidad de la información y el análisis tiene un efecto positivo en la gestión de procesos.

- H6: El enfoque hacia el cliente y el mercado tiene un efecto positivo en la la planificación y estrategia.

- H7: El enfoque hacia el cliente y el mercado tiene un efecto positivo en la gestión de recursos humanos. 
- H8: El enfoque hacia el cliente y el mercado tiene un efecto positivo en la gestión de procesos.

- H9: La planificación y la estrategia tiene un efecto positivo en la gestión de los recursos humanos.

- H10: La planificación y la estrategia tiene un efecto positivo en la gestión de procesos.

- H11: La gestión de los recursos humanos tiene un efecto positivo en los resultados de calidad.

- H12: La gestión de procesos tiene un efecto positivo en los resultados de calidad.

Todas las hipótesis son corroboradas excepto las hipótesis 4,6,9 y 10.

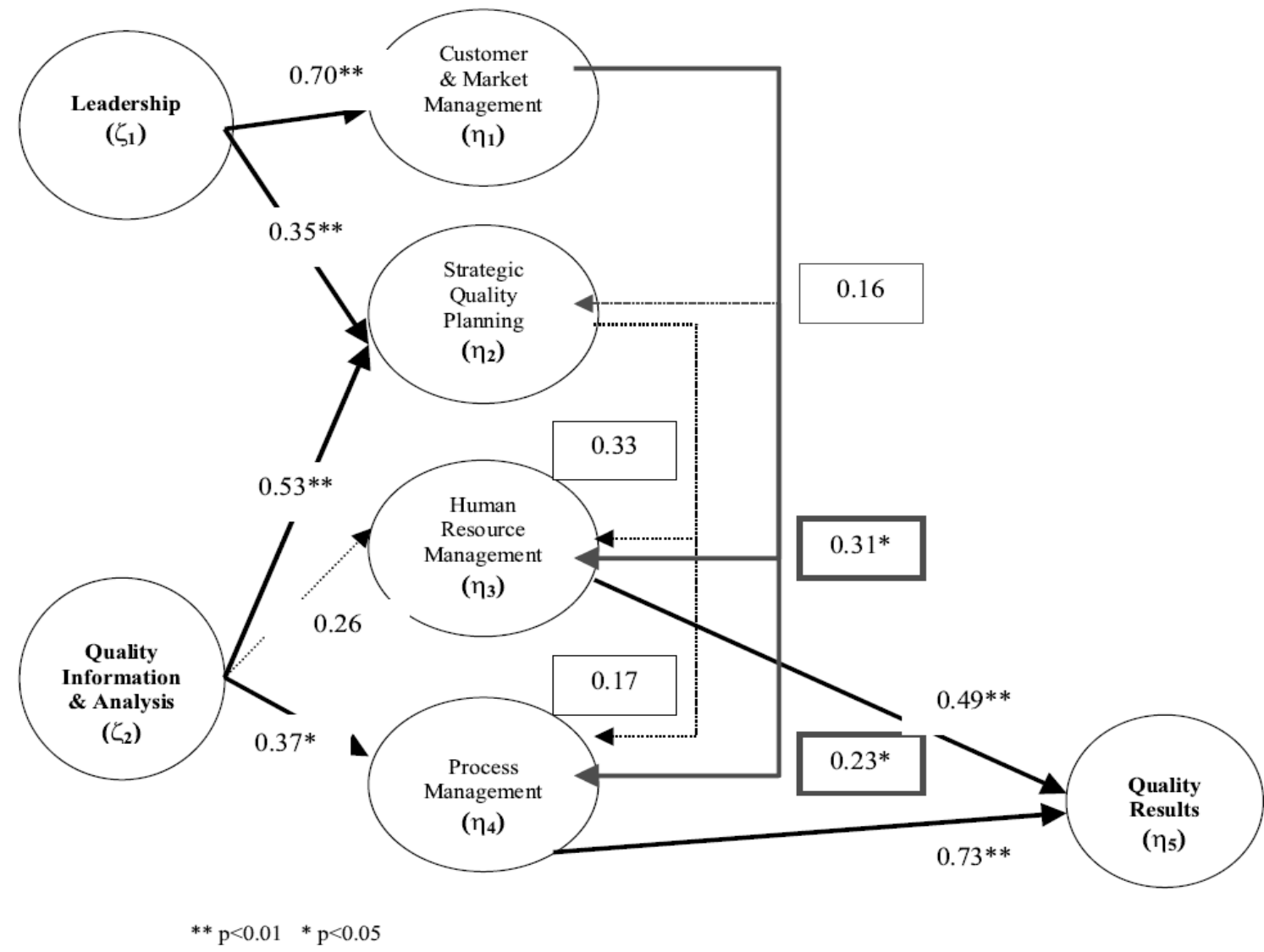

Figura 42 Modelo causal con resultados estadísticos

Las líneas continuas representan caminos con relevancia y las discontinuas, caminos sin relevancia. Mediante los resultados se observa que el liderazgo tiene efecto en la gestión del cliente y el mercado, y en la planificación estratégica. Por su parte la calidad de la información y el análisis tiene efecto en la planificación estratégica y la gestión de procesos, y no la tiene en la gestión de recursos humanos. Así vemos como el liderazgo conduce a un sistema de calidad y la calidad de la información y el análisis tienen un importante rol en el modelo causal modificado MBNQA2001. 
El enfoque hacia el cliente y el mercado influye en la gestión de los recursos humanos, aunque la gestión de procesos no esté influenciada por la planificación estratégica para las compañías koreanas. La planificación estratégica no muestra valores estadísticos significantes para relacionarla con la gestión de recursos humanos. Por último, la gestión de los recurso humanos y la gestión de procesos afectan fuertemente a los resultados de calidad, siendo la gestión de procesos 1,5 veces más importante que la gestión de los recursos humanos.

\section{3.- CONCLUSIONES}

Mediante la investigación se observan las siguientes conclusiones:

- El liderazgo como método para conducir la calidad, influencia fuertemente la gestión del cliente y el mercado, y la planificación estratégica. Este resultado implica que la alta dirección debe proporcionar los valores, las direcciones y el desempeño de las expectativas de la organización.

- La calidad de la información y el análisis juegan un rol importante al influenciar a la planificación estratégica y la gestión de procesos. En desacuerdo con el estudio de Wilson y Colliers, esta investigación no observa la influencia de la calidad de la información y el análisis en la gestión de los recursos humanos, lo que se puede deber a que los problemas entre los trabajadores y la dirección koreana hace que el entrenamiento sea más complicado.

- El enfoque hacia el cliente y el mercado es otro de los factores importantes en el sistema de calidad. Las compañías koreanas consideran este enfoque como una herramienta para mejorara su competitividad. El enfoque hacia el cliente y el mercado tiene fuerte influencia en la gestión de los recursos humanos y la gestión de procesos. MBNQA indica que el enfoque hacia el cliente y el mercado debe tener impacto en la planificación estratégica, a pesar de lo cual nuestra investigación no apoya esta idea.

- MBNQA también incide en la importancia de la planificación estratégica en la gestión de los recursos humanos, proposición que no es apoyada en este estudio. La gestión de los procesos tampoco está influenciada por la planificación estratégica para las compañías koreanas. Estos resultados indican que las industrias koreanas deben reforzar la relación entre la planificación estratégica, la gestión de los recursos humanos y la gestión de los procesos

- La calidad de los resultados está influenciada por la gestión de los recursos humanos y la gestión de los procesos. La gestión de los procesos tiene más importancia para las compañías koreanas que la gestión de los recursos humanos para la calidad de los resultados.

En resumen, la calidad de la información y el análisis, y el liderazgo son factores importantes tanto en el inicio de la implantación de los programas de calidad como en siguientes etapas de su implantación. Los resultados indican que las prácticas de calidad 
requieren mejores relaciones entre el liderazgo de la alta dirección y los sistemas de calidad, y la calidad de la información y el análisis con estos sistemas para obtener mejores resultados competitivos. El éxito de la organización no solo depende de adoptar programas de calidad, sino también de apoyarlos una vez se haya comenzado a implantarlos.

\subsection{0.- Relevance of Baldrige constructs in an international context: A study of national culture - Barbara B. Flynn, Brooke Saladin}

\section{1.-INTRODUCCIÓN}

El Premio Malcolm Baldrige ha servido de modelo para otros muchos de otros países. Algunos han adoptado los criterios y medidas de MBNQA mientras otros los han adaptado. El modelo de Baldrige es desarrollado para industrias norteamericanas por lo que se puede entender así las adaptaciones que tengan que realizarse para otros países.

Este estudio utiliza el estudio de Hofstede sobre las dimensiones de las culturas nacionales, para observar los factores teóricos de los criterios de Baldrige que son relevantes a través de diferentes culturas.

Es decir, se intenta observar si los elementos del modelo de Baldrige son aplicables a través de las diferentes culturas, y si es apropiado aplicar el modelo en culturas diferentes a la norteamericana o hay que hacer adaptaciones. En resumen, se examinan las relaciones entre el modelo Baldrige y las diferentes culturas en las que puede ser implantado. La cultura de cada país puede ser determinante en el éxito de las prácticas de gestión, ya que mientras las prácticas pueden cambiar rápidamente, la cultura de cada país evoluciona más lentamente.

\section{2.- DIMENSIONES DE LA CULTURA NACIONAL DE HOFSTEDE E HIPÓTESIS}

Hofstede (1980) encuentra 4 dimesiones que tienen influencia en las culturas:

- Distancia del poder: es el grado en que los miembros menos poderosos de las organizaciones en una nación esperan que el poder se distribuya por igual.

- Control de la incertidumbre: es el grado en el que las personas de una cultura se sienten incómodos con situaciones que ellos perciben como no estructuradas, claras o imprevistas.

- Individualismo/colectivismo: describe el grado en el que la gente está orientada hacia actuar individualmente o como parte de un grupo.

- Masculinidad/feminidad: describe el grado en el cual la agresividad y el éxito se valora, frente a la preocupación por las relaciones. 
Después de ver las aportaciones de Hofstede y otros autores sobre los factores culturales, se proponen una serie de hipótesis basadas en la literatura de la cultura para observar las relaciones entre las dimensiones de la cultura y los principios básicos del modelo de Baldrige. Para obtener los resultados se usan datos del proyecto WCM, que incluye datos de industrias de EE.UU (cultura anglosajona), Japón ( cultura independiente), Alemania (cultura germánica), Inglaterra (cultura anglosajona) e Italia (cultura latino europea).

\section{Liderazgo}

H1. Los valores encontrados para el liderazgo en esta investigación serán:

A. Superiores en los países con alta distancia de poder cultural.

B. Superiores en los países con mayores niveles de control de la incertidumbre.

C. Menores en los países con mayores niveles de individualismo.

D. Superioresen países con culturas más masculinas.

\section{Información y análisis}

H2. Los valores encontrados para la información y análisis en esta investigación serán:

A. Superiores en los países con alta distancia de poder cultural.

B. Superiores en los países con mayores niveles de control de la incertidumbre.

C. Menores en los países con mayores niveles de individualismo.

D. Menores en países con culturas más masculinas.

H3. Los valores encontrados para la planificación estratégica en esta investigación serán menores en países con mayor nivel de individualismo.

\section{Gestión de los recursos humanos}

H4. Los valores encontrados para la gestión de los recursos humanos en esta investigación serán:

A. Menores en los países con alta distancia de poder cultural.

B. Menores en los países con mayores niveles de individualismo.

C. Menores en países con culturas más masculinas.

\section{Gestión de los procesos}

H5. Los valores encontrados para la la gestión de los procesos en esta investigación serán:

A. Menores en los países con alta distancia de poder cultural.

B. Superiores en los países con mayores niveles de control de la incertidumbre.

C. Menores en los países con mayores niveles de individualismo.

D. Superiores en países con culturas más masculinas. 


\section{Resultados de los negocios}

H6. Los valores encontrados para los resultados en los negocios en esta investigación serán:

A. Superiores en los países con alta distancia de poder cultural.

B. Superiores en los países con mayores niveles de control de la incertidumbre.

C. Menores en los países con mayores niveles de individualismo.

D. Superiores en países con culturas más masculinas.

\section{Enfoque hacia el cliente y el mercado}

H7. Los valores encontrados para el enfoque hacia el cliente y el mercado en esta investigación serán:

A. Menores en los países con alta distancia de poder cultural.

B. Menores en los países con mayores niveles de individualismo.

C. Menores en países con culturas más masculinas.

\section{Interacciones}

H8. Las interacciones entre la distancia de poder y el control de la incertidumbre están relacionados con los factores principales del modelo Baldrige.

H9. Las interacciones entre la mascunilidad/feminidad y el control de la incertidumbre están relacionados con los factores principales del modelo Baldrige.

H10. Las interacciones entre la mascunilidad/feminidad y el individualismo/colectivismo están relacionados con los factores principales del modelo Baldrige.

H11. Las interacciones entre el individualismo/colectivismo y la distancia del poder están relacionados con los factores principales del modelo Baldrige.

\section{Valor de la congruencia}

H12. La implantación del modelo Baldrige será más eficaz en aquellos países cuyas culturas se ajusten más a los valores que subyacen a los criterios del modelo.

\section{3.- RESULTADOS}

Las dimensiones de la cultura están relacionadas con todos los factores principales del modelo de Baldrige, exceptuando el enfoque en el cliente y el mercado.

Las 4 dimensiones de la cultura están relacionadas con el liderazgo en la dirección que indican sus hipótesis desde la H1a hasta la H1d. Como se predijo en las hipótesis H2B y $\mathrm{H} 2 \mathrm{C}$, los valores de la información y el análisis fueron mayores en los países con mayor control de la incertidumbre y menor en aquellos que fueron más individualistas. También 
fueron mayores en los países que eran más masculinos, al contrario que lo observado en la hipotesis H2D. La hipótesis H2A no fue significativa, lo que indica que los valores de la información y análisis no estaban relacionados con la distancia de poder.

Los valores de la planificación estratégica son menores en los países más individualistas, lo que corrobora la hipótesis H3. Además, seran mayores en países con culturas más masculinas, relación sobre la que no se había hecho ninguna hipótesis.

Como predijo la hipótesis $\mathrm{H} 4 \mathrm{~b}$, los valores encontrados para la gestión de los recursos humanos fueron menores en los países que eran más individualistas. En contra de la predicción de las hipótesis $\mathrm{H} 4 \mathrm{C}$. y H4A, fueron superiores en países más masculinos, lo que indica la falta de relación entre las puntuaciones encontradas para la gestión de los recursos humanos y la distancia del poder. Las hipótesis 5B a 5D cuentan con apoyo absoluto.

Todas las hipótesis relacionadas con los resultados de los negocios son apoyadas son apoyadas, mientras que ninguna de las relacionadas con el enfoque hacia el cliente y el mercado no tienen apoyo.

Las hipótesis desde la $\mathrm{H} 8$ a la $\mathrm{H} 11$ son apoyadas, lo que indica que las interacciones entre las dimensiones de la cultura están relacionadas con algunos principios fundamentales del modelo Baldrige. La interacción entre el control de la incertidumbre y la baja distancia del poder está relacionada con el liderazgo y la gestión de los recursos humanos. La interacción entre la masculinidad y el control de la incertidumbre está relacionada con la gestión de los procesos. La interacción de la masculinidad con el colectivismo está relacionada con la planificación estratégica y los resultados de los negocios. La interacción entre la alta distancia de poder y el colectivismo está relacionada con la planificación estratégica y los resultados de los negocios.

Como se ve en los resultados, la información y el análisis, la planificación estratégica y la gestión de los recursos humanos tiene mayor influencia en culturas que muestran mayor colectividad y masculinidad. Por otra parte, el liderazgo, la gestión de procesos y los resultados de los negocios, tienen mayor influencia en culturas con mejor control de la incertidumbre y distancia del poder.

\section{4.- CONCLUSIONES}

En esta investigación se ha visto las claras diferencias de la influencia de los principios básicos del modelo de Baldrige en las diferentes culturas, proporcionando apoyo a la idea de que su implantación es más favorable en unos países que en otros. Por ello habrá que adaptar el modelo a las necesidades de cada país en el que se quiera implantar. En general, cada país deberá adaptar sus programas de calidad a las condiciones locales para una mejor implantación. 
Se observa que la cultura ideal para la implantación del modelo de baldrige tiene altos niveles de distancia de poder, control de la incertidumbre, masculinidad y colectivismo. La cultura japonesa tiene estas características por lo que será la mejor para la implantación, a pesar de que el modelo fuera desarrollado para los EE.UU.

Los resultados encontrados en la investigación sugieren cierta generalización en 3 de las 4 dimensiones de la cultura. Solo el control de la incertidumbre tiene un amplio rango de valores. Las otras tres dimensiones están limitadas hacia valores altos o bajos.: bajo nivel de distancia de poder, alto nivel de individualismo/colectivismo y alto nivel de masculinidad/feminidad.

La muestra tomada para la investigación es representativa de países con alta industrialización, por lo que podrían generalizarse los resultados para países con alta industrialización. Por otra parte el análisis indica que no hay diferencias entre los países en su nivel de enfoque hacia el cliente y el mercado.

Otros factores como la longevidad de los programas de calidad implantados, y la naturaleza de los mercados atendidos por los diferentes países también pueden tener efecto en los resultados estudiados en esta investigación, pero estos efectos son difíciles de demostrar.

\subsection{1.- An empirical assesment of the EFQM Excellence Model: Evaluation as a Tqm framework relative to the MBNQA Model - J.Carlos Bou-Llusar, Ana B. Escrig Tena, Vicnte Roca-Puig. Inmaculada Beltrán-Martín.}

\section{1.- INTRODUCCIÓN}

Desde los años 1990`s, muchas organizaciones utilizan los modelos de excelencia como marco general para implantar las iniciativas de Gestión de Calidad Total. En diferentes estudios, observan que los modelos de excelencia reproducen la GCT capturando sus partes, factores y principios esenciales. En esta investigación, los autores analizan si la estructura interna de la EFQM está relacionada con los principios básicos de la GCT para ver si es posible utilizarla como marco general para la implantación de la GCT.

En investigaciones anteriores se ve como la GCT consta de principios básicos que se pueden clasificar en 2 categorías: social, que está centrada en la gestión de los recursos humanos, trabajo en equipo, entrenamiento e implicación del empleado, y la categoría técnica que reflejan la orientación hacia la mejora de los métodos de producción y tratar de establecer un método de trabajo a través del establecimiento de procesos y procedimientos bien definidos para hacer posible la mejora continua de los servicios a los clientes. Estas dos categorías deben estar relacionadas y apoyarse una a otra para reflejar el carácter 
global de las iniciativas. Por último, la óptima gestión de los principios de la GCT hace mejorar el rendimiento de la organización.

Mientras se ha dado por hecho que los modelos de excelencia se pueden utilizar como marco general para la implantación de la GCT, hay que hay que analizar su estructura interna y la relación entre los elementos respecto a la GCT.

Al estar esta investigación realizada antes del 2010, hay que referirse con respecto ala EFQM del 2003,la cual no tiene muchas diferencias con la del 2010 descrita en la parte bibliográfica. La EFQM del 2003, consta de nueve elementos, cinco como agentes facilitadores (liderazgo, estrategia, personas, alianzas y recursos, y procesos) y 4 como resultados ( resultados en las personas, resultados en los clientes, resultados en la sociedad y resultados clave). Para validar la EFQM como marco general, hay que relacionarla con los aspectos de la GCT anteriormente mencionados: hay que observar si se pueden identificas la categoría técnica y social dentro del modelo y si su estructura interna refleja las relaciones entre los agentes facilitadores y los resultados.

Así, los agentes facilitadores son organizados en elementos sociales y técnicos y la relación entre los elementos del modelo se ven mediante: la interrelaciones entre los agentes facilitadores que produzcan la complementariedad entre sus componentes, interrelaciones entre los resultados que produzcan la complementariedad entre sus componentes, y la influencia positiva de los agentes facilitadores en los resultados (los buenos resultados para la organización vienen precedidos de un buen liderazgo, estrategia, implicación del empleado, etc..)

Para ver si todo esto ocurre se obtiene información de 446 compañías españolas de la industria manufacturera (52\%) y de la industria de los servicios (48\%). De estas 446 compañías $50 \%$ son pequeñas empresas, $42 \%$ medianas empresas y $8 \%$ grandes empresas, debido al predominio de la pequeña y mediana empresa en España.

\section{2.- RESULTADOS}

Se obtienen diferentes resultados sobre los diferentes criterios para la EFQM por medio de diferentes medio estadísticos.

Dimensionalidad: Los resultados no indica que todos los elementos son unidimensionales excepto los resultados en las personas que tienen 3 dimensiones (motivación en las personas, logros en las personas y satisfacción de las personas) y los resultados clave que tienen otras 3 (resultados financieros, resultados de los procesos externos y resultados de los procesos). Así encontramos los 13 factores para ser estudiados.

Fiabilidad: Los resultados indican la fiabilidad de todos los factores.

Validación convergente y discriminante: Altos valores en validación convergente y validación discriminante dan evidencia de la validez de los 13 criterios. 
Descripción estadística de los criterios: Los 13 criterios dan valores positivos y significantes que nos indican que son una integración de los criterios en la GCT.

Modelo multidimensional: Los 13 criterios son usados para crear la estructura del modelo multidimensional.

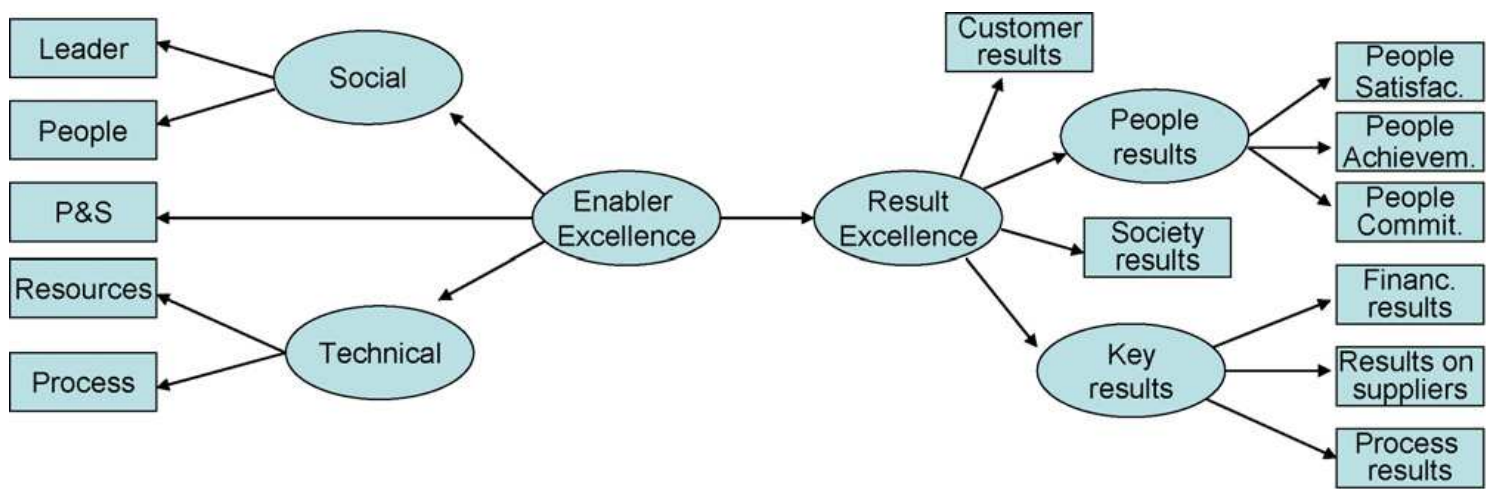

Figura 43 Modelo multidimensional de la estructura analizado

El modelo multidimensional es apoyado por los datos obtenidos. Tanto en el apartado de los agentes facilitadores como el de resultados, todos los criterios tienen altos valores estadísticos de significancia.

Relación entre resultados y agentes facilitadores: Los valores observados indican que los agentes facilitadores tienen una influencia positiva en los resultados, que es lo que se quería demostrar. También se ven efectos indirectos de los agentes facilitadores en cada uno de los criterios de los resultados, teniendo el mayor efecto en los resultados clave, y un menor efecto en los resultados en la sociedad.

Comparación entre industria de manufactura e industria de servicios: El mismo modelo puede ser aplicado para ambas industrias. En los agentes facilitadores ambas presentan altos resultados con un nivel un poquito mayor en la industria de servicios. En los resultados vemos altos valores para los resultados clave en ambas y más bajos para los resultados en la sociedad. En la relación entre resultados y facilitadores se observan altos valores en ambos casos, ligeramente superiores en la industria de los servicios. Así vemos como los resultados indican que no hay diferencias entre ambos casos.

\section{3.- CONCLUSIONES}

Esta investigación introduce un modelo multidimensional para explorar la estructura interna de la EFQM y analizar el modelo como marco general para la implantación de la GCT. La EFQM tiene en cuenta las dimensiones social y técnica de la GCT, y la implantación de la GCT requiere un enfoque común que gestione todos los elementos de los agentes facilitadores del modelo EFQM con el fin de mejorar los resultados. La validación del modelo propuesto para la muestra de compañías españolas apoya que : 
1- Los agentes facilitadores se separan en las dimensiones social y técnica de la GCT.

2- Estas dimensiones están interrelacionadas y reflejan la existencia de un enfoque global hacia la GCT.

3- Se obtiene valores positivos para los criterios de resultados y su relación.

4- Los agentes facilitadores tienen una fuerte y positiva influencia en los resultados.

Los resultados obtenidos hacen ver que la EFQM reproduce los principios básicos de la GCT y puede tomarse como marco general para la implantación de la Gestión de la Calidad Total, lo que apoya las ideas de muchos autores que pensaban así.

Por otra parte los resultados obtenidos refuerzan lo visto en previos estudios de otros autores sobre MBNQA. La comparación se llevaría a cabo observando si ambos modelos comparten los principios ya observados para la EFQM.

Así vemos como como mediante la observación de los estudios de diferentes autores, apoyan la existencia de una relación entre las categorías del modelo de Malcolm Baldrige y la GCT. Así vemos como diferentes atores promulgan que:

- El éxito de la organización depende de adoptar y apoyar programas de calidad.

- Hay relación entre la GCT y los factores básicos del MBNQA.

- Se encuentran similitudes a la existencia de las dimensiones social y técnica.

- Por último, la influencia positiva de los facilitadores en los resultados es apoyada en la mayoría de los estudios que analizan MBNQA.

\subsection{2.- Selection effective management tolos on setting European Foundation for Quality Management (EFQM) model by a quality function deployment (QFD) approach - Same Yousefie, Mahmood Mohammadi, Jalal Hghighat Monfared.}

\section{1.- INTRODUCCIÓN}

El modelo EFQM indica que el uso de herramientas de gestión que tienen relevancia en las necesidades de la organización, se han convertido en un factor estratégico en el entorno competitivo actual. Mediante la elección y aplicación de las mejores herramientas de gestión, las empresas pueden mejorar su rendimiento y la satisfacción del cliente, y obtener mejores cuotas de mercado. El propósito de esta investigación es la proposición de un enfoque basado en el QFD para la selección de herramientas de gestión de la calidad. La investigación se centra en el desarrollo de la casa de la calidad (HOQ) para mejorar el proceso de selección de las herramientas de gestión y la satisfacción de la empresa mediante su logro de la excelencia. Como ya es sabido, la casa de la calidad se utiliza para la mejora de la calidad de los productos conforme a los criterios del consumidor sobre los productos. Aquí se propone a la organización como el consumidor que tienen necesidades 
para llegar a la excelencia, y estas necesidades tienen que ser satisfechas mediante atributos técnicos para la excelencia.

El modelo se prueba en una empresa Iraní de la industria del automóvil. Para la realización del modelo se utilizan 15 categorías de herramientas de gestión y 5 criterios facilitadores de la EFQM. Mediante esta investigación se responde 4 preguntas : ¿Cuáles son los criterios efectivos para el establecimiento de la EFQM en la organización?, ¿cuál es el ranking de estos criterios en esta investigación?, ¿cuáles son las herramientas de gestión efectivas en el establecimiento de la EFQM en la organización?, ¿cuál es el ranking de estas herramientas de gestión?

\section{2.- RESULTADOS}

Como ya se ha dicho el modelo presentado se basa en la casa de la calidad.

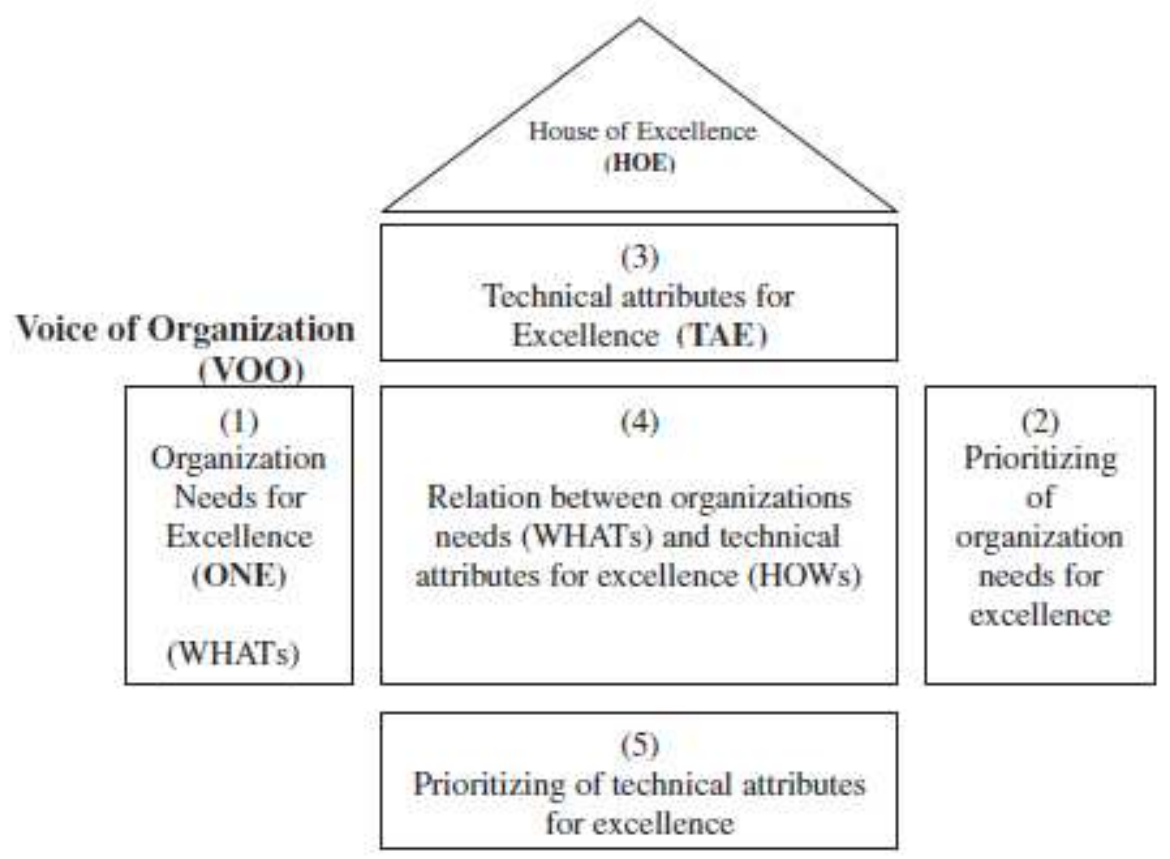

Figura 44 Modelo conceptual de la investigación

El modelo de la casa de la calidad propuesto se describe en 9 pasos que se observan en la siguiente figura. 


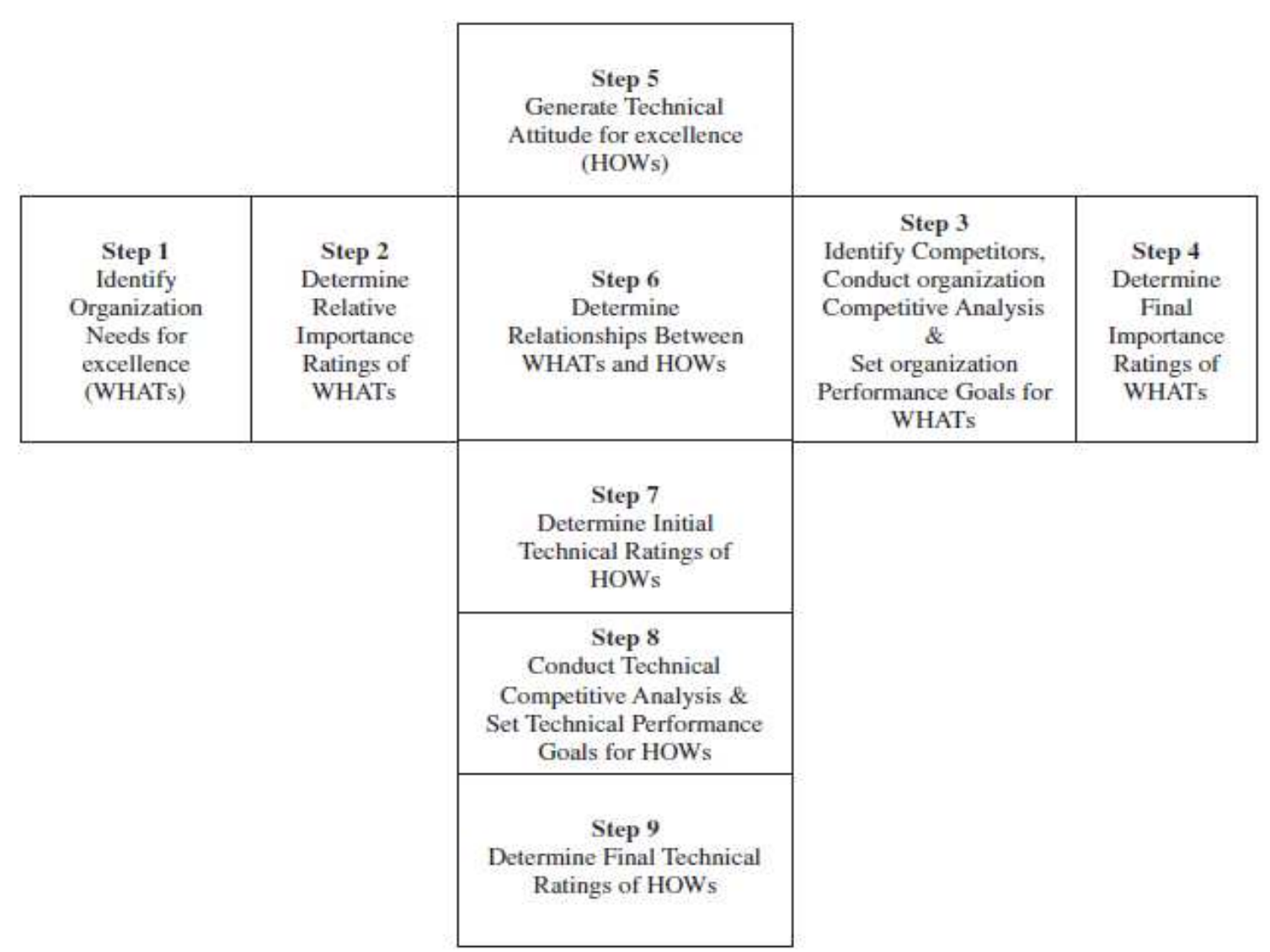

Figura 45 Los 9 pasos del modelo de la casa de la calidad

Paso 1: Identificación de las necesidades de la organización para la excelencia (what’s).

Mediante la revisión literaria de los criterios de establecimiento de la EFQM, se observan 5 necesidades o WHATs que son liderazgo, estrategia, empleados, recursos y participación, y procesos. Las mencionaremos como W1,..,W5. Esto responde a la primera pregunta 1.

Paso 2: Determinación de la importancia de las necesidades de la organización.

Las cinco necesidades observadas no tienen la misma importancia en cada organización por lo que se investiga la relación entre ellas para este caso.

Paso 3: Identificación de competidores y análisis competitivo de la organización.

Se identifican los competidores de la organización que llamaremos $\mathrm{C} 1$, que serán 6 , de C2 a C7. W5 es la mayor prioridad competitiva de la empresas seguida de W3,W4, y W2. En relación a los niveles del rendimiento de objetivos de la empresa C1 para las 5 necesidades, se observan estos resultados. $\mathrm{U}=(\mathrm{u} 1, \mathrm{u} 2, \mathrm{u} 3, \mathrm{u} 4, \mathrm{u} 5)=(1.2371,1.2575$, $1.3125,1.1798,1.2651)$.

Paso 4: Determinación de la importancia final de las necesidades 
La importancia final de las necesidades es: W5 $>\mathrm{W} 4>\mathrm{W} 3>\mathrm{W} 2>\mathrm{W} 1$.Así se responde a la segunda pregunta.

Paso 5: Generar indicadores técnicos para la excelencia (HOWs).

Se seleccionan 15 herramientas para la excelencia (hows) que se nombrarán de H1 a H15 consecutivamente a: gestión de inventarios, gestión de la calidad total, gestión de recursos humanos, gestión del conocimiento, gestión de la tecnología, gestión de la información, gestión de la energía, gestión de proyectos, gestión financiera, gestión de los cambios, gestión de la relación con el cliente, gestión de la cadena de suministro, gestión de los procesos. Gestión de la estrategia, y gestión de la producción. Así se responde a la tercera pregunta.

Paso 6: Determinación de las relaciones entre whats y hows.

Paso 7: Determinación de las calificaciones iniciales de los hows.

Los resultados indican que:

$\mathrm{H} 15>\mathrm{H} 13>\mathrm{H} 9>\mathrm{H} 5>\mathrm{H} 10>\mathrm{H} 6>\mathrm{H} 14>\mathrm{H} 12>\mathrm{H} 11>\mathrm{H} 3>\mathrm{H} 1>\mathrm{H} 4>\mathrm{H} 2>\mathrm{H} 7>\mathrm{H} 8$.

Paso 8: Análisis técnico de la competencia.

Se realiza un análisis de las ventajas competitivas para la empresa comparando los productos con respecto a los 15 hows. Los resultados indican que las prioridades competitivas son $\mathrm{H} 9, \mathrm{H} 15, \mathrm{H} 5$.

Paso 9: Obtención de los valores finales de los hows.

Mediante la integración de los valores iniciales y los valores de prioridades competitivas, se indican los resultados finales para los hows.

$\mathrm{H} 9>\mathrm{H} 15>\mathrm{H} 5>\mathrm{H} 11>\mathrm{H} 6>\mathrm{H} 13>\mathrm{H} 14>\mathrm{H} 10>\mathrm{H} 4>\mathrm{H} 1>\mathrm{H} 3>\mathrm{H} 2>\mathrm{H} 12>\mathrm{H} 8>\mathrm{H} 7$. Así se responde a la cuarta pregunta.

- Como resultado final se concluye que H7 puede ser eliminada en futuras investigaciones. $\mathrm{H} 8, \mathrm{H} 2$, y H12, también pueden sser eliminadas ya que no tienen influencia en las necesidades de la organización.

\section{3.- CONCLUSIONES}

La utilización de herramientas de gestión que son relevantes en las necesidades de la organización para la excelencia se han convertido en un factor importante. Se ha propuesto un método original para para valorar los criterios de la EFQM y las herramientas de gestión que una empresa puede utilizar para mejorar su rendimiento hacia la excelencia. Para ilustrar el modelo de la casa de la calidad se presenta el ejemplo en una empresa de 
automóviles que tiene 5 necesidades (criterios facilitadores EFQM), 15 atributos técnicos (herramientas de gestión) y 7 empresas competidoras.

La importancia de las herramientas de gestión permite a la empresa identificar los factores clave para la mejora de la excelencia. Los procesos emergentes del paso 4 son los factores más importantes desde el punto de vista de los expertos, y deben ser considerados como los criterios clave para la mejora del rendimiento de la organización.

Por otra parte, acorde al paso 3 y al paso 8 se observa que los whats y los hows tienen la misma importancia competitiva.

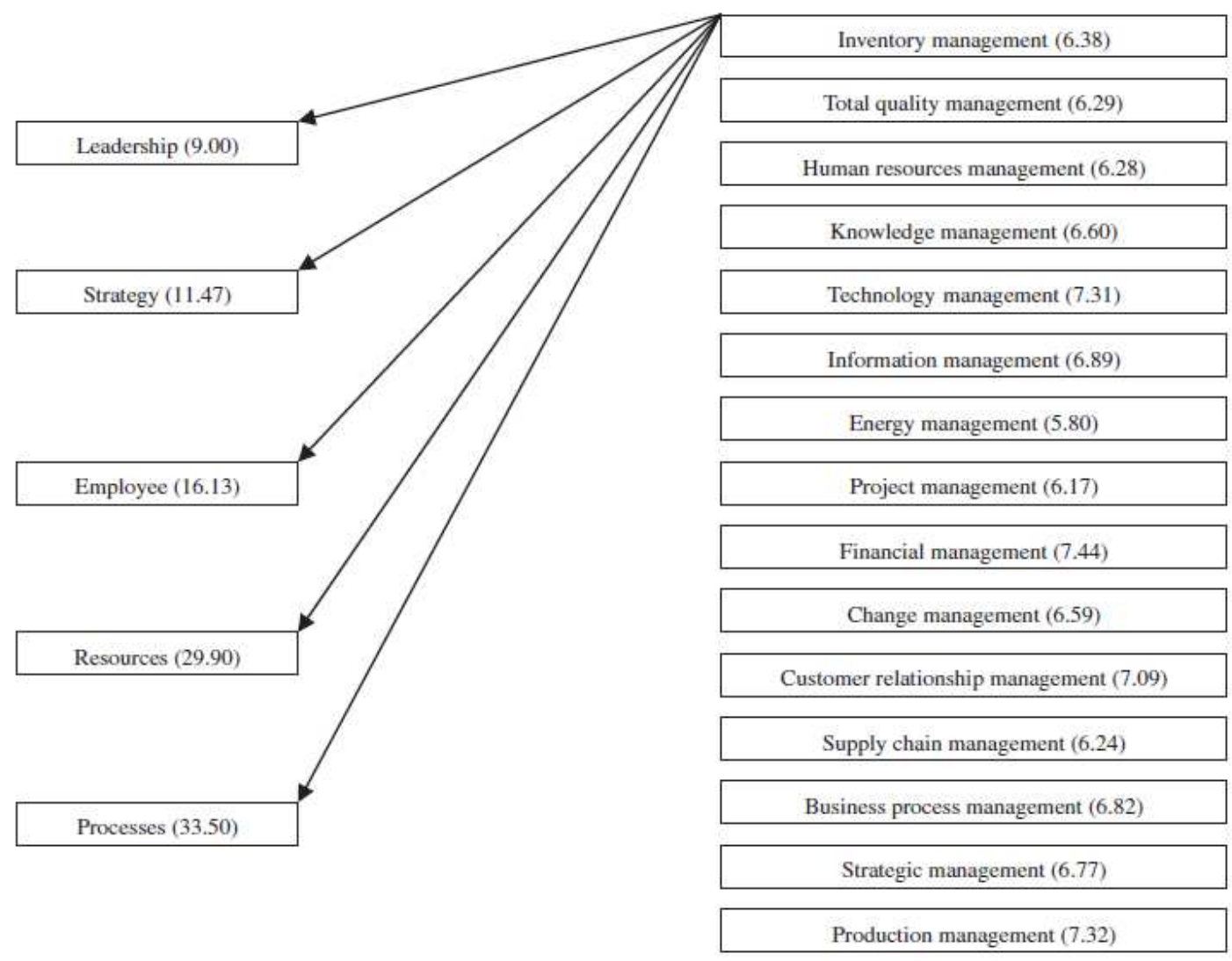

Figura 46 base para la asignación de recursos de programación y de organización para la excelencia

\subsection{3. - Business improvement strategy or useful tool? Analysis of the application of the $5 \mathrm{~S}$ concept in Japan, the UK and the US - Kaoru Kobayashi, Ron Fisher and Rod Gapp}

\section{1.- INTRODUCCIÓN}

Este estudio investiga como ha sido aplicado el concepto de las 5S para conseguir la mejora en los negocios en Japón, Gran Bretaña y Estados Unidos. Se observan los estudios 
de Osada $(1989,1991)$ e Hirano $(1995,1996)$, para más tarde hacer un análisis de 217 páginas web de los 3 países mencionados con el fin de observar si las $5 \mathrm{~S}$ son vistas como una estrategia de mejora de los negocios para guiar los procesos de la organización o como una herramienta útil para conseguir mejores resultados.

Osada (1989), define las 5S como una parte fundamental de la cultura y sociedad japonesa. Tanto para individuos $\mathrm{u}$ organizaciones, las $5 \mathrm{~S}$ promueven actividades de mejora en cualquier ambiente. Su aplicación puede descubrir problemas ocultos que de otra manera pueden pasar inadvertidos. El éxito de implantación aumenta tanto la eficiencia, como la productividad, calidad por coste y la eficiencia de la organización gracias a la cooperación. En resumen, las 5S son conceptualizadas e implantadas en los negocios japoneses para conseguir la excelencia en los negocios.

Por su parte, Hirano $(1995,1996)$ desarrolla una versión alternativa con un enfoque más práctico. Explica las 5S como una herramienta para la supervivencia corporativa, que facilita el JIT, más que una manera de orientar las acciones. Hirano pone énfasis en los dos primeros elemento Seiri y Seiton.

Así, para Osada ve las 5S como una estrategia para el desarrollo de la organización, aprendizaje y cambio, mientras que Hirano considera las $5 \mathrm{~S}$ como una fórmula industrial que intenta diferenciar una compañía de sus competidores.

\section{2.- RESULTADOS}

Los resultados nos indican cambios en la concepción de las 5S en los diferentes países:

- Para las organizaciones japonesas las 5S son una actividad generada por una filosofía, mientras que en los países occidentales las organizaciones entienden las $5 \mathrm{~S}$ como un proceso, sistema o herramienta, sin tenerla en cuenta como una filosofía.

- Japón percibe las 5S como necesarias e importantes. En Estados unidos se reconoce su importancia pero no su necesidad, mientras que para Gran Bretaña es menos importante y necesario.

- Las organizaciones británicas perciben que las $5 \mathrm{~S}$ no requieren compromiso de trabajo, viéndola como un deber de mayor manera que las organizaciones estadounidenses y japonesas. Esto indica que los británicos ven las $5 \mathrm{~S}$ más como una cosa de la dirección, que como un facilitador.

- Los datos obtenidos en los 3 países sugieren que las 5S aumentan la productividad y la eficiencia, pero las organizaciones británicas tienden a no considerar los costes mientras que las americanas y japonesas si lo hacen. Esto se puede deber a la poca familiaridad de laos organizaciones británicas con las $5 \mathrm{~S}$.

- Las organizaciones japonesas consideran que las 5S se implantan no sólo para beneficiar a la organización sino que también benefician al cliente. Las 
organizaciones británicas y americanas no les importa tanto saber quién es el que se beneficia de la implantación.

- Los 3 países consideran que los equipos de trabajo están más limpios y mejor organizados como resultado de la aplicación de las 5S. Las organizaciones japonesas y estadounidenses también consideran que las $5 \mathrm{~S}$ tratan con la información y el lugar de trabajo.

- Las organizaciones británicas y estadounidenses consideran que Seiri es la etapa en la que más énfasis se debe poner al ser la primera etapa e implicar un acto de eliminación de elementos innecesarios como resultado de las actividades de la organización.

- Hay más diferencias que similitudes en el propósito de la aplicación de las 5S entre los 3 países. Los datos muestran que las $5 \mathrm{~S}$ hacen frente a la calidad y la seguridad. Pero las organizaciones japonesas también consideran el propósito de la aplicación de las $5 \mathrm{~S}$ para la mejora de la gestión y la producción.

- En relación a resultados previos, en Japón se enfocan más al mantenimiento de las máquinas mientras que en Gran Bretaña y Estados Unidos consideran más la conexión entre las $5 \mathrm{~S}$ y lean manufacturing.

En resumen, la percepción de las 5S en Gran Bretaña y Estados Unidos está limitada al concepto relacionado al trabajo, mientras que los japoneses las interpretan como una manera de vida para las situaciones en los negocios. El resultado final es que se encuentran diferencias significantes en los aspectos de las 5S entre los diferentes países.

\section{3.- CONCLUSIONES}

Encontramos tres conclusiones teóricas sugeridas por los resultados del estudio. Primero, las organizaciones de los 3 países consideran las $5 \mathrm{~S}$ asociadas al trabajo y la gestión mediante la mejora de su lugar de trabajo a través de la organización y las actividades de limpieza. Más específicamente, estas organizaciones tienden a considerar a los siguientes aspectos de las 5S en una la misma manera: (1) la formación es muy importante, (2) equipos de la organización y la limpieza en el lugar de trabajo se llevan a cabo, (3) la productividad y la eficiencia se logran, y (4) el propósito principal de implementación de las $5 \mathrm{~S}$ es lograr una mejor calidad y seguridad. Por lo tanto, si el entrenamiento se proporcionase adecuadamente, el potencial de las $5 \mathrm{~S}$ también sería totalmente obtenido en Occidente.

En segundo lugar, cada componente de las 5S que constituyen el punto de vista japonés aún no se ha comprendido en el Reino Unido y EE.UU., donde se pone más énfasis en Seiri (organización). Esto podría deberse a las fuentes de las que las organizaciones occidentales adoptaron el concepto.

En tercer lugar, Japón reconoce las $5 \mathrm{~S}$ como una filosofía o manera de vida mientras que Gran Bretaña o Estados Unidos las consideran una herramienta o técnica. En Japón se pone énfasis en la participación total y la cooperación en la aplicación de las 5S.Esto 
también se puede deber al entendimiento de los principios de la Gestión de la Calidad Total en los diferentes países.

Por lo tanto, se sugiere que los practicantes $5 \mathrm{~S}$ o formadores deben considerar los beneficios de las $5 \mathrm{~S}$ como una estrategia de mejora de los negocios en lugar de sólo aplicaciones simplificadas. En particular, parece que las empresas en el Reino Unido y los EE.UU. no han comprendido la importancia de la participación total de las 5S. El desarrollo de una cultura organizacional dirigida a la consecución de la participación total conduciría a la implantación exitosa de las 5S.

\subsection{4.-Quality improvement supported by the 5S, an empirical case study of Mexican organisations - J. H. Ablanedo, B. Alidaee, J. C. Moreno y J. Urbina}

\section{1.- INTRODUCCIÓN}

Las 5S juegan un papel importante facilitando la introducción y el desarrollo de otros métodos de mejora de la calidad y mejora continua. En este estudio se investiga en la aplicación de las 5S en 20 organizaciones mexicanas del Estado de Hidalgo, observando sus factores importantes y las relaciones entre ellos a la hora de la implantación.

\section{2.- HIPÓTESIS Y RESULTADOS}

Esta investigación estudia las diferentes relaciones que acompañan a la puesta en práctica de las $5 \mathrm{~S}$ con el objetivo de identificar las prácticas de gestión de calidad que afectan a la calidad y el rendimiento del negocio.

Para ello se promulgan una serie de hipótesis que son observadas en las organizaciones mexicanas. Estas hipótesis se refieren a la aplicación práctica de las $5 \mathrm{~S}$ y al compromiso de la alta dirección en las prácticas 5S.

\section{Aplicación práctica de las 5S}

H1.1: Las organizaciones que han implantado las $5 S$ tienen un departamento de calidad.

Los resultados indican que esta relación no es significante. Este resultado sugiere un ambiente de trabajo orientado hacia la filosofía de la compañía, en vez de orientado a la filosofía del departamento de calidad. Mientras que algunos organizaciones muestran un departamento de calidad, la mayoría de ellos tienen una tendencia a incorporar $5 \mathrm{~S}$ en sus actividades cotidianas, según lo sugerido por Osada (1991). Por lo tanto, la filosofía de calidad deben ser incluidos en la filosofía de la organización y la práctica de las 5S no está sometido al departamento de calidad. 
H1.2: Las organizaciones que han implantado las $5 S$ han invertido en entrenamiento para $5 S$ en el personal.

Los resultados indican que esta relación es significante, el entrenamiento del personal es requerido para implantar programas de calidad en la organización.

H1.3: Las organizaciones que han implantado las $5 S$ han percibido que todas sus actividades están enfocadas a la mejora de la calidad y la mejora continua.

Esta relación no es significante. Mientras países como Japón se toman las $5 \mathrm{~S}$ como un modo de vida, México las ve como una herramienta de calidad. Un mayor entrenamiento se necesita en las organizaciones occidentales para adoptar las $5 \mathrm{~S}$ como un modo de vida.

\section{Compromiso de la alta dirección en la aplicación de las $5 \mathrm{~S}$}

Las hipótesis de la alta dirección con respecto a las $5 \mathrm{~S}$ con sus respectivos resultados se resumen en el cuadro siguiente.

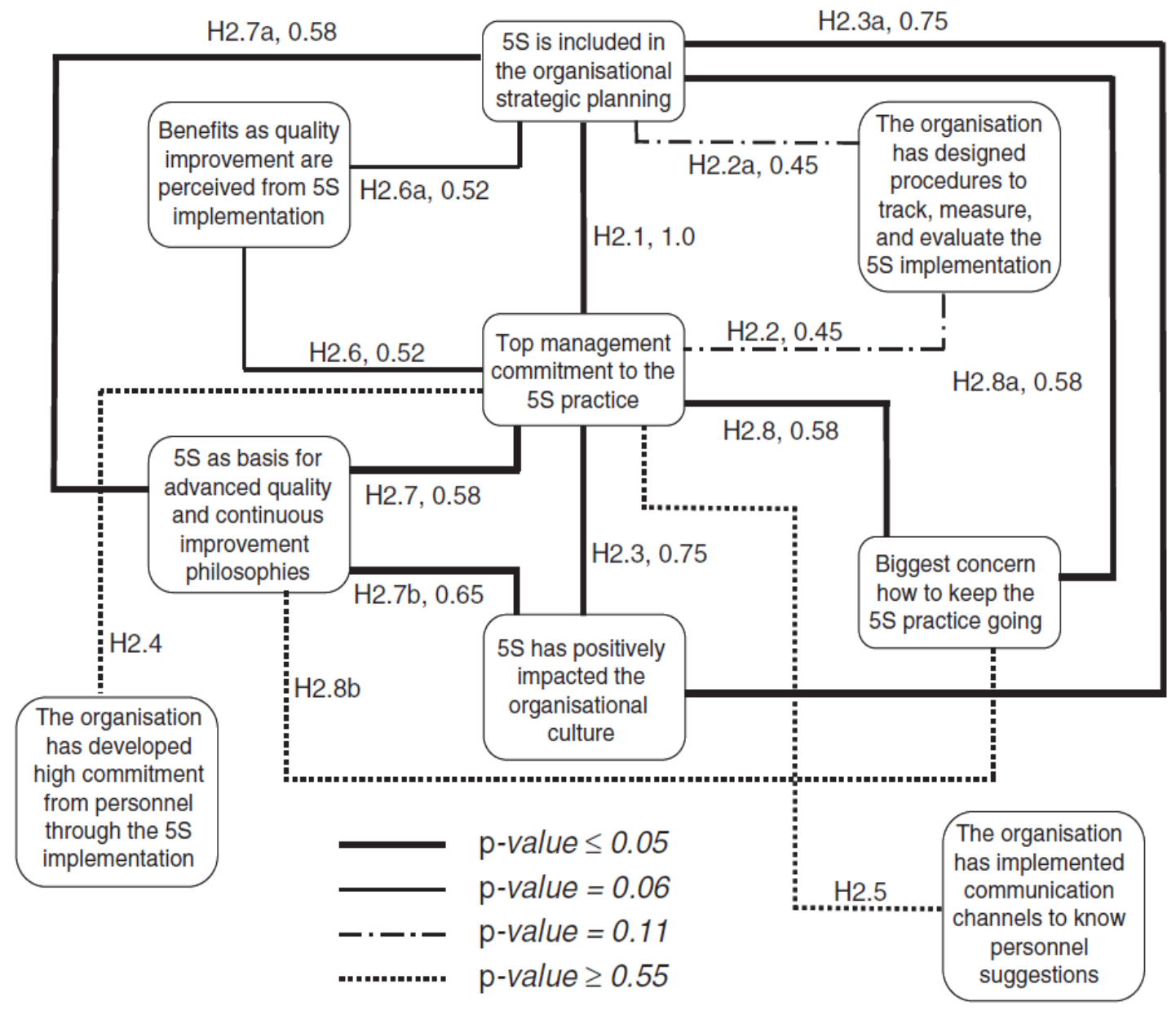

Figura 47 Cuadro de relaciones entre la alta dirección y las prácticas 5S 
Esta investigación encontró que los factores descritos en la Figura son los factores que se deben considerar como fundamentales para la implantación de las 5S. En primer lugar, el compromiso de la dirección en la práctica de las $5 \mathrm{~S}$ es necesario. A continuación, la alta dirección debe prestar atención a factores tales como: la organización ha percibido beneficios tales como la mejora de la calidad por la implantación de las $5 \mathrm{~S}$, las prácticas $5 \mathrm{~S}$ están incluidas en la planificación estratégica de la organización; la práctica $5 \mathrm{~S}$ se utiliza como base para las filosofías de calidad avanzada y mejora continua, la práctica $5 \mathrm{~S}$ tiene un impacto positivo en la cultura de la organización, y hay una preocupación de la organización acerca de cómo mantener la práctica de las $5 \mathrm{~S}$ en marcha; en las organizaciones encuestadas el compromiso de la alta dirección muestra una correlación grande y significativa con estos factores.

Igualmente la alta dirección debe prestar atención a los siguientes factores, aunque las organizaciones encuestadas muestren relaciones menos significantes o no significantes: la organización ha desarrollado un alto compromiso del personal a través de la implantación de las 5S; la organización ha puesto en marcha canales de comunicación para conocer las propuestas de mejora del personal, y la organización ha diseñado procedimientos para el seguir, medir y evaluar la implantación de las 5S.

\section{3.- CONCLUSIONES}

La práctica de las $5 \mathrm{~S}$ es una filosofía y un conjunto de principios que conducen a la la mejora continua en la organización. La implantación de las 5S no es una tarea fácil. Las organizaciones encuestadas identificaron los siguientes factores de éxito en la implantación: la inversión en formación 5S para la alta gerencia y los trabajadores; compromiso de la alta dirección con la práctica $5 \mathrm{~S}$; la práctica $5 \mathrm{~S}$ está incluida en la planificación estratégica de la organización, la organización se centra en cómo mantener la práctica de las $5 \mathrm{~S}$, la organización mide el impacto positivo de la implantación de las $5 \mathrm{~S}$ en la cultura de la organización; la práctica $5 \mathrm{~S}$ se utiliza como base para las filosofías calidad avanzada y la mejora continua, y la organización mide los beneficios de la implantación de las $5 \mathrm{~S}$ como la mejora de la calidad. Además, las organizaciones encuestadas mostraron oportunidades para mejorar la implementación de las 5S: el compromiso personal con las prácticas $5 \mathrm{~S}$, el diseño de los canales de comunicación oficiales para conocer las sugerencias del personal y mejorar sus puestos de trabajo, la orientación hacia la calidad y la mejora continua de todas las actividades y operaciones, el diseño de los procesos de seguimiento, medición y evaluación en la implementación de las 5S; y cómo mantener la práctica de las $5 \mathrm{~S}$ mientras se implantan programas avanzados de calidad. Parece que obtener el compromiso de la alta dirección y el del personal puede ayudar a hacer frente a los desafíos de la implantación de las 5S.

Esta investigación encontró que el primer paso para desarrollar la idea de las $5 \mathrm{~S}$ como estrategia y modo de vida en vez de como una herramienta para la calidad, es tener un mayor compromiso desde la alta dirección para dirigir la creación de una cultura organizacional, e incluir la práctica de las $5 \mathrm{~S}$ en la planificación estratégica de la 
organización. En segundo lugar, la formación continua es necesaria para mejorar la percepción de la práctica de las $5 \mathrm{~S}$ y adoptarla como un estilo de vida en lugar de una herramienta de gestión. Finalmente, los esfuerzos adicionales se debe realizar para: seguimiento, medición y evaluación en la implantación de las $5 \mathrm{~S}$, diseñar canales de comunicación, y para tomar ventaja de la práctica de las $5 \mathrm{~S}$ y poner en práctica las filosofías de calidad avanzada y mejora continua.

Una respuesta común de las empresas que investigamos fue el papel de liderazgo de las 5S para apoyar otros métodos de calidad y mejora. Un resultado interesante es que tanto en la mejora continua y la implicación de los empleados son apoyados por la práctica de las 5S, pero ninguna de las organizaciones encuestadas ha llegado a este nivel operativo.

El gran desafío es cómo incorporar la práctica de las $5 \mathrm{~S}$ en la vida de todos.

\subsection{5.- Critical success factors of Six Sigma implementations in Italian companies - Alessandro Brun}

\section{1.- INTRODUCCIÓN}

El presente estudio se centra en la investigación de la implantación de la metodología Seis Sigma en compañías italianas. En particular incluye las siguientes preguntas: ¿Están implantando las compañías italianas la metodología Seis Sigma como originalmente fue concebida por Motorola o tiene una manera diferente? ¿Reconocen las compañías italianas que implantan Seis Sigma los mismos factores críticos de éxito observados en la literatura internacional?

El objetivo principal de la investigación es encontrar un modelo de referencia para implantar Seis Sigma en las compañías italianas.

La gestión de la calidad total (TQM) puede ser considerada el padre de Seis Sigma, ya que muchos de los principios que son básicos para la gestión de la calidad total, también están comprendidos en Seis Sigma.

Seis Sigma fue lanzada en 1986 por Motorola gracias a Mikel Harry, Bill Smith y Bob Galvin. Originalmente concebida como un método de mejora de los procesos de fabricación, para más tarde pasar a tener un enfoque gerencial que gestiona a toda la organización. Cualquier implantación de Seis Sigma tiene el propósito de mejorar la satisfacción del cliente mediante la mejora da la capacidad del proceso. Esto es posible encontrando los Críticos de Calidad (CtQ) e implantando acciones de mejora para reducir la variabilidad de los procesos mejorando los CtQ. La mayoría de los programas Seis Sigma tienen similares características: 
- Seis Sigma incorpora la calidad en las funciones y departamentos de la compañía en vez de mantenerlos como entidades separadas.

- La implantación del programa Seis Sigma se extiende a todas las áreas de la compañía.

- Seis Sigma tiene el apoyo y la involucración en la gestión de toda la compañía, teniendo la calidad como prioridad.

- Seis Sigma tiene metas medibles y bien definidas.

- La estructura de la organización está basada en roles específicos (Green belt, black belt, etc).

Aparentemente Seis Sigma está basado en la gestión de la calidad total, pero tiene ciertas diferencias con ella:

- La GCT está orientada en el resultado final de los procesos, mientras Seis Sigma tiene el propósito de prevenir errores para reducir la variabilidad de los procesos.

- La GCT proporciona orientaciones generales para la gestión de la calidad, mientras Seis Sigma usa métodos de aplicación precisa (DMAIC y DFSS)

- En Seis Sigma el liderazgo tiene un rol crítico para facilitar el éxito del desarrollo de técnicas e instrumentos en medida que asegura alineamiento de los proyectos con los objetivos estratégicos de la organización. Este rol es menor en la GCT.

Por estas razones, diferentes autores consideran Seis Sigma como una evolución de la Gestión de la Calidad Total.

\section{2.- ESTUDIO REALIZADO}

En loa últimos años ha habido muchos estudios sobre Seis Sigma. Un ejercicio útil es observar los factores críticos de éxito (CSF) en la implantación de Seis Sigma en casos reales. Para obtener los resultados de esta investigación, se considera la lista presentada por Banuelas Coronado y Anthony (2000), haciendo únicamente 2 modificaciones expandiendo el entrenamiento en educación y entreneamiento, y la infraestructura organizacional en infraestructura organizacional y cultura. Así, los CSF son los siguientes:

- Participación constante y compromiso

- Cambio cultural

- Comunicación

- Infraestructura organizacional y cultura

- Educación y entrenamiento

- Relación de Seis Sigma con la estrategia de negocios

- Relación de Seis Sigma con los recursos humanos

- Relación de Seis Sigma con los proveedores

- Entendimiento de las técnicas e instrumentos de Seis Sigma

- Gestión de proyectos 
- Priorización de proyectos y selección

Por otra parte, el territorio industrial italiano difiere del estadounidense. Las empresas son pequeñas o medianas empresas y la mayoría negocios familiares, mientras las estadounidenses son empresas públicas. Debido a esto se presentan las preguntas Q1 y Q2:

- Q1: ¿ Están implantando las compañías italianas la metodología Seis Sigma como originalmente fue concebida por Motorola o tiene una manera diferente?

- Q2: ¿Reconocen las compañías italianas que implantan Seis Sigma los mismos factores críticos de éxito observados en la literatura internacional?

\section{2.-RESULTADOS}

\section{Q1- casos de implantación en compañías italianas}

Se comenzó la investigación con unos pocos casos para obtener una primera idea. Mediante el análisis preliminar se indican cuatro áreas que podrían sufrir modificaciones más importantes en relación a la implantación original de Seis Sigma: patrocinio, número de personal involucrado en el proyecto Seis Sigma, enfoque hacia el entrenamiento de Green belts, y manera de medir los resultados del proyecto.

Más tarde se observan diferentes casos en compañías italianas y en la General Electric (al ser una de las primeras que encontraron éxito después de Motorola). Estas empresas italianas son Fiat Services, Dow chemical, Cameron, Avio, ITT, Sony, SFK, Whirlpool y Axa. Al analizar empresas de diferente tamaño, diferentes industrias, etc, habrá que observar las diferencias y similitudes de los casos analizados.

Un aspecto interesante es la causa principal para implantar un proyecto Seis Sigma:

- En algunos casos la implantación en las compañías italianas ha sido decidida en sus sedes corporativas (Cameron y Dow).

- En otras compañías, la implantación es sugerida por el cliente principal (Avio y GCT).

- Otra posibilidad es la contratación de un manager de una compañía con una fuerte cultura de Seis Sigma.

Otras observaciones:

- El uso de un nombre original para identificar mejor la iniciativa de la compañía (Cartesio, OPEX o Axa way)

- Enfoque hacia ciertos aspectos, no hacia todos ( fase de definición, técnias estadísticas, ...)

- Contratación de la formación a un consultor externo.

- Entrenar al 100\% de los empleados a veces no es un objetivo.

- Miedo o falta de interés en transferir el enfoque de Seis Sigma a los proveedores. 


\section{Q2- Discusión de los expertos}

La segunda pregunta es discutida por expertos. Primero discuten cada uno de los 12 CSF con el doble objetivo de tener una interpretación homogénea del significado de cada CSF, y de cerciorarse si no han tenido en cuenta algún CSF que deba incluirse en el análisis. Después se pregunta a cada experto por la relevancia de cada CSF en un caso tradicional (como Motorola) y en una PYME italiana, y se presenta la siguiente hipótesis:

H0: el nivel de relevancia de un CSF no cambia, tanto se relacione con un caso tradicional como con una PYME italiana.

Esta hipótesis no se puede rechazar en cualquier nivel de confianza, para cualquiera de los CSF analizados. Con respecto al estudio de Banuelas y Anthony, solo se observa diferencias el factor "entendimiento de los instrumentos y técnicas de Seis Sigma", que tiene un valor de 3,6(tradicional) y 3,5 (PYME) en este estudio y un valor de 4,2 en el de Banuelas y Anthony.

En este análisis, así como en el de Banuelas y Anthony, el aspecto más importante es la participación constante y el compromiso (para ambos casos). Por otra parte también se observa una gran influencia del aspecto ralación de Seis Sigma con la estrategia de negocios (para ambos casos), y con el aspecto cambio cultural (para PYME).

\section{3.- CONCLUSIONES}

- En la situación italiana no siempre es fácil inculcar la involucración y el compromiso. La alta dirección debe buscar la forma para involucrar al empleado mediante una visión más clara del aspecto y un sistema de incentivos.

- La difusión de nuevos roles como los Yellow Belts o White Belts puede resultar ser una espada de doble filo, ya que el nuevo rol puede entrar en conflicto con la orientación jerárquica de la estructura de la metodología.

- En una PYME la disponibilidad de los recursos financieros limita la aplicación de Seis Sigma. Muchas compañías se enfocan solamente hacia ciertos aspectos de la metodología, o limitan su aplicación ala fabricación en vez de aplicarla en toda la organización.

- En el caso de las PYMEs,el factor con menos relevancia es la relación de Seis Sigma con los proveedores, debido a que la compañía debe implantar perfectamente la metodología en ella misma antes de transferirla a los proveedores.

- Algunas compañías contratan consultores externos para la formación de Black Belts y Master Black Belts, pero organizar esta formación entre compañías no es siempre fácil.

- Algunas compañías introducen los roles de estructura solamente una parte de tiempo (ej. black belt solo usan el 20 o $30 \%$ de su tiempo en la mejora de proyectos).Acorde con 
diferentes expertos, esto no va a obstaculizar las ventajas del enfoque de resolución de problemas llevadas a cabo por seis sigma.

Así con todo lo observado se ha presentado un modelo para la implantación de Seis Sigma en compañías italianas.

\subsection{6.- The envolving theory of quality management: The role of Six Sigma - Xingxing Zu, Lawrence D. redenhall, Thomas J. Douglas}

\section{1.- INTRODUCCIÓN}

Este estudio investiga las técnicas tradicionales de Gestión de la Calidad en la metodología Seis Sigma, y las prácticas novedosas que ofrece. Para ello realiza identifica tres nuevas prácticas críticas en la implantación de Seis Sigma para luego relacionarlas por medio de un modelo con las prácticas tradicionales de gestión de la calidad. Estas 3 nuevas prácticas de Seis Sigma son : estructura de Seis Sigma ( uso de un grupo de especialistas formados en Seis Sigma, master black belts, black belts y Green belts), procedimiento estructurado de mejora (método DMAIC), y la métrica de Seis Sigma (utilización de indicadores para la mejora continua usando datos objetivos para alcanzar los resultados, por medio de la medición en Sigma, CTQs,, medidas de defectos y capacidad del proceso).

Para obtener los resultados y analizar el modelo presentado, se realiza una encuesta a 226 fábricas de EE.UU. con ISO 9000, TQM, Seis Sigma, u otros métodos de mejora implantados.

\section{2.- MODELO E HIPÓTESIS}

Se proponen una serie de hipótesis, que han sido observadas en estudios previos de otros autores, para realizar un modelo en el que se observan las relaciones entre las prácticas tradicionales de la gestión de la calidad, las prácticas de Seis Sigma y sus efectos en el rendimiento. El modelo propuesto sugiere que ambas prácticas trabajan juntas para la obtención para mejorar la calidad y el rendimiento de los negocios. El modelo está dividido en : liderazgo de la alta dirección, infraestructura tradicional de la Gestión de la Calidad (relación con el cliente, relación con el proveedor, gestión de los recursos humanos), prácticas tradicionales básicas de la Gestión de la calidad (calidad de la información, diseño de productos y servicios, gestión de los procesos), infraestructura Seis Sigma ( Estructura Seis Sigma), prácticas básicas Seis Sigma (métrica Seis Sigma, procedimientos estructurados Seis Sigma), y resultados (rendimiento de la calidad, rendimiento del negocio). 


\section{Liderazgo de la alta dirección}

Hla: El liderazgo de la alta dirección está positivamente relacionado con las 3 prácticas tradicionales de infraestructura de gestión de la calidad.

H1b: El liderazgo de la alta dirección está positivamente relacionado con la estructura Seis Sigma

H1c: El liderazgo de la alta dirección está positivamente relacionado con la métrica de Seis Sigma.

\section{Prácticas tradicionales de la infraestructura de la gestión de la calidad}

H2a: La relación con el cliente está positivamente relacionada con la calidad de la información.

H2b: La relación con el proveedor está positivamente relacionada con el diseño del producto o servicio.

H2c: La relación con el proveedor está positivamente relacionada con la gestión del proceso.

H2d:La gestión de los recursos humanos está positivamente relacionada con las tres prácticas básicas de la gestión de la calidad.

\section{Prácticas infraestructurales de Seis Sigma}

H3a: La estructura de Seis Sigma está positivamente relacionada con la gestión de los recursos humanos.

H3b: La estructura de Seis Sigma está positivamente relacionada con los procedimientos estructurados de mejora de Seis Sigma.

\section{Prácticas básicas tradicionales de la gestión de la calidad}

H4a: La calidad de la información está positivamente relacionada con la relación con el proveedor

H4b: La calidad de l información está positivamente relacionada con el diseño del producto o servicio.

H4c: La calidad de la información está positivamente relacionada con la gestión de los procesos.

H4d: La calidad de la información está positivamente relacionada con la métrica de Seis Sigma. 
H4e:El diseño del producto o servicio está positivamente relacionado con el rendimiento de la calidad.

H4f: La gestión de los procesos está positivamente relacionada con el rendimiento de la calidad.

H4g: El diseño del producto o servicio está positivamente relacionado con la gestión de los procesos

\section{Prácticas básicas Seis Sigma}

H5a: Los procedimientos de mejora estructurados de Seis Sigma están positivamente relacionados con el diseño del producto o servicio.

H5b: Los procedimientos de mejora estructurados de Seis Sigma están positivamente relacionados con la gestión de los procesos.

H5c: : Los procedimientos de mejora estructurados de Seis Sigma están positivamente relacionados con la métrica de Seis Sigma.

H5d: La métrica de Seis Sigma está positivamente relacionada con el diseño del producto o servicio.

H5e: La métrica de Seis Sigma está positivamente relacionada con la gestión de los procesos.

\section{Resultados}

H6: El rendimiento de la calidad está positivamente relacionado con el rendimiento del negocio.

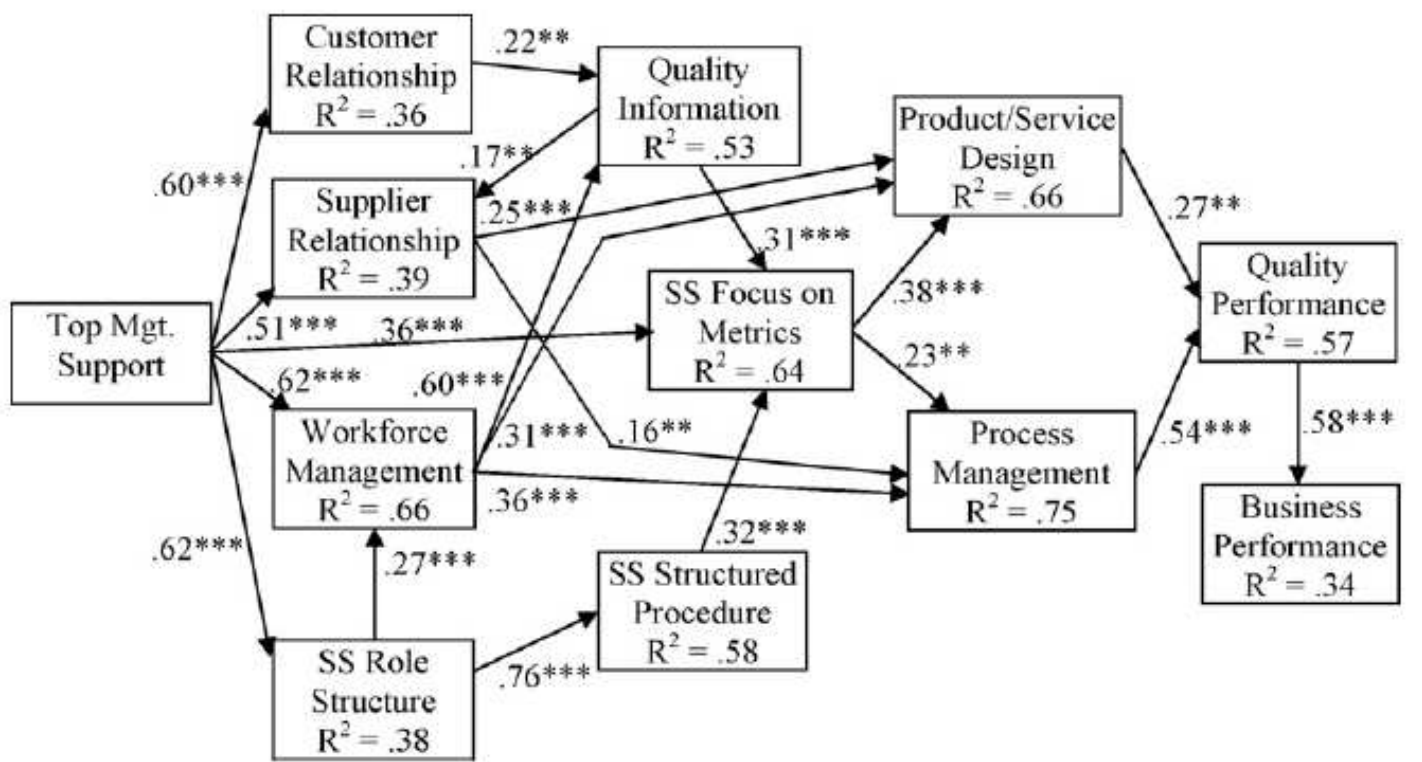


Figura 48 Modelo presentado con los resultados estadísticos

\section{3.- RESULTADOS}

Las mayoría de las relaciones propuestas en el modelo son apoyadas, aunque algunas no son estadísticamente significantes. Las relaciones no significantes son: calidad de la información y diseño de productos o servicios, calidad de la información y gestión de los procesos, procedimientos estructurados Seis Sigma y diseño de productos o servicios, procedimientos estructurados de Seis Sigma y gestión de procesos, y entre el diseño de productos o servicios y la gestión de procesos.

Los resultados sugieren la relación entre las prácticas de Seis Sigma y las prácticas tradicionales de Seis Sigma a la hora de mejorar el rendimiento de la calidad. El liderazgo de la alta dirección es un factor crítico para la gestión de la calidad tradicional y también es importante para Seis Sigma. Apoya directamente la estructura de Seis Sigma y la métrica de Seis Sigma, así como las prácticas infraestructurales de la gestión de la calidad. El éxito de la ejecución necesaria de los cambios que precisa Seis Sigma radica en como la alta dirección entiende y acepta los principios de Seis Sigma, y como apoyan y facilitan la restructuración de las políticas de la organización.

El apoyo de la estructura Seis Sigma a la gestión de los recursos humanos es una interesante información. La utilización de Seis Sigma mejora de los recursos humanos, especialmente en las áreas de la planificación de los recursos humanos, el entrenamiento y el reconocimiento al empleado.

Por su parte, la estructura de Seis Sigma favorece su procedimiento estructurado e indirectamente influye en la relación entre la gestión de los recursos humanos y el procedimiento estructurado de Seis Sigma. Tambíén afecta a las 3 prácticas tradicionales de la gestión de la calidad y a la métrica de Seis Sigma. Esto apoya que no solamente Seis Sigma recibe apoyo de las prácticas tradicionales de la gestión de la calidad sino que también relaciona un nuevo elemento con su infraestructura.

La relación con el cliente afecta a la calidad de la información, y la relación con el proveedor afecta al diseño de producto o servicio y la gestión de procesos. La calidad de la información está relacionada con la relación con el proveedor y la métrica de Seis Sigma. Esto indica que la colaboración con los clientes externos y proveedores siguen teniendo mucha importancia en Seis Sigma.

Aunque la calidad de la información no tiene un efecto directo en el diseño del producto y la gestión de los procesos, tiene una fuerte relación con la métrica de Seis Sigma, que afecta directamente a estos dos factores. La métrica de Seis Sigma también media entre el efecto de la calidad de la información y la estructura de Seis Sigma en el diseño del producto, lo que nos indica la importancia de los datos y las medidas objetivas en la mejora de la calidad. 
El diseño del producto y la gestión de los procesos son los factores que afectan directamente al rendimiento de la calidad. Para obtener resultados de mayor calidad, las empresas necesitan equilibrar su diseño y la gestión de los procesos, y perseverar en implantar estos apoyos en larga duración.

En resumen, el modelo estructural sugiere la importancia las prácticas de la gestión de la calidad en la metodología Seis Sigma, y las mejoras que Seis Sigma propone a la gestión de la calidad. Así, las prácticas de gestión de la calidad y las prácticas de Seis Sigma trabajan juntas para generar un mejor rendimiento de los negocios.

\section{4.- CONCLUSIONES}

Las empresas se encontraban con dos dilemas la hora de implantar Seis Sigma. Si no implantaban Seis Sigma por considerarla como los métodos tradicionales de la gestión de la calidad, perdían la oportunidad de tener beneficios sustanciales. Por otra parte si consideraban Seis Sigma como un nuevo método con prácticas novedosas, se encontraban con el lastre de ver cuales eran las nuevas prácticas que tenían que implantar.

Este estudio ayuda a clarificar la relación entre la gestión de la calidad y Seis Sigma. Seis Sigma está cimentada en las prácticas tradicionales de la gestión de la calidad y ofrece tres prácticas adicionales que proporcionan nuevos caminos para la mejora de la calidad.

El modelo integrado en este estudio revela algunas áreas importantes que los gerentes deben tener en cuenta cuando adecuen las prácticas Seis Sigma en su organización. El liderazgo de la dirección afecta directamente a la implantación de Seis Sigma y la estructura de Seis Sigma y la métrica de Seis Sigma, lo que sugiere que para la adopción exitosa de Seis Sigma, es fundamental que la alta gerencia acepte el concepto de Seis Sigma y esté dispuesto a asignar recursos para adaptar la organización, la estructura, las políticas y los procesos de Seis Sigma.

En el plano de las prácticas de la infraestructura, los administradores pueden complementar el manejo tradicional de mano de obra práctica con la estructura de roles de Seis Sigma para aumentar la capacidad del empleado para la mejora continua de la organización. En el plano de las prácticas básicas, es importante hacer hincapié en el uso de los procedimientos de mejora estructurados y la métrica de Seis Sigma para motivar y orientar las actividades de mejora en diseño de producto y gestión de procesos con el suministro de información de calidad oportuna y precisa 


\subsection{7.- Integrated Management Systems - three different levels of integration - Tine H. Jorgensen, Arne Remmen, M. Dolores Mellado. \\ 1.- INTRODUCCIÓN}

Diferentes enfoques para la integración de sistemas de gestión con distintos niveles de ambición han surgido. La tendencia al aumento de la compatibilidad entre estas normas ha allanado el camino para los debates en la manera de entender los diferentes aspectos de la integración.

El nivel de integración más ambicioso se refiere a la creación de una cultura de aprendizaje, la participación y la mejora continua del rendimiento para generar beneficios externos y contribuir a un desarrollo sostenible. Para obtener esto, el enfoque de la gestión del sistema tiene que estar en relación a la calidad basada en el cliente, y producción orientada hacia la gestión del medio ambiente y la responsabilidad social corporativa. En otras palabras, se distinguen 3 niveles de integración:

- Correspondencia: mayor compatibilidad con las referencias cruzadas entre los sistemas paralelos.

- Coordinación y coherencia: procesos genéricos enfocados en las tareas del ciclo de gestión.

- Estrategia e inherencia: una cultura organizacional de aprendizaje, mejora continua del rendimiento y participación de los interesados, relacionados con los desafíos internos y externos.

Estos tres niveles de integración reportan diferentes beneficios potenciales de:

- La reducción de las cargas administrativas debido a la mejora de la coordinación interna.

- Ventajas competitivas.

- El avance hacia la responsabilidad corporativa en relación con los tres pilares del desarrollo sostenible.

\section{2.- NIVELES DE INTEGRACIÓN}

\section{Normas compatibles centradas en los aspectos de los sistemas}

Las cuatro normas para la gestión de sistemas son las siguientes: ISO 9001 - Gestión de la calidad, ISO 14001- Gestión del medio ambiente, OHSAS 18001- Gestión de la salud y la seguridad, y SA 8000- Gestión de la responsabilidad social, en las que se observan estos aspectos de compatibilidad:

- ISO 9001:2000 se centra en la mejora continua, que también es uno de los aspectos de los demás sistemas. 
- La ISO 14001:2004 ha sido desarrollada para mejorar la coherencia con la ISO 9001:2000 y la conexión con los EMAS.

- Una norma común para auditorías de sistemas de calidad y medio ambiente se ha desarrollado (ISO 19011:2002).

Y los siguientes beneficios:

- Disminución de documentación y registros.

- Menos burocracia y reducción del papeleo.

- Ahorro de costes por la optimización de tiempo y recursos asignados a los sistemas.

- Simplificación de auditorías internas y externas.

\section{Sistemas genéricos de gestión centrados en la coordinación de los procesos}

El aumento de compatibilidad de las normas es la plataforma básica hacia los sistemas integrados de gestión. Un SIG también tiene que estar basado en los aspectos genéricos de la gestión: política, planificación, implantación, acciones correctivas y preventivas, y revisión de la gestión ( ciclo PDCA). Una norma para SIG basada en los elementos de los procesos genéricos de coordinación, tiene que extenderse a demandas específicas contenidas en los apéndices de las normas de calidad, medio ambiente, salud y seguridad y responsabilidad social. Las similitudes de los procesos genéricos en un sistema de gestión son: compromiso de la alta dirección, definición de la política, planificación de objetivos, procedimientos para formar empleados, procedimientos de comunicación, auditorías, documentación y control de registros, control de las disconformidades, acciones correctivas y preventivas y revisión de la gestión. Las ventajas de la integración basada en los procesos genéricos de diferentes sistemas de gestión son:

- Mayor enfoque hacia las interrelaciones entre calidad, medio ambiente salud y seguridad y responsabilidad social.

- Objetivos son afirmados, coordinados y equilibrados.

- Organización y responsabilidades se definen en un lugar.

Aspectos como la estructura de la organización, el tamaño, y la competitividad del mercado tienen influencia cuando una organización decide sin integrar o no sus sistemas de gestión, asi como su nivel de integración. Las PYMES están menos interesadas en la integración que las grandes compañías, y las organizaciones que realizan productos de alta calidad y necesitan requerimientos substanciales de documentación, deben tener los aspectos de calidad separados en un sistema de los demás.

\section{Integración - Arraigo de la organización y relación entre las partes interesadas}

\section{Entendimiento compartido:}


Un entendimiento compartido de los procesos genéricos es u paso importante, y más allá para asegurar mejoras continuas reales, el sistema de gestión debe estar internamente arraigado a través de la organización, y externamente con las relaciones entre las partes interesadas externas (proveedores y consumidores).

La integración se centra más en la cultura, aprendizaje y empleados que en los elementos comunes del sistema y los procesos genéricos. Si la sostenibilidad se institucionaliza mediante decisiones operacionales y estratégicas basadas en un entendimiento compartido, entonces el SIG se institucionalizará en la organización y transcenderá el enfoque hacia el sistema y los procesos.

\section{Aprendizaje de la organización:}

Los procesos de aprendizaje son esenciales a la hora de prevenir defectos en el diseño o rediseño de sistemas y asegurar la continua adaptación de nuevos desafíos. Para apoyar un proceso de aprendizaje continuo, son esenciales una política educacional, una alta calidad de información de los proveedores, y comunicación interna. Un SIG requiere continua reconstrucción, actualización e innovación en diferentes áreas del sistema.

La cultura está vista como una facilitadora para la mejora del rendimiento, por lo que el reto para organización es integrar diferentes responsabilidades como la organización cultural.

Organizaciones con múltiples proveedores y clientes puede que necesiten separar grupos encargados de las principales áreas como calidad, medio ambiente, y seguridad y salud, ya que cada área necesita diferentes tipos de conocimiento. Al mismo tiempo, los grupos deben trabajar estrechamente y entender los aspectos e influencias relacionadas con otras áreas de responsabilidad. En este sentido los grupos multifuncionales, trabajo en equipo, gestión del conocimiento, etc, se convierten en aspectos importantes a la hora de asegurar el arraigo de un SIG en la organización.

\section{Interacción y cooperación con las partes interesadas:}

En un mercado global enfocado en la innovación y la diferenciación del producto, las organizaciones tienen que entender los cambios entre las partes interesadas a través de la cooperación, transparencia y diálogo. El desafío es arraigar la sensibilidad en el SIG en la cultura organizacional para adaptarse a nuevas demandas, y a condiciones internas y externas.

Para las organizaciones este desafío hace importante la cooperación con el personal de la cadena de producción y otras partes interesadas, para mejorar las condiciones de calidad, medio ambiente, y salud y seguridad en el ciclo de vida del producto. Los campos de responsabilidad están continuamente creciendo, reflejando las cadenas mundiales de productos y dependiendo de las expectativas de todas las partes interesadas. 


\section{3.- CONCLUSIONES}

Dependiendo del entendimiento y el nivel de ambición que está detrás de los SIG, la integración es la solución a diferentes problemas. La integración como correspondencia entre las diferentes normas con referencias cruzadas y a veces un manual común genera beneficios administrativos a la organización como ahorro de tiempo y recursos, y alineamiento entre las demandas de las diferentes normas.

La integración como coordinación basada en un entendimiento común de los procesos genéricos genera beneficios como la descripción de responsabilidades, alineación de la política, objetivos, etc.

La integración como estrategia e inherencia es una solución a los problemas relacionados con la mejora continua como la mejora de la ventaja competitiva y la contribución al desarrollo sostenible.

Con el fin de predicar con el ejemplo las responsabilidades de calidad, medio ambiente, salud y seguridad, y responsabilidad social, tienen que ser integrados a través de la cultura organizacional, ya que las responsabilidades son inherentes en cada aspecto individual de las actividades de la organización.

Por último, se ha visto como en los últimos años diferentes países han desarrollado normas para la integración de sistemas. En el entorno español, los sistemas integrados se refieren a calidad, medio ambiente, y salud y seguridad, ya que las organizaciones españolas no han integrado totalmente la responsabilidad social todavía. Para guiar la integración de sistemas AENOR creó la UNE66177:2005.

\subsection{8.- How integrated are enviromental, quality and other standarized management systems? An empirical study - Marce Bernardo, Marti Casadesus, Stanislav Karapetovic, Iñaki Heras.}

\section{1.- INTRODUCCIÓN}

En los últimos años, muchas organizaciones han implantado Sistemas de Gestión del Medio Ambiente, y Salud y Seguridad para mejorar su gestión.

Una pregunta que se hacen las empresas que implantan 2 o más sistemas de gestión es si implantarlos individualmente o si implantar un sistema integrado que pueda beneficiarse de las relaciones entre ellos. La definición de proceso de integración y el sistema de gestión integrado final depende de la situación de la organización y en la forma de definición de los términos. La integración se puede definir como el proceso de relación de diferentes sistemas de gestión estandarizados con recursos comunes y propósito de mejora de la satisfacción de todas las partes interesadas. 
Para realizar eta integración encontramos diferentes estrategias, siendo la más seguida la implantación previa del sistema de gestión de calidad, a otros sistemas de gestión. Los métodos del proceso de integración dependen de la decisión de la organización, aunque a nivel nacional diferentes países ya han desarrollado guías para la integración como la UNE 66177:2005 en España. Por su parte, también podemos encontrar diferentes grados de integración, que también dependerán de la organización al no haber un único modelo para todas las organizaciones. Aun así, algunos académicos han definido diferentes grados de integración.

El propósito de este artículo es analizar si los sistemas de gestión medioambientales están realmente integrados con los de calidad y con otros sistemas de gestión estandarizados. Para ello se realiza una encuesta en 435 organizaciones de Cataluña, Madrid y País Vasco al ser España uno de los países con mayor número de certificaciones de ISO 9001:2000 e ISO 14001:2004. De las 435, 75 han implantado otro sistema de gestión adicional (OHS o CSR) a los sistemas de medioambiente y de calidad. La primera pregunta es si los sistemas están integrados en un solo sistema de gestión. El 14\% no los ha integrado, el 7\% los ha integrado parcialmente y el $79 \%$ los ha integrado totalmente. Después de esta pregunta se hacen otros tres grupos de preguntas relacionadas con la integración de los recursos humanos, los resultados y la documentación, y los procesos y procedimientos.

\section{2.- RESULTADOS}

\section{Generales}

Los resultados observados corresponden al $86 \%$ de las organizaciones que han integrado sus sistemas parcial o totalmente. La mayoría los ha integrado totalmente. Encontramos un alto porcentaje de organizaciones que han integrado sus sistemas en diferentes aspectos, pero no en recursos humanos. Por otra parte, con respecto a las metas y documentación la mayoría de las organizaciones ha integrado totalmente sus factores con un porcentaje alto para la política de la organización (78\%), objetivos (73\%) y manuales (82\%) que para los procedimientos, instrucciones y archivos. Estos resultados indican que los recursos de documentación que se integran primero son los relacionados con las áreas estratégicas de los sistemas, antes que las áreas relacionadas con las operaciones. Por último se observan cinco aspectos de los procedimientos integrados totalmente, las auditorías internas, revisión de la gestión, control de documentos, control de archivos y comunicación interna. Los procedimientos relacionados con la realización del producto son los menos integrados, mientras que los procedimientos relacionados con la medida, análisis y mejora son los de mayor nivel de integración. Lo mismo ocurre con los recursos humanos, siendo los procedimientos relacionados a los procesos operativos los menos integrados. 


\section{Integración parcial o total}

Los aspectos importantes para las organizaciones que han integrado sus sistemas parcialmente son: aparte de la política de la organización, con respecto a los procedimientos, el control de documentos, acciones preventivas y correctivas, control de disconformidades, control de archivos y mejora. La mayoría están relacionados con el capítulo 4 (Sistemas de Gestión de la calidad), y 8 (Medición, análisis y mejora) de la ISO 9001:2000. Así vemos como las organizaciones se enfocan hacia las áreas estratégicas más que a las áreas operacionales.

Con respecto a las organizaciones con integración total, las variables más integradas son las relacionadas con los procedimientos: procedimientos, política, manual y archivos.

En los dos casos hemos visto como las variables relacionadas a los recursos humanos forman parte de las variables más integradas, lo que indica que la integración de los recursos humanos no afectará al nivel de integración de los sistemas.

\section{Clasificación grupal}

Las organizaciones se dividen en 3 grupos con respecto a su nivel de integración de metas y documentación, y nivel de integración de procedimientos:

\section{GRUPO 1}

El 2\% están en este grupo, que tiene parcialmente integradas las metas, documentación y procedimientos. Los aspectos de estas organizaciones no pueden ser definidos, ya que se comportan de diferentes maneras. Las metas y documentación tienen un nivel de integración del 29\%, mientras que los procedimientos están a un nivel del 56\%. Esto nos puede indicar que estas organizaciones prestan más atención a la integración de los procedimientos que ha las metas y documentación.

Los documentos más integrados son: procedimientos (50\%), política de sistema (37\%), e instrucciones operativas (33\%). Los objetivos tienen un 25\%, los registros un 13\%, y los elementos menos integrados será el manual de sistemas de gestión.

Para los procedimientos específicos, el mayor nivel de integración es para la revisión de la gestión (94\%).,gestión de los recursos y comunicación interna (81\%), y control de documentos $(69 \%)$ Los demás procedimientos tienen un nivel de integración menor al $45 \%$.

\section{GRUPO 2}

En este grupo se encuentran el $11 \%$ de las organizaciones, en el que los procedimientos (66\%) están mínimamente más integrados que la documentación y las metas (62\%). A pesar de ello se observa que las metas, la documentación de los recursos y procedimientos está integrada a un nivel mayor del $62 \%$. 
En relación a las metas y documentación los elementos más integrados serán política $(78 \%)$, objetivos $(66 \%)$, y manual $(67 \%)$, mientras que los procedimientos tienen un $58 \%$, las instrucciones un 55\% y los archivos un 53\%. Estos resultados indican que las organizaciones de este grupo comienzan la integración con los aspectos estratégicos.

Con respecto a los procedimientos, los más integrados son la comunicación interna (74\%), auditorías internas (71\%), revisión de la gestión, gestión de los recursos y control de documentos (70\%), y mejora y control de archivos (66\%).

\section{GRUPO 3}

El $87 \%$ de las organizaciones forman parte de este grupo. Estas organizaciones tienen un nivel de integración del $86 \%$ para la documentación, y un $96 \%$ para los procedimientos.

Los aspectos más integrados para las metas y documentación son la política y objetivos (87\%) y el manual (94\%). Los documentos procesales tienen un $86 \%$ y las instrucciones y los archivos un $78 \%$.

Con respecto a los procedimientos, los elementos más integrados son los documentos y el control de los archivos (99\%), auditorías internas, comunicación interna, y acciones preventivas y correctivas (97\%), revisión de la gestión y mejoras (96\%) y control de disconformidades $(95 \%)$.

\section{3.- CONCLUSIONES}

La mayoría de organizaciones encuestadas muestran un nivel de integración a diferentes niveles ( $86 \%$ de las organizaciones). Esto niveles de integración se observan mediante la evaluación de los 3 grupos anteriormente comentados.

Estas organizaciones siguen un patrón de integración, siendo la documentación y los procedimientos los aspectos de más importancia. Comienzan por la integración de los aspectos más estratégicos de las metas, documentación y procedimientos para seguir después con los aspectos operacionales.

Por último se observa el rol que toma el personal involucrado en la integración de sistemas. En este estudio, la variable no es significante tanto para la integración parcial como para la total. No hay diferencias debido a la involucración del personal en la integración. La responsabilidad de la gestión del medio ambiente y la calidad a menudo está en manos de la misma persona estén o no integrados sus sistemas, o por otra parte dos personas manejen el sistema integrado. 


\subsection{9.-Integrating Management Systems: A dinámic study of Spanish firms - Alexandra Simon, Stanislav karapetovic, Marti Casadesus. \\ 1.- INTRODUCCIÓN}

Entre 2006 y 2009 el número de certificaciones de ISO 9001 e ISO 14001 ha aumentado considerablemente. Con el propósito de observar el impacto y la evolución en el tiempo de la integración de sistemas en diferentes organizaciones se realizan dos encuestas, una en 2006 y otra en 2010 , en organizaciones catalanas. 176 responden a la primera y 76 a la segunda. Para obtener los resultados se realizan preguntas sobre el nivel de integración, el uso de guías de integración, las dificultades de integración y la auditoría de integración.

\section{2.- RESULTADOS}

\section{Nivel de integración}

Se pueden observar 3 niveles de integración: no integración, integración parcial e integración total. El nivel de no integración crece de un $11 \%$ a un $16 \%$, mientras que la integración total crece de un $42 \%$ a un $62 \%$ entre 2006 y 2010. El nivel de integración parcial decrece de un $47 \%$ a un $22 \%$. La mayoría de las organizaciones que cuentan con múltiples sistemas los han integrado, incluyendo esta integración los sistemas habituales (QMS, EMS y OHS). Estos resultados nos indican que las organizaciones han optado por dos extremos, la integración total de sus sistemas (han percibido los beneficios de la integración) o no integrar ninguno de ellos (han encontrado dificultades en la integración). El nivel de integración es mayor en 2010 por lo que las compañías con más de un sistema de gestión prefieren la integración a la desintegración.

\section{Recursos involucrados en los diferentes sistemas de gestión}

Un sistema de gestión integrado puede ser conceptualizado como un conjunto de tres elementos que pueden ser integrados: recursos (recursos humanos), metas y procesos (documentación de recursos y metas).

Con respecto a los recursos humanos, tanto en 2006 como en 2010, el nivel de integración es mucho mayor en la gestión de la alta dirección que en el nivel del personal. Por otra parte los resultados indican un aumento del 5\% en el nivel funcional (managers de sistemas de gestión), mientras que encuentran un aumento del $20 \%$ en el nivel del personal (inspectores). Esto indica que el nivel de integración de los dos tipos de recursos humanos se aproxima al nivel de integración en la gestión.

En este periodo, solo los managers e inspectores de los sistemas de gestión encuentran diferencias significantes en la gestión de los recursos humanos, considerando un mayor nivel de integración en 2010 para los dos tipos de recursos humanos. 
Con respecto a la integración de la documentación de los recursos encontramos los siguientes resultados. La mayoría de organizaciones muestran una única política , con un conjunto de objetivos y un manual de sistemas de gestión, tanto en 2006 como en 2010. Con respecto a los resultados de 2006, el nivel de integración disminuye, moviéndose hacia los niveles operacionales y tácticos de la organización. A pesar de esto, el uso de registros integrados, instrucciones o procedimientos aumenta del $50 \%$ al 75\%.Por su parte el nivel de integración de objetivos, procedimientos y registros, también es mayor en 2010.

Uno de los aspectos más importantes es que las variables más significativas son las relacionadas con los niveles operacionales y tácticos de la organización (objetivos, procedimientos y registros), ya que experimentan un mayor aumento que las variables estratégicas como la política o el manual.

Con respecto a los procedimientos de los sistemas de gestión se encuentran altos niveles de integración en ambos años, siendo el control de documentos, y las acciones preventivas y correctoras, siendo los aspectos relacionados a la realización del producto y auditorías los menos integrados. En general la integración de los procedimientos ha aumentado en este periodo, estando todos los procedimientos al menos integrados al $60 \%$. Hay que reseñar el aumento en el nivel de la integración de las auditorías internas que era el segundo aspecto menos integrado en 2006 y pasa a ser unos de los más integrados en 2010 con un nivel de $80 \%$. Los resultados indican la importancia de las auditorías internas y su integración debido a los beneficios relacionados con ellas.

Diferencias significantes para los procedimientos se observan para la planificación, el control de las disconformidades, acciones correctivas y preventivas, la realización del producto, la mejora y los requerimientos, cuyo nivel de integración es mayor en 2010. Los resultados indican que los procedimientos relacionados con la realización del producto y la medición análisis y mejora, son los aspectos que experimentan un mayor aumento en el nivel de integración.

\section{3.- CONCLUSIONES}

La primera conclusión es que la mayoría de compañías con más de un sistema de gestión optan por integrarlos en un solo sistema. La mayoría integran sus sistemas u optan por la no integración, bajando el número de organizaciones que integra sus sistemas parcialmente.

Con respecto a los recursos humanos, solamente los managers e inspectores encuentran diferencias del 2006 al 2010, recayendo la responsabilidad de manejar los sistemas en una misma persona.

Con respecto a los procedimientos, se observa un aumento en la integración de la planificación, el control de las disconformidades, las acciones correctivas y preventivas, la realización del producto, la mejora y la determinación de los requerimientos de las partes interesadas. 
Por último, la documentación de los recursos y las metas tiene diferentes niveles de integración, con un aumento del nivel de los objetivos en 2010.

\subsection{0.- Integrated management systems: experiences in Italian organizations - Roberta Salomone}

\section{1.- INTRODUCCIÓN}

Los integración de sistemas de gestión está pasando a ser cada vez más importante, pero la implantación de un sistema integrado puede variar a través de regiones, tamaño de las organizaciones y sectores. El presente estudio investiga los aspectos que afectan a ala integración, en términos de motivaciones, obstáculos y presiones externas que las compañías encuentran al implantar ISO 9001, ISO 14001 y OHSAS 18001. Se observan las relaciones entre QMS, EMS, OHSMS, y SRMS en las operaciones de compañías italianas y se analizan las actividades de gestión que se integran en las actividades de las compañías. Estas empresas italianas tienen las siguiente características: obtención de las certificaciones ISO 9001, ISO 14001 y OHSAS 18001, principalmente del sector de la industria y parte en servicios, la mayoría en el norte de Italia, principalmente pequeñas o medianas empresas, y que operan en contextos europeos e internacionales.

\section{2.- RESULTADOS}

\section{Motivaciones y obstáculos al sistema de gestión de calidad.}

Las motivaciones que llevan a las empresas a adoptar un sistema de gestión de la calidad son : mejora continua (77\%), mejora de imagen (74\%), la oportunidad de tener una vantaja competitiva (58\%), ser capaz de encontrar oportunidades de mercado (45\%), ser capaz de realizar mejoras en los productos $(41 \%)$, y reducir los costes de gestión (30\%). Los obstáculos encontrados son mayoritariamente organizacionales (85\%), también relacionados con los altos costes de implantación del sistema de gestión de calidad (23\%), y la falta de recursos humanos competentes (22\%).

En lo que se refiere al sector, la presión del consumidor influye más en el sector de la manufactura que en los demás. Por su parte, las pequeñas y medianas empresas tienen como motivación la mejora continua y la mejora de la imagen, mientras que aparte de los obstáculos organizacionales las pequeñas empresas también encuentran el obstáculo del alto coste de la implantación del sistema, y un inadecuado apoyo financiero.

Por último se observa la certificación de los productos. El $69 \%$ no tiene marcas de calidad para sus productos, el $15 \%$ cuenta con certificación obligatoria y el $8 \%$ obtiene tanto la certificación obligatoria como la voluntaria. 


\section{Motivaciones y obstáculos a sistema de gestión ambiental}

Las motivaciones principales de las empresas para adoptar un EMS son: mejora de la imagen (80\%), y mejora continua (74\%). Otras son la competitividad en el mercado (37\%), explotar nuevas oportunidades de mercado (32\%), y reducción de costes de gestión (28\%). En lo que se refiere a los obstáculos, el $11 \%$ no encontró ningún obstáculo (principalmente empresas manufactureras del norte y de pequeño o medio tamaño). Por otra parte el $41 \%$ encontró obstáculos organizacionales, escasez de recursos humanos competentes (33\%) y alto coste de implantación del EMS (28\%).

Las diferencias más importantes se encuentran en el tamaño de la empresa, ya que para las microempresas encuentran sus mayores motivaciones en las nuevas oportunidades de mercado, seguido de mayor competitividad y mejora continua. En lo que se refiere a los obstáculos, mientras las grandes empresas encuentran obstáculos organizacionales, las microempresas tienen como mayores obstáculos los costes de implantación y la falta de información, y las medianas empresas encuentran obstáculos en la falta de recursos humanos competentes.

La investigación también revela otros aspectos: Aparte de la ISO 14001 las organizaciones también han obtenido la regulación EMAS, $99 \%$ son conscientes de los impactos ambientales asociados con sus operaciones de producción, 94\% vigilan los principales impactos ambientales de sus productos como parte de su sistema operativo, el $84 \%$ piensan que el sistemas puede promocionar innovación medioambiental para los productos, y el $38 \%$ afirma que a adoptado diferentes tipos de herramientas de gestión ambiental adicionales al EMS.

\section{Motivaciones y obstáculos al sistema de salud y seguridad}

Las motivaciones principales en la implantación de un sistema de salud y seguridad son: la mejora continua (83\%), y la mejora de la imagen (76\%). Otras razones son la mejora de la competitividad (27\%), reducción de costes (25\%), nuevas oportunidades de mercado (19\%) y mayor productividad (15\%). En lo que se refiere a los obstáculos se observan como principales lo obstáculos organizacionales (47\%). Otros son los altos costes (26\%), dificultar de encontrar recursos humanos competentes (24\%), y falta de información $(18 \%)$.

Para todos los sectores la mejora continua y la mejora de la imagen son las motivaciones predominantes, y para todo tamaño la mejora de la competitividad y la mejora continua. En relación a los obstáculos, las empresas de servicios encuentran mayores obstáculos en la falta de recursos humanos, mientras que las pequeñas empresas encuentran más obstáculos que las grandes empresas respecto a recursos humanos, costes e inadecuado apoyo financiero. 


\section{Motivaciones y obstáculos de los sistemas de responsabilidad social}

Solamente el 12\% de las empresas tienen certificación SA 8000, siendo principalmente empresas del norte, de la industria manufacturera y grandes empresas. Sus motivaciones son la mejora continua (80\%), mayor competitividad en el mercado (33\%) y nuevas oportunidades de mercado (20\%). Con respecto a los obstáculos el $27 \%$ no encuentra obstáculos, mientras que los obstáculos encontrados por las demás son dificultades organizacionales (36\%), escasez de información en la norma (27\%), falta de recursos humanos competentes $(18 \%)$.

\section{Sistemas integrados de gestión}

El análisis de los aspectos comunes en motivaciones y obstáculos en cada uno de los sistemas de gestión pone en evidencia que los factores que influyen al sistema integrado de gestión serán el mercado (consumidor, imagen y competitividad), los recursos humanos (reducción de la falta de conocimiento y dificultades en la gestión), y la mejora continua basada en el ciclo de Deming.

En esta investigación, el $73 \%$ de las empresas han integrado totalmente varios aspectos de QMS, EMS y OHSMS, y el 26\% declara que ha logrado una integración parcial. Esta integración se relaciona a las 3 normas (ISO 9001, OHSAS 18001, ISO 14001) para el $87 \%$ de las empresas, a la ISO 14001 y OHSAS 18001 para el 12\%, y a la ISO 9001 y OHSAS 18001 para el $1 \%$.

La integración de sistemas para la mayoría de las empresas (90\%) es debida a la conveniencia interna: derivada en primera instancia por la afinidad entre las normas, en segundo lugar para algunas empresas la integración evoluciona espontáneamente debido al trabajo del mismo personal en los diferentes sistemas, mientras que para otras empresas que tienen diferentes equipos para los sistemas de gestión se necesita organizar reuniones y asignar funciones y responsabilidades a los miembros específicos del personal. Para el $13 \%$ de integración fue una consecuencia de la presión de los organismos de certificación, mientras solo el $2 \%$ cita la presión del consumidor o los proveedores.

Los beneficios más destacados son la optimización y unificación de las auditorías tanto interna como externa (78\% y 65\%), reducción de documentación (69\%), y en general ahorro de tiempo, dinero y trabajo. El mayor obstáculo es el riesgo de no atribuir el nivel de importancia correcto a cada variable de calidad, medioambiente y seguridad (48\%), y la dificultad en la organización de un sistema de gestión integrado (46\%). El 10\% de las empresas que han integrado sus sistemas no han identificado obstáculos.

Por otra parte las empresas que han integrado sus sistemas han tomado medidas para activar los procesos unificados para el control y gestión de la documentación, lo que indica que el resultado principal que las empresas desean lograr con un sistema integrado de gestión es la reducción de la documentación y el control de los procedimientos de los 3 sistemas. El alto porcentaje asignado a otras actividades integradas refleja el deseo de las 
empresas de reducir los costes y el tiempo en la gestión de los 3 sistemas, y unificar estrategias relacionadas con las variables de los tres sistemas que puedan mostrar confusión.

\section{3.- CONCLUSIONES}

El número de empresas con más de una norma certificada está aumentando y muchas de ellas han optado por su integración. Para ello algunos países ya han desarrollado guías de integración.

Los resultados observados indican que tanto el área geográfica como el sector de la empresa tienen influencia en los beneficios y obstáculos para la integración de sistemas, pero el factor estructural de la empresa con más influencia es su tamaño.

Por último, el estudio también revela que la integración de sistemas de gestión evoluciona espontáneamente

\subsection{1.- Applying quality award criteria in R\&D Project assessment - V.Ojanen, , P. Piippo, M. Tuominen}

\section{1.-INTRODUCCIÓN}

La aplicabilidad de la Gestión de Calidad Total y los criterios de los premios a la calidad en la evaluación del proceso de I+D+i, es muy difícil. Este estudio se concentra en la aplicación de los criterios del MBNQA en la evaluación de proyectos de $\mathrm{I}+\mathrm{D}+\mathrm{i}$.

El significado de diferentes criterios de MBNQA son analizados desde el punto de vista de las actividades de $\mathrm{I}+\mathrm{D}+\mathrm{i}$ y proyectos individuales. Las medidas, los criterios de rendimiento y concretos aspectos medibles para la evaluación de un proyecto de $\mathrm{I}+\mathrm{D}+\mathrm{i}$ son derivados del análisis. Más tarde se discute la aplicabilidad de las medidas derivadas para la evaluación de proyectos de $\mathrm{I}+\mathrm{D}+\mathrm{i}$ desde el punto de vista de una compañía manufacturera que ha aplicado con éxito los criterios del Premio Nacional Finlandés a la Calidad (mismos criterios que el MBNQA más responsabilidad pública y efectos medioambientales). Esta empresa es Valtra Inc. (quinta manufacturera de tractores en el mundo).

El propósito principal del estudio es la promoción efectiva de la gestión de la I+D+i mediante la utilización de un análisis sistemático basada en MBNQA para lograr un mejor entendimiento del significado de cada área del MBNQA en la evaluación de la I+D+i como conjunto y como proyecto individual, así como para proponer nuevos temas de medición y métodos de evaluación para proyectos de $\mathrm{I}+\mathrm{D}+\mathrm{i}$. 
Este estudio también ofrece ejemplos de las nuevas medidas derivadas para proyectos de I+D+i gracias a MBNQA y las compara con las necesidades de nuestro caso de estudio (Valtra Inc).

\section{2.- RESULTADOS}

En este apartado se observa el análisis de la aplicación del MBNQA para la evaluación de proyectos de $\mathrm{I}+\mathrm{D}+\mathrm{i}$. Para obtener nuevas medidas para los proyectos de $\mathrm{I}+\mathrm{D}+\mathrm{i}$ se realiza el proceso que se ve en el siguiente cuadro.

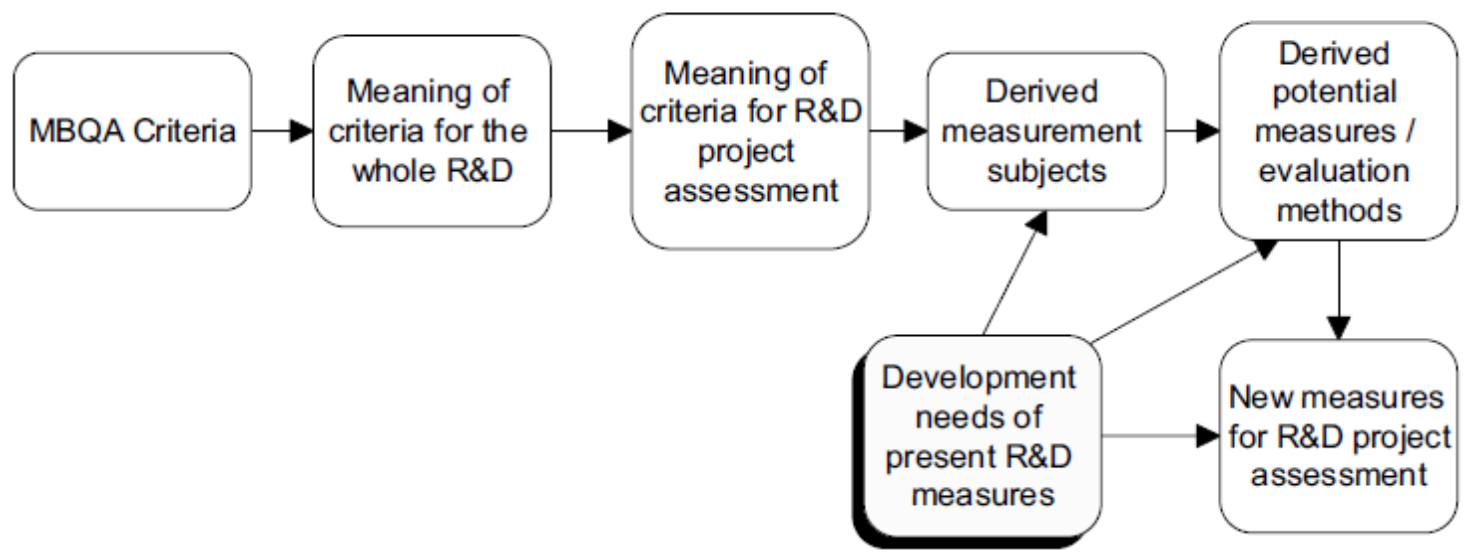

Figura 49 Fases del proceso de obtención de las nuevas medidas para proyectos de I+D+i.

Las medidas derivadas del modelo de calidad, son comparadas con las necesidades de desarrollo de la empresa para encontrar las medidas más aplicables a la evaluación de proyectos de I+D+i.

Valtra necesita nuevas medidas tanto a nivel de proyectos como a nivel de funciones, para apoyar un desarrollo continuo de la efectividad de la $\mathrm{I}+\mathrm{D}+\mathrm{i}$ y sus procesos. A nivel de proyectos, nuevas medidas son necesarias para clarificar el cumplimiento de los objetivos del proyecto, las especificaciones y necesidades de los clientes, así como a la eficacia de la ejecución y creación de nuevas soluciones innovadoras. Buenas medidas para clarificar el cumplimiento de los objetivos del proyecto, lo que necesita el consumido y las especificaciones son:

- La cantidad de necesidades de los clientes y las solicitudes se indican en encuestas avanzadas ejecutadas a los clientes.

- La cantidad de funciones que los clientes consideran como propias.

- El desempeño en las encuestas de satisfacción del cliente.

- La cantidad de contactos entre clientes clave, empresas de ventas y personal del proyecto.

- Proporción de resultados previstos de los proyectos con respecto a los objetivos de la empresa y su I+D+i.

- Proporción de especificaciones cumplidas en parte o totalmente. 
El presente valor neto del proyecto dividido por sus horas totales de trabajo y el desarrollo de los objetivos, así como los tiempos de entrega de las diferentes fases del proceso de producción en diferentes proyectos podrían ser medidas útiles para seguir la efectividad y la eficiencia de los proyectos. La calidad de la información de entrada podría aclarar las razones de los cambios de las especificaciones.

La innovación y el aprendizaje son aspectos de difícil medida, pero también son cada vez más importantes para el éxito de Valtra. Posibles nuevas medidas definidas en el proceso de derivación para Valtra son:

- Proporción de personal que ha producido nuevas ideas con respecto a la cantidad total de personal que trabaja en el proyecto.

- Proporción de ideas realizadas con respecto a la cantidad total de ideas presentadas en el proyecto.

- Porcentaje entre las áreas conocimiento/competencia y conocimientos disponibles en el proyecto.

- Evaluación de las competencias críticas antes y después del proyecto.

- Número de días que se trabaja conjuntamente con el cliente (por ejemplo en granjas).

\section{3.-CONCLUSIONES}

El propósito de esta investigación es el estudio de la aplicación de un modelo de calidad en la valoración de proyectos de $\mathrm{I}+\mathrm{D}+\mathrm{i}$ mediante la combinación de teoría y práctica, de modo que se deriven nuevos indicadores con la ayuda de un análisis de enfoque sistemático.

Tipos similares de nuevos indicadores para la evaluación del rendimiento de los proyectos son derivados del análisis de distintas categorías del MBNQA. Adicionalmente a los métodos comunes de evaluación, nuevos indicadores son el resultado de este análisis.

El proceso de derivación ayuda a la creación de medidas comunes para el nivel de proyectos y el nivel funcional, y aumenta el entendimiento de las relaciones entre estos niveles. Los indicadores que pueden ser utilizados para ambos niveles, pueden controlar el conjunto total de medidas de la compañía para I+D+i. 


\subsection{2.- The effect of TQM on performance in $R \& D$ environments: $A$ perspective from South Korean firms}

\section{1.- INTRODUCCIÓN}

En los años 1990s las compañías americanas comenzaron a observar que los principios de la gestión de la calidad eran necesarios en la gestión de la I+D+i. Sugieren que la aplicabilidad de los principios de la gestión de la calidad es mayor en otras áreas, por lo que la aplicación de la gestión de la calidad total en I+D+i puede ser problemática. A pesar de esto, la revisión de diferentes estudios demuestra el apoyo a la aplicabilidad de la gestión de la calidad en el contexto de la $\mathrm{I}+\mathrm{D}+\mathrm{i}$, demostrando que los principios de la GCT aporta importantes beneficios a la I+D+i.

Esta investigación examina la efectividad de las prácticas de la gestión de la calidad en el contexto de la I+D+i mediante la observación de los efectos de estas prácticas en el rendimiento de la $\mathrm{I}+\mathrm{D}+\mathrm{i}$ en términos de calidad del producto e innovación del producto.

Los datos para el estudio se recogen de 130 divisiones de $\mathrm{I}+\mathrm{D}+\mathrm{i}$ de industrias manufactureras koreanas. Dos preguntas son investigadas, relacionadas con la aplicación y la efectividad de la gestión de la calidad en el contexto de la I+D+i. La primera pregunta se enfoca en la manera en la que se aplican los principios de la gestión de la calidad en las divisiones de I+D+i koreanas: ¿ Muestran multidimensionalidad las prácticas de gestión de la calidad cuando se implantan en entornos de I + D? La segunda pregunta se enfoca en las relaciones entre la gestión de la calidad total, la calidad y la innovación: ¿ Tiene la gestión de la calidad total un impacto significante en la calidad del producto y la innovación del producto?

Para obtener los resultados se utilizan como variables seis criterios del Modelo Malcolm Baldrige (liderazgo, planificación estratégica, enfoque hacia el cliente, información y análisis, gestión del personal, y gestión de procesos), la calidad del producto (fiabilidad, rendimiento, durabilidad y conformidad a las especificaciones) y la innovación del producto (nivel de novedad, uso de últimas tecnologías, número de innovaciones, rapidez de innovación y rápida entrada al mercado).

\section{2.- RESULTADOS}

En respuesta a la pregunta de investigación 1, los hallazgos sugieren que la GCT muestra una fuerte convergencia medida por sus seis prácticas lo que significa que las prácticas de GCT son implantadas en un enfoque integrado en el entorno de la I + D estudiado.

Para responder a la segunda pregunta se encuentran los siguientes resultados. La relación entre la gestión de la calidad total y, la calidad del producto, y la innovación del producto es positiva y significante. Los coeficientes indican que en el entorno de la $\mathrm{I}+\mathrm{D}+\mathrm{i}$, la gestión de la calidad total tiene una mayor relación con la innovación del producto que 
con la calidad del producto. Esto es entendible de modo que el primer enfoque de la $\mathrm{I}+\mathrm{D}+\mathrm{i}$ es la innovación. Este resultado apoya la idea de que la gestión de la calidad cuenta con principios genéricos que pueden ser ajustados al contexto de su aplicación.

Al mismo tiempo, la relación entre la calidad del producto y la innovación del producto muestra una relación fuerte y significante. Esto demuestra que lograr innovación dará lugar a calidad, y viceversa. Además de que los resultados indican el enfoque de la I+D+i hacia la innovación, también apoyan que la I+D+i no puede ignorar la calidad. La mejora de la calidad resultará en una innovación del producto, que a su vez tiene el propósito de desarrollar nuevos productos con mayor rendimiento de calidad. Esta idea promociona la integración de calidad e innovación.

Así para responder a la pregunta 2, los resultados nos indican que la gestión de la calidad total tiene un fuerte efecto en el rendimiento de la I+D+i en términos de innovación del producto y calidad del producto.

Dos implicaciones importantes se extraen de estos resultados. En primer lugar, es importante que los líderes de la $\mathrm{I}+\mathrm{D}+\mathrm{i}$ entiendan los principios de la gestión de la calidad total. Esto e importante debido a que al haber estudiado divisiones de $\mathrm{I}+\mathrm{D}+\mathrm{i}$ de industrias manufactureras, la aplicación de la gestión de la calidad en estas divisiones es parte de un largo programa de calidad implantado en la organización. Los líderes de la I+D+i deben desarrollar su propia versión de las prácticas de gestión de la calidad basadas en los principios genéricos, y no aplicarlas tal cual.

En segundo lugar, así como la GCT se debe implantar en su totalidad con el fin de producir resultados significativos, los requisitos para el éxito de su ejecución que se han destacado en la literatura también son aplicables aquí, incluyendo el compromiso a largo plazo de la alta dirección, la aceptación y el compromiso de personal, apoyo de la cultura y el pensamiento sistemático. El pensamiento sistemático es lo más importante aquí, porque ya que las divisiones de $\mathrm{I}+\mathrm{D}$ incluidas en este estudio eran parte de empresas manufactureras, su diseño de procesos tienen que ser llevado a cabo dentro de contextos de negocios particulares, que requieren la integración interfuncional.

\section{3.- CONCLUSIONES}

Los resultados nos han indicado que las practicas de gestión de la calidad se aplican de una forma integrada en el entorno de la I+D+i.

Por otra parte, los resultados también nos indican los beneficios de la aplicación de la gestión de la calidad en el entorno de la $\mathrm{I}+\mathrm{D}+\mathrm{i}$. Las practicas de gestión de la calidad tienen fuerte efecto en la calidad del producto y la calidad en la innovación, reflejando que no solo creando nuevos productos, sino que también mejorar la calidad de los productos existentes es una parte importante del esfuerzo de I + D de las empresas manufactureras. Aun así, el efecto de las prácticas de gestión de la calidad es mayor en la innovación del producto que en la calidad del producto, de acuerdo con los principales resultados 
esperados de las funciones de $\mathrm{I}+\mathrm{D}+\mathrm{i}$. En general, la implicación de estos hallazgos es que la GCT no sólo es aplicable, sino que también es eficaz en mejorar el desempeño de las funciones de I + D 


\section{9.- ARTÍ́CULO EJEMPLO}

Una vez estudiada la evolución de la calidad, sus técnicas y sistemas, y sus aportaciones en campos novedosos como por ejemplo lo Sistemas Integrados de Gestión y la I+D+i, se presenta un artículo sobre uno de los temas sobre calidad en mayor auge en las empresas españolas. Este tema será los Sistemas Integrados de Gestión, debido a la reciente implantación de estos sistemas en el ámbito empresarial español en los últimos años.

\section{SISTEMAS INTEGRADOS DE GESTIÓN Y SU SITUACIÓN EN EL CONTEXTO EMPRESARIAL ESPAÑOL}

\section{RESUMEN}

El entorno competitivo actual hace que las organizaciones, aparte de contar con un sistema de gestión de la calidad, opten por implantar otros sistemas de gestión para garantizar la rentabilidad y fiabilidad de los resultados. Debido a ello, la integración de sistemas de gestión se ha convertido en un tema cada vez más importante para las empresas que esperan obtener diversos beneficios de dicha práctica.

Las empresas que han decidido integrar sus sistemas de gestión, mayoritariamente se enfocan hacia la integración de sus sistemas de Calidad (ISO 9001), Medio Ambiente (ISO14001) y Salud y Seguridad en el Trabajo (OHSAS 18001). En el presente artículo se observan los aspectos de mayor influencia en la integración y sus beneficios (reducción de costes, reducción de documentación, etc.), así como la situación de los sistemas integrados de gestión en el entorno español y su evolución en los últimos años.

\section{INTRODUCCIÓN}

El concepto de calidad ha ido evolucionando a lo largo de los años, ampliando objetivos y variando la orientación. Se puede decir que su papel ha tomado una importancia creciente al evolucionar desde un mero control o inspección, hasta convertirse en uno de los pilares de la estrategia global de la empresa. Su filosofía proporciona una concepción global que fomenta la Mejora Continua en la organización y la involucración de todos sus miembros, centrándose en la satisfacción tanto del cliente interno como del externo. Para conseguir estos objetivos, las empresas han implantado sistemas de gestión de la calidad acordes a los Modelos de Excelencia o a la norma ISO 9001. La implantación de la norma ISO 9001 ha propiciado que las organizaciones se familiaricen con la estructura de un sistema de gestión, documentando los distintos procesos, asignando responsabilidades y formalizando registros que permitan evidenciar el funcionamiento del sistema ante terceros.

Debido al entorno competitivo actual, las empresas cuentan con sistemas de gestión relacionados a otras áreas diferentes a la calidad, como el medio ambiente, y la seguridad y 
salud en el trabajo para controlar y mejorar los aspectos de la organización relacionados con estos temas. La responsabilidad que se toma en relación a la calidad, medio ambiente, salud y seguridad ocupacional, así como la responsabilidad social es importante para la competitividad y la imagen positiva de las organizaciones (Jorgensen et al. 2006 [2]). Los tres sistemas han tenido un origen diferente, la calidad se ha desarrollado impulsada fuertemente por la competencia y la necesidad de mejorar la competitividad empresarial, la seguridad ha sido impulsada por el establecimiento de regulaciones gubernamentales y por la presión de las organizaciones sindicales, mientras que el medio ambiente lo ha hecho por la legislación y la sociedad. A pesar de ello, existen muchas similitudes entre los conceptos de gestión de la calidad, gestión ambiental y gestión de la prevención de los riesgos laborales ya que los principios de una buena gestión son los mismos, así como sus implantaciones y puntos normativos.

Así, son muchas las organizaciones que han optado por la utilización de sistemas de gestión normalizados acordes a la ISO 9001 (gestión de la calidad), OHSAS 18001 (gestión de la prevención de los riesgos laborales), e ISO14001 (gestión ambiental), para garantizar la rentabilidad y fiabilidad de los resultados. Pero contar con tres sistemas independientes de gestión supone una multiplicación de recursos y un elevado coste que obliga a las organizaciones a observar las posibilidades de integración de sus sistemas. Por ello esta necesidad de aumentar la eficacia y rentabilidad ha provocado que muchas de estas organizaciones deseen integrar sus sistemas de gestión. El objetivo de un sistema de gestión integrada de la calidad, medio ambiente y PRL es la obtención de un mejor resultado empresarial gestionando las tres disciplinas de forma integrada, es decir, integrando los sistemas que las gestionan, los procesos que los soportan y las actividades que componen los procesos.

Esta integración tiene diferentes enfoques y diferentes niveles según las características de la empresa, así como diferentes metodologías de implantación. Tanto la estrategia y la metodología de implantación, como el grado de integración depende de la organización. No hay un único modelo para todas las organizaciones (Bernardo et al. 2009 [6]). Por ello, la Asociación Española de Normalización y Certificación AENOR creó en 2005 la norma UNE 66177: "Guía para la integración de los sistemas de gestión” con el objetivo de ofrecer una ayuda a las organizaciones a la hora de elegir un modelo de integración acorde a las necesidades de la estructura de la organización y desarrollar una estrategia para la obtención de resultados óptimos. Debido a todo esto, habrá que observar las características de las empresas españolas para tener una idea más clara sobre la integración de sistemas de gestión en el contexto empresarial español.

\section{OBJETIVO}

El propósito del estudio es familiarizar al lector con la integración de sistemas de gestión. Para ello se presentan los aspectos más importantes de los sistemas a estudio, los enfoques y niveles de integración, los factores más importantes a tener en cuenta a la hora de integrar los tres sistemas, así como los beneficios esperados gracias a dicha integración. 
Por otra parte se intenta aproximar lo visto anteriormente al contexto empresarial español observando los niveles y enfoques que toman las empresas españolas con respecto a la integración, los factores de mayor influencia a la hora de integrar, así como la evolución de los Sistemas Integrados de Gestión en los últimos años.

Para conseguir estos resultados nos ayudaremos de investigaciones previas de diferentes autores sobre los sistemas de gestión y su integración, así como de las normas ISO 9001, OHSAS 18001, ISO 14001 y UNE 66177.

\section{SISTEMAS DE GESTIÓN EN LA EMPRESA}

En la actualidad, las organizaciones cuentan con diferentes sistemas de gestión para aumentar la rentabilidad y fiabilidad de los resultados. La oportunidad para una organización de demostrar a sus interlocutores de la fiabilidad de su gestión y su buen manejo de calidad, medio ambiente, la salud y la seguridad y las cuestiones sociales está estrechamente vinculada a la certificación de sus sistemas (Salomone et al. 2008 [3]) Por ello, debemos observar individualmente diferentes aspectos de las normas ISO 9001, ISO 14001, y OHSAS 18001, para más tarde pasar al estudio de su integración.

\section{Sistema de gestión de la calidad. ISO 9001}

La norma ISO 9001 se crea en el año 1987 dentro de la serie ISO 9000 y se revisa por primera vez en 1994. Estas dos ediciones se basan en el aseguramiento de la calidad, y contaban con un sistema que se centró en permitir a las empresas producir la misma calidad de los productos especificando las políticas, procedimientos e instrucciones de un manual de calidad. El cambio llega con la edición ISO 9001 del año 2000, debido a su fuerte enfoque hacia el cliente y la mejora continua. Promueve la adopción de un enfoque basado en procesos cuando se desarrolla, implementa y mejora la eficacia de un sistema de gestión de la calidad, para aumentar la satisfacción del cliente mediante el cumplimiento de sus requisitos (ISO 9001:2008 [17]). Por último se encuentra la revisión del año 2008, que no incorpora nuevos requisitos, sino cambios para aclarar los requisitos ya existentes en la Norma ISO 9001, de la versión 2000. Así como el cambio de ISO 9001:1994 al ISO 9001:2000 fue tan fuerte y resultó de gran impacto para aquellas organizaciones que deseaban migrar del 94 al 2000, esta evolución al 2008 no implica severos cambios. No se encuentran más que algunos de forma y otros tantos que específicamente lo que intentan es alinear más al ISO 9001 con el famoso y ecológico ISO 14001:2004. La ISO 9001 está escrita de manera que sirva a todo tipo de organizaciones, independientemente se su estructura, sector, etc, y adapte su sistema de gestión de la calidad a sus necesidades, y se basa en 8 principios: enfoque al cliente, liderazgo, participación del personal, enfoque basado en los procesos, enfoque del sistema para la gestión, mejora continua, enfoque basado en hechos para tomar decisiones, y relaciones mutuamente beneficiosas con el proveedor. 
Muchos estudios se han centrado en observar las razones para la implantación de un sistema de gestión de la calidad acorde a la ISO 9001. Para D. Aggelogiannopoulos, "los resultados de diferentes estudios indican que las razones más importantes a la hora de implantar la ISO 9001 son las demandas de los clientes y del mercado, las necesidades de mejora continua en el proceso o los sistemas, el deseo para el despliegue global y la falta de concentración dentro de la organización ( Aggelogiannopoulos et al. 2006 [1]). Por otro lado Roberta Salomone observa las motivaciones y obstáculos para su implantación. Las principales motivaciones que llevan a una organización a implantar un sistema de gestión de la calidad son la, mientras los obstáculos se relacionan a los altos costes de implantación, la falta de recursos humanos competentes y obstáculos organizacionales (Salomone et al. 2008[3]).

Por todo esto en el año 2010 encontramos que la ISO 9001 cuenta con 1109905 empresas registradas en 178 países, con un crecimiento de 212976 certificaciones con respecto al 2006. (ISO Survey 2010 [20])

\section{Sistemas de gestión ambiental. ISO 14001}

En los últimos años muchas organizaciones han optado por implantar sistemas de gestión ambiental. Por ello se crea la norma ISO 14001 en el año 1996 y se revisa posteriormente en el 2004. Esta Norma Internacional especifica los requisitos para un sistema de gestión ambiental que le permita a una organización desarrollar e implementar una política y unos objetivos que tengan en cuenta los requisitos legales y la información sobre los aspectos ambientales significativos. Es su intención que sea aplicable a todos los tipos y tamaños de organizaciones y para ajustarse a diversas condiciones geográficas, culturales y sociales. El objetivo global de la ISO 14001 es apoyar la protección ambiental y la prevención de la contaminación en equilibrio con las necesidades socioeconómicas (ISO 14001: 2004 [18]). Los cambios que establece la versión del 2004 son menores, teniendo relación a mejorar la coherencia con la ISO 9001, mayor enfoque hacia el cumplimiento de reglamentos y demás disposiciones ambientales, obtención de objetivos y metas medibles, y la descripción de la revisión del sistema punto por punto.

La ISO 14001 muchas veces es implantada paralelamente o consecutivamente en organizaciones que ya cuentan con otro sistema de gestión estandarizado, que suele ser un sistema de gestión de la calidad basado en la ISO 9001. Los mayores beneficios de la ISO 14001 son la protección del medio ambiente, cumplimiento de la normativa,el avance en calidad de vida dentro y fuera de la empresa, uso racional de los recursos, y la prevención de los riesgos medioambientales. (G.Santos et al. 2011 [5]). Para Salomone et al [3], las motivaciones de una organización a la hora de implantar un sistema de gestión ambiental son principalmente la mejora de la imagen y la mejora continua, mientras también se observan otras como la mayor competitividad del mercado, exploración de nuevas oportunidades de mercado, reducción de costes de gestión, además de la posibilidad de 
vigilar constantemente el cumplimiento de la legislación ambiental y un verdadero deseo de proteger el medio ambiente. En relación a los obstáculos Salomone encuentra que la mayoría tienen que ver con aspectos organizacionales, falta de recursos humanos competentes y el alto coste de la certificación.

Por todo esto en el año 2010 encontramos que la ISO 14001 cuenta con 250972 empresas registradas en 155 países, con un crecimiento de 122761 certificaciones con respecto al 2006. (ISO Survey 2010 [20])

\section{Sistema de gestión de seguridad y salud ocupacional. OHSAS 18001}

La OHSAS 18001 se publica en 1999 en respuesta a la demanda de los clientes por una norma reconocible para el Sistema de Gestión en Seguridad y Salud Ocupacional contra el cual sus sistemas de gestión puedan ser evaluados y certificados, y posteriormente se revisa en el 2007. Esta norma OHSAS especifica requisitos para un sistema de gestión S\&SO para permitir a una organización desarrollar e implementar una política y objetivos que toman en cuenta requisitos legales e información acerca de los riesgos S\&SO. El propósito principal de esta norma OHSAS es soportar y promover las buenas prácticas S\&SO, en balance con las necesidades socio-económicas (OHSAS 18001:2007 [19]). Los cambios principales de la edición de 2007 con respecto a la previa edición son los siguientes: ahora pone un gran énfasis en la importancia de la "Salud", mejora significativa en el alineamiento con ISO 14001 a lo largo de la norma, y compatibilidad mejorada con ISO 9001, y OHSAS 18001 se refiere a si mismo como una norma lo que refleja el incremento de la adopción de OHSAS 18001 como base para estándares nacionales sobre Sistemas de Gestión de Seguridad y salud ocupacional.

Las organizaciones encuentran diferentes beneficios y obstáculos ante la implantación de un sistema de gestión de seguridad y salud ocupacional. Los tres beneficios más significativos son la disminución de la siniestralidad laboral, el cumplimiento de la legislación y el fomento de una cultura preventiva. Para Salomone et al [3] las motivaciones que encuentran las empresas para su implantación son la mejora continua, la mejora de la imagen, mayor competitividad, reducción de costes de gestión, nuevas oportunidades de mercado, mayor productividad y mejora de los productos, mientras que la mayoría de obstáculos son de carácter organizacional, dificultades para encontrar recursos humanos competentes, escasez de información e inadecuado apoyo financiero.

Por todo esto en el año 2010 encontramos que la OHSAS 18001 cuenta con 54357 empresas registradas en 116 países, con un crecimiento de 50459 certificaciones con respecto al 2003. (OHSAS certificates survey results [21]). 


\section{INTEGRACIÓN DE SISTEMAS DE GESTIÓN: ASPECTOS A TENER EN CUENTA Y BENEFICIOS}

La implantación de las normas ISO 9001, ISO 14001 y OHSAS 18001 por separado en la organización tiene como resultado una documentación excesiva y altos costes para la organización, por lo que se pierde mucho es mucho esfuerzo a la hora de desarrollarlos e implantarlos. Por otro lado, los sistemas de gestión de la calidad, medio ambiente, y seguridad y salud ocupacional cuentan con muchos aspectos similares como procedimientos, documentación, auditorías, etc. Por estas razones los sistemas integrados de gestión están siendo implantados en muchas organizaciones para obtener rentabilidad y fiabilidad en sus resultados.

Un sistema integrado de gestión aúna todos los componentes de gestión de cada uno de los sistemas a integrar, en un sistema coherente con el fin de facilitar el logro de sus objetivos y misiones. La integración provoca que los diferentes sistemas de gestión trabajen conjuntamente, compartiendo información, e implantando un único sistema de gestión para toda la organización. Así podemos resumir la integración como un proceso que relaciona diferentes sistemas de gestión normalizados para crear un único sistema de gestión con recursos comunes destinado a mejorar la satisfacción tanto de toda la organización como de los clientes (Bernardo et al. 2009 [6]). Por su parte definiremos un sistema integrado de gestión como "un conjunto formado por la estructura de la organización, las responsabilidades, los procedimientos, los procesos y los recursos que se establecen para llevar a cabo la gestión integrada de los sistemas (UNE 66177:2005 [22] )".

Esta integración provoca muchos beneficios tanto económicos como organizacionales. Por ello la integración de sistemas de gestión puede llegar a ser una de las principales estrategias para la supervivencia de las organizaciones en el S.XXI. (Zutshi et al. 2005 [8]).

\section{Estrategia, métodos y nivel de integración}

Los primeros aspectos que se deben estudiar son la estrategia, el método y el nivel de integración. Los tres aspectos dependen de la estructura de la organización así como de sus necesidades. Según la literatura no hay un único modelo de integración, aunque los académicos han definido diferentes estrategias, método y niveles para la integración de los sistemas de gestión.

La estrategia depende del tipo de sistemas que la organización pretende integrar y de su secuencia de implantación. Karapetovic y Wilborn [9] observan las opciones para la integración de un sistema de gestión de la calidad y un sistema de gestión ambiental. Para estos autores, se puede implantar primero el sistema de gestión de calidad y luego el ambiental, primero el ambiental y luego el de calidad, o los dos simultáneamente. Para la 
integración de más de dos sistemas Karapetovic y Jonker [11] se basan en la opción de integrar primero el sistema de gestión de la calidad y segundo el sistema de gestión ambiental:

1- Integrar el sistema de gestión de la calidad y otro sistema basado en el enfoque hacia los procesos.

2- Integrar el sistema de gestión ambiental y otro sistema de gestión basado en el modelo PDCA y,

3- Enlazar, alinear e integrar las funciones específicas de los sistemas de gestión.

La mayoría de investigaciones en diferentes países hacen que veamos como la opción más usada es la integrar primero el sistema de gestión de la calidad, para más tarde integrar el sistema de gestión ambiental y otros sistemas de gestión como el de seguridad y salud ocupacional.

Por su parte también encontramos diferentes metodologías de implantación que dependen de la decisión de la organización. No existe una norma internacional que nos guíe a la hora de elegir un método de implantación la ISO publicó un libro llamado "The Integrated Use of Management System Standars" para proponer referencias sobre metodologías. Por otra parte a nivel nacional, muchos países han desarrollado guías de integración : En España nos encontramos con la "UNE 66177: Guía para la integración de los sistemas de gestión”, desarrollada en 2005. Esta norma proporciona directrices para desarrollar, implantar y evaluar el proceso de integración de los sistemas de gestión de la calidad, gestión ambiental y gestión de la seguridad y salud en el trabajo, de aquellas organizaciones que han decidido integrar total o parcialmente dichos sistemas en busca de una mayor eficacia en su gestión y de aumentar su rentabilidad, ayuda al equipo directivo a diseñar e implementar un sistema integrado de gestión e identificar los métodos y herramientas aplicables durante la implementación de un sistema integrado de gestión.(UNE 66177:2005 [22]).

En lo que se refieren al nivel de integración, muchos estudios han observado diferentes niveles ( Jorgensen et al. 2006 [2], Wilkinson and Dale 1999 [12], etc). Para Karapetovic (2003 [10]), se definen dos niveles de interación:

- Integración parcial: que puede ir desde una simple colaboración al alineamiento y armonización de los objetivos, procesos y recursos de los sistemas de gestión independientes.

- Integración total: en la que los sistemas de gestión pierden sus identidades únicas, dando como resultado la integración completa a un único sistema de gestión integrado. 


\section{Elementos a integrar}

En el proceso de integración nos encontramos con diferentes elementos que deben ser integrados para obtener la integración completa de los sistemas de gestión.

El primer elemento a integrar serán las metas de la organización. Estas metas dependen la política y los objetivos de la organización. Para una correcta integración, la política y los objetivos de la organización deben de ser comunes para todos los sistemas de gestión y este es el primer aspecto que se necesita integrar. (Karapetovic y Wilborn 2003 [9]).

El segundo elemento de integración será los recursos humanos. El aspecto más importante de la integración de recursos humanos consiste en saber quién tiene la responsabilidad de manejar los diferentes sistemas de gestión, es decir, si las responsabilidades caen sobre una misma persona o sobre más de una (Bernardo et al 2009 [6]). Si los responsables de los sistemas de gestión coinciden en una misma persona se evita duplicidad de algunas actividades. Para ver el grado de integración de los recursos humanos se observan tres niveles de responsabilidad en la organización: alta dirección, los administradores de los sistemas de gestión, y los inspectores de los sistemas de gestión (A.Simon et al 2012 [7]). EN el punto "5.5 Apoyo de la alta dirección" de la UNE 66177:2005, se define las tareas que debe realizar la alta dirección entre las cuales está asignar un responsable o administrador del proyecto con autoridad y visión global de los sistemas y conocedor de la problemática de la empresa, a ser posible neutral frente a los sistemas existentes para lograr una mayor integración.

El tercer elemento a integrar son los recursos de documentación. Estos recursos de documentación están formados por el manual, los procedimientos, las instrucciones y los registros. La mayoría de documentos desarrollados tienen una estructura totalmente integrable. Un solo Manual tiene que integrar los elementos comunes e incorporar los elementos diferenciados, y definir las prácticas y la política de la organización. Describe el Sistema de Gestión Integrada y es la referencia que sirve para conocer el sistema. Como ya se ha explicado, los sistemas de gestión de calidad, medio ambiente, y seguridad y salud ocupacional contienen procedimientos e instrucciones comunes. Su integración consiste en preparar el documento común con el fin de no duplicar los procedimientos e instrucciones generales, y eliminar los específicos de cada sistema de gestión, que se elaboran por separado. Sin embargo, cuando los métodos sólo son aplicables a un sistema, no se pueden integrar. Así, se reduce el volumen de documentación necesaria para gestionar los sistemas y el el número de registros necesarios para demostrar la correcta implantación de los sistemas.

En la tabla 1 se relaciona una posible lista de elementos que podrían formar un sistema de gestión integrado. Por supuesto, las particularidades de cada organización pueden hacer variar dicho esquema, amén de las instrucciones de trabajo que la organización tenga a bien desarrollar por considerarlas de interés o imprescindibles. 
Por otra parte, para lograr la correcta integración de estos elementos hay que prestar atención a diversos factores como el liderazgo de la alta dirección, la provision de recursos, la formación, el control de los procesos, la estuctura de la documentación, la mejora continua y el enfoque hacia las partes interesadas ( H. Khanna et al 2009 [4]).

\begin{tabular}{|c|c|c|c|}
\hline INTEGRACIÓN PARA LOS SISTEMAS DE GESTIÓN & $\begin{array}{l}\text { REQUISITOS } \\
\text { ISO } 9001\end{array}$ & $\begin{array}{c}\text { REQUISITOS } \\
\text { ISO } 14001\end{array}$ & $\begin{array}{c}\text { SISTEMA } \\
\text { DE PRL }\end{array}$ \\
\hline Sistema integrado de gestión & - & - & - \\
\hline Requisitos generales & 4.1 & 4.1 & 4.1 \\
\hline Procesos (identificación e interacción) & - & - & - \\
\hline Aspectos medioambientales (identificación y evaluación) & $5.2,7.2 .1,7.2 .2$ & 4.3 .1 & 4.3 .1 \\
\hline Riesgos laborales (identificación y evaluación) & - & - & - \\
\hline Requisitos legales y otros requisitos & $5.2,7.2 .1,7.2 .2$ & 4.3 .2 & 4.3 .2 \\
\hline Requisitos de la documentación & 4.2 & 4.4 .4 & 4.4 .4 \\
\hline Estructura documental & - & - & - \\
\hline Control de la documentación & 4.2 .3 & 4.4 .5 & 4.4 .5 \\
\hline Control de los registros & 4.2 .4 & 4.5 .4 & 4.5 .3 \\
\hline Responsabilidad de la dirección & 5 & 4.4 .1 & 4.4 .1 \\
\hline Política del Sistema & 5.3 & 4.2 & 4.2 \\
\hline Objetivos y metas & 5.4 .1 & 4.3 .3 & 4.3 .3 \\
\hline Responsabilidad, autoridad y comunicación & 5.5 & 4.1 & 4.1 \\
\hline Responsabilidad y autoridad & 5.5 .1 & 4.4 .1 & 4.4 .1 \\
\hline Representante de la Dirección & 5.5 .2 & 4.4 .1 & 4.4 .1 \\
\hline $\begin{array}{l}\text { Información, comunicación (interna y externa) y } \\
\text { participación }\end{array}$ & $5.5 .3,7.2 .3$ & 4.4 .3 & 4.4 .3 \\
\hline Revisión por la dirección & 5.6 & 4.6 & 4.6 \\
\hline Gestión de los recursos & 6 & 4.4 .1 & 4.4 .1 \\
\hline Provisión de recursos & 6.1 & 4.4 .1 & 4.4 .1 \\
\hline Recursos humanos & 6.2 & 4.4 .1 & 4.4 .1 \\
\hline Infraestructura & 6.3 & 4.4 .1 & 4.4 .1 \\
\hline Ambiente de trabajo & 6.4 & 4.4 .1 & 4.4 .1 \\
\hline
\end{tabular}

Tabla 1: Elementos que podrían formar parte de un sistema de gestión integrado [22]. 


\begin{tabular}{|c|c|c|c|}
\hline INTEGRACIÓN PARA LOS SISTEMAS DE GESTIÓN & $\begin{array}{l}\text { REQUISITOS } \\
\text { ISO } 9001\end{array}$ & $\begin{array}{l}\text { REQUISITOS } \\
\text { ISO } 14001\end{array}$ & $\begin{array}{l}\text { SISTEMA } \\
\text { DE PRL }\end{array}$ \\
\hline Implantación y funcionamiento & - & - & - \\
\hline $\begin{array}{l}\text { Planificación de la realización del producto (incluir calidad, } \\
\text { medio ambiente y seguridad y salud en el trabajo) }\end{array}$ & 7.1 & 4.4 .6 & 4.4 .6 \\
\hline Procesos relacionados con el cliente. & 7.2 & 4.4 .6 & 4.4 .6 \\
\hline Diseño y desarrollo & 7.3 & 4.4 .6 & 4.4 .6 \\
\hline $\begin{array}{l}\text { Compras (incluir calidad, medio ambiente y seguridad y } \\
\text { salud en el trabajo) }\end{array}$ & 7.4 & 4.4 .6 & 4.4 .6 \\
\hline Producción y prestación del servicio & 7.5 & 4.4 .6 & 4.4 .6 \\
\hline $\begin{array}{l}\text { Control de los procesos (incluir calidad, medio ambiente y } \\
\text { seguridad y salud en el trabajo) }\end{array}$ & 7.5 .1 & 4.4 .6 & 4.4 .6 \\
\hline Validación de los procesos & 7.5 .2 & 4.4 .6 & 4.4 .6 \\
\hline Identificación y trazabilidad & 7.5 .3 & 4.4 .6 & 4.4 .6 \\
\hline Propiedad del cliente & 7.5 .4 & 4.4 .6 & 4.4 .6 \\
\hline Preservación del producto & 7.5 .5 & 4.4 .6 & 4.4 .6 \\
\hline Control de los dispositivos de seguimiento y de medición & 7.6 & 4.5 .1 & 4.5 .1 \\
\hline Emergencias & - & 4.4 .7 & - \\
\hline Medida, análisis y mejora & - & - & - \\
\hline Seguimiento y medición & 8.1 & 4.5 .1 & 4.5 .1 \\
\hline Satisfacción del cliente & 8.2 .1 & 4.5 .1 & 4.5 .1 \\
\hline Auditoría interna & 8.2 .2 & 4.5 .5 & 4.5 .4 \\
\hline Seguimiento y medición de los procesos & 8.2 .3 & 4.5 .1 & 4.5 .1 \\
\hline Seguimiento y medición del producto & 8.2 .4 & - & - \\
\hline Seguimiento y medición medioambiental & - & 4.5 .1 & - \\
\hline Seguimiento y medición de las condiciones de PRL & - & - & 4.5 .1 \\
\hline Evaluación del cumplimiento de la legislación & - & 4.5 .2 & - \\
\hline No conformidades & $8.3,8.5 .2,8.5 .3$ & 4.5 .3 & 4.5 .2 \\
\hline Accidentes e incidentes & - & 4.4 .7 & 4.4 .7 \\
\hline Análisis de datos & 8.4 & 4.5 .1 & - \\
\hline Mejora: acciones correctivas y preventivas & $8.3,8.5 .2,8.5 .3$ & 4.5 .3 & 4.5 .2 \\
\hline
\end{tabular}

Tabla 1: Elementos que podrían formar parte de un sistema de gestión integrado [22].

\section{Beneficios y obstáculos}

Como ya se ha comentado en los últimos años han comenzado ha implantar sistemas integrados de gestión debido a sus múltiples beneficios tanto internos como externos.

Así encontramos diferentes posibles beneficios a la implantación como el aumento de la eficacia y eficiencia en la gestión de los sistemas y en la consecución de los objetivos y las metas, la mejora de la capacidad de reacción de la organización frente a las nuevas 
necesidades o expectativas de las partes interesadas, una mayor eficiencia en la toma de decisiones por la dirección al disponer de una visión global de los sistemas, simplificación y reducción de la documentación y los registros, reducción de recursos y del tiempo empleado en la realización de los procesos integrados, reducción de costes del mantenimiento del sistema y de evaluación externa (simplificación del proceso de auditoría), mejora de la percepción y de la involucración del personal en los sistemas de gestión favoreciendo que toda la organización hable un único lenguaje de gestión, y la mejora tanto de la comunicación interna como de la imagen externa alcanzando mayor confianza de clientes y proveedores.

Parte de estos beneficios son observados en diferentes estudios sobre los sistemas integrados de gestión así como otros muchos: la reducción de la documentación (Douglas et al 2000 [15], Griffith et al 2000 [13], Zutshi et al 2005 [8], Mcdonald et al 2003 [16], Jorgensen et al 2006 [2], Salomone et al 2008 [3])y la reducción en los costes (Douglas et al 2000 [15], Zutshi et al 2005 [8], Mcdonald et al 2003 [16], Jorgensen et al 2006 [2], Zeng et al 2007 [14]) son los beneficios más destacados por parte de los autores, mientras que en la literatura también encontramos como beneficios la reducción en el tiempo de implantación, la satisfacción del cliente, la sinergia ente sistemas de gestión, reducción de auditorías, reducción en recursos para la formación, mejor comunicación entre departamentos, mejora operacional, mejora continua, mejora de la imagen de la compañía , logro de ventaja competitiva mayor enfoque hacia las metas de la compañía, y beneficios medioambientales.

Pero no todo son beneficios, sino que también hay diferentes obstáculos que pueden llevar a una organización a no querer integrar sus sistemas de gestión: dificultades derivadas de la resistencia al cambio por parte de la alta dirección y del personal de la organización, necesidad de recursos adicionales específicos para planificar y ejecutar el plan de integración, dificultad para elegir el nivel de integración adecuado al nivel de madurez de la organización y mayor necesidad de formación del personal implicado en el sistema integrado de gestión.

Parte de estos obstáculos son observados en diferentes estudios sobre los sistemas integrados de gestión así como otros muchos: Salomone et al (2008 [3] observa el riesgo de no atribuir el nivel correcto de importancia a cada variable de calidad, medio ambiente y seguridad así como la dificultad para organizar el sistema integrado, mientras que H.Khanna et al. (2009,[4]), atribuye como obstáculos la falta de liderazgo, conciencia, formación, comunicación y auditores, así como barreras culturales e insuficientes directrices para la implantación.

Así, si los beneficios esperados son mayores a los obstáculos que se encuentran para su implantación, la integración de sistemas de gestión será una gran oportunidad de aumentar la rentabilidad de los resultados de la organización, y la inversión hecha para su implantación estará justificada. 


\section{SITUACIÓN EN EL CONTETO EMPRESARIAL ESPAÑOL}

Las empresas españolas no se han quedado atrás a la hora de implantar sistemas de gestión acorde a la ISO 9001, ISO 14001 y OHSAS 18001. En el año 2010 contaba con 59854 certificaciones de ISO 9001 y 18347 certificaciones de ISO 14001 siendo el cuarto y tercer país con más certificaciones respectivamente (ISO Survey 2010 [20]). Por su parte la certificación de OHSAS 18001 está creciendo rápidamente en los últimos años. Por ello las empresas españolas han comenzado ha desarrollar sistemas de gestión integrada, siendo los más usuales los sistemas que integran ISO 9001 e ISO 14001, aunque debido al fuerte incremento en los últimos años de OHSAS 18001 muchas empresas cuentan con un sistema integrado para los tres sistemas de gestión.

La integración de los sistemas dependerá en parte de la estructura de la organización que quiera integrarlos. España es un país en el que en el 2011, el 99,88\% son PYMES. Mientras autores como Salomone no encuentran diferencias significativas a la hora de implantar un sistema integrado de gestión en lo que se refiere al sector Salomone et al (2008), el tamaño de la empresa si que puede ser un factor a tener en cuenta. Para D. Aggelogiannopoulos, la falta de recursos humanos y financieros son el mayor problema para una PYME a la hora de implantar un sistema de gestión (Aggelogiannopoulos et al. 2007 [1]), mientras Salomone encuentra que un sistema integrado ayudará a un PYME a eliminar conflictos entre las diferentes estrategias de la compañía y delimitar las responsabilidades, mientras encontrarán dificultades a la hora de asignar el nivel correcto de importancia a cada variable de los sistemas a integrar, y los problemas de dificultad para organizar un sistema integrado de gestión crecerán cuanto mayor sea la empresa (Salomone et al. 2008 [3]).

\section{Nivel de integración}

Los diferentes autores que han estudiado la situación de los sistemas integrados de gestión en España observan que la mayoría de empresas que cuentan con dos o más sistemas de gestión han optado por la integración. En sus encuestas a diferentes empresas española M. Bernardo el 14\% elige la no integración, el 7\% la integración parcial y el 79\% la integración total (Bernardo et al. 2009 [6]), mientras que para A. Simon el 16\% elige la no integración, el $22 \%$ la integración parcial, y el 62\% elige la integracíon total (A.Simón et al 2012 [7]). De estos resultados se puede resaltar la tendencia de las empresas españolas hacia los dos extremos, integración total y no integración. Esto se puede deber a la búsqueda de todos los beneficios que da la integración por parte de aquellos que integran totalmente sus sistemas, y a las dificultades encontradas por aquellas que deciden no integrar sus sistemas como la falta de recursos humanos y financieros. 


\section{Elementos a integrar}

Como ya se ha mencionado antes, el nivel de integración se observa por medio de la integración de las metas (política y objetivos), los recursos humanos, y la documentación (manual, procedimientos, instrucciones y registros).

En primer lugar encontramos que los recursos humanos no están totalmente integrados (Bernardo et al. 2009 [6]), lo que quiere decir que a pesar de que muchas empresas dan las responsabilidades de los sistemas de gestión a una misma persona (alta dirección, administradores de los sistemas de gestión, e inspectores de los sistemas de gestión), sigue habiendo otras que dan la responsabilidad de manejar cada sistema a personas diferentes. Este resultado concuerda con las ideas de D. Aggelogiannopoulos [1], que promulga que uno de los aspectos que dificultan la implantación de los sistemas de gestión en PYMES es la falta de recursos humanos.

En segundo lugar, observamos la integración de metas y documentación. La mayoría de las empresas tienen estos aspectos totalmente integrados, pero a pesar de esto se observa una mayor integración de la política, los objetivos y el manual que para los procedimientos las instrucciones y los registros (Bernardo et al 2009 [6]). Estos resultados indican que los recursos de documentación que se integran primero son aquellos relacionados a las áreas estratégicas de cada sistema de gestión, para más tarde integrar la documentación relacionada a las áreas operacionales.

Finalmente observamos los procedimientos que cuentan con un mayor nivel de integración. La mayoría de empresas tienen integrados totalmente los procedimientos de auditorías internas, revisión del sistemas de gestión, control de documentos, control de registros , comunicación interna, y acciones preventivas y correctivas (Bernardo et al. 2009 [6]). Acorde con los capítulos de la ISO 9001, los procedimientos más integrados corresponde al Capítulo 8: Medición, análisis y mejora (auditorías internas, control de no conformidades, acciones preventivas y correctivas, mejora), mientras que los procedimientos menos integrados tendrán que ver con el Capítulo 7: Realización del producto.

\section{Evolución}

Tanto el nivel de integración como la integración de sus elementos han ido evolucionando y seguirán haciéndolo.

Con respecto al nivel de integración, las empresas que optan por la integración va aumentando considerablemente, mientras que el nivel de empresas con integración parcial decrece bastante y aquellas que deciden no integrar sus sistemas tienen un nivel parecido. Como ya hemos observado antes, las empresas cada vez más se sitúan en uno de los dos extremos, integración total o no integración, optando la mayoría de empresas por la integración total gracias a los beneficios que de ella pueden obtener. 
En relación a los elementos a integrar deberemos ver la integración de metas, recursos humanos y documentación. La integración de los recursos humanos va evolucionando hacia una mayor integración ya que es el elemento que menos integrado se encuentra en los sistemas de gestión integrada de las empresas españolas. Las empresas van dejando las responsabilidades de los sistemas de gestión a una misma persona de la alta dirección y un administradores de los sistemas de gestión, mientras que gran parte seguirá contando con distintos inspectores (A.Simón et al 2012 [7]).

Con respecto a la integración de metas y documentación hemos observado como la mayoría de empresas cuentan con una única política, un único conjunto de objetivos y un manual. Al tener ya estos elementos totalmente integrados, poco a poco la integración de procedimientos, registros e instrucciones va aumentando hasta el punto que en la actualidad gran parte de las empresas los considera totalmente integrados (A.Simón et al. 2012 [7]). Las empresas deberán poner atención a la integración de los registros ya que es el documento que menos empresas tienen totalmente integrado.

Por último ,en lo referido a los procedimientos, la mayoría se moverá hacia un mayor nivel de integración con el tiempo. Uno de los procedimientos que diferentes autores creen que habrá que tener más en cuenta será el de las auditorías internas, ya que una integración total de estas provoca que los procesos objeto de examen a lo largo de todos sus controles tengan que ser evaluadas una sola vez y haya menos duplicación de esfuerzos durante la planificación, ejecución, e incluso el seguimiento de las fases de la auditoría.

\section{Obstáculos y beneficios}

En la implantación de los sistemas integrados de gestión las empresas españolas encuentran diferentes dificultades siendo la de mayor importancia la falta de recursos humanos (A. Simon et al. 2012 [7]). Otros obstáculos de menor importancia encontrados son la falta de pautas para la integración, apoyo en la administración, colaboración entre departamentos, auditores especializados, apoyo tecnológico, consultores especializados y motivación de los empleados, así como diferencias en los modelos, diferencias entre elementos comunes, implantación no eficiente del primer sistema de gestión, y excesivo tiempo excesivo para llevar a cabo la integración.

A pesar de todos estos obstáculos, obtienen diversos beneficios. Los beneficios de mayor importancia observado son la simplificación de las tareas (requisitos y documentación), el aumento de la eficiencia organizacional, un mejor uso de los resultados de las auditorías externas e internas, y la mejora de la imagen de la empresa. (A. Simon et al. 2012 [7]).Aparte de estos, encontramos otros como la mejora en el entendimiento de los sistemas y su uso, mejores opciones para incluir nuevos sistemas, mejora de la estrategia global de la empresa, mejora de la motivación del empleado, mayor implicación de las partes interesadas, mejor comunicación, mejora de la cultura organizacional, y eliminación de las barreras entre departamentos y mayor colaboración entre ellos. 


\section{CONCLUSIONES}

Debido al entorno competitivo actual las empresas han optado por implantar diferentes sistemas de gestión normalizados, siendo los más comunes los Sistemas de Gestión de la Calidad según la ISO 9001, los Sistemas de Gestión Ambiental según la ISO 14001, y los Sistemas de Seguridad y Salud Ocupacional según la OHSAS 18001. Esta implantación se debe a diversos objetivos que las empresas pretenden lograr gracias a ellos, como por ejemplo: la mejora continua, mejora de su imagen, la oportunidad de obtener una ventaja competitiva, la exploración de nuevas oportunidades de mercado, mejorar los productos, y la reducción de costes en la gestión, aparte de los propiamente inherentes a cada sistema. Pero su implantación por separado supone demasiada documentación y unos costes excesivos. Por ello y gracias a los paralelismos entre los sistemas (procedimientos, documentación, etc), las empresas han comenzado a integrar estos tres sistemas de gestión con el objetivo de obtener rentabilidad y fiabilidad en sus resultados.

Tanto la estrategia, el método y el nivel de integración dependerá de la estructura y de los objetivos de la organización. La estrategia empleada también dependerá del número de sistemas a integrar. Con respecto al método, en 2005 se crea la UNE 66177 con el objetivo de que las empresas españolas cuenten con una guía de referencia para la integración. El nivel de integración depende de la integración de sus elementos. Esta integración puede ser parcial o total. Estos elementos que deben ser integrados son los recursos humanos, las metas (política y objetivos) y la documentación (manual, procedimientos, instrucciones y registros). La correcta integración de estos elementos hace que la organización tenga diversos beneficios, siendo los más importantes la reducción de la documentación, la reducción de auditorias y la reducción de los costes. El mayor beneficio de la integración es la eliminación de la duplicidad de actividades comunes, documentación común, etc, lo que hace que se reduzcan los costes de gestión.

Por todo esto, las empresas españolas han decidido implantar diferentes sistemas de gestión, llegando a ser uno de los países con mayor número de certificaciones ISO 9001 e ISO 14001, mientras que la OHSAS 18001 está empezando a tener un rápido crecimiento. Debido a los numerosos beneficios de la integración de sistemas de gestión la mayoría de las empresas españolas que cuentan con dos o más sistemas de gestión normalizados optan pos su integración total, mientras que un menor número no los integra o los integra parcialmente.

Los elementos con un mayor nivel de integración en los sistemas integrados de gestión de las empresas españolas son la política, los objetivos y el manual. Los procedimientos las instrucciones y los registros muestran también muestran un gran nivel de integración, siendo algo menor que para los elementos mencionados anteriormente. En lo que se refiere a los procedimientos, la mayoría de empresas tienen integrados totalmente los 
procedimientos de auditorías internas, revisión del sistemas de gestión, control de documentos, control de registros, comunicación interna, y acciones preventivas y correctivas. Por el contrario, al ser PYMES la mayoría de empresas, los recursos humanos son el elemento que menos integrado se encuentra. Esta integración hace que las organizaciones españolas obtengan diversos beneficios, siendo la reducción de documentación y requisitos, el aumento de la eficiencia organizacional, un mejor uso de los resultados de las auditorías externas e internas, y la mejora de la imagen de la empresa, los que mayor importancia tienen.

En resumen, hemos visto como la integración de sistemas de gestión es una gran estrategia para todas aquellas organizaciones que quieran aumentar la rentabilidad y fiabilidad de sus resultados. El mayor beneficio que encontraremos de la integración de sistemas de gestión es que se evita la duplicidad de actividades, documentación, auditorías, etc. comunes a los tres sistemas, lo que hace obtener una reducción de costes y un ahorro de tiempo. Debido a esto, la integración de sistemas de gestión será importante para las organizaciones que quieran obtener una mejora continua y una excelencia empresarial, gracias a ayuda que ofrece para abordar eficientemente las cuestiones de calidad, medio ambiente, y seguridad y salud ocupacional, de manera más eficiente y de forma sistemática.

\section{Referencias}

[1] D. Aggelogiannopoulos, E.H. Drosinos, P. Athanasopoulos (2007). Implementation of a quality management system (QMS) according to the ISO 900 family in a Greek small-sized winery: A case study. Food Control 18, 1077-1085.

[2] Tine H. Jorgensen, Arne Remmen, M.Dolores Mellado (2006). Integrated managemet systems - thre different levels of integration. Journal of Cleaner Production 14, 713-722.

[3] Roberta Salomone (2008). Integrated management systems: experiences in Italian organisations. Journal of Cleaner Production 15, 1786-1806.

[4] H.Khanna, S.C. Laroyia, D.D. Sharma (2009). A survey on Indian Experience on Integrated Management Standards (IMS). International Journal for Quality research. UDK-378.014.3(497.11). Short cientific paper (1.03).

[5] Gilberto Santos, Fátima Mendes, Joaquim Barbosa (2011). Certification and integration of management systems: the experience of Portuguese small and mediun enterprises. Journal of Cleaner Production 19, 1965-1974.

[6] Marce Bernardo, Martí Casadesus, Stanislav Karapetovic, Iñaki Heras (2009). How integrated are environmental, quality and other standardized management systems? An empirical study. Journal of Cleaner Production 17, 742-750. 
[7] Alexandra Simon, Stanislav Karapetovic, Martí Casadesus (2012). Evolution of Integrated Management Systemsin Spanish firms. Journal of Cleaner Production 23, 8-19.

[8] Zutshi A, Sohal AS (2005). Integrated management system. The experience of three Australian organizations. International Journal of Quality and Reliability Management. 12(2):211-32.

[9] Karapetrovic S, Willborn W (1998). Integration of quality and environmental management systems. TQM Magazine 10(3):204-13.

10] Karapetrovic S (2003). Musings on integrated management systems. Measuring Business Excellence $.7(1): 4-13$.

[11] Karapetrovic S, Jonker J. (2003). Integration of standardized management systems: searching for a recipe and ingredients. Total Quality Management 14(4):451-9.

[12] Wilkinson G, Dale B. (1999) Integration of quality, environment and health and safety management systems: an examination of key issues. Proceedings of the Institution of Mechanical Engineers, Part B, Journal of Engineering Manufacture 213(3):275-83.

[13] Griffith, A., Stephenson, P. and Watson, P. (2000), Management Systems for construction, Longman, Harlow.

[14] Zeng, S X, Shi J J, Lou G X. (2007). A Synergetic Model for Implementing an Integrated Management System: An Empirical Study in China,” Journal of Cleaner Production 15(18): 1760-1767.

[15] Douglas A, Glen D. (2000) Integrated management systems in small and medium enterprises. Total Quality Management 11(4, 5 \& 6): pp. 686-690.

[16] McDonald M, Mors T A, Phillips A. Management system integration: Can it be done? Quality Progress 2003; 36: 67-74.

[17]ISO, 2008. ISO 9001: 2008. Norma Internacional: Sistemas de Gestión de la calidad. International Organization for Standarization. Ginebra, Suiza.

[18] ISO, 2004. ISO 14001:2004. Norma Internacional: Sistemas de Gestión Ambiental - Requisitos y orientación para su suso. International Organization for Standarization. Ginebra, Suiza.

[19] AENOR, 2007. OHSAS 18001:2007 Sistemas de gestión de la seguridad y salud en el trabajo Requisitos. AENOR. Madrid, España.

[20] ISO, 2011. The ISO Survey of Certifications - 2010. International Organization for Standarization. Ginebra, Suiza. Available at : http://www.iso.org/iso/iso-survey2010.pdf

[21] OHSAS Certificates survey results 2009. OHSAS PROJECT GROUP. Available at: http://ohsas18001 expert.com/wp-content/uploads/2011/05/2009-OHSAS-Certificates-Survey-Results.pdf

[22] AENOR, 2005. UNE 66177:2005 Sistemas de gestión. Guía para la integración de los sistemas de gestión, AENOR. Madrid, España. 


\section{0.- BIBLIOGRAFÍA}

\section{1.- LIBROS}

- INTRODUCCIÓN A LA GESTIÓN DE LA CALIDAD. F.J. Miranda González, Antonio Chamorro Mera, Sergio Rubio Lacoba. Ed Delta Publicaciones 2007.

- GESTIÓN DE LA CALIDAD TOTAL. Ed Díaz de Santos 1996.

-CAPÍTULO SOBRE GESTIÓN DE LA CALIDAD DE APUNTES DE DISEÑO INDUSTRIAL. Asignatura optativa de I.T.I (M). Pedro María Villanueva Roldán.

- MODELO EFQM DE EXCELENCIA 2010 . EFQM Publications 2010.

-MODELO DE EXCELENCIA EN LA GESTIÓN MALCOLM BALDRIGE. Baldrige National Quality Program USA. Traducción libre por Jose Antonio Villagra Villanueva.

- SEIS SIGMA. Fermín Gómez Fraile, José Francisco Vilar Barrio, Miguel Tejero Monzón. FC Editorial.2003

-KAIZEN: LA CLAVE DE LA VENTAJA COMPETITIVA JAPONESA. Masaaki Imai Ed México : Compañía Editorial Continental, 1989

-LAS 5S: ORDEN Y LIMPIEZA EN EL PUESTO DE TRABAJO. Francisco Rey Sacristán. FC editorial 2005

-SISTEMAS DE GESTIÓN INTEGRADA: CALIDAD, PREVENCIÓN y MEDIO AMBIENTE. Jenaro Romero Pastor. Ed Vision Net 2006

\section{2.- NORMAS Y REGLAMENTOS}

-ISO 9001:2000 - Norma Internacional: Sistemas de Gestión de la calidad.Requisitos. International Organization for Standarization. Ginebra, Suiza. 2000.

-ISO 9001:2008 - Norma Internacional: Sistemas de Gestión de la calidad.Requisitos. International Organization for Standarization. Ginebra, Suiza. 2008.

-ISO 14001:2004 - Norma Internacional: Sistemas de Gestión Ambiental - Requisitos y orientación para su suso. International Organization for Standarization. Ginebra, Suiza.2004.

-REGLAMENTO (CE) No 1221/2009 DEL PARLAMENTO EUROPEO Y DEL CONSEJO de 25 de noviembre de 2009 relativo a la participación voluntaria de organizaciones en un sistema comunitario de gestión y auditoría medioambientales (EMAS), y por el que se derogan el Reglamento (CE) no 761/2001 y las Decisiones 2001/681/CE y 2006/193/CE de la Comisión 
- OHSAS 18001:2007 Sistemas de gestión de la seguridad y salud en el trabajo Requisitos. AENOR. Madrid, España.2007.

-ILO-OHS 2001- Directivas relativas a los sistemas de seguridad y salud en el trabajo. OIT. Ginebra, Suiza. 2001.

-. UNE 66177:2005 Sistemas de gestión. Guía para la integración de los sistemas de gestión, AENOR. Madrid, España. 2005.

-UNE 166000:2006 - Gestión de la I+D+i: Terminología y definiciones de las actividades de I+D+i. AENOR. Madrid, España. 2006.

-UNE 166002:2006 - Gestión de la I+D+i: Requisitos del Sistema de Gestión de la I+D+i. AENOR. Madrid, España. 2006.

-The ISO Survey of Certifications - 2010. International Organization for Standarization. Ginebra, Suiza. Available at : http://www.iso.org/iso/iso-survey2010.pdf

-OHSAS Certificates survey results 2009. OHSAS PROJECT GROUP. Available at: http://ohsas18001expert.com/wp-content/uploads/2011/05/2009-OHSAS-CertificatesSurvey-Results.pdf

\section{3.- ARTÍCULOS}

- A longitudinal study of TQM implementation: factors influencing success and failure W.A. Taylor, G.H. Wright. Omega: The International Journal of Management Science 2003.

- Quality management practices and operational performance: empirical evidence on Spanish industry - J. Merino Diaz de Cerio. International Journal of Production Research.2003.

- Quality management practices and competitive performance: Empirical evidence from Japanese manufacturing companies. Anh Chi Phan, Ayman Bahjat Abdallah, Yoshiki Matsui. International Journal of Production Economics 2011.

- A replication study of a theory of quality management underlying the Deming management method: insights from an Italian context. Manus Rungtusanatham , Cipriano Forza , Roberto Filippini , John C. Anderson. Journal of Operations Management 1998.

- Implementation of Deming's style of quality management: An action research study in a plastics company. Douglas N. Hales, Satya S. Chakravorty. International Journal of Production Economics 2006. 
- Investigating total quality management practice's inter-relationships in ISO 9001:2000 certified organisations. Christos V. Fotopoulos, Evangelos L. Psomas y Fotis K. Vouzas.

Total Quality Management and Business Excellence 2010

- Implementation of a quality management system according to the ISO 9000 family in a Greek small-sized winery: A case study. D. Aggelogiannopoulos, E.H. Drosinos , P. Athanasopoulos. Food Control 2007.

- A study on the critical factors of ISO 9001:2000 and organizational performance of Indian manufacturing firms. P.Padma, L. S. Ganesh y C.Rajendran. International Journal of Production Research 2008.

- Impact of Baldrige National Quality Award Criteria on organizational quality performance. S.M.Lee, B-H Rho y S.G.Lee. International Journal of Production Research 2003.

- Relevance of Baldrige constructs in an international context: A study of national culture. Barbara B. Flynn, Brooke Saladin. Journal of Operations Management 2006.

- An empirical assesment of the EFQM Excellence Model: Evaluation as a Tqm framework relative to the MBNQA Model. J.Carlos Bou-Llusar, Ana B. Escrig Tena, Vicnte Roca-Puig. Inmaculada Beltrán-Martín. Journal of Operations Management 2009.

- Selection effective management tools on setting European Foundation for Quality Management (EFQM) model by a quality function deployment (QFD) approach. Same Yousefie, Mahmood Mohammadi, Jalal Hghighat Monfared. Expert Systems with Applications 2011.

- Business improvement strategy or useful tool? Analysis of the application of the $5 \mathrm{~S}$ concept in Japan, the UK and the US. Kaoru Kobayashi, Ron Fisher and Rod Gapp. Total Quality Management and Business Excellence 2008.

-Quality improvement supported by the 5S, an empirical case study of Mexican organisations. J. H. Ablanedo, B. Alidaee, J. C. Moreno y J. Urbina. International Journal of Production Research 2010.

- Critical success factors of Six Sigma implementations in Italian companies. Alessandro Brun. International Journal of Production Economics 2011.

- The envolving theory of quality management: The role of Six Sigma. Xingxing Zu, Lawrence D. redenhall, Thomas J. Douglas. Journal of Operations Management 2008.

- Integrated Management Systems - three different levels of integration. Tine H. Jorgensen, Arne Remmen, M. Dolores Mellado. Journal of Cleaner Production 2006. 
- How integrated are enviromental, quality and other standarized management systems? An empirical study. Marce Bernardo, Marti Casadesus, Stanislav Karapetovic, Iñaki Heras. Journal of Cleaner Production 2009.

-Integrating Management Systems: A dinámic study of Spanish firms. Alexandra Simon, Stanislav karapetovic, Marti Casadesus. 5th International Conference on Industrial Engineering and Industrial Management XV Congreso de Ingeniería de Organización

Cartagena 2011

- Integrated management systems: experiences in Italian organizations. Roberta Salomone. Journal of Cleaner Production 2008.

- Applying quality award criteria in R\&D Project assessment. V.Ojanen, , P. Piippo, M. Tuominen. International Journal of Production Economics 2002.

- The effect of TQM on performance in R\&D environments: A perspective from South Korean firms. Daniel I.Prajogo, SoonW.Hong. Technovation 2008.

- Evolution of Integrated Management Systemsin Spanish firms. Alexandra Simon, Stanislav Karapetovic, Martí Casadesus. Journal of Cleaner Production 2012

- Integrated management system. The experience of three Australian organizations. Zutshi A, Sohal AS. International Journal of Quality and Reliability Management. 2005.

- Integration of quality and environmental management systems. Karapetrovic S, Willborn W. TQM Magazine 1998.

- Musings on integrated management systems. Karapetovic S. Measuring Business Excellence 2003.

- Integration of standardized management systems: searching for a recipe and ingredients. Karapetovic S, Jonker J. Total Quality Management 2003.

- Integration of quality, environment and health and safety management systems: an examination of key issues. Wilkinson G, Dale B. Proceedings of the Institution of Mechanical Engineers, Part B, Journal of Engineering Manufacture 1999.

- Management Systems for construction. Griffith, A., Stephenson, P. and Watson, P. Longman, Harlow 2000.

- A Synergetic Model for Implementing an Integrated Management System: An Empirical Study in China," Zeng, S X, Shi J J, Lou G X. Journal of Cleaner Production 2007.

- Integrated management systems in small and medium enterprises. Douglas A, Glen D. Total Quality Management 2000. 
-. Management system integration: Can it be done? McDonald M, Mors T A, Phillips A. Quality Progress 2003.

- A survey on Indian Experience on Integrated Management Standards (IMS). H.Khanna, S.C. Laroyia, D.D. Sharma. International Journal for Quality research 2009.

- Certification and integration of management systems: the experience of Portuguese small and mediun enterprises. Gilberto Santos, Fátima Mendes, Joaquim Barbosa. Journal of Cleaner Production 2011.

\title{
10.4.-PÁGINAS WEB
}

\author{
-www.aec.es \\ -www.efqm.org \\ -www.baldrige.com \\ -www.iso.org \\ -WWW.aenor.es \\ -www.fomento.es \\ -WWw.sciencedirect.com \\ -WWW.scopus.com \\ -www.monografías.com \\ -es.wikipedia.org
}


Proyecto Fin de Carrera presentado el día 28 de Junio del 2012.

Estudiante

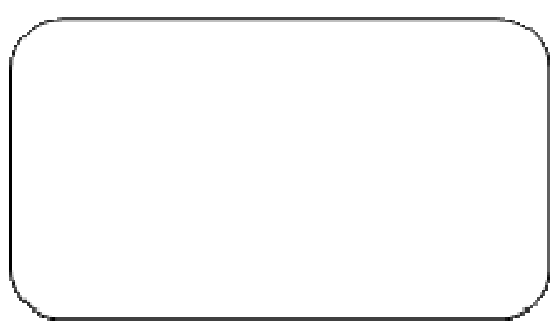

Julen Irurita Alzueta
Tutor

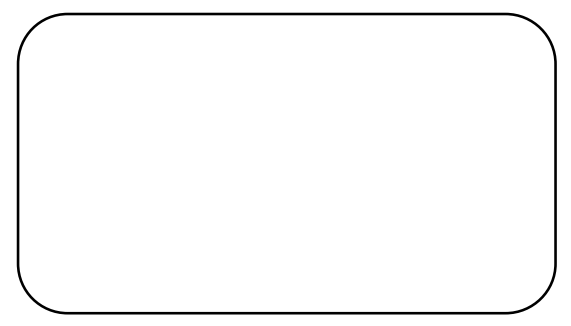

Dr. Pedro María Villanueva Roldán 